Luis Bértola · Jeffrey Williamson Editors

Has Latin American Inequality Changed Direction?

looking over the long run 
Has Latin American Inequality Changed Direction? 
Luis Bértola • Jeffrey Williamson Editors

\section{Has Latin American Inequality Changed Direction?}

Looking Over the Long Run

照 Springer Open 


\author{
Editors \\ Luis Bértola \\ Universidad de la República \\ Montevideo, Uruguay
}

\author{
Jeffrey Williamson \\ University of Wisconsin \\ MADISON, Wisconsin, USA
}

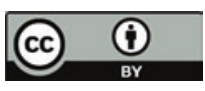

ISBN 978-3-319-44620-2

ISBN 978-3-319-44621-9 (eBook)

DOI 10.1007/978-3-319-44621-9

\section{Library of Congress Control Number: 2016952534}

(C) The Editor(s) (if applicable) and The Author(s) 2017. This book is published open access.

Open Access This book is distributed under the terms of the Creative Commons Attribution 4.0 International License (http://creativecommons.org/licenses/by/4.0/), which permits use, duplication, adaptation, distribution and reproduction in any medium or format, as long as you give appropriate credit to the original author(s) and the source, provide a link to the Creative Commons license and indicate if changes were made.

The images or other third party material in this book are included in the work's Creative Commons license, unless indicated otherwise in the credit line; if such material is not included in the work's Creative Commons license and the respective action is not permitted by statutory regulation, users will need to obtain permission from the license holder to duplicate, adapt or reproduce the material.

The use of general descriptive names, registered names, trademarks, service marks, etc. in this publication does not imply, even in the absence of a specific statement, that such names are exempt from the relevant protective laws and regulations and therefore free for general use.

The publisher, the authors and the editors are safe to assume that the advice and information in this book are believed to be true and accurate at the date of publication. Neither the publisher nor the authors or the editors give a warranty, express or implied, with respect to the material contained herein or for any errors or omissions that may have been made.

Printed on acid-free paper

This Springer imprint is published by Springer Nature

The registered company is Springer International Publishing AG

The registered company address is: Gewerbestrasse 11, 6330 Cham, Switzerland 


\section{Prologue}

\section{A Contribution to Settle the Large Pending Issue of Latin America}

On the initiative of Professors Luis Bértola and Jeffrey Williamson, the Institute for the Integration of Latin America and the Caribbean (INTAL), together with the IDB's Social Management, the ECLAC, and the World Bank, organized a regional conference in December 2014 with the motto "Latin American Inequality in the Long Run." Buenos Aires hosted worldwide experts to identify the historical roots of the problem and to contribute proposals to prevent inequality from remaining the region's distinguishing feature.

This book that we are now publishing constitutes a continuity and, at the same time, reinforces our commitment to the task. As the challenge is huge, there cannot be another way. In Latin America and the Caribbean, there are 175 million people who live in poverty conditions, 122 million informal workers without access to social security, and abysmal differences that persist in terms of opportunities of access to health, housing, and education services.

After a decade in which the middle class has multiplied, and welfare programs have proliferated, reaching to a fourth part of Latin Americans, social demands are increasingly higher and demand more of public policies. But the deceleration of several economies of the region and the stagnation of commerce of the last years created additional difficulties to the inclusion process.

In this scenario, regional and global integration is key to revert this trend, as most integrated societies - in the region and the world - are the ones that manage to grow more harmoniously, reducing the inequality gap between people. Integration and inclusion are the two sides of the same coin.

The first part of the book analyses the long-term tendencies in diverse subjects that range from income disparity to gender equality. The second part of this book examines more recent phenomena, with emphasis on fiscal policy, social policy, and agricultural development. 
After experiencing gradual improvements during recent times, the countries in the region have a shared interest in implementing second generation reforms that, disregarding false shortcuts, build the foundations of nations which are more egalitarians and integrated to the world.

We must spare no effort. Inequality generates antinomies and fragmentation among citizens, scarce social cohesion, and a major tendency to political destabilization, while social inclusion is the most finished example of a democracy that, instead of weakening, gains strength.

With a long-term vision that clears up permanent phenomena of transitory situations, this publication addresses this issue in an original way, with an interdisciplinary approach and scientific accuracy.

This is why we swell with pride of this contribution where different experiences and knowledge converge in the same objective: strengthen regional integration that implies a higher degree of social inclusion.

Washington, USA

Héctor Salazar Sánchez

Washington, USA

Gustavo Beliz 


\section{Contents}

Introduction

Luis Bértola and Jeffrey G. Williamson

\section{Part I Long-Run Trends}

Functional Inequality in Latin America:

News from the Twentieth Century

Pablo Astorga Junquera

The Political Economy of Income Inequality in Chile Since 1850.

Javier E. Rodríguez Weber

Using Heights to Trace Living Standards and Inequality

in Mexico Since 1850.

Moramay López-Alonso and Roberto Vélez-Grajales

Long-Run Human Development in Mexico: 1895-2010.

Raymundo M. Campos-Vazquez, Cristóbal Domínguez Flores, and Graciela Márquez

Inequality, Institutions, and Long-Term Development:

A Perspective from Brazilian Regions.

Pedro Paulo Pereira Funari

Historical Perspectives on Regional Income Inequality

in Brazil, 1872-2000

Eustáquio Reis

Racial Inequality in Brazil from Independence to the Present

Justin R. Bucciferro

The Expansion of Public Spending and Mass Education in Bolivia:

Did the 1952 Revolution Represent a Permanent Shock?

José Alejandro Peres-Cajías 
The Lingering Face of Gender Inequality in Latin America.....

María Magdalena Camou and Silvana Maubrigades

Fiscal Redistribution in Latin America Since the Nineteenth Century .....

Leticia Arroyo Abad and Peter H. Lindert

\section{Part II The Recent Inequality Downturn}

Inequality in Latin America: ECLAC's Perspective 285

Verónica Amarante and Antonio Prado

The Inequality Story in Latin America and the Caribbean:

Searching for an Explanation

Augusto de la Torre, Julian Messina, and Joana Silva

The Political Economy of Inequality at the Top

in Contemporary Chile

Diego Sánchez-Ancochea

Structural Change and the Fall of Income Inequality in Latin America: Agricultural Development, Inter-sectoral Duality, and the Kuznets Curve.

Martin Andersson and Andrés Palacio

Fiscal Policy and Inequality in Latin America, 1960-2012.

Judith Clifton, Daniel Díaz-Fuentes, and Julio Revuelta

Challenges for Social Policy in a Less Favorable

Macroeconomic Context.

Suzanne Duryea, Andrew Morrison, Carmen Pagés, Ferdinando Regalia, Norbert Schady, Emiliana Vegas, and Héctor Salazar 


\section{Introduction}

\section{Luis Bértola and Jeffrey G. Williamson}

After the so-called structural reforms of the 1970s and 1980s, most Latin American countries had shown that they could achieve fast growth and deal with structural change. However, income per capita failed to converge on the world leaders, and growth was followed by increasing inequality and, in some parts of Latin America, even increasing poverty. Noting this experience, observers began to wonder whether inequality had become a permanent feature of Latin American development and whether it had contributed to the region's disappointing long-run development performance (Bértola et al. 2010a).

A few years later, we were discussing something quite different. By 2014, Latin America had recorded fast growth for more than a decade and, contrary to what was going on in other parts of the world, inequality was falling. Had Latin America permanently changed its long-term direction? To what extent was decreasing inequality dependent on those high growth rates, and thus was it only temporary? What roles did market forces, institutions, and political ideology play during the inequality downturn? To start a search for answers, we sent out a call for papers for a conference in Buenos Aires, which was organized with support from the Economic Commission of Latin America and the Caribbean (ECLAC), the Inter-American Development Bank (IADB), and the International Bank for Reconstruction and Development (IBRD). The conference gathered together economic historians that had long been working on the history of Latin American inequality and poverty, with economists engaged in the study of inequality in the recent period.

By the time of the conference in December 2014, and even more clearly at the time of publication 2 years later, the atmosphere in Latin America had changed yet again.

L. Bértola $(\bowtie)$

Universidad de la República, Montevideo, Uruguay

J.G. Williamson

University of Wisconsin, Madison, WI, USA 
Even if it is too early to guess what will happen to inequality in the near future, we know for sure that the commodity-driven boom during the first years of the twentyfirst century has come to an end. In 2014, Latin America was already growing more slowly than the OECD, and prospects for 2015 were even worse. The expected GDP growth rate for the years ahead is sufficiently low to allow us to say that Latin American catch up on the world leaders has come to a halt.

Thus, the original question posed at our conference is even more dramatically posed by more recent events. Has Latin America changed direction and was the recent inequality downturn just the result of a globally induced economic boom, similar to so many other previous booms in Latin America since the nineteenth century? Were the recent inequality events transitory with no permanent change in political, institutional, and other fundamentals, ones that have been a feature of the region for the past two centuries or even longer?

\section{The Origins of Latin American Inequality}

Most studies of Latin American development written between the 1950s and 1970s stressed colonial heritage as the main explanation of its underachievement. Competing schools of thought at least agreed on this point: dependency theories, modernization theories, Marxist writings, and development economics all agreed that Latin America's colonial heritage contributed two key features: dependency on foreign powers, and inequality in civil rights, property rights, and political power. Things were made even worse due to the fact that the imperialists, Portugal and Spain, were relatively backward themselves compared with Western Europe.

Each of these thought that independence was jeopardized by the lack of a real social revolution, by the weakness of the local elites, by the failure to create a Latin American federation, and the development of new forms of unequal international relations, led by British "informal" imperialism, later followed by US hegemony. National states were consolidated during the last quarter of the nineteenth century. They implemented liberal reforms, by which the lands of the church, the peasant communities, and the state were privatized thus passing it on to an increasingly powerful landowning elite. Wage labor became dominant, but a varied array of coercive labor market mechanisms persisted. The landowning elite, together with merchants, foreign powers, state bureaucracies, and the military, formed an alliance which left the majority - mainly those of Afro-American and Indian ethnic origin without property, civil rights, and education.

This process took varied forms in different Latin American countries and regions. Three main groups were identified in the literature. The Indo-American group - the Andean, Central American, and Mexican regions - was the center in the colonial period, densely populated and rich in gold and silver. There, the interplay between the haciendas and the peasant communities, together with centralized forced labor for the mines, was at the heart of social relations as the region drifted towards capitalism (Salvucci 2014). The Afro-American regions (northern Brazil, coastal 
Columbia, coastal Venezuela, and the Caribbean) were those in which tropical crops were produced with slave labor on large plantations. The indigenous American mountain and inland regions (Peru, Ecuador, Mexico, and Central America) worked the mines and farmed the haciendas. The Euro-American regions (Chile, Argentina, Uruguay, and southern Brazil) were less densely populated, labor was scarce, and European settlement played a dominant role. Even in these southern regions the concentration of land holdings took place. These interpretations of Latin American underdevelopment help explain different attempts to introduce economic, social, and political reforms in the middle decades of the twentieth century, including an active state involvement in the economy (Cardoso and Brignoli 1979).

After the 1980s, however, the academic and political climate in Latin America changed significantly. The region was confronted with the crisis of state-led industrialization, by the debt crisis, and by a "lost decade" of very poor economic performance. Pro-market reforms were introduced, often combined with authoritarian regimes. The story told by a new political voice said that the problems faced by Latin America were not market failures that the state had tried to overcome, but rather state involvement itself. Efforts were made to liberalize trade and capital flows, as well as to implement macro stabilization policies, and these were consistent with pro-global policies flourishing all over the world.

The pattern of development adopted by most Latin American countries since the 1980s was fueled by export growth, but the domestic sector did not keep pace. Inequality increased and the region continued to experience significant macro volatility. After every crisis, divergence with world leaders was deepened.

While increasing dissatisfaction spread and developed a more powerful voice in the context of the continent's democratization, the dominant liberal discourse was challenged by neo-institutional approaches. While the neo-institutionalists agreed with conventional theory that free trade and unfettered capital movements were good for growth, they emphasized that domestic institutions were the ultimate factor explaining economic performance. Furthermore, institutions could not be expected to quickly change their character, since they tended simply to reproduce themselves in a path-dependent way. Thus, it was naïve to expect that the imposition of rules from outside sources would produce the expected results. Quite the contrary, foreign attempts to foster liberal reforms instead reinforced the power of rentseeking elites and their extractive institutions.

When modern neo-institutional thinking entered Latin American debate, it rediscovered only one part of what we already knew: that domestic institutions were extractive, that most of the population worked under coercive mechanisms, that large parts of the population did not have civil rights or wealth, and that ethnic features were the key carriers of social and political relations. Neo-institutional theories argued that colonialism was a problem only in colonial times, vanishing afterwards while the creation of those domestic institutions in different clothing became the center of the story. The origin of bad institutions might reside with the colonizing power (North et al. 2000), or with the endowments the conquerors found (Engerman and Sokoloff 1997, 2012), or the domestic interplay between economic and political institutions (Robinson 2006). In any case, the problems Latin America 
faced at the end of the twentieth century had to be interpreted in the light of the institutions established shortly after the region was colonized. Changes in international economic and political relations, due to events such as the Industrial Revolution, the war of independence, the second industrial revolution, the transport revolution, mass migration, the process of profound globalization, and more, were not taken into consideration by neo-institutional thinking. This literature is consistent with the traditional histories that believed that Latin America was a relatively unequal place in the mid-late nineteenth century, that this inequality was consistent with institutions that were extractive and rent-seeking, and that these facts helped explain Latin America's disappointing growth performance.

Coastworth (2008) challenged neo-institutional approaches. He argued that the problem faced by the independent Latin American economies was their lack of inequality. The elites were not powerful enough to expropriate land from inefficient peasant communities and a strong state was missing that would otherwise have invested in growth-enhancing infrastructure. It was during the first global century's trade boom, from the mid-nineteenth century to World War I, that nation states consolidated, inequality soared, accumulation rates rose, and economic growth quickened. Coatsworth's view was reinforced by the Inequality Possibility Frontier approach, developed by Milanovic et al. (2007). These authors argued that per capita income had to be high in order to produce a large surplus that could be appropriated by the elite, thus generating great inequality. Williamson (2010) has shown that in spite of this colonial legacy, inequality was no higher in Latin America just prior to its belle époque and early industrialization (c1870s) than in the western leaders prior to their industrial revolution (c1800s). Lindert and Williamson (2016) recently reported evidence showing that inequality in Latin America was also no higher than in the USA in 1860 (under slavery) or 1870 (after emancipation). We also know that inequality in Latin America grew significantly from 1870 to 1929 (Prados de la Escosura 2007; Bértola et al. 2010b), due in part to the impact of a secular commodity price boom that raised land rents relative to wages, but also because of the class power structure. Of course, the kind of inequality matters (Marrero and Rodriquez 2013; Bértola 2011). Inequality can be good for growth if it simply reflects rewards to those accumulating skills, taking risks, and innovating. Inequality can be bad for growth if it simply reflects successful rent-seeking or rising rents to land and mineral resources. While the assertion has not been confirmed with historical evidence, it seems plausible to think that late nineteenth century Latin American inequality was more of the "bad" kind while it was more of the "good" kind in the industrial leaders. After all, inequality is not only a matter of income and wealth but also a matter of opportunities, property rights, access to education, and civil rights. A continent with $25 \%$ slaves and $60 \%$ Indian peasants with very limited access to property, civil rights, education, and political power, as the Latin American case was since colonial times, can hardly be considered egalitarian whatever the income inequality measure. Moreover, Bértola et al. (2015) have shown how dangerous it can be to work with aggregate Gini-coefficients alone: during the middle decades of the nineteenth century, rural areas of Buenos Aires underwent a fall in inequality due to the huge rise in the labor share, while land concentration and the rental-wage ratio were increasing. In short, a low Gini-coefficient may hide a highly polarized society. 
Much of the debate about Latin America's inequality history has now focused on the twentieth century. The new question, posed recently by Williamson (2015), is whether Latin America failed to join the steep inequality downturn experienced by the developed world from World War I to the 1970s. Our knowledge about Latin American inequality trends over the period is still limited. We know much more about the increasing inequality between the 1960 s and 1990s. For the period up to the 1960 s, the problem is that we cannot generalize from what we know about only a few countries.

Bértola and Ocampo (2012: Chap. 1) identified three Latin American societies and all with different inequality trends. During the twentieth century, the IndoAmerican and the Afro-American societies seemed to converge towards labor markets which behaved like the Lewis unlimited-labor-supply model. In these regions, state-led growth and industrialization may have created new forms of inequalities: a highly concentrated industrial sector was able to create many jobs for relatively skilled and well-organized workers, while a large share of the labor force remained marginalized in low productivity jobs. The Euro-American societies in the southern cone experienced a different growth pattern. In Uruguay, the increasing inequality of the belle époque was followed by a slight reduction up to the 1930s. Afterwards, until the 1960s, inequality declined significantly in spite of a terms-of-trade boom. Contrary to what happened in previous booms (and contrary to the logic of the preceding bust of the 1930s), the institutional and political environment produced a significant inequality reduction: wage councils, industrial protectionism, welfare policies, and multiple exchange rates were tools that favored the egalitarian trend in a way that resembled the "Keynesian" atmosphere in the advanced countries (Bértola 2005). Many of these features could also be seen in Argentina and Chile. What happened after the 1960s in the Southern Cone is better known. Thus, the century-long trends appear to be ones of increasing inequality up to WWI, decreasing inequality up to the 1960 s, and increasing inequality up to the turn of this century. This pattern is also consistent with the Piketty (2014) description of post-World War I developments as a unique period of decreasing inequality in the middle of the twentieth century (see also Lindert and Williamson 2016: Chap. 8). Was this southern cone pattern repeated elsewhere in Latin America, or did most of the region miss the Great Levelling which occurred among the industrial leaders from WW1 to the 1970s?

This volume contains fresh new contributions to this Latin American inequality debate. Part I gives the economic historians a chance to speak to those issues by looking back before the recent downturn, and Part II gives the economists a chance to look again at the recent downturn with Part I in their rearview mirror.

\section{Part I: Looking Backwards for Explanations}

In Chap. 2, Pablo Astorga presents new data measuring the functional distribution of income, based on four income groups (three groups of wage earners and a group of capitalists) for six Latin American countries (Argentina, Brazil, Chile, Colombia, México, and Venezuela), covering the century 1900-2011. The first conclusion to be drawn from this new evidence is that no common pattern is shared by all 
countries. True, Astorga's new evidence documents that they all underwent increased inequality during the last decades of the twentieth century, a result consistent with other evidence. However, prior to 1960 secular trends in inequality differ. Argentina, like Uruguay (Bértola 2005), underwent rising inequality in the early decades, falling inequality in the middle decades, and then rising inequality in the closing decades. This is similar to what Rodríguez Weber finds for Chile (Chap. 3). In sharp contrast, Brazil shows stable inequality in the early decades followed by a rising trend in the middle decades which levels off in the closing decades. This characterization is consistent with what Buccifferro reports regarding Brazilian racial inequality in Chap. 8. A common feature found by Astorga is the existence of a sustained, even if moderate, narrowing of wage inequality in the middle decades of the twentieth century. However, that narrowing was offset by a rising share received by the top group, so that polarization widened during the period in all six economies, with the exception of Mexico. After 1970, the labor share fell while the mean income of the top earners rose, the clear winners over the last century. Another stylized fact revealed by Astorga's new estimates is that countermovements took place: there was increasing polarization between the income levels at the two extremes of the social scale, while the share of the middle increased. These contradictory trends appear to be consistent with a society composed of two parts, a traditional one in which unskilled rural labor coexisted with rich landowners, and a modern one in which migration from the countryside ended up in more diversified urban activities, with higher productivity and higher wage inequality. Later on, a large part of this urban labor force was transformed into informal low-skilled workers, thus increasing inequality. In any case, Astorga's contribution begins to fill a gap in our knowledge which will influence our thinking about Latin American inequality across the twentieth century.

In Chap. 3, Javier Rodríguez Weber explores income inequality in Chile since the $1850 \mathrm{~s}$. He provides a continuous series that reveals historically high and persistent inequality, with a wave-like pattern. Inequality rose until the 1870 s, then decreased after the Pacific War, due to a huge expansion of its northern and southern frontiers. Inequality rose again during the first decades of the twentieth century with the climax of export-led growth. The Great Depression mainly damaged the income of the elites, while, like Uruguay, inequality fell after World War II. As in Argentina and Uruguay, inequality rose significantly during the military dictatorship. After more than two decades of democracy and center-left governments which followed the dictatorship, inequality was little changed.

Chile shows very high inequality levels today, among the highest in the world. This fact calls for explanations. Rodríguez Weber argues that the elite have been able to shape the economic and political institutions in its favor. This power was rooted in the high concentration of wealth and the oligopolistic market structure which not only promotes high inequality but also undermines democratic institutions. The power of the elite has deep historical roots. Since the nineteenth century, the landowning interests in the Central Valley were able to control a weak peasant population that lived in the haciendas. 
The Mexican case is analyzed in Chaps. 4 and 5 using quite different evidence. Moromay López Alonso and RobertoVélez Grajales exploit data on heights to measure improvements and inequality in well-being. Using two different sources (passports and the army) they find increasing social inequality up to the 1930s. Differences between regions were less important than the inequality within regions. Since the 1930 s, the poor population benefited by national public health campaigns as well as a (modest) rise of the welfare state thus reducing inequality; before then, the majority of the population was excluded from health services and lacked opportunities for advancement. Using data for the period from the 1950s onwards, the authors conclude that inequality is higher among women, and that there exists a clear downward bias against the agrarian population. In short, it seems that inequality in living standards was reduced mainly during the central decades of the twentieth century. It continued to decline thereafter, but at a slower pace, and remaining high. In Chap. 5, Campos, Domínguez, and Márquez construct a Human Development Index for Mexico from 1895 to 2010 with data at the subnational level for illiteracy rates, urbanizations rates, and the number of physicians per capita, as proxies for education, income, and health, respectively. The authors find a significant increase in human development as well as some evidence of regional convergence, especially between 1940 and 1980. However, regional disparities increased again after the 1980s. In short, these studies of the Mexican experience seem to confirm two main features: inequality was high and persistent; and inequality was reduced only during the central decades of the twentieth century, but rose again during the last two decades of the century.

The Brazilian case is analyzed in Chaps. 6, 7, and 8 with quite different approaches.

In Chap. 6, Pedro Funari studies the varied development patterns in four Brazilian states (Minas Gerais, Pernambuco, São Paulo, and Rio Grande do Sul), which, given their different initial resource endowments and colonial experience, would be expected to have different de facto institutions. He explores the connection using standard land concentration measures, and a proxy for political concentration (the percentage of eligible voters), all at the municipal level. His results support the idea that it is difficult to find general rules for the relation between growth and inequality. In the fast growing states of Minas Gerais and São Paulo, he found a positive relationship between inequality in 1920 and development outcomes in 2000. The contrary is found in the southern state of Rio Grande do Sul. Pernambuco, a northeastern state, presents no evidence of a significant relationship between prior inequality and subsequent long-term development outcomes. With respect to political inequality and development, no significant relationship could be found. Funari explains this latter result as depending on the limited formal power of voters in relation to other more important de facto sources of power. It is also probable that inequality among landowners is not the best way to capture the impact of inequality on growth, especially when the economy becomes less dependent on agriculture and when the dynamic sectors are mainly urban. In any case, what seems to be confirmed is that Brazilian economic growth during most of the twentieth century was compatible with a very high level of inequality. 
In Chap. 7, Eustaquio Reis studies spatial inequality in Brazil by means of an ambitious reconstruction of data at the municipality level for the period 1872-2000. His approach is quite different from that of Funari (Chap. 11), since Reis emphasizes the role played by geography (land quality, climate, and transport costs), rather than informal institutions. He concludes that spatial inequalities did not experience significant changes over those 130 years: the rate of convergence is much slower than those found in other countries. The period of import substituting industrialization appears to have lowered regional inequality, while export-led growth increased it. Infrastructure development (particularly the railways) was important: the lack of adequate infrastructure investment was a major determinant of relatively slow growth. The only "institutional" factor that had an important impact on growth was the immigration rate, while human capital, slavery, land concentration, and political participation were not significant determinants of per capita income and productivity.

In Chap. 8, Justin Bucciferro studies racial inequalities in Brazil since the early nineteenth century, by analyzing data on income, primary school completion rates, literacy rates, life expectancy at birth, and occupation, augmented with qualitative sources. White, black, mixed race, indigenous, and Asian individuals were considered. He finds that progress has been made in the reduction of racial inequality in terms of health, education, and access to certain occupations, like industrial employment. However, racial disparities are still very large, and income gaps have not been significantly reduced. Bucciferro emphasizes how small the impact of emancipation on racial income gaps was since European immigrants undercut the bargaining power of the libertos. The Vargas populist period was the one in which most progress was made, while 1945-1980 recorded years of regression or stagnation in racial inequality. However, important progress was made during the last decades of the twentieth century and racial inequality seems to be at its lowest level today. If it is assumed that once ethnic-based inequality is reduced through cultural change and political empowerment, it should prove difficult to revert to previous levels. Thus, reductions in ethnic inequality should be long-lasting.

In Chap. 9, José Alejandro Pérez-Cajías asks whether the Bolivian Revolution of 1952 led to a significant institutional change in the delivery of education. His findings are based on the construction of impressive new evidence. After the revolution and until the 1980s, tax collections remained among the lowest in Latin America. Nevertheless, education spending as a share of GDP converged on Chile and Uruguay, two of the most developed Latin American countries. However, the quality and distribution of Bolivian education was not significantly modified: public spending on education was low and educational outputs were often among the worst in the region. Obviously, the main explanation for this was that per capita GDP remained extremely low in Bolivia. The question still unanswered is whether an increased effort in the educational system could have enhanced growth performance in the decades following the revolution.

In Chap. 10, María Camou and Silvana Maubrigades explore gender inequality in five Latin American countries (Argentina, Brazil, Chile, Mexico, and Uruguay). They find a tight correlation between total income inequality and the gender income gap. Those countries showing a lower gender wage gap are those that were 
successful in incorporating a larger share of women in the labor market in the first decades of the twentieth century, together with higher educational achievement. The countries with bigger gender gaps are those where women were incorporated into the labor market more slowly and which had a higher share of Indian and black workers with whom women first compete. The gender wage gap also increased throughout the period, a result consistent with their relative supply growth. In spite of their rising educational attainment, women are still underrepresented in the high-wage occupations.

In Chap. 11, Leticia Arroyo-Abad and Peter Lindert present a multi-country history of how Latin American government spending and taxes have reshaped the distribution of income. They combine historical time series for six countries with evidence on fiscal redistributions in the twenty-first century. While Latin America has followed the international trend with social spending increasing with per capita GDP growth, this social spending has not had a big distributional impact. As it turns out, the elderly have been favored by social spending in the form of pensions, and not by education and infrastructure that might have targeted the non-rich. Even though the redistribution did not favor the poor, its impact was still moderately positive, since social spending is distributed less unequally than pretax income and since the tax system is slightly progressive. The Southern Cone countries distributed more in favor of the elderly, but they were also most progressive in redistribution.

\section{Part II: The Recent Inequality Downturn}

The recent inequality decline in Latin America poses several questions. The first is whether inequality actually declined or whether it was mainly the result of incomplete data or incorrect measurement. The recent literature on top incomes has shown how much our perception of inequality can change if the results of household surveys are corrected by accurate measures of the income of the elite. Unfortunately, information on top incomes is still scarce: series for the twentieth century are only available for Argentina from the mid-1930s, for the first decade of this century they are only available for Argentina and Colombia, and estimates for a few recent years are available for Uruguay. By combining household surveys and top income figures, a more complete view of income distribution can be achieved, even though no clear conclusions can yet be drawn from so few cases. However, the World Bank (2014, pp. 35-39) concludes that while the drop in inequality is certainly moderated when top incomes are considered (for the limited sample), the downturn shown by household surveys still holds.

Important research has recently been reported on the recent downturn. LópezCalva and Lustig (2010), as well as the same authors together with Campos et al. (2016)), argue that a fundamental factor behind the decline in income inequality is the rise in supply of workers with post-secondary education. The case of Mexico is particularly important, as it is the case of an economy that experienced neither a commodity boom nor fast growth. 
Cornia (2014) concludes his edited volume stating that the inequality decline across the whole of Latin America can be characterized as a Polanyian process, in the sense that several social and political forces reacted against the outcomes of globalization and liberalization in the late twentieth century, with the result of increasing inequality. He concludes that inequality cannot be further reduced if some structural biases, as the lack of industrial policy, low savings, dependence on foreign capital, dependence on a few commodities, and reprimarization, remain unaddressed.

ECLAC has also been active in this field, producing a trilogy of reports with inequality at the center $(2010,2012,2014)$. These reports, while taking into consideration the role played by market forces, emphasize the role played by other social factors, as, for example, labor market institutions and the impact of the activity rate, including gender issues. Moreover, ECLAC emphasizes the political character of distributional issues and links inequality reduction to the structural transformation of the Latin American economies.

What follows is then a partial list of possible explanations for the inequality decline. First, improvements in education which augmented the supply of skilled labor, thus putting downward pressure on the skill premium. To that extent, schooling might have won the race with technology (Goldin and Katz 2008). Second, if growth based on maquila-industries and natural resource processing favors the demand for unskilled labor, inequality might diminish on this count as well. Third, fast growth associated with the commodity boom should have raised the employment rate, thus raising the income of the lowest deciles. Fourth, to the extent that political shifts favored pro-poor labor market policies-minimum wages, wage councils, formalization of employment, social transfers, and the like - an inequality downturn should be reinforced. Finally, the consolidation of democratic rule in most of Latin America should have weakened the tacit power of the elite and thus the importance of their opposition to pro-poor policies.

The following chapters confirm some of the previous studies, add new evidence, explore new topics (as structural change and fiscal policies), and offer some indepth political economy studies of national cases.

In Chap. 12, Verónica Amarante and Antonio Prado present a summary of ECLAC's findings published in what is called the equality trilogy (2010, 2012, 2014). While accepting the role played by demand and supply forces in the recent inequality decline, they stress the role played by labor market institutions. Minimum wage increases, for instance, accounted for a third of the recent drop in Argentina's Gini-coefficient, for $84 \%$ in Brazil and for $7 \%$ in Uruguay. Their research also finds that changes in formal employment shares and wage differentials between formal and informal jobs are as important as returns to education and changes in schooling levels - although there is considerable variance across the countries studied. The chapter also documents participation rates and income gaps by gender: the region exhibits great variation, some countries exhibiting huge gender gaps, and others almost parity. An exercise is performed exploring the impact on income inequality if these gender gaps closed. In the case of the labor participation rate, a reduction of about $5 \%$ points would be achieved in the poorer Latin American countries. In the case of income gaps, a reduction of about $4 \%$ would be achieved. 
In Chap. 13, Augusto de la Torre, Julian Messina, and Joana Silva confirm the recent decline in labor income inequality and conclude, in line with López-Calva and Lustig, that such changes were driven by labor market behavior. Furthermore, the reduction was largely driven by a decline in the skill premium (returns to tertiary vs. primary education). They note, however, that a similar increase in the supply of skilled workers took place in the 1990s, while inequality worsened. To account for the difference, they argue that in the recent decade technical change displaced old skills thus producing some knowledge obsolescence.

In Chap. 14, Diego Sánchez-Ancochea adopts a multidisciplinary approach to study the political economy of policymaking to learn about the explanations for Chile's high inequality. He confirms the persistent concentration of income at the top also found by Rodriquez Weber (Chap. 3). A few business groups control large segments of the economy, featured by high market and capital concentration, conditions that limit action by the State at the sector level. On the other hand, the State has been playing an increasingly active role in redistribution through social policy, thus creating opportunities for new progressive cross-class coalitions. In this context, the progress to be made on the margin depends mainly on the capacity to increase the tax burden of the elites. Thus, no radical changes are to be expected, unless more radical political changes take place.

In Chap. 15, Martin Andersson and Andrés Palacio ask whether the recent reduction in income inequality was driven, at least in part, by an agricultural resurgence, that is, whether the reduction of the rural-urban income gap played an important role. This seems to be the case, as agricultural labor productivity grew faster than in other sectors, reducing the intersectoral productivity and income gap. Nevertheless, the authors point to the fact that a new situation has appeared, featured by the increase in the share of the labor force employed in low productivity urban (especially informal) sectors. Thus, a new pattern of urban inequality may be replacing the old one of rural inequality. Furthermore, agrarian inequality can remain an important influence since productivity growth has been taking place mainly in large and capital intensive estates.

In Chap. 16, Judith Clifton, Daniel Díaz-Fuentes, and Julio Revuelta also explore the impact of fiscal policy on Latin American inequality, this time from 1960 to 2012. They find that fiscal policy had a much bigger influence during the period 1999-2012, than before. For the earlier years, fiscal policy had either a regressive or insignificant impact on inequality. During the more recent period, they find that the impact was higher in revenues than in expenditures. Furthermore, expenditures had a much bigger impact in urban than rural areas. With respect to revenues, direct taxation had a much more important impact on inequality reduction than indirect taxes. Given the fact that the tax burden in Latin America is much lower than in OECD countries, it is clear that a policy which increases the direct tax burden as per capita income grows would erase some inequality - although that might be hard to achieve politically.

Finally, in Chap. 17, Suzanne Duryea and coauthors recognize the recent achievements made by Latin American countries in terms of poverty and inequality reduction. But they then ask whether those achievements are sustainable and explore the possibility that the inequality downturn might cease or even reverse. They focus on three main 
policy areas that should help insure continued progress: an improved efficiency of social policy and the quality of services provided; the promotion of income stability and protection without distorting workers' incentives; and the exercise of caution with respect to the creation of potentially costly and irreversible commitments.

So, what do we conclude about recent Latin American inequality trends? While there has been great variety across Latin America, it appears that the recent inequality reduction was due, at least in part, to very specific conditions associated with the commodity boom. The boom raised labor participation and lowered unemployment, favoring those at the bottom of the distribution and thus reducing inequality. What the boom giveth, the bust can taketh away. But the boom combined the impact of long-run improvements in human capital formation (lowering skill premiums), with an increased demand for unskilled work linked to the export-led boom. More fundamentally, a cluster of socio-political shifts favored labor. The new wave of democratization strengthened the voice of the poor, and their demands for education, health, and social transfers. A number of leftist governments and center-left alliances promoted the development of different labor market institutions, which contributed to the income leveling. Tax reforms were introduced in many countries, which, combined with better designed spending, has helped improve conditions in the lower deciles. Minimum wages were raised in several countries, having an important impact on distribution.

An important conclusion is then that it is not possible to reduce the explanation of inequality reduction to a single cause. Inequality was reduced even in countries, as Mexico and El Salvador, that did not experience a commodity boom. The commodity boom cannot per se explain inequality reduction: Latin American economic history shows that commodity booms often led to increasing inequality and the actual results of booms and busts in terms of inequality cannot be understood without political economy considerations. When considering political economy issues, the role of the past becomes important, in the sense of understanding the origins and development of Latin American economic, social, and political forces.

The big question is whether this process of declining inequality will be sustained and deepened. Many of the forces that were driving the leveling of incomes now are gone. The commodity boom has disappeared, and some of its positive impacts may be reversed. The activity rate will probably decline and unemployment will probably rise. Demand for unskilled work will probably decline. On the other hand, investment in social spending may favor education in its race with technology (Goldin and Katz 2008), pressing inequality downwards.

Democratic rule is now a permanent feature in Latin America. We can, of course, doubt its quality. State powers are still weak, domestic and foreign elites still have an influence on governments, and state bureaucracies are still lacking important capabilities. The risk of mismanagement of social revenues and expenditures is always present, and the possibility that antidemocratic regression might prevail in critical situations cannot be excluded.

The future of inequality is not only a matter of pure market forces but also on how labor market institutions and the political climate evolve. 
Open Access This chapter is distributed under the terms of the Creative Commons Attribution 4.0 International License (http://creativecommons.org/licenses/by/4.0/), which permits use, duplication, adaptation, distribution and reproduction in any medium or format, as long as you give appropriate credit to the original author(s) and the source, a link is provided to the Creative Commons license and indicate if changes were made.

The images or other third party material in this chapter are included in the work's Creative Commons license, unless indicated otherwise in the credit line; if such material is not included in the work's Creative Commons license and the respective action is not permitted by statutory regulation, users will need to obtain permission from the license holder to duplicate, adapt or reproduce the material.

\section{References}

Bértola, L. (2005). A 50 años de la Curva de Kuznets: Crecimiento y distribución del ingreso en Uruguay y otras economías de nuevo asentamiento desde 1870. Investigaciones en Historia Económica, 3, 135-176.

Bértola, L. (2011). The institutional roots of Latin American divergence (Chapter 2). In J. A. Ocampo \& J. Ros (Eds.), The Oxford handbook of Latin American economics (pp. 26-49). Oxford: Oxford University Press.

Bértola, L., Castelnovo, C., Rodríguez Weber, J., \& Willebald, H. (2010a). Between the colonial heritage and the first globalization boom: on income inequality in the Southern Cone. Revista de Historia Económica, 28, 307-341.

Bértola, L., Gelman, J., \& Santilli, D. (2015). Income distribution in rural Buenos Aires, 1839-1867. Revista Uruguaya de Historia Económica, 2, 14-28.

Bértola, L., \& Ocampo, J. A. (2012). The economic development of Latin America since independence. Oxford: Oxford University Press.

Bértola, L., Prados de la Escosura, L., \& Williamson, J. (2010b). Latin American inequality in the long run. Revista de Historia Económica, 28, 219-226.

Campos, R., Lopez-Calva, L. F., \& Lustig, N. (2016). Declining wages for college-educated workers in Mexico: Are younger or older cohorts hurt the most? Policy Research Working Paper, No. WPS 7546. Washington, DC: World Bank Group.

Cardoso, C. F. S., \& Brignoli, H. P. (1979). Historia Económica de América Latina (vol. 1 and 2). Barcelona: Crítica.

Coastworth, J. H. (2008). Inequality, institutions and economic growth in Latin America. Journal of Latin American Studies, 40, 545-569.

Cornia, G. A. (Ed.). (2014). Falling inequality in Latin America: Policy changes and lessons, WIDER studies in development economics. Oxford: Oxford University Press.

ECLAC. (2010). Time for equality: Closing gaps, opening trails. Santiago de Chile: ECLAC.

ECLAC. (2012). Structural change for equality: An integrated vision of development. Santiago de Chile: ECLAC.

ECLAC. (2014). Compacts for equality. Santiago de Chile: ECLAC.

Engerman, S. L., \& Sokoloff, K. L. (1997). Factor endowments, institutions, and differential paths of growth among new world economies. In S. Haber (Ed.), How Latin America fell behind (pp. 260-304). Stanford, CA: Stanford University Press.

Engerman, S. L., \& Sokoloff, K. L. (2012). Economic development in the Americas since 1500: Endowments and institutions. New York: Cambridge University Press.

Goldin, C., \& Katz, L. (2008). The race between education and technology. Cambridge, MA: Belknap Press for Harvard University Press. 
Lindert, P. H., \& Williamson, J. G. (2016). Unequal gains: American growth and inequality since 1700. Princeton, NJ: Princeton University Press.

López-Calva, L. F., \& Lustig, N. (2010). Declining inequality in Latin America. A decade of progress? Washington, DC: Brookings Institution and UNDP.

Marrero, G. A., \& Rodriquez, J. G. (2013). Inequality of opportunity and growth. Journal of Development Economics, 104, 107-122.

Milanovic, B., Lindert, P., \& Williamson, J. (2011). Pre-Industrial Inequality. Economic Journal $121,551,255-272$.

North, D. C., Weingast, B., \& Summerhill, W. (2000). Order, disorder and economic change. Latin America versus North America. In B. Bueno de Mesquita \& H. L. Root (Eds.), Governing for prosperity (pp. 17-58). New Haven: Yale University Press.

Piketty, T. (2014). Capitalism in the twenty-first century. Cambridge, MA: Belknap Press for Harvard University Press.

Prados de la Escosura, L. (2007). Inequality and poverty in Latin America: A long-run exploration. In T. J. Hatton, K. H. O'Rourke, \& A. M. Taylor (Eds.), The new comparative economic history (pp. 291-315). Cambridge, MA: MIT Press.

Robinson, J. (2006). El equilibrio de América Latina. In F. Fukuyama (Ed.), La brecha entre América Latina y Estados Unidos. Argentina: Fondo de Cultura Económica.

Salvucci, R. (2014). Capitalism and dependency in Latin America. In L. Neal \& J. G. Williamson (Eds.), The Cambridge history of capitalism: Volume I: The rise of capitalism: From ancient origins to 1848 (pp. 403-430). Cambridge: Cambridge University Press.

Williamson, J. G. (2010). Five centuries of Latin American inequality. Journal of Iberian and Latin American Economic History, 28(2), 227-252.

Williamson, J. G. (2015). Latin American inequality: Colonial origins, commodity booms, or a missed 20th century great leveling? Journal of Human Development and Capabilities (Special Issue), 16, 324-341.

World Bank. (2014). Inequality in a lower growth Latin America. Semiannual report. Washington, DC: Office of the Senior Regional Chief Economist.

Luis Bértola holds a Ph.D. in Economic History and an M.Sc. in Economic History from the University of Gothenburg, Sweden. He was research vice-rector at the Universidad de la República, Uruguay, and the Dean of Social Science and professor of economic and social history at the same university. He has worked as advisor for the Economic Commission for Latin America and the Caribbean, the Inter-American Development Bank, and the Uruguayan Budget and Planning Department.

Jeffrey Gale Williamson is Laird Bell Professor of Economics, emeritus, Harvard University. His most recent books are The Spread of Modern Manufacturing to the Periphery since 1870 (forthcoming Oxford: ed. with Kevin O'Rourke); Unequal Gains: American Growth and Inequality since 1700 (Princeton 2016: with Peter Lindert); The Cambridge History of Capitalism (Cambridge 2014: ed. with Larry Neal); and Trade and Poverty: When the Third World Fell Behind (MIT 2011). 


\section{Part I \\ Long-Run Trends}




\title{
Functional Inequality in Latin America: News from the Twentieth Century
}

\author{
Pablo Astorga Junquera
}

\section{Introduction}

Two things are certain about income inequality in Latin America: first, that inequality reached very high levels in the closing decades of the twentieth century, and, second, that it has shown a broadly shared narrowing trend in the last 10 years or so of this century. ${ }^{1}$ This evidence, based on comprehensive and largely consistent household budget surveys, raises crucial questions. Those concerned about the future are keen to know if this is a sustainable and lasting improvement that can survive the end of the recent commodity boom that has helped to finance redistributive policies. Those studying long-term inequality and its determinants would like to know whether inequality has always been high - a structural feature of these societies, or rather whether the structural transformation and changes in development policies have been key forces shaping the inequality outcome in the region.

According to the dominant view of the institutionalist approach (Engerman and Sokoloff 2000; De Ferranti et al. 2004), the story of a highly unequal region largely reflects the persistence of the actions and omissions of the Iberian colonisers. However, this claim is somehow at odds with evidence that Latin American countries in the pre-industrial era were not especially unequal in an international comparison (Dobado and Garcia 2010; Milanovic et al. 2011). Also, inequality estimates during the First Globalisation show a rising trend from circa 1870 to 1920 in countries in the Southern Cone (Williamson 1999; Willebald 2011; Arroyo 2013), indicating that the region's relatively high inequality is mainly a late nineteenth-century

\footnotetext{
${ }^{1}$ Income inequality in Latin America since 1980 or so has been widely studied. Some of the key contributions are Morley (2000), López and Perry (2008), López-Calva and Lustig (2010), Széquely and Sámano (2012), Gasparini et al. (2011) and Birdsall et al. (2011). Urrutia (1975) surveys inequality studies and data in Colombia, Mexico and Venezuela covering the middle decades.
}

P.A. Junquera $(\bowtie)$

Instituto Barcelona de Estudios Internacionales (IBEI), Barcelona, Spain 
phenomenon - though conditioned by inherited structural features. The latest revisionist contribution is Williamson (2015) who, adopting a comparative perspective, argues that the colonial inequality burden is a myth. Myth or not, concerns about this burden seem to have been overemphasised in the literature at the expense of focusing on the influence of forces acting in a more recent period. It is as if, when trying to understand certain characteristics of a child, we give priority to investigating the lives of the great grandparents and fail to ask basic questions about the parents and the sort of upbringing they provided.

Therefore, without assuming that the Big Bang occurred in 1900, this study will focus on inequality in the twentieth century and possible explanatory factors acting within this period. Here there are interesting inequality stories that we would like to explore in the light of a new historical dataset. First, we consider the implications of the different development and growth strategies implemented over the century (FitzGerald 2008; Prados de la Escosura 2007; Bértola 2005; Frankema 2012). Second, by adopting a functional approach in the construction of our inequality estimates, we are in a position to track the distributional fate of different occupational groups, particularly those of the top earners (dominated by property income) and the earnings of the unskilled. Thus we can study in a broader time frame Palma's (2011) findings of the dominance of centrifugal forces operating in highly unequal middle-income countries (and in particular Chile and Mexico under neo-liberal reforms since the 1970s) that resulted in increasing income polarisation. Third, in a global comparative perspective, this is the century of the "Great Levelling" from 1913 to the 1970s in the leading industrial economies (Atkinson et al. 2011; Lindert and Williamson 2016, Chap. 8). And it is of interest to know whether Latin America experienced a similar phenomenon, and, if not, why not.

In recent years there have been important efforts in quantifying inequality in the region in the longer term. Regarding multi-country studies, ${ }^{2}$ Williamson $(1999,2002)$ teased out developments in inequality by calculating ratios of GDP per worker to unskilled wages in the pre-WW2 period for a set of periphery countries (including Argentina, Brazil, Colombia, Cuba, Mexico and Uruguay). ${ }^{3}$ Based on Williamson's inequality ratios and available household-survey Ginis, Prados de la Escosura (2007) constructed pseudo-Ginis over the last century for Argentina, Brazil, Chile and Uruguay (adding Colombia and Mexico since 1913). Frankema (2010) studied the pattern of change in the distribution of labour income shares in Argentina, Brazil and Mexico during the twentieth century, finding that in all three countries the labour income share peaked in the middle decades of the last century. Also Frankema (2012) examines the long-run industrial wage inequality in Argentina, Brazil and Chile based on benchmark industrial surveys and census data.

\footnotetext{
${ }^{2}$ At a country level there are long-term inequality series for Uruguay (Bértola 2005) and Chile (Rodriguez Weber 2014). Both studies are valuable inputs to our work.

${ }^{3}$ Bértola et al. (2010) constructed Gini benchmarks (based on census data) for Brazil, Chile and Uruguay. But, unfortunately for our purposes, such benchmarks are far apart and with only one Gini in the twentieth century (1920), so that they do not provide an indication of trends.
} 
However, one important limitation of the above contributions is that they only provide a partial picture of long-term trends, as they either cover a limited period; are based on benchmark years; concentrate on a small sample of countries; or do not make allowances for non-labour income. These limitations make it difficult to provide a comprehensive picture of long-run inequality, particularly one that can link in a consistent manner outcomes from the pre-official statistics period with those of the more recent decades with regular household surveys. Some of these limitations are addressed by FitzGerald (2008) who assembles a consistent set of yearly estimates of earnings for four occupational groups that are used to generate Gini coefficients for the 1900-2000 period for Argentina, Brazil, Chile, Colombia and Mexico. However, one important shortcoming of these Ginis is that they rely on sectoral series of output per economically active person to estimate earning levels in two of the four skill groups. This implies well-functioning markets, a strong assumption for a developing region, particularly during the first half of the last century. Also, sectoral productivity estimates are subject to a large margin of error in the early decades.

Therefore, the first step to study secular inequality and its determinants in the region is to construct consistent and comparable series covering the long run. In this chapter we adopt the approach used by FitzGerald but calculate the Ginis using a newly assembled dataset of real wages for three occupational categories of the labour force (low skilled, semi-skilled and skilled labour). In this way we can offer new yearly series of functional inequality for Argentina, Brazil, Chile, Colombia, Mexico and Venezuela (LA-6) since 1900. Together the LA-6 have accounted for more than $80 \%$ of the region's population and income since 1900. Perhaps the main virtue of this work is to put on the table estimates that should inform us about longterm inequality and about differences and similarities across countries. Moreover, the methodology adopted can give a rough indication of the property-labour income split, as well as the relative contributions made by the income share received by the top earners (dominated by non-labour income) and by wage inequality (based on the three wage series).

When dealing with inequality in Latin America it is usually assumed that there exists a broad commonality in both patterns and timing across countries, so that regional averages are representative of individual country performance. Examples of this view include the use of a Latin American dummy in cross-country studies and its interpretation (Barro 2000), or the prominence given to a shared institutional heritage that perpetuates a common path of high inequality in the region (Bourguignon and Morrisson 2002). However, to the extent that country-specific factors have played a dominant role, regional averages might not be representative enough and general claims about inequality in the region would need to be qualified, or indeed avoided, if the dispersion is high. Commonality and divergence are two aspects to which we pay special attention here.

For the sake of brevity, this chapter concentrates on three aspects: the methodology used in the construction of the inequality series; the analysis of the contributions of the top income group, on the one hand, and wage inequality, on the other; and regional averages. We largely leave for a future publication a more rigorous analysis of fundamental forces associated with structural change, factor endowments, 
demographic transitions and commodity cycles. The remainder of the chapter is structured as follows. Section 2 summarises the methodology used to construct the functional (between groups) Ginis and provides complementary evidence on the estimation of incomes of the top group. Section 3 presents the new Ginis by country and a comparison with other inequality measures, and looks at the relative contributions of the top income group and of wage inequality. Section 4 presents regional averages. An Appendix includes charts by country.

\section{Methodology ${ }^{4}$}

Our method is akin to that used in the construction of dynamic social tables (combining benchmark years from censa data with annual data on income from other sources) for Uruguay (Bértola 2005) and Chile (Rodríguez Weber 2014), as well as social tables (using only selected benchmark years) in pre-industrial societies (Milanovic et al. 2010; Lindert and Williamson 1982). ${ }^{5}$ In our case, we rely on annual income series (of overall income and three wage categories) and interpolation between benchmarks for the shares of economically active population (EAP). Following the occupational categories used in ECLAC (2000), for each country we divide the EAP into four groups: Group 1 (employers, managers and professionals); Group 2 (technicians and administrators); Group 3 (semi-skilled blue-collar workers, other urban workers in relatively low-productivity sectors such as retailing and transport, and artisans); and Group 4 (rural workers and personal serviceincluding domestic servants - plus unskilled urban workers and street vendors). To ensure consistency with the overall EAP series, the labour force in Group 3 is calculated as a residual.

The main rationale for drawing the distinction between the four groups is differences in education levels and skills. ${ }^{6}$ This has been a key factor in explaining inequality in the region in recent decades (Morley 2000; Contreras and Gallegos 2011). The reduced number of groups reflects data limitations during most of the period covered, especially on income. ${ }^{7}$ Also some arbitrary aggregation is difficult to avoid. For instance, in Group 1 owners of capital and landlords are lumped together with managers and professionals. This group is dominated by non-wage

\footnotetext{
${ }^{4}$ For more details on procedure, assumptions, data issues, sources and by-country figures on employment shares and income ratios see the background paper (Astorga 2015a), particularly annexes $\mathrm{B}$ and $\mathrm{C}$.

${ }^{5}$ Our method is also in the spirit of the distribution tables (with three main groups: the bottom $50 \%$, the middle $40 \%$ and the top $10 \%$ ) used by Piketty (2014, Part III), although a key difference is that, in our case, the relative size of our income groups varies over time.

${ }^{6}$ The mean years of education by each of the four groups circa 2000 are estimated by ECLAC as 11.4 years for Group 1; 11.2 years for Group 2; 6.5 years for Group 3; and 3.5 years for Group 4. ${ }^{7}$ One example of groupings with higher data demands is Portes and Hoffman (2003) who work with six groups defined by their control over skills and capital and their incorporation into the modern economy.
} 
income, including property income and compensation for labour. Group 2 includes a mix of manual and clerical workers (or blue- and white-collar workers) with comparable years of formal education (e.g. bank tellers, typists, mechanics, turners). Group 3 lumps together urban informal workers with precarious incomes and highly skilled artisans with rather secure employment. Some administrators of micro firms included in Group 2 can have earnings below those of relatively qualified workers in commerce included in Group 3. Finally, Group 4 comprises unskilled rural workers, together with workers in personal services, including domestic services, largely in urban areas.

Based on the four occupational categories we calculate the EAP share of each group $\left(n_{i}\right)$, the income share of each group $\left(s_{i}\right)$, the mean income in each group $\left(y_{i}\right)$ and the ratio of the mean income in each group to that for the EAP as a whole $\left(r_{i}\right)$. We have then a functional income distribution defined as

$$
\sum_{i}^{4} n_{i} r_{i}=1
$$

The income share for Group $1\left(s_{1}\right)$ is defined as the residual by subtracting the income shares for the other three groups. This is then divided by the respective proportion of the EAP to yield the group's relative income level:

$$
r_{1}=s_{1} / n_{1}=\left\{1-\sum_{2}^{4} n_{i} r_{i}\right\} / n_{1}
$$

The income of Group 1 is likely to capture income from property (profits, dividends, interest, and land and natural resource rents) for all the EAP, together with earnings from highly paid workers. ${ }^{8}$ Because of the way it is calculated, the income for this group may be subject to a significant margin of error. However, this method is likely to generate better estimates in Latin America than calculations based on tax data (famously unreliable to gauge income at the top, if available at all) and on household surveys (which are only available for the later period and tend to miss information on top earners). At the end of this section we offer some complementary evidence showing that, in general, our estimates for the first half of the last century are consistent with data available on top earners. Also, in the following section we provide some additional consistency checks for our calculated $s_{1}$ based on comparisons with official estimates of property income shares available for the second half of the century.

To estimate mean earnings of the remaining three occupational groups we rely on three real wage series assembled to reflect, when possible, differences in skills: relatively high, medium and low. We use the same deflator (usually the CPI) for

\footnotetext{
${ }^{8}$ The long-term evidence in developed economies (Piketty 2014) shows that income from property tends to be concentrated in the individuals included in our top group, which means that the misplacement of property income of individuals included in the middle and bottom groups is unlikely to be significant.
} 
both overall income per worker and wages, so that the ratios are equivalent to those calculated from nominal values. There is a possibility that we are overestimating earnings in Group 3 by assigning the average semi-skilled wage to all workers in the group which is calculated as a residual and is likely to include workers in the informal sector. We performed sensitivity analysis to our inequality results by assigning the minimum urban wage to the estimated informality share post- $1950,{ }^{9}$ and found no significant impact.

The methodology used to estimate gross income inequality is subject to a number of potential measurement biases associated with the subsistence economy and the unemployed. As to the size of the subsistence economy there is little systematic and consistent evidence for our countries which could be used to make a correction. Subsistence agriculture was particularly important in the early decades of the last century in Brazil, Colombia, Mexico and Venezuela, and less so in the relatively more advanced and urbanised economies of Argentina and Chile (Berg 1970). To the extent that the measured overall income underestimates the subsistence economy, our estimates are biased against inequality because it would reduce the actual size of Group 1's income, which is calculated as a residual. However, this potential bias may be offset by the equally likely underestimation of those working outside the market economy in the EAP data. The latter would result in an underestimation of the relative importance of Group 4's earnings and, as a consequence, in higher inequality.

Regarding unemployment, there is a potential bias when estimating earnings at group level. Since the average wage is taken as a proxy for average earnings of the three lower income groups, any variance in the unemployment rate across groups will impart errors in our estimates. Thus at times of high unemployment, our series will overestimate $r_{2}, r_{3}$ and $r_{4}$, and underestimate $r_{1}$, underestimating inequality. This problem can be especially relevant during the early years of the Great Depression or during the outbreak of the Debt Crisis in the 1980s. In order to minimise the potential impact of this bias, we calculate deviations of the unemployment rate (where such data are available) from an assumed long-term rate (as a proxy for the natural rate of unemployment) and then adjust our overall income per worker series accordingly.

Table 1 presents a summary of our estimated EAP shares and relative income ratios for the top and bottom groups for selected years. Differences among the countries' EAP shares are largely driven by variations in the urbanisation process, timing of the structural change and improvements in the education level of the labour force. Broadly speaking, Argentina and Chile already had significant urban populations by 1900 reflected in relatively lower values for the economically active persons in Group 4 dominated by low-paid workers in rural areas, whereas according to these estimates, Brazil, Colombia, Mexico and Venezuela started the twentieth century with shares for that group between 65 and $75 \% .{ }^{10}$ All six countries had inflection points (preceding acceleration) in population growth in the 1930s and in urbanisa-

\footnotetext{
${ }^{9}$ The average share of urban informality reported for the region during the early 1950 s and late $1970 \mathrm{~s}$ is about 25\% (PREALC 1982). We estimate that Group 3 may include $10 \%$ and Group $415 \%$.

${ }^{10}$ The estimates for the urbanisation rates circa 1900 are Argentina $38 \%$, Chile $34 \%$, Brazil $23 \%$, Mexico 28.3 and Venezuela $11 \%$. The first observation available for Colombia is $30.9 \%$ in 1938 . Our calculations are based on censa data.
} 
Table 1 EAP shares and relative income ratios, selected groups and years

\begin{tabular}{l|l|l|l|l|l|l|l|l|l|l|l|l}
\hline & \multicolumn{1}{l|}{ Argentina } & \multicolumn{1}{l}{ Brazil } & \multicolumn{3}{l}{ Chile } \\
\hline & $n_{1}$ & $n_{4}$ & $r_{1}$ & $r_{4}$ & $n_{1}$ & $n_{4}$ & $r_{1}$ & $r_{4}$ & $n_{1}$ & $n_{4}$ & $r_{1}$ & $r_{4}$ \\
\hline 1900 & 4.0 & 39.0 & 11.3 & 0.42 & 3.5 & 72.5 & 6.9 & 0.57 & 6.0 & 42.1 & 7.5 & 0.28 \\
\hline 1920 & 4.3 & 35.2 & 12.5 & 0.32 & 3.9 & 69.0 & 8.4 & 0.54 & 5.1 & 41.9 & 9.4 & 0.47 \\
\hline 1940 & 4.6 & 33.6 & 10.6 & 0.34 & 3.9 & 64.5 & 9.1 & 0.61 & 5.5 & 40.9 & 8.4 & 0.35 \\
\hline 1960 & 6.2 & 21.2 & 8.3 & 0.32 & 4.0 & 55.5 & 14.0 & 0.31 & 7.5 & 32.5 & 6.3 & 0.27 \\
\hline 1980 & 8.3 & 17.3 & 6.6 & 0.17 & 6.5 & 43.4 & 9.8 & 0.18 & 9.6 & 22.7 & 6.5 & 0.14 \\
\hline 2000 & 12.1 & 15.1 & 4.6 & 0.22 & 7.9 & 31.9 & 6.8 & 0.14 & 13.7 & 22.0 & 4.8 & 0.16 \\
\hline & Colombia & & & Mexico & & & Venezuela & & \\
\hline & $n_{1}$ & $n_{4}$ & $r_{1}$ & $r_{4}$ & $n_{1}$ & $n_{4}$ & $r_{1}$ & $r_{4}$ & $n_{1}$ & $n_{4}$ & $r_{1}$ & $r_{4}$ \\
\hline 1900 & 6.2 & 65.5 & 6.7 & 0.37 & 3.3 & 70.8 & 9.6 & 0.56 & 4.1 & 69.6 & 7.9 & 0.41 \\
\hline 1920 & 6.0 & 60.7 & 7.9 & 0.37 & 3.5 & 70.8 & 11.9 & 0.53 & 4.6 & 60.0 & 7.8 & 0.37 \\
\hline 1940 & 5.7 & 56.9 & 9.0 & 0.35 & 2.9 & 66.0 & 10.7 & 0.54 & 4.2 & 50.3 & 7.6 & 0.34 \\
\hline 1960 & 7.3 & 48.9 & 7.9 & 0.30 & 4.0 & 55.3 & 10.8 & 0.42 & 5.8 & 37.8 & 10.2 & 0.20 \\
\hline 1980 & 7.5 & 39.8 & 7.4 & 0.31 & 7.2 & 40.5 & 7.4 & 0.39 & 12.5 & 24.3 & 5.4 & 0.24 \\
\hline 2000 & 9.1 & 36.0 & 6.5 & 0.27 & 9.5 & 32.4 & 5.8 & 0.19 & 12.3 & 23.7 & 4.9 & 0.28 \\
\hline
\end{tabular}

All figures are 3-year averages except those for 1900 based on 2 years

EAP shares circa 2000 use benchmark from ECLAC (2000) except Argentina which uses ILO's data

tion in the 1940s (earlier in Argentina). Differences in the level of development circa 1900 are also reflected in the timing of the decline of the share of Group 4. The initial share for Argentina and Chile (around 40\%) is only reached by 1955 in Venezuela, and around 1980 in Brazil, Colombia and Mexico. This largely reflects different educational realities. ${ }^{11}$

The relative income ratios for the top group tend to show high and rising values during the first half of the last century (especially in Brazil, Colombia, Mexico and Venezuela) and then a decline in the second half. The rising trend indicates a growing share of property income in total income and slow increases in the number of top earners. The falling trend reflects an increase in the numbers of EAP in that group after 1960 or so (reducing the group's income per person engaged) in line with better access to education and a rapid increase in GDP per worker between 1950 and 1970 in most countries (raising the denominator of the ratio). Meanwhile, the ratios of the bottom group are dominated by a steady decline over the century. This is largely the result of increases in the wage of the unskilled lagging behind advances in the overall average income. In absolute terms (not shown), the gains of the average income of the whole labour force compared to the gains in the mean real income or those in Group 4 between the start and the end of the twentieth century were 2.1-fold for the overall income and 1-fold for Group 4 in Argentina; 5.9 and 1.2 in Brazil; 6.2 and 3.1 in Chile, 6.2 and 4 in Colombia; 3.3 and 1.1 in Mexico (circa 1921 vs. 2000); and 6.5 and 3.6 in Venezuela.

\footnotetext{
${ }^{11}$ According to the Barro and Lee (2011), the average years of schooling and the percentage share of the population without schooling in 1950 were 4.9 years and $15 \%$ in Argentina, 2.1 years and $63 \%$ in Brazil, 3.7 years and $21 \%$ in Chile, 2.3 years and $40 \%$ in Colombia, 2.2 years and $45 \%$ in Mexico and 1.6 years and $49 \%$ in Venezuela.
} 


\subsection{The Top-Income Group}

In this section we provide complementary information for the relative income of top earners. Table 2 presents comparisons for four of our countries. For Brazil we calculate a wage ratio using data for Rio de Janeiro for factory managers and semiskilled workers (e.g. masons and carpenters) for the period 1900-1930 ( $r_{1}$ proxy), and compare them with our calculated income ratio for Group $1\left(r_{1}\right)$. Both ratios remain stable up to 1915 and then rise to higher values between 1920 and 1930. This rising trend continues to be a feature of $r_{1}$ up to 1950. For Chile (1900-1940) we have two complementary ratios: the mean income of employers (representing about $2 \%$ of the labour force) relative to the average wage ( $r_{1}$ proxy_1) and representative salaries of top-rank officials (e.g. ministers and directors) ${ }^{12}$ relative to an average of semi-skilled workers in the public sector (e.g. archivist and postman) $-r_{1}$ proxy_2. Despite different order of magnitude, both $r_{1}$ and $r_{1}$ proxy_1 move in line between 1900 and 1930. The comparison between our ratio and $r_{1}$ proxy_2 shows values of similar magnitude, but with lower coincidence in trends, perhaps reflecting a more stable wage structure in the public sector.

Table 2 Top earners' mean income relative to average income (circa values)

\begin{tabular}{|c|c|c|c|c|c|c|c|c|c|c|c|}
\hline & 1900 & 1905 & 1910 & 1915 & 1920 & 1925 & 1930 & 1935 & 1940 & 1945 & 1950 \\
\hline \multicolumn{12}{|l|}{ Brazil } \\
\hline$r_{1}$ proxy & 8.2 & 7.9 & 7.8 & 7.0 & 9.1 & n.a. & 9.1 & n.a. & n.a. & n.a. & n.a. \\
\hline$r_{1}$ & 6.9 & 6.8 & 6.3 & 5.1 & 8.4 & 8.8 & 8.6 & 6.7 & 9.1 & 11.6 & 11.5 \\
\hline \multicolumn{12}{|l|}{ Chile } \\
\hline$r_{1}$ proxy_1 & 12.1 & 9.8 & 17.2 & 20.9 & 22.9 & 23.2 & 18.0 & n.a. & n.a. & n.a. & n.a. \\
\hline$r_{1}$ proxy_2 & 7.0 & 6.3 & 6.6 & 5.6 & 6.1 & 5.5 & 6.3 & 5.4 & 5.3 & n.a. & n.a. \\
\hline$r_{1}$ & 7.5 & 7.1 & 6.0 & 7.0 & 9.4 & 10.6 & 9.5 & 10.0 & 8.4 & 7.6 & 7.0 \\
\hline \multicolumn{12}{|l|}{ Colombia } \\
\hline$r_{1}$ proxy & n.a. & n.a. & 5.4 & 4.5 & 4.2 & 4.8 & 5.0 & 5.8 & 5.7 & 4.4 & 4.9 \\
\hline$r_{1}$ & 6.7 & 6.9 & 7.9 & 8.0 & 7.9 & 8.9 & 8.7 & 8.0 & 9.0 & 8.9 & 8.7 \\
\hline \multicolumn{12}{|l|}{ Venezuela } \\
\hline$r_{1}$ proxy & 6.0 & 6.8 & 6.5 & 6.3 & 6.7 & 6.1 & 6.4 & 5.9 & n.a. & n.a. & n.a. \\
\hline$r_{1}$ & 7.9 & 7.4 & 7.2 & 10.0 & 7.8 & 7.0 & 6.6 & 8.7 & 7.6 & 7.9 & 9.3 \\
\hline
\end{tabular}

$r_{1}$ : Mean income of Group 1 relative to overall income per worker

$r_{1}$ proxy, calculated using representative occupations as follows:

Brazil: Salary of a factory manager to a semi-skilled worker (Lobo 1978)

Chile 1: Earnings per employers relative to average wages from Rodriguez Weber (2014)

Chile 2: Salaries of high-rank officials relative to medium salary in the public sector from Rojas (1982)

Colombia: Average salary "spokesperson and treasurer" to "doorman" in city councils (Lopéz Uribe 2008).

Venezuela: Avg. salary of high-rank officials to median government salary (Carrillo Batalla 1999-2003)

\footnotetext{
${ }^{12}$ Although the employment share of the public sector tended to be relatively small in the early decades (e.g. about $5 \%$ in Chile and Venezuela), the salaries paid to high-rank officials could well be representative of earnings in Group 1.
} 
In the case of Colombia (1908-1950) we take as representative earnings for Group 1 the average wage of some high-rank officials in local government divided by the wage of low-skilled occupations in local government. Both series show higher ratios for the period 1925-1940 compared to early values. For Venezuela (1900-1936), we use the average wage of top officials in ministries divided by the median income in the central government. Although both ratios show similar order of magnitude, the proxy ratio shows no trend-again likely to reflect a more stable wage structure in the public sector. In sum, this complementary information on top earners does not show any significant divergence from our calculated relative incomes for Group 1 in the four countries.

\section{Functional Inequality}

The between-group inequality component (Lambert and Aronson 1993) is calculated as

$$
G i n i_{-} b=\sum_{i=2}^{4} \sum_{j=1}^{i=1} n_{i} n_{j}\left|r_{i}-r_{j}\right|
$$

We assume that all individuals within a group earn the mean income of such a group, so that the within inequality component is zero. ${ }^{13}$ Elsewhere (Astorga 2015a), we offer some estimates of within-group inequality for selected periods from various sources (including ILO's October Enquiry) for Argentina (1936-1976), Brazil (1911-1937), Chile (1938-1971), Mexico (1936-1982) and Venezuela (1940-1982). This complementary evidence shows that geographical dispersion in earnings rose from early to the middle decades, and thus played a role in boosting group inequality. Data available for Brazil and Mexico confirms this. The evidence available for the middle decades (mostly for wage dispersion in Groups 3 and 4) also suggests that within-group inequality trends reinforced those in between-group Ginis. Bértola (2005) and Rodriguez Weber (2014) also found such reinforcing trends in Uruguay and Chile, respectively. In short, we think that the latter measure is a reasonable proxy for trends in overall functional inequality.

\subsection{Comparison with Other Inequality Measures}

Figure A.1 presents our functional Gini series (Gini_b) as 5-year, centred moving averages. We also plot three additional inequality measures. First, available household income inequality Ginis (Gini_hs): ${ }^{14}$ Note that our inequality series exclude

\footnotetext{
${ }^{13}$ Relying on between-group inequality is a common feature in inequality studies covering the long run (Milanovic et al. 2011).

${ }^{14}$ Thorp (1998, Statistical Appendix), Széquely and Sámano (2012) and ECLAC website.
} 
taxes and transfers, whereas the household Ginis are usually based on disposable income. Secondly, the inverse of the Williamson ratio (W-ratio) from 1900 to circa 1940 in Argentina, Brazil, Chile, Colombia and Mexico. And, third, Frankema's Theil index of inter-industry inequality ( $F_{-}$ind, with a fitted moving average line).$^{15}$ In Chile we add the income Gini series estimated by Rodríguez Weber (2014). In the case of Mexico, because of data limitations and the distortions caused by the hyperinflation during the revolution, we estimate separately the earnings Gini for the 1900-1910 period. Thus the pre-1910 levels are not fully comparable with those after 1921.

The comparison with the household Ginis from a more recent period serves to assess the capacity of our between-group Ginis to reflect the trends in overall personal income inequality. For the years from 1950 to 2000, our series correlate reasonably well with Gini_hs, especially for Brazil, Chile and Colombia. This gives us some reassurance that our between-group trend estimates during the first half of the last century are also good proxies for personal inequality trends. The association between both series in the first decades of this century is poor for Venezuela, which may be explained by the fact that our Ginis do not reflect the impact on inequality of recent social transfer programmes (Roberts 2012).

On the other hand, the correlation between Gini_b and the W-ratio (1900-1940) is mixed, with Argentina and Mexico offering the best fit, confirming a rise in inequality up to about 1920, whereas in Brazil and Chile there are important discrepancies in the trends of both measures. Overall, this evidence does not offer unambiguous support for claims that the final years of the First Globalisation episode brought about a significant increase in inequality.

Intra-industry inequality also correlates well with our between-group inequality trends, especially for Argentina and Mexico. In Brazil both measures rise from 1920 up to the 1980s (with an inflection point in the mid-1930s likely to reflect the industrialisation plus urbanisation process), but then diverge during the last two decades of the last century or so. In Colombia the limited number of observations for $F \_$ind shows an upward trend between the early 1960s and the late 1990s, a trend also apparent in Gini_b. And in Mexico, the acceleration in $F \_$ind during the 1990s (likely to be associated with the country's incorporation into NAFTA in January 1994) is also in line with the rising trend in Gini_b. Overall, rising inequality since 1960 or so in both measures suggests that skill-biased technological change was a contributing force (either by stretching the wage structure or by boosting profits)

\footnotetext{
${ }^{15}$ We calculate the ratio $(1913=1)$ GDP per capita to real unskilled wage using Williamson (1998). In Brazil we present only the ratio for the Southeast region. For intra-industry inequality we calculated an index $(1996=1)$ using original data in Frankema (2012). We drop an outlier observation in 1984 for Chile. Both indices are plotted on the right-hand side scale of the charts, whereas the two Ginis are on the left-hand side. We are not including the pseudo-Ginis series in Prados de la Escosura (2007) because they are largely a combination of the Williamson ratios and the household Ginis, both included in the charts.
} 
particularly during the closing decades of the last century, which was dominated by more open economies and trade liberalisation. ${ }^{16}$

Some additional comments are in order about our calculations for Brazil and Venezuela. Our Gini_b for Brazil shows a relatively low and trendless level up to about 1930 (though with significant fluctuations). This outcome is consistent with evidence from the 1920 population census of a large share of the labour force (about $80 \%$ ) being rural, illiterate and low skilled (Bértola et al. 2009). Under such circumstances, it is likely that the maximum feasible income Gini was relatively low but that the extraction rate was relatively high, reflecting the fact that poorer societies have a smaller surplus for the elite to extract (Milanovic et al. 2010). The Brazilian daily wage data in rural areas available for the benchmark years 1911, 1921 and 1936 (IBGE) indicate a relatively stable wage structure. A stable wage structure is also confirmed by urban wage series in Rio de Janeiro during the first three decades of the twentieth century (Lobo 1978), as well as by data assembled by Ball (2013) for industrial workers in selected firms in São Paulo from 1891 to 1930.

There is scant earnings data prior to 1936 for Venezuela, so our estimates for those years should be taken as a gross approximation. According to Valecillos (2007: 103), the general picture of the labour market is one dominated by roughly constant wages and stable wage structure up to the mid-1930s when wages started to rise gradually, driven by the growing importance of the oil industry. This situation is consistent with a roughly stable inequality shown by our Gini in the early period. According to De Corso (2013), GDP per worker rose 1.1 times between 1905 and 1922 , pointing to a relative increase in the remuneration to land and capital during the period, but not enough to result in a clear rising trend in functional inequality until the oil sector was in full swing.

\subsection{The Top-Income Group and the Rest}

Here we focus on the relative contributions to inequality of the income share of Group 1 (capturing concentration at the top) and a Gini coefficient of the three wage groups (capturing developments in the wage structure). Following Alvaredo (2010), the overall Gini coefficient can be expressed as

$$
G i n i=G i n i^{\mathrm{Top}} n_{1} s_{1}+\operatorname{Gini}^{\mathrm{Rest}}\left(1-n_{1}\right)\left(1-s_{1}\right)+s_{1}-n_{1},
$$

\footnotetext{
${ }^{16}$ Scholars studying the wage structure in the region based on evidence for the middle decades of the last century already stressed the tendency of the leading industries to pull up the general level of wages in the rest of the economy, with the oil or mining industry (Chile, Venezuela) as prime examples (Berg 1968, 4). For Colombia, Cárdenas and Bernal (1999) found that during the period 1976-1996 both trade liberalisation and skill-complementary technological change had a positive impact on skill premia in manufacturing and, in turn, on inequality.
} 
where $s_{1}$ and $n_{1}$ are the income and population shares of the top group and Gini ${ }^{\text {Top }}$ and $G i n i^{\text {Rest }}$ are the Gini coefficients for the top group and for the rest of the population, respectively. For $n_{1}$ sufficiently small, (Eq. 4) can be approximated as

$$
G i n i=\operatorname{Gini}^{\text {Rest }}\left(1-s_{1}\right)+s_{1} \text {, }
$$

In our case, because of lack of data $G i n i^{\mathrm{To} p}$ is equal to zero anyway, and Gini ${ }^{\text {Rest }}$ is approximated by the between-group Gini coefficient of the three wage groups $($ Gini_w). Thus, the overall Gini in (Eq. 5) becomes the between-group Gini (as in Eq. 3) and can be expressed as

$$
G i n i_{-} b=G i n i_{-} w\left(1-s_{1}\right)+s_{1} .
$$

This decomposition makes it possible to separate the action of the forces affecting property and labour income, a distinction that is missing in Gini coefficients based on household income data. Labour income inequality is driven by demand and supply conditions in the labour market, as well as by institutional factors such as minimum wage legislation or the action of unions. Ultimately, they are influenced by changes in technology, international trade, structural change and developments in human capital formation. In the case of property income, the usual dominant forces are savings and investment behaviour, inheritance laws and rate of return to wealth. Unambiguous inequality trends emerge when there is a falling topincome share and wage compression, or rising top-income share and wage expansion, occurring simultaneously.

Figure A.2 offers time series on $s_{1}(G 1 \%)$ together with Gini_b and Gini_w. For comparative purposes we are also including available official estimates for the property income share or, when this is not directly available, the complement of the labour share (Prop\%). ${ }^{17}$ Trends in G1\% and Prop\% are broadly consistent. ${ }^{18}$ The second half of the twentieth century and the 2000s are dominated by upward trends in $61 \%$. The rise starts in the early 1940s in Brazil, Colombia and Venezuela; in the late 1950s in Argentina and Chile; and in the mid-1960s in Mexico. Prior to that, the tendency for the secular top-income share was to fluctuate considerably around a trendless mean. ${ }^{19}$

A falling trend in the labour share (or a rising trend in $61 \%$ ) is a common feature in Latin America during the closing decades of the twentieth century dominated by

\footnotetext{
${ }^{17}$ The sources are the BCRA (1976) in Argentina 1935-1962, van Ginneken (1979) in Mexico 1950-1967 (our calculation, using labour shares for 1950, 1954, 1958, 1963, 1967 and 1975 from official sources) and the BCV for Venezuela 1957-1997. Otherwise ECLAC website (operating profits).

${ }^{18}$ Also, our proxies for the labour share behave similarly to the labour shares estimated by Frankema (2010) for Argentina (1913-2000), with a 0.69 correlation, and Mexico (1913-2000), with a 0.68 correlation. And it is partly consistent in Brazil (1920-2000), with a 0.76 correlation in the subperiod 1950-1980.

${ }^{19}$ Relatively low values in the early decades in Brazil are likely to reflect an underestimation of income per worker, whereas in Mexico and Venezuela they may reflect an overestimation of wages.
} 
market-friendly reforms. ${ }^{20}$ In the cases of Chile and Mexico, Palma (2011) locates the origin of the trend with the emergence of a "scissors" effect between the average real wage and labour productivity. In Fig. A.3 we show equivalent series for our six countries accompanied by the ratio between the mean incomes of Group 1 and Group 4 ( $y_{1} / y_{4}$, or top-bottom ratio). ${ }^{21}$ We also found a "scissors" effect in Argentina, Brazil, Colombia and Venezuela, although in the last three cases the gap starts developing before the wave of neo-liberal reforms.

As to the behaviour of the top-bottom ratio, there are rising secular trends in Brazil, Chile, Colombia, Mexico and Venezuela starting in the 1920s or the 1930s. Argentina is the odd case with a steep fall in this ratio from the first half to the second half of the twentieth century (except for the spike in the late 1980s, likely to be associated with hyperinflation and a decreed freeze in wages). ${ }^{22}$ The spike in Mexico circa 1950 is consistent with the surge of business opportunities in the country (amid subdued wages) created by the war effort in the USA. In Venezuela the doubling of the ratio in the 1950s is associated with a 1.9-fold rise in oil production and a $25 \%$ increase in oil prices - which peaked in early 1957 during the Suez Crisis (Baptista 1997). Bértola (2005, Chart 9) presents a similar measure in Uruguay showing a significant drop during the mid-1950s and the mid-1960s, followed by a recovery of the ratio later on. In general the evolution of the top-bottom ratio indicates that in most cases the top earners were able to increase - or at least keeptheir position relative to the mean income of the unskilled.

\subsection{Wage Inequality}

Secular movements in wage inequality (also reflecting the wage structure) and in the average real wage are plotted in Figs. A.2 and A.3, respectively. The early decades, dominated by export-led growth, are characterised by an expanding or a constant wage structure. This is the case only after 1920 or so for Brazil and Chile. Our evidence is consistent with the claim that during the first export-led growth era, immigration, lack of a well-integrated labour market and coercion (Bulmer-Thomas 1994: 7) undermined the potential of demand-led growth favouring unskilled labour and wage compression (Bértola and Ocampo 2012).

\footnotetext{
${ }^{20}$ Falling labour shares is also a common trend in both developed and developing countries since the 1970 s or so that has been attributed primarily to globalisation, increased role of financial activity and labour market deregulation (Stockhammer 2013).

${ }^{21}$ The wage series are weighted by the labour shares of Groups 2, 3 and 4. Labour productivity is calculated as GDP at constant prices divided by overall EAP. The timing of the scissors effect is robust to the use of GDP per worker series using the CPI as deflator.

${ }^{22}$ In the case of Argentina, Alvaredo (2010) estimates the top $1 \%$ income share for the period 1932-1972 and 2002 using tax data. This share reaches a peak in early 1940s, and then, there is a significant fall from 1947 to 1952 followed by a steady decline to 1972 . This pattern is roughly consistent with trends in our top-bottom ratio for the country.
} 
The middle decades were dominated by the import-substitution industrialisation strategy led by the state (Cárdenas et al. 2000). The average real wage experienced a sustained rise in all six countries. There was narrowing wage inequality in Argentina, Colombia, Mexico and Venezuela, but a widening in Brazil and Chile. ${ }^{23}$ Wage compression was favoured in some cases by government intervention in the labour market and by the introduction of minimum wage legislation - particularly effective in Argentina, Brazil and Mexico (Méndez 1950; Ericksson 1966: 16-17). Frankema (2012) studied industrial wage inequality in Argentina, Brazil and Chile and found significant differences whose origin lies in the nature of the labour market policies and political developments, particularly in the post-WW2 decades. Whilst in Argentina and Chile major trend breaks can be attributed to political regime changes (with military coups in 1976 and 1972, respectively), in Brazil the process of wage inequality was gradual and in tune with a strong rise of interindustry labour productivity differentials.

The closing decades show the implementation of market-friendly reforms including more flexible labour markets - and the return of export-led growth as the dominant strategy. During this period there is a tendency towards a rise in the property income share and a widening in wage inequality, amid falling real wages. This is particularly clear during the "lost decade" of the 1980s marked by rising topbottom ratios (in most cases, also during the 1990s), indicating that wage earners largely bore the cost of the adjustment. In Mexico widening wage inequality was driven by the trade liberalisation reform of 1985 which affected unskilled labour disproportionately (Hanson and Harrison 1999). Venezuela is the exception with a constant (1980s) and falling (1990s) wage inequality, the causes of which are likely to be found in the growth implosion that occurred after the end of the 1970s which particularly affected wages in the middle groups. In addition, within-group inequality (by educational categories) grew in Argentina and Brazil (Morley 2000).

In general, widening inequality during this period was driven by institutional changes that weakened the power of the unions and by a decline in real minimum wages. The military regimes in place in Argentina (1976-1983), Chile (1973-1990) and Brazil (1963-1980) effectively restricted - or banned - the action of unions, increased flexibility in the labour market and reduced the coverage of the minimum wage as part of the reform agenda (Morley 2000). Unionisation plummeted across the region averaging only $10.7 \%$ of the workforce in 2005 compared to a peak of $23 \%$ in the 1970s (Roberts 2012). And, according to ECLAC figures, the average real minimum wage for the LA-6 fell, on average, 5.9\% per year during the $1980 \mathrm{~s}$, followed by a moderate recovery of $1.7 \%$ annual growth in the 1990s. In the first decade of the current century wage inequality tended to decline, a trend consistent with that shown by labour earnings Ginis calculated from household surveys (World Bank 2012: 28).

\footnotetext{
${ }^{23}$ In addition, evidence on within-group wage dispersion for Groups 3 and 4 in Argentina, Chile, Mexico and Venezuela (Astorga 2015a) points to narrowing or constant wage spreads in the period.
} 


\section{Regional Averages}

In this section we present some regional indices and then proceed to explore whether they tend to reflect commonality or if results are driven by country-specific features. We calculate regional inequality first as the simple average of individual countries using our income Ginis together with a Gini available for Uruguay ${ }^{24}$ (LA-7) and, second, as a population-weighted average. Figure 1 (chart on the left) shows 5-year, centred moving averages of the two regional averages for LA-7. We add polynomial fitted lines to reflect secular movements. In addition, we show the simple-average inequality curve for the Southern Cone-Argentina, Chile and Uruguay. This separation is of interest because this group of countries industrialised relatively early and tends to display different inequality-growth dynamics.

The LA-7 averages reveal a secular process resembling a "reclined S"-shaped curve for 1900-2011 with an inflection point around 1940 and a peak in the closing decades. The peak appears a little earlier for the population-weighted Gini. There is a moderate decline in inequality in the early decades driven by developments in Brazil and Colombia (inequality in the Southern Cone remains stable). According to this evidence, the final years of the Belle Époque (1900-1914) were not accompanied by rising inequality. In the middle decades, there was a rise in inequality driven by the latecomer industrialisation (Brazil, Colombia and Venezuela), but inequality fell in the Southern Cone which might be attributed to protectionist policies favouring urban workers and labour policies fostering wage compression. From the 1930 s, average inequality rose steeply to a plateau around the "lost decade", and then declined with the turn of the new century. The "reclined S" shape is more pronounced in the case of the population-weighted series.

Figure 1 (chart on the right) shows the LA-6 simple averages of G1\%, Gini_w and Gini_b. The early decades of the last century show no trend in either the top group income share or the inequality among the three wage groups. But there are differences after the 1930s. Wage inequality rises less steeply in the 1940s and 1950 s followed by a fairly stable wage structure in the 1960s and 1970s. Then there is a relatively rapid rise in wage inequality in the closing decades and wage compression in the 2000s. By contrast, the top-income share accelerates from the mid1930s to the end of the 1970s, followed by a more moderate rise in the closing decades. What is apparent in Fig. 1 is that trends in between-group inequality were primarily driven by trends in the top group.

The chart on the left of Fig. 2 shows simple averages for the LA- 6 of the real wage series for the three lower occupational groups (used to estimate the mean income of each group), and the resulting EAP-weighted average real wage. To facilitate the comparison Gini_w is also included. Both the average wage (wage_avg) and wage inequality show a rising trend from the early 1930s up to the 1960 s,

\footnotetext{
${ }^{24}$ For Uruguay we use Bértola (2005) for the period 1908-1966 and then use Gini values based on household surveys from ECLAC website to complete the series to 2011. The averages during the period 1911-1921 exclude Mexico.
} 

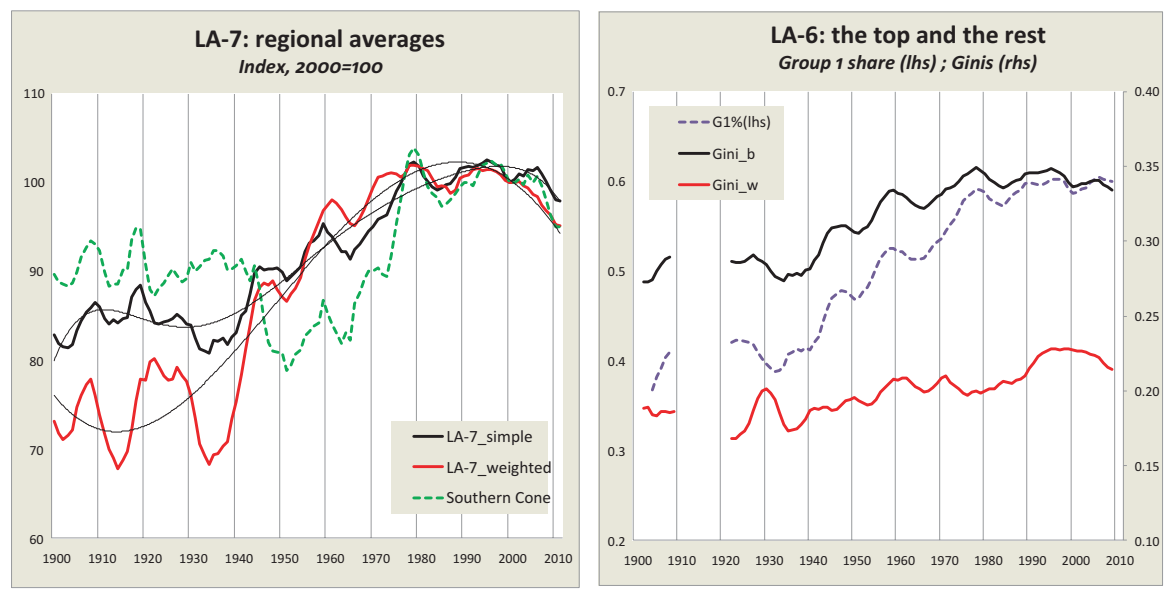

Fig. 1 Regional functional inequality
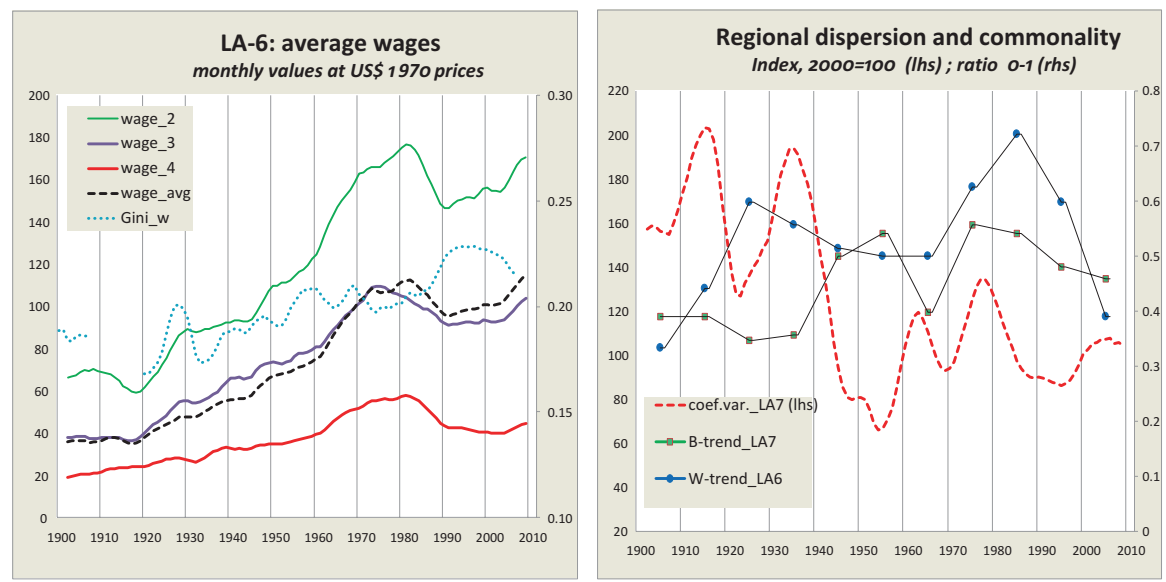

Fig. 2 Regional wages and inequality dispersion

implying that more skilled workers benefited more than the less skilled. In the following two decades or so, the real wage accelerated while the wage structure remained roughly stable, indicating that wage earners benefited more evenly from economic growth.

The closing decades of the twentieth century were marked by falling real wages and widening wage inequality. The average real wage for the unskilled in the LA-6 (wage_4) around 2000 returned to their 1960 levels (and 30\% below the peak around 1975). But there was significant labour mobility. The regional EAP share of Group 4 (see Table 1) came down to about $30 \%$ in 2000 from about $45 \%$ in 1960 and $65 \%$ in 1900. Those able to acquire more skills and move upwards to Group 3 
did rather better, seeing a $20 \%$ rise in their average real wage (wage_3) between 1960 and 2000 (though the 2000 value is about $15 \%$ below the peak reached around 1975). The average LA-6 worker in Group 2 had a 30\% rise between 1960 and 2000, and a $10 \%$ fall from a peak around 1980 .

\subsection{Dispersion and Trend Commonality}

Figure 2 (chart on the right) includes three measures to account for dispersion in Gini levels and trend commonality. First is the coefficient of variation for the between-group Gini for the LA-7 (coef.var._LA7, 5-year moving averages). This measures diversion - or convergence - in levels, showing a clear split between two periods: one of relatively high average dispersion 1900-1940 (with a trough in the early 1920s and two spikes of dispersion in the mid-1910s and mid-1930s), and the other of relatively low dispersion 1940-2011 (with a trough around 1950 and two spikes of dispersion in the early 1960 s and late 1970s). ${ }^{25}$ One possible interpretation of this result is that although the inequality outcome over time differs across the seven countries, this reflects a different timing of a common underlying process (e.g. of a Kuznets-Lewis type) that would eventually lead to a similar end. This interpretation is supported by the outcome of a panel data analysis that reveals important regularities in the LA- 6 associated with the action of common fundamental forces (Astorga 2015b).

One drawback of the above measure is that it does not capture commonality or divergence in trends, so that a low value in the coefficient of variation can indicate catching up in Gini levels but with countries undergoing opposite inequality trends (as during the middle decades). To address this limitation, Fig. 2 includes two measures to track the extent of trend commonality or synchronicity over natural decades in the between-group Ginis ( $B$-trend_LA7) and in the wage Ginis (W-trend_LA6). A high value in a given natural decade (shown as an observation in the middle of the decade) indicates that most countries were experiencing similar trends. ${ }^{26}$

Over the century there was higher trend synchronicity in the wage Ginis than in the overall, between-group, Ginis, pointing to a higher level of uniformity in developments in the labour markets (e.g. associated with minimum wage legislation and unionisation) than in the forces affecting incomes at the top. Movements in both

\footnotetext{
${ }^{25}$ The pattern of between-country dispersion (not shown) for G1\% and Gini_w resembles that of Gini_b.

${ }^{26}$ The score of trend commonality is calculated in two steps. First, in each country the dominant trend pattern in each decade is identified (rising, constant, falling, or a combination of these options). Then, the number of times that a given pattern occurs is added up, assigning a "1" for a dominant trend over a given decade or a " 0.5 " when there are two salient patterns (e.g. for the B-trend_LA7 in the 1980s: rising $=4.5$; constant $=0$, falling $=2.5$ ). Those partial results are multiplied by itself and then added up to obtain an overall score $(4.52+02+2.52=26.5)$. Finally, the overall score is divided by the maximum possible score $(26.5 / 49=0.54)$. See more details in Astorga (2015a, Table B-3).
} 
trend measures show diverging trends in the first half of the twentieth century (consistent with high values for the coefficient of variation) but a clear move towards synchronicity during the second half. Overall, based on this evidence, the 1970s and the 1980 s come out as the decades with the highest commonality in inequality trends.

\section{Conclusions}

We have presented new estimates of functional income Ginis for the period 1900 2011 covering six Latin American countries, which use newly assembled wage series for three occupational categories. It offers a consistent and comprehensive view of long-term inequality. Our method and the data have their limitations, so our findings need to be corroborated by future research. That said, the key findings can be summarised as follows:

Secular trends as well as fluctuations in inequality across the twentieth century exhibit important country variations, particularly prior to 1960 . Our series do not show a shared inequality rising trend during the end of the Belle Époque, and reveal mixed results in the middle decades. But by the early 1960s inequality was on the rise in most countries reaching a peak in the closing decades of the last century amid the implementation of the "Washington Consensus" policies. The regional Gini averages (simple and population weighted) of the LA-7 show a "reclined S" shape with an inflection point around 1940 and a peak in the 1990s (a decade earlier in the population-weighted curve).

Our evidence on relative incomes and employment shares is broadly consistent with the Kuznets-Lewis thesis. The early decades were characterised by a high proportion of rural unskilled labour with polarised income between them and those at the top, largely reflecting disparities between capital or land owners and low-skilled landless workers. As the structural change got underway, and labour moved from low to higher productivity sectors, wage inequality rose. It was expected that the urban labour force would improve their educational levels and skills, whilst the fall in the rural workforce and the modernisation of agriculture would bid up their wages. However, there is a well-known twist to the standard Kuznets-Lewis process in Latin America. Industrialisation stagnated in the final quarter of the last century and workforce growth swelled the urban informal sector creating the conditions for worsening inequality.

There is an absence of episodes in which falling property shares and wage compression reinforced each other, generating a sustained fall in inequality. The tendency for wage compression, or slow wage expansion, during the decades of industrialisation under protection suggests that potentially dis-equalising forcesarising from still limited access to education and a delayed demographic transition favouring returns on skills - were curbed, particularly in the Southern Cone, by government intervention in the labour market, unionisation and workings of mini- 
mum wage policies. However, overall, they could not offset the action of centrifugal forces boosting disparities between those at the top and the rest of the distribution.

Inequality in the twentieth century is a story of increased polarisation but at the same time one of significant social mobility. For the LA- 6 as an average, the estimated mean real income of top earners rose from 17 times the income of the unskilled around 1900, 30 times around 1970 and 27 times around 2000. Those at the top experienced a 3.3-fold rise in their mean income between 1900 and $2000 \mathrm{far}$ above the 2.4-fold increase of those at the bottom. A second key development was the expansion of the middle groups, which went from about $32 \%$ of the overall EAP at the start of the century to $62 \%$ by the end. The mean income of those at the middle grew 2.9-fold between 1900 and 2000. But in all three occupational wage groups the absolute mean income at the end of the century was no higher than that of about 1970.

Acknowledgement I am grateful for comments from Leticia Arroyo, Marc Badia-Miro, Luis Bértola, Martín Cuesta, David Doyle, Valpy FitzGerald, Ewout Frankema, Matthias vom Hau, Peter Lindert, Javier Rodríguez Weber, Carmen A. Romero, Xavier Tafunell, Héctor Valecillos, Henry Willebald and participants at conferences held during 2014 in Madrid (XI Congreso Internacional de la AEHE, September) and Oxford (Workshop in Honour of Professor Valpy FitzGerald, November). Special thanks to Jeffrey Williamson for helpful ideas and encouragement. 


\section{Appendix}
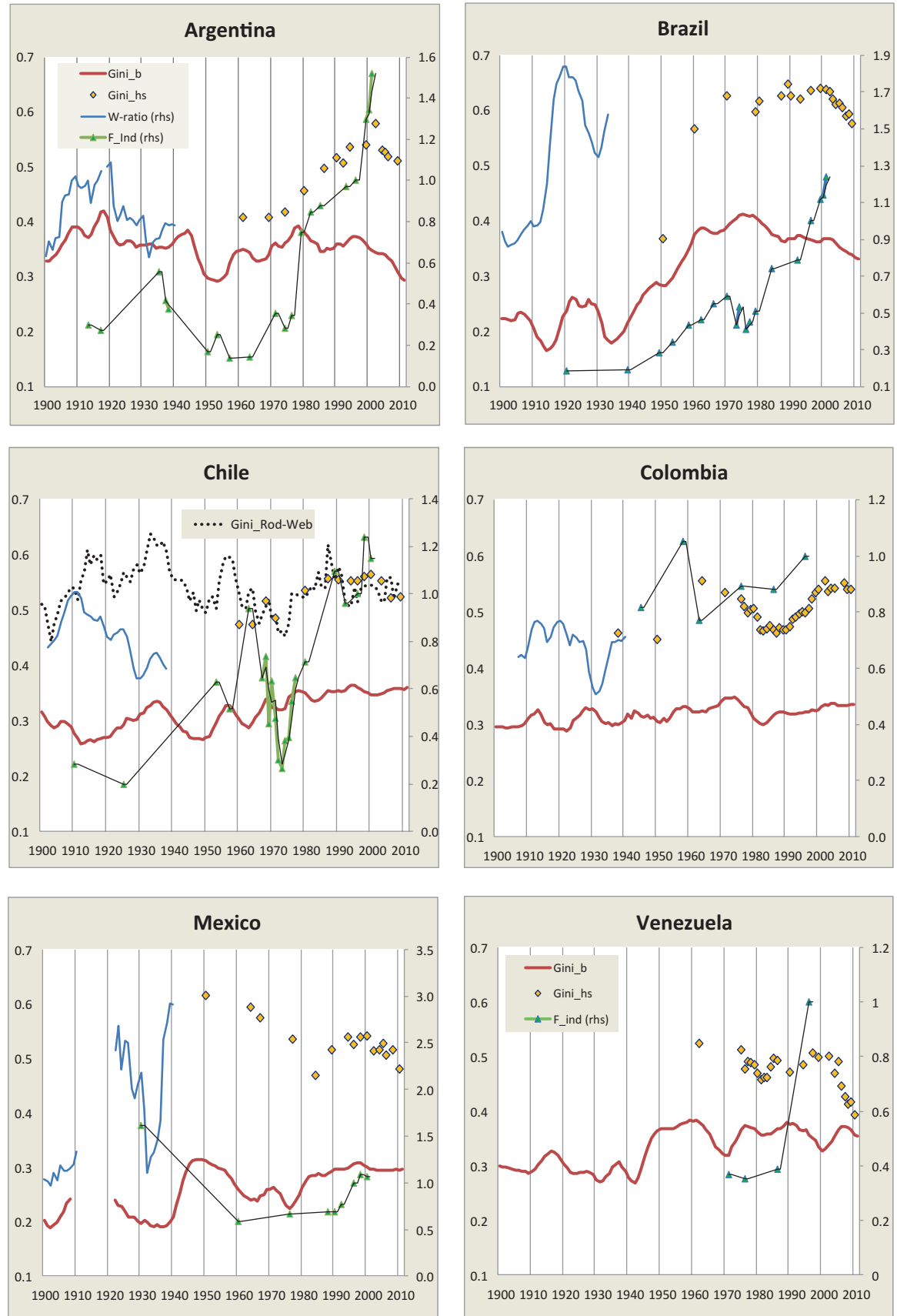

Fig. A.1 Inequality measures by country (lhs axes: Gini coefficients; rhs axes: ratios) 

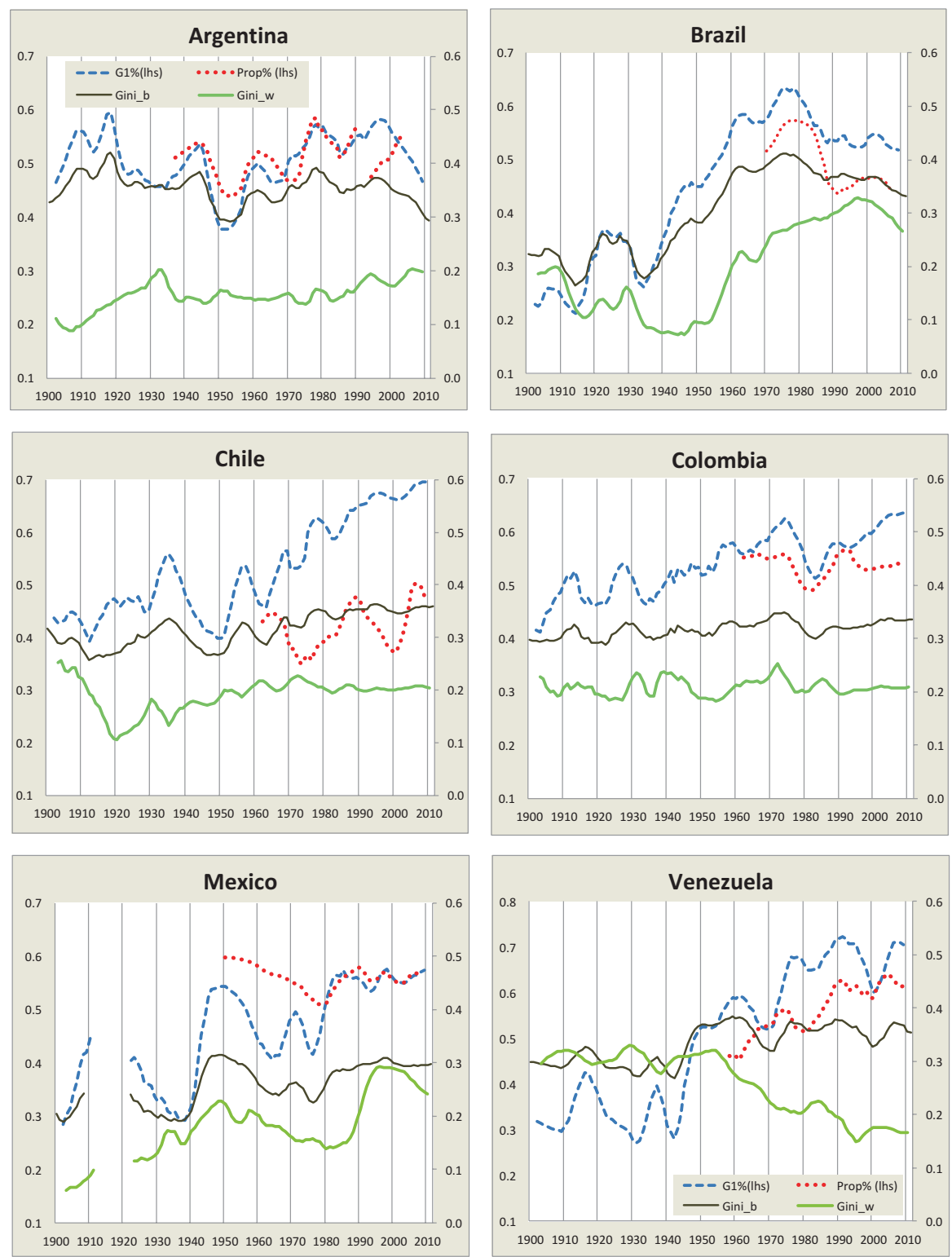

Fig. A.2 Concentration at the top and wage inequality (lhs: shares; rhs: Gini coefficients; all series 5 -year m.a.) 

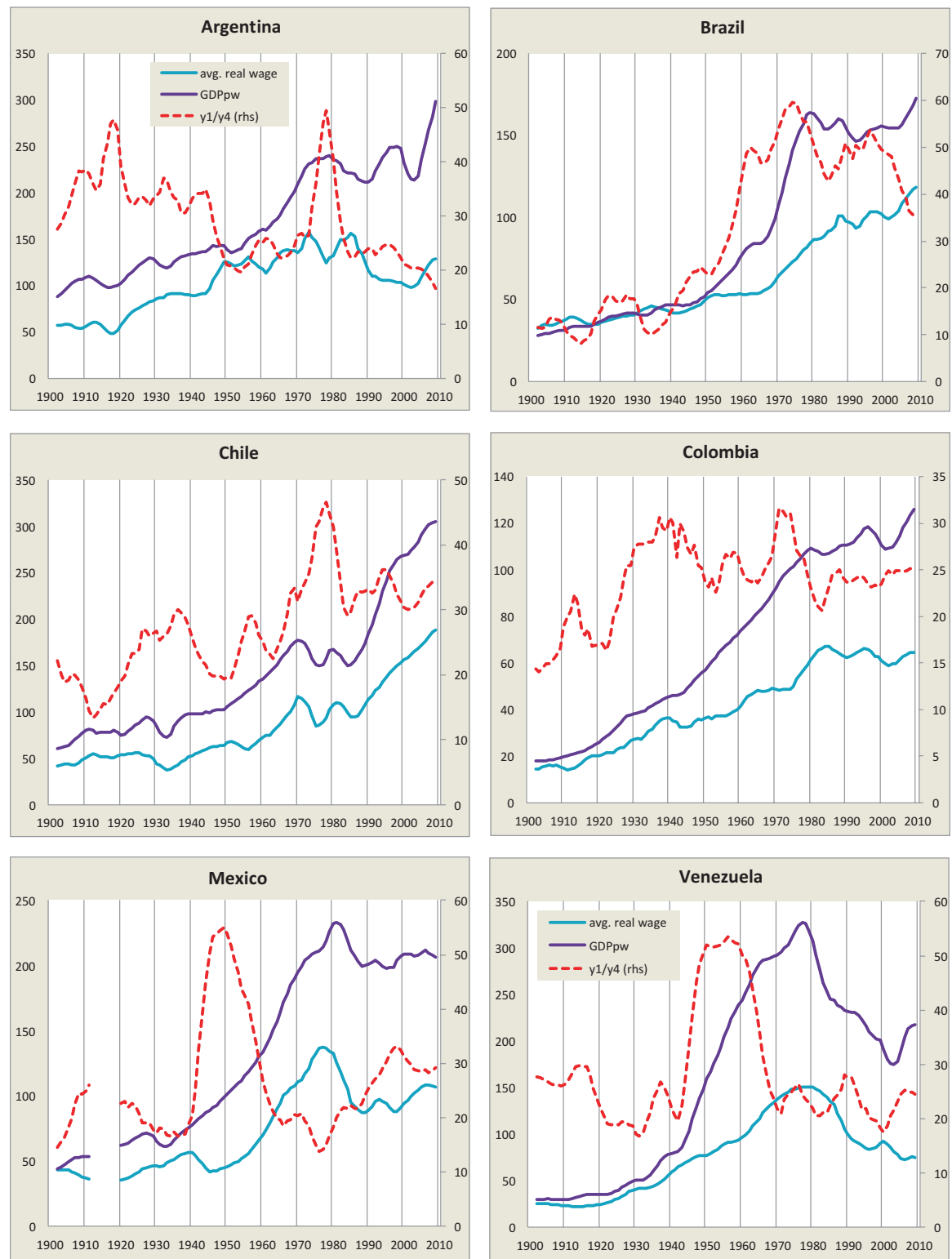

Fig. A.3 Average wage, GDP pw and top-bottom ratios (lhs: US\$ per worker/month, 1970 prices; rhs: ratio; all series 5-year m.a.) 
Open Access This chapter is distributed under the terms of the Creative Commons Attribution 4.0 International License (http://creativecommons.org/licenses/by/4.0/), which permits use, duplication, adaptation, distribution and reproduction in any medium or format, as long as you give appropriate credit to the original author(s) and the source, a link is provided to the Creative Commons license and indicate if changes were made.

The images or other third party material in this chapter are included in the work's Creative Commons license, unless indicated otherwise in the credit line; if such material is not included in the work's Creative Commons license and the respective action is not permitted by statutory regulation, users will need to obtain permission from the license holder to duplicate, adapt or reproduce the material.

\section{References}

Alvaredo, F. (2010). The rich in Argentina over the twentieth century 1932-2004 (Chapter 6). In A. Atkinson \& T. Piketty (Eds.), Top incomes vol. II: A global perspective. Oxford: Oxford University Press.

Arroyo Abad, L. (2013). Persistent inequality? Trade, factor endowments, and inequality in republican Latin America. Journal of Economic History, 73(1), 38-78.

Astorga, P. (2015a, April). Functional inequality in Latin America: News from the twentieth century. Discussion papers in Economic and Social History, Oxford University, p. 135.

Astorga, P. (2015b). Inequality and economic development in Latin America, 1900-2011. Paper was presented at the 11th European Historical Economics Society Conference held in Pisa, 4-5 September 2015.

Atkinson, A., Piketty, T., \& Saez, E. (2011). Top incomes in the long run of history. Journal of Economic Literature, 49(1), 3-71.

Ball, M. C. (2013). Inequality in São Paulo's old republic: A wage perspective, 1891-1930. Ph.D. dissertation, University of California, Los Angeles.

Banco Central de la República Argentina (BCRA). (1976). Series Históricas de Cuentas Nacionales de la Argentina 54. p. 226.

Baptista, A. (1997). Bases Cuantitativas de la Economía Venezolana, 1830-1995. Caracas: Ediciones Fundación Polar.

Barro, R. J. (2000). Inequality and growth in a panel of countries. Journal of Economic Growth, 5 , $5-32$.

Barro, R., \& Lee, J. W. (2011). International data on educational attainment: Updates and implications. Retrieved from www.barrolee.com/

Berg, E. J. (1968). Wage structure in less developed countries. Center for Research on Economic Development. Discussion Paper 1. University of Michigan.

Berg, E. J. (1970). Wages and employment in less developed countries. Center for Research on Economic Development. Discussion Paper 13. University of Michigan.

Bértola, L. (2005). A 50 años de la curva de Kuznets: crecimiento y distribución del ingreso en Uruguay y otras economías de nuevo asentamiento desde 1870. Investigaciones en Historia Económica, 3(Fall), 135-176.

Bértola, L., \& Ocampo, J. A. (2012). The economic development of Latin America since independence. Oxford: Oxford University Press.

Bértola, L., Castelnovo, C., \& Willebald, H. (2009). Income distribution in Brazil 1870-1920. Paper presented at the conference A Comparative Approach to Inequality and Development: Latin America and Europe, Instituto Figuerola, Universidad Carlos III, Madrid, May 8-9. 
Bértola, L., Castelnovo, C., Rodríguez Weber, J., \& Willebald, H. (2010). Between the colonial heritage and the first globalization boom: On income inequality in the southern cone. Revista de Historia Económica, 20(2), 307-341.

Birdsall, N., Lustig, N., \& McLeod, D. (2011). Declining inequality in Latin America: Some economics, some politics. Center for Global Development Working Paper 25 (May).

Bourguignon, F., \& Morrisson, C. (2002). Inequality among world citizens. American Economic Review, 92(4), 727-744.

Bulmer-Thomas, V. (1994). The economic history of Latin America since independence. Cambridge: Cambridge University Press.

Cárdenas, E., Ocampo, J. A., \& Thorp, R. (Eds.). (2000). Industrialisation and the state in Latin America: The black legend and the post war years. Macmillan, Oxford.

Cárdenas, M., \& Bernal, R. (1999). Changes in the distribution of income and the new economic model in Colombia. Reformas Económicas, 36, CEPAL, Santiago de Chile.

Carrillo Batalla, T. E. (1999-2003). Cuentas Nacionales de Venezuela 1800-1935 (Vol. 1-6). Banco Central de Venezuela: Caracas.

Contreras, D., \& Gallegos, S. (2011). Desigualdad salarial en América Latina: una década de cambios. Revista CEPAL, 103, 27-45.

De Corso, G. (2013). El crecimiento económico de Venezuela desde la oligarquía conservadora hasta la revolución bolivariana: 1830-2012. Una visión cuantitativa. Revista de História Económica, 31(3), 321-358.

De Ferranti, D., Perry, G., Ferreira, F., \& Walton, M. (2004). Inequality in Latin America and the Caribbean: Breaking with history? Washington, DC: The World Bank.

Dobado, R., \& Garcia, H. (2010). Colonial origins of inequality in Hispanic America? Some reflections based on new evidence. Revista de História Económica, 28(2), 253-278.

ECLAC. (2000). Panorama social in América Latina. Santiago de Chile: UN Economic Commission for Latin America and the Caribbean.

Engerman, S., \& Sokoloff, K. (2000). Institutions, factor endowments, and paths of development in the new world. Journal of Economic Perspectives, 14(3), 217-232.

Ericksson, J. R. (1966). Wage structures and economic development in selected Latin American countries. Ph.D. dissertation, University of California, Berkeley.

FitzGerald, V. F. K. (2008). Economic development and fluctuations in earnings inequality in the very long run: The evidence from Latin America 1900-2000. Journal of International Development, 20, 1028-1048.

Frankema, E. (2010). Reconstructing labor income shares in Argentina, Brazil and Mexico 18702000. Journal of Iberian and Latin American Economic History, 28(2), 343-374.

Frankema, E. (2012). Industrial wage inequality in Latin America in global perspective, 19002000. Studies in Comparative International Development, 47, 47-74.

Gasparini, L., Cruces, G., \& Tornarolli, L. (2011). Recent trends in income inequality in Latin America. Economía, 10(Spring), 147-201.

van Ginneken, W. (1979). Grupos socioeconómicos y distribución del ingreso en México. RevistaInternacional del Trabajo, 98(2), 235-247.

Hanson, G. H., \& Harrison, A. (1999). Trade liberalization and wage inequality in Mexico. Industrial and Labor Relations Review, 52(2), 271-288.

Lambert, P. J., \& Aronson, J. R. (1993). Inequality decomposition and the Gini coefficient revisited. Economic Journal, 103, 1221-1227.

Lindert, P., \& Williamson, J. G. (1982). Revising England's social tables 1688-1812. Explorations in Economic History, 19, 308-402.

Lindert, P., \& Williamson, J. G. (2016). Unequal gains: American growth and inequality since 1700. Princeton, NJ: Princeton University Press.

Lobo, E. M. (1978). História do Rio de Janeiro (do Capital Comercial ao Industrial e Financiero). Rio de Janeiro: IBMEC.

López, J. H., \& Perry, G. (2008). Inequality in Latin America: Determinants and consequences. Policy Research Working Paper 4504, The World Bank, Washington, DC.

López-Calva, L. F., \& Lustig, N. (2010). Declining inequality in Latin America: A decade of progress? Washington, DC: Brookings Institution. 
Lopéz Uribe, M. P. (2008, November). Diferenciación salarial y condiciones de vida en Bogotá, 1900-1950. Documentos CEDE 25.

Méndez, J. (1950). Minimum wages in Latin America. International Labour Review, 62, $116-140$.

Milanovic, B., Lindert, P., \& Williamson, J. G. (2011). Pre-industrial inequality. The Economic Journal, 121, 255-272.

Morley, S. (2000). La Distribución del Ingreso en América Latina y el Caribe. Santiago de Chile: Fondo de Cultura Editorial and CEPAL.

Palma, J. G. (2011). Homogeneous middles vs. heterogeneous tails, and the end of the "invertedU": It's all about the share of the rich. Development and Change, 42(1), 87-153.

Piketty, T. (2014). Capital in the twenty-first century. Cambridge, MA: Harvard University Press.

Portes, A., \& Hoffman, K. (2003). Latin American class structures: Their composition and change during the neoliberal era. Latin American Research Review, 38(1), 41-82.

Prados de la Escosura, L. (2007). Inequality and poverty in Latin America: A long-run exploration. In T. J. Hatton, K. H. O'Rourke, \& A. M. Taylor (Eds.), The new comparative economic history (pp. 291-315). Cambridge, MA: MIT Press.

PREALC. (1982). Mercado de Trabajo en Cifras. 1950-1980. Lima: PREALC publications.

Roberts, K. M. (2012). The politics of inequality and redistribution in Latin America's postadjustment era. UNU-WIDER Working Paper 2012/8.

Rodriguez Weber, J. (2014). La Economía Política de la Desigualdad del Ingreso en Chile, 18502009. Ph.D. dissertation, Universidad de la República, Uruguay.

Rojas, M. E. (1982). Sueldos y Salarios, 1860-1940. Facultad de Ciencias Económica y Administrativas, Universidad de Chile.

Széquely, M., \& Sámano, C. (2012). Did trade openness affect income distribution in Latin America? Evidence for the years 1980-2010. UNU-WIDER Working Paper 2012-2013.

Stockhammer, E. (2013). Why have wage shares fallen? A panel analysis of the determinants of functional income distribution. ILO Working Papers 470913, ILO.

Thorp, R. (1998). Progress, poverty and exclusion: An economic history of Latin America in the 20th century. Washington, DC: Inter-American Development Bank.

Urrutia, M. (1975, April). Review of income distribution data: Colombia, Mexico and Venezuela. Woodrow Wilson School Discussion Paper 56.

Valecillos, H. (2007). Crecimiento Económico, Mercado de Trabajo y Pobreza. La Experiencia Venezolana en el Siglo XX. Caracas: Ediciones Quinto Patio.

Willebald, H. (2011). Natural resources, settler economies and economic development during the first globalization: Land frontier expansion and institutional arrangements. Ph.D. dissertation, Universidad Carlos III, Madrid.

Williamson, J. G. (1998). Real wages and relative factor prices in the third world, 1820-1940: Latin America. Harvard Institute of Economic Research Working Papers 1853.

Williamson, J. G. (1999). Real wage inequality and globalization in Latin America before 1940. Revista de Historia Económica, XVII(special issue), 101-142.

Williamson, J. G. (2002). Land, labor, and globalization in the third world, 1870-1940. Journal of Economic History, 62(1), 55-85.

Williamson, J. G. (2015, January). Latin American inequality: Colonial origins, commodity booms, or a missed 20th century leveling? NBER Working Paper 20915.

World Bank. (2012). The labor market story behind Latin America's transformation. Washington, DC: World Bank.

Pablo Astorga Junquera is Research Fellow at the Barcelona Institute of International Studies (IBEI). Previously, he was Senior Economist at Oxford Economics and researcher at the Latin American Centre in Oxford. His research has focused on the economic development of Latin America over the long run, including income inequality, economic growth, and productivity. He holds a D.Phil. in Economics and an M.Sc. in Development Economics from Oxford University. 


\title{
The Political Economy of Income Inequality in Chile Since 1850
}

\author{
Javier E. Rodríguez Weber
}

\section{Introduction ${ }^{1}$}

Inequality is again at the center of the political and economic debate. At the beginning of 2014 Barack Obama called it "the defining challenge of our time."2 Soon after the publication of the English version of Capital in the 21st Century, by Thomas Piketty (2014), aroused a deep debate on the role played by inequality in developed countries since the eighteenth century and the challenges it poses to the future.

Inequality has always been a matter of concern in Latin America. Many believe that inequality is the most important obstacle to development and Chile, often called an "economic success story," is one of the most unequal countries in the region. Shortly after Obama's speech and, while assuming for a second time the

\footnotetext{
${ }^{1}$ This chapter is based on my Ph.D. dissertation. I want to thank to Luis Bértola, its supervisor, and those scholars who made insightful comments which helped me throughout the writing process: Alfonso Herranz, Branko Milanovic, Brian Loveman, Carolina Román, César Yáñez, Gabriel Oddone, Henry Willebald, José Díaz Bahamonde, José Martínez-Carrión, Jorge Álvarez, Marc Badía, María Camou, Mario Matus, Natalia Pérez Barreda, Paola Azar, Peter Lindert, Reto Bertoni, Rosemary Thorp, Sabrina Siniscalchi, Sebastián Fleitas, Silvana Maubrigades, Tarcísio Botelho, Verónica Amarante, Vicente Neira, and y Xavier Taffunel. Jeffrey Williamson was a careful reader of an earlier version of this chapter and provided many insightful comments and suggestions, for which I am thankful. All mistakes are, of course, my responsibility.

${ }^{2}$ Barack Obama: State of the Union Address, on http://www.whitehouse.gov/the-pressoffice/2014/01/28/president-barack-obamas-state-union-address.

J.E. Rodríguez Weber $(\triangle)$

Programa de Historia Económica y Social, Universidad de la República Uruguay,

Montevideo, Uruguay
} 
presidency of Chile, Michelle Bachelet said that inequality was the biggest opponent of her country. ${ }^{3}$

This chapter summarizes a 400-page dissertation on the political economy of inequality in Chile between 1850 and 2009 (Rodríguez Weber 2014). The thesis aims to contribute to understanding the relationship between inequality and economic growth in the long run. I analyze the relationship as the result of the interaction between market forces and institutions. The aim is to highlight the mutual influences and to unravel the relationship between the overall process, historical specificities, and contingencies. This is what I call a political economy approach to inequality.

In the remainder of this chapter I present the leading evidence and the main arguments for a brief economic history of income inequality in Chile between 1850 and 2009. The second section discusses a methodological strategy capable of measuring the main trends of income inequality in the long run, and capturing at least part of the relationship between the market forces and the institutions which led to these trends. In Sect. 3, the core of the chapter, I report income inequality trends and summarize its relationship with the general development process. Section 4 concludes with some reflections on the past, the present, and the future of Chilean inequality.

\section{The Problem, the Approach, the Method, and the Data}

\subsection{Inequality and Development in Chile}

Regardless of where someone lives, his or her life is very different today than it was two centuries ago. The place they live, the way they earn their living, the way they relate to each other, the political system that makes the laws that rule their behavior, and every single aspect of their lives have been radically transformed by the developments that occurred in the last two centuries. Nevertheless, saying that every part of the globe has been affected by the transformation is not the same as saying that all have been affected in the same way. Modern economic growth has multiplied the capacity to produce goods and services by several times, but these goods and services have been unevenly distributed. Economic inequality has two dimensions: between regions and/or countries and between people and/or groups inside each country. With what is by Latin American standards a homogeneous population, Chile-an OECD member-has a GDP per capita which is a half that of OECD average. But it is its Gini coefficient of 0.53 (PNUD 2013) that makes Chile a typical Latin American country.

\footnotetext{
3“'Chile tiene un solo gran adversario, y eso se llama desigualdad!”, see Michelle Bachelet, takeover address, http://www.gob.cl/2014/03/11/presidenta-michelle-bachelet-en-su-primer-discurso-al-pais/.
} 
I study the relationship between market income distribution and development in Chile for two reasons. As I will explain below, I do not think that the complexity of this subject can be studied in the aggregate way that characterizes the Kuznets Curve literature. Furthermore, the history of Chile is rich enough to study all of the problems that the literature has posed as central to the development and inequality relationship. In the last century and a half, Chile has been beneficiary of and prejudiced by the international economy and has gone through many different political regimes and development strategies. Therefore, Chile presents a large diversity of experiences that can be used to test different theories and hypothesis on how income inequality and development are related.

\subsection{A Political Economy Approach}

Most of the attempts to analyze the relationship between inequality and development derive a hypothesis from a general theory and use data to test it. Typically, these works assume the ceteris paribus clause. If I want to measure the effect of market integration on wage inequality, I must look for cases where nothing else has changed. The problem is that development transforms every aspect of social life, and changes in one area usually affect others. While economists may try to control for everything else but their favored variable, their success is always debatable. Certainly it is not possible to study all of them at the same time, so there is a need for simplification. I chose to highlight the interaction between institutions and market forces, the way that each one influences the other, and how both of them influence income distribution.

Inequality cannot be studied as the single outcome of market forces. Supply and demand are - of course - relevant, but no market factor exists without institutions and asymmetric power relations between those who interchange in it. In other words, it is necessary to recognize that beyond the market, there are social and political relations between individuals and groups, as well as a state that can - and usually does - intervene not only in market exchanges, but in what can be calledbroadly speaking - the distributive conflict.

The state can shape market income distribution through different procedures, for example, by regulating rights and obligations of those who interchange, like property rights and the minimum wage. In other cases, it can intervene directly in a distributive conflict - by sending the police or military forces to dissolve a strike, or by pressuring the entrepreneurs to accept a rise in wages.

This is why a "pure" market income distribution does not exist, in the sense of a distribution solely determined by supply and demand forces. The political side of the economy is always there, especially when we are talking about inequality (Robinson 2010; Piketty 2014, 2015; Atkinson 2015). 


\subsection{Estimates: Dynamic Social Tables}

How to measure market inequality among Chileans from 1850 to 1970 ? Income tax data is unavailable and using proxies like the ratio between income per capita and wages seemed unsatisfactory, so I opted to build dynamic social tables. ${ }^{4}$ A social table is constructed assigning income recipients to different categories, usually occupations. Two kinds of data are needed for each category: how many there are and how much they earn. Typically, this methodology is used to estimate income inequality at a specific point in time. To study the evolution of inequality over time requires that social tables are built for different benchmark years (Lindert and Williamson 1982, 1983, 2013; Londoño 1995; Bértola et al. 2009). A "dynamic" social table estimates instead the number of income recipients and their income for each category for every year over a period of time. ${ }^{5}$ Therefore, what makes a social table "dynamic" is the fact that it covers a period of time, not just a year-or a set of years. Within that period, the categories remain constant, but the number of people included and their income change every year. Metaphorically speaking, if the use of different social tables enables the derivation of inequality trends from a set of "pictures," a dynamic social table allows us to "see the whole movie."6

In order to estimate income inequality and other related variables in Chile, I built two dynamic social tables, one for the period 1860-1929 and the other for 19291970. The first one has 49 categories ( 9 in agriculture -7 of landowners, from peasant to big landlords, and 2 of workers -3 in mining, 10 in industry, 20 of civil servants, 5 in transport, and 2 in others-professionals and domestic service). The second one (1929-1970) has 116 categories. The different sectors and branches represented include agriculture, mining ( 3 branches), industry ( 23 branches), commerce, transport, and public and private services ( 3 branches), and they were segregated between employers, self-employed, employees (white collar), and workers (blue collar). Sometimes one of these categories was also disaggregated, like employers in the agriculture sector who were divided into nine categories according to the size and quality of their properties. Another problem is that the sources allowed us to measure pretax income inequality between income earners only. To estimate inequality after taxes and transfers or between households is impossible (at least for the whole period).

The main sources of data were population and economic census, statistical yearbooks, and a myriad of secondary sources - mainly historical statistics, ${ }^{7}$ but also historical sources. Many assumptions were necessary, and I grounded them on theoretical and historical knowledge-e.g., the composition of peasant incomes, or the share of utilities in the mining sector appropriated by foreign capital. Sometimes

\footnotetext{
${ }^{4}$ Household surveys are only available for Santiago and the metropolitan zone from 1957 onwards. ${ }^{5}$ The term "dynamic" was proposed by Branco Milanovic in a workshop in Montevideo in 2011. ${ }^{6}$ A similar strategy was carried forward by Lindert and Williamson (2014) and Astorga's paper in this book.

${ }^{7}$ For example: Haindl (2007), Díaz et al. (2010), and Matus (2012).
} 
there were alternative sources - e.g., rural wages between 1880 and 1925 (Bauer 1975; Matus 2012) - and I used what I thought were the best examples.

It is impossible to describe here the entire methodology applied, but some decisions that were taken are important enough to be presented in some detail. ${ }^{8}$ This is specially the case for the top-income earners. If the estimation of the incomes of the top centiles presents several problems in the present, these are even more pronounced in the case of historical statistics. In order to deal with these problems, the two tables were created following different procedures. In the first table, which covers the years between 1860 and 1930, there are four categories of high-income earners. The first one is composed by elite civil servants (president, ministers, governors, etc.) where I used their annual salaries. Regarding landowners and industrialists, I estimated their income for a base year in which I had a reliable source and then projected it by an index which takes account of the evolution of prices, productivity, and wages. Finally, in the case of mining owners, first I estimated the sector's GDP at current prices for the whole period and then calculated the operating surplus which accrued to Chilean capitalists. ${ }^{9}$ The procedure for estimating the operating surplus was also used in the second table (1929-1970), but in this case I used the series of GDP at current prices estimated by Haindl (2007). The total profits were then distributed between employers through different procedures - for example, in the case of the seven categories of landowners they were assigned to them according to the distribution of property and capital which was estimated from the agricultural censuses.

Many assumptions are controversial. To evaluate how sensitive the results are to them, different series were estimated, changing sources or assumptions. Figure 1 presents the maximum and minimum Gini estimates for each year between 1860 and 1970. Two conclusions are suggested. First, the different sources and assumptions of a wide range in levels of inequality, especially from WWI to early 1920s. Second, trends and cycles coincide. In short, level comparisons with other countries may be a source of error, but volatility and trends are unlikely to be. ${ }^{10}$

For the period after 1970 I used household surveys. The period 1850-1859 was estimated by a procedure adapted from van Zanden et al. (2011) which was inspired, in turn, by the concept of Inequality Possibility Frontier (Milanovic et al. 2011).

Nevertheless, there are some assumptions and sources that are, in my opinion, better than others. These lead to what I consider "the best" estimates, presented in Figs. 2 and 3. Both figures present two different measures of market income inequality. The former measures factor income distribution as the profit share in gross domestic income. Figure 3, on the other hand, measures market income distribution among Chileans and excludes the estimate of profits of foreign capital in the mining sector. This "best" estimate will be used in the remainder of the chapter.

\footnotetext{
${ }^{8}$ The reader will find a full description of the methodology in Rodríguez Weber (2014: chapter 3).

${ }^{9}$ Note that foreign capital was very important in the mining sector. See Figs. 4 and 6.

${ }^{10}$ The reader will find a deeper analysis of the reliability of the estimated data in Rodríguez Weber (2014: 110-123).
} 


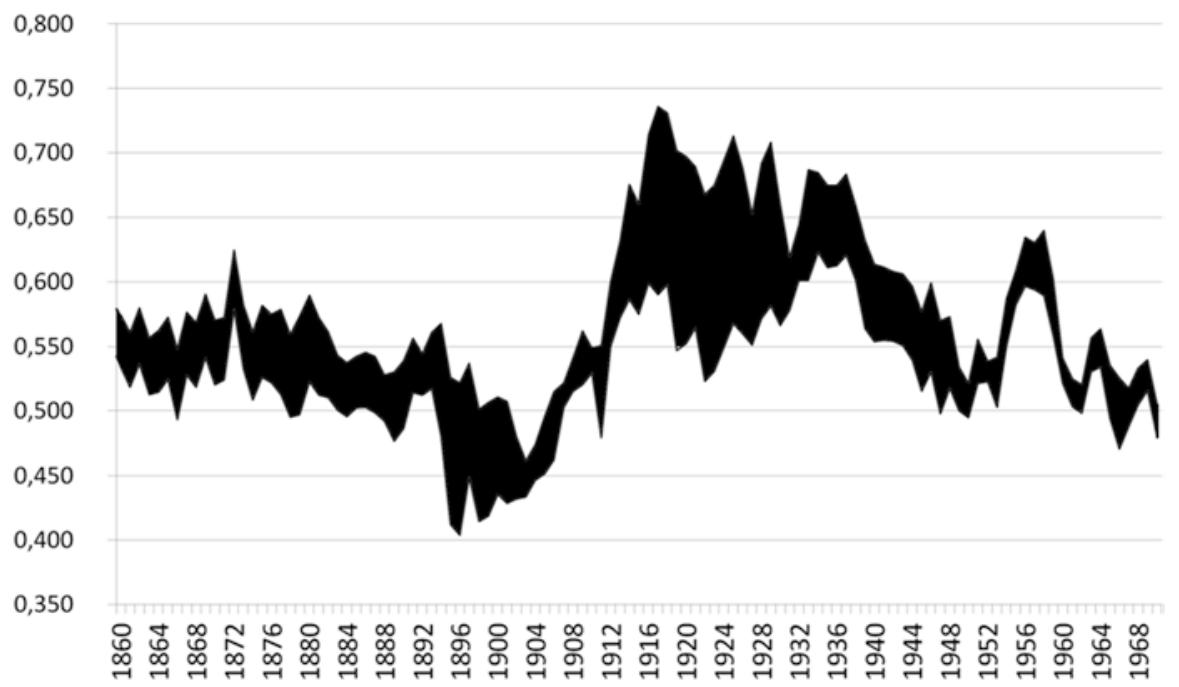

Fig. 1 Income distribution among Chileans between 1860 and 1970. Maximum and minimum estimations obtained through different sources and methods. Source: Own estimate. The estimates differ in their sources and/or assumptions

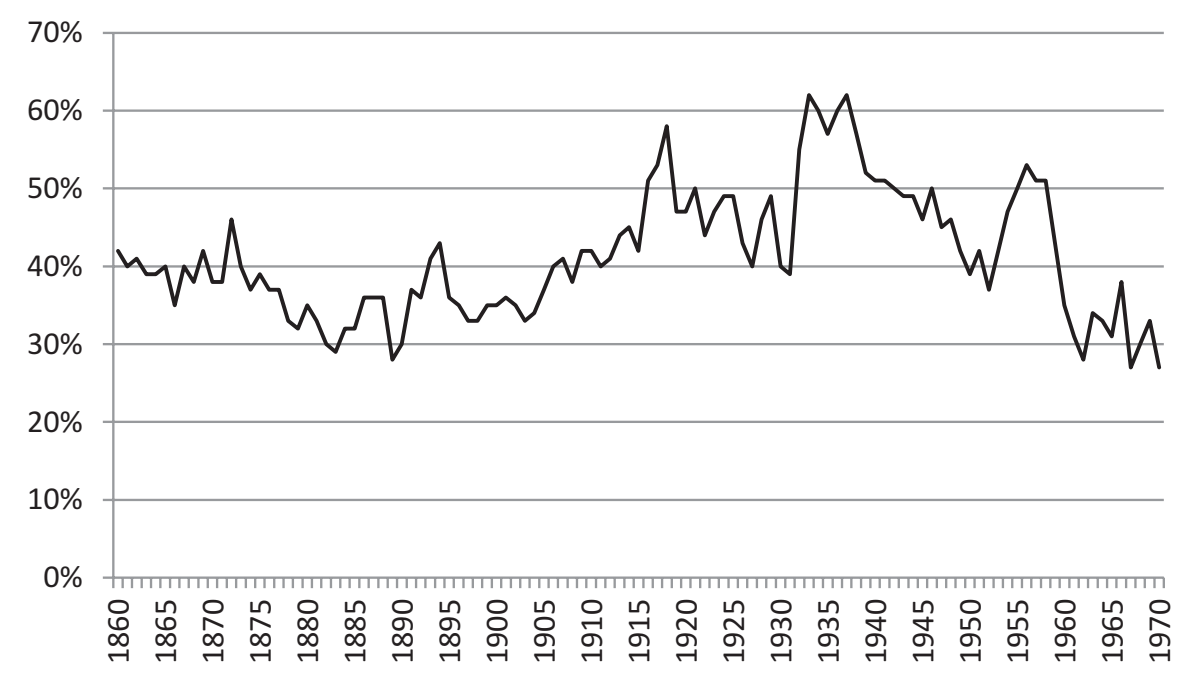

Fig. 2 The "best estimate" of factor income inequality, 1860-1970. Profit share as a percentage of gross domestic income in Chile, 1860-1970. Source: Own estimate 


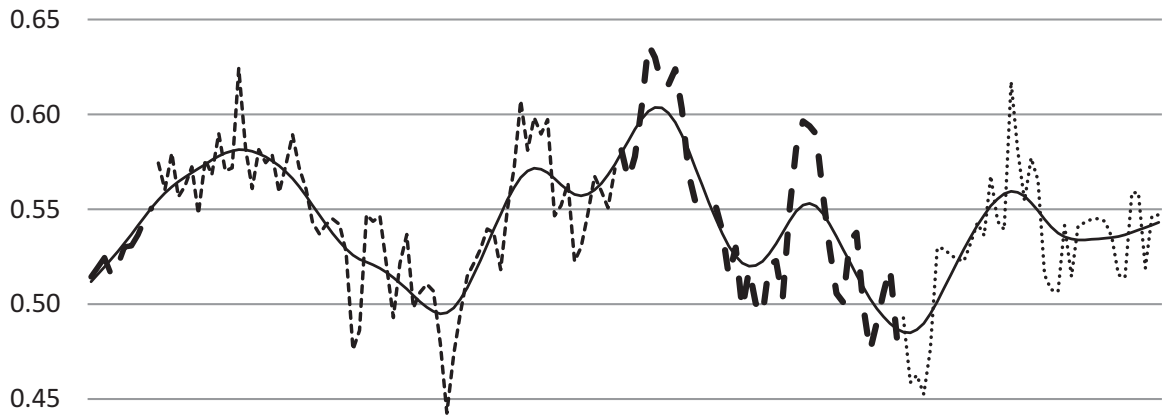

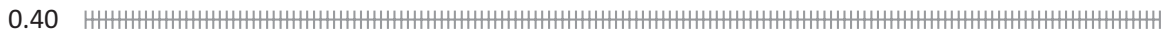

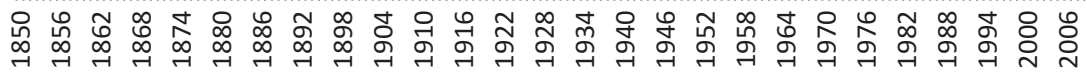

— - (1850-1860) Estimaded through Extraction Ratio

--.-- (1860-1929) Dynamic Social Table 1: 1860-1930

- - (1929-1970) Dynamic Social Table 2: 1929-1970

.......... (1970-2009) Household surveys (Gran Santiago)

Hodrick-Prescott (smoothing parameter=100)

Fig. 3 The "best estimate" of Chilean income earner inequality, 1850-2009. Gini coefficient. Source: Own estimate. The different lines and dots represent different estimation methods. The pitfalls of each methodology and the splice of estimations obtained through different methodologies imply that only the midterm tendencies, obtained through the Hodrick-Prescott filter, will be used in the historical analysis

\section{A Brief History of Income Inequality in Chile}

\subsection{Globalization and Institutions, 1850-1873}

Unlike what happened in most of Latin America after independence, Chile State was rapidly consolidated. Although there were civil wars in the 1850 s, postindependence conflicts had ended by 1830 . In those decades of political stability, Chile benefited from growing international demand for copper and wheat. The first was driven by the expansion of the industrial revolution, and the second one by rise in world living standards and declining international transport costs. This commodity boom generated export-led growth.

Thus began the modern era of Chilean economic history, characterized by a virtuous cycle between exports, imports, and state revenues. Increasing world demand stimulated the production of tradables, the increase in foreign exchange earnings financed increased imports, and the tariffs on foreign commerce-the main source of tax revenues - allowed the expansion of public spending, especially on infrastructure. As a result, Chile's economy grew faster and foreign trade share rose ${ }^{11}$ (Cariola and Sunkel 1982; Collier and Sater 1998; Salazar and Pinto 2002; Ortega 2005).

\footnotetext{
${ }^{11}$ Between 1850 and 1873 the annual growth rate for GDP per capita, exports, imports, and fiscal revenues were 3.8, 6.2, 5.9, and 4.1\% (Rodríguez Weber 2014: Table 5.2).
} 


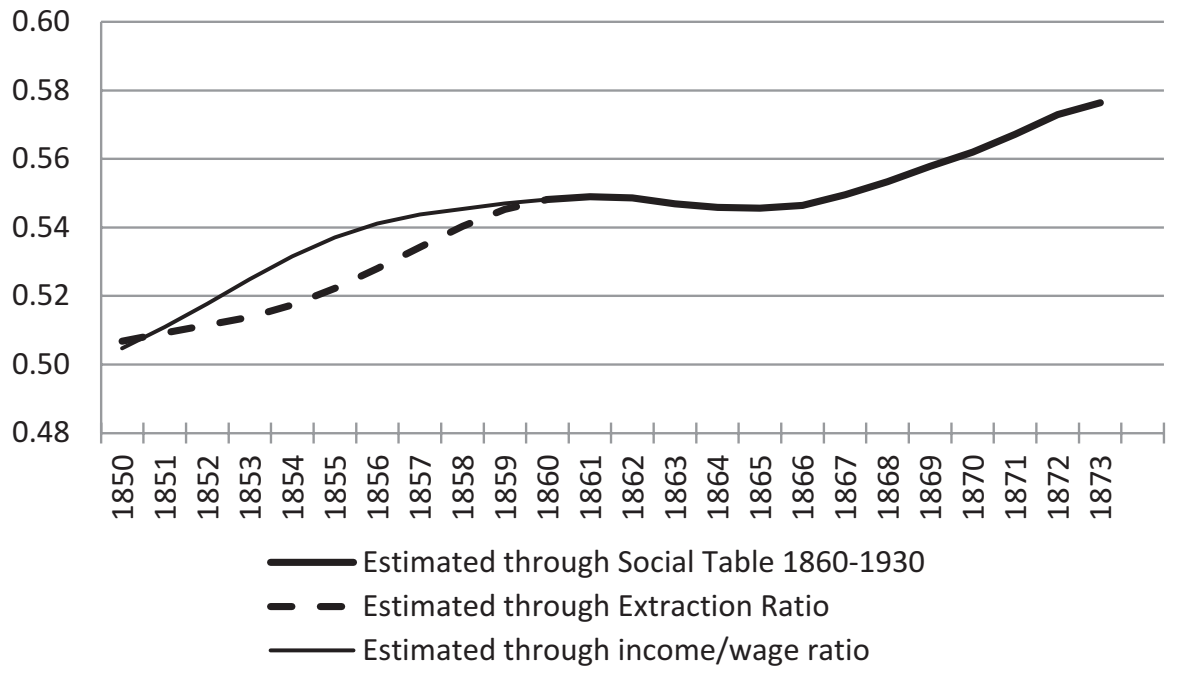

Fig. 4 Market income inequality among Chileans, 1850-1873. Gini index. Source: Own estimate. The period 1850-1859 was estimated by projecting the value of 1860 through two different methods. Both are based on assumptions which are consistent with historical knowledge (Rodríguez Weber 2015)

According to Williamson $(2002,2011)$ these global forces led to an increase in the rental/wage ratio which benefited landowners and implied a worsening income distribution. This was precisely what happened in Chile between 1850 and the mid-1870s (Fig. 4). The exports of wheat to California and Australia during the gold fever in the 1850s, and to Great Britain the decade that followed, promoted the use of land that was previously idle. But this land, although unused, had owners. So, new lands were placed into production on established haciendas. In a process which has been compared to the "second serfdom" of Eastern Europe, globalization forces tended to reinforce the archaic institution of the inquilinos (Bauer 1975, 1992; Bengoa 1988). ${ }^{12}$ Part of the labor force of the haciendas since the seventeenth century, the inquilinos were paid with the right to use a piece of land, and they and their families had the obligation to work in the landlords' fields. During this period, the value of land rose as a consequence of the increased demand for Chilean wheat (Gay 1863), and the obligations of the inquilinos increased as their rights diminished (Bauer 1975). Pushed by external demand, the economy grew, but the institutional framework which had the hacienda system at its core-which affected the lives of $80 \%$ of the Chileans at that time-assured that growth went almost exclusively to the elite. Most people maintained a living standard barely above subsistence. As a consequence, income distribution worsened (Rodríguez Weber 2015).

\footnotetext{
${ }^{12}$ It's worth noting that, contrary to other Latin American countries, there wasn't an ethnic divide between Chilean peasants and landowners. The Chilean population was homogenous. Thus, at the end of the colonial period, the indigenous population accounted only for $9.5 \%$ of total population, while Spaniards/whites were $74.5 \%$ (Newson 2006, Table 5.3).
} 


\subsection{Crisis, Frontier Expansion, and Foreign Investment, 1873-1903}

Income inequality fell between 1873 and 1903, surprisingly since it was still export led, but this trend obscures the fact that the period contained two different situations: 1873-1880 was a time of crisis that ended with the Pacific War (1879-1883), and 1880-1903 was a time of expansion.

Global forces that led to growth following the gold fever of the 1850 s provoked a serious crisis in 1873 . The quantity and the prices of exports fell strikingly, fiscal incomes sunk, and the whole economy collapsed (Sater 1979; Ortega 2005). The elite, and perhaps some civil servants in the middle - in any case the upper decilewere the only ones affected by the crisis, because most people were at subsistence. Reduced incomes in the top, even though it remained stable for the poor, implied a reduction in income inequality.

But things changed after 1880, when Chile initiated a second cycle of exportled growth, this time driven by the nitrate exports. This cycle was characterized by a process of frontier expansion in which the area of land controlled by Chile increased in almost $50 \%$. This was a consequence of two military victories: the first one over Peru and Bolivia in the North, which allowed Chile to gain control over the nitrate fields, and the second one over the mapuches, in the South, which allowed Chile to expand its agricultural frontier. As a result, the land/labor ratio increased by $30 \%$. The incorporation of natural resources, above all the nitrate fields, led to the second growth cycle of nineteenth century, which ended in 1913 (Cariola and Sunkel 1982).

Income inequality fell in the 1870 s as a consequence of the crisis, but the same trend is seen after 1880 , in a context of high growth led by nitrate exports. Why did this happen? The answer consists of two parts. First, the elite, weakened by the crisis, could not preserve the nitrate business for themselves. Instead, it was rapidly controlled by foreign capital - mainly the British. Therefore, an important share of the profits from the core industry during this period went to foreigners (Fig. 5).

In other words: foreign control of the industry and the burden of taxes collected by the state over the nitrate activity implied that a significant portion of income which would have gone to Chilean elite, if it had maintained control, ended up in foreign hands.

The other process which explains the counterintuitive fall in income inequality during this post-1880 period of export-led growth was the impact of frontier expansion on wages. During the last two decades of the century, Chile expanded its territory both to the north and to the south. In the north, salaries were high enough to attract the labor force to work on the inhospitable environment of the nitrate fields. In the south, after the Chilean Government won a war against the mapuches, thousands of people from the Central Valley migrated and occupied a piece of landwhich had no owners, except, of course, the mapuches themselves. As a consequence, between 1880 and 1900 many people abandoned the rural sector of the Central Valley - the mainland of the hacienda system (Table 1). 


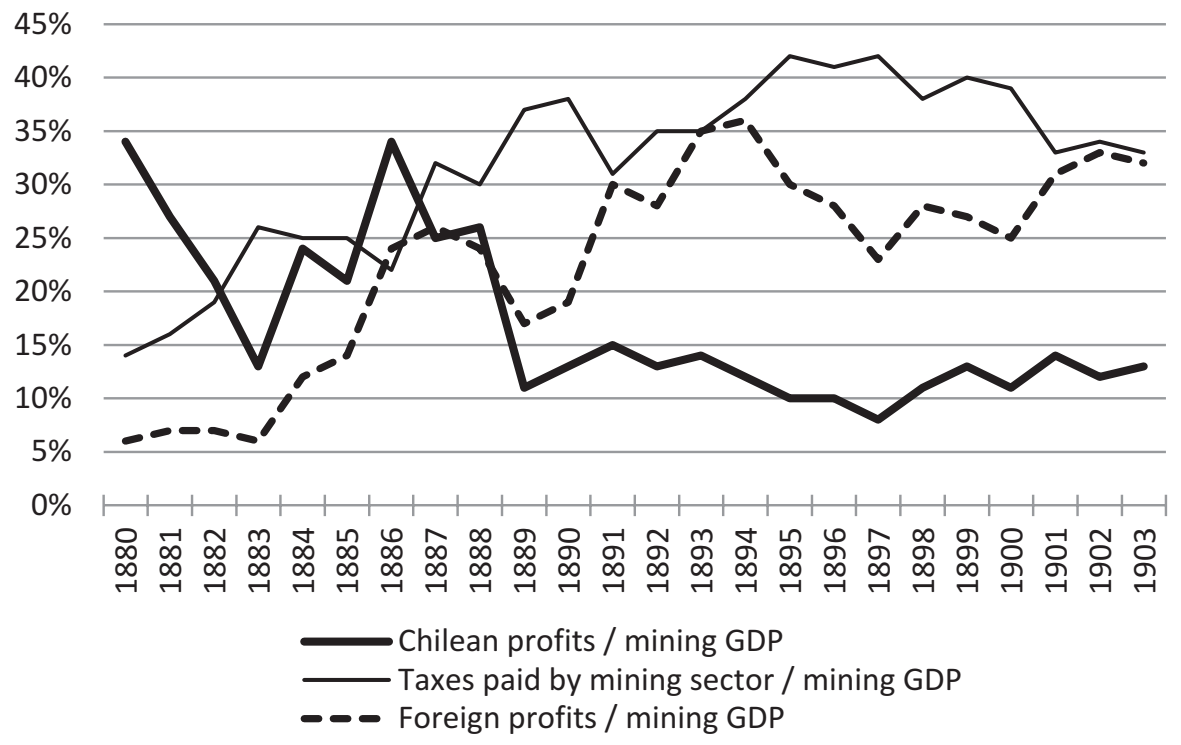

Fig. 5 Distribution of mining GDP between foreign investors, local investors, and the state, 18801903. Source: Own estimate. See Rodríguez Weber (2014: Cuadro AE 16)

Table 1 Population by regions and average growth rates between censuses

\begin{tabular}{|c|c|c|c|c|c|c|c|c|}
\hline \multirow[b]{2}{*}{ Region } & & \multicolumn{4}{|c|}{ Population by region $(\%)$} & \multicolumn{3}{|c|}{$\begin{array}{l}\text { Population growth: Annual rate } \\
\text { by period }(\%)\end{array}$} \\
\hline & & 1875 & 1885 & 1895 & 1907 & $\begin{array}{l}1875- \\
1885\end{array}$ & $\begin{array}{l}1885- \\
1895\end{array}$ & $\begin{array}{l}1895- \\
1907\end{array}$ \\
\hline \multirow[t]{2}{*}{ North } & "Big" north & 0.1 & 4 & 6 & 8 & 48.9 & 3.9 & 4.0 \\
\hline & "Small" north & 11 & 10 & 8 & 7 & 0.6 & -0.9 & 0.7 \\
\hline \multirow[t]{2}{*}{ Center } & Central Valley & 68 & 61 & 60 & 54 & 0.9 & 0.9 & 0.5 \\
\hline & Concepción & 13 & 14 & 12 & 11 & 2.8 & -0.5 & 0.9 \\
\hline \multirow[t]{3}{*}{ South } & Frontera & 0.9 & 4 & 6 & 10 & 13.9 & 6.1 & 5.9 \\
\hline & The Lakes & 4 & 5 & 5 & 7 & 3.1 & 2.0 & 4.0 \\
\hline & Austral & 3 & 3 & 3 & 3 & 1.3 & 0.6 & 1.1 \\
\hline \multicolumn{2}{|l|}{ Total } & 100 & 100 & 100 & 100 & 2.0 & 1.0 & 1.5 \\
\hline
\end{tabular}

Sources: Population census (1907) and Hurtado (1966, Cuadro 2). The Big North includes the provinces of Tacna, Tarapacá, and Antofagasta. The "Small" North includes the provinces of Atacama and Coquimbo. The Central Valley includes the provinces of Aconcagua, Valparaíso, Santiago, O'Higgins, Colchagua, Curicó, Talca, Linares, Maule, and y Nuble. Concepción is formed by the provinces of Concepción, Arauco, and Bío-Bío. Frontera region by Malleco and Cautín. The Lakes by Valdivia and Llanquihue, and Austral zone by provinces of Chiloé and Magallanes territory

Therefore, labor demand increased as a consequence of the emerging nitrate industry and the growth of cities, at the same time that people were abandoning the rural area of Central Valley. Meanwhile, the growth of public education-enabled by state revenues collected over nitrates - initiated a slow but steady expansion of 
Table 2 Annual income by categories of income earners. Constant shields of 1960

\begin{tabular}{|c|c|c|c|c|c|c|c|c|}
\hline \multirow[b]{2}{*}{ Period } & \multirow[b]{2}{*}{$\$$} & \multirow{2}{*}{$\begin{array}{l}\text { Total } \\
\text { Mean }\end{array}$} & \multirow{2}{*}{$\begin{array}{l}\text { Elite } \\
\text { Top } \\
1 \% \\
\end{array}$} & \multicolumn{3}{|c|}{ Unskilled labor } & \multirow{2}{*}{$\begin{array}{l}\text { Skilled } \\
\text { labor } \\
\text { Total }\end{array}$} & \multirow{2}{*}{$\begin{array}{l}\text { Salaried } \\
\text { Total }\end{array}$} \\
\hline & & & & Urban & Rural & Total & & \\
\hline 1880-1884 & $\begin{array}{l}\text { Shields } \\
\text { of } 1960\end{array}$ & 298 & 7.425 & 299 & 121 & 214 & 1.735 & 311 \\
\hline 1900-1904 & $\begin{array}{l}\text { Shields } \\
\text { of } 1960\end{array}$ & 428 & 8.183 & 412 & 231 & 324 & 1.811 & 445 \\
\hline $\begin{array}{l}1880- \\
1884 / 1900-1904\end{array}$ & $\begin{array}{l}\text { Total } \\
\text { growth }\end{array}$ & $43.9 \%$ & $10.2 \%$ & $37.7 \%$ & $91.1 \%$ & $51.4 \%$ & $4.4 \%$ & $43.4 \%$ \\
\hline
\end{tabular}

Source: Own estimate. See Rodríguez Weber (2014: Cuadros AE3, AE4, AE6, and AE7)

0.60

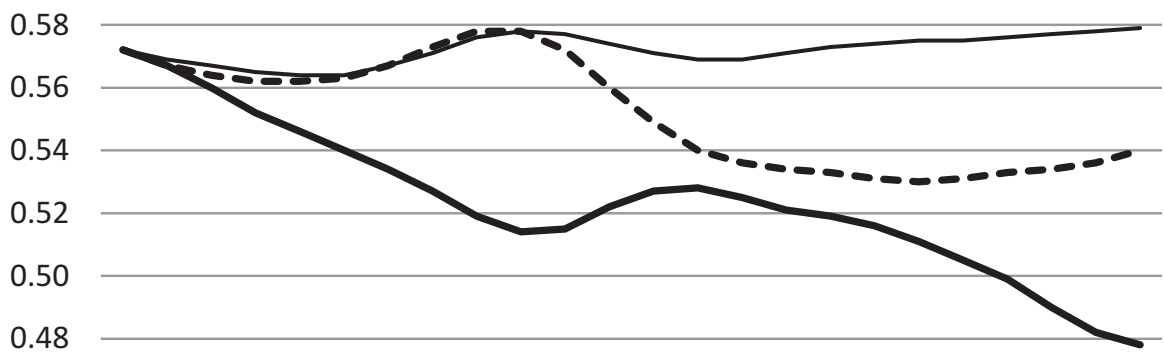

0.46
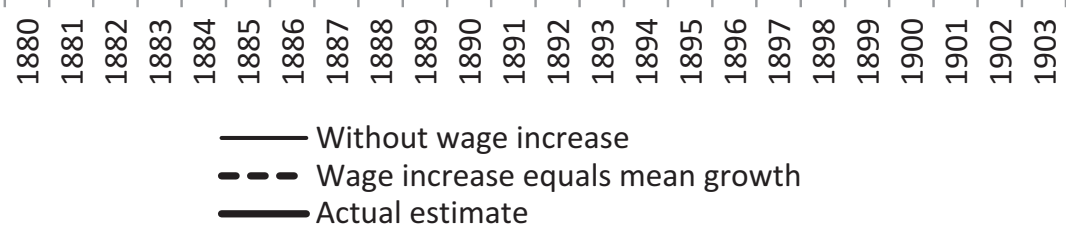

Fig. 6 Estimating the effect of the increase of wages on inequality. Gini coefficient, 1880-1903. Source: Own estimate

the middle classes and an increase in the supply of skilled workers (Rodríguez Weber 2014: Cuadro AE 12). All of this led to a bigger increase in unskilled wagesespecially in rural wages - than in the mean income and elite income (Table 2). As the counterfactual exercise shown in Fig. 6 demonstrates, the increase in unskilled wages was big enough to have an important equalizing effect.

Why is it that we do not see the same evolution in other examples of frontier expansion during the same period like Argentina, New Zealand, or Australia? Because in these cases the expansion of the frontier went hand in hand with a population explosion due to an important immigration process. In Argentina, for example, between 1875 and 1914 the supply of agricultural land increased from 55 to 83 million of hectares. But population growth was even more important, from 1.7 
to 7.8 million in the same period. As a consequence, the hectares per capita decreased from 31 to 11. The same process is seen in New Zealand (Álvarez 2012). That is to say, in both cases it followed the opposite tendency than in Chile, when hectares per capita increased from 18 to 23 between 1875 and 1885 .

In sum, unskilled wages increased at the same time that most of the profits generated in the nitrate sector went outside the country. As a result, personal income distribution among Chileans fell in a context of economic growth led by exports of natural resource-intensive goods. Profit share, on the other hand, remained almost constant although at a lower level than in the 1860s (Fig. 2).

\subsection{Zenith and Decay of the "Oligarchic Republic," 1903-1938}

Between 1903 and 1913, the real mean income grew at an annual rate of $1.9 \%$, the real income of the top $1 \%$ by $8.0 \%$, and the real income of the unskilled workers decreased at a rate of $-1.5 \%$ (Rodríguez Weber 2014: Tabla 7.1). As a result, the total real income increased by $33 \%$, the income of the top percentile rose $137 \%$, and that of the bottom $99 \%$ increased by only $17 \%$. In other words, the top $1 \%$ appropriated $55 \%$ of the total growth of the period. Why the difference between 1873 and 1903 ?

The crisis of 1873 affected the income of the elite, but not its power. Their control over the state was so total that it is accurate to talk about an "oligarchic republic" (Vial Correa 2010) or "aristocratic regime" (Reinsch 1909). When the effects of frontier expansion and internal migration passed, the elite could turn into almost the unique beneficiary of the last decade of growth in the nitrate era. ${ }^{13}$ When growth declined after 1913, the elite could keep their privileged situation, until the effects of the crisis facilitated a social alliance between urban workers and middle sectors which in turn overthrew the oligarchic republic.

To talk about an "oligarchic republic" while studying the political economy of income inequality requires a theoretical stance. One can expect that under such a regime the state will promote policies beneficial to the elite in their conflicts with other classes. Hence, while much has been debated about the impact of oligarchic institutions on economic growth in the long run,${ }^{14}$ the consequences for inequality are much less debatable.

There were three causal mechanisms derived from the elite's political control over the state, which allowed them to become the main beneficiary of the economic growth at the end of the nitrate era and which explain the rapid increase in income inequality between 1903 and 1913 and into the 1920s (Fig. 3).

\footnotetext{
${ }^{13}$ This time growth was led in the first place by increasing prices. Nitrates were used for explosives, so demand increased in the decade before the Great War.

${ }^{14}$ See Acemoglu et al. (2005), Coatsworth (2008), Bértola (2011), Dobado (2009), and Mahoney (2010).
} 


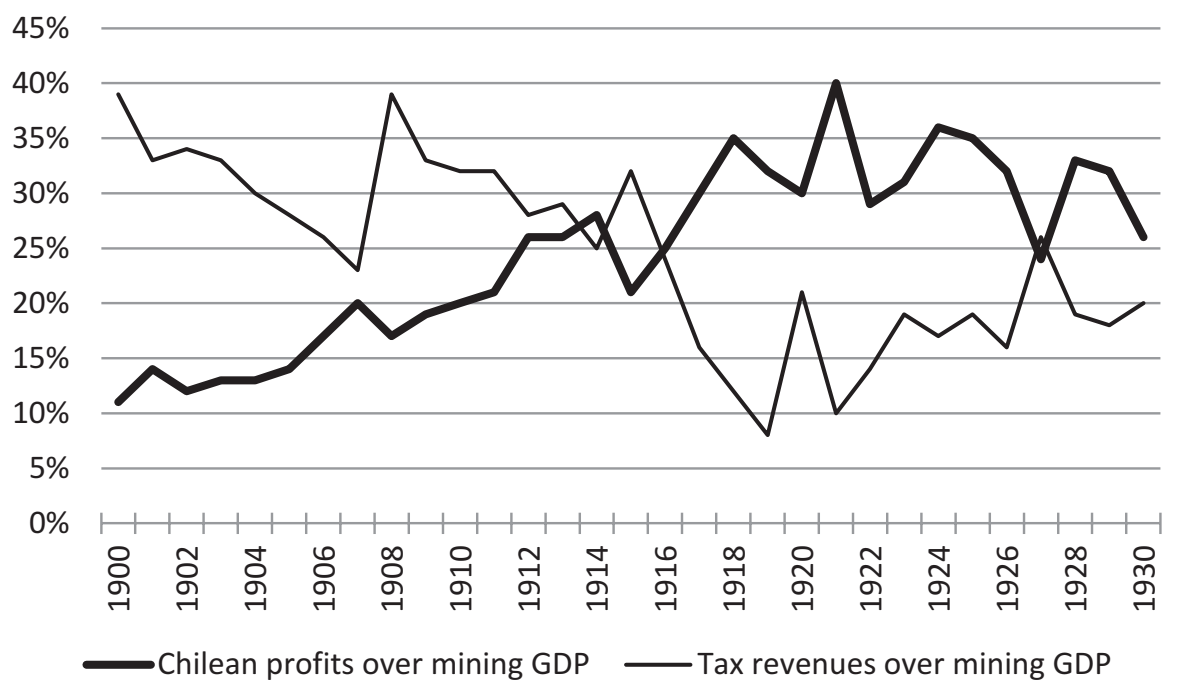

Fig. 7 Chilean profits and tax revenues collected in the mining sector as a percentage of mining GDP. Source: Own estimate. See Rodríguez Weber (2014: Cuadro AE 16)

First, the elite took control over the nitrate industry. In fact, between 1901 and 1925 the participation of the Chilean capital in the industry increased from 14 to $68 \%$. Meanwhile, the British share was reduced from 55 to $23 \%$ (Cariola and Sunkel 1982: Cuadro 16). At the same time, the portion of the mining GDP collected by the state as tax revenues was significantly reduced (Fig. 7).

Second, during the decade before the Great War, monetary police led to increased inflation ${ }^{15}$ which reduced real wages since nominal wages grew more slowly. When urban and mining workers organized in their recently formed unions and demanded an increase in nominal wages to match inflation, as well as other improvements in labor conditions, they were wildly repressed. The massacre of 1907 in Iquique, when more than 2000 mining workers and their families were strafed in a school by the army, became the bold symbol of the period. ${ }^{16}$ After that, the union activity fell off, as did real wages (Fig. 8). In sum, the unions could not prevent the fall in real wages and the economic growth directly benefited the elite. But this was not the result of "impersonal market forces." It was, instead, the direct consequence of the policies carried forward by the oligarchic republic in favor of the elite.

Third, the property rights over the land taken from the mapuches in the South were now regularized in a way that they systematically benefited the great landowners in detriment to the mapuches and the people who had settled there in the previous

\footnotetext{
${ }^{15}$ The increase in the consumer price index was $10 \%$ in 1905, $17.3 \%$ in $1906,24.4 \%$ in 1907 , and $12.2 \%$ in 1908 (Matus 2012).

${ }^{16}$ The number of workers dead as a consequence of state repression during this period was similar to the Chilean casualties during the Pacific War.
} 


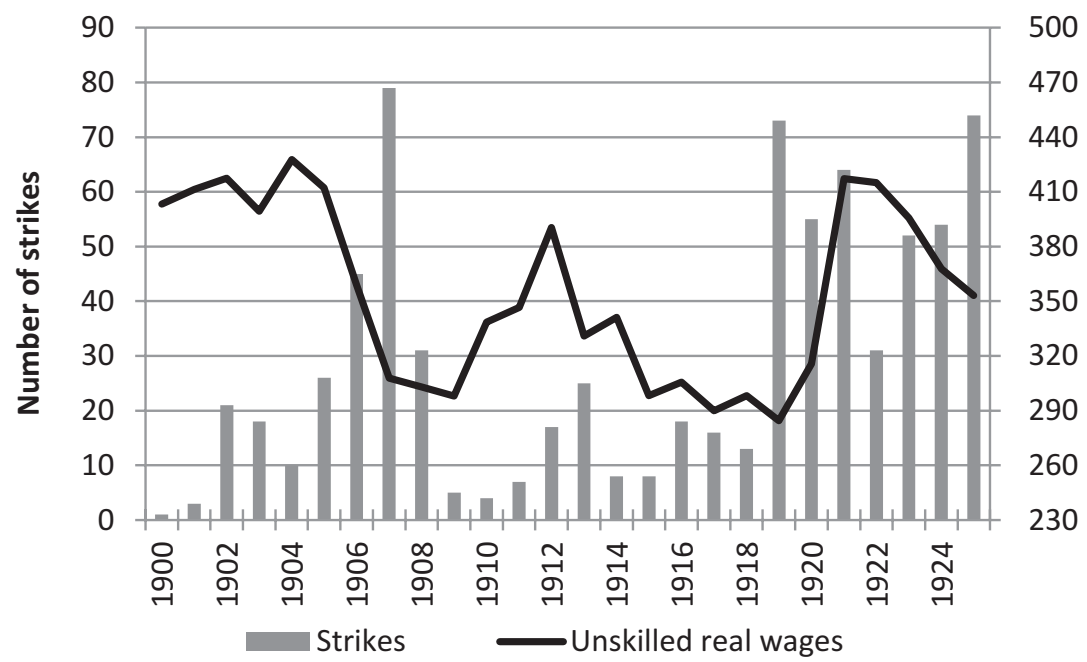

Fig. 8 Index of real wages for unskilled workers $(1913=100)$ and number of strikes in Chile, 1900-1925. Sources: Strikes: Pizarro (1986: cuadros 2 y 7). Real wages: Own estimate

period. The control of the elite over the state guaranteed that the hacienda system expanded to the frontier (Solberg 1969; Bengoa 1988; Almonacid 2009). ${ }^{17}$

These are the fundamental mechanisms that explain the rapid increase of income inequality between 1903 and 1913. After that, inequality remained high, but the economic context changed radically.

Between 1913 and 1938, there was hardly any economic growth at all. This was the net result of interwar volatility and the Great Depression. This situation of stagnation with volatility, if not affected the privileged place of the elite in economic terms, at least undermined its political role.

The crisis severely affected fiscal revenues. The taxes on foreign commerce had fed state expansion, but now public earning and spending sunk. In 1917 fiscal expenditures were at $44 \%$ of their 1912 levels (Diaz et al. 2010). As the state was a central player in the skilled labor market - teachers, military officers, and civil servants - the fiscal crisis reduced the demand for skilled workers, whose wages fell jointly with fiscal expenditures. Between 1912 and 1917 skilled wages fell by $38 \%$. They recovered during the 1920s but dropped again after 1930. Between 1912 and 1937, skilled wages fell at an annual rate of $2.0 \%$. During the same period the ratio between skilled and unskilled wages fell from 6 to 2.9 (Rodríguez Weber 2014: Cuadro AE 7). This, together with the increase in the strikes-by that time the unions had recovered from their defeat of 1907-fed political discontent, social turmoil, and sabre-rattling. The oligarchic republic was in steep decline.

After 1920 different presidents acceded to the government against the elite's desires - something unthinkable a few years earlier. In 1938, after two decades of

\footnotetext{
${ }^{17}$ See also Rodríguez Weber (2014: 227-232).
} 
political turbulence - which included two dictatorships and a first attempt to set up a socialist republic - the elections were won by the Frente Popular, a left-wing alliance formed by social democrats, socialists, and communists.

\subsection{Achievements and Pitfalls of the "Mesocratic Republic," 1938-1973}

The expansion of education between 1910 and 1940-when Chile narrowed the education gap with core countries (Bértola et al. 2012: Cuadros 8 and 9) -allowed an increase in skilled labor in the next decades. Thus, the "mesocratic republic," between 1938 and 1973, was a time of expansion and growing importance of the middle sectors, both in political and economic terms. It was also a period of an increasing role of state regulation on economic activity. Its influence was particularly important in the promotion of industry. This led to a structural change in three ways. First, it fed the urbanization process. Between 1940 and 1970 urban population increased from 53 to $75 \%$. Second, the structure of sectoral GDP and working labor changed dramatically. As elsewhere in Latin America, this was an era of industrialization (Thorp 1998; Bértola and Ocampo 2012). Between 1935 and 1970 the industrial share in GDP increased from 12 to $23 \%$. Meanwhile, the agricultural and mining shares fell. In terms of the labor force, the structural change was characterized by the fall in agriculture and the expansion of services. Third, there was a relative expansion of employees, especially skilled. Between 1940 and 1970 whitecollar workers increased from 14 to $39 \%$ of the total labor force, and from 21 to $47 \%$ of the urban workers (Rodríguez Weber 2014: Cuadro AE 12).

The political scene was increasingly dominated by left-wing parties and unions. The center-left controlled the executive between 1939 and 1952, and again between 1964 and 1970. Furthermore, between 1971 and 1973, Chile passed through a revolutionary process under the presidency of Salvador Allende. The new political context of the 1940s and 1960s was correlated with an increase in the union activity. Between 1936 and 1941 the unionization rate of white-collar workers increased from 20 to $45 \%$. Although it later declined, it rose again during the Christian Democratic government, from $25 \%$ in 1964 to $45 \%$ in 1970. Unionization grew also within the industrial sector, but less than in the case of white-collar workers. For rural workers, unionization was almost nonexistent before the victory of the Christian Democratic Party, but rocketed after 1964, reaching $74 \%$ of the rural labor force by 1970 (Rodríguez Weber 2014: Cuadro AE 19).

Between 1940 and 1970, inequality fell as a consequence of various forces. Only in the 1950s was this trend partially reversed (Fig. 3). The mechanisms by which distribution was improved were of two types. First, the process of structural change undermined the importance of a sector which was highly unequal (agriculture) in favor of the urban economy, where inequality was lower (Rodríguez Weber 2014: Cuadro AE 23).${ }^{18}$ More important was the increase in the middle sectors - mainly

\footnotetext{
${ }^{18}$ The same was true in Colombia and Uruguay (Londoño 1995; Bértola 2005).
} 


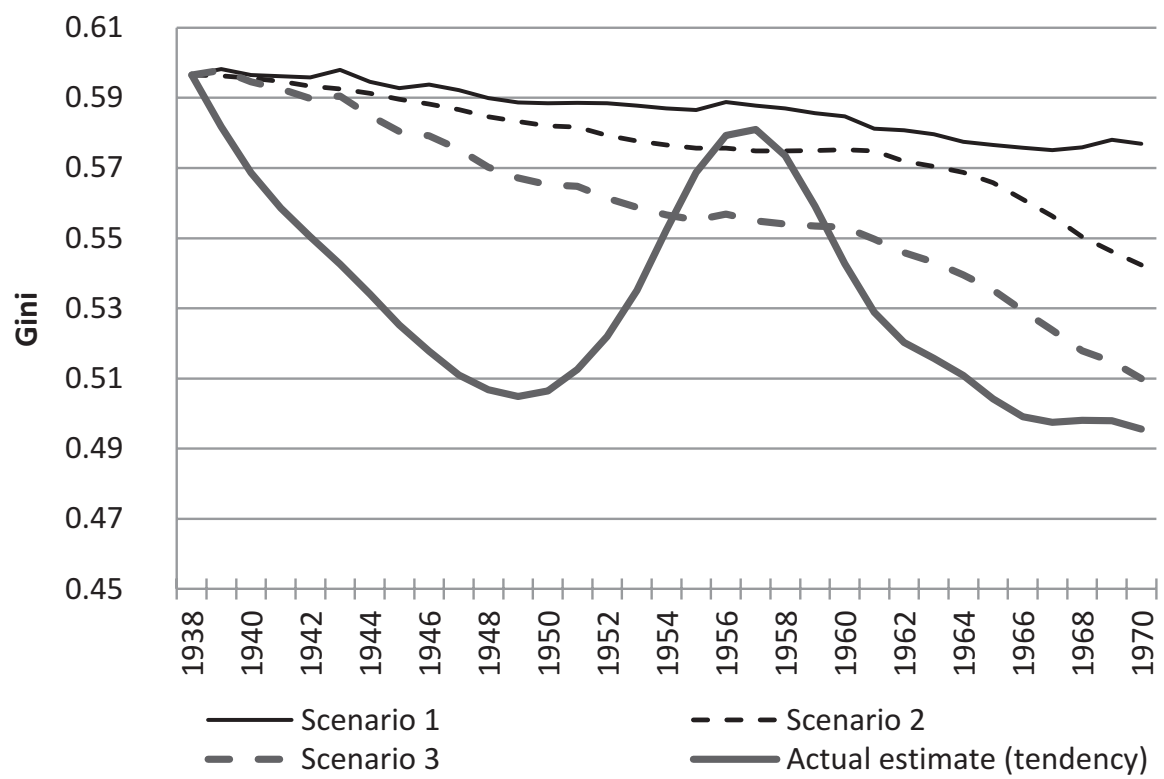

Fig. 9 Estimating the effect of structural change on income inequality reduction. Source: Own estimates. See text for descriptions of the different scenarios

employees - which meant that an augmented portion of workers earned salaries nearer the mean of the distribution. Thus, between 1940 and 1970, income recipients which earned between 50 and $200 \%$ of the mean income increased from 42 to $55 \%$ of total income earners (Rodríguez Weber 2014: Gráfico 8.14).

The combination of both processes of structural change, between sectors and between categories of workers (that is, the increased importance of employees), had a strong equalizing effect, especially in the 1940s and 1960s when the process accelerated. This can be seen from the counterfactual scenarios presented in Fig. 9. The purpose of the exercise was to capture the effect of the different aspects of structural change on income inequality, so the level of income for each category was maintained constant at its level of 1938. In the first scenario, income inequality was estimated assuming that the structural change was only due to the migration of unskilled workers between sectors. Thus, scenario 1 captures the effect of the rural workers moving on to urban unskilled jobs. ${ }^{19}$ In scenario 2 , inequality was estimated assuming no structural change between sectors but only between categories of workers, i.e., between blue-collar workers and white-collar employees. Thus, this scenario captures the effect of the "skilling" within sectors. Finally, in scenario 3 income inequality was estimated assuming shifts between sectors and categories of

\footnotetext{
${ }^{19}$ The gap between rural and unskilled urban wages grew during the period, in accordance with the increasing gap in productivity and differences in the institutions that ruled both labor markets. In 1938, 1950, and 1970, rural wages were 41, 44, and $24 \%$ of unskilled urban wages (Rodríguez Weber 2014: AE 7).
} 
workers but, as in the other scenarios, income levels remained constant for all categories. As can be seen, if only this had occurred, then income inequality would have fallen by about the same magnitude that actually occurred.

The second kind of mechanisms was related to the effect that the new political context had in the labor market institutions. During the 1940s, both government intervention-especially through the implementation and increase of the minimum wage for employees - and union activity favored an increase in the income earned by the poorest of the white-collar workers. Between 1940 and 1953, minimum wage systematically increased above the inflation rate of the previous year, a policy that not only reduced inequality within employees - the Gini coefficient for employees fell from 0.40 in 1939 to 0.28 in 1950 (Rodríguez Weber 2014: Cuadro AE 22) - but also seemed to affect unskilled wage growth (Rodríguez Weber 2014: 296-297).

Nevertheless, the redistributive goal was put in second place as inflation became the first policy concern. As it accelerated, the minimum wage lost its role as a redistributive tool during the 1950s; real wages fell, and income distribution worsened for a while (Fig. 3).

During that time, conservative forces gained influence and a monetarist adjustment was attempted. ${ }^{20}$ The goal was to freeze wages at the reduced level that they were after the inflation accelerated. Whereas during the 1940s the increase in the legal minimum wage for employees was a tool to promote real wage growth, now it was used as a way to contain the growth of prices. Nevertheless, this policy was impossible to implement under the institutional conditions of the mesocratic republic. The white- and blue-collar unions fought against the monetary policy, and it was progressively abandoned.

In the 1960s, the redistributive agenda took a new impulse, and it now reached the countryside. The agrarian reform led by the Christian Democratic government was the last attempt to transform the structure of inequality by ending the hacienda, the ancient institution which had its origins in the encomienda system of the colonial times (Loveman 1976; Santana Ulloa 2006; Rodríguez Weber 2013). This path of transformation was reinforced by Allende's victory in 1970. In that election, a vast majority of Chileans opted to deepen the structural reforms. However, street riots, and the attempt to build a socialist economy, alarmed a vast part of those in the middle, which by 1973 sided with the elites in opposition to the government. A military coup overthrew Allende on September 11th of 1973.

\subsection{The Legacy of Repression and the Debt of Democracy, 1973-2009}

The period 1973-2009 exhibits a unique style of development, characterized by the return to the export-led growth strategy, and the withdrawal of the state from the economy and a commitment to the centrality of the market in allocating resources,

\footnotetext{
${ }^{20}$ Due to the Klein-Sacks mission.
} 
but it is useful to distinguish between two different stages. Between 1973 and 1989 Chile was under the dictatorship of General Pinochet, whose regime was guilty of massive violation of human rights. The state repressed organizations like political parties and trade unions which play a central role in distributive conflicts. This was also a period of high economic volatility, marked by two deep recessions in 1975 and 1982/1983, and modest economic growth. It was under such circumstances that inequality reached its highest level since the 1930s (Fig. 3).

Chile has been governed by a democratic political system since 1990 . This most recent period was characterized by greater stability, higher levels of investment, and a higher growth rate. Nevertheless, the center-left coalition that ruled Chile between 1990 and 2009 was unable to reduce the extreme level of inequality which inherited from the authoritarian regime.

The high level of inequality that Chile faces today arose in a highly repressive political context, characterized by the prohibition of political parties and the repression of the trade unions and any kind of opposition. It was under these circumstances that the military dictatorship led by General Pinochet and his advisors promoted a radical transformation of the economy and society (Gárate Chateau 2012). Inequality arose because the policies carried forward by the government led to redistribute in favor of the elite. This was evident both in the structural reforms they boosted as well as in the short-term measures they adopted in response to the crisis of 1975 and 1982. The combination of high inflation, unemployment, and repression sank real wages. Poverty rocketed and income distribution worsened radically in few years (Fig. 3; see also Rodríguez Weber 2014: Cuadros 9.3, 9.6, and 9.8).

But the legacy of inequality that Pinochet and the Chicago boys left to Chilean democracy was settled in its structural transformations. First, the privatization of public enterprises and services - made in a highly opaque context (Gárate Chateau 2012; Mönckeberg 2001)_implied that profits could now be made from selling services that were considered rights a few years before. Instead of the perfect competitive markets that were promised by the Chicago boys who led the transformation, these services were increasingly provided by oligopolies which extracted huge profits by providing services that were once provided by the state (Solimano 2012). ${ }^{21}$

Secondly, the liberalization of the labor market, where a reform was introduced with the explicit aim of debilitating union's bargaining power (Coloma and Rojas 2000), left the vast majority of workers unarmed to face the power of the huge economic groups born under the dictatorial rule. And that is the third structural change provoked by the dictatorship that anchored inequality until 2009. The extremely rich elite, ${ }^{22}$ whose economic and political power is similar today to what it was during the oligarchic republic at the beginning of the twentieth century, ${ }^{23}$ impose

\footnotetext{
${ }^{21}$ Even The Economist admitted that Chilean capitalism had several problems on this subject. See http://www.economist.com/node/21552566.

${ }^{22}$ According to the population of their country, Chilean billionaires are overrepresented in the Forbes list. Related to Chile's GDP, their fortunes are also bigger than in most countries.

${ }^{23}$ Between 1913 and 1937 the $28 \%$ of income went to top $1 \%$ of income earners. In the first decade of twenty-first century the proportion was about $30 \%$ (Rodríguez Weber 2014: Tabla 9.5).
} 
formal and informal rules that undermine Chilean democracy (Garretón 2003; Gárate Chateau 2012). Even under democracy, the elite have been able to stop the timid attempts made by the government to improve income distribution. These, jointly with the fears of the parties which ruled between 1990 and 2009 that progressive policies like labor reform could destabilize the economic and political system, explain why inequality did not improve after 20 years of center-left governments. Inequality still is, as Michele Bachelet recognized, the major debt of democracy.

\section{Income Inequality in Chile: Past, Present, Future}

Chilean inequality has changed over time because it is part of the broader historical process. Among the market forces that have had an impact on income distribution it is useful to distinguish between those affecting the supply side from those acting on the demand side. The former include the frontier expansion, which in turn increased the land/labor ratio, and the expansion of education, which fueled the supply of skilled labor. Among the latter, of most importance were the changes in the market for Chilean exports. Finally, the processes of structural change-industrialization, urbanization, and expansion of the public sector-have affected both the demand and supply of labor, resulting in a reallocation of labor between sectors and categories of workers. However, changes in supply and demand of productive factors have never acted separately, and its consequences for inequality have always been mediated by the institutional environment. For example, the capacity of collective actors to build organizations like trade unions in defense of their interests, as well as the relationships - usually conflictive - they built with other players in the distributive conflict influenced the development of redistributive policies carried forward by the state, as well as the institutions governing property rights and factor markets. On the other hand, state intervention as a relatively autonomous player influenced not only the capacity of the agents to succeed in the distributive conflict, but it also affected the prices of relative factors. In other words, markets and institutions were the two sides of the same coin. It was the development of their relationship as a part of the general historical process which shaped inequality trends.

Nevertheless, to say that history matters implies not only that things changed over time, but also its persistence, a fact whose importance over the present and future of Chilean inequality is difficult to overestimate. At first sight, the fact that Chile is nowadays one of the most unequal countries in the world is due to the policies carried forward under the dictatorship. But a closer scrutiny shows that this was the last-although the nastiest-episode of a series in which the state assumed a role in promoting inequality. And this is, in turn, a consequence of a long-term trend: the control of the elite over the state, which allows it to shape the economic and political institutions in its favor. In this sense, and similarly to the argument developed by Sánchez-Ancochea in his chapter for this book, to achieve a better understanding of Chilean inequality today, but especially to forecast what might 
happen with it in the future, it is essential to analyze how the actual economic and political power of the elite evolves: a power that is rooted in the high concentration of wealth and the oligopolistic market structure which not only promotes high inequality of wealth and income, but also undermines democratic institutions. ${ }^{24}$

Open Access This chapter is distributed under the terms of the Creative Commons Attribution 4.0 International License (http://creativecommons.org/licenses/by/4.0/), which permits use, duplication, adaptation, distribution and reproduction in any medium or format, as long as you give appropriate credit to the original author(s) and the source, a link is provided to the Creative Commons license and indicate if changes were made.

The images or other third party material in this chapter are included in the work's Creative Commons license, unless indicated otherwise in the credit line; if such material is not included in the work's Creative Commons license and the respective action is not permitted by statutory regulation, users will need to obtain permission from the license holder to duplicate, adapt or reproduce the material.

\section{References}

Acemoglu, D., Johnson, S., \& Robinson, J. (2005). Institutions as the fundamental cause of longrun growth. In P. Aghion \& S. N. Durlauf (Eds.), Handbook of economic growth (Vol. 1A, pp. 386-472). Amsterdam: Elsevier.

Almonacid, F. (2009). El problema de la propiedad de la tierra en el sur de Chile (1850-1930). Historia, I(42), 5-56. enero-junio.

Álvarez, J. (2012). The evolution of inequality in Australasia and the river plate, 1870-1914. Paper presented at the 16th World Economic History Congress, 9-13 July 2012, Stellenbosch University, South Africa.

Atkinson, A. (2015). Inequality: What can be done? London: Harvard University Press.

Bauer, A. (1975). Chilean rural society from the Spanish conquest to 1930. New York: Cambridge University Press.

Bauer, A. (1992). Chilean rural society and politics in comparative perspective. In C. Kay \& P. Silva (Eds.), Development and social change in the Chilean countryside: From the pre-land reform period to the democratic transition (Volume 62 of Latin America Studies). Amsterdam: Centre for Latin American Research and Documentation.

Bengoa, J. (1988). Historia social de la Agricultura Chilena. Tomo I. El poder y la subordinación. Santiago: Ediciones Sur.

Bértola, L. (2005). A 50 años de la Curva de Kuznets: Crecimiento y distribución del ingreso en Uruguay y otras economías de nuevo asentamiento desde 1870. Investigaciones en Historia Económica, 3, 135-176. otoño.

Bértola, L. (2011). Institutions and the historical roots of Latin American divergence. In J. A. Ocampo \& J. Ros (Eds.), The Oxford handbook of Latin American economics. New York: Oxford University Press.

\footnotetext{
${ }^{24}$ The scandals which exploded at the beginning of 2015 over the role of the PENTA Group - a holding which has its origins in the privatizations made under Pinochet -in political financing, tax evasion, and bribery are the most recent-and evident-example of this "incestuous relationship between money and politics" as Marta Lagos called it. See "Executives Are Jailed in Chile Finance Scandal," the New York Times, March 8, 2015, page A9.
} 
Bértola, L., Castelnovo, C., Rodríguez Weber, J., \& Wilebald, H. (2009). Income distribution in the Latin American southern cone during the first globalization boom and beyond. International Journal of Comparative Sociology, 50(5-6), 452-485.

Bértola, L., Hernández, M., \& Siniscalchi, S. (2012). Un Índice Histórico de Desarrollo Humano de América Latina y algunos países de otras regiones: metodología, fuentes y bases de datos. Documento de Trabajo on Line No. 28/Reedición, Programa de Historia Económica y Social, UDELAR.

Bértola, L., \& Ocampo, J. A. (2012). The economic development of Latin America since independence. Oxford: Oxford University Press.

Cariola, C., \& Sunkel, O. (1982). Un siglo de Historia económica de Chile 1830-1930. Dos ensayos y una bibliografía. Madrid: Ediciones Cultura Hispánica.

Coatsworth, J. H. (2008). Inequality, institutions and economic growth in Latin America. Journal of Latin American Studies, 40, 545-569.

Collier, S., \& Sater, W. (1998). Historia de Chile, 1808-1994. Madrid: Cambridge University Press.

Coloma, F., \& Rojas, P. (2000). Evolución del mercado laboral en Chile, reformas y resultados. In F. Larraín \& R. Vergara (Eds.), La transformación económica de Chile (pp. 491-540). Santiago de Chile: Centro de Estudios Públicos.

Comisión Central del Censo. (1907). Censo 1907. Memoria presentada al Supremo Gobierno.

Díaz, J., Lüders, R., \& Wagner, G. (2010). La República en Cifras. EH Clio Lab-Iniciativa Científica Milenio. Retrieved from http://www.economia.puc.cl/cliolab.

Dobado, R. (2009). Herencia colonial y desarrollo económico en Iberoamérica: una crítica a la "nueva ortodoxia". In E. Llopis \& C. Marichal (Eds.), Latinoamérica y España, 1800-1850: un crecimiento económico nada excepcional. Madrid: Marcial Pons Historia.

Gárate Chateau, M. (2012). La revolución capitalista de Chile. Santiago: Ediciones Universidad Alberto Hurtado.

Garretón, M. A. (2003). Incomplete democracy: Political democratization in Chile and Latin America. Chapel Hill: The University of North Carolina Press.

Gay, C. (1863). Historia física y política de Chile. Agricultura. Tomo Primero. Santiago: Museo de Historia Natural.

Haindl, E. (2007). Chile y su desarrollo económico en el siglo XX. Santiago: Editorial Andrés Bello.

Hurtado, C. (1966). Concentración de población y desarrollo económico. El caso chileno. Santiago: Instituto de Economía de la Universidad de Chile.

Lindert, P., \& Williamson, J. (1982). Revising England's social tables 1688-1812. Explorations in Economic History, 19, 308-402.

Lindert, P., \& Williamson, J. (1983). Reinterpreting Britain's social tables 1688-I913. Explorations in Economic History, 20, 94-109.

Lindert, P., \& Williamson, J. (2013). American incomes before and after the revolution. The Journal of Economic History, 73(03), 725-765.

Lindert, P., \& Williamson, J. (2014). American colonial incomes, 1650-1774. NBER Working Paper No. 19861.

Londoño, J. (1995). Distribución del ingreso y desarrollo económico. Colombia en el siglo XX. Bogotá: Tercer Mundo Editores, Banco de la República, Fedesarrollo.

Loveman, B. (1976). Struggle in the countryside: Politics and rural labor in Chile 1919-1973. Bloomington: Indiana University Press.

Mahoney, J. (2010). Colonialism and postcolonial development. Bloomington: Cambridge University Press.

Matus, M. (2012). Crecimiento sin desarrollo: Precios y salarios reales durante el ciclo salitrero en Chile (1880-1930). Santiago de Chile: Editorial Universitaria.

Milanovic, B., Lindert, P., \& Williamson, J. (2011). Pre-industrial inequality. The Economic Journal, 121, 255-272.

Mönckeberg, M. O. (2001). El saqueo de los grupos económicos al Estado chileno. Santiago de Chile: Ediciones B Grupo Zeta. 
Newson, L. (2006). The demographic impact of colonization. In V. Bulmer-Thomas, J. H. Coatsworth, $\&$ R. Cortés Conde (Eds.), The Cambridge economic history of Latin America (The colonial era and the short nineteenth century, Vol. 1). Cambridge: Cambridge University Press.

Ortega, L. (2005). Chile en ruta al capitalismo: cambio, euforia y depresión 1850-1880. Santiago: Lom ediciones.

Piketty, T. (2014). Capital in the twenty-first century. Cambridge, MA: Harvard University Press.

Piketty, T. (2015). Putting distribution back at the center of economics: Reflections on capital in the twenty-first century. The Journal of Economic Perspectives, 29(1), 67-88.

PNUD (2013). Informe sobre Desarrollo Humano 2013. El ascenso del Sur: Progreso humano en un mundo diverso. New York: Programa de las Naciones Unidas para el Desarrollo.

Reinsch, P. S. (1909). Parliamentary government in Chile. The American Political Science Review, 3(4), 507-538.

Robinson, J. (2010). The political economy of redistributive policies. In L. F. López Calva \& N. C. Lustig (Eds.), Declining inequality in Latin America. Washington, DC: Brookings Institution Press.

Rodríguez Weber, J. E. (2013). Economía política de la distribución del ingreso rural en Chile durante la decadencia de la Hacienda, 1930-1971. Revista Uruguaya de Historia Económica, $3,33-62$.

Rodríguez Weber, J. E. (2014). La Economía Política de la Desigualdad de Ingreso en Chile, 1850-2009. Tesis de Doctorado en Historia Económica, Programa de Historia Económica y Social, Facultad de Ciencias Sociales, Universidad de la República, Uruguay.

Rodríguez Weber, J. E. (2015). Globalización, instituciones y la economía política de la desigualdad en Chile entre 1850 y 1873. Revista Uruguaya de Historia Económica, 7, 45-64.

Salazar, G., \& Pinto, J. (2002). Historia contemporánea de Chile III. La economía: mercados, empresarios y trabajadores. Santiago: Lom Ediciones.

Santana Ulloa, R. (2006). Agricultura chilena en el siglo XX: contextos, actores y espacios agrícolas. Santiago: DIBAM.

Sater, W. F. (1979). Chile and the world depression of the 1870s. Journal of Latin American Studies, 11(1), 67-99.

Solberg, C. (1969). A discriminatory frontier land policy: Chile, 1870-1914. The Americas, 26(2), $115-133$.

Solimano, A. (2012). Capitalismo a la Chilena y la prosperidad de las élites. Santiago: Catalonia.

Thorp, R. (1998). Progress, poverty and exclusion: An economic history of Latin America in the 20th century. Washington, DC: International Development Bank.

van Zanden, J. L., Baten, J., Foldvari, P., \& van Leeuwen, B. (2011). The changing shape of global inequality - exploring a new dataset. Centre for Global Economic History Working Papers No. 0001, Utrecht University.

Vial Correa, C. (2010). Chile, cinco siglos de historia: desde los primeros pobladores prehispánicos, hasta el año 2006. Volumen 2. Santiago: Zigzag.

Williamson, J. G. (2002). Land, labor and globalization in the pre-industrial third world. The Journal of Economic History, 62(1), 55-85.

Williamson, J. G. (2011). Trade and poverty: When the third world fell behind. Cambridge, MA: MIT Press.

Javier Rodríguez Weber holds a Ph.D. in Economic History and is a researcher at the Economic and Social History Program of the Faculty of Social Sciences, Universidad de la República, Uruguay. Author of "Desarrollo y Desigualdad en Chile, 1850-2009. Historia de su economía política," Centro de Estudios Diego Barros Arana - Dirección de Bibliotecas Archivos y Museos de Chile: Santiago de Chile (forthcoming). 


\title{
Using Heights to Trace Living Standards and Inequality in Mexico Since 1850
}

\author{
Moramay López-Alonso and Roberto Vélez-Grajales
}

\section{Introduction}

Mexico is a country of inequalities. Since the 1950 s economists have devoted enormous time and effort to measure inequalities and design policies to decrease it. The purpose of this study is to trace the evolution of inequality since 1850 by using anthropometric measures as an indicator of living standards and inequalities. The findings show that in Mexico there were different trajectories in the evolution of biological standards of living of the population that mirror the evolution of inequality. The trajectories are defined by region, social strata, health condition (life expectancy), as well as participation in the process of economic modernization and growth, progress opportunities, and allocation/protection of property rights. The databases for the period 1850-1950 will allow us to identify three trends in living standards for three different social groups: the rich, the laboring classes who were integrated in the formal economy, and the remainder of the popular classes. The group at the top of the social ladder got taller over time. Despite political instability, economic stagnation, and poor state of public finances suffered during much of the second half of the nineteenth century, the better-off portion of the population experienced a living standard improvement until the first decades of the twentieth century. Working-class people inserted in the formal economy also grew taller albeit they were shorter than the elite. In contrast, during the second half of the nineteenth century, the great majority of the population belonging to the lower income levels underwent a gradual deterioration in their biological standards of living. For most of the 1850-1950 period, the living standards of the largest portion of the popular

\author{
M. López-Alonso ( $\square)$ \\ Rice University, Houston, TX, USA \\ e-mail: moramay@rice.edu \\ R. Vélez-Grajales \\ Centro de Estudios Espinosa Yglesias, Ciudad de México, Mexico \\ e-mail: rvelezg@ceey.org.mx


classes do not coincide with the evolution of GDP per capita. Neither do they coincide with the evolution of living standards of the middle and upper-middle classes. Regional comparisons show that, in general, people from the north and center-north (bajio) of the country were taller than people from the center and south.

The analysis for the period 1951-1992 is based on the work by Vélez-Grajales (2016), which is an extension of the study by López-Alonso and Vélez-Grajales (2015). ${ }^{1}$ In particular, in comparison with the previous study, in the present one the covered period is extended from 1986 to 1992, and female height estimations for the post-1950 period are also included. Results show a constant positive trend on heights since the late 1960s. The observed increases were not enough to converge on height levels of other similar economies (Brazil, Colombia) . Results suggest that there is a rural penalty. And even more, estimations show that education disparities make significant differences in height. Moreover, the socioeconomic inequality captured by school attainment differences is even deeper for females. Once the social stratification that characterizes Mexico is taken into account, it is easier to understand why average height increases have been moderate. Finally, and based on the historical periods analyzed in the present study, we trace a long-run height trend from 1850 to 1992 . The exercise, made only for males, shows a trend with almost a W-shape.

The study is organized as follows. In Sect. 2 we present the sources and methods with which human stature can be used as a proxy for living standards and how this measure also assesses inequality. In the third section we examine the period 1850-1950. The fourth section analyzes trends in height for the post-1950 period. The fifth section concludes.

\section{Sources and Methods}

There are several methods to measure changes in living standard and income distribution over time. Anthropometric methods, that use height and body mass, is one way of looking at the evolution of living standards and income distribution. Height can be used as a proxy of well-being because the final height of an adult is the result of the interaction of several variables, which are all related to income. ${ }^{2}$ These interactions make it a multidimensional measure of well-being as it assesses the effect of nutrition, health, education, and income on living standards. The logic behind this is as follows: if people during their childhood years have a good nutrition, adequate clothing, and reasonable shelter, and receive some schooling, they are more likely

\footnotetext{
${ }^{1}$ López-Alonso and Vélez-Grajales (2015) "Measuring Inequality" and Vélez-Grajales (2016), The Biological Standard of Living During Post-Revolutionary Mexico.

${ }^{2}$ Timothy Cuff, The Hidden Cost of Economic Development: The Biological Standard of Living in Antebellum Pennsylvania (Burlington, VT: Ashgate Publishing Company, 2005), 10-11; Kenneth Sokolff, "The Heights of Americans in Three Centuries: Some Economic and Demographic Implications," in The Biological Standard of Living on Three Continents: Further Explorations in Anthropometric history, ed. John Komlos, (Boulder, CO, Westview Press, 1995), 134.
} 
on average to grow taller than those people who, despite having the same genetic endowment, grow up under less favorable conditions (Steckel 1995, 1998). Not being fed by one or several of these inputs puts an individual at a disadvantage to fully develop his/her height potential. Thus, in a given society, people from richer income strata would be taller than people from poorer income strata. Due to its multidimensional nature, and even though there is a vast literature on the subject, there is no widely accepted model of income based on heights. ${ }^{3}$

Two additional points give relevance to height as a measure of living standards and income distribution. First, in pre-monetized societies the use of statures is one valid way to measure living standards. In the case of agrarian societies where peasants receive their income in kind or in the consumption of their own production, it is difficult if not impossible to estimate incomes. Second, heights are observable in all societies, providing us an easier way to draw comparisons at the international level and over time, as economies experienced transformation of the productive processes. The challenge would be to have the data availability but other measures of well-being share the same challenge. Also, due to its nature, arranging adults by cohort allows us to do longitudinal analysis with a single cross-section data source.

Some economic historians, however, argue that even if heights are a robust indicator of health and well-being it cannot be taken for granted for all periods and regions, and moreover, that its usefulness could fade in the future. ${ }^{4}$ They also clarify that heights can be a useful measure to analyze the effectiveness of social policy, to assess well-being in societies that still struggle with income inequality issues, and for countries that may suffer from very poor and incomplete data collection. ${ }^{5}$

Mexico is one case where adult heights remain a valuable proxy to assess wellbeing and inequality. This approach allows us to examine the effects of political transformations and the effectiveness of social policies intended to decrease inequality. The data sources for the analysis are more than just a single one. For the 18501950 period, data will be drawn from sources normally used for historical studies, namely military and passport records. ${ }^{6}$ For the post-1950 period, we will use national statistics; this is the 2000 Mexican National Health Survey (ENSA-2000) and the 2006 and 2012 Mexican National Survey on Health and Nutrition (ENSANUT-2006 and ENSANUT-2012). ${ }^{7}$ These are all national probabilistic surveys, conducted by the Instituto Nacional de Salud Pública and were designed

\footnotetext{
${ }^{3}$ For some examples on modeling the relationship between height in income variables see Steckel, "Height and Per Capita Income" (1983), Brinkman et al. "Height and income: A new method for the estimation of historical national income series" (1988), and Coll, "The relationship between human physical stature and GDP (some experiments with European Time Series)" (1998).

${ }^{4}$ Timothy Leunig and Hans Joachim Voth, (2006) "Height and the High Life," in The Economic Future in Historical Perspective, p. 419.

${ }^{5}$ Idem, p. 431.

${ }^{6}$ To have more detailed information on the sources and methods for the 1850-1950 see LópezAlonso Measuring Up, Sect. 2, Chap. 1.

${ }^{7}$ To have more detailed information on the sources and methods for the post-1950 period see López-Alonso and Vélez-Grajales (2015) "Measuring Inequality" and Vélez-Grajales 2016, The Biological Standard of Living During Post-Revolutionary Mexico.
} 
to obtain information on accessibility, quality, coverage, and use of health services. Anthropometric measures such as height and weight are captured. ${ }^{8}$ The surveys were conducted in the 32 Mexican States.

\section{Living Standards and Inequality from 1850 to 1950}

This section examines the evolution of living standards in Mexico from 1850 to 1950 by tracking the trends in heights of the population samples presented in the previous section. This study focuses on the macro trends in long-term perspective. Acknowledging, however, that disparities across regions and across social classes are ubiquitous in Mexican history, it remains important to trace their evolution within this context as well. We will analyze the evolution of heights over time and make inferences on the evolution of biological standards of living and their correlation to the evolution of inequality. As we examine our data, we will indicate which of the independent variables that we are working with are the most important determinants of height. We will run the tests of the main sample of heights as well as of the subsamples (geographical, socioeconomic, literate/illiterate, urban/rural) to evaluate the differences among them in long-term trends. In this way, we can have an idea of the compositional changes of the population and their relationship with the average heights and the biological standards of living. ${ }^{9}$

Examining the trajectories in biological standards of living of different groups is also a way to analyze inequality in well-being. Human adult stature is an output variable that reflects the effects of nutrition, health, education, and income on living standards. Hence by analyzing the trends in stature across regions, social classes, and other categories we can also ascertain the evolution of inequality. Because height is a multidimensional variable we will not be measuring income inequality in living standards that encompasses a broader definition of quality of life; this would be measuring not only how much people make but also how well they spend it based on their knowledge of what enhances living standards.

Applying a regression analysis to the data that we gathered on the heights of the Mexican military, rural police, and passport records, we will be able to infer if there was a secular increase in the average height of the Mexican population for the cohorts born between 1850 and 1950; this will give us an idea of the evolution of the biological living standards of the entire population. ${ }^{10}$ We can also ascertain

\footnotetext{
${ }^{8}$ Individuals were measured with stadimeter.

${ }^{9}$ All these tests will be done with regression analysis techniques. The accuracy of the analysis corresponds to the quality of the data; as all anthropometric history literature explain, there will always be inaccuracies in the estimations due to data quality when compared to studies of the contemporary period. Notwithstanding, it has to be kept in mind that this is a common risk in all historical research. By determining the extent and direction of the biases inherent in the data by the use of standard techniques we can reach a higher level of accuracy.

${ }^{10}$ Anthropometric history literature defines "secular trend" in heights when there is an increasing trend in average heights over time when there are periods of economic growth.
} 
if there were different trends in height, or not, across regions and across social classes. As we mentioned earlier, there is no widely accepted model of income based on height. As a result, the majority of studies on anthropometric history define class in a more sociological way: by occupation or educational status.

\subsection{The Trend Analysis}

\subsubsection{The Military Samples ${ }^{11}$}

There is a downward trend in the height sample for the period 1850-1950. The 40-year period during which this downward trend lasted corresponds to people growing up during the second half of the nineteenth century and the first decade of the twentieth century; this suggests deterioration in living standards of the working classes during the last half of the nineteenth century. However, we should keep in mind that the rurales sample, in which we observe the decline, is drawn from a particular portion of the popular classes, farm hands and craftsmen, but not miners or factory workers. It was men who worked in trades that were being displaced by the introduction of the railroad or artisans driven out of business by machines and manufactures. ${ }^{12}$ For the most part these were men in the mid-30s, temporarily unemployed who enlisted in the rurales, until something better came along. Over time the height of this sample declined and this suggests that the biological standard of living of this portion of the popular classes was deteriorating, a reflection of what was happening in the sectors of the economy where they had worked prior to joining the rurales militia. The cause of this decline in height sheds light on how the end of the preindustrial era in Mexico affected certain portions of the population. The transformation of the economy fostered growth but, in the process, it also left some sectors of the population out of work; hence their standards of living deteriorated. ${ }^{13}$ This phenomenon can also be interpreted as increased inequality as a result of the modernization of the economy. Moreover, this trend is also indicative of a rise in inequality vis-à-vis those groups who did grew wealthier with the economic takeoff experienced in the last decades of the twentieth century.

There is a difference in trends between the rurales and the federales for cohorts born in the 1880s and 1890s for the regression results; this difference is driven by the number of observations for those decades in each sample. For the 1890s the number of rurales born in that decade aged 23 or more is particularly small; most of the observations for the decade correspond to young men who had not attained their final height. Let us remember that the rural police dissolved in 1913 after Francisco

\footnotetext{
${ }^{11}$ For a thorough discussion on how to overcome biases when working with military samples presented here see López-Alonso and Vélez Grajales, "Measuring Inequality," 2015.

${ }^{12}$ Vanderwood, (1981) Disorder and Progress: Bandits, police and Mexican development, 108-9.

${ }^{13}$ Kessing, (1969) "Structural Change in Early Development: Mexico's changing industrial and and occupational structure from 1895 to 1950," Journal of Economic History, 723; Alan Knight, The Mexican Revolution, vol. 1, Porfirians, Liberals and Peasants (Cambridge University Press, 1986), 79-80.
} 
I. Madero's assassination. The federal soldiers sample has a higher number of men 23 and older. Moreover, the recruits in the federales sample come from a wider variety of trades than their rurales counterparts (Table 1).

Traditional historiography asserts that the Díaz administration was detrimental to the living standards of the popular classes because of the capitalist development model with which economic growth was set in motion. This model was based on the exploitation of the laboring classes, and in the case of peasants, it also meant the seizure of lands. ${ }^{14}$ Nonetheless, the evidence presented here suggests that the decline in standards of living began little over two decades before the Díaz dictatorship was actually inaugurated; thus, Porfirian administration policies could not have been the only reason for this decline. Political instability, transformation of modes of production that marked the end of the preindustrial era and displaced people from their traditional occupations, dire circumstances in the public finances, and disentailment of communal peasant properties were all causes of this decline.

The federales military sample covers a period that includes generations growing up during the Porfiriato, the revolution, and the first decades of the postrevolutionary period. Changes are not as steep as one would expect in a period marked by so many changes and instability. The first three decades covered in this sample show stagnation that would correspond to cohorts born during the last decade of the dictatorship and the revolution, with a decline in average statures for those born and growing up in the 1910s and 1920s. The last three decades of the period display a recovery trend that accelerates during the 1940s, which coincides with a period of growth for the middle classes, rapid population growth, and stagnation of the lower income strata.

In terms of evolution of biological standards of living there does not appear to be any significant deterioration due to the dictatorship that allegedly induced pauperization of the lower classes; the improvement observed for cohorts born toward the end of the Díaz period is modest compared to its economic performance that generated prosperity for the higher income strata. Industrialization processes taking place and economic growth did not produce an improvement in the quality of life of populations from which the army was getting its recruits. This evolution in the average height of soldiers is understandable given that industrialization at its early stages does not necessarily translate into an improvement in the biological standards of living of a population. ${ }^{15}$ In addition, as we mentioned earlier, changes in land tenure were not conducive to improving the livelihood of the average peasant. All these suggest that economic modernization did not narrow the gap in living standards across social classes.

The average stature of recruits born in the 1910s decade decreased; these are people growing up and during the revolution and the first decades of the postrevolutionary period. It is not surprising to observe a decline. It might, however, be surprising that the decline is not steeper given the chaos created by the years of armed

\footnotetext{
${ }^{14}$ Alan Knight, The Mexican Revolution, vol. 1, Porfirians, Liberals and Peasants (Cambridge University Press, 1986), 79-80.

${ }^{15}$ Steckel, (1995) "Stature and the Standard of Living"; Komlos, (1998) "Shrinking."
} 


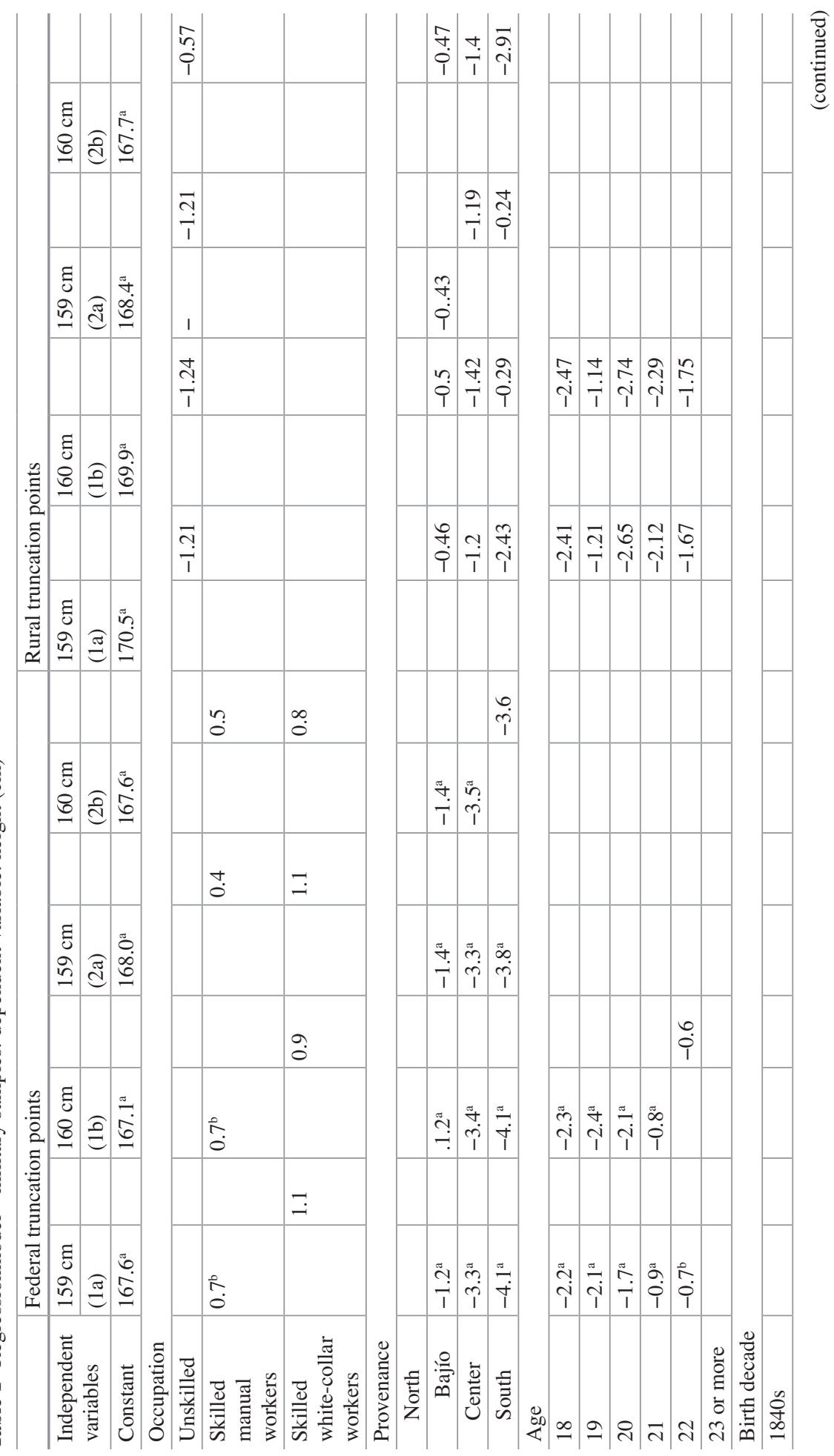




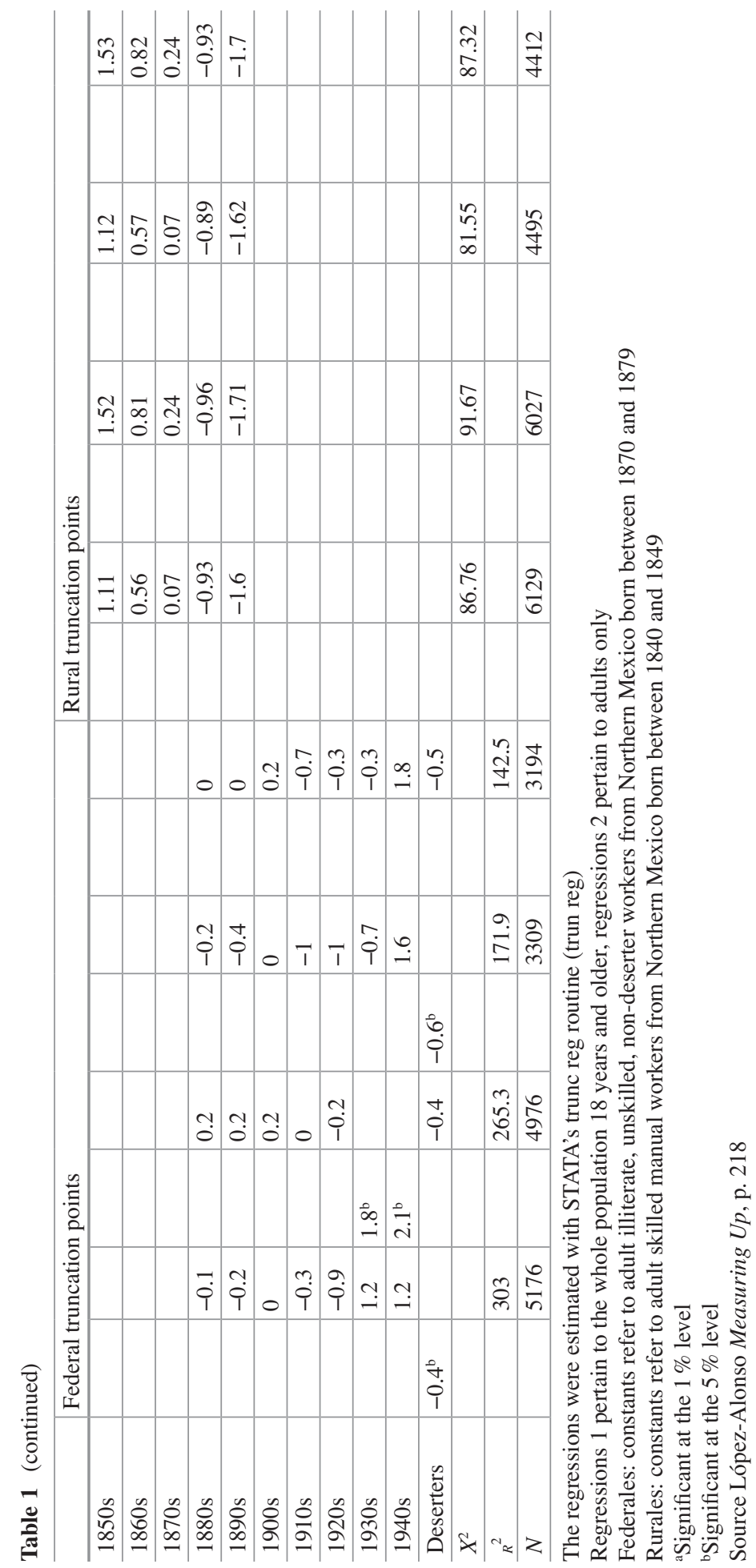


rebellion. After all, this was a violent war that took a heavy toll in human life. One explanation for this could be formulated under the Malthusian postulate that anything that raises the death schedule, for example, war, disorder, disease, or poor sanitary conditions, will increase material living standards. A fixed amount of resources is distributed among fewer people. Although this postulate applies to preindustrial societies, given that industrialization was only taking place in a small number of regions compared to the extent of the Mexican territory, we would argue that in this case the Malthusian argument holds.

The high death rate increasing material living conditions hypothesis is compatible with the meager recovery in stature observed for cohorts born during the following two decades. Still, this seems too meager a recovery for a revolution based on the granting of worker's rights and the undertaking of an agrarian reform. The improvement observed in living standards is rather deceptive and suggests that institutional reforms mandated by the 1917 constitution were meant to favor the popular classes but were only enforced to ameliorate the lives of a reduced portion of the working classes, namely those inserted in the formal economy.

In contrast, the substantial increase in average stature for cohorts born during the late 1930s and 1940s coincides with the launching of a welfare state and with government's commitment and recognition of its responsibility to assist the poor during the Lázaro Cárdenas administration, especially with the introduction of universal public health initiatives, such as national vaccination campaigns for children. The social development that stemmed from this commitment appears to have yielded positive results in the standards of living of the population from which the military were enlisting their recruits in the mid-twentieth century. We can then argue that there was a reduction in inequality in living standards starting in the 1930s.

With regard to regional disparities and differences across social classes in these samples, we can say that regression results for both samples are consistent. Recruits born in the north and Bajío are taller than their counterparts in other regions. Enlisted soldiers who were originally from the central and southern regions were shorter, with the exception of Mexico City and Veracruz, which were more economically dynamic regions than many parts of the center and south at the time.

Environmental differences play a relevant role, too. The north and Bajío had lower densities of population and were big-cattle-raising regions. Lower densities of population meant a lower exposure to diseases and epidemics. Throughout history, it has been observed that hunter-gatherers, seminomadic groups, and communities living in small settlement were less likely to be exposed to infectious diseases and epidemics; hence, their health tended to be better in general than that of sedentary communities. ${ }^{16}$ Regions that have significant cattle production normally will have a higher meat intake in their diet and will sell meat at relatively lower prices than regions that do not raise cattle. Traditional diet in the northern and Bajío regions was richer in animal protein, and this had a positive impact on final adult statures.

\footnotetext{
${ }^{16}$ For a more thorough discussion on the synergies between health, nutrition, and living standards see Measuring Up, Sect. 3 Chap. 1.
} 
Regression results also show that in both samples unskilled workers are slightly shorter than skilled workers. Such height differences suggest that men who had a trade were taller than those who did not. Being trained in a trade results in a form of human capital that correlated positively with a better biological standard of living.

\subsection{Passport Sample}

The stature of passport applicants increased throughout the period covered in this sample. The heights of applicants were also comparable to average heights of samples of males from the Western World. Such improvement suggests that men in this sample were not affected by the urban penalty of growing cities or the disentailment and privatization of communal property in the countryside. In contrast, it makes one think that the men in this sample benefited from all the positive transformations that were taking place, such as economic growth, investments in sanitary infrastructure, professionalization of medical services that allowed for more accurate diagnoses and prevention of most common infectious diseases, and, last but not least, better nutrition due to the increased availability of a wider array of foodstuffs.

Unlike other studies that use medical services as a determinant of human development, in this part of the study we do not make a more specific measurement of inequality in living standards with respect to health care services because of the profound transformation of the medical profession during this period and public health services. ${ }^{17} \mathrm{~A}$ brief glance at the history of medicine in the world and in Mexico will show us that medicine did not become a more scientific profession at the end of the nineteenth century; vaccination campaigns did not begin to have substantial impact on infant mortality until the 1920s; and it is not until the adoption and widespread availability of antibiotics that infectious diseases - closely correlated to malnutrition and poverty - we finally reduced. Medical services could only be afforded by well-to-do people and doctors tended to live in cities for the most part. Most rural areas had no doctors and even in those places where there were doctors, there was little they could actually cure until the 1940s. Having access to sanitary infrastructure and a good balanced nutrition was a stronger determinant of better health. $^{18}$

There is a regional disparity in this sample of the same nature as the military sample. This means that among passport applicants, males for the south and center were shorter than their Bajío and northern counterparts. ${ }^{19}$ There are disparities across social classes, but the gap tends to narrow over time; the elite and white-collar

\footnotetext{
${ }^{17}$ See Campos Vásquez and Márquez “Long-Run Human Development in Mexico 1895-2010” in this volume.

${ }^{18}$ For a more detailed discussion on the relevance of the medicine in the evolution of living standards see López-Alonso 2012, Sect. 3.

${ }^{19}$ Let us not forget that there is an undercount of people from border states in this sample.
} 
Table 2 Regression model for passport applicants

\begin{tabular}{|c|c|c|c|c|c|c|c|c|}
\hline \multirow{2}{*}{$\begin{array}{l}\text { Independent } \\
\text { variables }\end{array}$} & \multicolumn{2}{|l|}{ Males } & \multicolumn{2}{|l|}{ Females } & \multicolumn{2}{|l|}{ Males } & \multicolumn{2}{|l|}{ Females } \\
\hline & (1a) & & (1b) & & $(2 a)$ & & (2b) & \\
\hline \multicolumn{9}{|l|}{ Unskilled } \\
\hline $\begin{array}{l}\text { Skilled } \\
\text { manual } \\
\text { workers }\end{array}$ & $0.93^{b}$ & & $1.22^{\mathrm{a}}$ & & $0.84^{\mathrm{b}}$ & & $1.01^{\mathrm{a}}$ & \\
\hline $\begin{array}{l}\text { Skilled } \\
\text { white-collar } \\
\text { workers }\end{array}$ & $1.21^{\mathrm{b}}$ & & $0.62^{\mathrm{b}}$ & & $1.06^{\mathrm{b}}$ & & $0.41^{\mathrm{a}}$ & \\
\hline Elite & $2.45^{\mathrm{a}}$ & & $1.32^{\mathrm{a}}$ & & & 2.33 & $1.04^{\mathrm{a}}$ & \\
\hline North & $2.82^{\mathrm{a}}$ & & $2.53^{\mathrm{a}}$ & & $2.59^{\mathrm{a}}$ & & $2.32^{\mathrm{a}}$ & \\
\hline Bajío & $2.11^{\mathrm{a}}$ & & $1.66^{\mathrm{a}}$ & & $2.04^{\mathrm{a}}$ & & & 1.57 \\
\hline Center & $1.37^{\mathrm{a}}$ & & $0.81^{\mathrm{b}}$ & & $1.18^{\mathrm{a}}$ & & & 0.64 \\
\hline \multicolumn{9}{|l|}{ South } \\
\hline \multicolumn{9}{|l|}{ Age 18} \\
\hline Age 19 & & -0.77 & & -0.51 & & & & \\
\hline Age 20 & & 0.35 & & -0.67 & & & & \\
\hline Age 21 & & -0.15 & & -0.03 & & & & \\
\hline Age 22 & & 0.47 & & 0.1 & & & & \\
\hline Age 23 or + & & 0.54 & & -0.03 & & & & \\
\hline \multicolumn{9}{|l|}{ Born 1860} \\
\hline Born 1870 & & 0.96 & $2.54^{\mathrm{b}}$ & & & 0.95 & $2.59^{\mathrm{b}}$ & \\
\hline Born 1880 & & 1.15 & $3.97^{\mathrm{a}}$ & & & 1.14 & $4.01^{\mathrm{a}}$ & \\
\hline Born 1890 & $2.28^{\mathrm{b}}$ & & $4.85^{\mathrm{a}}$ & & $2.27^{\mathrm{a}}$ & & $4.89^{\mathrm{a}}$ & \\
\hline Born 1900 & $2.57^{\mathrm{b}}$ & & $5.16^{\mathrm{a}}$ & & $2.58^{\mathrm{a}}$ & & $5.23^{\mathrm{a}}$ & \\
\hline Born 1910 & $3.06^{\mathrm{a}}$ & & $5.13^{\mathrm{a}}$ & & $3.02^{\mathrm{a}}$ & & $5.15^{\mathrm{a}}$ & \\
\hline Born 1920 & $3.29^{\mathrm{a}}$ & & $5.62^{\mathrm{a}}$ & & (Dropped) & & & 8.59 \\
\hline Constant & $164.83^{\mathrm{a}}$ & & $153.50^{\mathrm{a}}$ & & $165.64^{\mathrm{a}}$ & & $153.76^{\mathrm{a}}$ & \\
\hline$R^{2}$ & & 0.0235 & & 0.0277 & & 0.0229 & & 1.0286 \\
\hline$N$ & & 11,390 & & 5207 & & 9693 & & 4424 \\
\hline
\end{tabular}

Note: Method OLS, constants refer to adult unskilled workers, from the South of Mexico, born between 1860 and 1869

${ }^{\text {aSignificant at } 1 \%}$

${ }^{\mathrm{b}}$ Significant at $5 \%$

Source López-Alonso Measuring Up, p. 218

workers are taller than their unskilled and skilled manual counterparts, but there is a pattern of convergence (see Table 2).

What may raise some sort of conundrum is that the heights of all subsamples are increasing. Why are unskilled and skilled manual workers in this sample getting taller while their counterparts from the military sample are following a trend in the opposite direction? The answer is inequality across different groups; within the working classes there were differences in opportunities for advancement. There were groups who benefitted from institutional changes and others that did not. This applies to all groups, namely, skilled manual workers, unskilled workers, peasants, day laborers, and domestic servants. Passport applicants were individuals who 
could travel abroad legally, but for Mexicans going to the USA this was far from being the norm: they were literate, and had a birth certificate. They could be categorized as the aristocracy of the laboring classes. Most likely, these applicants were workers who did benefit from institutional transformations that granted them more rights and higher incomes, and these workers were not affected by the absence of a properly defined state welfare system. On the other hand, men from military samples were representative of a portion of the lower strata of the population different from passport applicants; recruits belonged to segment living with a great scarcity of resources. Except for recruits born in the 1940s, soldiers in our sample did not have to present a birth certificate upon recruitment, and a substantial number were illiterate. The average stature of passport applicants improved. Although they remained shorter than the better-off strata of the society, there is convergence in heights across social classes. This suggests that at least for the better-off portion of the working classes, the evolution of biological standards of living looked more promising, and access to sanitary infrastructure and a higher income, as well as the possibility of a better diet, did become a reality for them.

On the subject of inequality, these trends show dispersion among the different groups of the laboring classes, thus suggesting that the process of economic modernization and growth did not impact working classes the same way. Those workers inserted in the formal economy followed the same path as the upper income strata group. In contrast, those people working on trades negatively affected by the transformation of the economy were left behind and their biological standards of living stagnated or deteriorated at a time in which they could have potentially improved just by having access to sanitary infrastructure and by not being vulnerable to famines.

\subsection{Women's Statures}

In analyzing the trends in statures of the female sample, there are several points that need to be considered regarding sexual dimorphism, literacy, and urbanization. Sexual dimorphism concerns the differences between males and females. One difference is adult height. In a given population living under normal circumstances, women are on average $12-13 \mathrm{~cm}$ shorter than adult men. This is a consequence of a different timing in growth spurts, which leaves boys on additional 2 years of growth before the end of the spurt. ${ }^{20}$ Another difference pertains to resilience to environmental insults such as food shortages and diseases that could be caused by war, famines, or exposure to a new pathogen. Women's growth tends to be more resistant to deprivation than men's; therefore, gender difference in stature is relatively larger in good times and shrinks under bad conditions. ${ }^{21}$ In addition, females tend to

\footnotetext{
${ }^{20}$ Bogin, (2001) Growth of Humanity, 131.

${ }^{21}$ J.M. Prince and Richard H. Steckel, "Tallest in the World: Native Americans of the Great Plains in Nineteenth Century" (National Bureau of Economic Research Working Paper Series, Historical Papers No. 112, 1998), 10.
} 
recover more quickly from environmental insults than males: "similarly girls recover from growth arrest more quickly than boys. The physiological reason for this greater stability is not known." 22 We should then expect to find less variation in stature for female height samples.

All women in the samples are both literate and urban. Both of these features are representative of a somewhat privileged minority of the female population on both accounts. At that time Mexicans were mainly rural and literacy levels were approximately $30 \%$. Being literate in an urban environment in our samples is a potential advantage vis-à-vis their illiterate rural counterparts given that they had access to the sanitary infrastructure available at the time, they had the skills and access to make the most of the information on best hygienic practices, and they had the resources to implement their hygienic measures. ${ }^{23}$

In the passport sample there appears to be no substantial difference in heights across regions. Differences across social classes are smaller than in the male sample and they also show a convergence pattern. Sexual dimorphism can explain why differences are smaller than in the male sample and they also show a convergence pattern. Sexual dimorphism can explain why differences are smaller among women than among men. For biological reasons, stature variation among females is expected to be smaller, and basic material living conditions across social classes in this sample were not too strikingly different. This means that women from the upper and upper-middle classes had a substantially higher standard of living; working class women in this sample did have means to cover the basic material conditions for good health and nutrition.

By examining the trends of these different samples we conclude that there is not one single trajectory in the evolution of the biological standards of living for the period 1850-1950. Also, having different trajectories explains the patterns of inequality. The trajectory of the military samples (federales and rurales) declines, stagnates, and has a slight recovery, a slight decline, and then a substantial recovery that leaves cohorts born in the 1950s with a similar height to their counterparts that were born a century before. In contrast, the trajectory of the passport sample is one of constant increase. The military samples are built with working-class recruits from diverse backgrounds (agricultural workers, artisans, factory workers, etc.), whereas the passport sample is built with people from different income levels.

Comparing these trajectories in the evolution of standards of living with the economic performance during the same period would shed light on the degree of prevailing inequality in living standards at the time. One way to establish this comparison is to examine the evolution of GDP per capita (see Fig. 1) in contrast with

\footnotetext{
${ }^{22}$ Tanner, (1978) Foetus into man, 166.

23 "Hygienic education was promoted in books, magazines, fliers and through the free public and popular conferences, and certain doctors and hygienists wrote about medical practice or domestic hygiene in books in which they gave detailed information of what every member of society would have to do to preserve health and prevent diseases. According to the medical profession, women were natural allies to hygienist endeavors, mothers in particular since they had a misión of motherhood and children's education" (Claudia Agostoni, "Discurso médico, cultura higiénica y la mujer en la ciudad de México al cambio del siglo [XIX-XX], Mexican Studies/Estudios Mexicanos 18, no. 1 [Agostoni 2002]: 22).
} 


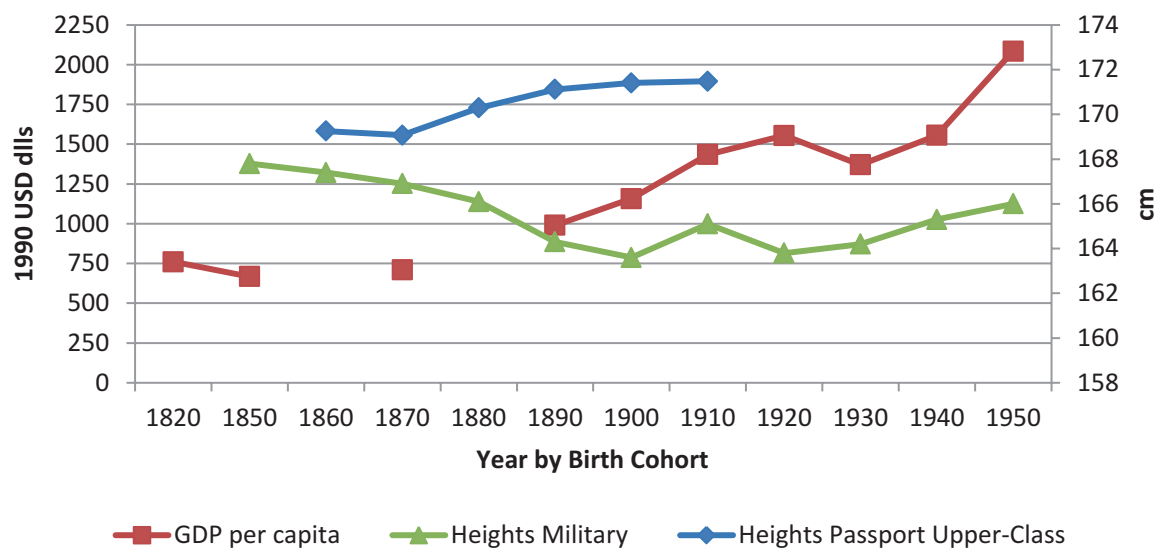

Fig. 1 Male height and Geary-Khamis GDP per capita (1990 USD)

that of heights of the different groups presented earlier. Passport samples follow a similar trend as GDP per capita follows opposite trends, such as for cohorts born and growing up during the second half of the nineteenth century. In contrast, there is a period when the average statures followed the same trend as GDP per capita, such as the cohorts born after the 1930s. These changes in correlation between GDP per capita and adult male average stature are plausible in light of the fact that economic growth does not necessarily improve the biological standards of living of a given population.

\section{Living Standards and Inequality After $1950^{24}$}

After the Great Depression, Mexico experienced a 40-year period of sustained economic growth. In particular, since the 1940s, the country shows GDP annual average growth rates over $4 \% .{ }^{25}$ It was until the 1980 s economic crisis when such positive trend stopped. In this section it is shown that heights also experienced a positive trend since the end of the 1960s. However, and given the existent inequalities in other dimensions different than GDP, it is also shown that height differences among socioeconomic strata have persisted. National improvements were not limited to economic growth. Life expectancy at birth, for example, grew from 34 years in 1930 to 49 years in 1950 , reaching 71 years by $1990 .{ }^{26}$ In the dimension of education, the national literacy rate in 1950 was of $64 \%$ and reached $87 \%$ by $1990 .{ }^{27}$ In the case of adult heights, the trend is also positive.

\footnotetext{
${ }^{24}$ This section is mainly taken from Vélez-Grajales (2016), The Biological Standard of Living During Post-Revolutionary Mexico.

${ }^{25}$ Marquez (2010). "Evolución y estructura del PIB, 1921-2010."

${ }^{26}$ INEGI. Indicadores sociodemográficos de México (1930-2000). México, 2001.

${ }^{27}$ PNUD, Informe sobre desarrollo humano 2002. México, 2003.
} 
Table 3 Regression results for female and male heights

\begin{tabular}{|c|c|c|}
\hline & Females & Males \\
\hline \multicolumn{3}{|l|}{ Birth cohort } \\
\hline 1951-1956 (omitted) & $\ldots$ & $\ldots$ \\
\hline $1957-1962$ & $-0.179(0.196)$ & $-0.083(0.286)$ \\
\hline 1963-1968 & $-0.649 * * *(0.187)$ & $-0.411(0.275)$ \\
\hline 1969-1974 & $-0.453 * * *(0.180)$ & $0.319(0.265)$ \\
\hline $1975-1980$ & $-0.123(0.177)$ & $0.643 * *(0.270)$ \\
\hline $1981-1986$ & $0.268(0.187)$ & $1.157 * * *(0.277)$ \\
\hline $1987-1992$ & $0.873 * * *(0.193)$ & $1.641 * * *(0.274)$ \\
\hline \multicolumn{3}{|l|}{ Education } \\
\hline Incomplete primary & $2.268 * * *(0.234)$ & $1.767 * * *(0.3745)$ \\
\hline Complete primary & $4.374 * * *(0.224)$ & $2.887 * * *(0.359)$ \\
\hline Secondary & $5.399 * * *(0.228)$ & $3.981 * * *(0.360)$ \\
\hline High school & $6.957 * * *(0.238)$ & $6.094 * * *(0.371)$ \\
\hline Bachelor & $8.255 * * *(0.290)$ & $7.160 * * *(0.412)$ \\
\hline Graduate studies & $9.208 * * *(1.056)$ & $7.016 * * *(1.087)$ \\
\hline No school (omitted) & $\ldots$ & $\ldots$ \\
\hline \multicolumn{3}{|l|}{ Current residence } \\
\hline Dummy for rural (1) & $-0.898 * * *(0.109)$ & $-0.805 * * *(0.149)$ \\
\hline Intercept & $148.926 * * *(0.244)$ & $162.122 * * *(0.394)$ \\
\hline$R^{2}$ & 0.104 & 0.080 \\
\hline$N$ & 19,649 & 12,797 \\
\hline
\end{tabular}

Standard errors in parentheses

Note: OLS regression

Source: Own estimations

$* 10 \%$

$* * 5 \% \mathrm{y}$

$* * * 1 \%$

\subsection{New Height Estimations and International Comparisons: 1951-1992}

A simple model of individual height determinants is estimated to obtain predicted average heights for the period 1951-1992. Once it is controlled for birth cohort dummies, variables for education attainment and current residence are included as determinants of height (see Table 3). As it is reported, birth cohorts are not making a significant difference. On the other hand, higher education levels and urban current residence result in taller individuals. ${ }^{28}$ The latter suggests that there is a rural penalty.

\footnotetext{
${ }^{28}$ For height estimation models $R^{2} \mathrm{~s}$ in regressions are always low. That happens because most of the variation in adult height is natural (genetic) and unexplained. John Komlos and Benjamín E. Lauderdale, (2007) "Spatial Correlates of US Heights," p. 63.
} 


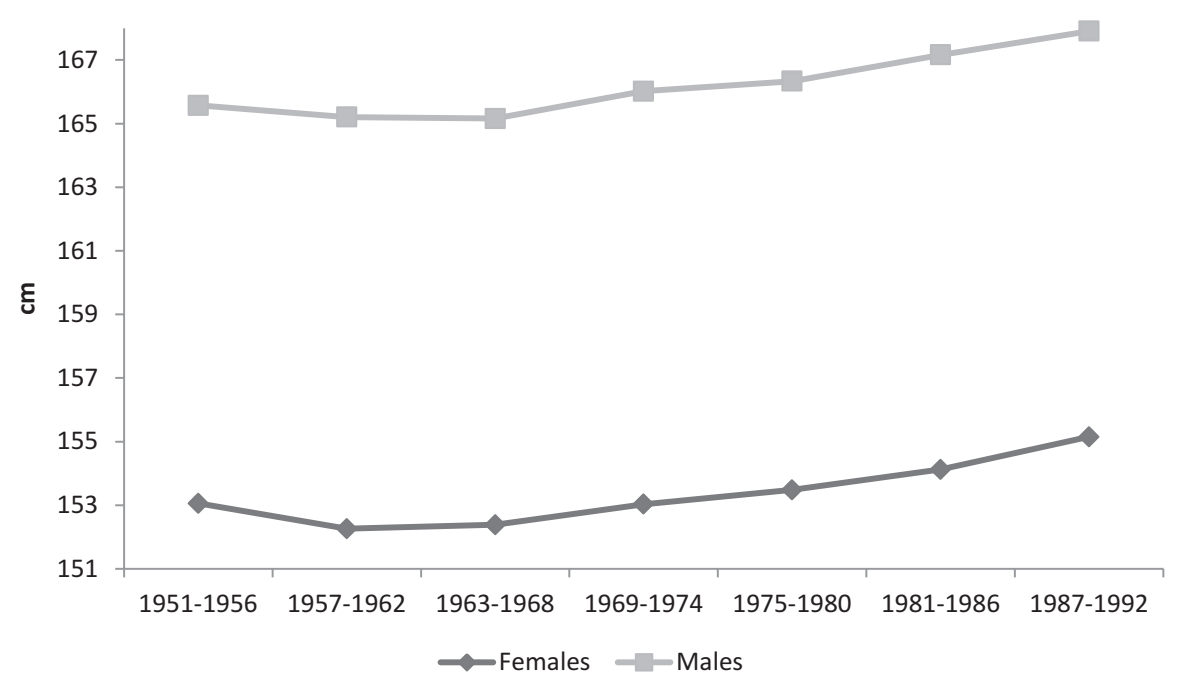

Fig. 2 Predicted national height (in cm) by 6-year birth cohorts, Mexico, 1951-1992 (National Surveys)

Table 4 Height comparison: Brazil, Colombia, and Mexico, by gender, 1951-1992

\begin{tabular}{l|l|l|l|l|l}
\hline \multicolumn{2}{l|}{ Birth cohort } & \multicolumn{3}{l|}{ Males } & Females \\
\hline & $\begin{array}{l}\text { Brazil- } \\
\text { Monasterio } \\
\text { et al. (estimated) }\end{array}$ & $\begin{array}{l}\text { Colombia- } \\
\text { Meisel and Vega }\end{array}$ & $\begin{array}{l}\text { Mexico } \\
\text { predicted) }\end{array}$ & $\begin{array}{l}\text { Colombia- } \\
\text { Meisel and Vega }\end{array}$ & $\begin{array}{l}\text { Mexico } \\
\text { (predicted) }\end{array}$ \\
\hline $1951-1956$ & 168.3 & 167.9 & 165.6 & 156.5 & 153.1 \\
\hline $1957-1962$ & 168.8 & 168.3 & 165.2 & 157.0 & 152.3 \\
\hline $1963-1968$ & 169.2 & 168.8 & 165.2 & 157.3 & 152.4 \\
\hline $1969-1974$ & 169.8 & 168.9 & 166.0 & 157.2 & 153.0 \\
\hline $1975-1980$ & 170.3 & 169.8 & 166.3 & 158.0 & 153.5 \\
\hline $1981-1986$ & & 170.6 & 167.2 & 158.7 & 154.1 \\
\hline $1987-1992$ & & & 167.9 & & 155.1 \\
\hline
\end{tabular}

Source: Mexico: own estimations; Colombia: Meisel and Vega (2007); Brazil: Monasterio et al. (2006)

In Fig. 2, both female and male height series are shown. In both cases, after a stagnation process during the $50 \mathrm{~s}$ and $60 \mathrm{~s}$, a constant and positive height growth took place. But how good was such performance? Was it sufficient in order to converge to other country levels? A simple comparison is made with other two Latin American countries: Brazil and Colombia. As we can see in Table 4, both Brazilian and Colombian males were and are still taller than Mexicans. In the same table a similar result is shown for the comparison between Mexican and Colombian females. Moreover, the gap for both males and females during the observed period was not closed.

The explanation for this poor performance can be related to inequality. In terms of income, in 1950 the highest state GDP per capita was more than six times bigger 


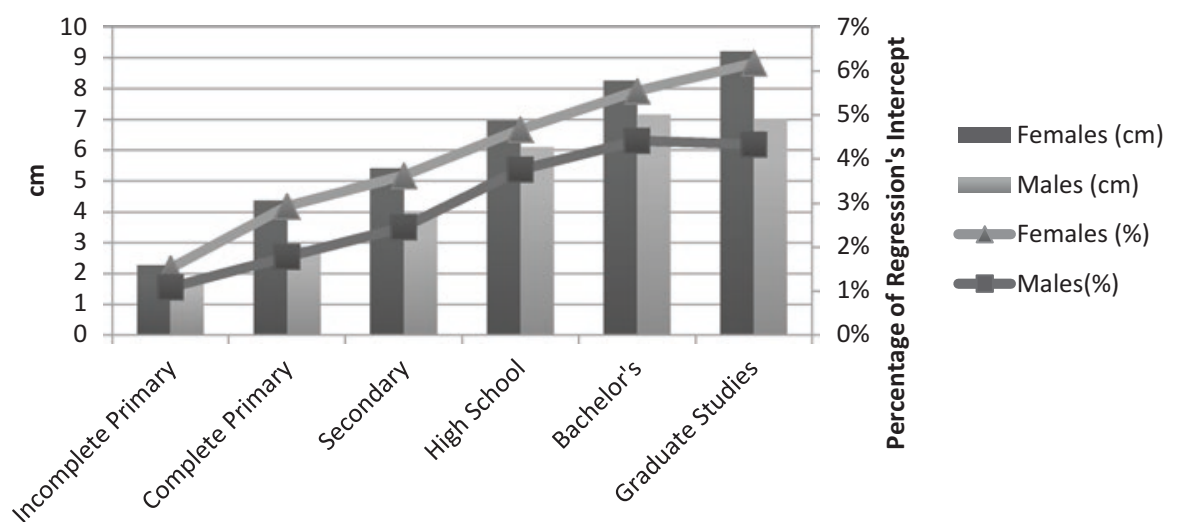

Fig. 3 The education penalty: no schooling versus other education levels

than the lowest one. By 1990 such difference was reduced, but it was still significant: a proportion of almost five to one..$^{29}$ In the case of literacy, in 1950 the highest state level rate was more than double the lowest one: 86 versus 39. By 1990, such difference was also reduced, but still, the difference was significant: 96 versus $70 \%$.

For the present analysis, it has to be noted that ENSA-2000, ENSANUT-2006, and ENSANUT-2012 were not designed to get retrospective information. Moreover, they do not include information on the place of origin (birthplace). Dimensions such as age, education, and location, however, are commonly good predictors of adult height. As a result, the OLS regression for heights in Table 3 includes a set of dummy variables: age (cohorts), educational attainment, and current rural-urban residence. Results show that socioeconomic differences that we can infer from education and location variables have repercussions on adult heights. The estimation shows that both rural females and rural males are shorter by around $0.8 \mathrm{~cm}$. Even more, education disparities make significant difference. As we can see in columns of Fig. 3, those females with no schooling are shorter than those with incomplete primary education by $2.3 \mathrm{~cm}$. The education penalty reaches $9.2 \mathrm{~cm}$ when the comparison is made between those with no schooling and those with graduate degree. For males, differences for both cases are $1.8 \mathrm{~cm}$ and $7 \mathrm{~cm}$, respectively. Absolute differences are larger among females, and such differences are even larger when they are estimated in relative terms (lines in Fig. 3). This result suggests that the socioeconomic inequality captured by school attainment differences is more profound for females.

These results beg the question: Has Mexico been capable to tackle the schooling inequality problem? One way to measure the effect of public policy in such a matter is by estimating the intergenerational mobility on education. As it is reported by Vélez, Campos, and Huerta (2013, pp. 32-34), "Educational coverage has widened over recent decades, and absolute educational opportunities for the Mexican people have increased along with it. However, ... it becomes apparent that educational

${ }^{29}$ Ibid. 


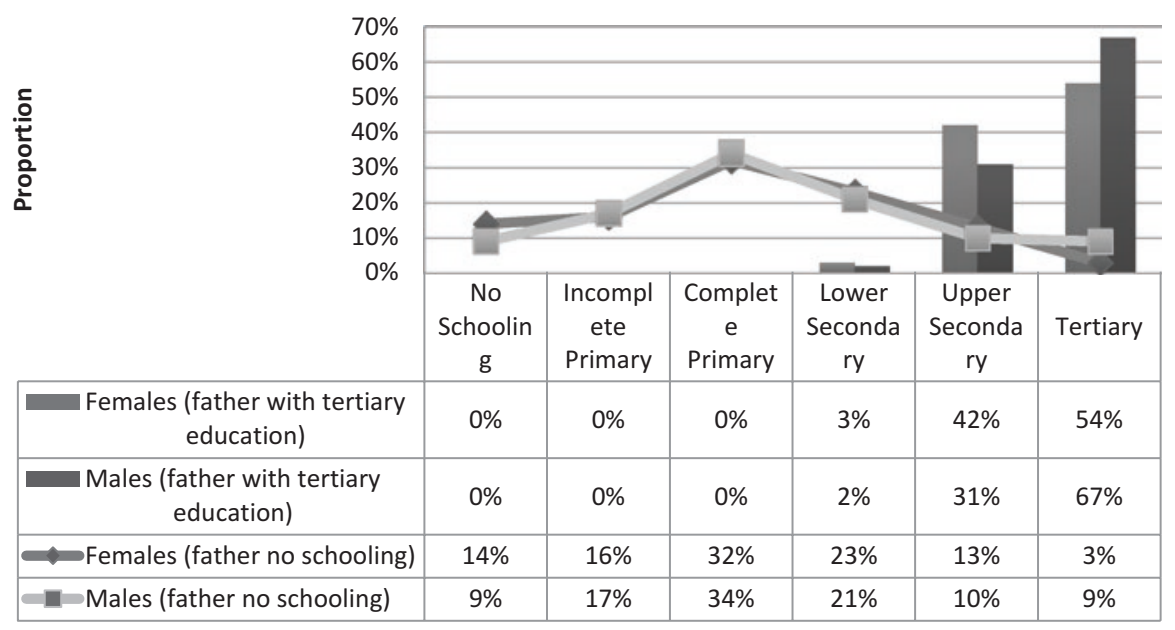

Fig. 4 Educational attainment by father's education level in Mexico, by gender: birth cohort 1947-1986

mobility in Mexico is limited at particular levels. For the first levels of education, primary and lower secondary school, socioeconomic origin has hardly any influence on achievement in higher levels of education. However, socioeconomic origin does affect achievement in upper secondary school and even more so in tertiary education." Moreover, as estimations on intergenerational mobility presented in Fig. 4 show, for the lower (lines) and higher (columns) ends of the spectrum, the probability of educational achievement conditional to father's education level is lower for females than for males. These results suggest that status quo, including gender inequality, persists in Mexico. In particular, firstly, there is a barrier related to socioeconomic origin that limits the options for women to reach upper secondary/ tertiary education for those coming from the lower end of the spectrum; this is women from a lower income level. Secondly, females coming from the lower end of the spectrum are less capable than their male counterparts to overcome such a barrier. And thirdly, even women from an upper income strata show a lower achievement rate in education than men of the same group. Once these results are translated into height trends, and given the social stratification that characterizes Mexico, it is easier to understand why average height increases have been moderate.

\section{Conclusion}

For the period 1850-1950, the evolution of living standards was heterogeneous across social classes mirroring inequalities in living standards. The trend in heights of the military tells a different story than that of the passport applicants. Passport applicants get taller over time. The military, on the other hand, experience 
deterioration and stagnation and do not recover their 1850s' height until 1950. There are regional disparities in both samples; the northerners and Bajio dwellers are taller than their counterparts in the center and south. Regional differences are larger in the military sample. Nonetheless, regional differences are not as marked as those across social classes; hence inequality in living standards across social classes is sharper than across regions.

The comparison in results between passport and military samples shed light on poverty and inequality issues. There are passport applicants from different social classes and, although the members of the upper strata are taller than applicants from the working classes, they all get taller over time and the gap between them decreases over time. This trajectory resembles the case of countries of the Western world where heights converge over time. This trajectory mirrors the evolution of the economy when we draw a comparison with per capita GDP. These results should be taken into consideration without losing sight of the fact that passport applicants represent a minority of the population and are not representative of the population at large. These were all urban, literate people who could afford to travel abroad legally. These three features are not common among the average Mexican born between 1850 and 1950 since the passport sample is representative only of the wealthy and of the small portion of the working classes that were favored by Mexico's economic growth and development during this period. Industrial development, export-led growth, and building of sanitary infrastructure contributed to the increase in stature of these passport samples. For the latter part of this period, it represents workers who did indeed benefit from the new labor legislation stemming from the 1917 Constitution. For those born and growing up during the decade of the Revolution's worst warfare (1910-1920), we observe that there is no height penalty. This suggests that these people were not hit by biological stressors such as food shortages and disease, so ubiquitous in places hit by warfare. The heights of working-class passport applicants can be used as a counterfactual hypothesis of what would have been the fate of the popular classes had the government's development policies also included efforts to integrate the population at large into the profound transformations that were taking place. The evolution of heights of the sample of women is similar to that of men. There is an increase over time.

The evolution of heights of the military samples reveals the impact on the great majority of the population of industrialization, displacement of traditional sectors of the economy, periods of political instability, and adoption of a development model that for the longest time gave little attention to human capital investments. The statures of the military recruits decreased for four decades (1850-1890); then they stagnated during the last decade of the nineteenth century. There is a modest improvement for the generation born around the turn of the century. This improvement is lost for the following generation; this reflects the penalty in living conditions for people who did endure the ravages of war during the Mexican Revolution. It should come as no surprise that the improvement in heights coincides with the launching of national-level public health campaigns as well as the launching of a welfare state in the late 1930s that reduced inequality in living standards; before then, the majority of the population was excluded from positive changes and lacked opportunities for advancement. 
Based on the ENSA-2000, ENSANUT-2006, and ENSANUT-2012, female and male average heights are estimated for the period 1951-1992. OLS regressions are used to estimate heights. Besides seven birth cohort dummies, variables on education and rural-urban residence are included in the regression. Results show that after a height stagnation during 1950s and 1960s, height growth continued until the end of the period of study. It has to be noted, however, that observed increases were not enough to converge to height levels of other similar (Brazil, Colombia) economies. Finally, in the case of females, Mexicans are still shorter than women from countries reported in the present study. Moreover, in comparison with Colombian females, the height gap is even bigger than for males.

Macro inequality in dimensions such as life expectancy at birth and education has been reduced, but there is still a significant gap. Results suggest that there is a rural penalty. Moreover, estimations show that education disparities yield significant differences in height. In addition, the socioeconomic inequality captured by school attainment differences is more profound for women. Based on evidence for levels of educational intergenerational mobility it is argued that status quo, including gender inequality, persists in Mexico. Once these results are translated into trends in height, and given that there is high social stratification in Mexico, it is easier to understand why average height increases were moderate for cohorts born between 1950 and 1992.

Finally, and based on the historical periods analyzed in the present study, it is possible to trace a long-run height trend in stature. Given the length of the 1850 1950 series, the exercise is made only for males. Results are presented in Fig. 5. For the 1850-1950 period, we use the military sample as one more representative of median Mexican. The whole trend shows an almost W-shape. There was a constant height decrease during the second half of nineteenth century. The decline did not stop until the late Porfiriato (1890s-1900s). However, due to the Mexican civil war in 1910 such improvement stopped, and it was just after the end of the civil war (circa 1920) and the Great Depression when the height trend became positive (1930s). In the 1950s and 1960s average height stagnated again, and it was only

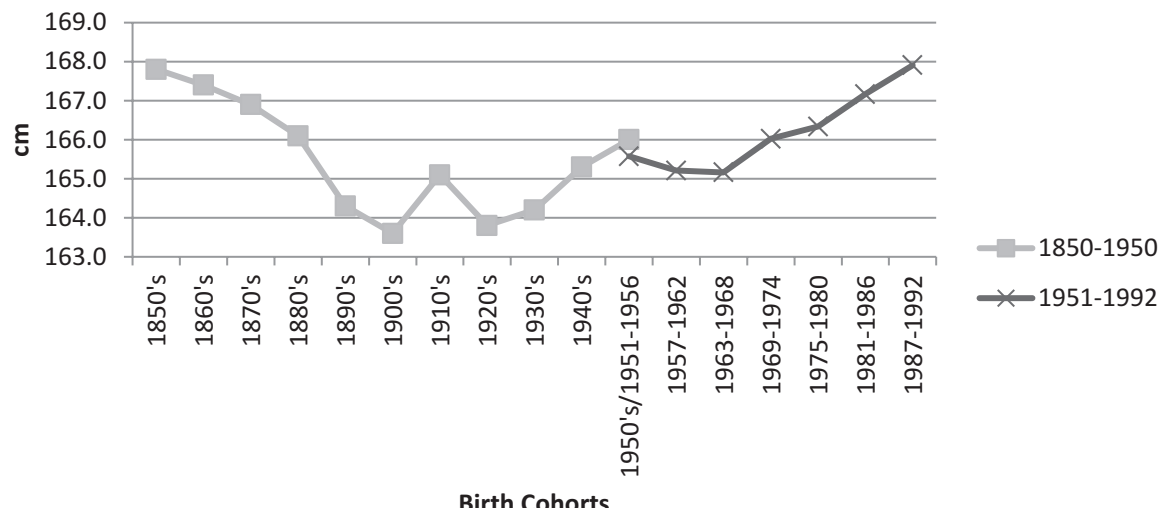

Fig. 5 Male mean height trends in Mexico, by birth cohorts: 1850-1992 
since the end of the 1960s when it experienced a constant increase until the end of the period of study.

For the post-1950 period further research is needed. Firstly, we still have to analyze the dynamics behind the 1950s' and 1960s' height stagnation. And secondly, even though it is not possible to control for birthplace, and therefore it is not possible to check for potential migration biases with ENSANUT, a deeper analysis on interregional differences than the one by López-Alonso and Vélez-Grajales (2015) is still needed.

Open Access This chapter is distributed under the terms of the Creative Commons Attribution 4.0 International License (http://creativecommons.org/licenses/by/4.0/), which permits use, duplication, adaptation, distribution and reproduction in any medium or format, as long as you give appropriate credit to the original author(s) and the source, a link is provided to the Creative Commons license and indicate if changes were made.

The images or other third party material in this chapter are included in the work's Creative Commons license, unless indicated otherwise in the credit line; if such material is not included in the work's Creative Commons license and the respective action is not permitted by statutory regulation, users will need to obtain permission from the license holder to duplicate, adapt or reproduce the material.

\section{References}

Agostoni, C. (2002). Discurso Médico, Cultura Higiénica Y La Mujer En La Ciudad de México Al Cambio de Siglo (XIX-XX). Mexican Studies/Estudios Mexicanos, 18(1), 1-22. doi:10.1525/ msem.2002.18.1.1.

Anand, S., \& Ravallion, M. (1993). Human development in poor countries: On the role of private incomes and public services. Journal of Economic Perspectives, 7(1), 133-150.

Baten, J. (2000). Economic development and the distribution of nutritional resources in Bavaria, 1797-1839. Journal of Income Distribution, 9(1), 89-106.

Baten, J., Pelger, I., \& Twrdek, L. (2009). The anthropometric history of Argentina, Brazil and Peru during the 19th and early 20th century. Economics and Human Biology, 7, 319-333.

Bogin, B. (1988). Patterns of human growth. Cambridge: Cambridge University Press.

Bogin, B. (2001). The growth of humanity. New York: Wiley-Liss.

Brinkman, H. J., Drukker, J. W., \& Slot, B. (1988). Height and income: A new method for the estimation of historical national income series. Explorations in Economic History, 25(3), 227-264.

Challú, A. (2009). Agricultural crisis and biological well-being in Mexico, 1730-1835. Historia Agraria, 47, 21-44.

Coll, S. (1998). The relationship between human physical stature and GDP (some experiments with European Time Series). In J. Komlos \& J. Baten (Eds.) Biological standard of living in comparative perspective. Contributions to the conference held in Munich, January 18-22, 1997, for the XIIth congress of the International Economic History Association (pp. 384-407). Stuttgart: Franz Steiner Verlag.

Cuff, T. (2005). The hidden cost of economic development: The biological standard of living in antebellum Pennsylvania. Aldershot: Ashgate Publishing.

David, P. A., \& Thomas, M. (2003). The economic future in historical perspective. Oxford: Oxford University Press for the British Academy. 
Eveleth, P. B., \& Tanner, J. M. (1990). Worldwide variation in human growth (2nd ed.). Cambridge, England: Cambridge University Press.

Floud, R. (1984, April). The heights of Europeans since 1750: A new source for European economic history. NBER Working Paper Series, No. 1318.

Floud, R., Wachter, K., \& Gregory, A. (2006). Height, health and history: Nutritional status in the United Kingdom, 1750-1980. Cambridge: Cambridge University Press.

Grajales-Porras, A., \& López-Alonso, M. (2011). Physical stature of men in eighteenth century Mexico: Evidence from puebla. Economics and Human Biology, 9, 265-271.

Haines, M. R., Craig, L. A., \& Weiss, T. (2003). The short and the dead: Nutrition, mortality, and the "Antebellum Puzzle" in the United States. The Journal of Economic History, 63(2), 382-413.

INEGI, Indicadores sociodemográficos de México. (1930-2000). México, 2001.

Keesing, D. B. (1969). Structural change early in development: Mexico's changing industrial and occupational structure from 1895 to 1950. The Journal of Economic History, 29(04), 716-738.

Knight, A. (1986). The Mexican revolution. Cambridge: Cambridge University Press.

Komlos, J. (1987). The height and weight of west point cadets: Dietary change in antebellum America. The Journal of Economic History, 47(4), 897-927.

Komlos, J. (1993). The secular trend in the biological standard of living in the United Kingdom, 1730-1860. The Journal of Economic History, 46(1), 115-144.

Komlos, J. (1995). The biological standard of living on three continents: Further explorations in anthropometric history. Boulder: Westview Press.

Komlos, J. (1998). Shrinking in a growing economy? The mystery of physical stature during the industrial revolution. The Journal of Economic History, 58(3), 779-802.

Komlos, J. (1999). On the nature of the Malthusian threat in the eighteenth century. The Economic History Review, 52(4), 730-748. New Series.

Komlos, J. (2004). How to (and how not to) analyse deficient height samples. Historical Methods, $37(4), 160-173$.

Komlos, J., \& Baten, J. (2004). Looking backward and looking forward: Anthropometric research and the development of social science history. Social Science History, 28(2), 191-210.

Komlos, J., \& Kim, J. H. (1990). Estimating trends in historical heights. Historical Methods, 23(3), $116-120$.

Komlos, J., \& Lauderdale, B. E. (2007). Spatial correlates of US heights and body mass indexes, 2002. Journal of Biosocial Science, 39, 59-78.

Leunig, T., \& Voth, H. J. (2006). Height and the high life. In P. A. David \& M. Thomas (Eds.), The economic future in historical perspective. Oxford: Oxford University Press.

López-Alonso, M. (2007). Growth with inequality: Living standards in Mexico, 1850-1950. Journal of Latin American Studies, 39, 81-105.

López-Alonso, M. (2012). Measuring up: A history of living standards in Mexico, 1850-1950. Stanford, CA: Stanford University Press.

López-Alonso, M., \& Condey, R. P. (2003). The ups and downs of Mexican economic growth: The biological standard of living and inequality, 1870-1950. Economics and Human Biology, 1(2), 169-186.

López-Alonso, M., \& Vélez-Grajales, R. (2015). Measuring inequality in living standards with anthropometric indicators: The case of Mexico, 1850-1986. Journal of Human Development and Capabilities, 16(3), 374-396.

Margo, R. A., \& Steckel, R. H. (1983). Heights of native-born whites during the antebellum period. The Journal of Economic History, 43(1), 167-174.

Martínez Carrión, J. M. (2001). Estatura, salud y bienestar en las primeras etapas del crecimiento económico español. Una perspectiva comparada de los niveles de vida. Documento de Trabajo, Asociación española de historia económica, DT-AEHE no. 102.

Meisel, A., \& Vega, M. (2007). The biological standard of living (and its convergence) in Colombia, 1870-2003: A tropical success story. Economics and Human Biology, 5(1), 100-122.

Monasterio, L. M., Nogueról, L. P. F., \& Shikida, C. D. (2006, June). Growth and inequalities of height in Brazil (1939-1981). Work presented in the Third Economics and Human Biology Conference in Strasbourg, France. 
Niewenweg, R., Smit, M. L., Walenkamp, M. J. E., \& Witt, J. M. (2003). Adult height corrected for shrinking and secular trend. Annals of Human Biology, 30(5), 563-569.

PNUD. (2003). Informe de Desarrollo Humano Mexico 2002. Madrid: Mundi-Prensa.

Prince, J. M., \& Steckel, R. H. (1998, December). The tallest in the world: Native Americans of the great plains in the nineteenth century. Working Paper. National Bureau of Economic Research.

Quiroga, G., \& Coll, S. (2000). Income distribution in the mirror of height differences: The case of Spain 1895-1950. Journal of Income Distribution, 9(1), 107-131.

Sen, A. (1985a). Commodities and capabilities. North-Holland: Amsterdam.

Sen, A. (1985b). Well-being, agency and freedom: The Dewey lectures 1984. Journal of Philosophy, 82(4), 169-221.

Sen, A. (1987). The standard of living. Cambridge: Cambridge University Press.

Sen, A. (2000). A decade of human development. Journal of Human Development and Capabilities, $1(1), 17-23$.

Sierra, J., \& O'Gorman, E. (1969). The political evolution of the Mexican people. With notes and a new introduction by Edmundo O'Gorman. Prologue by Alfonso Reyes (C. Ramsdell, Trans.). Austin: University of Texas Press.

Sokoloff, K. L. (1995). The heights of Americans in three centuries: Some economic and demographic implications. In J. Komlos (Ed.), The biological standard of living on three continents: Further explorations in anthropometric history (pp. 133-150). Boulder: Westview Press.

Sorkin, J. D., Muller, D. C., \& Andres, R. (1999). Longitudinal change in height of men and women: Implications for interpretation of the body mass index. American Journal of Epidemiology, 150(9), 969-977.

Steckel, R. H. (1983). Height and per capita income. Historical Methods, 16(1), 1-7.

Steckel, R. H. (1995). Stature and the standard of living. Journal of Economic Literature, 33(4), 1903-1940.

Steckel, R. H. (1998). Strategic ideas in the rise of the new anthropometric history and their implications for interdisciplinary research. The Journal of Economic History, 58(3), 803-821.

Tanner, J. M. (1978). Foetus into man: Physical growth from conception to maturity. Cambridge, MA: Harvard University Press.

Vanderwood, P. J. (1981). Disorder and progress: Bandits, police, and Mexican development. Lincoln: University of Nebraska Press.

Vélez-Grajales, R. (2016). The biological standard of living during post-revolutionary Mexico. Doctoral dissertation, University of Oxford.

Voth, H.-H., \& Leunig, T. (1996). Did smallpox reduce height? Stature and the standard of living in London. Economic History Review, 49(3), 541-560.

Voth, H.-H., \& Leunig, T. (2006). Height and the high life. In P. A. David \& M. Thomas (Eds.), The economic future in historical perspective. Oxford: Oxford University Press.

Wachter, K. W., \& Trussell, J. (1982). Estimating historical heights. Journal of the American Statistical Association, 77(378), 279-293.

Weber, G., Seidler, H., \& Hauser, G. (1995). Secular change in height in Austria: An effect of population stratification? Annals of Human Biology, 22(4), 277-288.

Moramay López-Alonso is an associate professor of History at Rice University. She is an economic historian of Latin America. She is the author of Measuring Up: A History of Living Standards in Mexico 1850-1950 (Stanford University Press 2012), winner of the 2013 Mexican History Book Prize awarded by the American Historical Association, and published in Spanish with Fondo de Cultura Económica in 2015. She holds a Ph.D. in History from Stanford University and a degree in Economics from Instituto Tecnológico Autónomo de México (ITAM).

Roberto Vélez Grajales is the director of the Social Mobility Program at the Espinosa Yglesias Research Centre in Mexico City. He is an Economist with doctoral studies in Modern History. His research interest subjects include social mobility, human development, and anthropometric history. On all these areas he has coordinated, authored, or worked as a consultant for several academic studies or public policy reports. 


\title{
Long-Run Human Development in Mexico: 1895-2010
}

\author{
Raymundo M. Campos-Vazquez, Cristóbal Domínguez Flores, \\ and Graciela Márquez
}

\section{Introduction}

In 1990, the United Nations Development Program (UNDP) proposed an alternative measure of development, the Human Development Index (HDI), a composite indicator of health, education, and income. Since then, researchers have increasingly used HDI estimates to explain the long-run evolution of standards of living in different countries and periods. In this chapter, we use the HDI to study long-run regional development in Mexico at subnational levels.

The literature using the HDI to measure well-being over time is extensive. Crafts $(1997,2002)$ calculated estimations for a set of 24 countries in the period 1870-1999, concluding that by the end of the twentieth century the gaps between Western Europe and developing regions were smaller than those present in the middle of the century. In a similar study, Prados de la Escosura (2010) concludes that the gap between developed and developing countries has narrowed over time, although the degree of convergence has slowed since 1970. Astorga et al. (2005) construct an HDI series for Latin American countries and conclude that the region experienced the largest gains in living standards in the middle decades of the twentieth century. Bértola et al. (2010) compute an inequality-adjusted historical human development index for Argentina, Brazil, and Uruguay in the twentieth century. These authors compare the results to developed countries (France, Germany, the UK, and the USA) and find divergence in Argentina from the early decades of the twentieth century, while Uruguay began the same pattern in the 1950s.

This chapter has benefitted by comments from the participants of the seminar "Latin American Inequality in the Long Run” Buenos Aires, 3-5 December, 2014. We also want to thank the insightful suggestions by Jeff Williamson and Luis Bértola. All remaining errors are our responsibility.

R.M. Campos-Vazquez $(\bowtie) \bullet$ C.D. Flores $\bullet$ G. Márquez

El Colegio de Mexico, Camino al Ajusco 20, Mexico City 10740, Mexico

(C) The Author(s) 2017

L. Bértola, J. Williamson (eds.), Has Latin American Inequality

Changed Direction?, DOI 10.1007/978-3-319-44621-9_5 
Brazil was steadily catching up until 1980, when it finally began to diverge from the core countries. ${ }^{1}$ It is worth noting that these papers compare the indices across countries over time, and that little research exists on well-being within countries using HDI estimates.

In Mexico, the study of living standards has been developed using different approaches, considering income and non-income components. Bortz and Águila (2006) analyze real wages from the Porfiriato (1876-1911) to the early twenty-first century and conclude that the largest increases took place between 1952 and 1970, while the economic crises of the 1980s and 1990s caused a drastic reduction in real wages. López-Alonso (2007, 2012) uses anthropometric measures (adult heights) drawn from military and passport data. These studies identify a deterioration in the standard of living of the laboring classes over time, in contrast to an increase for the elite and upper middle classes. ${ }^{2}$ Recently, Challú and Gómez (2015) found that real wages of non-skilled workers in Mexico City exhibited a secular decline since the mid-eighteenth century and only partially recovered from the late 1860s to 1930 . Esquivel (1999) finds convergence in GDP per capita at state level from 1940 to 1960, and a relative constant dispersion thereafter.

Campos-Vazquez and Velez (2012) calculate a human development index to study human development at the state level from 1895 to 1910 . Their results show important improvements in the 1895-1910 period, but these improvements are not distributed proportionately among states. Márquez (2012) applies the methodology developed by these two authors to study state-level human development in 1930 . Her study shows an improvement in human development in comparison to the 1895-1910 period. Interestingly, the regional development pattern found by Campos-Vazquez and Velez is also found in this study, suggesting an important structural difference in development between the northern and southern regions of the country.

In this chapter, we analyze the development of Mexico over the long run (1895-2010) using an HDI measurement at the subnational level to facilitate a comparison across regions. Our methodology provides a consistent standard of living measure based upon proxy variables to those generally used for recent periods. ${ }^{3}$ The chapter is organized as follows. Section 2 discusses the historical background

\footnotetext{
${ }^{1}$ These results are at odds with those of other scholars, which show a general pattern of "convergence in the central decades of the century and relatively stable situation afterwards" (Bértola et al. 2010, p. 219).

${ }^{2}$ See, for example: "The evolution of the biological standards of living of the laboring classes, measured as the evolution of stature, does not follow trends in Mexico's overall economic performance, while that of the elite and upper middle classes does. The trends in stature suggest that the living standards of the laboring classes gradually deteriorated from the 1870s" (López-Alonso 2007, p. 102).

${ }^{3}$ Esquivel et al. (2003) analyze convergence of HDIs since 1950. García-Verdú (2005) analyzes human development at the state level for 2000. Permanyer (2013) calculates HDIs at the municipal level in 1990, 2000, and 2010. Recently, Aguilar Retureta (2015) documents relative participation of GDP per capita across states in Mexico. He finds, similar to our results, that inequality increases up to 1940 and then steadily declines.
} 
on Mexico's history since 1895 and the literature that have applied human development concepts to the Mexican experience. Section 3 presents the methodology and data sources used in our estimates. Following, in Sect. 4, we offer main results of our study. Section 5 summarizes our findings and offers some conclusions.

\section{Historical Background}

Mexico experienced significant economic changes along the twentieth century that enabled the country to overcome past obstacles to growth while facing new challenges to improve the well-being of the population. In the last quarter of the nineteenth century Mexico grew at a sustained rate, in sharp contrast with the performance of the first 50 years after independence. Indeed, from 1821 to around 1870, Mexico stagnated, with episodes of weak recoveries and decline. ${ }^{4}$ Although economic historians have debated the pace of the slow secular growth, there is consensus on the recovery from the 1870s to the outbreak of the Mexican Revolution in 1910. During the Porfiriato (1876-1911) railroad construction, foreign demand for mineral and agricultural products, and enactment of regulations to secure property rights all contributed to the modernization of crucial sectors of the economy.

By 1910, Mexico was a wealthier economy than 30 years earlier. Ports, major cities, mines, and industrial centers were all connected by railroads, larger banks had branches throughout the country, and internal taxes increased their share of total federal revenue. However, economic growth did not reach all regions of the country with the same intensity. Mining districts, industrial centers, and export-oriented agriculture became engines of growth, but they coexisted with low-productivity agriculture and isolated regions with few connections to international markets.

The Mexican Revolution had uneven consequences on the economy. The areas disputed by different leaders were hit hard by the civil war. But even in this situation economic production did not come completely to a halt: the production of foodstuffs continued, in many instances promoted by revolutionary leaders; oil fields increased their output in response to growing international demand; and the geographic isolation of the Yucatan peninsula allowed henequen haciendas to supply the American market. By the end of the armed phase of the revolution a new institutional arrangement, centered in the 1917 Constitution, set in motion a land reform program and changes in labor legislation. Also, the government acquired a more interventionist stance in the economy which shaped social and economic policy in the decades to follow.

The economic disturbances caused by the revolutionary upheaval were neither generalized nor permanent, but their consequences differed across regions and sectors. In the 1920s mineral and agricultural exports continued to drive economic growth.

${ }^{4}$ For a discussion of the growth trajectory since independence see Cárdenas (2003), Coatsworth (1978), Márquez (2013), and Sánchez Santiró (2009). 
New investment in manufacturing also contributed to the recovery of the economy while the banking system slowly regained its basic functions. In contrast, Mexico was in arrears, without access to foreign loans, and in difficult negotiations with its creditors. Private investors were more reluctant to channel resources to agriculture than to manufacturing and mining, in part because of uncertainty created by the land reform program implemented by postrevolutionary governments.

Also, certain policies changed radically in the new institutional environment. In restructuring the economy the federal government introduced direct taxation (income tax), created the central bank, and established development banks in support of agriculture and industry. The provision of education and health services became priorities for the federal and state governments. Vaccination campaigns, eradication of epidemics, and sewage projects gained support among public officials. The School of Public Health was founded in 1922, and national health campaigns emerged as part of the social policy of the 1920s. The establishment of the Ministry of Public Education (Secretaría de Educación Pública, SEP) included an ambitious literacy program and the establishment of rural schools, and the federal government increased its efforts to centralize education policy (Fierro et al. 2009).

By 1926, as foreign demand for Mexican products tapered off, an economic slowdown was evident, and the international crisis in 1929 aggravated an already delicate situation. A sharp decline in international prices and the collapse of external markets constrained Mexico's capacity to grow, and that of other countries in Latin America, until 1932. However, the resumption of growth in that year initiated a 50-year period of sustained economic expansion. The closure of foreign markets during the 1930s opened up favorable conditions for the production of consumer and intermediate goods, while the early recovery from the external shock guaranteed domestic demand. Under the Lázaro Cárdenas administration (1936-1940) social expenditure soared and land reform policy broadened. Although the pace of land distribution leveled off subsequently, the government performed an active role in the economy through public investment in infrastructure, provision of cheap energy, and subsidies of raw materials and intermediate goods. Industrialization reached its stride with protectionist policies, fiscal incentives, and restrictions on foreign capital. The 1950 s and early 1960s were characterized by low inflation, exchange rate stability, and average GDP yearly growth of more than $6 \%$. In addition to high growth rates and price stability the expansion of health services and public education all contributed to improvements in social welfare and a betterment of income distribution.

In the mid-1960s the so-called Mexican miracle showed the first signs of profound economic woes. A growing trade and public deficits, lack of competitiveness of the industrial sector, and falling productivity in agriculture reveal serious obstacles to sustain sound economic growth in the years to come. By the early 1970s, structural problems mounted. The government chose fiscal expansion as the means to deal with its economic difficulties, resulting in rising inflation, an exploding public deficit, and an external deficit that required increased foreign borrowing. Inflation and devaluation ensued. The discovery of rich oil deposits coupled with the rise in international oil prices changed the prospects for the Mexican economy at the end of the 1970s. 
Growth resumed without resolution of the structural problems. Foreign debt was initially devoted to building an oil export platform, but the overvaluation of the peso and the deindustrialization associated with the so-called Dutch disease soon forced the government to increase borrowing. In 1981, international oil prices declined and interest rates rose, limiting the possibility of foreign financing. A year later, neither the devaluation of the peso nor the exchange rate controls had proven sufficient and, in consequence, the government declared a 3-month moratorium on the external debt and the nationalization of private banks. Mexico shared with other Latin American countries the problem of not only overindebtedness, but also an industrial base dependent on imported inputs, overprotected domestic markets, and a lack of international competitiveness. Severe cuts in public investment, a reduction in bureaucracy, elimination of subsidies, and price controls failed to recover a path of sustained growth or control inflation. Overall, in the 1980s, growth was mediocre. ${ }^{5}$

In the midst of the external debt crisis Mexico took a risky gamble. Instead of tightening the protectionist barriers, President Miguel de la Madrid (1992-1998) decided to liberalize the economy. A first step towards this goal was to join the General Agreement on Tariffs and Trade (GATT), which required the elimination of quantitative import controls and the lowering of import duties. To avoid future policy reversals, President Carlos Salinas (1988-1994) promoted the North American Free Trade Agreement (NAFTA) with the USA and Canada. Opening up the economy had initially aimed at increasing the flow of foreign direct investment; yet actual capital flows to the Mexican economy fell short of expectations (both in the mid-1980s and in the early 1990s). However, liberalization became the cornerstone for a new model of growth, one that placed significant emphasis on exports as the driving force of the economy. Completing the shift to this model also required a change in the role of the government. The sale of public enterprises at the start of the foreign debt crisis began as a measure to reduce the public deficit, but later became one of the pillars supporting a shift to a market-oriented economy. ${ }^{6}$

The changes in the Mexican economy were so profound that some authors did not hesitate to describe them as a revolution. ${ }^{7}$ In addition to NAFTA, President Salinas (1988-1994) launched ambitious economic reforms including the landholding regime of the ejido to allow peasants to sell their plots, recasting the Bank of Mexico as an autonomous agency with a mandate to control inflation, passage of an antitrust law with establishment of a Federal Competition Commission, as well as privatization of banks, steel plants, the telephone company, television stations, and railroads, among other industries. However, these reforms were insufficient to recover high rates of growth needed to compensate for the "lost decade" of the $1980 \mathrm{~s} .^{8}$

\footnotetext{
${ }^{5}$ See Moreno-Brid and Ros (2009), Chap. 6, and Cárdenas (2010).

${ }^{6}$ Haber et al. (2008).

7 "If by 'revolution' we mean a dramatic change in the institutions that organize economic, political, and social life, then Mexico has undoubtedly been in the midst of a revolution since the early 1980s" (ibid., p. 1).

${ }^{8}$ Márquez and Meyer (2010).
} 
A currency crisis in late 1994 led the Mexican economy to a severe drop in output equivalent only to that of the 1930s. Despite a quick recovery, the effects on well-being were not easy to overcome. After a decade of mediocre growth in the 1980s, the new crisis deepened the vulnerabilities of the middle- and low-income strata of society. In the first decade of this century, social programs coupled with macroeconomic stability had ameliorated the effects of years of slow growth. However, the international financial turmoil of 2008 caused another large dip in the growth trajectory, losing the gains in well-being brought about by social programs.

Over the course of more than a century the Mexican economy experienced a profound transformation. At the end of the nineteenth century the majority of the population lived and worked in rural areas, the railroad grid was crucial to the transportation of mineral and agricultural exports, and education and health services were limited and provided mostly in urban areas. In 2010, most Mexicans lived in cities, most children had access to primary education, and the country's export basket combined raw materials and manufactures. Between these two moments of Mexican history, the country changed its patterns of growth from a primarily export model to an import substitution industrialization strategy, and finally to a marketoriented economy. How did well-being develop over time? Can we observe any continuity in regional patterns? These questions are addressed in the following sections, where we present the results of estimates of human development indexes from 1895 to 2010 .

\section{Methodology and Data}

In its original version the HDI was calculated as a simple average of the health, education, and income indexes. The health index is related to life expectancy, the education index to enrollment and literacy rates, and the income index to per capita income. Since 2010, the HDI has been calculated as a geometric mean of its components:

$$
\text { HDI }=\text { Health }^{1 / 3} \cdot \text { Education }^{1 / 3} \cdot \text { Income }^{1 / 3}
$$

This new methodology has several advantages. First, it avoids the perfect substitutability problem of the simple average aggregation. In other words, if one subindex gains at the expense of another, the previous formula would not reflect a changed HDI, while the new formula does. Second, as a consequence of imperfect substitutability, uneven progress can be accounted for as a negative effect on the overall index. Finally, the maxima chosen in the normalization of each subindex are irrelevant (Klugman et al. 2011). ${ }^{9}$

\footnotetext{
${ }^{9}$ We calculate the geometric mean in order to apply the current HDI methodology to our index. Using the previous methodology, mean with equal weights to each index, does not change the main conclusions of this chapter.
} 
In order to construct the HDI in Eq. (1), we use proxy variables for each subindex following Campos-Vazquez and Velez (2012) and Ian Morris (2013). First, the calculation of the education index takes into account the variables and weights proposed by UNDP (2010). The only difference is that we restrict the upper bound of the age range of literacy rates for individuals to 12 years instead of 24 years as specified by UNDP (2010). We thus calculate the education index as a weighted average of literacy rates (LR) for individuals older than 15 years of age and enrollment rates (ER) for individuals aged 6-12 years such that

$$
\text { Education }=\frac{2}{3} \mathrm{LR}+\frac{1}{3} \mathrm{ER} \text {. }
$$

Second, instead of using life expectancy, we use the number of physicians for each 10,000 inhabitants. Our proxy variable is a good measure of the health standard if we considered the effect of access to medical services in overall health. There is a large range of studies documenting the importance of the number of physicians on the health status of the population. For example, Shi $(1992,1994)$ has shown that US states where the number of physicians per capita is higher have better health outcomes. This is in line with results of Robst and Graham (1997, 2004) also for the USA. They show a positive influence of the number of physicians on the health status of the population. Moreover, they find a higher correlation in rural areas across the USA than urban areas. Vogel and Ackermann (1998) have shown a positive relation between a higher supply of physicians and life expectancy. Finally, Pièrard (2009) shows that a higher supply of general practitioners in Canada is correlated with better health outcomes, including self-reported measures of health status.

Our proxy variable for life expectancy, the number of physicians per 10,000 inhabitants, is a good measure of the health standard if we consider the effect of access to medical services on overall health. ${ }^{10}$ To construct this subindex, we use the number of physicians (NP) per 10,000 inhabitants relative to 35, which was the corresponding figure for 2001 in Switzerland, the country in Europe with the highest life expectancy. The health index is thus constructed as

$$
\text { Health }=\frac{N P}{35}
$$

\footnotetext{
${ }^{10}$ There is a large range of studies documenting the importance of the number of physicians to the health status of the population. For example, Shi $(1992,1994)$ and Robst and Graham $(1997,2004)$ show a positive influence of the number of physicians on the health status of the US population; the latter, moreover, find a higher correlation in rural areas than in urban ones. Vogel and Ackermann (1998) show a positive relation between number of physicians and life expectancy. Finally, Piérard (2009) shows that a greater supply of general practitioners in Canada is correlated with better health outcomes, including self-reported measures of health status. In the data section, we provide the sample correlations of number of physicians and life expectancy for recent years.
} 
Third, instead of using income, we use urbanization rates. There is a long tradition in economic history of using urbanization rate as a proxy for economic development. Paul Bairoch $(1975,1988)$ presents a compelling argument that urbanization is correlated with economic development for both developed and developing regions. A book by Komlos (1994) reaches a similar conclusion. Moomaw and Shatter (1996) formally test the previous argument using a panel data of countries and find that indeed urbanization increases with GDP per capita. More recently, Acemoglu et al. (2002) convincingly argue that population density and urbanization are a good proxy for economic development. For a sample of Latin American countries, Astorga et al. (2005) find that urbanization is positively correlated with living standards in the period 1900-2000. In the study of how culture affects economic development in Europe, Tabellini (2010) argues that urbanization rates are a good proxy for economic development. Nunn and Qian (2011) argue that the introduction of potatoes to the Old World improved nutrition and agricultural productivity which lead to higher urbanization rates and higher economic development. Finally, Cali and Menon (2013) find that urbanization causes rural poverty to decline through increased demand for agricultural products in the case of Indian districts. Furthermore, disaggregated urbanization data for developing countries is generally more easy to find whereas GDP per capita estimates were often inexistent or lacked precision as the analysis moved back in time. In so doing we attempt to provide a basis of comparison with cases or historical periods with little information. Nevertheless, we should keep in mind that urbanization is a good proxy for income in the long run, but urbanization may not follow the same short-run fluctuation as income. The positive results of the consistency test (see next section) support our choice of urbanization as a proxy for income in the long run. As urbanization is already a number between zero and one, we do not need to transform it into an index; we simply introduce it in Eq. (1) as proxy of the subindex income.

Table 1 summarizes the definitions of the subindices explained above. In sum, as a proxy for per capita income we use urbanization rate. For health, we use the number of physicians per 10,000 inhabitants. For education, we can closely mimic the official definition in the HDI calculation.

Table 1 Components of HDI as in UNDP (2010) and variables used in the study

\begin{tabular}{|c|c|c|}
\hline Subindex & UNDP (2010) & Our estimation \\
\hline Income & GDP per capita & Urbanization rate \\
\hline \multirow[t]{2}{*}{ Education } & $\begin{array}{l}\text { Enrollment rate of individuals } \\
\text { older than } 15 \text { years }\end{array}$ & $\begin{array}{l}\text { Enrollment rate of individuals older than } 15 \\
\text { years }\end{array}$ \\
\hline & $\begin{array}{l}\text { Literacy rate in individuals aged } \\
6-24 \text { years }\end{array}$ & Literacy rate in individuals aged 6-12 years \\
\hline Health & Life expectancy rate & $\begin{array}{l}\text { Physicians per } 10,000 \text { inhabitants relative to } \\
35 \text { (physicians in Switzerland in 2001) }\end{array}$ \\
\hline
\end{tabular}




\subsection{Construction of the Education Index}

Education variables are the best measured variables in our dataset. Literacy rates for the population aged 15 years and older are available at the state level for every year of interest in Estadísticas Históricas de México (INEGI 2009) and Censo General de Población y Vivienda (INEGI 2010a, b). Enrollment rates are defined as the share of population aged 6-12 years who are enrolled in school. From 1920 to 2010, enrollment rates are calculated using data available in the population censuses. Rates from 1900 to 1910 are calculated using data from Estadísticas económicas del Porfiriato (Colegio de México 1964) and Estadísticas sociales del Porfiriato (Secretaría de Economía 1956). Only the enrollment rates from 1895 have to be estimated. ${ }^{11}$ Both literacy rates and enrollment rates are also calculated using microdata from the Population Censuses from 1990 onwards provided by IPUMS (Minnesota Population Center 2011).

It would be preferable to use enrollment rates for the population aged 6-24 years, but there is not enough data available for 1920, 1930, and 1940 to calculate them. Correlations between enrollment rates for persons aged 6-12 years and those aged 6-24 years for 1950,1970 , and 1990 are $0.98,0.96$, and 0.81 , respectively. ${ }^{12}$

\subsection{Construction of the Health Index}

The number of physicians per 10,000 inhabitants is the best proxy variable that can be used for the whole period of study. Although the origin of the data is varied, the number of physicians per state is available for most of the years under study. The number of doctors at the state level is available in Estadísticas Sociales del Porfiriato (Secretaría de Economía 1956) for the period 1895-1910, in Mendizábal (1947) for 1930, in Huerta Maldonado (1960) for the mid-1950s, in N. Myers (1971) for 1960, and in Frenk et al. (1995) for 1970 and 1990. Numbers for 1980

\footnotetext{
${ }^{11}$ State-level enrollment rates for 1895 were estimated by pooling ordinary least squares using data from 1900 to 1910:

$$
\begin{aligned}
& \text { enroll }_{i, t}=11.6+0.19 \text { Dens }_{i, t}+0.368 \text { Prof }_{i, t}-7.31 \text { Dummy }^{2} \\
& \text { se : }(2.19)(0.15)(0.16)(1.37) \quad R^{2}=0.65
\end{aligned}
$$

where enroll $\mathrm{i}_{\mathrm{i}, \mathrm{t}}$ is the enrollment rate in percentage points for state $i$ at year $t$, Dens $_{\mathrm{i}, \mathrm{t}}$ is the population density per square kilometer, Prof $\mathrm{i}_{\mathrm{i}, \mathrm{t}}$ is the number of teachers per 10,000 persons, and Dummy is a binary variable that takes value 1 if the enrollment rate is less than $10 \%$ for either of the 2 years and zero otherwise.

${ }^{12}$ The Spearman correlations for 1950,1970 , and 1990 are $0.99,0.96$, and 0.74 , respectively. The hypothesis of independence between both variables for every year is rejected at any typically used significance level. The correlation between the variables is clearly reduced from 2000 onwards, when enrollment rates in elementary school reached levels closer to $90 \%$.
} 
were interpolated from the latter source, and yearbooks published by the National Statistical Institute (INEGI) provided the observations from 2000 to 2010 in a more homogenous manner. ${ }^{13}$

There is no data available for the number of physicians at the state level for 1920 and 1940, so we impute these values using econometric methods. Trends of physician concentration were clearly different before and after 1930, so two estimations are needed. The number of physicians for 1920 is estimated using data from 1895, 1900, 1910, and 1930, and the number for 1940 using data from 1950, 1960, and $1970 .{ }^{14}$

Statistical evidence also supports the proposition that the number of physicians is a good proxy variable for the health dimension. The correlations between the number of physicians and life expectancy for 1950, 1990, and 2000 are $0.78,0.61$, and 0.54 , which implies a strong positive relation. ${ }^{15}$ Furthermore, we expect that the relationship between physicians and life expectancy should be stronger for earlier years of the study, given that transportation costs were higher.

\footnotetext{
${ }^{13}$ Specifically, we are using data from the Anuario de Estadísticas por Entidad Federativa (INEGI 2004, 2009, 2011).

${ }^{14}$ We estimated the number of physicians for 1920 and 1940 using different datasets, pooling ordinary least squares. For 1920, we restricted data to 1895, 1900, 1910, and 1930:

$$
\begin{aligned}
& \text { phys }_{i, t}=6.78+0.0028 \text { Dens }_{i, t}+0.034 \mathrm{Mort}_{i, t}-4.89 \mathrm{reg} 1 \\
& -4.59 \mathrm{reg} 2-6.54 \mathrm{reg} 3-6.88 \mathrm{reg} 4-5.92 \mathrm{reg} 5 \\
& \text { se : }(1.19)(0.0012)(0.016)(0.95) \\
& (1.13)(0.80)(0.74)(0.87) \quad R^{2}=0.70
\end{aligned}
$$
}

For 1940, we restricted data to 1950,1960 , and 1970:

$$
\begin{aligned}
& \text { phys }_{i, t}=22.2-0.0007 \mathrm{Dens}_{i, t}-0.158 \text { Mort }_{i, t}-14.6 \mathrm{reg} 1 \\
& -15.1 \mathrm{reg} 2-16.8 \mathrm{reg} 3-16.4 \mathrm{reg} 4-16.9 \mathrm{reg} 5 \\
& \text { se }:(4.05)(0.0018)(0.054)(3.93) \\
& (3.93)(3.81)(3.73)(3.87) \quad R^{2}=0.71
\end{aligned}
$$

where phys $\mathrm{i}_{\mathrm{i}, \mathrm{t}}$ is the number of physicians for state $i$ at year $t$, Dens $\mathrm{s}_{\mathrm{i}, \mathrm{t}}$ is the population density per square kilometer, Mort $\mathrm{i}_{\mathrm{i}, \mathrm{t}}$ is the mortality rate, and reg1-reg5 are dummy variables per region as previously defined. We estimated different interpolation models but we obtained qualitatively similar results.

${ }^{15}$ The Spearman correlations for 1950, 1990, and 2000 are 0.69, 0.67, and 0.53, respectively. The hypothesis of independence between both variables for every year is rejected at any typically used significance level. 


\subsection{Construction of the Income Index}

The urbanization rate is defined as the share of the population living in communities with more than 2500 inhabitants. ${ }^{16}$ We need to rely on an estimation of the urbanization rate only for the year 1895. ${ }^{17}$ Data available in Estadísticas económicas del Porfiriato (El Colegio de México 1964) is used to calculate urbanization rates for 1900 and 1910, and population census data is used for the period 1920-2010. Statistical evidence also supports that urbanization is a good proxy variable for the income dimension; correlations between urbanization and per capita income for 1970,1990 , and 2000 are $0.76,0.78$, and 0.84 , respectively. ${ }^{18}$

\section{Results}

\subsection{Consistency}

Table 2 includes the calculations for each subindex in the period 1895-2010 as well as the value of the historical HDI using Eq. (1). Before analyzing these results we need to establish their relation to existing estimates using the definitions and variables specified by UNDP (2010). We performed a consistency test comparing our estimates with existing HDI estimates for the 1950-2000 period. We obtained 1950-2010 values of the HDI from the results of Gerardo Esquivel et al. (2003), and PNUD (2003, 2012). We contrasted these values (referred as HDI* in Fig. 1) with our measure of HDI. The result is shown as a scatterplot in Fig. 1.

Figure 1 shows HDI on the $x$-axis and HDI* on the $y$-axis; each dot represents a state in the period 1950-2010. We also included a regression line for reference. The two series are highly collinear. Indeed, the correlation coefficient is equal to 0.88 (the Spearman coefficient, 0.87). The slope parameter in the regression line is 0.61 and is significant at the $1 \%$ level. Because the HDI is highly related to HDI* we are

\footnotetext{
${ }^{16}$ It might be argued that this threshold is too low. However, homogenous data using a different threshold is not available. Moreover, it is not clear that we should use a higher threshold (for example 15,000) for recent periods.

${ }^{17}$ We use the same estimation as Campos-Vazquez and Velez (2012), p. 616. The data was obtained by pooling ordinary least squares:

$$
\begin{aligned}
& \mathrm{Urb}_{i, t}=31.77+0.094 \text { Dens }_{i, t}+1.189 \mathrm{NP}_{i, t}-8.261 \text { Dummy } \\
& \text { se }:(1.649)(0.011)(0.512)(0.879) R^{2}=0.884
\end{aligned}
$$

${ }^{18}$ The Spearman correlations for 1970, 1990, and 2000 are $0.73,0.73$, and 0.81 , respectively. The hypothesis of independence between both variables for every year is rejected at any of the typically used significance levels.
} 
Table 2 National HDI and components

\begin{tabular}{l|l|l|l|l}
\hline & & Subindexes & \\
\cline { 3 - 5 } Year & Human development index & Urbanization & Education & Health \\
\hline 1895 & 0.133 & 0.277 & 0.164 & 0.052 \\
\hline 1900 & 0.151 & 0.283 & 0.220 & 0.055 \\
\hline 1910 & 0.155 & 0.285 & 0.230 & 0.057 \\
\hline 1920 & 0.174 & 0.309 & 0.290 & 0.059 \\
\hline 1930 & 0.195 & 0.335 & 0.371 & 0.060 \\
\hline 1940 & 0.231 & 0.351 & 0.379 & 0.093 \\
\hline 1950 & 0.317 & 0.426 & 0.504 & 0.149 \\
\hline 1960 & 0.364 & 0.507 & 0.600 & 0.159 \\
\hline 1970 & 0.435 & 0.587 & 0.696 & 0.202 \\
\hline 1980 & 0.533 & 0.663 & 0.784 & 0.292 \\
\hline 1990 & 0.605 & 0.713 & 0.866 & 0.358 \\
\hline 1995 & 0.629 & 0.735 & 0.906 & 0.374 \\
\hline 2000 & 0.654 & 0.746 & 0.909 & 0.412 \\
\hline 2005 & 0.673 & 0.765 & 0.926 & 0.431 \\
\hline 2010 & 0.703 & 0.768 & 0.932 & 0.485 \\
\hline
\end{tabular}

Source: Own calculations

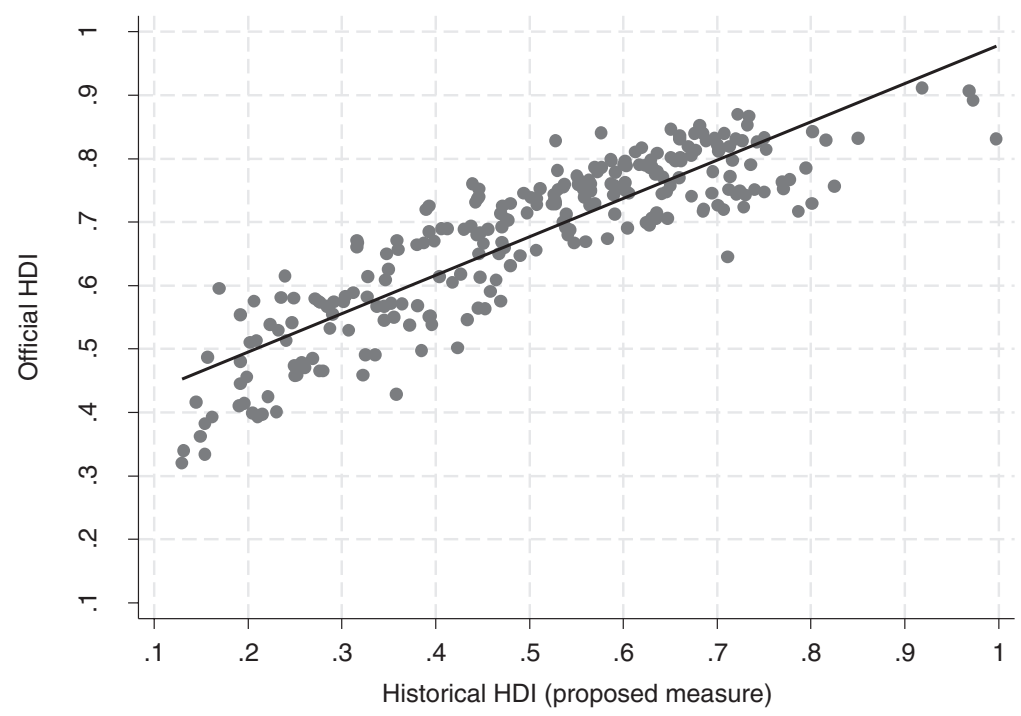

Fig. 1 Relationship between official HDI and proposed historical HDI: 1950-2010. Sources: Historical HDI obtained from results calculated by the authors. Official HDI from 1950 to 1995 obtained from Esquivel et al. (2003), 2000 from PNUD (2003), and 2010 from PNUD (2012). Notes: Calculated by the authors. Includes all HDI and HDI* values of each state for the period 1950-2010, including 1995 and 2005. There is a total of 256 observations. The correlation coefficient is equal to 0.878 and the Spearman correlation is equal to 0.868 and significant at the $1 \%$ level. The regression obtained is equal to $H D I=0.37+0.61$ ProposedHDI, with a $t$-statistic on the coefficient of HDI equal to 29.3 and $R^{2}$ of 0.77 
HDI: Mean, Minimum, and Maximum

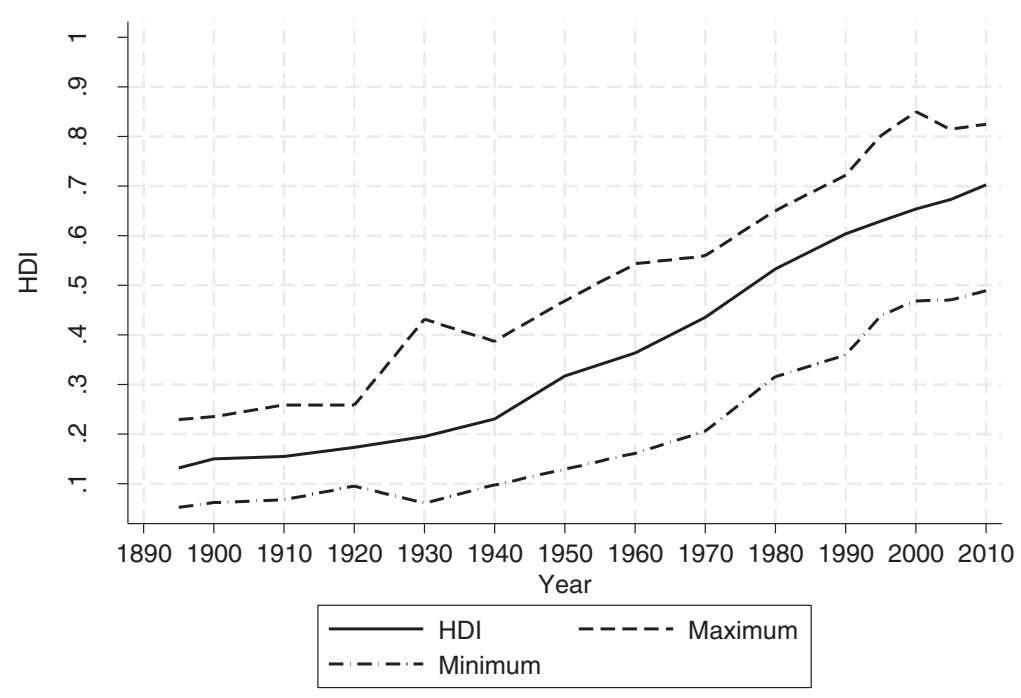

Fig. 2 HDI, 1895-2010. HDI mean, minimum, and maximum. Notes: Calculations by the authors. The figure includes the evolution of HDI for the full sample over time using an average weighted for the population in each state and period. The maximum refers to the second maximum, as the first maximum is always Mexico City

able to draw inferences on long-run human development for Mexico at the national and the regional levels.

\subsubsection{Main Results at National Level}

Figure 2 shows the evolution of the national-level HDI, calculated as the average of state-level HDI weighted by population. Human development shows an improving trend over the twentieth century, a result comparable to the rise in heights found by Moramay Lopez-Alonso and Roberto Velez in this volume. Furthermore, for the period as a whole, Mexico shows an average acceleration rate of $1.45 \%,{ }^{19}$ very close to the figure of $1.4 \%$ reported by Prados de la Escosura (2010) for a sample of 88 countries in the period 1870-2005, suggesting that Mexico's experience in human development is similar to that of the rest of the world.

The long-term evolution of the HDI allows us to differentiate three periods: one before 1940 with moderate increases; a second from 1940 to 1980 , with major gains in the standard of living; and a third beginning in 1980 with indices of wellbeing still increasing but at a slower rate. These three periods are clearly related to

${ }^{19}$ We thank Luis Bértola for pointing out that this is an acceleration rate. 
the historical processes described in the historical review. First, from 1895 to 1940, encompassing the late Porfiriato, the revolution, and the postrevolutionary period, Mexico experienced low-to-moderate improvements in standards of living resulting from uneven economic growth and erratic social policies. Second, from 1940 to 1980 there are important gains in human development. As discussed in Sect. 2, the manufacturing sector became the engine of growth, and the country registered significant increases in public and private investment as well as the establishment of social security in 1943, and the expansion of universal primary education, hospitals, and public health campaigns. ${ }^{20}$ Third, since 1980, improvements in human development have slowed down in light of the advancements of those achieved in the previous four decades. ${ }^{21}$ The acceleration rate of the HDI from 1980 to 2010 was reduced due to sluggish economic performance and the serious macroeconomic shocks of the foreign debt crisis of the 1980s, the currency crisis of 1995 , and the recession of 2008-2009. Social spending has ameliorated the effects on well-being, but half of the Mexican population still lives below the poverty line. In sum, Mexico showed large gains in human development in the twentieth century, but these were mostly driven by policies in the decades of urbanization and rapid industrialization.

\subsubsection{Convergence}

Studies of convergence of the GDP per capita of Mexican states have found a significant reduction of regional disparities in the period between 1940 and 1990 (see for example Esquivel 1999). Furthermore, Esquivel et al. (2003) in their study of HDI from 1950 to 2000 identified absolute convergence for the HDI and its components. However, previous studies have not used a long-run series since 1895 as we do in this chapter. The literature on convergence identifies "absolute convergence" or "unconditional convergence" when the poorest states or countries in the initial year grow faster during the full period than richest states or countries (on average). Using the HDI instead of GDP, we find absolute convergence for the full period 1895-2010. Figure 3 plots the average growth rates of the HDI between 1895 and 2010 and the $\log$ of the HDI in the initial year (1895). The statistical significance of the negative slope proves the existence of absolute convergence. Similarly, we find absolute convergence in the HDI components: urbanization, health, and education. ${ }^{22}$

\footnotetext{
${ }^{20}$ On health and education see Brachet-Márquez (2010) and Loyo (2010).

${ }^{21}$ GDP per capita fell during the 1980s in Mexico. However, we find that HDI increased during this period, although its growth rate is lower compared to previous periods. It is possible that urbanization (our income proxy) is increasing through informal labor of rural workers tied with economic decline. We thank Luis Bértola for this remark.

${ }^{22}$ In his analysis of the Atlantic economy from 1870 to 1910 George R. Boyer (2007) finds convergence in living standard measures with a stronger trend for the non-income components of well-being.
} 


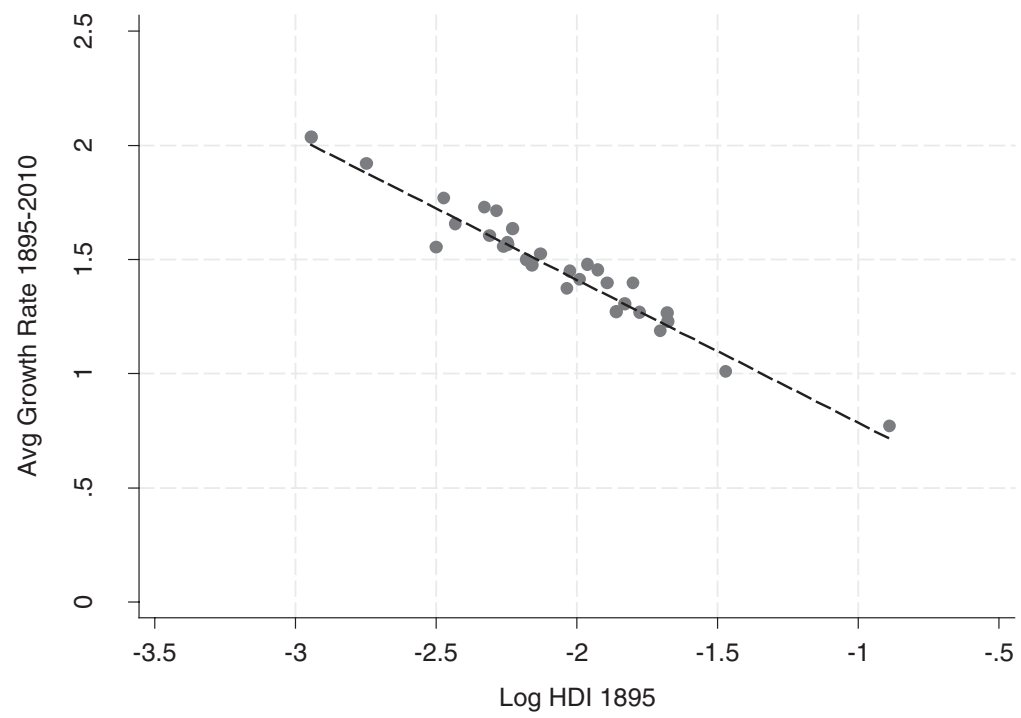

Fig. 3 HDI: absolute convergence. Sources: Historical HDI obtained from results calculated by the authors. Notes: Calculated by the authors. The regression obtained is equal to growth $=0.16-0.62 H D I 1895$, with a $t$-statistic on the coefficient of HDI equal to 26 and $R^{2}$ of 0.96 . Spearman's rank correlation of -0.95

As shown in Fig. 4, the trends in convergence of regional disparities, we find that for the HDI, urbanization and education were relatively stable in the pre-1940 period. In contrast, the health index trend showed an increase between 1920 and 1930, perhaps as a result of successful health campaigns with partial coverage of the national territory. A sharp convergence was common to all indicators from 1940 to 1980. The stability of the coefficient of variation from 1980 to 2010 demonstrates that the gap among Mexican states has stalled in the last 40 years.

\subsubsection{Regional Results}

The HDI is calculated on the regional level as the average of the HDI of the states in the region weighted by their relative population shares. Figure 5 shows the regional HDI for every year of the sample. As in the case of the national data, every region shows improvements in human development over the period of analysis, described by an S-shaped curve. The most significant improvements in human development for every region, excluding Mexico City, occurred between 1950 and 1970, coinciding with the processes of industrialization and urbanization together with the expansion of public education and health services. After 1980 lesser improvements in human development in Mexico's regions are related to the 


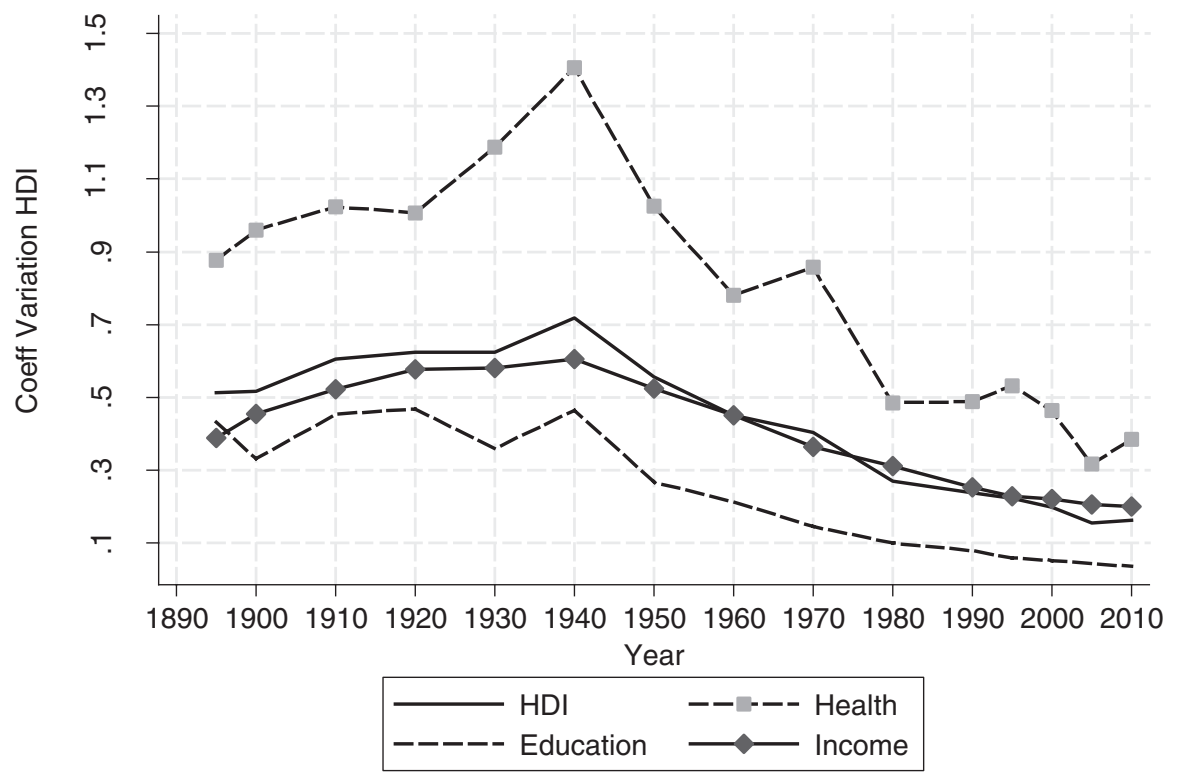

Fig. 4 HDI and components: coefficient of variation. Sources: Historical HDI obtained from results calculated by the authors. Notes: Calculated by the authors using all periods and states

transition to an open economy since the mid-1980s in which macroeconomic adjustments included public expenditure cuts and falling real wages.

Important disparities in human development among states have existed since 1895, as shown in Fig. 5. Mexico City shows the highest standard of living in the sample by a large margin in every year. The northeast and northwest regions consistently show development levels above the national level from 1895, which is comparable to the findings of taller inhabitants of these regions in the analysis of Lopez-Alonso and Velez-Grajales in this volume. In contrast, the center, westcenter, and south-southeast regions have development levels lower than those of the country as a whole. Furthermore, the southern region shows the lowest levels of development for the entire period of study.

One of the most interesting features of Fig. 5 is the comparison between the center and south-southeast regions. Before 1960, the regions' development trends were nearly identical. However, HDI for the center region subsequently improved, catching up with the west-center region and national levels.

The relative positions of the states and the relationship of differences with location are shown in Fig. 6 with the states classified according to their relative development position for the years 1895, 1920, 1940, 1970, 1990, and 2010. Northern states commonly have the highest HDI, while southern and especially southeastern states have the lowest. States in the center and west-center regions have more variable results but in general they are middle ranked. These results suggest a persistence in relative development with a strong spatial distribution. 


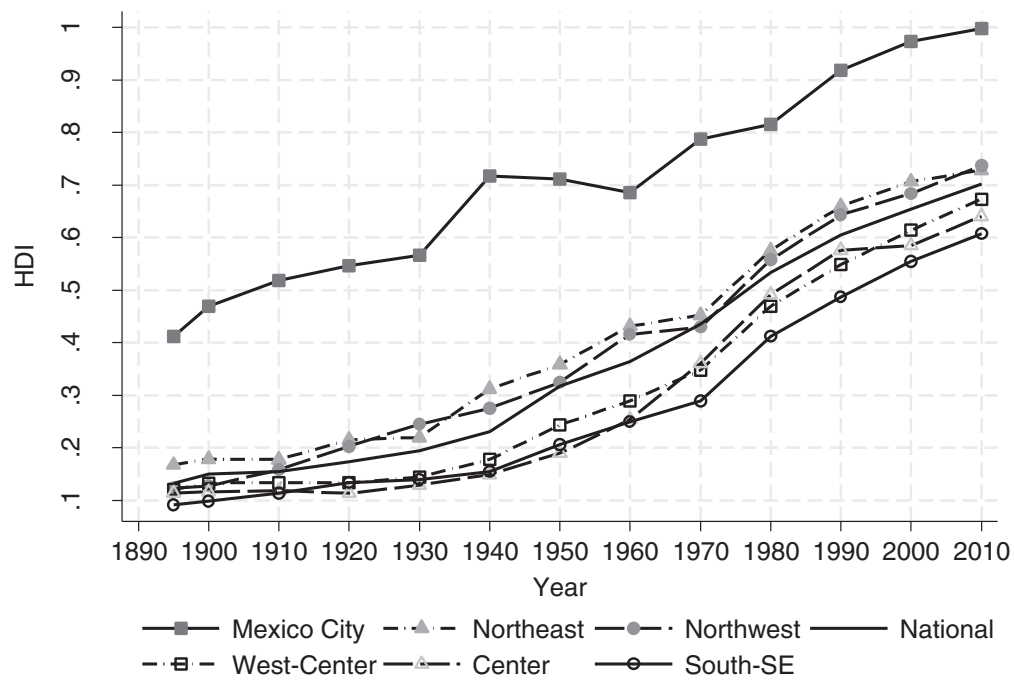

Fig. 5 HDI by region, 1895-2010. Notes: Calculated by the authors, weighted for population of each state and period. Regions are defined as follows: Northeast Coahuila, Chihuahua, Durango, Nuevo León, and Tamaulipas. Northwest Baja California, Baja California Sur, Sinaloa, and Sonora. West-Center Aguascalientes, Colima, Guanajuato, Jalisco, Michoacán, Nayarit, Querétaro, San Luis Potosí, and Zacatecas. Center Hidalgo, Mexico State, Morelos, Puebla, and Tlaxcala. South and Southeast Campeche, Chiapas, Guerrero, Oaxaca, Quintana Roo, Tabasco, Veracruz, and Yucatán

Figures 4 and 5 allow us to understand this pattern. In 1895, northern and Yucatan Peninsula states and Mexico City showed the highest levels of development. During the Porfiriato, foreign trade was key to the economic performance of these states and thus their higher standard of living. This pattern became more evident in the 1920s when northern bordering states rose to the top, along with Mexico City.

The highest dispersion among states is found in 1940. In that year the northern border states and Mexico City still show the highest levels of development, and the center and southeast regions their lowest levels before import substitution industrialization. By 1970, the pattern is not significantly different, although the state of Jalisco has a top position in the standard of living ranking. As dispersion between states is reduced over time, states in the center and the Yucatan peninsula are less uniformly ranked. Guerrero and Oaxaca, however, have ranked in the bottom $25 \%$ since 1895 .

After the debt crisis of 1982 and structural changes to open the economy, regional patterns of development in 1990 remained unaltered. The northern states still ranked highest in human development, but Jalisco, Aguascalientes, and Colima were reaching levels similar to those of the north. Southern states continued in the lowest positions. In 2010, the dispersion had reduced significantly with northern and west-center states experiencing similar levels of development. Although the center has made important improvements, it still includes some of the lowest ranking states in the country. 
A. 1895

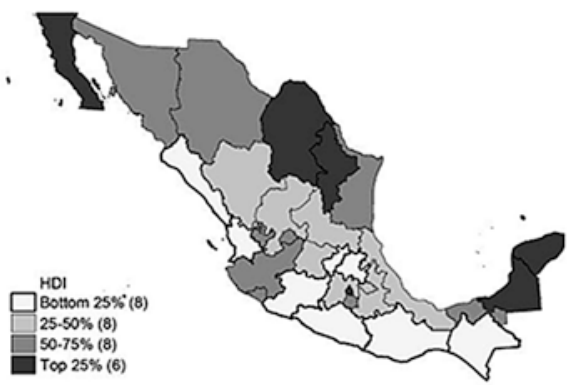

C. 1940

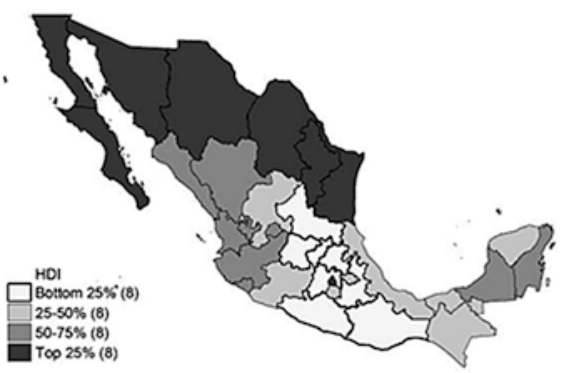

E. 1990

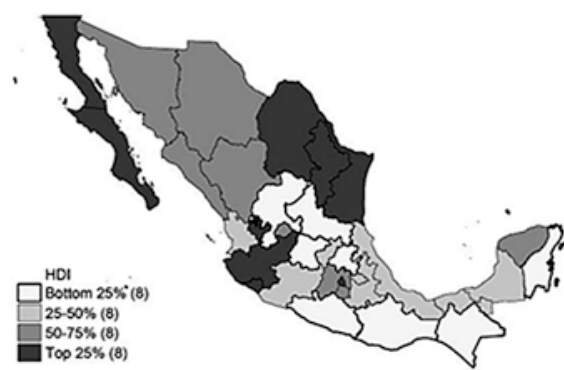

B. 1920

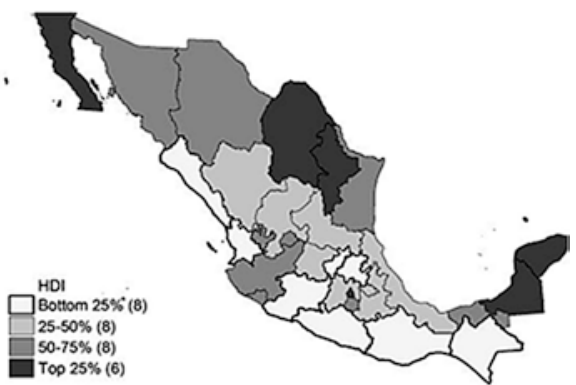

D. 1970

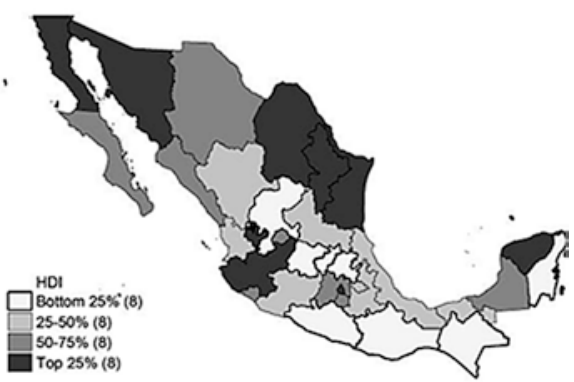

F. 2010

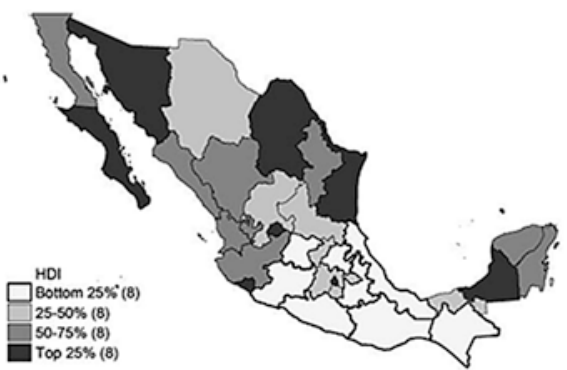

Fig. 6 Development of Mexico, (a) 1895, (b) 1920, (c) 1940, (d) 1970, (e) 1990, (f) 2010. Notes: Calculated by the authors. Mexico has 32 states including the Federal District (Mexico City). Data not available for Baja California Sur and Quintana Roo in 1895 or 1920

Figure 7 shows the scatterplot of the HDI of the states minus their mean for 1895 ( $x$-axis) against the HDI of the states minus their mean for multiple years of the study ( $y$-axis). This plot shows a clear concentration of states in the first and third quadrants, confirming that states with above-average development levels since 1895 remain above average in subsequent periods, and those with below-average levels remain below average - an astonishing persistence in relative development among states. 


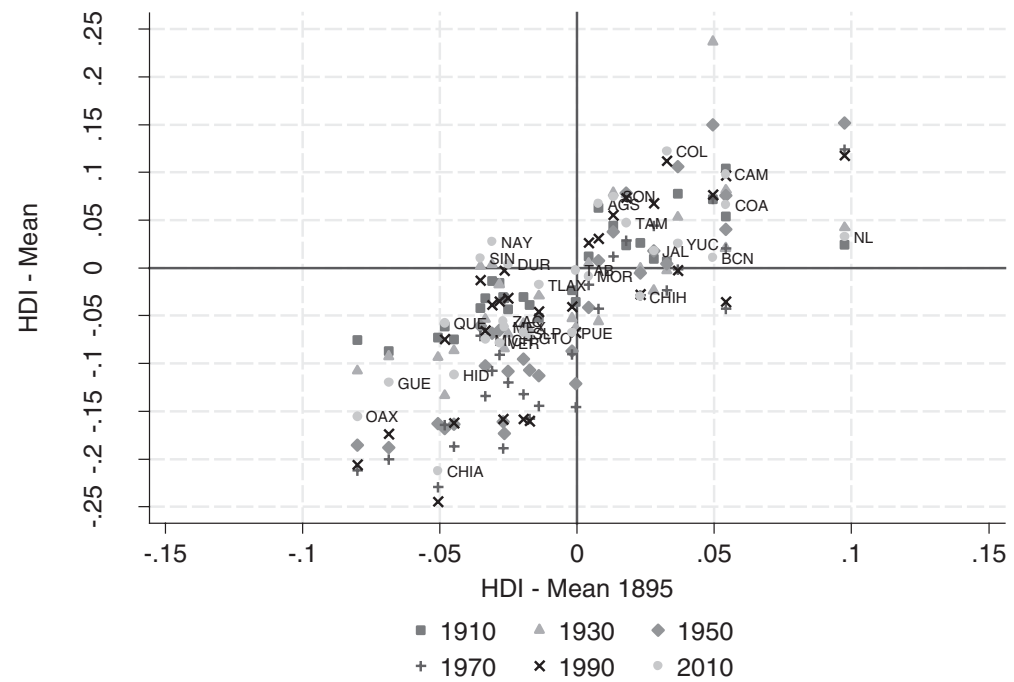

Fig. 7 HDI minus national mean by state, 1895-2010. Notes: Calculated by the authors. $Y$-axis refers to the difference between the HDI of each state and the mean HDI across states for each reference year. Figure does not include Mexico City. States are indicated as follows: AGSAguascalientes, BCN-Baja California, BCS-Baja California Sur, CAM-Campeche, COACoahuila, COL-Colima, CHIA-Chiapas, CHIH-Chihuahua, DUR-Durango, GTO-Guanajuato, GUE-Guerrero, HID-Hidalgo, JAL-Jalisco, MEX-Mexico State, MICH-Michoacán, MORMorelos, NAY-Nayarit, NL-Nuevo León, OAX-Oaxaca, PUE-Puebla, QUE-Querétaro, QROOQuintana Roo, SLP-San Luis Potosí, SIN-Sinaloa, SON-Sonora, TAB-Tabasco, TAM-Tamaulipas, TLAX-Tlaxcala, VER-Veracruz, YUC-Yucatán, ZAC-Zacatecas

Studies by Crafts $(1997,2002)$ and Prados de la Escosura (2010) comparing a sample of countries over time have found that the main determinant for increases in human development is health. Figure 8 shows the decompositions of the sources of growth in the HDI results per decade. ${ }^{23}$

The main determinant of human development until the 1920s is education (measured in literacy and enrollment rates), which contributes approximately $65 \%$. Next in importance from 1895 to 1910 is health (number of physicians), while for the postrevolutionary period it is income (urbanization). The 1930s began a trend of health (number of physicians) as the main contributor to growth in human development. The large expansion in the 1930s can be explained both by the major effort during the presidency of Lázaro Cárdenas to expand health coverage in the rural sector and by the expansion of the welfare state in the 1940s (Brachet-Márquez 2010). Health continued to be the largest contributor to human development after the 1930s (except in the

${ }^{23}$ We follow the decomposition formula as in Prados de la Escosura (2010), p. 18. The formula can be easily derived from taking the total differential to Eq. (1) in natural logarithm:

$$
\text { dlogHDI }=\left(\frac{1}{3}\right) \text { dlogHealth }+\left(\frac{1}{3}\right) \text { dlogEducation }+\left(\frac{1}{3}\right) \text { dlogIncome }
$$




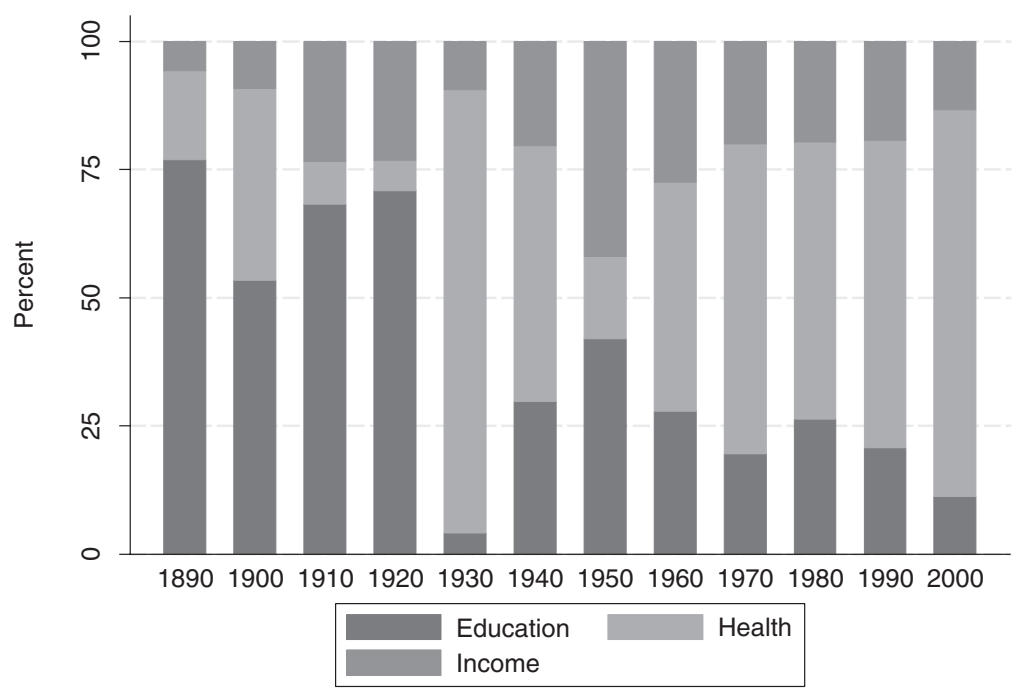

Fig. 8 Decomposition of HDI. Notes: Calculated by the authors. We follow the decomposition formula as in Prados de la Escosura (2010), p. 18. The formula can be easily derived by taking the total differential to Eq. (1) in natural logarithm:

dlogHDI $=\left(\frac{1}{3}\right)$ dlogHealth $+\left(\frac{1}{3}\right)$ dlogEducation $+\left(\frac{1}{3}\right)$ dlogIncome. The contribution of each index is thus calculated as each term in the previous formula over the change in the Q-HDI. The $\mathrm{x}$-axis refers to the contribution of each index for all decades. So we compare the growth rate and the contribution of each index between 1900 and 1910, 1910 and 1920, and so on. The initial year in the 1890 decade is 1895

1950s). On average, health contributes close to $55 \%$ of human development growth for the period 1930-2010. Prados de la Escosura (2010) finds that health contributes $52 \%$ worldwide to human development for the period 1870-2005. Mexico's development is thus relatively close to the international value for the period after 1930 .

\section{Conclusions}

In this chapter, we estimate a measure of long-run development in Mexico by calculating a human development index from 1895 to 2010 at subnational level. This is the longest homogenous series to date that tracks this phenomenon at the national and state levels. We discuss Mexico's well-being in terms of multidimensional characteristics, but we also focus on measurements at the subnational level in order to disentangle regional patterns.

We find that there is a significant increase in human development over the period studied. We identified absolute convergence in the HDI and each of its components with a trend of sharp convergence in the period 1940-1980. Our index begins at 0.13 in 1895 and ends at 0.70 in 2010, representing an acceleration rate of $1.45 \%$. 
For the period from 1895 to 1910, well-being grows at a rapid rate but slows down by the end of the period. For the revolutionary and postrevolutionary period (1910-1930), standards of living increase, although the increase is not homogenous across regions. The largest increases in human development are from 1940 to 1980. From 1950 onward, the gap across states decreases substantially, and after 1980, disparities increased again. Health contributes close to $65 \%$ of total growth before 1930, and $55 \%$ thereafter. These patterns of results are similar to those found by Prados de la Escosura (2010) in an international sample.

We also find a large persistence in regional development patterns across states. Northern states are wealthier than the rest from the beginning of the period, while southern states are the poorest. States surrounding Mexico City were as poor as southern states at the beginning of the century, but they developed more rapidly from 1940 to 1980 . The expansion of the welfare state thus failed to modify the spatial distribution of relative levels of well-being in the country.

In sum, this chapter makes an important contribution to the long-run measurement of well-being in Mexico. Future studies for other countries may take advantage of our methodology to analyze regional patterns, and deepen our understanding of the determinants of change in well-being across regions within countries.

Open Access This chapter is distributed under the terms of the Creative Commons Attribution 4.0 International License (http://creativecommons.org/licenses/by/4.0/), which permits use, duplication, adaptation, distribution and reproduction in any medium or format, as long as you give appropriate credit to the original author(s) and the source, a link is provided to the Creative Commons license and indicate if changes were made.

The images or other third party material in this chapter are included in the work's Creative Commons license, unless indicated otherwise in the credit line; if such material is not included in the work's Creative Commons license and the respective action is not permitted by statutory regulation, users will need to obtain permission from the license holder to duplicate, adapt or reproduce the material.

\section{References}

Acemoglu, D., Johnson, S., \& Robinson, J. A. (2002). Reversal of fortune: Geography and institutions in the making of the modern world income distribution. Quarterly Journal of Economics, 117(4), 1231-1294.

Aguilar Retureta, J. (2015). Regional income distribution in Mexico: New long-term evidence. Working paper E15/323, Universitat Barcelona Economics.

Astorga, P., Berges, A. R., \& Fitzgerald, V. (2005). The standard of living in Latin America during the twentieth century. Economic History Review, 58(4), 765-796.

Bairoch, P. (1975). The economic development of the third world since 1990 (C. Postan, Trans.). Berkeley: University of California Press.

Bairoch, P. (1988). Cities and economic development: From the dawn of history to the present. Chicago: University of Chicago Press.

Bértola, L., et al. (2010). Human development and inequality in the twentieth century: The mercosur countries in a comparative perspective. In R. Salvatore, J. H. Coatsworth, \& A. Challú 
(Eds.), Living standards in Latin American history: Height, welfare, and development, 1750 2000 (pp. 197-232). Cambridge, MA: Harvard University David Rockefeller Center for Latin American Studies.

Bortz, J., \& Águila, M. (2006). Earning a living: A history of real wage studies in twentiethcentury Mexico. Latin American Research Review, 41(2), 112-138.

Boyer, G. R. (2007). The convergence of living standards in the Atlantic economy, 1870-1930. In T. J. Hatton, K. O'Rourke, \& A. M. Taylor (Eds.), The new comparative economic history. Essays in honor of Jeffrey G. Williamson. Cambridge, MA: MIT Press.

Brachet-Márquez, V. (2010). Salud y Seguridad Social, 1917-2008: ¿Quién decide? In J. L. Méndez (Ed.), Los grandes problemas de México (Vol. 13, pp. 343-378). Mexico City: El Colegio de México.

Cali, M., \& Menon, C. (2013). Does urbanization affect rural poverty? Evidence from Indian districts. World Bank Economic Review, 27(2), 171-201.

Campos-Vazquez, R. M., \& Velez, R. (2012). Did population well-being improve during porfirian Mexico? A regional analysis using a quasi-human development index. Journal of Human Development and Capabilities, 13(4), 597-620.

Cárdenas, E. (2003). Cuándo se originó el atraso económico de México. La economía mexicana en el largo siglo XIX, 1780-1920. Madrid: Biblioteca Nueva.

Cárdenas, E. (2010). La economía en el dilatado siglo XX, 1929-2009. In S. K. Ficker (Ed.), Historia económica general de México: de la colonia a nuestros días (pp. 503-548). Mexico City: El Colegio de México.

Challú, A. E., \& Galvarriato, A. G. (2015). Mexico's real wages in the age of the great divergence, 1730-1930. Revista de Historia Económica, 33, 83-122.

Coatsworth, J. H. (1978). Obstacles to economic growth in nineteenth-century Mexico. American Historical Review, 83(1), 80-100.

Colegio de México. (1964). Estadísticas económicas del Porfiriato: Fuerza de trabajo y actividad económica por sectores. Mexico City: El Colegio de México.

Crafts, N. (1997). The human development index and changes in standards of living: Some historical comparisons. European Review of Economic History, 1(3), 299-322.

Crafts, N. (2002). The human development index, 1870-1999: Some revised estimates. European Review of Economic History, 6(3), 395-405.

Esquivel, G. (1999). Convergencia regional en México, 1940-1995. El Trimestre Económico, 66(4), 725-761.

Esquivel, G., López-Calva, L. F., \& Velez, R. (2003). Crecimiento Económico, Desarrollo Humano y Desigualdad Regional en México 1950-2000. Estudios Sobre Desarrollo Humano. PNUD México, 32, 2003-03.

Fierro, C., Tapia, G., \& Rojo, F. (2009). Descentralización educativa en México: Un recuento analítico. OECD working paper. Retrieved from http://www.oecd.org/mexico/44906363.pdf

Frenk, J. L., et al. (1995). Los médicos en México, 1970-1990. Salud Pública de México, 37(1), 19-30.

García-Verdú, R. (2005). El índice de desarrollo humano y su aplicación a las entidades federativas en México. Gaceta de economía, 10(20), 5-29.

Haber, S., Klein, H. S., Maurer, N., \& Middlebrook, K. J. (2008). Mexico since 1980. Cambridge and New York: Cambridge University Press.

Huerta Maldonado, M. (1960). El nivel de vida en México. Revista Mexicana de Sociología, 22(2), 463-527.

INEGI (Instituto Nacional de Estadística y Geografía). (2004). Anuario de estadísticas por entidad federativa 2003. Aguascalientes, Mexico: INEGI.

INEGI (Instituto Nacional de Estadística y Geografía). (2009). Anuario de estadísticas por entidad federativa 2008. Aguascalientes, Mexico: INEGI.

INEGI (Instituto Nacional de Estadística y Geografía). (2010a). Censo General de Población y Vivienda 2010. Aguascalientes, Mexico: INEGI.

INEGI (Instituto Nacional de Estadística y Geografía). (2010b). Estadísticas históricas de México 2009. Aguascalientes, Mexico: INEGI. 
INEGI (Instituto Nacional de Estadística y Geografía). (2011). Anuario de estadísticas por entidad federativa 2010. Aguascalientes, Mexico: INEGI.

Klugman, J., Rodríguez, F., \& Choi, H.-J. (2011). The HDI 2010: New controversies, old critiques. United Nations Development Programme, Human Development Research Paper 2011/01.

Komlos, J. (Ed.). (1994). Statures, living standards and economic development. Chicago: University of Chicago Press.

López-Alonso, M. (2007). Growth with inequality: Living standards in Mexico, 1850-1950. Journal of Latin American Studies, 39(1), 81-105.

López-Alonso, M. (2012). Measuring up: A history of living standards in Mexico, 1850-1950. Palo Alto: Stanford University Press.

Loyo, E. (2010). La educación del pueblo. In Historia Mínima de la Educación en México (coordinated by D. Tanck de Estrada, pp. 154-187). Mexico City: El Colegio de México.

Márquez, G. (2012). Growth and living standards: Evidence from post-revolutionary Mexico. Paper presented at the 16th World Economic History Congress, Stellenbosch, South Africa, 9-13 July 2012.

Márquez, G. (2013). En torno a la depresión del siglo XIX. Las aristas del debate. Unpublished manuscript, El Colegio de México.

Márquez, G., \& Meyer, L. (2010). Del autoritarismo agotado a la democracia frágil, 1985-2010. In Nueva Historia General de México (coordinated by B. García Martínez, pp. 747-792). Mexico City: El Colegio de México.

Mendizábal Othón de, M. (1947). Distribución geográfica de los médicos en la República Mexicana. In Obras Completas (Vol. 6, pp. 529-541). Mexico City: Talleres Gráficos de la Nación.

Minnesota Population Center. (2011). Integrated Public Use Microdata Series (International: Version 6.1) [Machine-readable database]. Minneapolis: University of Minnesota, 2011.

Moomaw, R. L., \& Shatter, A. M. (1996). Urbanization and economic development: A bias toward large cities? Journal of Urban Economics, 40(1), 13-37.

Moreno-Brid, J. C., \& Ros, J. (2009). Development and growth in the Mexican economy. Oxford: Oxford University Press.

Morris, I. (2013). The measure of civilization: How social development decides the fates of nations. Princeton: Princeton University Press.

Myers, C. N. (1971). Proyección de la demanda de médicos en México: 1965-1980. Demografía y Economía, 5(2), 193-227.

Nunn, N., \& Qian, N. (2011). The Potato's contribution to population and urbanization: Evidence from a historical experiment. Quarterly Journal of Economics, 126(2), 593-650.

Permanyer, I. (2013). Using census data to explore the spatial distribution of human development. World Development, 46, 1-13.

Piérard, E. (2009). The effect of physician supply on health status as measured in the NPHS. Working Paper No. 901, Department of Economics, University of Waterloo. Retrieved from http://ideas.repec.org/p/wat/wpaper/0901.html.

PNUD (Programa de las Naciones Unidas para el Desarrollo). (2003). Informe sobre Desarrollo Humano México 2002. Mexico City: Ediciones Mundi-Prensa.

PNUD (Programa de las Naciones Unidas para el Desarrollo). (2012). El índice de desarrollo humano: Cambios metodológicos e información para las entidades federativas. Mexico City: Offset Santiago.

Prados de la Escosura, L. (2010). Improving human development: A long-run view. Journal of Economic Surveys, 24(5), 841-894.

Robst, J., \& Graham, G. (1997). Access to health care and current health status: Do physicians matter? Applied Economic Letters, 4, 45-48.

Robst, J., \& Graham, G. (2004). The relationship between the supply of primary care physicians and measurements of health. Eastern Economic Journal, 30(3), 467-486.

Sánchez Santiró, E. (2009). El desempeño de la economía mexicana tras la independencia, 18211870: nuevas evidencias e interpretaciones. In Latinoamerica y España, 1800-1850. Un crecimiento nada excepcional (coordinated by E. Llopis \& C. Marichal (Eds.), Madrid: Marcial Pons Historia/Instituto Mora 
Secretaría de Economía. (1956). Estadísticas sociales del porfiriato 1877-1910. Mexico City: Talleres Gráficos de la Nación.

Shi, L. (1992). The relationship between primary care and life chances. Journal of Health Care for the Poor and Underserved, 3, 321-335.

Shi, L. (1994). Primary care, specialty care and life chances. International Journal of Health Services, 24(3), 431-458.

Tabellini, G. (2010). Culture and institutions: Economic development in the regions of Europe. Journal of the European Economic Association, 8(4), 677-716.

UNDP (United Nations Development Programme). (1990). Human development report 1990. New York: Oxford University Press.

UNDP (United Nations Development Programme). (2010). Human development report 2010. New York: Palgrave Macmillan.

Vogel, R. L., \& Ackermann, R. J. (1998). Is primary care physician supply correlated with health outcomes? International Journal of Health Services, 28(1), 183-196.

Raymundo M. Campos Vázquez is a research professor at the Center for Economic Studies in El Colegio de México. He holds a Ph.D. in Economics from the University of California, Berkeley, a Master's in Economics from El Colegio de Mexico, and a B.A. in Economics from Tecnológico de Monterrey. His research fields are labor economics, development economics, and econometrics.

Cristóbal Domínguez obtained his Master's in Economics at El Colegio de Mexico and his B.A. in Economics at Tecnológico de Monterrey. His fields of research are economic history and social mobility.

Graciela Márquez holds a Ph.D. in History from Harvard University. Since 2003, she is a research professor at the Center for Historical Studies in El Colegio de Mexico. Her areas of interest are fiscal history of Mexico, history of trade policy, and the reconstruction of the GDP series. Her recent publications include "Claves para la Historia Económica de México" (Fondo de Cultura Económica 2014). 


\title{
Inequality, Institutions, and Long-Term Development: A Perspective from Brazilian Regions
}

\author{
Pedro Paulo Pereira Funari
}

\section{Introduction}

Inequality is a subject of intrinsic interest, in the sense that it is related to moral concepts such as justice and fairness. ${ }^{1}$ Notwithstanding, it is also important for its effects, for example, on the growth and educational attainments of a society. Ironically, it is one of the most hotly debated subjects within growth and development economics literature and one which is far from reaching a consensus.

A first wave of development literature (as characterized by Easterly 2007, p. 756) presents the idea that high inequality could promote growth by concentrating income in the hands of high-saving capitalists (Kuznets 1955; Kaldor 1956). As presented in Aghion et al. (1999b), the view that wealth inequality could be growth enhancing is based on three arguments: (1) the marginal propensity to save of the rich is higher than that of the poor; (2) investment indivisibilities; and (3) the trade-off between productive efficiency and equality. However, later works indicate a possible negative effect of economic inequality on growth, both theoretically and empirically. ${ }^{2}$ Several mechanisms were suggested as causes of this, such as political economy mechanisms (Alesina and Rodrik 1994; Persson and Tabellini 1994), imperfect capital markets (Banerjee and Newman 1991; Galor and Zeira 1993; Perotti 1992) and investment in human capital (Bourguignon and Verdier 2000; Galor et al. 2009; Galor and Zeira 1993; Perotti 1996), the composition of the aggregate demand (Murphy et al. 1989), and macroeconomic instability (Aghion et al. 1999a). ${ }^{3}$

\footnotetext{
${ }^{1}$ These concepts and interrelations are investigated since the birth of philosophy in Ancient Greece. See the works of Plato (e.g., The Republic) and his disciple Aristotle (e.g., Politics).

${ }^{2}$ For comprehensive reviews, see Aghion (1999b) and Bénabou (1996).

${ }^{3}$ For the effects of redistribution on growth, see Easterly and Rebelo (1993), Perotti (1996), and Aghion (1999b).

P.P.P. Funari $(\bowtie)$

University of California, Davis
} 
Three important studies followed, casting doubt on the robustness of what were then considered consistent results, and finding no negative relationship between economic inequality and growth. Using new data and panel techniques, Forbes (2000) finds a positive relationship between economic inequality and growth. Barro (2000) and Banerjee and Duflo (2003) also present evidence against such a clear-cut negative relationship. However, Easterly (2007), using an insightful instrument, finds again a negative relationship between inequality and economic performance.

There are also important studies correlating political inequality and development. Acemoglu (2008) shows how political inequality may retard development due to the unwillingness of incumbent elites to allow the entry of new agents. Elites might also block the introduction of new technologies (Acemoglu and Robinson 2000). Bates (1981) shows how, in a politically concentrated environment, there might be little interest in the provision of public goods, including schooling. As noted by Acemoglu et al. (2008), political inequality will also tend to be associated with the absence of political competition and accountability, two factors that help to guarantee that political systems generate desirable outcomes.

Even more important for the present work are Engerman and Sokoloff's comprehensive series of studies on development of the Americas. Engerman and Sokoloff (1997, 2002) argued that factor endowments had a major influence on the colonization strategies throughout the American continent that, in turn, established different initial levels of inequality that account for the divergent institutional paths of American societies that resulted in the differential development standards of these regions today. Therefore, in Engerman and Sokoloff's view, inequality had prejudicial effects on development in a cross-country framework. ${ }^{4}$

It is to this context of apparently contradictory evidence that Acemoglu et al.'s (2008) study belongs. Their study distinguishes empirically between economic and political inequality in their exploration of the effects of inequality. As the authors correctly note, economic inequality is probably endogenous in regressions without a political inequality variable, since we expect them to be linked, and this might bias the econometric evidence on the effects of economic inequality. The authors not only construct different variables for economic inequality (the land Gini) and political inequality (a political concentration index) but also deal with a constant de jure institutional environment, the region of Cundinamarca in Colombia, which, according to Pande and Udry (2005), might provide deeper insights into the specific channels through which inequality affects development.

\footnotetext{
${ }^{4}$ Two brief comments on Engerman and Sokoloff's thesis: (i) Theories presented by North et al. (2000), which emphasize the importance of metropolitan objectives in contrast to local conditions, and Frankema (2010), which supports the role of precolonial institutions, are likely complementary to the one by Engerman and Sokoloff (for a review of these theories, see Frankema 2009, Chap. 3); and (ii) we believe that the validity of Engerman and Sokoloff's theory is in a crosscountry framework, and, therefore, studies such as those by Nunn (2008), Acemoglu et al. (2008), and Dell (2010) do not necessarily oppose their views. Moreover, as shown by Nugent and Robinson (2010), there can be heterogeneities with Latin America.
} 
The authors present intriguing evidence. Overall, they find a negative relationship between economic and political inequality for nineteenth-century Colombia and a positive association between economic inequality in the nineteenth century and development outcomes in the late twentieth century. These results are unexpected, as it is generally expected for Latin American countries to have high inequality, both economic and political, and that they are positively correlated (mutually reinforcing each other). The interpretation of the authors, based on Bates' (1981) insights on Africa, is that in "weakly institutionalized" societies, where few constraints were imposed on the actions politicians could take, large landowners had the power to keep in check the rapacious tendencies of these politicians. ${ }^{5}$

We provide a similar investigation for the complex case of Brazil. With unique data from the beginning of the twentieth century - the Brazilian Economic and Demographic Census of 1920 - we were able to construct from scratch unique indicators of economic inequality (the land Gini coefficient among landowners) and of political inequality (the proportion of individuals that were eligible to vote) at the municipal level in selected Brazilian states. However, we not only analyze how inequality (both economic and political) is related to long-term development, but we also go further into analyzing how inequality is related to long-term development within different de facto institutional environments while controlling for a constant de jure context (in line with Pande and Udry's reorientation argument).

Therefore, we are able to integrate both the inequality literature and the recent institutional literature (see, e.g., Acemoglu et al. 2001, 2002; Pande and Udry 2005; Banerjee and Iyer 2005). ${ }^{6}$ We calculate the respective inequality indicators for all the municipalities in four Brazilian states: Minas Gerais, São Paulo, Pernambuco, and Rio Grande do Sul. The states were carefully selected in order to capture how inequality is related to long-term development in different de facto institutional environments greatly influenced by the unique colonial experiences of these regions. Our analysis presents evidence of a heterogeneous relationship between inequality and long-term development indicators, broadly consistent with the colonial experiences of the states considered, likely a reflection of different de facto institutional environments.

Furthermore, our study intersects with an important recent literature on the Brazilian case. Naritomi et al. (2012) present evidence that colonial experiences indeed shaped different de facto institutional environments within the country. Summerhill (2010), exploring the state of São Paulo, does not find a negative effect of land inequality on long-term development. ${ }^{7}$ Moreover, and in line with our results, the author does not find a significant relationship between political inequality measured by the extent of the franchise and long-term economic growth. In a statelevel analysis, Wegenast (2010) argues that Brazil's different agrarian structures determined, in the long run, the educational outputs. His analysis suggests that in

\footnotetext{
${ }^{5}$ The concept of "weakly institutionalized societies" is developed in Acemoglu et al. (2004).

${ }^{6}$ For a more systematic approach and review of the institutional literature, see Acemoglu et al. (2005).

${ }^{7}$ De Carvalho Filho and Colistete (2010), examining the same state of São Paulo at the beginning of the twentieth century, find a negative correlation between land concentration and supply of public education at that time.
} 
states with higher land concentration, there were fewer incentives to invest in education. Moreover, for the Latin American context, Dell (2010), investigating the negative effects of the mita, suggests that land concentration would have been a beneficial factor, for it is hypothesized that the long-term presence of large-scale landowners in non-mita districts provided a stable land tenure system that encouraged public goods provision.

The chapter is organized as follows. In the next section, we explore the Brazilian development process from a historical perspective. We then proceed to the data analysis. Next, we present the econometric results. The last section concludes.

\section{The Brazilian Context}

\subsection{Some History}

Brazil was first claimed by modern Europeans in 1500. The interest of Crown and settlers would soon turn to the production of sugar, which became the colony's first major export. International prices were high and the supply, especially from Sicily, Atlantic islands such as Cape Verde and Madeira, and the East, was low and restricted. At the time, the main production centers were in Pernambuco and in Bahia. Brazil was the biggest sugar producer in the world until mid-seventeenth century - the heyday of the sugar enterprise in Brazil-when competition from Central American colonies and the Antilles became stronger (Prado Jr. 1956 [1945]). ${ }^{8}$

As expected, geographical characteristics were determinant for the success of this enterprise. Moreover, although there was no general overall plan for the sugar enterprise, potential problems were largely avoided thanks to favorable circumstances. Production techniques, the creation and expansion of a consumer market, and financing were largely dealt with by the Dutch, who practically controlled the so-called Portuguese enterprise. Due to economies of scale, production was based on large land properties with a single owner, called latifúndios, characterized mainly by monoculture and slave labor. Prado Jr. (1956 [1945]) notes the absence of complex methods of production in colonial Brazil, both in terms of space and time, or even significant improvement in methods. Production expansion was based on the extension of land under cultivation and on slave population growth rather than on changes in the production process and increased productivity. ${ }^{9}$

\footnotetext{
${ }^{8}$ The competition from the Antilles was a direct consequence of the Dutch experience with the sugar industry in Brazilian lands before their expulsion in 1654. After learning the technical and organizational aspects, they were able to implement a similar structure in the Caribbean territories and generate higher profits (Furtado 2006 [1959]).

${ }^{9}$ According to Prado Jr., Brazil's development problems are a direct consequence of the dependence of the colony on exports of primary products produced in large properties with slave labor. However, Villela (2013) argues that none of these elements can explain for themselves Brazil's lack of growth at the time, the lack of efficiency gains being the fundamental problem.
} 
Furtado (2006 [1959]) argues that the high profitability of an economy with a high import coefficient tends to hinder investments in secondary activities, such as food production. The intense specialization of the sugar economy would be then associated with its high profitability (Furtado 2006 [1959], p. 93). As a result, cattle raising shifted to the countryside of the Northeastern region. This activity was radically different from the sugar industry, occupying extensive areas of land, and the impact of the dry seasons was reflected in the absence of permanent occupation. Not only was there no need for large initial capital investments, but also the large amount of land available hindered productivity increases.

In the early seventeenth century, sugar exports began to decline, mainly due to increasing competition from British, Dutch, and French colonies. Prices continued to fall throughout the eighteenth century. With the decline of the sugar industry, income fell also in the cattle farming sector, which then became mostly a subsistence activity, allowing a continued growth of the population since the activity could be easily expanded due to the availability of land. The growth of the share of the cattle farming sector in relation to the sugar industry brought with it a decline in the region's average per capita productivity and income.

The problem was that the accelerated growth of the sugar enterprise had no structural counterpart. The economic system, under which almost all the net income generated stayed with the large landowners, often resorted to importing luxury goods, slaves, or machines for that same sugar industry, and underwent no significant change during this period. Therefore, the whole enterprise depended heavily on the external market. With the continued fall in prices and the increased opportunity costs due to the emergence of the mining regions, the sugar economy entered a "secular lethargy" (Furtado 2006 [1959], p. 91) that endured until the nineteenth century.

At the same time, economic enterprises in the Northeast did not completely stagnate with the decline of sugar production. The second half of the eighteenth century saw a rise in international demand for other agricultural products, particularly cotton, due mainly to the Industrial Revolution. The rural parts of the state of Pernambuco, being drier and, therefore, more suitable for the production of cotton rather than cattle raising, would also benefit.

During most of the sixteenth and seventeenth centuries, the southern part of the colony was relatively free of direct intervention from the Crown. With the main economic interest focused on sugar production, settlers in those other regions lived at the margin of the colonial enterprise. Soon after the fall of sugar prices after 1650 , this geopolitical structure changed. In the last years of the seventeenth century, gold and other precious metals were discovered in the countryside of the Portuguese territory, especially in Minas Gerais. By the mid-eighteenth century, gold mining had reached its greatest land extent and highest levels of production. For almost a century (1675-1765) gold mining would be the focus of the attentions of the Crown (Prado Jr. 1956 [1945]). Migrants arrived from different parts of the country and new towns sprang up in the mining districts. Along with the shift of the colony's economic center from the Northeast to the Southeast, there was also shift in the political center. As a consequence, Rio de Janeiro replaced Salvador (Bahia) as the capital of the colony in 1763 . 
Although mining also made use of slave labor, the social structure was less rigid than in the sugar-producing areas. Slaves were never the majority among the population. Gold mining led to greater social inclusion, for it was not necessary to have important amounts of initial capital. Possibilities were greater even for slaves, who could often work for themselves and buy their freedom. Therefore, although the average income in the gold economy was inferior to the average income at the apogee of the sugar economy (Furtado 2006 [1959]), income was more broadly distributed and the percentage of free people was higher. This influx of wealth led the Portuguese Crown to rapidly establish a bureaucratic apparatus to avoid tax evasion. ${ }^{10}$ The heyday of the Brazilian gold rush was in the $1750 \mathrm{~s}$, when exports reached 2.5 million British pounds (Furtado 2006 [1959]). ${ }^{11}$

However, the decline of the Brazilian gold rush came soon, due to its geographical characteristics (alluvial), inferior extraction techniques, and a bureaucracy incapable of providing sustainable incentives to the enterprise. Denis (1911, p. 61) notes: "As the surface of the alluvial workings became exhausted by wasteful methods, a great part of the population was gradually absorbed by agriculture and stockraising. (...) During the nineteenth century the mining activities of Minas were not very notable: although it was discovered that the alluvial deposits had been merely scratched on the surface." With the decline of the gold cycle and the persistent low international prices for sugar, the last years of the eighteenth century were characterized by economic difficulties in the colony. All in all, "the latifundium, slavery, and the export trade remained, as the historian Caio Prado Jr. has said, for more than 300 years the principal institutions of Brazilian society" (Dean 1971, p. 607).

Early in the nineteenth century, a major political event changed the development path followed by the colony. In 1808, by order of Prince Regent Dom João, fleeing from Napoleon's troops, the Portuguese royal family is transferred to Brazilian lands. ${ }^{12}$ In 1822, in a country with approximately 3.9 million inhabitants (of which 1.2 million approximately were slaves), Dom Pedro - son of Dom João (who was then in Portugal), the colony's regent at the time-declared independence and was proclaimed Constitutional Emperor, remaining in power until 1831. After a regency period (1831-1840) characterized by great social instability, his son, Dom Pedro II,

\footnotetext{
${ }^{10}$ Examples of important administrative controls by the Portuguese Crown are the payment of onefifth of the production (and their careful supervision through all stages of the mining activity), prohibition on individual negotiations, establishment of special trading monopolies, and tight control on local manufacturing.

${ }^{11}$ In 1780 the value of gold exports was less than one million British pounds (Furtado 2006 [1959]).

${ }^{12}$ According to Prado Jr. (1956 [1945]) this was effectively the end of the colonial period for Brazil. New economic measures were soon adopted. The first and probably the most important measure was a manifesto declaring that all Brazilian ports should be considered open to trade with the entire world, and that goods might be exported under any flag. At the same time, royal monopolies were abolished and import duties reduced, laws prohibiting the establishment of industries were repealed, a national press was established (Denis 1911), and new educational and financial institutions (such as the first Banco do Brasil, in 1808) were established as well.
} 
became the new emperor in 1840. Finally, in 1889 the Republic was proclaimed and 1891 saw the implementation of a new constitution.

Notwithstanding the government's intention of dealing with land concentration under the Empire, efforts would eventually fail, largely because the political system was dominated by a landed elite (Dean 1971). Furthermore, the positive effects on prices of the events at the end of the eighteen century and beginning of the nineteenth century were due to a confluence of particular circumstances. ${ }^{13}$ Once international markets returned to normal conditions, a new phase of difficulties began for the colony: conflicts with England, on which newly independent Brazil had become dependent, mainly due to the unilateral application of the liberal economy by the former (Furtado 2006 [1959]) and worries with the end of the slave trade, the scarcity of the government's financial resources, and the increasing dissatisfaction in practically every region led to a series of social rebellions. In the midst of these difficulties, a new source of wealth would emerge: coffee, which led to a new period of economic affluence in the country. ${ }^{14}$

Like Minas Gerais, the region that corresponds to what is today the state of São Paulo was only of marginal economic importance during the first centuries of colonization. Although São Paulo was not completely outside the great sugar enterprise, it was coffee that made the region especially important. Coffee was introduced into the country in 1727 and large-scale production started at the end of the eighteenth century. ${ }^{15}$ However, it was at the beginning of the nineteenth century that Brazilian production became significant in international terms. ${ }^{16}$

It is around this time that the labor question became delicate. With the abolition of slavery it became clear that the country's best option was to import foreign workers. After initial problematic experiences and with government's generous intervention, it was possible, for the first time in the country's history, to attract a massive influx of European migrants. ${ }^{17}$ The average numbers of non-slave immigration grew steadily from the 1860 s to the end of the century. ${ }^{18}$

\footnotetext{
${ }^{13}$ Important international events were beneficial for a colony whose main activity was the export of primary products: the Industrial Revolution, the American War (1775-1783), the French Revolution (1789-1799), the Napoleonic Wars (1803-1815), and the upheaval in many of the Spanish colonies had a significant impact on the supply and, therefore, prices of primary goods in which Brazil had an idle production capacity, such as sugar, cotton, and leather.

${ }^{14}$ According to Goldsmith (1986), we have the following figures for the average growth in GDP per capita: $1850-1860$ : 1.4\%; 1860-1870: $1.0 \% ; 1870-1880:-0.2 \% ; 1880-1890: 0.4 \% ; 1890-1900$ : $-1.7 \%$. For a different view, see Leff (1997).

${ }^{15}$ The USA was the main market for the Brazilian product (Prado Jr. 1956 [1945]).

${ }^{16}$ Figures provided by Furtado (2006 [1959]) show that the production was of 3.7 and 5.5 million sacks in the periods $1880-1881$ and 1890-1891, respectively, rising to 16.3 million between 1901 and 1902 (one sack was equivalent to $60 \mathrm{~kg}$ ).

${ }^{17}$ For example, after several charges of abuse, Germany prohibited emigration to Brazil in 1859.

${ }^{18}$ The figures for the annual average numbers of immigrants, by decade, are 1860-1869: 9850; 1870-1879: 20,780; 1880-1889: 47,890; 1890-1899:118,170; and 1900-1909: 66,651 (Leff 1972).
} 
As we have seen, the last years of the nineteenth century were extremely favorable for the production of coffee in the Brazilian lands, especially in Rio de Janeiro, São Paulo, and Minas Gerais regions. Not only were internal conditions conducive towards increasing production, but there was also the auspicious external circumstances of supply shortages. ${ }^{19}$ However, considering the inelasticity of international demand and the large availability of lands and relative production advantages, it was inevitable that the coffee supply would continue to increase, with a consequent decline in prices. The response of the coffee planters and the government (tightly connected) to these adverse prospects was to implement valorization programs that consisted in buying and storing the excess coffee so as to control international prices. ${ }^{20}$ However, this mechanism for protecting the coffee economy was only "a process that transferred, to the future, the solution of a problem that would only become more and more serious" (Furtado 2006 [1959], p. 256). The policy was relatively successful until the 1920s, when the Great Depression brought Brazil into a new era of difficulties and political disruption.

Rio Grande do Sul would only become economically relevant in the second half of the eighteenth century. The region's economy would be based on cattle farming. According to Prado Jr. (1956 [1945]), the cattle would reproduce rapidly due to the favorable natural environment, providing the region with the greatest concentration of cattle in the colony. Production of derivatives such as dairy products and leather was also of considerable importance. Agriculture would be developed only in a small sector near the coast (Prado Jr. 1956 [1945]). Initially, similar to the country side of the Northeast region, cattle farming developed as an extensive activity. Leather exports helped to maintain what was then a low-profitability activity afloat. It was only with the already mentioned discovery of gold that the activity faced a "true revolution," being finally integrated with the rest of the colony (Furtado 2006 [1959], p. 121).

Following Prado Jr. (1956 [1945]) and Engerman and Sokoloff (1997, 2002), we can say that a different colonization method was structured. Variations in geographic characteristics such as climate and soil meant that the lands that today form the state of Rio Grande do Sul were not suited for the production of tropical products such as sugar. In order to protect the region from possible competitors such as Spain, the solution was to establish a settlement strategy similar to the one in the USA and Canada. Recruitment was made among poor and middle-class Portuguese families and peasants and considerable advantages were offered to those willing to emigrate (Prado Jr. 1956 [1945]).

Thus, the settlement of the South region of the country, especially Rio Grande do Sul, was unlike any others in Brazilian colonization. Land was more equally divided, slave labor was used in much smaller scale, and the population was rather homogeneous (Prado Jr. 1956 [1945]).

\footnotetext{
${ }^{19}$ Supply constraints in the main production centers, such as the Portuguese Ceylon-present-day Sri Lanka-encouraged the Brazilian production.

${ }^{20}$ Brazil had practically a monopoly on coffee production, being responsible, at its height, for producing more than three-quarters of the international supply (Furtado 2006 [1959]).
} 


\subsection{Political Aspects}

In terms of political participation, Love (1970) states that the end of the Empire and the establishment of the Republic (1889) saw a democratization of the formal political process at three levels. The first is that the number of elective positions at all levels of government was increased (governors and the president and vice president of the Republic were now to be elected). Second, suffrage was expanded compared to the Empire. Under the first republican Constitution on 1891, all literate males 21 and older could vote. Finally, authority was decentralized.

There is some divergence between Love's (1970) and Leal's (2012 [1948]) views. Probably the reality was closer to Leal's explicit exposition, which notes the great fragility and dependence of the municipal administration, despite some increase in revenues noted by Love (1970). As we will see in greater detail later, the introduction of these liberal constitutional mechanisms of government, broader suffrage, and decentralization did not result in the type of de facto political structure that the members of the 1890-1891 constituent assembly had envisaged (Love 1970).

A central aspect of the Brazilian history for our study is the coronelismo, one of the most important characteristics of the First Republic (1889-1930). Leal (2012 [1948]) defines it as the result of a combination of the representative system of the time and an inadequate social and economic structure. In other words, coronelismo is a peculiar manifestation of the private sector, an adaptation through which residual elements of old and excessive private power have managed to coexist in a political regime of (theoretically) broad representation. It is a commitment between the public sector, progressively strengthened, and the decadent influence of the local chiefs, mainly the landowners (Leal 2012 [1948]). "Without the requisite social and economic structures, universal suffrage could either produce long-term political stability or strengthen traditional conservative elements against liberal reforms" (Love 1970, p. 4), and in the Brazilian case during the First Republic, "the official liberal ideology, on which the Constitution of 1891 was based, had outpaced the social and economic evolution of the country" (Love 1970, p. 10).

According to Leal (2012 [1948]), these manifestations of private sector power, especially in rural areas, are due to the agrarian structure of the country, characterized mainly by strongly concentrated land ownership. ${ }^{21}$ The vast distances and empty areas within the territory, as well as the scarcity of people, greatly influenced the situation (Carvalho 1946). Therefore, the public sector commitment is explained by the sufficiently broad franchise that makes the government dependent on the rural electorate. The essence of this commitment is that local chiefs provide unconditional

\footnotetext{
${ }^{21}$ According to Love (1970), the nation remained $90 \%$ rural in the early years of the Republic. Furthermore, Love (1970) argues that the critical role played by urbanization is based on three main points: (i) Brazilian rural society, owing to its historical roots, has a much stronger patriarchal tradition than its urban counterpart, and for this reason the rural vote was easier to control; (ii) the rural sector offered more opportunity for manipulation of the vote through fraud and violence, because the state and its mechanisms for guaranteeing free suffrage were less effective in the countryside; and (iii) the access of the urban population to greater opportunities for education meant that a large percentage of urban dwellers would vote than their rural counterpart.
} 
support to the "official" candidates in state and federal elections, and in return, the states give the local chiefs a free hand in almost all issues that concern the municipality, including the appointment of state positions at local level (Leal 2012 [1948]).

In an agrarian society with high land concentration, where the public sphere was largely absent in rural areas, the coronel was often responsible for improving local conditions, especially in terms of the provision of public goods and services: schools, roads, railroads, churches, and hospitals among others. It was, therefore, mostly with such improvements (some of which depend only on his political prestige while others might demand personal contributions or contributions from friends) that the municipal chief built and maintained his leadership position (Leal 2012 [1948]).

Leal's (2012 [1948]) analysis stressed the importance of the reciprocity in the system. On the one side, the municipal chiefs and the coronéis who decided the choices of many voters and, on the other, the politically dominant situation in the state controlled the budget, the jobs, the favors, and the police force. The weakness of the municipalities was therefore a deciding factor in maintaining the coronelismo.

Just as coronelismo ruled relations between municipalities and states, the politica dos governadores ("governors' policy") ruled relations between the states and the federal government. ${ }^{22}$ Leal (2012 [1948]) shows clearly the contradiction in the system: by arguing that there should be constraints placed on the powers of the municipalities to avoid rule by local oligarchies, legislation gave the governors of the states every means for encouraging the very same local oligarchies, albeit to their benefit, creating state oligarchies and the consequent politica dos governadores. ${ }^{23}$ Both the commitment between the governors and the coronéis and the one between the president and the governors were based on the inconsistency of the rural electorate, a direct consequence of the type of agrarian structure dominant in the country.

\section{The Data ${ }^{24}$}

\subsection{The Census of 1920}

The Census of 1920 is the fourth population census and the first agricultural and industrial census to have been conducted in Brazil. In accordance with the International Statistical Congress, which took place in Belgium in 1853, the purpose

\footnotetext{
${ }^{22}$ It was a "system in which the president assured the governors of the states that their parties would always win elections in their respective jurisdictions in exchange for support of presidential policies in congress (which favored export agriculture) and electoral support of the president's successor" (Love 1970, p. 9).

${ }^{23}$ The politics of the coronéis led to the strengthening of the state power in a much more effective way than the politica dos governadores guaranteed the reinforcement of the federal power, especially in terms of the different possibilities of the use of violence (Leal 2012 [1948]).

${ }^{24}$ As we can see from Table 2, the number of municipalities has increased considerably between 1920 and 2000. In order to assess the effects of inequality on development in the long term, we had to match the municipalities in 2000 (2150 municipalities) to their counterpart in 1920 (512 municipalities). The construction of the comparable territorial units (CTU) was done manually using the reports of IBGE of each municipality's origin. Table 2 presents the number of CTU for each state.
} 
Table 1 Brazilian agricultural statistics, 1920

\begin{tabular}{l|l|l|r|c}
\hline $\begin{array}{l}\text { Extension of the rural } \\
\text { properties (ha) }\end{array}$ & $\begin{array}{l}\text { Number of rural } \\
\text { properties }\end{array}$ & $\begin{array}{l}\text { Percentage to } \\
\text { total }(\%)\end{array}$ & Area (ha) & $\begin{array}{l}\text { Percentage } \\
\text { to total }(\%)\end{array}$ \\
\hline Smaller than 41 & 317,785 & 49.0 & $6,115,158$ & 3.5 \\
\hline $41-100$ & 146,094 & 22.5 & $9,593,156$ & 5.5 \\
\hline $101-200$ & 71,377 & 11.0 & $10,454,242$ & 6.0 \\
\hline $201-400$ & 48,877 & 7.6 & $14,079,761$ & 8.0 \\
\hline $401-1000$ & 37,705 & 5.8 & $23,881,734$ & 13.6 \\
\hline $1001-2000$ & 13,186 & 2.0 & $18,891,552$ & 10.8 \\
\hline $2001-5000$ & 8963 & 1.4 & $28,667,844$ & 16.4 \\
\hline $5001-10,000$ & 2498 & 0.4 & $17,928,532$ & 10.2 \\
\hline $10,001-25,000$ & 1207 & 0.2 & $18,256,042$ & 10.4 \\
\hline Bigger than 25,000 & 461 & 0.1 & $27,236,654$ & 15.6 \\
\hline Total & 648,153 & 100.0 & $175,104,675$ & 100.0 \\
\hline
\end{tabular}

Source: IBGE (1923). Census of 1920. Rio de Janeiro: IBGE, Vol. 3

of an agricultural census is to "indicate the facts in which the complete knowledge of the conditions, process, and results of the agrarian statistics of each country at a specific time, depends" (IBGE 1923, p. v). Therefore, it is the first reliable survey of the agrarian conditions throughout the nation.

The Census contains detailed information on the quantity and average size of rural properties at the municipal level, which enables us to construct our measures of land inequality, which we use as proxy for economic inequality, for each of the four states of interest: Minas Gerais, São Paulo, Pernambuco, and Rio Grande do Sul. ${ }^{25}$

The number of rural properties surveyed throughout the country is 648,153 , with a total area of $175,104,675$ ha (Table 1 ), which corresponds to $20.6 \%$ of the country's entire area. We have data on 115,655 rural properties in the 178 municipalities of Minas Gerais, 80,921 rural properties in the 204 municipalities of São Paulo, 23,336 rural properties in the 59 municipalities of Pernambuco, and 124,990 rural properties in the 71 municipalities of Rio Grande do Sul. Specifically, surveyed rural properties corresponded to $46.1 \%$ of the area of Minas Gerais $(27,393,210$ ha of a total of $59,381,000), 56.2 \%$ of the area of São Paulo $(13,904,631$ ha of a total of 24,723,900), $52.0 \%$ of the area of Pernambuco $(5,157,198$ ha of a total of 9,925,400), and $65.1 \%$ of the area of Rio Grande do Sul $(18,589,996$ ha of a total of 28,528,900).

Table 1 gives us an indication of the concentration of land distribution in Brazil. Nearly half $(49.0 \%)$ of the properties are smaller than 41 ha. However, these rural properties constitute only $3.5 \%$ of the surveyed area. The largest share of the surveyed area consists of properties between 2001 and 5000 ha (16.4\%). Impressively, properties larger than 25,000 ha correspond to $15.6 \%$ of the surveyed area (more than the area occupied by properties smaller than 200 ha, which is $14.9 \%$ ).

\footnotetext{
${ }^{25}$ The average territorial extension of the rural properties is divided into the following measurements: (i) less than 41 ha; (ii) 41-100 ha; (iii) 101-200 ha; (iv) 201-400 ha; (v) 401-1000; (vi) 1001-2000 ha; (vii) 2001-5000 ha; (viii) 5001-10,000 ha; (ix) 10,001-25,000 ha; and (x) 25,001 ha or more.
} 
As expected due to its large area and economic importance, Minas Gerais is the most populous state, with a population of 5,888,174 inhabitants. The second most populous state is São Paulo (population: 4,592,188), followed by Rio Grande do Sul (population: 2,182,713), and finally Pernambuco (population: 2,154,835). However, Pernambuco has the highest population density: 0.22 persons per hectare. Figures for São Paulo, Minas Gerais, and Rio Grande do Sul are 0.19, 0.10, and 0.08, respectively (Table 2).

Table 2 also presents figures on the number of foreigners and occupational shares. Consistent with the recent inflow of migrants, foreigners represent $18.1 \%$ of the population of São Paulo. Figures for Minas Gerais and Pernambuco are much lower: $1.5 \%$ and $0.5 \%$, respectively. Rio Grande do Sul, in between São Paulo and Minas Gerais and Pernambuco, has $6.9 \%$ of its population composed by foreigners. Agricultural activities are the main occupation for the four considered states. The percentage of individuals working on these activities ranges from $16.9 \%$ in Rio Grande do Sul to $21.4 \%$ in Pernambuco. Figures for Minas Gerais and São Paulo are $21.0 \%$ and $18.3 \%$, respectively. Industrial activities include a much lower share of the population. Minas Gerais has the lowest share of population working in such activities: $2.5 \%$. As expected, São Paulo has the highest share of population working in industrial activities: $5.0 \%$. Figures for Pernambuco and Rio Grande do Sul are 3.3 and $3.9 \%$. Less than $1.0 \%$ of the respective populations work in "liberal professions."

Considering the large and detailed data set provided by the census, we note with curiosity the lack of studies using the data to determine the levels of inequality. One possible reason is that the information has not yet been digitalized, which makes data collection very onerous. For this study, both data compilation and elaboration of the indexes have been done from scratch and have resulted in what are, to our knowledge, unique for the municipal level in Brazil for 1920.

\subsection{Land Distribution and Political Concentration}

Land has been very unequally distributed in Brazil since colonial times. Brazil's agrarian structure has been largely characterized by large landholding. Figures from the Census of 1920 show that $71.5 \%$ of the rural properties surveyed were smaller than 101 ha, while only $4.1 \%$ were bigger than 1000 ha. However, the same $71.5 \%$ of rural properties corresponded to only $9.0 \%$ of the total area surveyed, while the $4.1 \%$ corresponded to $63.4 \%$ of the total area. Of the 648,153 rural properties surveyed, only $461(0.1 \%)$ were larger than 25,000 ha, which nevertheless corresponded to $15.6 \%$ of the total area surveyed (a higher proportion than the 535,256 properties smaller than 201 ha, $14.9 \%$ ). However, the larger the landholdings, the lower the unit value of land (IBGE 1923, p. xii).

Table 3 presents the figures broken down by state, revealing several important features. First, Rio Grande do Sul, with 124,990 rural properties, is the state with the highest number of properties surveyed. Minas Gerais follows with 115,655 rural 


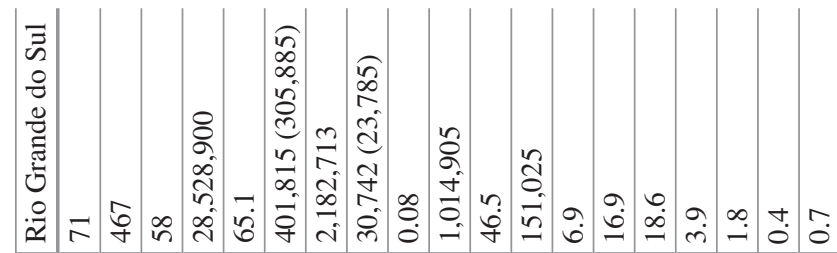

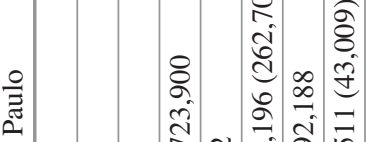

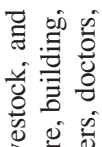

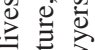

i

㠰

驺声

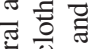

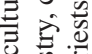

票

कृ

旁

\section{$\widehat{ษ}$}

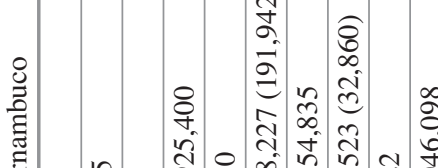

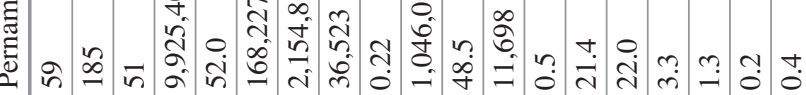

|

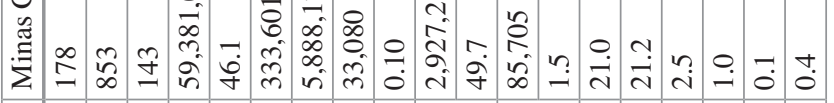

$=$ si

बू

$\Xi$

恵

.

)

๙ิ

帘

递

를

$\stackrel{0}{0}$

is

०)

कि के

(애

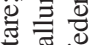

迅

+ 范

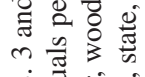

赔苛

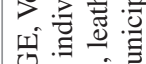

نि.

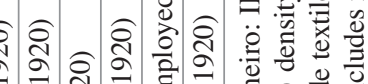

चं च⿱

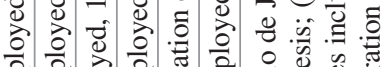

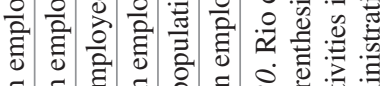

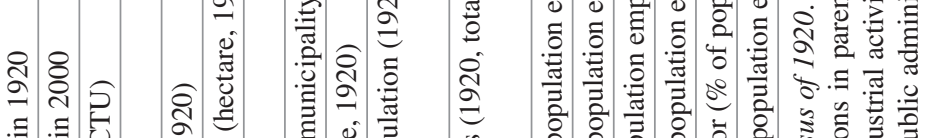

产

पे पै

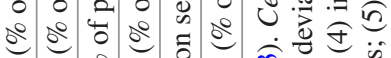

tั)

苟

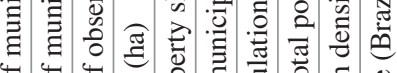

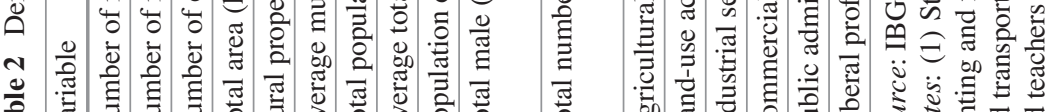

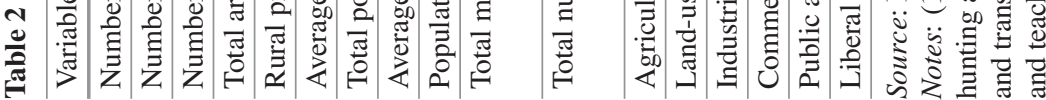




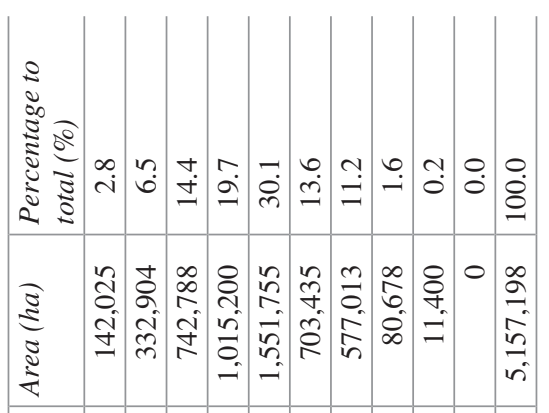

2

2
0
0
$\infty$

$\stackrel{2}{\stackrel{2}{8}}$

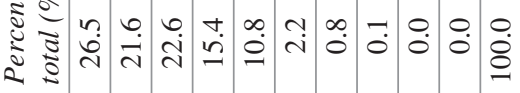

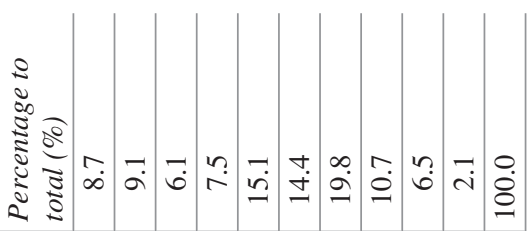

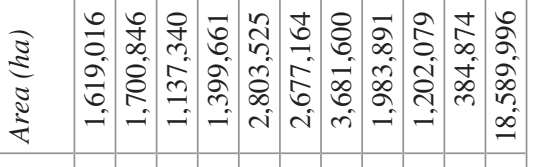
2 $\therefore$ $\stackrel{3}{\Xi}$

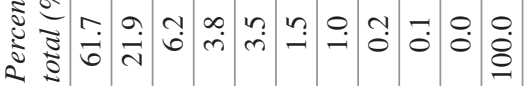
ज

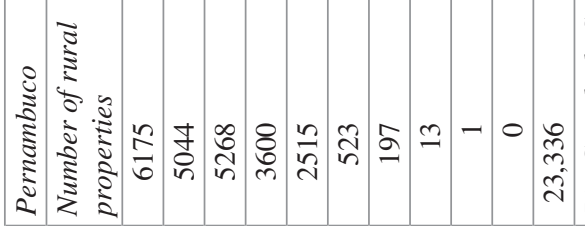

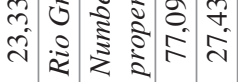

2

品

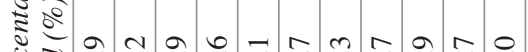

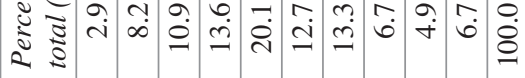

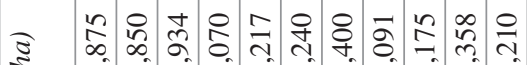

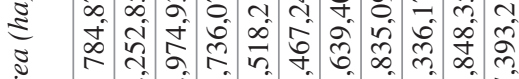

$\stackrel{2}{2}$

$\stackrel{8}{8}$

$\frac{3}{3} \frac{2}{3}$

๙ิ

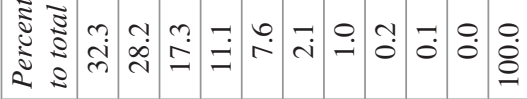

这

营

$\Xi$

.ֶ)

营

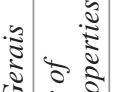

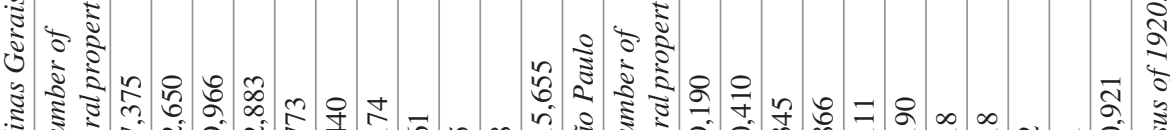

$\therefore$

8

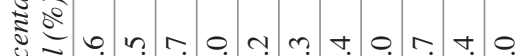

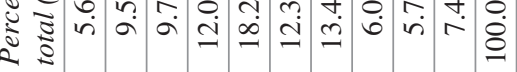

₹

ะ

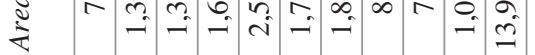

\section{$\therefore \frac{2}{8}$}

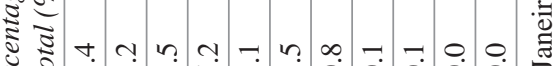

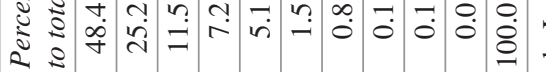

a

운

离

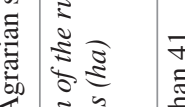

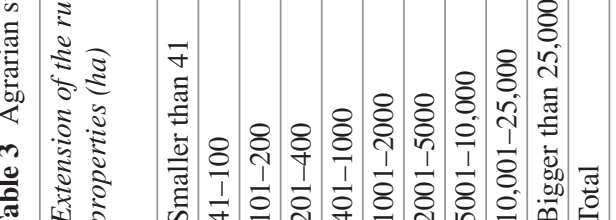

ñ

\section{용}


properties while São Paulo and Pernambuco had 80,921 and 23,336 rural properties, respectively. However, the total area of the properties surveyed is larger in Minas Gerais $(27,393,210$ ha) than in Rio Grande do Sul $(18,589,996$ ha). This is consistent with our second feature: while all states present a similar pattern to the country as a whole by presenting a higher concentration of rural properties smaller than 101 ha, there are important variations within this pattern. Whereas only $26.5 \%$ of the rural properties in Pernambuco are smaller than 41 ha (with $48.1 \%$ smaller than 101 ha), a total of $61.7 \%$ of the rural properties in Rio Grande do Sul are smaller than 41 ha (with $83.6 \%$ smaller than 101 ha). The figures for São Paulo and Minas Gerais are $48.4 \%$ (with $73.7 \%$ smaller than 101 ha) and $32.3 \%$ (with $60.5 \%$ smaller than $101 \mathrm{ha}$ ), respectively. Third, of the total area surveyed, rural properties smaller than 101 ha represent only $9.2 \%$ for Pernambuco (with $2.8 \%$ of properties smaller than $41 \mathrm{ha}$ ) and $11.1 \%$ for Minas Gerais (with $2.9 \%$ of properties smaller than 41 ha). However, properties smaller than 101 ha make up $17.9 \%$ of the surveyed area for Rio Grande do Sul and $15.2 \%$ for São Paulo.

Another important aspect of the agrarian structure of the country is that the largest share of the surveyed area is usually composed of properties between 401 and 1000 ha: $20.1 \%$ of the area of Minas Gerais, $30.1 \%$ of the area of Pernambuco, and $18.2 \%$ of the area of São Paulo. However, for Rio Grande do Sul properties between 2001 and 5000 ha occupy the largest relative area: 19.8\%. Finally, we highlight the impressive share of properties bigger than 25,000 ha in São Paulo and Minas Gerais: $7.4 \%$ and $6.7 \%$, respectively.

With the available information, we were able to construct two types of measures of economic inequality. The first one is the standard land Gini coefficient, which measures land inequality among landowners. ${ }^{26}$ The average land Gini considering all the comparable territorial units (CTU) from the four states was 0.61. The average coefficient was 0.60 for Minas Gerais, 0.44 for Pernambuco, 0.65 for São Paulo, and 0.63 for Rio Grande do Sul (Table 4).

Although widely used, the standard land Gini does not capture one important aspect of economic inequality: it does not take into account individuals who do not own land. If, for example, land is divided equally among $10 \%$ of the individuals in a given society, while the other $90 \%$ remain without land, the standard land Gini coefficient will indicate that this society is perfectly egalitarian. Therefore, if we want a proxy for economic inequality for the population as a whole, we need an

${ }^{26}$ For each municipality we constructed the Gini coefficient using the same formula as Nunn (2008): $1+(1 / n)-\frac{2 \sum_{i=1}^{n}(n-i+1) a_{i}}{n \sum_{i=1}^{n} a_{i}}$, where $n$ is the number of rural properties, $a_{\mathrm{i}}$ is the farm size, and $i$ denotes the rank, where rural properties are ranked in ascending order of $a_{\mathrm{i}}$. The calculation is made using the Stata programs ineqdec and ineqdeco. 
Table 4 Descriptive statistics (CTU)

\begin{tabular}{|c|c|c|c|c|c|}
\hline & All CTU & $\begin{array}{l}\text { Minas } \\
\text { Gerais }\end{array}$ & Pernambuco & São Paulo & $\begin{array}{l}\text { Rio Grande } \\
\text { do Sul }\end{array}$ \\
\hline \multirow[t]{2}{*}{ Land Gini (1920) } & 0.61 & 0.60 & 0.44 & 0.65 & 0.63 \\
\hline & $(0.13)$ & $(0.08)$ & $(0.12)$ & $(0.11)$ & $(0.18)$ \\
\hline \multirow{2}{*}{$\begin{array}{l}\text { Overall land Gini } \\
(1920)\end{array}$} & 0.85 & 0.87 & 0.87 & 0.87 & 0.71 \\
\hline & $(0.14)$ & $(0.06)$ & $(0.12)$ & $(0.13)$ & $(0.21)$ \\
\hline \multirow[t]{2}{*}{ Voters $(\%, 1920)$} & 7.56 & 8.14 & 5.52 & 6.71 & 10.71 \\
\hline & $(2.61)$ & $(2.41)$ & (199) & $(1.85)$ & $(2.47)$ \\
\hline $\begin{array}{l}\text { GDP per capita }(\log , \\
2000)\end{array}$ & $8.50(0.62)$ & $8.35(0.51)$ & $7.65(0.52)$ & $8.77(0.51)$ & $8.71(0.53)$ \\
\hline \multirow{2}{*}{$\begin{array}{l}\text { Average years of } \\
\text { schooling }(2000)\end{array}$} & 5.18 & 4.93 & 3.67 & 5.63 & 5.68 \\
\hline & (111) & $(0.91)$ & (1.12) & $(0.87)$ & $(0.86)$ \\
\hline \multirow[t]{2}{*}{ Infant mortality (2000) } & 23.50 & 25.42 & 54.75 & 15.53 & 17.15 \\
\hline & $(14.03)$ & $(6.55)$ & $(14.47)$ & $(4.90)$ & $(3.79)$ \\
\hline \multirow[t]{2}{*}{ HDI (2000) } & 0.76 & 0.76 & 0.64 & 0.79 & 0.79 \\
\hline & $(0.06)$ & $(0.04)$ & $(0.05)$ & $(0.03)$ & $(0.03)$ \\
\hline \multirow[t]{2}{*}{ Poverty $(\%, 2000)$} & 28.76 & 31.04 & 62.16 & 19.17 & 24.84 \\
\hline & $(17.60)$ & $(14.30)$ & $(11.15)$ & (10.26) & $(9.54)$ \\
\hline \multirow[t]{2}{*}{ Income Gini (2000) } & 0.55 & 0.56 & 0.59 & 0.54 & 0.55 \\
\hline & $(0.04)$ & $(0.04)$ & $(0.04)$ & $(0.04)$ & $(0.05)$ \\
\hline
\end{tabular}

Source: (1) IBGE. Censuses; (2) IPEA; (3) Own calculations

Notes: (1) Standard deviations in parenthesis; (2) these are descriptive statistics constructed for the CTU

overall land Gini. We constructed our overall land Gini for the municipalities in 1920 using the same formula as Acemoglu et al. (2008) and Summerhill (2010), by computing the same equation assigning zero landholdings to the estimated number of families that do not have landholdings. ${ }^{27}$ The average overall land Gini for the CTU considered in this study is 0.85 . The average overall land Gini coefficients are 0.87 for Minas Gerais, Pernambuco, and São Paulo (with the standard deviation for Minas Gerais, 0.06, being half of those for Pernambuco and São Paulo, 0.12 and 0.13 , respectively), and 0.71 for Rio Grande do Sul (Table 4).

The Census of 1920 also allows the construction of our proxy for political inequality in the early twentieth century: the percentage of individuals eligible to vote.

According to the Constitution of 1891, only literate Brazilian men 21 and older were eligible to vote. ${ }^{28}$ Therefore, using the data on population and literacy for

\footnotetext{
${ }^{27}$ Acemoglu et al. (2008) use an estimate of ten members per family, while Summerhill (2010) constructs his coefficients by assigning five members per family. We constructed the overall land Gini with the assumption of 7, 10, and 15 members per family. Our main variable is the one using an estimate of 15 individuals per family because it supposedly includes relatives and other aggregates living in the same property, an important element in early twentieth-century Brazil.

${ }^{28}$ The Constitution of 1891 was in force from 1891 to 1934.
} 
municipalities, we can easily calculate the percentage of the population of each municipality which was eligible to vote in 1920 . The average percentage of individuals eligible to vote considering all the CTU of our study is 7.6. In 1920, the average percentage of individuals eligible to vote was 8.1 for Minas Gerais, 5.5 for Pernambuco, 6.7 for São Paulo, and 10.7 for Rio Grande do Sul (Table 4). We see that Rio Grande do Sul appears to be more equal not only in an economic sense (overall land Gini coefficient), but in a political sense as well. Moreover, we see a higher level of political inequality in Pernambuco, where a high percentage of the population was illiterate at the beginning of the twentieth century.

\section{Quantitative Analysis}

\subsection{Inequality and Long-Term Development}

In order to explore the long-term consequences of land (economic) inequality and political inequality for development in Brazil, we exploit the cross-sectional variation in the CTU for our four states of interest: Minas Gerais, Pernambuco, São Paulo, and Rio Grande do Sul.

We first estimate cross-sectional ordinary least squares (OLS) regressions of the form

$$
y_{i}^{2000}=\alpha \cdot g_{i}^{1920}+\beta \cdot p_{i}^{1920}+\delta^{\prime} \cdot x_{i}+\varepsilon_{i}
$$

where $y_{i}{ }^{2000}$ is a measure of development for the CTU $i$ for the year 2000, $x_{i}$ is a vector of control covariates, and $\varepsilon_{i}$ is an error term. The key variables in this equation are $g_{i}{ }^{1920}$ and $p_{i}{ }^{1920}$, the (standard) land Gini coefficient for the CTU $i$ in 1920 and the constructed variable for political inequality (percentage of eligible voters) for the same CTU $i$ in 1920, respectively. ${ }^{29}$ Therefore, our main interest is the consistent estimation of $\alpha$ and $\beta$.

The regressions will be estimated with all the observations and dummy interactions, allowing for differential statistical relationships for each state. We will therefore be able to capture possible different de facto institutional environments, with such differences rooted in specific colonial experiences of each state. As dependent variables, we will first use what we call "main outcome variables," which are GDP per capita, average years of schooling, and infant mortality.

As previously discussed, the inclusion of these specific states has a clear purpose. Each of these regions is representative of a particular colonial experience within a constant de jure environment. This likely led to different de facto institutional environments that might cause inequality to relate in heterogeneous ways with each

\footnotetext{
${ }^{29} \mathrm{We}$ note that there is no uniform framework in the literature for the econometric analysis of the effects of historical inequality. In this study, we follow mainly Acemoglu et al. (2008).
} 
development indicator. Pernambuco is representative of the old agrarian structure, of great importance during the colonial era due to the sugar production that had far-reaching implications for the political, economic, and social structure of the region. Minas Gerais was the center of the gold cycle and later became an important producer of coffee and a center for the supply of goods for the domestic market. São Paulo was the main coffee producer, and in the late nineteenth century became Brazil's most important economic center, a position that it still occupies today. Rio Grande do Sul had a later occupation with characteristics associated to those of North America (see, e.g., Engerman and Sokoloff 1997, 2002), and vast numbers of European immigrants (as in São Paulo) shaping its development path.

The main econometric concern with this specification is the possible endogeneity bias generated by omitted variables. ${ }^{30}$ In other words, if omitted factors in $\varepsilon_{i}$ are correlated with the explanatory variables, the estimation by OLS will generate inconsistent estimators. Easterly (2007), based on the extensive economic history developed by Engerman and Sokoloff, has argued that growing conditions (topography, climate, and soil) favorable to the production of cash crops contribute to higher inequality. Therefore, we will control for a rich set of covariates (included in the vector $x_{i}$ ).

\subsection{Contemporary Outcomes}

We start by providing results of simple regressions (weighted correlations), using as independent variables the land Gini (as discussed, among landowners) and the percentage of eligible voters (our franchise-political inequality-indicator) and one

\footnotetext{
${ }^{30}$ The key condition for OLS consistency is the absence of correlation between the independent variables and the error term. A sufficient condition is the zero conditional mean assumption:

$E(\varepsilon / x)=0$, which means that the error term is not correlated with any function of the independent variables. In applied econometrics, endogeneity arises in one of the three ways: (1) omitted variable bias; (2) measurement error; and (3) simultaneity (Wooldridge 2010). Our main concern is the omitted variable bias due to the inability to control directly for variables such as land quality. The usual formula for analyzing the omitted variable bias is $p \lim \hat{\beta}_{k}=\beta_{k}+\gamma \cdot\left[\frac{\operatorname{cov}\left(x_{k}, q\right)}{\operatorname{var}\left(x_{k}\right)}\right]$ (Wooldridge 2010, p. 67). Our strategy in this study is to use a proxy variable solution. There are

two formal requirements for a proxy variable for the omitted variable $q$ : (1) the proxy variable should be redundant in the structural equation, $E(y \mid x, q, z)=E(x, q)$, where $z$ is the proxy variable; and (2) the correlation between the omitted variable $q$ and each $x_{\mathrm{j}}$ be zero once we partial out $z: L\left(q \mid 1, x_{1}, \ldots, x_{k}, z\right)=L(q \mid 1, z)$, where $L($.) represents a linear projection (Wooldridge 2010).

${ }^{31}$ Technically, we have a simple regression when there is only one independent variable. In our case, we have at least four dummy interactions for each variable. Aiming to keep language as simple as possible, I will use the term "simple regressions" when there is only one independent variable of interest (irrespective of the number of interactions).
} 
multiple regression, including both inequality variables. ${ }^{31}$ As dependent variables we will use our "main outcome variables," namely (natural logarithm of) GDP per capita, (natural logarithm of) average years of schooling, and infant mortality. ${ }^{32}$

Table 5 presents the estimated coefficients. As we can see from Column 1, the bivariate relationship between the land Gini and GDP per capita is heterogeneous. The estimated coefficients for Minas Gerais and São Paulo are positive and highly significant (2.43 and 1.25, respectively). While the coefficient for Pernambuco is not significant, the estimated coefficient for Rio Grande do Sul is not only significant, but also negative (-1.09). The simple regression of GDP per capita on the percentage of eligible voters is presented on Column 2. Only for Minas Gerais and Rio Grande do Sul the estimated coefficients are significant. Nevertheless, they have the expected positive sign. When we regress GDP per capita on both inequality variables, the picture remains broadly the same, a reflection of the surprising low correlation between the land Gini and the percentage of eligible voters $(0.09$, considering all CTU).

Columns 6 and 11 suggest similar relationships between economic inequality in the early twentieth century and average years of schooling and infant mortality. In other words, we estimated, for both dependent variables, positive and highly significant coefficients for Minas Gerais and São Paulo, a negative and significant coefficient for Rio Grande do Sul, and a nonsignificant coefficient for Pernambuco. Concerning the bivariate relationship between the percentage of eligible voters and average years of schooling, the coefficients are positive and highly significant (Column 7). There is, however, a surprise when we estimate the regressions with infant mortality as the dependent variable: the significant coefficient for São Paulo suggests a positive relationship between political equality and infant mortality (Column 12). We discuss these results in greater detail below. Regressions including both inequality variables present similar results (Columns 8 and 13).

Although important in their own right, the results discussed above are only historical correlations. The natural concern with those correlations is the possible bias generated by the inconsistency of OLS estimation in the presence of omitted variables. We attempt to correct the estimation for this bias by controlling for a rich set of control variables. Another concern is that the positive correlation between the political inequality variable is being driven by the association of this variable with an educational indicator. In order to construct the franchise indicator, we took the number of literate males, which is likely to reflect the educational environment of that particular CTU. In order to control for this specific source of bias, we control for the educational variables in 1920 .

We now discuss the extended results from regressions with GDP per capita as the dependent variable. The inclusion of educational controls reduces marginally, for Minas Gerais and Rio Grande do Sul, the significance of the estimated coefficients

\footnotetext{
${ }^{32}$ For now on, when I mention "GDP per capita" or "average years of schooling” I will be referring to their natural logarithms.
} 


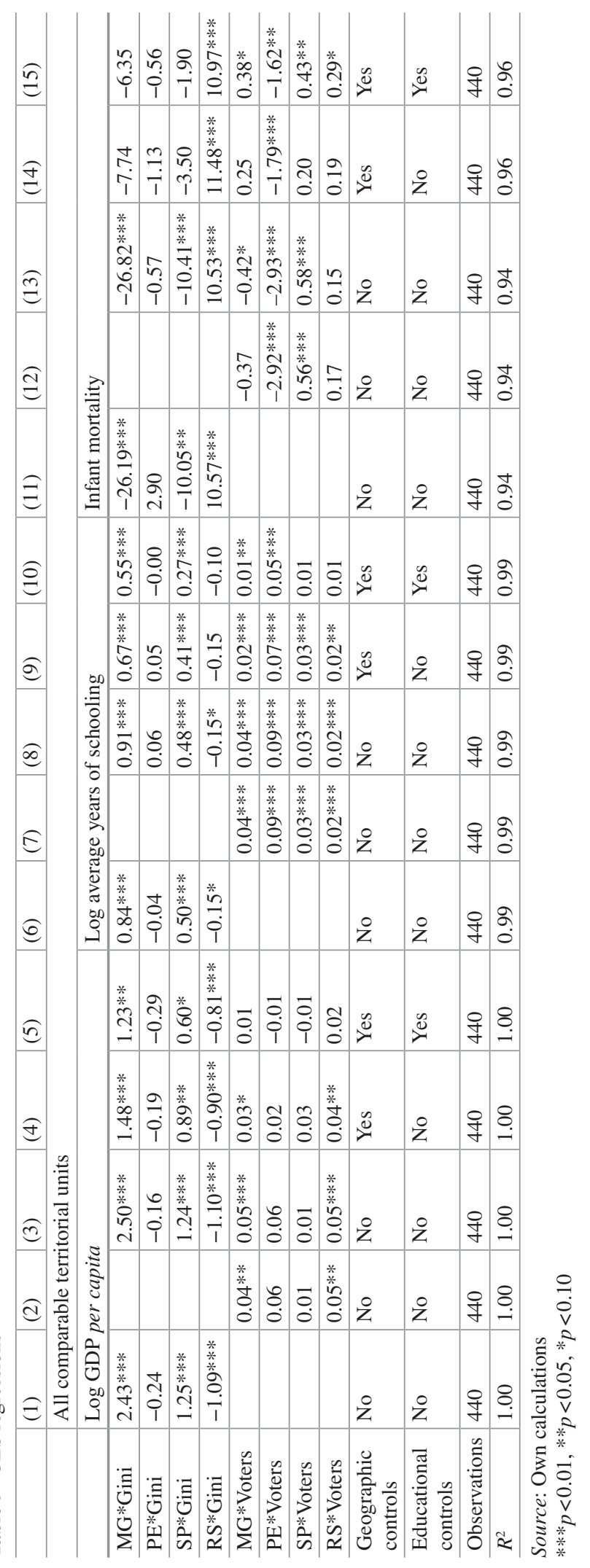


for the percentage of eligible voters (Column 4). We note that, while this is not the case for average years of schooling (Column 9), the picture is similar when infant mortality is the dependent variable (Column 14). When geographic and educational controls are included, we have a clearer picture. Column 5 shows that the results for Minas Gerais and São Paulo, of economic inequality in 1920 being positively and significantly correlated to GDP per capita in 2000, are robust. For Pernambuco, economic inequality appears to be non-correlated with income in the long run. For Rio Grande do Sul, economic inequality in 1920 remains negatively (and highly significant) correlated to GDP per capita in 2000. Moreover, all estimated coefficients for our political inequality variable become insignificant with the inclusion of geographic variables.

However, the results for average years of schooling and infant mortality are different. First, economic inequality in 1920 is only significantly related to average years of schooling in 2000 for Minas Gerais and São Paulo, the states in which the coefficients are positive (Column 10). In other words, only positive relationships between economic inequality and educational attainments in the long run are significant. Considering infant mortality, we have the opposite picture: only negative relationships, as the case of Rio Grande do Sul, between economic inequality and development in the long run are significant (reflected in a positive estimated coefficient, Column 15). The percentage of eligible voters does not appear to have had important effects on development in the long run. Either the coefficients lose their significance or they present small magnitudes (Columns 10 and 15).

We now expand our analysis by introducing the overall land Gini calculated index. This variable, as already mentioned, shows the inequality of land distribution across the whole population. Extending the analysis in this direction provides further insights into the relationship between inequality and long-term development.

Table 6 presents the regression results. Several noteworthy aspects emerge. First, when including both Gini variables and the percentage of eligible voters in regressions with no controls and GDP per capita as the dependent variable, the land Gini among landowners remains significant for Minas Gerais and São Paulo, while the overall land Gini is significant for Pernambuco (Column 1). The inclusion of controls makes all overall land Gini coefficients become insignificant (Column 2). Moreover, regressions with the overall land Gini as the only economic inequality variable (and with control variables) show no significant relationship (Column 3). Regressions with average years of schooling as the dependent variable present similar results (Columns 4-6), somewhat more favorable to the standard land Gini (the coefficient for Rio Grande do Sul is significant, Columns 4 and 5). Coefficients for the overall land Gini remain broadly insignificant as well in regressions with infant mortality as the dependent variable the inclusion of the control variables (Columns 8 and 9). Notwithstanding, the comparison of regressions with the standard land Gini (Table 5, Columns 5, 10, and 15) with regressions with the overall land Gini (Table 6, Columns 3, 6, and 9) indicates a stronger effect of the standard land Gini.

Therefore, our empirical results suggest that the effects of land inequality among landowners would possibly dominate over the effects of the inequality of land distribution across the population as a whole. 


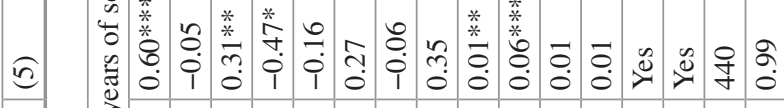
萬

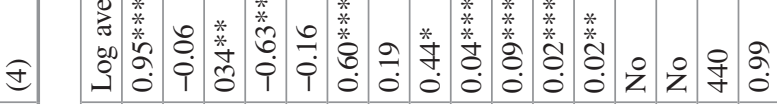

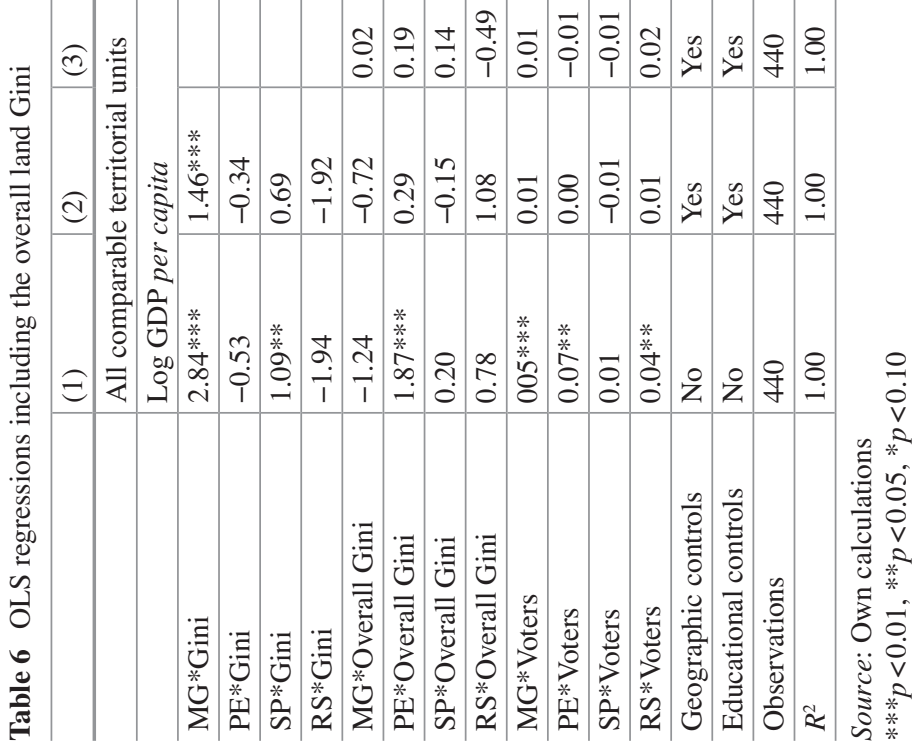




\subsection{De Facto Institutional Environments and Structural Change}

This section presents the estimated inequality coefficients when controlling for different occupations and for immigration. The reason behind these exercises is straightforward: our hypothesis - that the heterogeneous relationships between inequality and development indicators within Brazil in the long run reflect the different de facto institutional environments rooted in differing colonial experiences is only implicit. However, other elements could plausibly account for our statistical results. Our main concern is with possible structural changes that might have taken place during our time span. In particular, we control for industrialization, urbanization, and immigration in the various considered municipalities.

Fortunately, the Census of 1920 provides detailed data on the number of foreigners and of individuals working in particular occupations. We sorted the data for each municipality and constructed the share of the population dedicated to each particular category. Our main control variables are (1) the share of immigrants; (2) the share of individuals working in agricultural activities (as a proxy for urbanization); and (3) the share of individuals working in industry (such as textiles, metallurgy, and construction).

The econometric approach is the same as in previous exercises. Table 7 presents the estimated coefficients using the GDP per capita as the dependent variable.

Table 7 OLS regressions with structural controls: GDP per capita

\begin{tabular}{|c|c|c|c|c|c|c|}
\hline & (1) & (2) & (3) & (4) & (5) & (6) \\
\hline & \multicolumn{6}{|c|}{ Log GDP per capita } \\
\hline & \multicolumn{2}{|c|}{ Immigration } & \multicolumn{2}{|c|}{ Agriculture } & \multicolumn{2}{|c|}{ Industrialization } \\
\hline MG*Gini & $2.38 * * *$ & $1.41 * * *$ & $2.48 * * *$ & $1.26 * *$ & $2.28 * * *$ & $1.22 * *$ \\
\hline PE*Gini & -0.19 & -0.31 & -0.29 & -0.34 & -0.15 & -0.21 \\
\hline SP*Gini & 0.46 & 0.37 & $1.15 * * *$ & $0.60 *$ & $0.94 * * *$ & 0.54 \\
\hline RS*Gini & $-0.99 * * *$ & $-0.82 * * *$ & $-1.27 * * *$ & $-0.88 * * *$ & $-1.25 * * *$ & $-0.95 * * *$ \\
\hline MG*Voters & $0.05 * * *$ & 0.02 & $0.04 * *$ & 0.01 & 0.03 & 0.01 \\
\hline PE*Voters & 0.06 & 0.00 & 0.04 & -0.01 & 0.00 & -0.02 \\
\hline SP*Voters & $0.04 *$ & 0.01 & -0.00 & -0.01 & -0.02 & -0.01 \\
\hline RS*Voters & $0.06 * * *$ & $0.03 * *$ & $0.04 * *$ & 0.02 & 0.02 & 0.01 \\
\hline $\begin{array}{l}\text { Immigration (1920, } \\
\%)\end{array}$ & $0.02 * * *$ & $0.01 * * *$ & & & & \\
\hline $\begin{array}{l}\text { Agricultural } \\
\text { activities }(1920, \%)\end{array}$ & & & $-0.01 * * *$ & -0.01 & & \\
\hline $\begin{array}{l}\text { Industrial sector } \\
(1920, \%)\end{array}$ & & & & & $0.07 * * *$ & $0.04 * *$ \\
\hline Geographic controls & No & Yes & No & Yes & No & Yes \\
\hline Educational controls & No & Yes & No & Yes & No & Yes \\
\hline Observations & 440 & 440 & 440 & 440 & 440 & 440 \\
\hline$R^{2}$ & 1.00 & 1.00 & 1.00 & 1.00 & 1.00 & 1.00 \\
\hline
\end{tabular}

Source: Own calculations

$* * * p<0.01, * * p<0.05, * p<0.10$ 
An interesting picture emerges. When controlling for the share of individuals working in agricultural activities, we still have a positive and significant relationship between economic inequality and GDP per capita in the long run for Minas Gerais and São Paulo, even when geographic and educational controls are included; for Pernambuco, coefficients remain largely insignificant; as for Rio Grande do Sul coefficients remain negative and highly significant (Columns 3 and 4).

However, controlling for immigration the economic inequality coefficient for São Paulo is no longer significant even in regressions without further controls (Column 1). Although the remaining coefficients maintain similar properties as the above-made discussion, this analysis suggests that the effects of land inequality in São Paulo might be reflecting the positive effects of immigration. Moreover, when controlling for the percentage of individuals in industrial activities São Paulo's land Gini coefficient remains significant only in regressions without geographic and educational controls (Columns 5 and 6). Finally, we note that, with the exception of agriculture in regressions with the usual controls (Column 4), all coefficients of structural controls are highly significant and have the expected sign.

Thus, we have presented a robustness check for our hypothesis that the heterogeneous relationships between economic inequality and development within Brazil are due to the different de facto institutional environments. Several regression specifications show that controlling for variables proxying structural changes nonetheless maintains the heterogeneous results within the country. This evidence is in accordance with the hypothesis.

\subsection{Inequality Yesterday and Inequality Today}

Finally, we present a natural extension of our investigation: the relationship inequality in the past and inequality today. This is an especially interesting question in the Brazilian context, for Brazil is one of the most unequal countries in the world, often portrayed as an example of high structural and persistent inequality.

Using a framework similar to previous investigations, we econometrically examine the relationship between the (standard) land Gini in 1920 and inequality today, measured by the income Gini in 2000. Again, our units of analysis are the CTU. Results are in Table 8.

Results are broadly the same across specifications. For Minas Gerais the estimated coefficient for economic inequality in 1920 is not significant in regressions with no controls (Column 1) and with the full set of controls (Column 3). Moreover, we find no significant relationship between political inequality in 1920 and economic inequality today. For São Paulo, although the estimated coefficient changes its sign (it is negative in regressions with no controls, Column 1), the land Gini estimated coefficient is never significant. The estimated coefficient for the percentage of eligible voters is only significant without the inclusion of the controls and is very small across specifications. Therefore, we find no statistical significance for the relationship between economic or political inequality in the early twentieth century and economic inequality in 2000 in Minas Gerais and in São Paulo. 
Table 8 OLS regressions for the income Gini (2000)

\begin{tabular}{l|l|l|l}
\hline & $(1)$ & $(2)$ & $(3)$ \\
\hline & \multicolumn{2}{|l}{ All CTU } \\
\hline & \multicolumn{2}{|l}{ Gini (2000) } & \multicolumn{2}{l}{} \\
\hline MG*Gini & 0.01 & $0.06^{*}$ & 0.06 \\
\hline PE*Gini & $0.06^{*}$ & $0.06^{*}$ & $0.06^{*}$ \\
\hline SP*Gini & -0.02 & 0.02 & 0.01 \\
\hline RS*Gini & $0.19^{* * *}$ & $0.14 * * *$ & $0.14^{* * *}$ \\
\hline MG*Voters & -0.00 & 0.00 & -0.00 \\
\hline PE*Voters & $0.01 * * *$ & $0.01 * *$ & $0.01^{* *}$ \\
\hline SP*Voters & $0.01 * * *$ & $0.00^{* *}$ & 0.00 \\
\hline RS*Voters & 0.00 & $0.00^{* *}$ & $0.00^{*}$ \\
\hline Geographic controls & No & Yes & Yes \\
\hline Educational controls & No & No & Yes \\
\hline Observations & 440 & 440 & 440 \\
\hline$R^{2}$ & 1.00 & 1.00 & 1.00 \\
\hline
\end{tabular}

Source: Own calculations

$* * * p<0.01, * * p<0.05, * p<0.10$

Results for Pernambuco and Rio Grande do Sul are different. For Pernambuco, the state for which no statistical significance was found for the relationship between the land Gini in 1920 and several development outcomes (see Table 5), we now find a positive and significant relationship between economic inequality in 1920 and economic inequality in 2000 (Column 1), a result which remains robust when controls are included (Columns 2 and 3). For Rio Grande do Sul, we find even stronger relationships. The estimated coefficient for the land Gini is positive and highly significant in all specifications (Columns 1-3). The estimated coefficient for political inequality, although sometimes significant, is again of very small magnitude for both states.

Therefore, there is a positive relationship between economic inequality at the beginning of the twentieth century and economic inequality in 2000 precisely in those states where we do not find a statistically significant positive relationship between economic inequality in 1920 and development in the long run. In other words, where economic inequality is not "structural," there is a positive relationship between inequality in land distribution and long-term development.

\section{Conclusion}

This study aimed to investigate the historical consequences of inequality and the role of institutions. By focusing on the Brazilian case, we provide evidence of the relative and potentially distinct roles of economic inequality and political inequality on long-run development. We believe this to be a necessary step to improve our understanding of the causes of underdevelopment in Latin America.

We constructed from scratch both economic inequality variables (the standard land Gini and the overall land Gini) and a variable proxy for political concentration 
(the percentage of eligible voters) at the municipal level for the states of Minas Gerais, Pernambuco, São Paulo, and Rio Grande do Sul. The states were specifically chosen for their different colonial experiences, which probably shaped their de facto institutional environment. Our selection was made on the basis of the abundant data provided by the 1920 Census, a source which, surprisingly, had not yet been exploited for this purpose.

The results are surprising. First, we find almost no correlation between the land Gini and the percentage of eligible voters in Brazilian municipalities in 1920 . Second, and somewhat unexpectedly, we find a positive relationship between economic inequality in early twentieth century and development outcomes in 2000 for the states of Minas Gerais and São Paulo, both from the Southeast region. Pernambuco, a Northeastern state, presents no evidence of a significant relationship between economic inequality and long-term development outcomes, while the evidence for the South, the state of Rio Grande do Sul, is that the relationship is negative. Third, we find no robust significant relationship between political inequality, measured by the percentage of eligible voters, and long-term development outcomes. Fourth, the effects of economic inequality are largely due to the concentration of land among landowners, as shown by the insignificance of the overall land Gini.

These are interesting results, for they appear to contradict the general view that economic inequality would always be costly for a society and that greater political participation would foster development. The answer to part of this riddle might lie in the fact that political participation was very low in early twentieth-century Brazil, and a marginal increase (the econometrically captured effect) might have given more irrelevant votes to a captured political system, leaving the economic outcomes unchanged. In other words, greater franchise might not have given the population more political participation. With regard to the effects of economic inequality, when considering the land Gini in an agrarian structure, these are likely to be strongly linked to collective action problems. In a captured political system such as Brazil in the Old Republic, land concentration might have differing effects, especially when taking into account that, in some regions, landowners were largely responsible for the provision of public goods.

Further important analyses were conducted. First, we find evidence that there is almost no correlation between economic (land) inequality in the early twentieth century and recent income inequality in states where there is a positive relationship between economic inequality and long-term development (Minas Gerais and São Paulo). In other words, the positive effects of inequality are associated with a particular structural organization at a specific time, in contrast to a more structural inequality, which, as exemplified by the cases of Pernambuco and Rio Grande do Sul, would have either negative or no significant effects on long-term development.

Finally, our hypothesis that different de facto institutional environments are associated with different relationships between inequality and long-term development was, initially, only implicit in our analysis. Important structural changes that occurred during this time span might be responsible for the heterogeneous 
relationships found previously between inequality and long-term development. Three elements were our main concern: (1) immigration; (2) industrialization; and (3) urbanization. After controlling for these variables, our main results were maintained, strengthening our hypothesis.

It is important to note that we do not argue that inequality is conducive to development in general. We present evidence that inequality might be associated with better development outcomes in the long run in a particular political context in a within-country framework. It is possible that the theoretically harmful effects of inequality are better reflected in a cross-country framework, in which the mechanisms are related to the different de jure institutional environment. In other words, relative equality would be better for a particular country, but within an unequal country (with certain sociopolitical and economic characteristics) more inequality would be associated with better outcomes.

Much work remains to be done. We mention some possible extensions. First, there are few works that attempt to control for different de facto institutional environments. Further employment of this strategy likely will provide beneficial insights in order to better understand the development paths of societies. Second, empirical and theoretical studies that offer a differentiation between within-country and cross-country effects of variables are largely welcome. ${ }^{33}$ Third, models attempting to capture the within-country effects of variables such as inequality in politically captured environments are lacking. Finally, the external validity of our results remains questionable. Comparative studies within Latin America are a logical next step.

Acknowledgment I would like to thank my Masters' supervisor Renato Colistete for his guidance and support. I have benefited from conversations with William Summerhill, Luis Bértola, Alfonso Herranz, Ewout Frankema, Leonardo Weller, Mauro Rodrigues, Pedro Duarte, Rodrigo Soares, Gilberto Lima, Thales Pereira, and Gabriel Corrêa, as well as comments from participants at the 4th Southern Hemisphere Economic History Summer School at Universidad de la Republica, 42nd National Economic Meeting (ANPEC), Latin American Inequality Conference, IV CLADHE, 10th Conference of the EHES, and the FEA-USP Workshop on Economic History. Financial support from FAPESP and CAPES is gratefully acknowledged.

Open Access This chapter is distributed under the terms of the Creative Commons Attribution 4.0 International License (http://creativecommons.org/licenses/by/4.0/), which permits use, duplication, adaptation, distribution and reproduction in any medium or format, as long as you give appropriate credit to the original author(s) and the source, a link is provided to the Creative Commons license and indicate if changes were made.

The images or other third party material in this chapter are included in the work's Creative Commons license, unless indicated otherwise in the credit line; if such material is not included in the work's Creative Commons license and the respective action is not permitted by statutory regulation, users will need to obtain permission from the license holder to duplicate, adapt or reproduce the material.

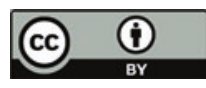

\footnotetext{
${ }^{33}$ See, for example, Robinson (2006).
} 


\section{References}

Acemoglu, D. (2008). Oligarchic versus democratic societies. Journal of the European Economic Association, 6(1), 1-44.

Acemoglu, D., Johnson, S., \& Robinson, J. A. (2001). The colonial origins of comparative development: An empirical investigation. American Economic Review, 91(5), 1369-1401.

Acemoglu, D., Johnson, S., \& Robinson, J. A. (2002). Reversal of fortune: Geography and institutions in the making of modern world income distribution. Quarterly Journal of Economics, 117(4), 1231-1294.

Acemoglu, D., \& Robinson, J. A. (2000). Political losers as a barrier to economic development. American Economic Review: Papers and Proceedings, 90, 126-130.

Acemoglu, D., Robinson, J. A., \& Verdier, T. (2004). Kleptocracy and divide and rule: A theory of personal rule. Journal of the European Economic Association, 2, 162-192.

Acemoglu, D., Johnson, S., \& Robinson, J. A. (2005). Institutions and the fundamental cause of long-run growth. In P. Aghion \& S. Durlauf (Eds.), Handbook of economic growth. NorthHolland: Amsterdam.

Acemoglu, D., et al. (2008). Economic and political inequality in development: The case of Cundinamarca, Colombia. In E. Helpman (Ed.), Institutions and economic performance. Cambridge, MA: Harvard University Press.

Aghion, P., Banerjee, A., \& Piketty, T. (1999a). Dualism and macroeconomic volatility. The Quarterly Journal of Economics, 114(4), 1359-1397.

Aghion, P., Caroli, E., \& García-Peñalosa, C. (1999b). Inequality and economic growth: The perspective of the new growth theories. Journal of Economic Literature, 37, 1615-1660.

Alesina, A., \& Rodrik, D. (1994). Distributive politics and economic growth. Quarterly Journal of Economics, 109(2), 465-490.

Banerjee, A., \& Duflo, E. (2003). Inequality and growth: What can the data say? Journal of Economic Growth, 8, 267-299.

Banerjee, A., \& Iyer, L. (2005). History, institutions, and economic performance: The legacy of colonial land tenure systems in India. American Economic Review, 95(4), 1190-1213.

Banerjee, A., \& Newman, A. (1991). Occupational choice and the process of development. Journal of Political Economy, 101(2), 274-298.

Barro, R. (2000). Inequality and growth in a panel of countries. Journal of Economic Growth, 5, 5-32.

Bates, R. (1981). Markets and states in tropical Africa. Berkeley, CA: University of California Press.

Bénabou, R. (1996). Inequality and growth. NBER working paper, no. 5658.

Bourguignon, F., \& Verdier, T. (2000). Oligarchy democracy, inequality and growth. Journal of Development Economics, 62, 285-313.

Carvalho, O. (1946). Política do Município. Rio de Janeiro: Livraria AGIR Editora.

De Carvalho Filho, I., \& Colistete, R. P. (2010). Educational persistence: Was it all determined 100 years ago? Evidence from São Paulo, Brazil. MPRA paper, no. 24494.

Dean, W. (1971). Latifundia and land policy in nineteenth-century Brazil. The Hispanic American Historical Review, 51(4), 606-625.

Dell, M. (2010). The persistent effects of Peru's mining mita. Econometrica, 78(6), 1863-1903.

Denis, P. (1911). Brazil. New York: Chas. Scribner's Sons.

Easterly, W. (2007). Inequality does cause underdevelopment: Insights from a new instrument. Journal of Development Economics, 84, 755-776.

Easterly, W., \& Rebelo, S. (1993). Fiscal policy and economic growth: An empirical investigation. Journal of Monetary Economics, 32, 417-458.

Engerman, S., \& Sokoloff, K. (1997). Factor endowments, institutions, and differential paths of growth among new world economies: A view from economic historians of the United States. NBER working paper series on historical factors in long run growth, no. 66.

Engerman, S., \& Sokoloff, K. (2002). Factor endowments, inequality, and paths of development among new world economies. Economía, 3(1), 41-88. 
Forbes, K. (2000). A reassessment of the relationship between inequality and growth. American Economic Review, 90(4), 869-887.

Frankema, E. (2009). Has Latin America always been unequal? A comparative study of asset and income inequality in the long twentieth century. Global economic history series (vol. 3). Boston, Leiden: Brill.

Frankema, E. (2010). The colonial roots of land inequality: Geography, factor endowments, or institutions? Economic History Review, 63(2), 418-451.

Furtado, C. (2006 [1st ed. 1959]). Formação econômica do Brasil (34th ed.). São Paulo: Companhia das Letras.

Galor, O., Moav, O., \& Vollrath, D. (2009). Inequality in landownership the emergence of humancapital promoting institutions, and the great divergence. Review of Economic Studies, 76, 143-179.

Galor, O., \& Zeira, J. (1993). Income distribution and macroeconomics. Review of Economic Studies, 60, 35-52.

Goldsmith, R. W. (1986). Brasil 1850-1984: Desenvolvimento financeiro sob um século de inflação. São Paulo: Harper and Row.

IBGE - Instituto Brasileiro de Geografia e Estatística. (1923). Censo demográfico de 1920: População (Vol. 3). Rio de Janeiro: IBGE.

Kaldor, N. (1956). Alternative theories of distribution. Review of Economic Studies, 23(2), 83-100.

Kuznets, S. (1955). Economic growth and income inequality. American Economic Review, 45(1), $1-28$.

Leal, V. N. (2012 [1st ed. 1948]). Coronelismo, enxada e voto: O município e o regime representativo no Brasil. São Paulo: Companhia das Letras.

Leff, N. (1972). Economic retardation in nineteenth-century Brazil. Economic History Review, 25(3), 489-507.

Leff, N. (1997). Economic development in Brazil, 1822-1913. In S. Haber (Ed.), How Latin America fell behind. Stanford: Stanford University Press.

Love, J. (1970). Political participation in Brazil, 1881-1969. Luso-Brazilian Review, 7(2), 3-24.

Murphy, K., Shleifer, A., \& Vishny, R. (1989). Income distribution, market size, and industrialization. Quarterly Journal of Economics, 104(3), 537-564.

Naritomi, J., Soares, R., \& Assunção, J. (2012). Institutional development and colonial heritage within Brazil. Journal of Economic History, 72(2), 393-422.

North, D., Summerhill, W., \& Weingast, B. (2000). Order, disorder and economic change: Latin America versus North America. In B. Mesquita \& H. Root (Eds.), Governing for prosperity. New Haven: Yale University Press.

Nugent, J., \& Robinson, J. A. (2010). Are factor endowments fate? Journal of Iberian and Latin American Economic History, 28(1), 45-82.

Nunn, N. (2008). Slavery, inequality, and economic development in the Americas: An examination of the Engerman-Sokoloff hypothesis. In E. Helpman (Ed.), Institutions and economic performance. Cambridge, MA: Harvard University Press.

Pande, R., \& Udry, C. (2005). Institutions and development: A view from below. In R. Blundell, W. Newey, \& T. Persson (Eds.), Proceedings of the 9th World Congress of the Econometric Society. Cambridge: Cambridge University Press.

Perotti, R. (1992). Fiscal policy, incomes distribution, and growth. Columbia University working paper, no. 636.

Perotti, R. (1996). Growth income distribution, and democracy: What the data say. Journal of Economic Growth, 1, 149-187.

Persson, T., \& Tabellini, G. (1994). Is inequality harmful for growth? American Economic Review, 84(3), 600-621.

Prado, C. Jr. (1956 [1st ed. 1945]). História econômica do Brasil (4th ed.). São Paulo: Brasiliense.

Robinson, J. A. (2006). Equity institutions, and the development process. Nordic Journal of Political Economy, 32, 17-50.

Summerhill, W. (2010). Colonial institutions, slavery, inequality, and development: Evidence from São Paulo, Brazil. MPRA paper, no. 22162. 
Villela, A. (2013). O desenvolvimento econômico no Brasil Pré-1945. In F. Veloso, P. Ferreira, F. Giambiagi, \& S. Pessôa (Eds.), Desenvolvimento econômico: Uma perspectiva Brasileira. Rio de Janeiro: Elsevier.

Wegenast, T. (2010). Cana, café, cacau: Agrarian structure and educational inequalities in Brazil. Journal of Iberian and Latin American Economic History, 28(1), 103-137.

Wooldridge, J. (2010). Econometric analysis of cross section and panel data (2nd ed.). Cambridge, MA: The MIT Press.

Pedro Paulo Pereira Funari holds a Master of Science in Economics and a Bachelor of Science in Economics from the School of Economics, Business and Accounting of the University of São Paulo. He is currently a Ph.D. candidate at the University of California, Davis. His main interests are economic history, institutions, and development. 


\title{
Historical Perspectives on Regional Income Inequality in Brazil, 1872-2000
}

\author{
Eustáquio Reis
}

\section{Introduction}

Brazil is one of the most unequal societies in contemporary world. From 1960 to 2000 , the Gini coefficients of income per capita distribution remained practically constant around 0.6, one of the highest levels recorded at national level (Ipeadata 2014). In broad historical perspective, both institutional and geographic factors played fundamental roles in the generation and reproduction of Brazilian inequality in space and time. Slavery has had and still has overwhelming implications for social equity. Concentration of income and wealth and the low levels of education prevailing today are, to a large extent, her legacies. Needless to say, this is not an excuse for the ostensible lack of social concerns of government policies during most of the twentieth century.

Geographic factors were also decisive for spatial inequality. The continental size and the geographic heterogeneity of the country compounded with very high transport costs to create wide spatial disparities in the levels of productivity and income per capita. According to our estimates, The Gini coefficient of the distribution of municipal GDP per capita was above 0.45 in 1872 and remained above 0.4 from 1940 to 1980 when it started declining to reach 0.3 in 2000. Moreover, Theil decomposition exercises show that the contribution of the interregional component

\footnotetext{
A first version of this paper was prepared while the author was as Visiting Fellow to the project desiguALdades.net at the Freie Universität Berlin, in 2013. Preliminary versions were presented at IPEA, the Department of History of UCLA, the Spatial Economics Association Meeting, and the Harvard-Brazil Seminar. The author gratefully acknowledges hospitality and financial support from IPEA, CNPq and FAPERJ/PRONEX to the Project Nemesis-Proc. E52 168.171/2006 http://www.nemesis.org.br"www.nemesis.org.br); and to desiguALdades.network. He is also grateful for the comments from Jeffrey Williamson and Luis Bertola and the computer assistance and data compilation of Márcia Pimentel, Ana Isabel Alvarenga, and Maria do Carmo Horta.

E. Reis $(\square)$

IPEA, Rio de Janeiro, Brazil

e-mail: ejreis1@gmail.com
} 
to inequality of municipal GDP per capita increased systematically from $20 \%$ in 1872 to almost 50\% in 2000 (Barros et al. 1995; Azzoni 1997, 1999; Azzoni et al. 2000).

The historical roots of regional disparities are widely discussed in the Brazilian literature (Bértola et al. 2006; Buescu 1979; Cano 1993, 1997; Castro 1969; Denslow 1977; Furtado 1968, 1970; Leff 1972, 1973, 1991; Marcondes 2005). The discussion, however, lacks an adequate empirical basis. Statistical evidence when available is restricted to sparse data at state or macro-regional level. The sharp economic differences inside Brazilian states are completely neglected.

The chapter provides historical perspectives on spatial economic inequalities in Brazil. For this purpose it analyzes the spatial patterns of Brazilian economic growth making use of a database on Brazilian municipalities from 1872 to 2000. The first section offers a succinct account of the geographic forces shaping the secular development of the Brazilian economy highlighting the evolution of transport costs. The second section uses a series of maps to describe the spatial progression of income per capita and labor productivity from 1872 to 2000 . In a more rigorous fashion, the third section estimates econometric models of growth convergence for municipal income per capita and labor productivity during the same period. The econometric analysis for the period 1919-2000 is refined in three ways. Firstly, by assuming spatial correlation among variables of the model; secondly, by disaggregating the model for urban and rural activities; and, thirdly, by enlarging the model to take account of the factors conditioning the patterns of spatial growth convergence in the twentieth century. The final section summarizes the results and proposes research extensions. The database is described in Reis (2014).

The main findings of the chapter are: (1) Municipal concentration of income per capita in Brazil, both between and within regions, is extremely high and has deep historical roots. (2) Spatial convergence of income per capita since 1872 has been very slow when compared to the economies of Europe, the USA, and Japan. (3) Spatial convergence, if any, was particularly slow during the import substitution phase from 1920 to 1980 compared to the primary export-led phases that took place in the other periods. (4) The main factors conditioning the growth of municipal income per capita from 1920 to 2000 are the conditions of accessibility (measured by the index of potential market in 1920) and transport infrastructure (measured by the presence of a railroad station in 1920), as well as the share of foreigners in total population in 1920. (5) The effects of railroad on urban output and foreigners on rural output were persistent throughout the decades. (6) Otherwise, institutional factors measured by variables like concentration of wealth (farm ownership in 1920), illiteracy rates in 1920, electoral participation in 1914, and share of slaves back in 1872 , individually or jointly considered, have no significant effects on the growth of municipalities from 1920 to 2000. Thus, except by the effects of foreigner's contribution, it is fair to say that institutions played no role and therefore the chapter endorses the preeminence of geographic factors as determinants of the growth of Brazilian municipalities during the twentieth century. 


\section{Geography and History}

The main historical driver of the geographic patterns of economic development in Brazil was the prohibitive transport costs to the hinterland imposed by the strong declivity of the coastal mountain range running parallel to the Atlantic shoreline (Ellis 1951; Goulart Filho and Queiroz 2011; Silva 1949; Summerhill 2003). The slope of the Serra do Mar-reaching $1000 \mathrm{~m} 100 \mathrm{~km}$ away from the sea-complemented by the intense summer rainfall and the dense rainforest hindered the development of a transportation infrastructure and therefore the economic settlement of the Brazilian hinterland.

In the Northeast region, the Borborema Range as well as the poor soil and dry climate of the Semiarid areas made agricultural settlements hardly unsustainable beyond the seashore strip occupied by the sugar plantations since early colonial times (Milet 1881; Andrade 1973). The settlement of the mining areas in the CenterSouth region during the eighteenth century was made feasible by the negligible transport costs - high specific value - of precious minerals (Cano 1973). But with historical hindsight, it is fair to say that after the exhaustion of mines, high transport costs became a severe constraint to the economic development of the region during most of the nineteenth century (Martins 2004; Bergad 1999; Libby 1988). Finally, in the Amazon region where navigable rivers sanctioned low transport costs, the wild vegetation, unhealthy climate, and the poor quality of soil precluded agrarian settlement up to the last quarter of the twentieth century. Starting in 1850, however, rubber extraction supported a thriving regional economy up to 1912 when the competition of Asian plantations brought the collapse to rubber prices and export values (Santos 1980; Weinstein 1983). ${ }^{1}$

The railroad investments in the third quarter of the nineteenth century were crucial for the viability of agrarian settlements in the hinterland. Transport cost reductions in the order of $80 \%$ pushed the coffee frontier towards western São Paulo (Matos 1974; Milliet 1982; Summerhill 1997; Pinto 1903) and southeast Minas Gerais (Lima 1981, Oliveira 2005). Concomitantly, the city of São Paulo emerged as the most important hub (the node with minimum transport cost) of the railway network, thus pulling industries to exploit economies of scale and emerging as the sustainable industrial growth pole of the country in the beginning of the twentieth century (Cano 1985). For other regions, however, the reduction in transport costs provided by railways had diverse consequences leading to the specialization in agriculture and to the loss of competitiveness in manufacturing and handcraft production which were previously protected by the high transport costs (Cano 1993; Martins 1983; Reis and Monasterio 2010; Restitutti 2008; Stein 1957; Trew 2014).

\footnotetext{
${ }^{1}$ The Brazilian Pampas located in the temperate zones of the extreme south of the country is a double exception to the extent that soils are flat and thus with low transport costs, and high fertility (Bell 1998). Trade costs, however, were high given the frontier situation and the distance to Brazilian domestic and international markets. As a consequence, cattle raising remained as an extractive activity up to the mid-nineteenth century.
} 
Starting in the 1890s, the concentration of industry in São Paulo was enhanced by the synergies and externalities provided by the agglomeration of technological knowledge and human capital of foreign immigrants (Cano 1993; Reis and Monasterio 2010; Versiani 1993). Conversely, subsidized foreign immigration aggravated the segmentation of the Brazilian labor market reducing their effectiveness in reducing regional disparities in productivity and income. Thus, until the 1930s, internal migration to São Paulo was relatively meager despite huge regional differences in productivity and income per capita (Graham 1972; Graham and Hollanda 1971).

In the second half of the twentieth century, government investment in transport infrastructure concentrated on highways which gradually replaced the railroads. The initial impact of the highway option, however, was to reinforce the hegemonic position of São Paulo, thus preserving regional disparities. Indeed, the dispersed network of highways reduced logistics costs of the distribution of manufactured goods in the domestic market in relation to the long haul transport cost incurred to export primary products. Analogously, it reduced the costs of internal migration, thus stimulating the migration flows to large cities and ensuring "unlimited" supply of labor that dampened pressures for urban wage increases, particularly in Sao Paulo and Rio de Janeiro (Barat 1978; Castro 2003; Galvao 1999; Graham 1972; Graham and Hollanda 1971; Oliveira 1977).

During the 1960s, the federal capital moved to Brasília and the federal government started to implement other regional development policies, combining investments in infrastructure, fiscal, and credit incentives. The priority given to highways in detriment of railways was inadequate for the transportation requirements of the agricultural exports from flatlands of the Cerrado areas in the Center-West and North regions of the country. As a consequence, the growth of agricultural productivity and output in these areas were retarded in the last quarter of the century (Castro 2002; Gasques and Yokomizo 1985; Reis and Blanco 2000; Reis and Margullis 1990; Silveira 1957; Weinhold and Reis 2008; Andersen et al. 2002).

From 1968 to 1995, the expansion of the road infrastructure reduced the costs of moving one unit of cargo to São Paulo (a good proxy for the domestic market) more than $40 \%$. Despite that, high transport costs still remain one of the most critical obstacles to Brazilian competitiveness and development. In the Cerrado areas in the Center-West and North regions, in addition to the reduction of transport costs, the profitability of economic activities was enhanced by the possibilities of agricultural mechanization of the flatlands. Another crucial factor in this way was Embrapa's agricultural research which adapted new cultivars - in particular soybeans, rice, and cotton - to the ecological conditions prevailing in the region (Arantes and Souza 1993; Helfand and Rezende 1998; Homma 2003). Naturally, the causal relationships between transport infrastructure, mechanization, and biogeochemical innovations are hard to disentangle. 


\section{Spatial Patterns of Growth, 1872-2000}

This section uses a series of maps and graphs to illustrate the spatial patterns of Brazilian development. The number of Brazilian municípios increased from 642 in 1872 to 5507 in 2000. Thus, to allow consistent inter-temporal analysis, municípios are combined in 432 Minima Comparable Geographic Areas from 1872 to 2000 (MCA 1872-2000; Reis 2008, 2014; Reis et al. 2005, 2011). ${ }^{2}$ Though the time benchmarks of the analysis are primarily determined by Census years, they are useful to provide a fairly broad characterization of the main phases of Brazilian development during the period (Reis et al. 2002).

Figure 1a, f shows the huge spatial disparities of income per capita and labor productivity in 1872. The Northeast, in particular the semiarid areas of the hinterland, was already the poorest region of the country.

The richest areas were located around the city of Rio de Janeiro, which was then the capital and the largest port of the country, and the cities of Rio Grande and Porto Alegre in the extreme south of the country which were the main ports for the fertile Pampas. The high productivity and income per capita levels in the Amazon region are explained by the rubber boom. Note, in passing, that the economic activity in the highlands was practically restricted to the old mining areas of the Center-South region.

From 1872 to 1920 , growth was mainly driven by the export of primary commodities, in particular rubber in the North region and coffee in the Center-South region which pushed the economic frontier in the southwest direction. Figure $1 \mathrm{~b}, \mathrm{~g}$ shows that, in 1920, São Paulo and Rio Grande do Sul display the highest levels of income per capita and labor productivity, both states combining a very productive agriculture with emerging manufacturing activities. By then, the rubber exports in the Amazon had busted.

From 1920 to 1950, the country completed the first stage of industrialization mainly based upon the import substitution of consumer goods. During this period, the city of São Paulo and her surroundings consolidated their place as the dominant industrial pole of the country. Figure $1 \mathrm{c}$, h shows that the concentration of income per capita in São Paulo was intensified by the mid-twentieth century when the processes of urbanization and industrialization reached their peaks. Coffee expansion explains the spread of high income per capita towards the southwest areas of São Paulo and Paraná.

From 1950 to 1980, coupled with an accelerated urbanization process, high trade protection, and strong state intervention, the import substitution industrialization deepened going into durable consumer goods, basic raw materials, and capital goods industries. Despite record high rates of growth, by the end of this period, the Brazilian economy was autarkic and inefficient with a definite policy bias against primary exports. Figure 1d, i shows that, during this period, economic activity

\footnotetext{
${ }^{2}$ The map excludes the State of Acre because in 1872 she was still part of Bolivian territory; only in 1905 she became part of the Brazilian territory.
} 


\begin{tabular}{|l|c|c|}
\hline Year & $\begin{array}{c}\text { Figures A to E } \\
\text { Income per capita (GDP/Population) }\end{array}$ & $\begin{array}{c}\text { Figures F to J } \\
\text { Labor productivity (GDP/Labor force) }\end{array}$ \\
\hline 1872 & & \\
\hline 1919 & & \\
\hline 1950 & & \\
\hline
\end{tabular}

Fig. 1 Brazil: Geographic distribution (AMC 1872-2000) of income per capita (GDP/population) and of labor productivity (GDP/labor force) in (a, f) 1872, (b, g) 1919, (c, h) 1949, (d, i) 1980, and (e, j) 2000 (units and scale variable). Source: IBGE and author's estimates

definitely turned towards the northwest direction led by the move of the federal capital to Brasilia as well as by other regional policies which fostered the expansion of the agricultural crops like cattle, rice, soybean, and corn.

After 1980, autarky and inefficiency charged their tolls with debt crisis, hyperinflation, and stagnation. In the ensuing decades the unavoidable policies were 


\section{Curva de Lorenz da distribuição do PIB municipal segundo a população municipal, 1872-2000}

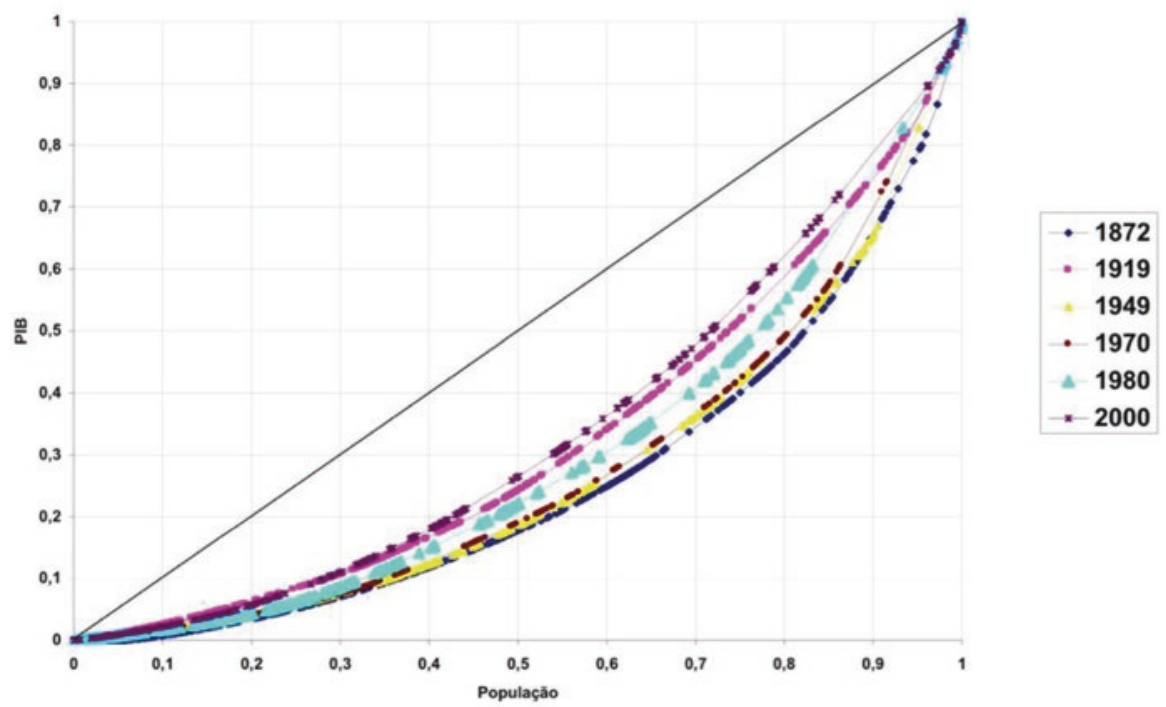

\section{Source: Author's estimates}

Fig. 2 Lorenz curves of the municipal distributions of GDP according to municipal population, 1872-2000. Source: Author's estimates

stabilization, fiscal adjustment, and liberalization which are still lurking. Trade liberalization policies eliminated a large part of the bias against exports of primary commodities which became one of the main sources of growth during this period. On top of that, the country faced the end of the urbanization process and the emergence of population ageing. With the vanishing of import substitution policies, the high levels of income per capita started spreading towards the agricultural frontier in the Center-West and North regions. São Paulo and Rio Grande do Sul kept their leading positions while the Northeast region lagged far behind the rest of the country. By 2000, both in terms of income per capita and labor productivity, the secular divide of the country in the northwest-southeast direction still persisted. ${ }^{3}$

Closing this section, Fig. 2 presents Lorenz curves for the municipal income per capita distribution for the Census years. ${ }^{4}$ The highest spatial concentration took place in $1872($ Gini $=0.45)$ with the respective Lorenz curves practically enveloping

\footnotetext{
${ }^{3}$ It is curious to observe that his division line resembles the southern boundaries of the InterTropical Convergence Zone (ITCZ) observed in the Brazilian territory around January-April, thus suggesting that geographic factors like El Niño might have a persistent effect on the spatial distributions of labor productivity and income per capita.

${ }^{4}$ To be precise, Gini coefficients refer to the 432 comparable areas from 1872 to 2000 and not to municipalities in each Census year. For that reason inequality figures are downward biased. Using comparable areas for 1970-2000, Gini coefficients are 0.5 in 1970, 0.45 in 1980, and 0.41 in 2000, but not strictly comparable with previous Census years.
} 
the other years. Conversely, the lowest spatial concentration took place in 2000 $($ Gini $=0.32)$ with a Lorenz curve that is practically enveloped by all the other years. But the process of spatial dispersion of income per capita was far from monotonic. The curves display a strong dispersion from 1872 to 1919 (Gini decreases from 0.45 to 0.36 ), when the economy was driven by coffee and rubber exports, and more so from 1970 to 2000 (Gini decreases from 0.45 to 0.32 ) when growth was driven by mining and the agricultural frontier in the Cerrado areas of the Center-West region. Conversely, there is strong concentration from 1919 to 1970 (Gini increases from 0.36 to 0.45 ) during the heydays of urbanization and import substitution industrialization. It should be kept in mind, however, that during the import substitution period growth rates of the economy were significantly higher.

\section{Secular Patterns of Convergence of Labor Productivity and Income Per Capita in Brazil, 1872-2000}

This section analyzes the patterns of spatial convergence of municipal income per capita and labor productivity from 1872 to 2000 . For this purpose, it estimates very simple convergence models where the growth rates of income per capita and of labor productivity in a period of time are specified as a function of the respective variable - income per capita or labor productivity - in the initial year of the period in case.

The basic specification of the convergence model is thus

$$
\log \left(y_{i, t} / y_{i, t-n}\right)^{1 / n}=\alpha+\beta \cdot \log \left(y_{i, t-n}\right)
$$

where

$y_{i, t}=\left(Y_{i, t} / \mathrm{Pop}_{i}\right)$ is GDP per capita (or GDP per labor force) in municipality $i$, Census year; $Y_{i, t}$ is GDP per capita in municipality $i$, Census year $t$; and Pop $_{i, t}$ is population (or labor force) in municipality $i$, Census year $t$. $\beta$ is an estimated coefficient that measures the speed of convergence of income per capita (or labor productivity) of municipalities.

To further investigate the processes of convergence estimations were also made assuming spatial autocorrelation in both the dependent (SACD) and residual (SACR) variables of the equations.

The first model (SACD) assumes spatial inertia in the growth of income or of labor productivity. Thus, without specifying the underlying causes, the model assumes that growth is transmitted to contiguous municipalities through contagion. Emulation, migration of labor, capital, and/or technology are possible explanations of the contagious processes.

The second model (SACR) assumes that the residuals of the growth variables are subject to spatial autocorrelation. That is, the determinants of the growth processes 
other than the initial income per capita or labor productivity, though unknown, are supposed to be subject to spatial inertia as in the case of most geographic variables, or else to be subject of spatial contagion through markets, social contacts, shared local culture, or institutions. Note, however, that the speed of convergence is now measured among groups of contiguous municipalities that have some common unspecified determinants of the growth of productivity. In this way, it is a convergence conditionally measured. Spatial clusters of municipalities are converging to different steady-state levels of income per capita or labor productivity.

Estimates of $\beta$, the speed of municipal convergence, of both income per capita (GDP/Population) and labor productivity (GDP/Labor force) for the three models in the 1872-2000 period, as well as for the subperiods 1872-1919, 1919-2000, 19191949, 1949-1980, and 1980-2000, are presented in columns 2-5 of Table 1 (Reis 2014 for more detailed results). Columns 3 and 5 show the coefficients of spatial autocorrelations (SAC) of the dependent variables and the residuals of the respective equation.

Before coming to the regression results it is interesting to observe that, in the period 1872-2000, average municipal growth rates were slightly higher for income per capita ( $1.80 \%$ p.a.) than for labor productivity (1.65\% p.a.), thus indicating that, on average, labor force grew a bit faster than population, that is, on average, the dependency ratio increased $0.015 \%$ during this period. Equivalent figures for 1920 2000 are $3.4 \%$ p.a. and $4.5 \%$ p.a., respectively, thus indicating that, on average, the dependency ratio decreased $1.1 \%$ p.a.

For the whole 1872-2000 period, OLS estimates of $\beta$ for income per capita and labor productivity are -0.006 and -0.005 , both significant at 0.001 probability level. Thus, municipalities with $1 \%$ more in the level of income per capital in 1872 had 0.005 less in their annual average growth rates from 1872 to 2000 . The speed of convergence is quite small and practically the same for both income per capita and labor productivity.

Spatial autocorrelation effects are relatively large for the residual of the equation of income per capita and thus taking account of them makes a difference for the estimate of the speed of convergence of income per capita. Thus, from 1872 to 2000, unexplained geographic as well as other spatially correlated factors (like quality of soil, altitude, climate, distance to sea or to the state capital, culture, institutions) had a significant effect on the growth of municipal income per capita - but not on the productivity of labor.

Looking across subperiods, note first that the speed of convergence, $\beta$, for the 1872-1919 period shows a significant increase for labor productivity but not for income per capita. A suggested explanation is the effects on labor productivity of the changes in the dependency ratio and women participation rates related to the demise of slavery and impact of foreign immigration. The second observation is that spatial autocorrelation of the residuals in the equation of labor productivity is much higher for this period but the convergence of labor productivity is not much affected. 


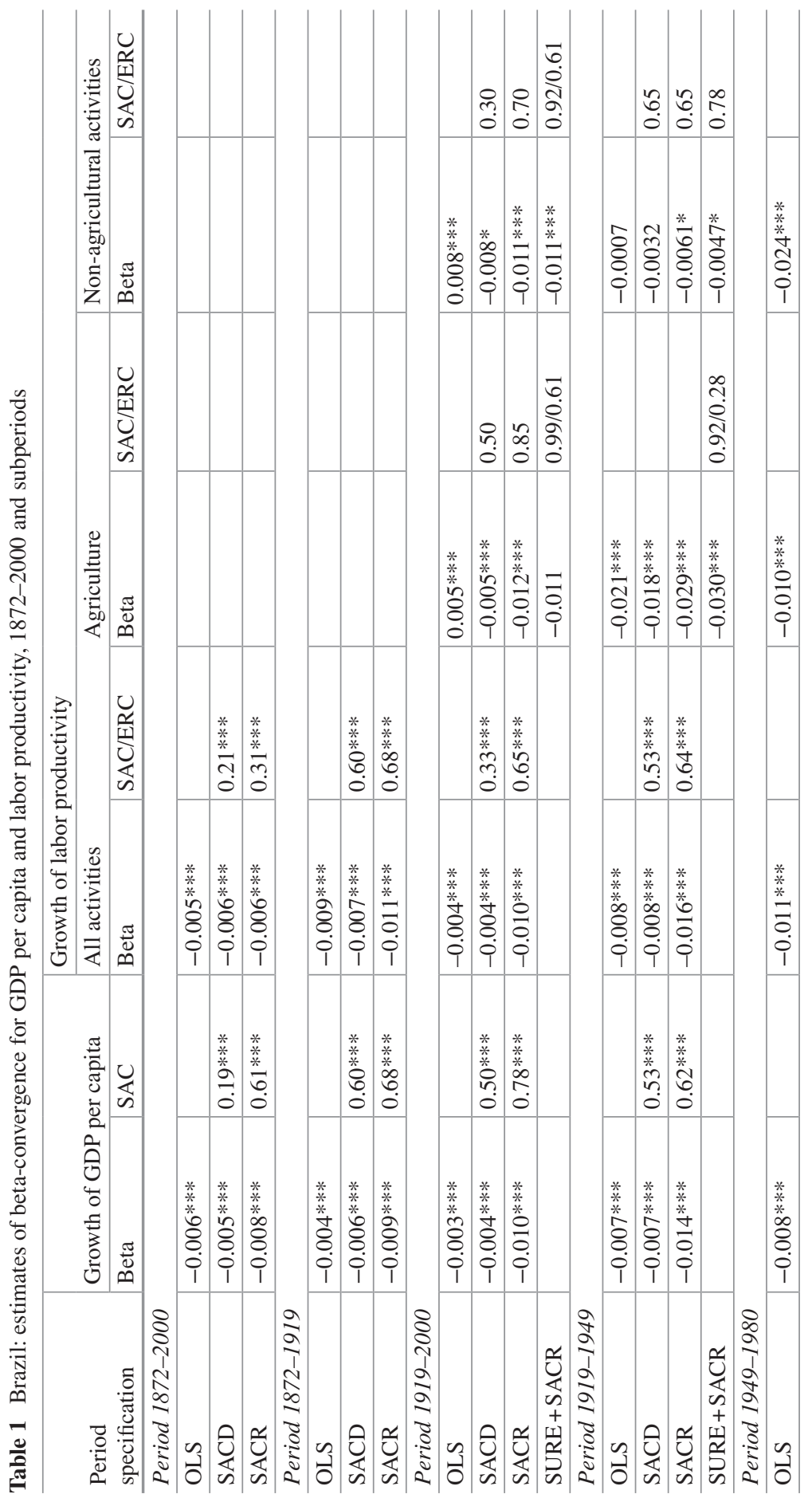




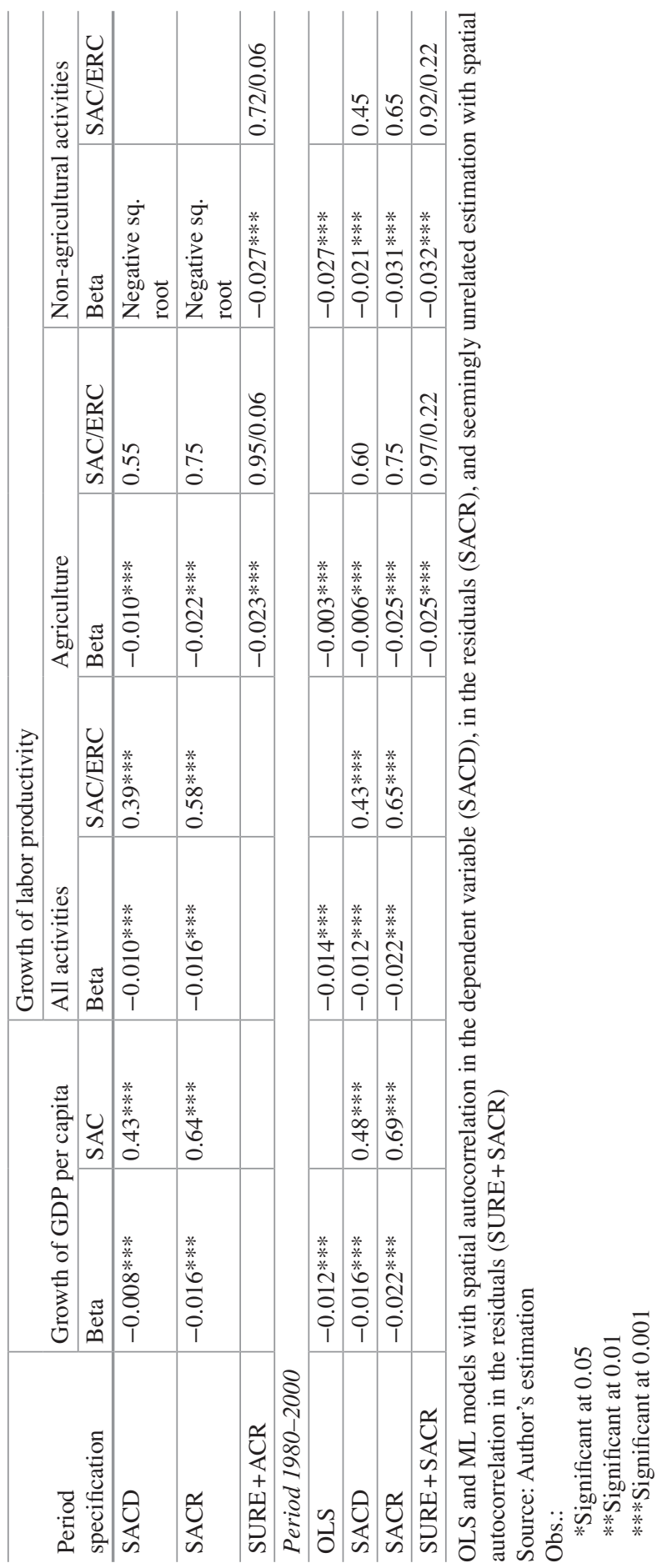


From 1920 to 2000, the speed of convergence of income per capita and labor productivity became even slower, except for the estimation taking account of the spatial autocorrelation of residuals of the respective equations. Thus, geographic as well as other factors correlated in space played an even more important role in the processes of municipal growth during the twentieth century. Looking at specific subperiods, however, the speed convergence is relatively faster, particularly from 1980 to 2000 .

It is difficult to pinpoint the forces shaping this historical pattern of convergence. From 1872 to 1919, the collapse of rubber frontier in the North Region is part of the explanation of the slower rates of convergence estimated. From 1919 to 1980, the import substitution industrialization was associated with urban concentration, economies of scale, and agglomeration, thus implying the slow rates of convergence of income and productivity. After 1970, regional government policies coupled with the natural resources content of the exports of minerals and agricultural commodities were responsible for the faster growth dispersion in both industry and agriculture. It should be kept in mind, however, that average growth rates were much higher in the import substitution phases. Finally, changes in the dependency ratio associated with migration and urbanization trends probably played differential roles across subperiods.

Compared to other countries, the convergence of municipal income per capita in Brazil was quite slow. Indeed, estimates of $\beta$ are close to -0.02 , both in the case of personal income in the US states in the period 1950-1980 and of income per capita of Japanese municipalities in the period 1955-1987 (Barro and Sala-iMartin 1995). Equivalent estimates for income per capita of Italian municipalities are -0.025 for the period $1951-1970$, and -0.003 for the period 1970-2000 (Arbia et al. 2002; Felice 2013)). The magnitude of those estimates is significantly higher than those estimated for Brazil in the periods 1950-1980 or 1980-2000.

For the whole 1872-2000 period estimations are also disaggregated by main regions - North, Northeast, Center-South, South, and Center-West - to get a more detailed picture of geographic patterns of convergence of income per capita and labor productivity. Results not reported here (see Reis 2014) show that in all regions the speed of convergence was a bit faster than in the country as a whole, thus suggesting a secular process of divergence among regions which was counteracted by a slow process of spatial convergence inside each region. The concentration of import substitution industrialization in the Center-South region of the country and the marked regional contrasts in soil aptitude and agricultural development were, undoubtedly, major factors in process of regional divergence. Inside the regions, the speed of convergence was faster in the South and in the North Region, but slow in the Northeast. For all regions, however, $\beta$ estimates were still exceedingly low in international perspective.

In what follows, the analysis of growth convergence of labor productivity in the period 1919-2000 will be detailed in two ways: first, by the disaggregation of the analysis for urban and rural activities, and, second, by assuming spatial correlation among the variables of the model as well as among equations of describing the 
processes of urban and rural growth. This is made possible because for the 19192000 period the economic censuses allow the estimation of separate convergence equations for labor productivity in rural (agriculture) and urban (nonagricultural) activities. $^{5}$

A preliminary finding is that the average growth of labor productivity was higher in agriculture $(2.6 \%$ p.a.) than in urban activities $(2.4 \%$ p.a.). To a large extent the explanation lies in the weight of the service sector and all kinds of low-productivity informal activities in the growth of urban output and employment.

Convergence was faster for labor productivity than for income per capita, both however extremely low when compared with other countries. The faster convergence of labor productivity is difficult to interpret without further analysis of demographic patterns of growth-dependency ratio, in particular-during this period.

Convergence equation for the growth of labor productivity in rural and urban activities in the 1920-2000 period shows that the speed of convergence was faster for urban activities, though both are still very low compared to international standards. This result sounds reasonable given the relatively footloose characteristics of urban activities, while agriculture depends on the availability of adequate soils and climate which are concentrated in specific areas-particularly in the South and Center-West regions - of the country.

It is interesting to observe that both rural and urban activities show higher speed of convergence than aggregate labor productivity in the economy, thus suggesting that there were synergies and cross-correlations between the processes of growth in labor productivity in both sectors. Rural and labor productivity grew faster or slower in the same areas, thus characterizing patterns of growth high-high or low-low in both sectors.

Finally, the last model combines the assumption of correlation of residuals of the growth convergence equations for labor productivity in urban and rural activities with the assumption of spatial autocorrelation in the residuals of each of the equations (SURE+SACR). The results are pretty similar to the ones obtained with the SACR model. Thus, what matters most for the process of convergence of labor productivity in rural and urban activities is the spatial autocorrelation observed for each of these activities and not the correlation between the growth of productivity in rural and urban activities. Thus, residual factors in the growth convergence equations of labor productivity in the rural and urban activities and the growth of labor productivity in rural and urban activities in the Brazilian economy during the twentieth century were quite independent processes with each of them subject to spatial inertia processes.

\footnotetext{
${ }^{5}$ The sectorial disaggregation is not made for income per capita simply because the Census of 1920 did not collect data on rural and urban population despite collecting data on labor force according to major economic activities.
} 


\section{Factors Conditioning Convergence Patterns, 1920-2000}

To analyze the determinants of the growth patterns of the Brazilian economy in the period 1920-2000, the specifications of the growth convergence equations are enlarged to incorporate the determinants of steady-state growth rates of Brazilian municipalities. This is made by the specification of a conditional model introducing variables like infrastructure, geographical attributes, institutions, and human capital, among others, as exogenous determinants of the growth of municipalities from 1920 to $2000 .^{6}$

In the case of the growth of GDP per capita, the model to be estimated becomes

$$
\log \left(y_{i, t} / y_{i, t-n}\right)^{1 / n}=\alpha+\beta \cdot \log \left(y_{i, t-n}\right)+\gamma \cdot X_{i, t-n}
$$

where

$y_{i, t}=Y_{i, t} / \mathrm{Pop}_{i}$ ( or $Y_{i, t} /$ Labor $_{i}$ ) is the aggregate, urban, or rural labor productivity (GDP/labor force) or GDP per capita of município $i$ in year $t$.

$Y_{i, t}$ is the aggregate, urban, or rural GDP of município $i$ in year $t$; $\operatorname{Pop}_{i, t}$ is the total, urban, or rural population of município $i$ in year $t$.

Labor $_{i, t}$ is the aggregate urban or rural labor force of the município $i$ in year $t$.

$X_{i, t-n}=$ matrix of explanatory variables including all the exogenous variables that explain the steady-state rate of growth of Brazilian municipalities from 1920 to 2000.

The explanatory factors are listed in the first column of Table 2. They include major characteristics of the municipalities in terms of geography (area, latitude, longitude, altitude, temperature, precipitation, soil types, etc.), demography (population, foreign population, labor force), economy (GDP by sectors, landownership concentration, electricity generation, area of farms, share of coffee in cropped area), accessibility and transport (existence and age of railway station, distance to sea, and distance to capital, potential market index), human capital and education (literacy, enrollment, and number of primary schools), and a few institutional dimensions like the number of slaves in 1872 and the number of voters in 1910. Most of the variables refer to 1920. The exceptions are slavery, schools, and voters which were not available for 1920, and, obviously, geographic conditions. For a description of the definition and measurement of exogenous variables see Reis (2014) and Reis et al. (2007).

Estimation results presented in Table 2 show that initial socioeconomic conditions in 1920 explain more than $50 \%$ of the variance of the growth rates of Brazilian municipalities in the period 1920-2000. Note that the OLS estimations of simple growth convergence in equations of Table 2 explained around $15 \%$.

The speed of convergence is approximately equal to 1 for both income per capita and labor productivity. For urban and agriculture activities the estimates for GDP per worker are 1.2, approximately. These values are relatively small given that they

\footnotetext{
${ }^{6}$ It was not possible to extend the analysis to 1872 because all the conditional variables available were used to estimate income per capita for this year, thus making them unavoidably correlated to endogenous variables.
} 
Table 2 Brazil: OLS estimation of conditional growth convergence of GDP per capita and labor productivity in urban and rural activities, 1919-2000

\begin{tabular}{|c|c|c|c|c|c|}
\hline \# & & $\begin{array}{l}\text { Growth of } \\
\text { GDP per } \\
\text { capita } \\
1919-2000\end{array}$ & $\begin{array}{l}\text { Growth of } \\
\text { aggreg. labor } \\
\text { productivity } \\
\text { 1919-2000 }\end{array}$ & $\begin{array}{l}\text { Growth of } \\
\text { rural labor } \\
\text { productivity } \\
1919-2000\end{array}$ & $\begin{array}{l}\text { Growth of } \\
\text { urban labor } \\
\text { productivity } \\
1919-2000\end{array}$ \\
\hline 1 & N. obs. & 397 & 397 & 395 & 397 \\
\hline 2 & $F$-value & 7.193 & 6.898 & 8.600 & 6.632 \\
\hline 3 & $R$-square & 0.552 & 0.541 & 0.597 & 0.532 \\
\hline 4 & Adj. $R$-square & 0.475 & 0.463 & 0.527 & 0.451 \\
\hline 5 & Dependent mean & 0.034 & 0.030 & 0.026 & 0.024 \\
\hline 6 & Root MSE & 0.006 & 0.005 & 0.008 & 0.006 \\
\hline 7 & Coeff. var. & 16.567 & 18.419 & 32.072 & 22.852 \\
\hline 8 & Variables & & & & \\
\hline 9 & Intercept & $-0.188 * *$ & $-0.155^{*}$ & -0.065 & -0.098 \\
\hline 10 & $\begin{array}{l}\text { Log (GDP per capita } \\
\text { 1919) }\end{array}$ & $-0.010 * *$ & & & \\
\hline 11 & $\begin{array}{l}\text { Log (labor } \\
\text { productivity 1919) }\end{array}$ & & $-0.010 * *$ & & \\
\hline 12 & $\begin{array}{l}\text { Log (labor } \\
\text { productivity rural } \\
1919 \text { ) }\end{array}$ & & & $-0.012 * *$ & \\
\hline 13 & $\begin{array}{l}\text { Log (labor } \\
\text { productivity urban } \\
\text { 1919) }\end{array}$ & & & & $-0.012 * *$ \\
\hline 14 & $\begin{array}{l}\text { Log (population in } \\
1920 \text { ) }\end{array}$ & -0.004 & -0.005 & -0.005 & -0.003 \\
\hline 15 & $\log$ (labor force 1920) & 0.000 & 0.002 & $-0.014^{*}$ & 0.003 \\
\hline 16 & $\begin{array}{l}\text { Log (labor force in } \\
\text { agriculture 1920) }\end{array}$ & 0.002 & 0.002 & $0.012 * *$ & 0.000 \\
\hline 17 & $\begin{array}{l}\text { Log (labor force in } \\
\text { manufacture1920) }\end{array}$ & 0.000 & 0.000 & -0.001 & 0.000 \\
\hline 18 & $\begin{array}{l}\log (\text { foreigners in } \\
1920)\end{array}$ & $0.001 * *$ & $0.001 *$ & $0.002 * *$ & 0.001 \\
\hline 19 & Log (literates in 1920) & 0.001 & 0.000 & 0.004 & -0.002 \\
\hline 20 & $\begin{array}{l}\text { Students public } \\
\text { primary school 1920/ } \\
\text { population } 1920\end{array}$ & -0.128 & -0.108 & 0.018 & -0.077 \\
\hline 21 & $\begin{array}{l}\text { Students private } \\
\text { primary school 1920/ } \\
\text { population } 1920\end{array}$ & 0.084 & 0.082 & 0.158 & 0.106 \\
\hline 22 & $\begin{array}{l}\text { Number of state } \\
\text { primary schools in } \\
1920 / \text { population in } \\
1920\end{array}$ & 2.300 & 1.978 & 0.487 & 0.755 \\
\hline 23 & $\begin{array}{l}\text { Number of private } \\
\text { primary schools in } \\
1920 \text { /population in } \\
1920\end{array}$ & 3.313 & 2.582 & -0.684 & -0.899 \\
\hline
\end{tabular}


Table 2 (continued)

\begin{tabular}{|c|c|c|c|c|c|}
\hline \# & & $\begin{array}{l}\text { Growth of } \\
\text { GDP per } \\
\text { capita } \\
1919-2000\end{array}$ & $\begin{array}{l}\text { Growth of } \\
\text { aggreg. labor } \\
\text { productivity } \\
1919-2000\end{array}$ & $\begin{array}{l}\text { Growth of } \\
\text { rural labor } \\
\text { productivity } \\
1919-2000\end{array}$ & $\begin{array}{l}\text { Growth of } \\
\text { urban labor } \\
\text { productivity } \\
1919-2000\end{array}$ \\
\hline 24 & $\begin{array}{l}\text { Dummy for railway } \\
\text { station in } 1920\end{array}$ & $0.148 *$ & $0.141^{*}$ & -0.066 & $0.153 * *$ \\
\hline 25 & $\begin{array}{l}\text { Inaugural year of } \\
\text { railway in the } \\
\text { municipality }\end{array}$ & $0.000^{*}$ & $0.000^{*}$ & 0.000 & $0.000 * *$ \\
\hline 26 & $\begin{array}{l}\text { Dummy for electricity } \\
\text { generation station in } \\
1920\end{array}$ & 0.277 & 0.298 & 0.254 & 0.340 \\
\hline 27 & $\begin{array}{l}\text { Inaugural year of } \\
\text { electricity in the } \\
\text { municipality }\end{array}$ & 0.000 & 0.000 & 0.000 & 0.000 \\
\hline 28 & $\begin{array}{l}\text { Number of electrical } \\
\text { motors in municipality } \\
1920\end{array}$ & -0.001 & -0.001 & 0.000 & -0.001 \\
\hline 29 & $\begin{array}{l}\text { Power of electrical } \\
\text { motors in municipality } \\
1920 \text { (Kwh) }\end{array}$ & $0.000^{*}$ & $0.000^{*}$ & 0.000 & $0.000^{*}$ \\
\hline 30 & $\begin{array}{l}\text { Number of enterprises } \\
\text { generating } \\
\text { hydroelectricity } 1920\end{array}$ & $0.001 *$ & $0.001^{*}$ & 0.000 & $0.001^{*}$ \\
\hline 31 & $\begin{array}{l}\text { Number of registered } \\
\text { voters in 1914/ } \\
\text { Population in } 1920\end{array}$ & -0.011 & -0.005 & $-0.070 *$ & 0.002 \\
\hline 32 & $\begin{array}{l}\text { Share of slaves in total } \\
\text { population } 1872\end{array}$ & 0.007 & 0.006 & 0.000 & 0.006 \\
\hline 33 & $\begin{array}{l}\text { Log (area of } \\
\text { agricultural } \\
\text { establishments in } \\
\text { 1920) }\end{array}$ & 0.001 & 0.001 & $0.002 * *$ & 0.001 \\
\hline 34 & $\begin{array}{l}\text { Crop area of coffee } \\
1920 / \text { area of farms } \\
1920\end{array}$ & -0.005 & -0.006 & 0.008 & -0.001 \\
\hline 35 & $\begin{array}{l}\text { Theil index of } \\
\text { landownership } \\
\text { inequality in } 1920\end{array}$ & 0.000 & 0.000 & 0.000 & 0.000 \\
\hline 36 & $\begin{array}{l}\text { Log (GDP potential } \\
\text { market in 1919) }\end{array}$ & $0.007 * *$ & $0.007 * *$ & -0.002 & $0.006^{* *}$ \\
\hline 37 & $\begin{array}{l}\text { Log (geographic area } \\
\text { of AMC) }\end{array}$ & 0.000 & 0.000 & -0.001 & 0.000 \\
\hline 38 & $\begin{array}{l}\text { Latitude of seat of } \\
\text { municipality }\end{array}$ & -0.0003 & -0.0002 & $-0.0015^{* *}$ & 0.0000 \\
\hline 39 & $\begin{array}{l}\text { Longitude of } \\
\text { municipality seat }\end{array}$ & 0.0001 & 0.0001 & 0.0002 & 0.0000 \\
\hline
\end{tabular}


Table 2 (continued)

\begin{tabular}{|c|c|c|c|c|c|}
\hline \# & & $\begin{array}{l}\text { Growth of } \\
\text { GDP per } \\
\text { capita } \\
1919-2000\end{array}$ & $\begin{array}{l}\text { Growth of } \\
\text { aggreg. labor } \\
\text { productivity } \\
\text { 1919-2000 }\end{array}$ & $\begin{array}{l}\text { Growth of } \\
\text { rural labor } \\
\text { productivity } \\
1919-2000\end{array}$ & $\begin{array}{l}\text { Growth of } \\
\text { urban labor } \\
\text { productivity } \\
\text { 1919-2000 }\end{array}$ \\
\hline 40 & $\begin{array}{l}\text { Dummy for state } \\
\text { capital }\end{array}$ & $0.0050 * *$ & $0.0038^{*}$ & 0.0004 & 0.0032 \\
\hline 41 & $\begin{array}{l}\text { Geodesic distance to } \\
\text { the state capital (in } \\
\mathrm{km} \text { ) }\end{array}$ & 0.0000 & 0.0000 & $0.0000 * *$ & 0.0000 \\
\hline 42 & $\begin{array}{l}\text { Geodesic distance to } \\
\text { the sea (in } \mathrm{km} \text { ) }\end{array}$ & 0.0000* & $0.0000 *$ & 0.0000 & 0.0000 \\
\hline 43 & $\begin{array}{l}\text { Share of area w/ } \\
\text { altitude } 0 \text { a } 99 \mathrm{~m}\end{array}$ & $0.007 * *$ & $0.007 * *$ & 0.006 & $0.009 * *$ \\
\hline 44 & $\begin{array}{l}\text { Share of area w/ } \\
\text { altitude } 200 \text { a } 499 \mathrm{~m}\end{array}$ & -0.002 & -0.003 & 0.002 & -0.001 \\
\hline 45 & $\begin{array}{l}\text { Share of area w/ } \\
\text { altitude } 500 \text { a } 799 \mathrm{~m}\end{array}$ & 0.001 & 0.000 & $0.008^{*}$ & 0.002 \\
\hline 46 & $\begin{array}{l}\text { Share of area w/ } \\
\text { altitude } 800 \text { a } 1199 \mathrm{~m}\end{array}$ & 0.002 & 0.000 & 0.000 & 0.001 \\
\hline 47 & $\begin{array}{l}\text { Share of area w/ } \\
\text { altitude } 1200 \text { a } \\
1799 \mathrm{~m}\end{array}$ & -0.007 & -0.005 & 0.006 & -0.002 \\
\hline 48 & $\begin{array}{l}\text { Share of area w/ } \\
\text { altitude } 1800 \mathrm{a} \\
3000 \mathrm{~m}\end{array}$ & -0.131 & -0.127 & 0.105 & -0.125 \\
\hline 49 & $\begin{array}{l}\text { Share of area } \\
7.5-15 \% \text { declivity- } \\
\text { moderate erosion }\end{array}$ & -0.006 & -0.005 & -0.006 & -0.003 \\
\hline 50 & $\begin{array}{l}\text { Share of area } 30-45 \% \\
\text { declivity-strong } \\
\text { erosion }\end{array}$ & -0.005 & -0.004 & -0.006 & -0.004 \\
\hline 51 & $\begin{array}{l}\text { Share of municipal } \\
\text { soil in class } 1\end{array}$ & $0.158^{*}$ & $0.144 *$ & 0.062 & 0.093 \\
\hline 52 & $\begin{array}{l}\text { Share of municipal } \\
\text { soil in class } 2\end{array}$ & $0.160 *$ & $0.145^{*}$ & 0.058 & 0.095 \\
\hline 53 & $\begin{array}{l}\text { Share of municipal } \\
\text { soil in class } 3\end{array}$ & $0.144 *$ & $0.128 *$ & 0.054 & 0.080 \\
\hline 54 & $\begin{array}{l}\text { Share of municipal } \\
\text { soil in class } 4\end{array}$ & $0.150^{*}$ & $0.136^{*}$ & 0.057 & 0.087 \\
\hline 55 & $\begin{array}{l}\text { Share of municipal } \\
\text { soil in class } 5\end{array}$ & $0.149 *$ & $0.135^{*}$ & 0.048 & 0.091 \\
\hline 56 & $\begin{array}{l}\text { Share of municipal } \\
\text { soil in class } 6\end{array}$ & $0.156^{*}$ & $0.141^{*}$ & 0.061 & 0.092 \\
\hline 57 & $\begin{array}{l}\text { Share of municipal } \\
\text { soil in class } 7\end{array}$ & $0.160 *$ & $0.145^{*}$ & 0.059 & 0.096 \\
\hline 58 & $\begin{array}{l}\text { Share of municipal } \\
\text { soil in class } 8\end{array}$ & $0.158^{*}$ & $0.143^{*}$ & 0.058 & 0.094 \\
\hline
\end{tabular}


Table 2 (continued)

\begin{tabular}{l|l|l|l|l|l}
\hline$\#$ & & $\begin{array}{l}\text { Growth of } \\
\text { GDP per } \\
\text { capita } \\
1919-2000\end{array}$ & $\begin{array}{l}\text { Growth of } \\
\text { aggreg. labor } \\
\text { productivity } \\
1919-2000\end{array}$ & $\begin{array}{l}\text { Growth of } \\
\text { rural labor } \\
\text { productivity } \\
1919-2000\end{array}$ & $\begin{array}{l}\text { Growth of } \\
\text { urban labor } \\
\text { productivity } \\
1919-2000\end{array}$ \\
\hline 59 & $\begin{array}{l}\text { Share of municipal } \\
\text { soil in class 9 }\end{array}$ & $0.161^{*}$ & $0.148^{*}$ & 0.083 & 0.084 \\
\hline 60 & $\begin{array}{l}\text { Share of municipal } \\
\text { soil in class 10 }\end{array}$ & $0.156^{*}$ & $0.141^{*}$ & 0.058 & 0.092 \\
\hline 61 & $\begin{array}{l}\text { Share of municipal } \\
\text { soil in class 11 }\end{array}$ & $0.146^{*}$ & $0.131^{*}$ & 0.055 & 0.083 \\
\hline 62 & $\begin{array}{l}\text { Share of municipal } \\
\text { soil in class 12 }\end{array}$ & -0.049 & -0.068 & 0.309 & -0.159 \\
\hline 63 & $\begin{array}{l}\text { Average precipitation } \\
\text { Dec-Feb 1961-1990 }\end{array}$ & $-0.00005^{*}$ & -0.00003 & 0.00003 & -0.00004 \\
\hline 64 & $\begin{array}{l}\text { Average precipitation } \\
\text { Jun-Aug 1961-1990 }\end{array}$ & $-0.00004^{*}$ & -0.00002 & $0.00009 * *$ & -0.00002 \\
\hline 65 & $\begin{array}{l}\text { Average precipitation } \\
\text { Mar-May 1961-1990 }\end{array}$ & 0.00004 & 0.00003 & 0.00000 & 0.00000 \\
\hline 66 & $\begin{array}{l}\text { Average precipitation } \\
\text { Sep-Nov 1961-1990 }\end{array}$ & 0.00002 & 0.00000 & -0.00007 & 0.00003 \\
\hline 67 & $\begin{array}{l}\text { Average temperature } \\
\text { Dec-Feb 1961-1990 }\end{array}$ & -0.00210 & -0.00138 & $-0.00613 * *$ & 0.00039 \\
\hline 68 & $\begin{array}{l}\text { Average temperature } \\
\text { Jun-Aug 1961-1990 }\end{array}$ & -0.00129 & -0.00040 & $-0.00507^{* *}$ & 0.00092 \\
\hline 69 & $\begin{array}{l}\text { Average temperature } \\
\text { Mar-May 1961-1990 }\end{array}$ & 0.00189 & 0.00115 & $0.00549 *$ & -0.00136 \\
\hline 70 & $\begin{array}{l}\text { Average temperature } \\
\text { Sep-Nov 1961-1990 }\end{array}$ & 0.00100 & 0.00009 & $0.00743 * *$ & -0.00060 \\
\hline S0urc: Aut & & & & \\
\hline 6
\end{tabular}

Source: Author's estimates (pib14si.xls)

Obs.:

*Significant at $5 \%$ level

**Significant at $1 \%$ level

refer to estimates of the speed of conditional growth convergence of municipalities which had similar conditions in 1920. Thus, even among municipalities with similar initial conditions the speed of convergence is slow compared to other countries.

In Table 2 the variables with estimated coefficients significant at 5\% level are considered relevant as growth factors and as such marked with one asterisk. Two asterisks denote the threshold of $1 \%$ significance level. Whenever meaningful, variables were specified as logarithm except when there is a high incidence of null observations in which case they were specified in per capita terms.

Estimation results show that population in 1920 is not significant in all the equations (marginally in the case of the growth labor productivity) but is kept as a normalizing variable for all the other variables.

The most important variable is the dummy for the existence of a railway station in 1920. Ceteris paribus, that would imply an increase of $14 \%$ p.a. in average growth rates from 1920 to 2000 . This a huge impact but is restricted to urban activities; 
growth rates of agricultural productivity were not significantly affected by the existence of a railroad in 1920. The problem with the estimation of this coefficient is that railroad stations could be capturing the effects of omitted variables related to transportation costs, accessibility, and other previous locational advantages. Places which had previous advantages in terms of access and natural resources availability were likely to grow faster in the long run and to that extent railroad stations would be endogenously located and its coefficient biased upward. A possible solution would be to use as instrumental variables describing transport accessibility previous to railways like, for example, distance to main seaports by mule troops in prerailways times. The difficulty, however, is the ubiquity of mule roads which imposes the need of some qualification. A better alternative, perhaps, would be to use transport costs to main markets instead of railroad station. Our future research will be directed in both ways.

The age of the railway station is also significant though it has very small positive effect on the average growth rate. Early comers in the railway access have had a small lasting growth advantage.

To be a state capital was also an important factor for the secular growth rate of both income per capita and labor productivity. The increases in average growth rates in the period 1920-2000 were $0.5 \%$ for GDP per capita and $0.4 \%$ for GDP per worker. The suggested explanation is the better accessibility to all kinds of infrastructure and government services. Surprisingly, perhaps, when we disaggregate the results, the effect is only marginally significant in the growth for urban activities, and, as expected, not significant for the growth of agricultural productivity.

The distance to a state capital, however, had a positive effect on the growth rate of labor productivity in agriculture but none on the other growth variables. It looks like as the consequence of home market effects or some form of access to technology, since state capital is both more rich and populated as well as sources of knowledge and human capital.

Other infrastructure variables with significant effects have to do with electricity generation. Both the number of companies of electricity generation installed in a municipality in 1920 and their capacity of generation (in Kw) in that same year had a significant positive effect on the secular growth rate of GDP per capita and per worker. Each additional company brings $0.1 \%$ of increase in the annual average secular growth of the municipality. The effect is wholly due to industry. Growth rates of GDP per worker in agriculture are not affected by electricity infrastructure, as we should expect, given the fact the electrification of rural areas was practically absent in 1920.

Apart from infrastructure, the other important factor is the potential market of the municipality in 1920 measured by the average GDP of Brazilian municipalities weighted by the inverse of their geographic distances to the municipality in case. Each percent implied $0.001 \%$ more of average growth rates in 1920-2000. Thus, municipalities that were close to rich municipalities in 1920 grew more in the 19202000 period. Thus, market agglomeration effects were important and, as a consequence, demand factors and historical accidents probably played important roles in the spatial pattern of growth. 
Foreign-born population was also an important factor of productivity and income per capita growth. Interestingly, however, the effect was mainly felt in the growth of agricultural productivity. For the growth of urban productivity it was not significant. Suggested explanations are capital, technology, human capital, as well as cultural and institutional innovations introduced by the immigrants in the agricultural sector. ${ }^{7}$ It could as well be that migrants anticipated the agricultural growth prospects of the areas for where they migrated. In that case, the coefficient would be biased upward. Note, however, that coffee as percent of agricultural establishments is not a significant explanatory variable. And apart from that fact, it is difficult to envisage their successful prospection methods, in particular because they were likely to be ignorant about the agronomic conditions and growth possibilities of the different areas.

Agricultural activities tend to show some inertial or cumulative features in that the growth of agricultural productivity was higher in the municipalities with larger labor force in agriculture and area of a larger share of agricultural establishments in 1920. Note, however, that the size of total labor force tends to decrease the growth of agricultural productivity.

Geographic variables have some expected effects and other quite surprising. Thus, the effects of temperature and precipitation on the growth of GDP per capita are not significant. Moreover, the significance of soils in GDP per capita growth is probably capturing the the effects of state dummy that should be introduced as shown by the joint significance tests reported below.

Finally, the model tests the importance of some institutional conditions on the development of municipalities (Engerman and Sokolloff 1997, 2012; Nunn 2007). The proxies of institutional conditions included were the share of slaves in total population in 1872; Theil index for landownership concentration in 1920; a group of variables related to education including the literacy rate of population in 1920, and four other variables describing the availability of schools as well as the attendance of schools in 1907; and, finally, political participation in 1914 as measured by the share of registered voters in total population.

The results show that, surprisingly, solely or jointly considered, none of the institutional proxies selected were statistically significant (at the 5\% level) factors for the growth of Brazilian municipalities in the twentieth century. The only significant proxy of institutional factors is, therefore, the share of foreign-born population in 1920.

To test the institutional hypothesis, variables were jointly tested in three groups of variables composed as follows:

(A) Slavery in $1872+$ Registered voters in $1910+$ landownership concentration in 1920

\footnotetext{
${ }^{7}$ For a thoughtful discussion of the interactions of culture and institutions in the development process, see (Alesina and Giulano 2013). International comparative analysis and evidence on institutional factors can be found in (Lagerloef 2004, 2005) and (Engerman and Sokoloff 2012).
} 
(B) Education condition described by literacy rate in $1920+$ students enrolled in public and private schools in $1910+$ the number of public and private primary schools in 1910

(C) The share of foreign-born population in 1920

As shown in Table 3, F-tests for the joint significance of $\mathrm{A}, \mathrm{B}, \mathrm{A}+\mathrm{B}$, and $\mathrm{A}+\mathrm{B}+\mathrm{C}$ were conducted with the result that, at $5 \%$ confidence level, $\mathrm{A}, \mathrm{B}$, and $\mathrm{A}+\mathrm{B}$ are not significant in all cases. Only $\mathrm{A}+\mathrm{B}+\mathrm{C}$ is significant which is not surprising given that the share of foreign-born population was already significant when singly considered. But in the case of the growth of labor productivity in urban activities even $\mathrm{A}+\mathrm{B}+\mathrm{C}$ is not significant. Thus, climate conditions were binding factors for Brazilian agricultural growth but soil conditions and altitude were circumvented.

Finally, Table 3 also presents test of joint significance for the main geographic factors. Results show that, jointly considered, temperature and precipitation were significant explanatory factors for the growth of rural labor productivity. Surprisingly, however, altitude and geomorphology of soils were significant explanatory factors for the growth of income per capita and of labor productivity in the economy, as well as of the growth of labor productivity in urban areas, but not for the growth of rural labor productivity.

It should be pointed that the prevalence of slavery in 1872 gives a biased picture of the secular and persistent effects of the institution because concentration of the slave population in the booming coffee areas took place in a few decades during the mid-nineteenth century. Indeed, contradicting Nunn (2007), there is a strong positive correlation between the slave share of population in 1872 and the growth of income per capita from 1920 to 2000 . Thus, to some extent the share of slaves in 1872 is also endogenous to the development prospects of this region. To circumvent

Table $3 F$-tests of joint significance for the conditional growth equations of GDP per capita and labor productivity, 1919-2000

\begin{tabular}{|c|c|c|c|c|c|c|c|c|}
\hline \multirow[b]{3}{*}{ Groups of variables } & \multirow{2}{*}{\multicolumn{2}{|c|}{$\begin{array}{l}\text { Growth of GDP } \\
\text { per capita }\end{array}$}} & \multicolumn{6}{|c|}{ Growth of labor productivity } \\
\hline & & & \multicolumn{2}{|c|}{ Aggregate } & \multicolumn{2}{|l|}{ Rural } & \multicolumn{2}{|l|}{ Urban } \\
\hline & $F$-value & $\operatorname{Pr}>F$ & $F$-value & $\operatorname{Pr}>F$ & $F$-value & $\operatorname{Pr}>F$ & $F$-value & $\operatorname{Pr}>F$ \\
\hline $\begin{array}{l}\text { (A) Slave + politic + farm } \\
\text { Theil }\end{array}$ & 1.02 & 0.38 & 0.34 & 0.42 & 1.37 & 0.25 & 0.87 & 0.46 \\
\hline (B) Education & 1.78 & 0.11 & 1.37 & 0.24 & 1.24 & 0.29 & 1.27 & 0.28 \\
\hline (C) $\mathrm{A}+\mathrm{B}$ & 1.51 & 0.15 & 1.23 & 0.28 & 0.96 & 0.47 & 1.13 & 0.34 \\
\hline (D) $A+B+$ foreign & 2.67 & 0,01 & 2.08 & 0.03 & 3.21 & 0.00 & 1.34 & 0.22 \\
\hline (E) Temperature & 0.56 & 0.69 & 0.44 & 0.78 & 6.84 & 0.00 & 0.71 & 0.59 \\
\hline (F) Precipitation & 1.77 & 0.14 & 1.07 & 0.37 & 7.33 & 0.00 & 1.35 & 0.25 \\
\hline (G) Declivity & 1,15 & 0.32 & 1.09 & 0.34 & 0.53 & 0.59 & 0.43 & 0.65 \\
\hline (H) Altitude classes & 3.93 & 0.00 & 4.38 & 0.00 & 1.60 & 0.15 & 4.61 & 0.00 \\
\hline (I) Soil geo-morphol. & 2.30 & 0.01 & 2.31 & 0.01 & 0.67 & 0.78 & 1.73 & 0.06 \\
\hline
\end{tabular}

Source: Author's estimates 
this problem we use instead the data on free black population in 1872 . The rationale is that a large share of free blacks (pardos e pretos livres in 1872) is a better proxy for the historical prevalence of slavery in the municipality and thus to capture the long-run effects of slavery. Though the correlation with secular growth is negative in this case, the coefficients of this variable in the specified model were not significant.

A final interesting question to be posed is how persistent were the effects of railroads stations and foreign-born population in 1920 on the growth of Brazilian municipalities. To analyze this question we estimate the same conditional growth convergence model for each of the subperiods 1919-1950, 1950-1980, and 19802000 , that is, using the same specification except by the year of the lagged dependent variable. Figure 3a, b summarizes the values (and standard deviation) of the coefficients estimated for B-convergence, the station railroad dummy, and the foreign-born population in 1920 for each activity and subperiod. The capped vertical lines show the two standard deviation confidence interval of the estimates of $\beta$, and the figures in parenthesis in the horizontal axis refer to the number of observation for each estimation period. ${ }^{8}$

Figure 3a shows that the effects of 1920 railroad station dummies on growth of municipalities were significant and persistent in the case of labor productivity in industrial and, to a lesser extent, in urban activities. They were practically nonsignificant for income per capita and total productivity and productivity in urban activities. Figure $3 \mathrm{~b}$ shows that the share of foreign-born population had significant pervasive effects from 1919 to 1949 but the lasting effects were restricted to the rural activities.

\section{Conclusions and Extensions}

The basic hypothesis of this chapter is the overwhelming role played by the geographic factors, especially transport costs, in the historical generation and reproduction of spatial inequalities in Brazil. Empirical evidence is presented by the analysis of the spatial patterns of growth of labor productivity and income per capita of the Brazilian municipalities from 1872 to 2000 .

The main result of the analysis is that spatial inequalities in the density of economic activity, income per capita, and labor productivity remained practically unchanged with negligible reductions from 1872 to 2000 . The maps show clearly the secular persistent northwest-southeast divide of income per capita and productivity of the country.

Econometric estimations of models of growth convergence provide a more rigorous test of the hypotheses. Estimation reported shows that the speed of convergence of both income per capita and labor productivity was very slow compared to other countries. Disaggregation of the analysis by subperiods, regions, and sectors shows

\footnotetext{
${ }^{8}$ Regression result not reproduced in the chapter is available upon request.
} 


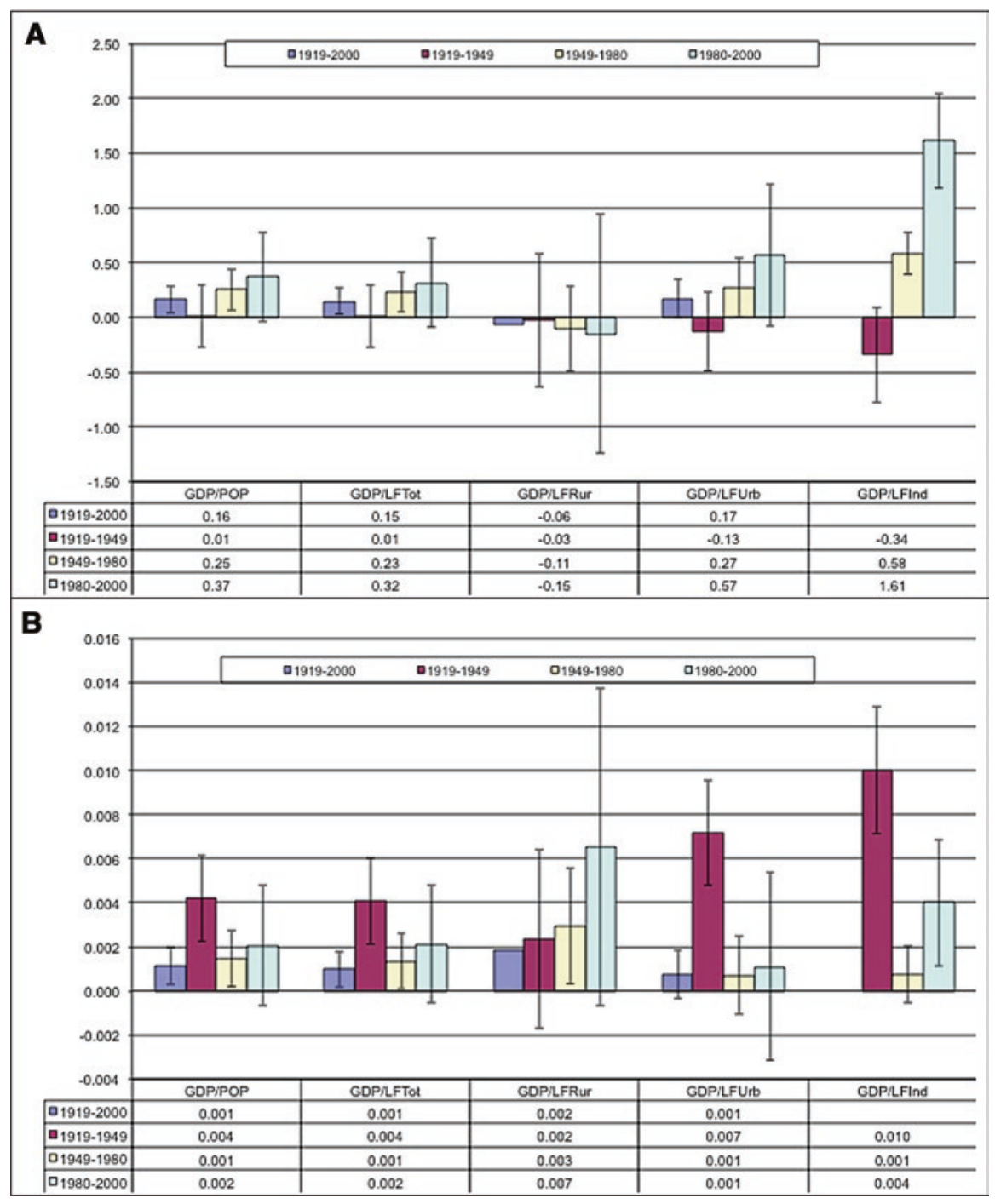

Fig. 3 Persistence in time of the effects of railroad stations in 1920 and the share of foreign-born population in 1920. (a) Impact of railroad stations in 1920 in the growth of income per capita (GDP/POP) and labor productivity (GDP/LF) in selected activities and periods (changing only the year of lagged dependence variable for each period; lines show 1 std-error). (b) Elasticity of foreign-born population in 1920 in the growth of income per capita (GDP/POP) and labor productivity (GDP/LF) in selected activities and periods (changing only the year of lagged dependence variable for each period; lines show 1 std-error) 
that phases of export-led growth were more dispersive than the import substitution phases; convergence was faster inside each region and thus regional disparities reinforced spatial inequalities in the country as a whole; and convergence of labor productivity was faster in urban activities than in rural activities.

More notably, estimated parameters show that conditions of access to infrastructure in 1920 - as proxied by the existence of railway station in the municipality were by far the most important factor conditioning the growth of Brazilian municipalities during the twentieth century. Other variables related to accessibility like the distance to the state capitals and the market potential of the municipality also played roles in the long-run growth of municipalities. This strong result corroborates the perception that Brazilian development strategies during the second half of twentieth century had misguidedly disregarded investment in transport infrastructure, particularly in railways, which as a consequence remains as a crucial hindrance to steady growth.

In contrast, institutional factors - as proxied by slavery (in 1872), education and human capital, political participation, and landownership concentration-did not play a significant role in long-run growth of income per capita or labor productivity of Brazilian municipalities. Even when jointly tested, their coefficients remained insignificant. The exception is the cultural and institutional innovations brought with the European immigrants as evinced by the share of foreign-born population in 1920 which shows a significant and positive effect on the secular rates of growth of both labor productivity and income per capita, specially in the agricultural activities.

Needless to say, the results are still preliminary and further extensions and scrutiny are required. A research priority, in this way, is the need of a more rigorous econometric treatment of the problems of endogeneity which affects the estimation of the coefficients of railroad station, foreign-born population, and slavery, among other variables.

A related priority is to undertake a panel data analysis including the inter-census periods from 1872 to 2010, thus allowing to circumvent some of the econometric problems and, consequently, to estimate in more rigorous way the interplay between factors conditioning the growth of Brazilian municipalities in the diverse development phases, in particular to update the analyses for the period 2000-2010 to disentangle the role played by spatial inequalities in the recent redistributive process (Rodrigues-Silveira 2012; Hoffman 2013).

In this way the tasks ahead are to complete the historical database on the conditioning factors - in particular on demographic aspects related to migration and dependency ratio; urban and transportation infrastructure; education and human capital; political participation, etc. - for the periods from 1872 to 2010 .

Open Access This chapter is distributed under the terms of the Creative Commons Attribution 4.0 International License (http://creativecommons.org/licenses/by/4.0/), which permits use, duplication, adaptation, distribution and reproduction in any medium or format, as long as you give appropriate credit to the original author(s) and the source, a link is provided to the Creative Commons license and indicate if changes were made. 
The images or other third party material in this chapter are included in the work's Creative Commons license, unless indicated otherwise in the credit line; if such material is not included in the work's Creative Commons license and the respective action is not permitted by statutory regulation, users will need to obtain permission from the license holder to duplicate, adapt or reproduce the material.

\section{References}

Alesina, A., \& Giulano, P. (2013). Culture and institutions. NBER working paper series. Retrieved from http://www.nber.org/papers/w19750

Andersen, L. E., Granger, C. W. J., Reis, E. J., Weinhold, D., \& Wunder, S. (2002). The dynamics of deforestation and economic growth in the Brazilian Amazon. Cambridge: Cambridge University Press.

Arantes, N. E., \& Souza, P. I. M. (1993). Cultura da soja nos cerrados. Piracicaba: PotafosAssociação Brasileira para Pesquisa da Potassa e do Fosfato.

Arbia, G., Basile, R., \& Salvatore, M. (2002). Regional convergence in Italy 1951-1999: A spatial econometric perspective. ISAE, Istituto di studi e analisi economica.

Azzoni, C. R. (1997). Concentração regional e dispersão das rendas per capita estaduais: Análise a partir de séries históricas estaduais de PIB, 1939-1995. Estudos Economicos, 27(3), 341-393.

Azzoni, C. R. (1999). Personal income distribution within states and income inequality between states in Brazil: 1960, 70, 80 and 91. In G. Hewings, M. Son, M. Madden, \& Y. Kimura (Eds.), Understanding and interpreting economic structure (pp. 287-296). Berlin: Springer.

Azzoni, C. R., Menezes-Filho, N., Menezes, T. A., \& Silveira-Neto, R. (2000). Geography and income convergence among Brazilian states. Washington, DC: Inter-American Development Bank.

Barat, J. (1978). A evolução dos transportes no Brasil. Rio de Janeiro: IBGE.

Barro, R., \& Sala-i-Martin, X. (1995). Economic growth. New York: McGraw Hill.

Bell, S. (1998). Campanha gaúcha-A Brazilian ranching system. Stanford, CA: Stanford University Press.

Bergad, L. W. (1999). Slavery and the demographic and economic history of Minas Gerais, Brazil, 1720-1888. Cambridge: Cambridge University Press.

Bértola, L., Willebald, H., Castelnovo, A. C., \& Reis, E. (2006, August 21-25). An exploration of the distribution of income in Brazil, 1839-1939. Paper presented at the XIV International Economic History Congress, Helsinki, Finland.

Buescu, M. (1979). Brasil: Disparidades de renda no passado: subsídios para o estudo dos problemas brasileiros. Rio de Janeiro: APEC.

Cano, W. (1973). Economia do Ouro em Minas Gerais. Contexto, 7.

Cano, W. (1985). Padrões diferenciados das principais regiões cafeeiras. Revista Estudos Econômicos, 15(2), 291-306.

Cano, W. (1993). Raízes da Concentração Industrial em São Paulo (2nd ed.). Rio de Janeiro: DIFEL.

Cano, W. (1997). Concentração e Desconcentração Econômica Regional no Brasil: 1970/95. Economia e Sociedade, 8, 101-139.

Castro, N. de. (2002). Expansão Rodoviária e Desenvolvimento Agrícola dos Cerrados. Texto para Discussão. Nemesis. IPEA.

Castro, N. de. (2003). Logistic costs and Brazilian regional development.

de Andrade, M. C. (1973). A terra e o homem no nordeste. São Paulo: Brasiliense. 
de Barros, R. P., Mendonça, R., \& Camargo, J. M. (1995). Pobreza no Brasil: Quatro Questões Básicas. In R. Henriques (Ed.), Desigualdade e Pobreza no Brasil (pp. 15-44). Rio de Janeiro: IPEA.

de Castro, A. B. (1969). 7 Ensaios sobre a economia Brasileira (Vol. 1/2). Rio de Janeiro: Forense. de Matos, O. N. (1974). Café e Ferrovias (Vol. 2). São Paulo: Editora Alfa-Omega.

de Oliveira, F. (1977). A Economia da Dependência Imperfeita. Rio de Janeiro: Graal.

Denslow, D., Jr. (1977). As origens da desigualdade regional no Brasil. In F. R. Versiani \& J. R. M. de Barros (Eds.), Formação Econômica do Brasil. São Paulo: Saraiva.

Ellis, A., Jr. (1951). O café e a Paulistânia. São Paulo: Universidade de São Paulo.

Engerman, S. L., \& Sokoloff, K. L. (2012). Economic development in the Americas since 1500: Endowments and institutions. Cambridge, MA: Cambridge University Press.

Engerman, S. L., \& Sokoloff, K. L. (1997). Factor endowments, institutions, and differential paths of growth among new world economies: A view from economic historians of the United States. In S. Haber (Ed.), How Latin America fell behind. Stanford: Stanford University Press.

Felice, E. (2013). Regional income inequality in Italy in the long run (1871-2001). Patterns and determinants. Documents de treball, Universitat Autònoma de Barcelona, Unitat d'Història Econòmica, 2013_08.

Furtado, C. (1968). Formação econômica do Brasil (8th ed.). São Paulo: Companhia Editora Nacional.

Furtado, C. (1970). Formação Econômica da América Latina. Rio de Janeiro: Lia Editor.

Galvao, O. J. de A. (1999). Comercio interestadual por vias internas e integracao regional no Brasil: 1943-69. Revista-Brasileira-de-Economia, 53(4), 523-558.

Gasques, J. G., \& Yokomizo, C. (1985). Avaliação dos incentivos fiscais na Amazônia. Mimeo: Instituto de Planejamento Econômico e Social.

Goulart Filho, A., \& Queiroz, P. R. C. (Eds.). (2011). Transportes e formação econômica regional: Contribuições à história do transporte no Brasil. Dourados, MS: Editora UFGD.

Graham, D. H. (1972, December). Foreign migration and the question of labor supply in the early economic growth of Brazil. Paper presented at the Economic History Workshop.

Graham, D. H., \& de Hollanda, S. B. (1971). Migration, regional and urban growth and development in Brazil: A selective analysis of the historical record, 1872-1970 (Vol. 1). São Paulo: Instituto de Pesquisas Econômicas.

Helfand, S. M., \& Rezende, G. C. (1998). Mudanças na distribuição espacial da produção de grãos, aves e suínos no Brasil: O papel do centro-oeste. Rio de Janeiro: IPEA.

Hoffman, R. (2013). Transferências de renda e desigualdade no Brasil (1995-2011). In T. Campello \& M. C. Neri (Eds.), Programa Bolsa Família: Uma década de inclusão e cidadania (pp. 207 216). IPEA: Brasília.

Homma, A. K. (2003). História da agricultura na Amazônia: Da era pré-colombiana ao terceiro milênio. Brasília: Embrapa Informação Tecnológica.

Ipeadata. (2014). Base dados sobre a economia brasileira do IPEA. Brasilia: IPEA - Instituto de Pesquisa Econômica Aplicada. Retrieved from http://www.ipeadata.gov.br.

Lagerloef, N. P. (2004). Regional income gaps in the U.S.A. today-what can geography and slavery explain? Paper presented at the Society for Economic Dynamics Meeting Papers.

Lagerloef, N.-P. (2005). Geography, institutions, and growth: The United States as a microcosm. Toronto, ON: Department of Economics, York University.

Leff, N. H. (1972). Economic retardation in nineteenth-century Brazil. The Economic History

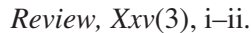

Leff, N. H. (1973). Tropical trade and development in the nineteenth century: The Brazilian experience. Journal of Political Economy, 81(3), 678-696.

Leff, N. H. (1991). Subdesenvolvimento e desenvolvimento no Brasil. Rio de Janeiro: Expressão e Cultura.

Libby, D. C. (1988). Transformação e trabalho em uma economia escravista: Minas Gerais no Século XIX. São Paulo: Editora Brasiliense.

Lima, J. H. (1981). Café e indústria em Minas Gerais, 1870-1920. Petrópolis: Vozes. 
Marcondes, R. L. (2005). Desigualdades regionais brasileiras: Comércio marítimo e posse de cativos na década de 1870. Tese de Livre-docência). Ribeirão Preto: Universidade de São Paulo.

Martins, R. B. (1983). A industria textil doméstica de Minas Gerais no Século XIX. Paper presented at the II Seminário sobre a economia mineira: história econômica de Minas Gerais e a economia mineira dos anos oitenta, Diamantina.

Martins, R. B. (2004). A historiografia sobre o Século XIX em Minas Gerais: notas para um debate. Paper presented at the Seminário Internacional sobre Historiografia de Minas Gerais, Instituto Cultural Amilcar Martins (ICAM). Belo Horizonte.

Milet, H. A. (1881). A lavoura da canna de assucar. Pernambuco: Typografia do Jornal de Recife.

Milliet, S. (1982). Roteiro do Café e Outros Ensaios. São Paulo: Editora Hucitec.

Nunn, N. (2007, November). Slavery, inequality and economic development in the Americas: An examination of the Engerman Sokoloff hypothesis, MPRA Paper No. 5869.

Oliveira, G. (2005). Juiz de Fora, Industrialização: Uma abordagem historiográfica. 1850-1930. In I Colóquio do Laboratório de História Econômica e Social da Universidade Federal de Juiz de Fora. Juiz de Fora: Editora da UFJF.

Pinto, A. A. (1903). História da Viação Pública de São Paulo (Basil). São Paulo: Typographia e Papelaria de Vanorden \& Cia.

Reis, E. (2014). Historical perspectives on regional income inequality in Brazil, 1872-2000. Working paper series (vol. 66). In Berlin research network on inequalities in Latin AmericadesiguALdades.net.

Reis, E. J., \& Blanco, F. A. (2000). Causes of Brazilian Amazon deforestation. In M. P. H. Vanhanen (Ed.), World forests: From deforestation to transition (pp. 143-165). London: Kluwer Academic Publishers.

Reis, E., \& Monasterio, L. M. (2010). Mudanças na concentração espacial das ocupações nas atividades manufatureiras do Brasil, 1872-1920. In T. R. Botelho \& M. H. D. van Leeuwen (Eds.), Desigualdade social na América do Sul: Perspectivas históricas (1st ed., pp. 243-274). Belo Horizonte, MG: Veredas e Cenários.

Reis, E., Tafner, P., Pimentel, M., Serra, R. V., Reiff, L. O., Magalhães, K., \& Medina, M. (2005). O PIB dos municípios brasileiros: Metodologia e estimativas, 1970-1996 (Texto para discussão). Rio de Janeiro: IPEA.

Reis, E. (2008). Income per capita of Brazilian municipalities in the 1870's. Rio de Janeiro: IPEA.

Reis, E. J., \& Margullis, S. (1990). Options for slowing Amazon jungle clearing. In R. Dornbusch \& J. M. Poterba (Eds.), Global warming: Economic policy responses (pp. 335-380). Cambridge, MA: The MIT Press.

Reis, E., Anderson, K., \& Speranza, J. (2007). The effects of climate change on the profitability and land use in Brazilian agriculture: A municipal cross-sectional analysis. Paper presented at the XV Congresso Brasileiro de Agrometeorologia, Aracaju, SE.

Reis, E., Blanco, F., Morandi, L., Medina, M., \& Abreu, M. (2002). O Século XX nas Contas Nacionais. In Estatísticas do Século XX. Rio de Janeiro: IBGE.

Reis, E., Pimentel, M., Alvarenga, A. I. M., \& Santos, M. C. H. (2011). Áreas mínimas comparáveis para os períodos intercensitários de 1872 a 2000. Paper presented at the I Simposio Brasileiro de Cartografia Histórica, Parati, RJ.

Restitutti, C. C. (2008). As fronteiras da província: rotas de comércio inter-provincial, Minas Gerais (1839-1884). Paper presented at the Simpósio de Pós- Graduação em História Econômica, Natal, RN.

Rodrigues-Silveira, R. (2012). Gobierno local y estado de bienestar: Regímenes y resultados de la política social en Brasil. Salamanca: Fundación Manuel Giménez Abad de Estudios Parlamentarios y del Estado Autonómico.

Santos, R. (1980). História Econômica da Amazônia. São Paulo: TAQ.

Silva, M. M. F. (1949). Geografia dos transportes no Brasil. Rio de Janeiro: IBGE-Instituto Brasileiro de Geografia e Estatística.

Silveira, P. (1957). A nova capital. Goiânia: Pongetti.

Stein, S. J. (1957). Vassouras: A Brazilian Coffee County, 1850-1900. Cambridge: Harvard University Press. 
Summerhill, W. R. (1997). Railroads and the Brazilian economy before 1914. Business and Economic History, 26(2), 318-322.

Summerhill, W. R. (2003). Order against progress. Stanford, CA: Stanford University Press.

Trew, A. (2014). Spatial takeoff in the first industrial revolution. CDMA working paper series, University of St. Andrews - Center for Dynamic Macroeconomic Analysis.

Versiani, F. R. (1993). Imigrantes, trabalho qualificado e industrialização, Rio e São Paulo no início do Século. Paper presented at the Encontro Anual da Anpec.

Weinhold, D., \& Reis, E. J. (2008). Land use and transportation costs in the Brazilian Amazon. Global Environmental Change, 18(1), 54-68.

Weinstein, B. (1983). The Amazon rubber boom 1850-1920. Stanford, CA: Stanford University Press. 


\title{
Racial Inequality in Brazil from Independence to the Present
}

\author{
Justin R. Bucciferro
}

\section{Introduction}

There is a broad effort to reduce racial inequality in Brazil and, over the past decade or two, it appears to have been successful. Affirmative action was introduced under the Secretary of State for Human Rights in 2002, for example, and a new Secretary of Policy for the Promotion of Racial Equality was established in 2003. Disparities between races - formally defined as black (preto), white (branco), mixed-race (pardo), Asian (amarelo), and indigenous (indígena)- have declined in terms of literacy (Rossetto and Paixão 2010), level of schooling (Marteleto 2012), and employment and earnings (International Labor Organization 2007), although not university enrollment (IBGE 2008). Is this recent experience attributable to policy or part of a much longer trend?

This chapter considers racial inequality in Brazil back to the colonial era (pre1822), addressing the social construction and historiography of race, and illustrating the comparative size of racial groups over time. The relative well-being of Afro-Brazilians (pardos or pretos) and whites (brancos) is described across major historical periods - the Imperial Era (1822-1889), First Republic (1889-1930), Vargas Era (1930-1945), Second Republic (1946-1964), Military Rule (1964-1985), and Return to Democracy (1985 to present) - in terms of life expectancy, literacy, primary school completion, years of schooling, occupation, and income.

Race is somewhat arbitrary, but nonetheless meaningful given the drastic differences across groups and their reproduction over time. During the late eighteenth and nineteenth century, Brazil was predominantly black or mixed race; over the twentieth century, white; and in the twenty-first century, again Afro-Brazilian. In the Imperial Era, slaves were employed throughout the economy, but they comprised a

\footnotetext{
J.R. Bucciferro $(\bowtie)$

Department of Economics, Eastern Washington University,

311 Patterson Hall, Cheney, WA, 99004, USA 
declining share of the population: $5 \%$ of Brazilians and fewer than $10 \%$ of blacks and mulattos upon abolition. Net hire rates for slaves between 1870 and 1887 from Mello (1977) and wage rates for day laborers from Dean (1976) suggest that a slave received in kind just $35 \%$ of what a free laborer could earn.

In the southeast after abolition, favored colono or settler contracts were given to European immigrants, whereas blacks left the plantation or found unstable employment as camaradas or day laborers. Elsewhere in Brazil, former slaves were integrated back into the plantation economy as wage laborers. In urban São Paulo, the race and occupation of individuals from Incident Reports spanning 1912-1920 (from Jacino 2012) combined with average salaries from the 1920 census reveal that blacks were overrepresented in the lowest paying jobs; further wage discrimination suggests that blacks earned as little as $40 \%$ of whites.

The situation of Afro-Brazilians improved after Vargas took power in 1930, and through the economic boom of the 1950s, as blacks became politically organized and made relative gains in terms of both industrial employment and literacy. During the military dictatorship, however, black activism was curtailed and occupational or wage discrimination appears to have increased. In contrast, recent decades have witnessed the public recognition of Afro-Brazilian disadvantage and the introduction of targeted policies to ameliorate racial inequality.

Overall, racial groups became more equal during the twentieth century. There was a rise in literacy, education, and income for all groups, and a decline in occupational segregation; the relative status of nonwhites was variable, however, and only began to noticeably improve around 1980. Black-and-white income during the 1980s and 2000s converged moderately, in contrast to the divergence of Asian and indigenous income during the former period and real declines for both groups in the latter. Only in the past 10 years has the black-white income gap narrowed beyond its 1960 level, although it is now probably at its lowest point ever.

This investigation expands upon the analyses of Hasenbalg (1978), Silva (1985), and Lovell (1999) which parts from the 1960 decennial census, and integrates additional census and annual survey data after 1980 as employed by Arcand and D'Hombres (2004), Arias et al. (2004), and Campante et al. (2004). Race is an important aspect of inequality and this analysis is unique in providing a narrative of national trends in relative well-being which spans the breadth of Brazil's postcolonial history.

\section{Conceptualizations of Race in Brazil}

A "race" is defined as a group of people with a common ancestry, or sharing certain physical markers such as skin tone, hair texture, and facial features. Such traits may not necessarily be indicative of one's genetic origins, though, particularly within the demographic milieu that is the New World. Regardless, there is no biological basis for classifying humans into racial groups, and the (untestable) postulate must therefore be accepted that no so-called race is inherently inferior to another. 
If race is an arbitrary concept, why is it so powerful in explaining relative outcomes? Race - "a socially constructed mode of human categorization," (Loury 2002; p. 5) - is imbued with meaning upon which individuals act, for which it retains its currency. If a group is stereotyped as being inexperienced, for instance, people within this group may receive fewer job offers and, indeed, come to have less experience. In this section, the origins of "race," the changing social meanings which have been attributed to groups in Brazil, and the historiography of race in Brazil are described from the early twentieth century to present.

Prior to the fifteenth century, when slave production was introduced on the Atlantic islands and the "New World" was revealed to Europeans, the nature of slavery was quite different: one's status as a slave was less directly related to his or her race or ethnicity, and slaves had a greater possibility of someday integrating into society as freemen (Klein 2010). In the colonies of the Americas, the scale and harshness of slavery were unprecedented: over ten million African slaves survived the middle passage over the course of the traffic (Trans-Atlantic Slave Trade Database), many of whom spent the remainder of their lives producing sugar, coffee, cotton, and other commodities. The system required justification, an underlying ideology which could ensure its continuation amidst acute inequality, hence the invention of race.

The differential status of Europeans, Natives or "Indians," and Africans in the New World was institutionalized by both church and state. The legacy of fifteenthcentury inquisition thinking was that Indians possessed a soul whereas Africans did not; in response to the rapid decline of native populations during colonization, the Spanish and Portuguese crowns prohibited their (unjust) enslavement in the 1540s. The result was an increasing reliance on African slaves: in Brazil, the workforce on coastal plantations came to be predominantly African by the beginning of the following century (Klein and Luna 2010).

The relative size of Afro-Brazilian and white populations over time is a rough indicator of inequality because similar numbers of African slaves and European immigrants ultimately arrived in Brazil - what better measure of long-run adaptive success is there than a group's ability to survive? Consider the cumulative number of slaves imported up until each period and, separately, the cumulative number of immigrant arrivals: the size of the "flow" versus the "stock" gives a crude sense of the fate of each group.

An estimated 5.5 million African slaves were shipped to Brazil (4.9 million disembarked) over three centuries of the Atlantic slave trade, relatively close to the population of 5.8 million "blacks" in $1872 .{ }^{1}$ While this implies a zero natural increase, there is ample evidence of positive growth of the free black population during the eighteenth century, suggesting an offsetting negative change among slaves. Negative growth of the slave population implies, in turn, high mortality rates and low living standards. In contrast, the white population increased sixfold between 1820 and 1890, to six million; yet fewer than two million immigrants had arrived

\footnotetext{
${ }^{1}$ Estimated number of slaves who embarked for Brazil, according to the Trans-Atlantic Slave Trade Database (http://slavevoyages.org), accessed 11/2014.
} 
until that time. ${ }^{2}$ In short, the demographics imply a very big gap in the black-white mortality rates and in living standards in the nineteenth century. The flow of immigrants only reached the volume of the slave trade in 1950, at which point the white population numbered over 32 million.

The Portuguese who settled colonial Brazil were predominantly men (as were two-thirds of African slaves), and had children of mixed indigenous, African, and European ancestry. According to Ribeiro (1995), the children of Europeans and Indians (mamelucos or mestiços) and Africans (mulattos) were prototypical of a new unified people: Brazilians. The importance of racial markers, however, indicates a lesser degree of assimilation than Ribeiro implies; nonetheless, race is a qualitatively different concept in Brazil than in other countries.

The current classifications of race can be traced to at least the eighteenth century: In 1776, Portugal issued a circular which ordered a census to include counts by age and sex; although not required, some governors decided to collect racial information as well (Alden 1963). The population was classified into three or four racial groups: brancos (whites), pardos (literally "browns"; mulattos), pretos ("blacks"; Negroes), and indios (Christian Indians). In subsequent regional censuses, alternative terms like caboclo (Indian or mestiço) have been used, always omitting un-contacted aboriginals.

Beginning with the first national census of 1872 and continuing through the most recent decennial censuses, the same general racial categories have been employedbranco, pardo, preto, and índigena-as well as amarelo (literally "yellow" or Asian); however, race was not included in the 1920 or 1970 censuses, and "Indian" was not a category in the 1940 census. The racial makeup of Brazil, according to national censuses from 1872 to 2010 and earlier figures as compiled by Bucciferro (2013), is shown in Fig. 1.

The population of the colonies, excluding un-contacted aboriginals, was primarily indigenous until 1725; around 1750, people of African descent became the predominant racial group and remained so until the mass immigration of whites between 1890 and 1940. During the twentieth century the majority were white, but in the most recent census it was again Afro-Brazilian. Two key questions emerge: Is such a broad color-based classification meaningful? Does it correspond to the social construction of race as formalized by individuals?

One issue is that mestiço, of mixed Indian and European descent, is not included as a category in the census; therefore such individuals may classify as either pardo or branco. Furthermore, individuals of mixed African and European descent may also be classified as pardo or branco, hence such outmoded terms as branco da terra (light-skinned mestiço) and branco da bahia (light-skinned mulatto). Individuals within each group are invariably of mixed descent, which belies the biological determinism associated with race.

Scholars have generally considered racial disparities in terms of a white/ nonwhite or white/brown/black categorization, but its validity has been questioned

\footnotetext{
${ }^{2}$ Number of immigrants who arrived in Brazil, according to IBGE, 500 anos de povoamento, Rio de Janeiro: IBGE, 2000; for figures prior to 1820 and after 1975, only Portuguese immigrants are included.
} 


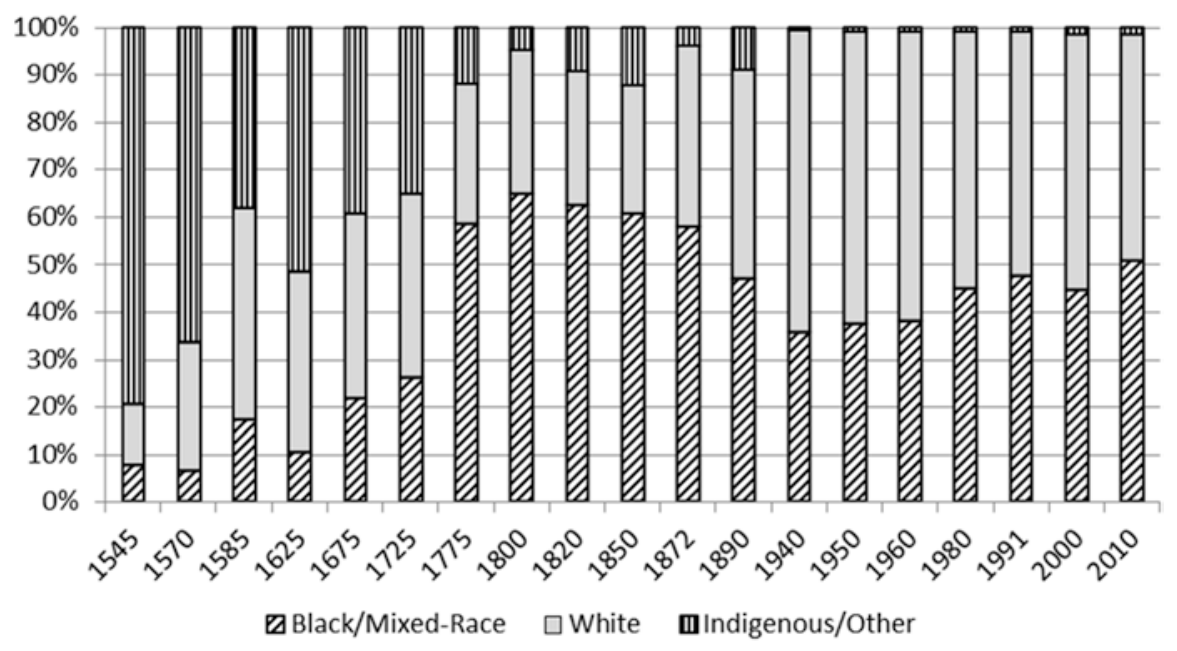

Fig. 1 The racial composition of Brazil. Sources: Figures before 1850 are from Bucciferro (2013; for 1825-1850, these refer to regional censuses across proximate years excluding the state of Ceará); the population and its racial makeup for the periods from 1872 to 2010 are from the IBGE (http://seriesestatisticas.ibge.gov.br/): "Tendências demográficas: uma análise dos resultados da amostra do censo demográfico 2000," Rio de Janeiro: IBGE (2004); 2010 Demographic Census; Directoria Geral de Estatística (1930[187?]), "Recenseamento do Brazil 1872/1920"; Censo demográfico 1940/2010; "Estatísticas do Século XX," Rio de Janeiro: IBGE (2007) in Anuário Estatístico do Brasil, Rio de Janeiro: IBGE 54 (1994)

(Harris et al. 1993; Silva and Leão 2012): the first of these studies involves an experiment which indicates a substantially different racial distribution depending on whether the official term (parda) or vernacular term (morena) is used to refer to the mixed-race population; the latter cites wide variation in the size of the black population depending on how it is defined, as well as a differing perception of race and discrimination among pardos. These results are consistent with Bailey et al. (2013), who show that alternative combinations of racial subcategories could result in Brazil having either a white or a black majority.

The potential drawbacks of the current configuration have not been overlooked, however. In the 1976 household survey, individuals were asked both an open-ended question on race and one with the four standard options (branca, parda, preta, or amarela): just six racial categories - including branca, parda, and preta, as well as morena, morena-clara, and clara-encompassed $94 \%$ of respondents (Wood et al 1988). Although morena was as common a response in the open question as was parda in the structured one (34\% of respondents in each instance), its usage is perhaps too general to function as a census category (Telles 1995). ${ }^{3}$

\footnotetext{
${ }^{3}$ A similar survey was conducted by the newspaper Folia de São Paulo in 1995 that produced consistent results; also, interviewers recorded what they perceived as the person's race and found that people of higher socioeconomic status were more likely to classify into "whiter" categories than those assigned by interviewers (Silva 2001).
} 
Racial identity may be fungible, but the schemas employed in Brazil nonetheless correspond to real social divisions, shaped by ancestry as well as class: the progressive "whitening" of the population was a result of racial mixing and the higher fertility/lower mortality of whites, not only the implicit incentive for pretos and pardos to self-select as pardos and brancos (Ribeiro 1995). Although the current categories of race are oversimplified, they reflect the heritage of Brazilian people and are preferable to a simple white/nonwhite dichotomy which groups together indigenous, African, and Asian elements.

\section{Race and the Labor Force}

This section recounts social, political, and economic developments as they affected whites and Afro-Brazilians after independence, across six time periods which mark key changes in their relative status: the Imperial Era (1822-1889), First Republic (1889-1930), Vargas Era (1930-1945), Second Republic (1946-1964), Military Rule (1964-1985), and Return to Democracy (1985 to present). The independence of Brazil contrasts other Latin American countries because a constitutional monarchy was formed, as opposed to a republican democracy, and slavery expanded, contrary to being abolished.

\subsection{The Imperial Era}

The royal court relocated to Rio de Janeiro upon Napoleon's 1807 invasion of Portugal; João VI became king in 1816, returned to Portugal in 1821, and the ensuing year his son Pedro I declared Brazil independent and himself emperor (Merrick and Graham 1979). Pedro I abdicated in 1831 and was succeeded by Pedro II, only 5 years old, who was crowned in 1840 and served until the republican coup of 1889 . While there was much continuity with the colonial era, this period spanned the unprecedented expansion of the southeast slave economy, suspension of the international slave trade in 1850, and ultimate abolition of slavery in 1888.

Coffee-whose cultivation was introduced into São Paulo during the mid1700s and spread to Rio de Janeiro, Espírito Santo, and Minas Gerais (Filho 1952) - surpassed sugar as Brazil's most valuable export by the 1830s (Bethell and Carvalho 1989). To satisfy growing labor demand, the external and internal slave trades reached new heights: An estimated one million African slaves disembarked in Brazil between 1801 and 1825 and another million between 1826 and 1850 , together $42 \%$ of the entire volume of the slave trade (Trans-Atlantic Slave Trade Database). Internally, up to 200,000 slaves were transported by sea from northern to southern states between 1850 and 1888 (Klein 1971); substantial numbers also migrated to the southeast from the interior states of Mato Grosso, Goiás, and Minas Gerais. 
For coffee producers, investment in slaves yielded above average rates of return around 12-15\% (Mello 1977). To quantify the relative standard of living of slaves, I consider the fraction of earnings which they would have received in goods and services (e.g., clothing, food, and medical care) versus the wages of free workers. The ratio of free to slave "wages" is based on monthly slave hire rates from Journal de Comerçio advertisements compiled by Mello; slave productivity in coffee from Soares (1860), Taunay (1939), and Conrad (1972); and estimated annual earnings of immigrants on coffee plantations from Dean (1976) and Hall (1969).

In Fig. 2, the daily hire rate paid to the slave owner is shown against the value of goods and services consumed by a slave, half the daily earnings of an immigrant family (colono), and the going wage rate for a day laborer (camarada) from 1870 to 1915. The "in-kind wage rate" corresponds to the difference between the gross and net hire rates, or the cost of slave maintenance. The immigrant family wages, with two working adults, and slave hire rates are not very different, but the family could potentially double its income by selling subsistence crops or animals and was provided with housing: the immigrant family money wage is therefore a good proxy for the earnings of an adult.

The individual daily colono money wage (calculated as one-half of the family wage) is relatively close to the average value of goods and services received by slaves per day. Including proceeds from the sale of subsistence crops estimated by Dean (1976), the colono daily wage approximates the daily slave hire rate. Both, however, are below the going rate paid to day laborers. This does not imply that

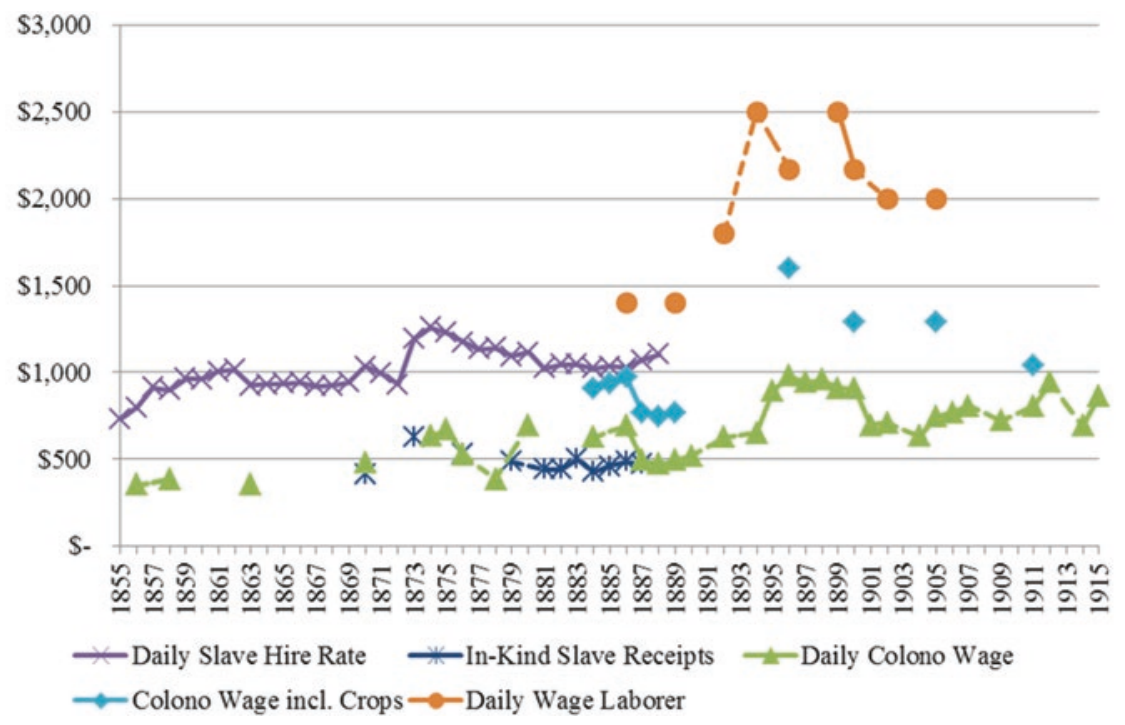

Fig. 2 Daily wages for slave/free workers, 1855-1915 (Nominal Milreis). Sources: Slave hire rates and in-kind slave receipts (cost of slave maintenance) are from de Mello (1977); colono wages, including and excluding crops, and day-laborer (camarada) wages are from Dean (1976) and Hall (1969); daily earnings based on 52 6-day workweeks 
camaradas were better off: on the contrary, their employment was relatively infrequent and annual wages were probably at or below those of colono families. In 1886, slaves received in kind just $35 \%$ of the daily wage of a free laborer.

Slaves were not just producing coffee but employed in every conceivable occupation, from gang laborers on the plantations to shipbuilders and urban merchants (Klein and Luna 2010). In relative terms, however, they formed less than half of the black-and-mulatto population. ${ }^{4}$ The free Afro-Brazilian population was a growing majority: circa $1825,61.0 \%$ of the population was black or mulatto but "only" one-third (33.2\%) was enslaved; circa 1850, $62.8 \%$ of the population was of African descent with one-quarter (25.5\%) enslaved; and in 1872, 58.0\% was black or mulatto and less than one-sixth $(15.2 \%)$ slaves. ${ }^{5}$

The numbers of free Afro-Brazilians, as well as their diverse employments and those of slaves, give the impression that discrimination was relatively subdued (e.g., Luna and Klein 2004). Flory (1977) considers the ambiguous nature of race after independence: free and slave blacks were often treated indifferently by contemporary legislation - vagrancy laws did not explicitly mention race, for instance (but were selectively enforced) - and the citizenship of free native-born blacks was recognized by the 1824 constitution. Periodicals catering to mulattos were founded in the 1830 s, but race was more frequently referred to within the context of politics rather than discrimination.

The topic of race was nominally taken up in the press and public discourse, but deeper issues were at stake which could not be articulated. As Pierson (1942) has implied, social mobility existed for people of mixed descent - the "mulatto escape hatch" referred to by Degler (1971) - yet it was limited and beyond the reach of the third of the population who were slaves. Brazil was already an outlier in the international context: the Haitian revolution (1794) and cessation of the north-Atlantic slave trade (1807) were decades passed.

In spite of gestures that it would end the international trade, it was condoned until 1850 when the British intervened and escorted intercepted slaves back to Africa (Bethell 1970). The newly inelastic supply of labor prompted panic. The basis for continued economic growth was connecting labor with abundant land on the frontier and this was at risk; although there were many native Brazilians, they were overwhelmingly in the subsistence sector and withdrawn from the money economy (Furtado 2006[1959]). Cognizant of the potential end to slavery, planters began to experiment with European immigrant labor.

The movement towards abolition accelerated after 1850: in 1871, the Law of the Free Womb declared the children of slave mothers were free upon maturity and gave

\footnotetext{
${ }^{4}$ For example, the population of Mariana, Minas Gerais, included 22,130 free blacks/mulattos compared to 19,020 enslaved blacks/mulattos and 8914 whites (Bergad 1996). In 1775, among the combined populations of Pará, Rio de Janeiro, and Rio Grande do Sul, $45 \%$ were slaves and $55 \%$ free (regional censuses compiled by Alden 1963). On the positive growth of Afro-Brazilian populations in Minas Gerais, see Boxer (1962) and Russell-Wood (1982).

${ }^{5}$ Sources: circa 1825 and 1850, data are from state censuses in Klein and Luna (2010); 1872 and 1890, national censuses (IBGE). The slave population is from Stein (1957) and Conrad (1972), as published in Hasenbalg (1978).
} 
slaves the right to purchase their own freedom; the Sexagenarian Law followed in 1885, which freed slaves over 60 years of age; and the Golden Law ended slavery altogether in 1888 (Andrews 1991). Even though the princess regent signed the law, it was not a political victory: active rebellion by slaves had made abolition imminent and the monarchy was overthrown the following year.

\subsection{The First Republic}

Freedom brought its challenges to former slaves in Brazil. In the southeast, discrimination by employers and ex-slaves' demands for independence led to the latter's substitution by European immigrants. In other regions, after the immediate upheaval of abolition, life resumed a pattern similar to the previous regime. There was noticeable variation, however, in the adaptation of workers to the new situation. Abolition was a mixed blessing in that it awarded slaves freedom but not necessarily a material improvement in quality of life.

Racism, prevalent at the end of the nineteenth century, contributed to employers' preference for workers from Europe but cannot fully explain it. If there were large numbers of freed slaves (libertos) and other Brazilians (trabalhadores nacionais) available, why were planters determined to hire European immigrants? On one side, whites blamed Afro-Brazilians for the disruptions in the labor force associated with abolition (Ianni 1962); on the other, freed slaves only desired to return to the plantation on certain terms, and not the money wage per se.

The conditions under which ex-slaves would transform into wage laborers were very limited (Furtado 2006[1959]): if freed slaves were given a "subsistence" salary the old system would remain fundamentally unchanged, but if there were abundant unoccupied lands they would prefer to engage in subsistence agriculture. In Brazil, the northeast sugar zone was already fully settled and bound by the caatinga (scrublands) to the west, under which circumstances the labor of former slaves could be secured at a relatively low wage; in the southeast coffee zone, in contrast, lands were abundant and wages relatively high.

Free blacks wanted to distance themselves from the plantation because physical work was culturally considered demeaning and associated with slaves (Ianni 1962). Afro-Brazilian families withdrew women and children from the fields, and occasionally the workforce entirely; immigrant families, in contrast, supplied female and child labor in order to make ends meet, an attractive feature for employers (Andrews 1991). The solution to the labor scarcity problem was consequently to flood the market with immigrants and thereby drive down wages.

Beginning in 1881, programs were created in collaboration with the São Paulo provincial government to subsidize the transportation of migrants from Europe to Brazil. The Society for the Promotion of Immigration was created in 1886 and worked with the province until its dissolution in 1895 (when the government assumed this function), having facilitated the immigration of nearly 220,000 people (Hall 1969). The immigration program was successful: Compared to 195,000 
immigrants who arrived in Brazil between 1870 and 1889, immigration between 1890 and 1909 totaled 1,100,000, half of whom $(515,000)$ were Italian (Kodama 2007). In the 1890s, about as many immigrants entered São Paulo as there were slaves in all of Brazil the year before abolition. ${ }^{6}$

Many labor arrangements existed on the fazendas (plantations), but immigrants to São Paulo commonly became colonos; other salaried positions were camaradas and empreiteiros. The colonos, named for the groups of homes they inhabited among the groves, received a fixed monetary income for maintaining a certain number of coffee trees plus a variable payment depending on the volume of the harvest (Furtado 2006[1959]). ${ }^{7}$ The camaradas, who commonly resided on the plantation in dormitories (usually remodeled slave quarters), were individual laborers paid daily or monthly (Stein 1957; Monsma 2006). Finally, empreiteiros (or, more precisely, gangs of laborers working under an empreiteiro, or contractor) travelled from plantation to plantation completing jobs at a flat rate (Stein 1957).

The estimated daily wages of a typical colono family between 1884 and 1915 are presented in Fig. 2. ${ }^{8}$ Wages were favorable for immigrant families in the years around abolition, declined in real terms from 1892 to 1894, and then spiked in 1895 when the value of output per worker reached an all-time high above $\$ 2,000,000$ réis. After 1900, the increasing price level and stagnant earnings prompted hundreds of thousands to return migrate: on net, only 50,000 immigrants came to São Paulo between 1900 and 1910 (Hall 1969).

In the rest of Brazil, there was no subsidized immigration program and the postabolition experience of Afro-Brazilians varied. Hasenbalg (1978) writes, "In the Northeast, abolition occurred without great readjustment, and the ex-slaves were incorporated into the various fractions of the northeastern peasantry" (p. 153). Domingues (2008a) summarizes three recent works describing the situation of blacks outside São Paulo: (1) In Sergipe, the elite adopted a series of vagrancy laws whose purpose was to force the free population back onto the sugar plantations (Subrinho 2000); (2) in Bahia, freed slaves wanted to limit their labor in the sugar industry as much as possible, and dedicate more time to subsistence farming (Filho 2006); and

\footnotetext{
${ }^{6}$ The overall slave population of Brazil in 1887 was 723,419 (Conrad 1972); between 1890 and 1899, 734,985 immigrants entered São Paulo (Kodama 2007; from Instituto de Estudos Brasileiros, 1973).

${ }^{7}$ Hall (1969) describes the wages on São Paulo coffee plantations: in 1884, the fixed payment (carpa) was about $\$ 50$ réis per 1000 trees plus $\$ 500$ réis per $50 \mathrm{~L}$ of coffee; in 1895 , it was $\$ 90$ and $\$ 600$ réis; in 1904, $\$ 60$ and $\$ 450$ réis; and in 1914, $\$ 80$ and $\$ 400$ réis, respectively. After adjusting for the price level (using the cost of rice as a proxy), he concludes that real wages declined by more than $50 \%$ between 1884 and 1914 .

${ }^{8}$ Each worker tended an average of about 3000 trees and produced $1500 \mathrm{~kg}$ of coffee per year, the equivalent of 25 sacks or 100 arrobas, based on Filho (1952) - yields are based on 3000 trees per worker; Sobrinho (in Hall 1969) - figures refer to the 1890s in São Paulo; Carvalho de Mello (1977) - based on slave yields during 1850-1888 period; Dean (1976) - based on 225 arrobas produced by two-adult family; Hall (1969) - estimate based on aggregate figures for 1910-1914; Klein and Luna (2010) - no. of trees based on 543 plantations during early 1880s, yield/worker from 1820s plantations; Oliveira (in Klein and Luna 2010) - yield/slave referring to 1854; and Stein (1957) - planter's approximation of average output per slave.
} 
(3) in Juiz de Fora, Minas Gerais, some libertos stayed with their former employers while others migrated to the city in search of work (Guimarães 2006).

In Vassouras (northeast São Paulo State), blacks refused to work under conditions associated with slavery. According to Stein (1957), former slaves faced less competition with immigrants because they went to the more profitable plantations of the west; black and mulatto women resigned from field and domestic labor after abolition, but many eventually returned at a piecemeal rate, likewise with men, who were pressured back onto the plantations (by vagrancy laws, for example) and took up positions as camaradas or colonos not altogether different from their previous occupations. In the city of São Paulo, blacks in many occupations (e.g., artisans, small merchants) were substituted by foreigners; new arrivals found only inconstant and menial work (Fernandes 1965; Hasenbalg 1978). Immigrants comprised the majority of the industrial workforce; while this may owe to their relative mobility, they regularly hailed from rural areas and had little previous urban manufacturing experience (Leff 1982).

Knowledge of racial inequality during the early twentieth century is limited because there was only one national census (1920) and it omitted race. A new data source on occupational segregation in São Paulo, however, reveals widespread employment inequality: incident reports (Boletins de Ocorrências) collected from 1912 to 1920 , including information on race and occupation, suggest the wholesale exclusion of blacks from certain jobs. These statistics (from Jacino 2012) are combined with salary data from the 1920 São Paulo census (Table 1), making it possible to calculate the extent of wage inequality caused by occupational segregation.

Blacks tended to be employed in lower paying occupations: they were overrepresented as domestic servants and underrepresented in construction, clothing, health, and liberal professions. Nonetheless, there was proportional representation of blacks among operators (unskilled factory workers), carpenters, painters, and shoemakers. If there was hypothetically no discrimination by race within each occupation, then the average black worker would have earned $\$ 4046$ réis per day compared to $\$ 4911$ réis for the average white worker - in other words, the average income of Afro-Brazilians could have been no greater than $82 \%$ of whites.

It was actually far less than that because of wage discrimination within job classes. According to Domingues (2003), a woman advertised her domestic service in the black journal $O$ Alfinete in 1921 at a rate of $\$ 60,000$ to $\$ 80,000$ réis per month (then thought "exorbitant"). This amount corresponds to \$2000 to \$2667 réis per day, versus $\$ 2640$ earned by the average female domestic and far short of the average $\$ 3750$ (\$112,500/year) for a native-born worker. Adjusting for the racial distribution of the Brazilian population, blacks or mulattos may have been paid wages that were around $50 \%$ of white workers within the same industry. ${ }^{9}$

\footnotetext{
${ }^{9}$ In São Paulo State, the census reported that $82 \%$ of the population was Brazilian and $18 \%$ was foreign in 1920; furthermore, the best estimate from Fernandes (1965) of the black or mulatto share in the overall population of São Paulo City is $9 \%$. About $11 \%$ of the native-born population was therefore Afro-Brazilian, and the average wage of white Brazilian domestics would have been several percentage points higher than that for national workers.
} 
Table 1 Racial segregation and wages by occupation, São Paulo, 1920

\begin{tabular}{|c|c|c|c|c|}
\hline Industry and occupation & Whites & Blacks & Total & Avg. wage \\
\hline \multicolumn{5}{|l|}{ Domestic service } \\
\hline Domésticos & 12,185 & 3191 & 15,376 & $\$ 2759$ \\
\hline \multicolumn{5}{|l|}{ Agriculture } \\
\hline Lavradores & 241 & 0 & 241 & $\$ 5391$ \\
\hline Lenheiros & 108 & 0 & 108 & $\$ 4979$ \\
\hline Tropeiros & 102 & 0 & 102 & $\$ 4062$ \\
\hline Agrónomos & 31 & 0 & 31 & $\$ 4049$ \\
\hline Lenhadores & 28 & 0 & 28 & $\$ 4392$ \\
\hline Leiteiros & 179 & 36 & 215 & $\$ 4115$ \\
\hline \multicolumn{5}{|l|}{ Civil construction } \\
\hline Pedreiro & 731 & 84 & 815 & $\$ 7268$ \\
\hline Oleiros & 137 & 0 & 137 & $\$ 6000$ \\
\hline Marmoris tas & 96 & 0 & 96 & $\$ 6727$ \\
\hline Pintores & 289 & 53 & 342 & $\$ 3205$ \\
\hline Eletricistas & 216 & 0 & 216 & $\$ 6197$ \\
\hline \multicolumn{5}{|l|}{ Transportation } \\
\hline Carroceiro & 1871 & 60 & 1931 & $\$ 4374$ \\
\hline Maquinistas da Railway & 42 & 0 & 42 & $\$ 7684$ \\
\hline \multicolumn{5}{|l|}{ Metalwork } \\
\hline Mecânicos & 721 & 0 & 721 & $\$ 8821$ \\
\hline Ferreiros & 144 & 0 & 144 & $\$ 8228$ \\
\hline Caldeireiros & 121 & 0 & 121 & $\$ 9547$ \\
\hline Polidores & 53 & 0 & 53 & $\$ 5626$ \\
\hline Fundidores & 42 & 0 & 42 & $\$ 8405$ \\
\hline Torneiros & 42 & 0 & 42 & $\$ 7506$ \\
\hline Serralheiros & 6 & 5 & 11 & $\$ 7380$ \\
\hline \multicolumn{5}{|l|}{ Wood } \\
\hline Carpinteiros & 415 & 61 & 476 & $\$ 6433$ \\
\hline Marceneiros & 84 & 0 & 84 & $\$ 7409$ \\
\hline \multicolumn{5}{|l|}{ Textiles } \\
\hline Tintureiros & 162 & 30 & 192 & $\$ 5363$ \\
\hline Tecelões & 137 & 0 & 137 & $\$ 6307$ \\
\hline \multicolumn{5}{|l|}{ Clothing } \\
\hline Alfaiates & 432 & 102 & 534 & $\$ 6382$ \\
\hline Bordadeiras & 108 & 0 & 108 & $\$ 3700$ \\
\hline Costureiras & 150 & 0 & 150 & $\$ 3911$ \\
\hline Chapeleiros & 72 & 0 & 72 & $\$ 6500$ \\
\hline Sapateiros & 307 & 41 & 348 & $\$ 5687$ \\
\hline \multicolumn{5}{|l|}{ Operators (general) } \\
\hline Operários & 9137 & 1351 & 10,488 & $\$ 5700$ \\
\hline Foguistas da Inglesa & 54 & 0 & 54 & $\$ 5819$ \\
\hline
\end{tabular}


Table 1 (continued)

\begin{tabular}{|c|c|c|c|c|}
\hline Industry and occupation & Whites & Blacks & Total & Avg. wage \\
\hline \multicolumn{5}{|l|}{ Commerce/proprietors } \\
\hline Empregados no comércio & 2089 & 150 & 2239 & $\$ 8974$ \\
\hline Capitalistas & 60 & 0 & 60 & $\$ 48,077$ \\
\hline \multicolumn{5}{|l|}{ Health } \\
\hline Barbeiros & 66 & 0 & 66 & $\$ 2564$ \\
\hline Enfermeiros & 84 & 0 & 84 & $\$ 5929$ \\
\hline Médicos & 65 & 0 & 65 & $\$ 10,121$ \\
\hline \multicolumn{5}{|l|}{ Liberal professions } \\
\hline Professores & 97 & 0 & 97 & $\$ 12,019$ \\
\hline Advogados & 61 & 0 & 61 & $\$ 9615$ \\
\hline Engenheiros & 30 & 0 & 30 & $\$ 12,543$ \\
\hline Total obs./avg. wage & 30,995 & 5164 & 36,159 & $\$ 4787$ \\
\hline
\end{tabular}

Sources: Occupational distribution by race and sex (not shown) is from Boletins de Ocorrências spanning 1912-1920 in Sao Paulo, compiled by Ramatis Jacino (2012). Mean daily nominal wages for Sao Paulo state are principally from the 1920 Recenseamento do Brasil, Vol. V, part 2 ("Salarios"), complemented by some national wage figures from this source, and in a few instances annual wage data for neighboring Rio de Janeiro in 1920 (based on 52 6-day workweeks) from Eulalia Lahmeyer Lobo, História do Rio de Janeiro (1978)

In some aspects, abolition brought more equality among races - now citizens, former slaves could choose where to live and work - and in others, it brought less libertos were often relegated to inferior employments than previously held. In much of the country, repression and a lack of options for blacks impeded broader material improvements in their welfare; in the southeast, massive immigration operated to undercut wages and push blacks into the subsistence sector or insecure urban employment. Nationalist sentiment after the Revolution of 1930, however, opened up new opportunities for Afro-Brazilians.

\subsection{The Vargas Era, Second Republic, Military Rule, and Return to Democracy}

During the First Republic, institutions of black civil participation were fomenting. Numerous societies (beginning with Clube 28 de Setembro in 1897) and periodicals (starting with A Pátria in 1899) were established to discuss issues pertinent to Afro-Brazilians (Domingues 2007). This culminated in the early 1930s, when black organizations mobilized support and garnered political influence. The black movement would produce tangible benefits for workers, but would fail to breach higher level political constraints.

Getúlio Vargas overthrew the republican government in 1930 with the support of landowners in his home state of Rio Grande do Sul, as well as Minas Gerais and the 
northeast (Andrews 1991). Afro-Brazilians, who had suffered under the Republic, initially supported Vargas; in turn, he helped integrate them into politics and the economy. The Ministry of Labor was established and the Law of Nationalization of Labor passed in 1931, which required that at least two-thirds of the industrial workforce be native Brazilian (Andrews 1991).

The Brazilian Black Front (FNB) was established in 1931 and by 1936 it had thousands of members and 60 delegates in other states (Domingues 2008b). The organization supported Vargas because, like him, it championed Brazilian nationalism. The FNB promoted the well-being of blacks, and even established an elementary school and health clinic, but became increasingly affiliated with fascism. Disillusionment with the Estado Novo (New State) lessened the imperative for political organization, but the following period was nonetheless one of notable economic progress for blacks (Andrews 1991).

After Vargas lost hold of power, new groups would lead the Afro-Brazilian movement: namely the União dos Homens de Cor, founded in Porto Alegre in 1943, and the Teatro Experimental do Negro, founded in Rio de Janeiro in 1944 (Domingues 2007). The UHC sought to "raise the economic and intellectual level of people-ofcolor" (p. 108), and the TEN promoted Afro-Brazilian culture and anti-discriminatory legislation. The situation of blacks and mulattos nonetheless remained very different from that of whites: the literacy rate for whites was $46.9 \%$ in 1940 and $52.7 \%$ in 1950, versus $22.6 \%$ in 1940 and $25.7 \%$ in 1950 for nonwhites (Hasenbalg 1978). In São Paulo, however, the rate of growth of industrial employment among Afro-Brazilians was comparatively high (Hasenbalg and Salazar 1994).

The military coup of 1964 marked the beginning of the dissolution of progressive Afro-Brazilian societies (Domingues 2007). As stated by Lovell (1999): "Military leaders quickly denounced any criticism of racial democracy as an 'act of subversion' and brutally silenced all opposition movements through imprisonment, censorship, and decree" (p. 400). The race/color question was removed from the 1970 census; partial information is available from other sources for 1976, but statistics on racial inequality are generally unavailable until 1980. In the 1976 National Household Survey (PNAD), whites earned on average 2.8 times more than blacks (3433 $\mathrm{Cr} \$$ to $1210 \mathrm{Cr} \$$ ), and 2.0 times more than people of mixed race (3433 Cr\$ to $1722 \mathrm{Cr} \$$ ); Silva (1985) estimates that $32.9 \%$ of the difference between white and mixed-race individuals is attributable to discrimination, and $26.3 \%$ of that between blacks and whites.

Only in 1978 did black civil society reemerged in the public sphere, with the foundation of the Movimento Negro Unificado (MNU) or Unified Black Movement (Domingues 2007). From the 1980s forward, efforts to eliminate racial discrimination grew and with them public awareness of and scholarship on race. The new generation of Afro-Brazilian organizers, inspired by pan-Africanism and the US black power movement, emerged with a more militant orientation after two decades of suppression by the dictatorship (Andrews 1992).

Many improvements in the social status of Afro-Brazilians followed: the MNU adopted the term "negro" for both blacks and mulattos, and it lost the negative connotation it had during the First Republic; the holiday commemorating abolition was moved from the 13th of May to November 20th, and the 13th was named the 
National Day for the Denunciation of Slavery; school curricula were revised, recognizing multiculturalism and the historical role of blacks; and African cultural heritage was generally asserted (Domingues 2007). In the political arena, the Partido do Movimento Democrático Brasileiro (PDMB) held majority control of the government after 1982 and created a state agency, the Conselho de Participação e Desenvolvimento da Comunidade Negra, directed towards protecting the rights of the black community (Andrews 1992). Over the 1990s and 2000s, improvements in income, life expectancy, and education were greater for blacks than for whites (Charão 2014).

The last decade has witnessed some promising, yet controversial, developments in the effort against discrimination: In 2003, the Secretary of Policy for the Promotion of Racial Equality was established by law (http://www.seppir.gov.br). Its broad charge is to aid in the creation and implementation of public policies regarding racial equality, including the National Program of Affirmative Action enacted on the 13th of May 2002 under direction of the Ministry of Justice, Secretary of State for Human Rights (http://www.planalto.gov.br).

\section{Trends in Racial Inequality from Abolition to the Present}

Important strides have been made in Brazil towards racial equality, but are recent advances part of a larger trend or do they form a unique historical episode? The previous section describes the experience of whites (brancos) and Afro-Brazilians (pretos and pardos) over the past two centuries. This section reports available quantitative evidence on absolute and relative changes, by race, in life expectancy, literacy, education, occupation, and income.

\subsection{Life Expectancy}

Available statistics on life expectancy at birth for whites (brancos) and nonwhites (pardos and pretos), and the difference between them, are presented in Table 2. The white/nonwhite dichotomy is shown here because it was standard in the sources where these figures were published; hereafter, each race is presented separately.

Table 2 Life expectancy at birth (years) by race, 1950-2008

\begin{tabular}{l|c|l|l|l|c}
\hline & 1950 & 1960 & 1980 & 1991 & 2008 \\
\hline White & 47.5 & 54.7 & 66.1 & 70.8 & 73.1 \\
\hline Nonwhite & 40.1 & 44.7 & 59.4 & 64.0 & 67.0 \\
\hline Difference & 7.4 & 10.0 & 6.7 & 6.8 & 6.1 \\
\hline
\end{tabular}

Source: Data from the 1950 and 1980 censuses, as presented in Wood et al. (1988), and Lovell (1999), who adds the 1960 figures; data for 2008 are from LAESER (2010; p. 197/9) based on the 1991/2000 censuses and Ministry of Health 1997-2000 micro-data 
As of 1950 , life expectancy at birth was 47.5 years for whites and 40.1 years for nonwhites - a difference of 7.4 years that increased to 10 years a decade later. The white/nonwhite difference in life expectancy at birth is much lower today than it was in 1960: the largest gain in terms of race equality was between 1960 and 1980, although this gap slightly increased in the 1990s. It appears that recent experience reports a steeper decline than the average since 1980.

\subsection{Literacy}

The comparative illiteracy rates of racial groups in Brazil are illustrated in Fig. 3 (white $=1.00$ ) based on census data (for 1970, when figures are not available, the linear trend is shown). Asian illiteracy rates went down relative to whites through 1960, were flat from 1960 until 1991, and then rose after 1991. Black/mixed-race illiteracy was increasing compared to whites, who were becoming literate at a faster rate, and only falling during the 1990s. Indigenous illiteracy is at a high level, and was also increasing in relative terms from 1960 onwards, with the exception of the decade after 1990.

Prior to 1940 , there is no literacy information by racial group in the censuses. The figures shown for 1900, 1910, 1920, and 1930 are the illiteracy rates for the 70-79, 60-69, 50-59, and 40-49 cohorts in the 1950 census: individuals who would

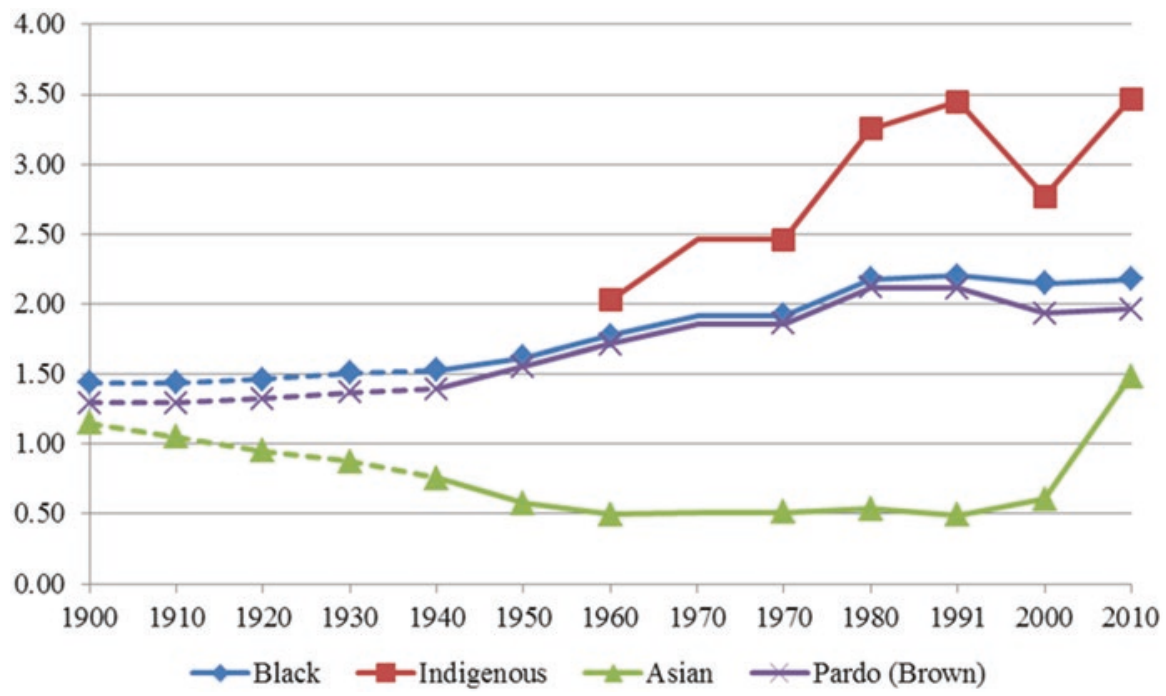

Fig. 3 Illiteracy of racial groups in Brazil relative to whites. Sources: Recenseamento Geral do Brasil 1940, 1950. IBGE census microdata 1960, 1980, 1991, 2000, 2010 from the Minnesota Population Center, Integrated Public Use Microdata Series (IPUMS), International. Minneapolis: University of Minnesota, 2014. Dotted lines correspond to the 40-49 to 70-79 cohort illiteracy rates in 1950 
have been from 20 to 29 in each respective decade, and having literacy levels typical of the population. This method is similar to that of Musacchio et al. (2014), but more robust because the sample is older: the illiteracy rates of the 30-39 racial cohorts in 1950, for instance, are within 5\% of those for the 20-29 cohorts in 1940, whereas the 15-19 and 5-9 age groups differ by as much as $66 \%$.

The illiteracy levels of all groups noticeably declined across the twentieth century: they ranged from $81 \%$ for blacks to $40 \%$ for Asians in 1940, compared with $29 \%$ for indigenous peoples and just $8 \%$ for whites in 2010 . This process accelerated after 1980 - there was an impressive drop in the indigenous illiteracy rate during the 1990s - although in the last decade illiteracy among Asians increased, possibly as a result of migration. Relative declines for whites outpaced those of blacks/mulattos between 1940 and 1980, but stabilized afterwards and Afro-Brazilian illiteracy fell versus whites during the 1990s; there was convergence after 1980, with the exception of a comparative jump in indigenous illiteracy after 2000.

\subsection{Education}

There are various measures of educational completion but the one which is comparable across the twentieth century, and particularly meaningful in terms of individual capabilities and public policy, is primary school completion. Figure 4 presents the

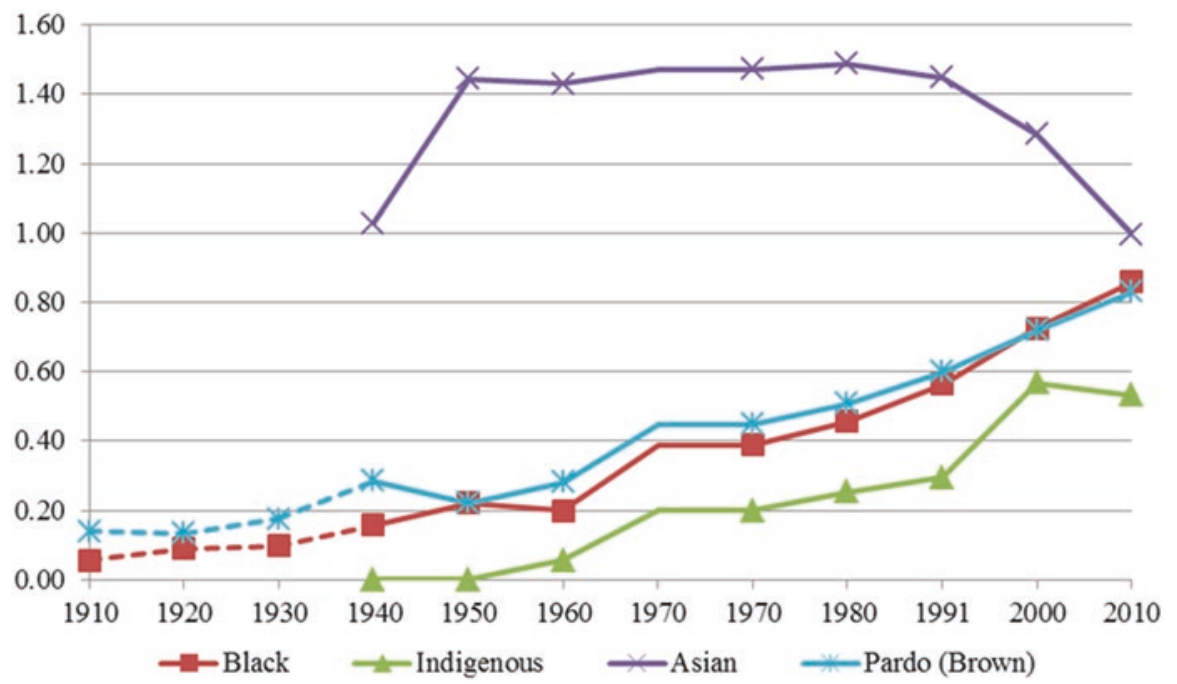

Fig. 4 Relative primary education achievement, 1910-2010. Sources: Recenseamento Geral do Brasil 1940, 1950. IBGE census microdata 1960, 1980, 1991, 2000, 2010 from the Minnesota Population Center, Integrated Public Use Microdata Series (IPUMS), International. Minneapolis: University of Minnesota, 2014. Observations for 1910-1930 correspond to 56-60 age cohorts in 1960 (Musacchio et al. 2014) 
Table 3 Average years of schooling, 1976-2008

\begin{tabular}{l|l|l|l|l}
\hline & 1976 & 1986 & 1998 & 2008 \\
\hline White & 4.5 & 5.4 & 6.8 & 8.3 \\
\hline Nonwhite & 2.7 & 3.9 & 4.7 & 6.5 \\
\hline Difference & 1.8 & 1.5 & 2.1 & 1.8 \\
\hline
\end{tabular}

Sources: Figures from PNAD household surveys; the 1976 and 1986 figures are published in Silva and Hasenbalg (2000), and 1988-1998-2008 overlapping series in LAESER (2010)

percent of individuals within each race who report having completed primary school, defined as grades one through four. The responses are standardized for the 1940/1950 and 1960-2010 periods. ${ }^{10}$ Five percent of the sample had attained a basic education in 1940: $13 \%$ in 1950; $9 \%$ in $1960 ; 26 \%$ in $1980 ; 33 \%$ in $1991 ; 42 \%$ in 2000; and $51 \%$ in 2010.

There were sustained gains in primary educational attainment among mixedrace, black, and indigenous peoples: black or mulatto attainment shows an increasingly positive trend, going from $10 \%$ in 1910 to $84 \%$ of whites in 2010 . Indigenous peoples were less likely to have reported completing primary school, and the size of the relative gap with Afro-Brazilians was roughly constant between 1940 and 1980 (ranging from 18 to 22\%), and wider in 1991 and 2000. Asians were at parity with whites in both 1940 and 2010, with completion rates about $40 \%$ higher in intermediate years. In general, there was a smooth convergence of educational attainment after 1980, with the indigenous experience of the 2000s being the sole outlier.

Table 3 presents data for whites and nonwhites from an alternative source, annual household surveys, for another education indicator, average years of schooling. The PNAD was first administered in 1976, and then every year after 1980, and is used in most current studies of racial inequality. In terms of average years of schooling, there was essentially no trend over the 1976-2008 periods.

In 1976, whites had on average 1.8 years more schooling than nonwhites, and 1.5 extra years a decade later; by 1998, however, the achievement gap was higher than before, and in 2008 at the same level as in 1976. This pattern is somewhat congruous with Fig. 4-education is increasing for all groups in reversing magnitudesbut there was greater educational equality in primary school attainment as opposed to average years of schooling, likely explained by proportionally higher secondary and tertiary completion among whites.

\footnotetext{
${ }^{10}$ The 1940/1950 censuses report those who have completed elementary, middle, or superior education, whereas the standardized responses after 1960 include many intermediate classifications. The frequency with which responses are coded into certain categories alternates, but only significantly in 2010 when there were many vague replies.
} 
Table 4 Occupational segregation by race

\begin{tabular}{l|c|l}
\hline Year (sample) & D-D index & $\%$ Afro-Brz. \\
\hline 1907 (S. Carlos) & 8.98 & 12.80 \\
\hline 1920 (S. Paulo) & 36.51 & 17.24 \\
\hline 1936 (Bahia) & 54.12 & 75.35 \\
\hline 1940 & 11.55 & 36.34 \\
\hline 1950 & 12.79 & 37.79 \\
\hline 1960 & 6.49 & 36.29 \\
\hline 1980 & 21.07 & 43.34 \\
\hline 1991 & 17.58 & 46.32 \\
\hline 2000 & 17.43 & 43.91 \\
\hline 2010 & 14.30 & 48.46
\end{tabular}

Sources: 1940 and 1950 Recenseamento geral do Brasil; 1960-2010 decennial censuses from IBGE National Census Microdata, IPUMS International, University of Minnesota (2014); São Carlos 1907 from Monsma (2006); São Paulo 1920, Boletins de ocorrência in Jacino (2012); and Bahia 1936, Pierson (1942)

\subsection{Occupational Distribution}

The degree of occupational segregation over time is examined using census data from 1940 to 2010, as well as three regional observations for previous decades when the national censuses did not consider race: urban São Paulo circa 1920 from the incident reports compiled by Jacino (2012); São Carlos (western São Paulo state) in 1907 from Monsma (2006); and Salvador (the capital of the northeast state of Bahia) for 1936 from Pierson (1942).

I adopt the Duncan and Duncan Index of occupational segregation, which was originally applied to gender (Wolff 2009). The D-D index is the summation across occupations of the absolute value of the difference between the percent of total white $\left(w_{i}\right)$ and black $\left(b_{i}\right)$ employees in occupation $i$, divided by two $\left(\mathrm{DD}=\Sigma\left|w_{i}-b_{i}\right| / 2\right)$. The results are shown in Table 4, along with the percent of the population that was Afro-Brazilian. ${ }^{11}$

Occupational segregation tripled between 1960 and 1980, from moderate levels in the 1940s and 1950s, and has since gradually declined back to its earlier level. It dropped from 12.8 to 6.5 (on a scale of 100) between 1950 and 1960, and then reverted to a high of 21.1 in 1980 . The degree of employment segregation decreased during the 1980s and 2000s, settling slightly above its 1940/1950 level in 2010. Before 1940, it was relatively high in urban São Paulo (36.5) and Bahia (54.1), and

\footnotetext{
${ }^{11}$ The employment segregation indices are based on a consistent grouping of individual jobs into ten common occupational classes: public administration, agriculture-fishing-forestry, commerce of real property, commerce of merchandise, national defense-public safety, manufacturing industry, extractive industry, liberal professions, services-social activities, and transport-communications.
} 


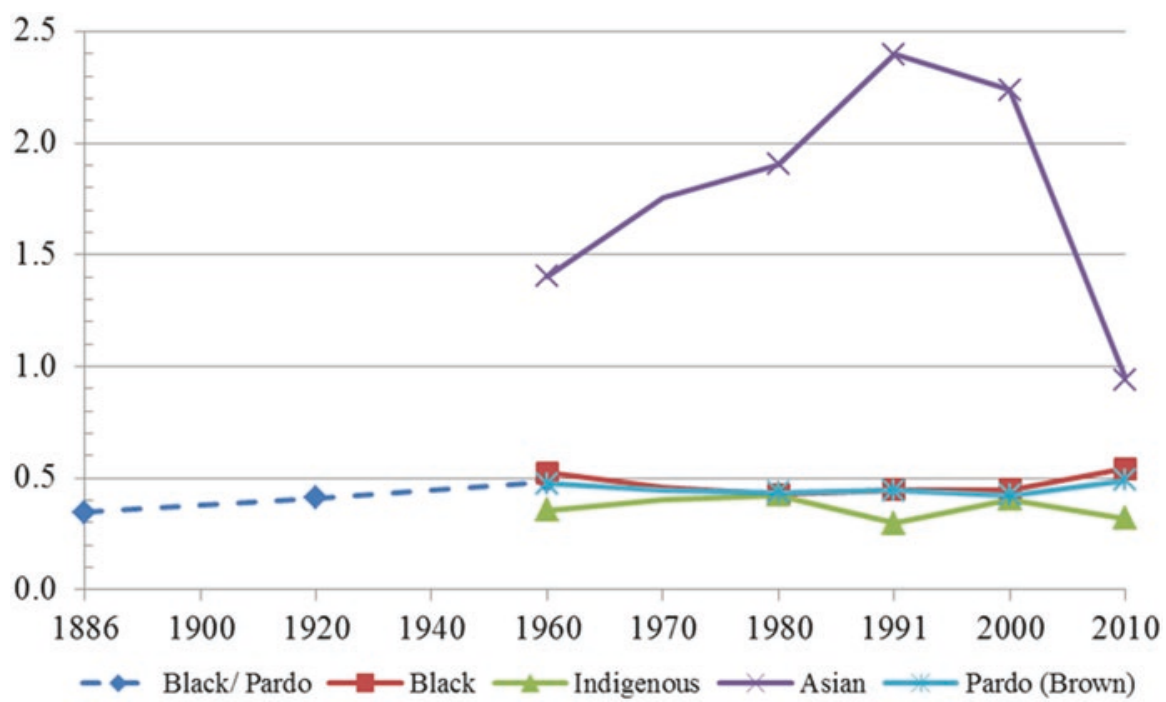

Fig. 5 Brazilian income by racial group relative to whites. Sources: IBGE census microdata 1960, 1980, 1991, 2000, 2010 from the Minnesota Population Center, Integrated Public Use Microdata Series (IPUMS), International. Minneapolis: University of Minnesota, 2014. Dashed series based on author's calculations

relatively low in rural western São Paulo (9.0). There appears to be more segregation where blacks comprised a greater share of the population, although the sample sizes and methods of data collection require caution in making such comparisons.

\subsection{Income}

Life span, literacy, education, and employment-human capital in general-affect one's income; hence, racial inequality must also be salient in terms of earnings given the disparities in these areas. I consider differences in reported income by race using the 1960-2010 census micro-data. The average real annual income was \$111 in 1960: $\$ 236$ in 1980; \$430 in 1991; \$645 in 2000; and \$749 in 2010. ${ }^{12}$ Figure 5 displays the ratio of each race's mean income to that of whites (the highest in 2010).

The paths of relative incomes after 1960 are relatively flat: the income gap widened through 1980 and has since narrowed, with little change during the 1990s - an unexceptional record in comparison with the improvement of the preceding 75 years. The ratios of indigenous- and Asian-to-white incomes fell between 2000 and 2010,

\footnotetext{
${ }^{12}$ Mean incomes expressed in 2010 reales by the author adjusting for currency revaluations and using consumer price indices from 10/1980 to 7/1999 and 1/1994 to 10/2014 (IBGE, Sistema Nacional de Índices de Preços ao Consumidor), as well as benchmark 1960-1980 inflation rates from Allen (2009).
} 
but there was a rise in the relative incomes of whites and Afro-Brazilians - the two predominant racial groups in Brazil. ${ }^{13}$ LAESER (2010) confirms that the multiples of average per capita nonwhite to white household earnings for 1988, 1998, and 2008 were $0.433,0.417$, and 0.505 , respectively.

The pre-1960 trend of Afro-Brazilian-to-white income-based on slave in-kind earnings and urban occupational segregation, respectively — shows a big positive change: In terms of goods and services consumed, a typical black or mulatto slave in 1886 could earn $35 \%$ of a free white worker; in São Paulo, the employment distribution and classified advertisements suggest that blacks or pardos in 1920 may have earned $41 \%$ of whites; the census data for 1960 give a corresponding figure of $49 \%$. Although Afro-Brazilians today earn just over half of whites, this is more than in 1960 which makes it the smallest recorded income gap.

\section{Conclusion}

Racial equality in Brazil has been getting a lot of attention, and for good reason: health, education, employment, and income have become more similar across races, accompanied by increased public policy and activism targeting discrimination. This chapter explores changes in these variables for pretos, pardos, brancos, indigenas, and amarelos after 1900 and between whites (brancos) and Afro-Brazilians (pretos and pardos) since independence in 1822 .

During the Imperial Era (1822-1889), Afro-Brazilians comprised a majority of the population and the fraction enslaved gradually diminished until abolition in 1888. The transition to freedom under the First Republic (1889-1930) was difficult as libertos had to compete with immigrants in the south; elsewhere, freed slaves settled back into agricultural life or moved to cities. The status of blacks improved during the Vargas Era (1930-1945) as industrial positions opened; was set back by the repressive Estado Novo; advanced along with the economy in the Second Republic (1946-1964); and was again hindered under Military Rule (1964-1985).

In summary, economic outcomes improved for most races relative to whites from 1940 to 1960 , though their comparative levels of education and life expectancy worsened. The general trend was poor from 1960 to 1980 in terms of occupational segregation and the size of the income gap, but there were relative advances in life expectancy and completion of basic education. Over 1980-2010, there was a positive overall experience in terms of reducing racial inequality, although gains were somewhat muted during the 1990s. The situation of Afro-Brazilians is better than it was a few decades ago, and race has become imbued with pride; yet progress has been irregular and opportunity remains far from equal.

\footnotetext{
${ }^{13}$ Real incomes were strictly increasing over this 50-year span, with the exception of 2000/2010 when there was a stunning $51 \%$ decline in the average income of Asians and moderate $8 \%$ reduction in that of indígenas. There were relatively few Asians in Brazil in 2000, but by 2010 their share of the population had doubled.
} 
Acknowledgments The author is grateful to participants at the Latin American Inequality in the Long Run conference (Buenos Aires, 12/2014), above all Jeff Williamson, Luis Bértola, Eustaquio Reis, José Peres-Cajías, and Moramay López-Alonso, as well as the Economic History of Race, Gender, and Class conference (Middlebury, 4/2015), particularly Lety Arroyo Abad, Catalina Vizcarra, Peter Lindert, Jenny Bourne, and Bob Margo. Thanks also go to Renato Araujo da Silva and librarians at the Museo Afro Brasil (São Paulo), periodical staff at the Arquivo Público do Estado de São Paulo, and the Instituto Brasileiro de Geografia e Estatística (IBGE) for assistance in locating source materials.

Open Access This chapter is distributed under the terms of the Creative Commons Attribution 4.0 International License (http://creativecommons.org/licenses/by/4.0/), which permits use, duplication, adaptation, distribution and reproduction in any medium or format, as long as you give appropriate credit to the original author(s) and the source, a link is provided to the Creative Commons license and indicate if changes were made.

The images or other third party material in this chapter are included in the work's Creative Commons license, unless indicated otherwise in the credit line; if such material is not included in the work's Creative Commons license and the respective action is not permitted by statutory regulation, users will need to obtain permission from the license holder to duplicate, adapt or reproduce the material.

\section{References}

Alden, D. (1963). The population of Brazil in the late eighteenth century: A preliminary study. Hispanic American Historical Review, 43(2), 173-205.

Allen, L. (2009). The encyclopedia of money (2nd ed.). Santa Barbara: Greenwood Publishing Group.

Andrews, G. R. (1991). Blacks \& whites in São Paulo, Brazil 1888-1988. Madison: University of Wisconsin Press.

Andrews, G. R. (1992). Black political protest in São Paulo, 1888-1988. Journal of Latin American Studies, 24(1), 141-171.

Arcand, J.-L., \& D'Hombres, B. (2004). Racial discrimination in the Brazilian labor market: Wage, employment, and segregation effects. Journal of International Development, 16, 1053-1066.

Arias, O., Yamada, G., \& Tejerina, L. (2004). Education, family background and racial earnings inequality in Brazil. International Journal of Manpower, 25(3/4), 355-374.

Bailey, S. R., Loveman, M., \& Muniz, J. O. (2013). Measures of 'race' and the analysis of racial inequality in Brazil. Social Science Research, 42(1), 106-119.

Bergad, L. W. (1996). After the mining boom: Demographic and economic aspects of slavery in Mariana, MG, 1750-1808. Latin American Research Review, 31(1), 67-98.

Bethell, L. (1970). The abolition of the Brazilian slave trade: Britain, Brazil and the slave trade question, 1807-1869. Cambridge: Cambridge University Press.

Bethell, L., \& de Carvalho, J. M. (1989). 1822-1850. In L. Bethell (Ed.), Brazil: Empire and republic, 1822-1930 (pp. 45-112). Cambridge: Cambridge University Press.

Boxer, C. R. (1962). The golden age of Brazil. Berkeley: Cambridge University Press.

Bucciferro, J. R. (2013). A forced hand: Natives, Africans, and the population of Brazil, 15451850. Revista de Historia Económica/Journal of Iberian and Latin American Economic History, 31(2), 285-317. 
Campante, F. R., Crespo, A. R. V., \& Leite, P. G. P. G. (2004). Desigualdade salarial entre raças no Mercado de trabalho urbano Brasileiro: aspectos regionais. Revista Brasileira de Economia, 58(2), 185-210.

Charão, C. (2014). O longo combate às desigualdades raciais. Retrieved from http://www.ipea. gov.br/.

Conrad, R. E. (1972). The destruction of Brazilian slavery, 1850-1888. Berkeley: University of California Press.

Dean, W. (1976). Rio Claro: A Brazilian plantation system, 1820-1920. Stanford, CA: Stanford University Press.

Degler, C. N. (1971). Neither black nor white: Slavery and race relations in Brazil and the United States. New York: Macmillan.

Domingues, P. (2003). Uma história não contada: Negro, racismo e branqueamento em são paulo no pós-abolição. São Paulo: Senac.

Domingues, P. (2007). Movimento negro Brasileiro: alguns apontamentos históricos. Tempo, 23, $100-122$.

Domingues, P. (2008a). Decifrando os segredos internos: a transição do trabalho escravo para o livre no Brasil. Iberoamericana, 8(31), 197-205.

Domingues, P. (2008b). A nova abolição. São Paulo: Selo Negro.

Fernandes, F. (1965). A integração do negro na sociedade de classes (Vol. 2). São Paulo: Dominus. Filho, O. B. (1952). A Fazenda do café em São Paulo. Rio de Janeiro: Ministério da Agricultura.

Flory, T. (1977). Race and social control in independent Brazil. Journal of Latin American Studies, 9(2), 199-224.

Furtado, C. (2006[1959]). Formação econômica do Brasil. São Paulo: Companhia das Letras.

Filho, W. F. (2006). Encruzilhadas da liberdade: histórias de escravos e libertos na Bahia (18701910). Campinas, SP: Editora da Unicamp.

Guimarães, E. S. (2006). Múltiplos viveres de afrodescendentes na escravidão e no pos-emancipação: família, trabalho, terra e conflito (Juiz de Fora-MG, 1828-1928). Paulo: Anna-blume.

Hall, M. M. (1969). The origins of mass immigration in Brazil, 1871-1914. Doctoral thesis, Columbia University.

Harris, M., Consorte, J. G., Lang, J., \& Byrne, B. (1993). Who are the whites? Imposed census categories and the racial demography of Brazil. Social Forces, 72(2), 451-462.

Hasenbalg, C. A. (1978). Race relations in post-abolition Brazil: The smooth preservation of racial inequalities. Doctoral thesis, UC-Berkeley.

Hasenbalg, C., \& Salazar, G. (1994). Perspectivas sobre raza y clase en Brasil. Estudios Sociológicos, 12(34), 75-99.

Ianni, O. (1962). As metamorfoses do escravo: Apogee e crise da escravatura no Brasil meridional. São Paulo: Difusão Européia do Livro.

Instituto Brasileiro de Geografia e Estatística. (2000). Brasil: 500 anos de povoamento. Rio de Janeiro: IBGE.

Instituto Brasileiro de Geografia e Estatística. (2008). Síntese de indicadores sociais: uma análise das condições de vida da população Brasileira. Estudos \& Pesquisas, 23, 209-230.

International Labor Organization. (2007). Igualdade no trabalho: Enfrentando os desafios. Geneva: United Nations.

Jacino, R. (2012). O negro no mercado de trabalho em São Paulo pós-abolição - 1912/1920. Doctoral thesis, Universidade de São Paulo.

Klein, H. S. (1971). The internal slave trade in nineteenth century Brazil: A study of slave importations into Rio de Janeiro in 1852. Hispanic American Historical Review, 51(4), 567-585.

Klein, H. S. (2010). The Atlantic slave trade. Cambridge: Cambridge University Press.

Klein, H. S., \& Luna, F. V. (2010). Slavery in Brazil. New York: Cambridge University Press.

Kodama, K. (2007). O sol nascente do Brasil: um balanço da imigração Japonesa. In Brasil: 500 anos de povoamento (pp. 199-213). Rio de Janeiro: IBGE.

Laboratório de Análises Econômicas, Históricas, Sociais e Estatisticas das Relações Raciais (LAESER). (2010). Relatório Annual das Desigualdades Raciais no Brasil, 2009-2010. Rio de Janeiro: UFRJ. 
Leff, N. H. (1982). Underdevelopment and development in Brazil (Vol. 1). London: George Allen \& Unwin.

Loury, G. C. (2002). The anatomy of racial inequality. Cambridge: Harvard University Press.

Lovell, P. A. (1999). Development and the persistence of racial inequality in Brazil: 1950-1991. The Journal of the Developing Areas, 33(3), 395-418.

Luna, F. V., \& Klein, H. S. (2004). Slave economy and society in Minas Gerais and São Paulo, Brazil in 1830. Journal of Latin American Studies, 36, 1-28.

Marteleto, L. J. (2012). Educational inequality by race in Brazil, 1982-2007: Structural changes and shifts in racial classification. Demography, 49, 337-358.

Mello, P. C. de. (1977). The economics of labor in Brazilian coffee plantations, 1850-1888. Doctoral thesis, University of Chicago.

Merrick, T. W., \& Graham, D. H. (1979). Population and economic development in Brazil: 1800 to the present. Baltimore: Johns Hopkins University Press.

Monsma, K. (2006). Symbolic conflicts, deadly consequences: Fights between Italians and Blacks in Western São Paulo, 1888-1914. Journal of Social History, 39(4), 1123-1152.

Musacchio, A., Fritscher, A. M., \& Viarengo, M. (2014). Colonial institutions, trade shocks, and the diffusion of elementary education in Brazil, 1889-1930. Journal of Economic History, 74(3), 730-766.

Pierson, D. (1942). Negroes in Brazil: A study of race contact at Bahia. Chicago/London: University of Chicago Press.

Ribeiro, D. (1995). O povo Brasileiro. São Paulo: Companhia das Letras.

Rossetto, I., \& Paixão, M. (2010). Acesso ao sistema de ensino e indicadores de proficiência. In Relatório annual das desigualdades raciais no Brasil: 2009-2010 (pp. 205-248). LAESER. Rio de Janeiro: UFRJ.

Russell-Wood, A. J. R. (1982). The black man in slavery and freedom in colonial Brazil. London: Macmillan.

Silva, N. d. V., \& Hasenbalg, C. (2000). Tendências da desigualdade educacional no Brasil. Dados, 43(3), 423-445.

Silva, N. D. V. (2001). Race, poverty, and social exclusion in Brazil. In E. Gacitúa, C. Sojo, \& S. H. Davis (Eds.) Social exclusion and poverty reduction in Latin America and the Caribbean. Washington, DC: World Bank.

Silva, N. D. V. (1985). Updating the cost of not being white in Brazil. In P. M. Fontaine (Ed.) Race, class, and power in Brazil. Los Angeles: UCLA.

Silva, G. M., \& de Souza Leão, L. T. (2012). O paradox da mistura: identidades, desigualdades e percepção de discriminação entre Brasileiros pardos. RBCS, 27(80), 117-255.

Soares, S. F. (1860). Notas estatísticas sobre a produção agrícola e carestia dos géneros alimentícios no império do Brazil. Rio de Janeiro: Typ. Imp. e Const. de J. Villeneuve e Comp.

Stein, S. (1957). Vassouras: A Brazilian coffee county, 1850-1900. Cambridge: Harvard.

Subrinho, J. M. d. P. (2000). Reordenamento do trabalho: trabalho escravo e trabalho livre no Nordeste açucareiro: Sergipe 1850-1930. Aracaju: Funcaju.

Taunay, A. de E. (1939). Historia do café no Brasil (Vol. 2). Rio de Janeiro: Departamento Nacional do Café.

Telles, E. E. (1995). Racial ambiguity among the Brazilian population. UCLA working paper.

Trans-Atlantic slave trade database. Retrieved 11, 2014, from www.slavevoyages.org.

Wolff, E. N. (2009). Poverty and income distribution (2nd ed.). Malden, MA: Wiley-Blackwell.

Wood, C. H., Alberto, J., \& Magno, de C. (1988). The demography of inequality in Brazil. Cambridge: Cambridge University Press.

Justin Bucciferro is an associate professor of economics at Eastern Washington University. His research centers on the economic history and development of the Americas, addressing the interrelationships between demography, geography, and inequality. He earned a Ph.D. in Economics from the University of Colorado at Boulder and an M.B.A. from Clarkson University. His research appears in the Economic History Review, Economic Anthropology, and the Journal of Iberian and Latin American Economic History. 


\title{
The Expansion of Public Spending and Mass Education in Bolivia: Did the 1952 Revolution Represent a Permanent Shock?
}

\author{
José Alejandro Peres-Cajías
}

\section{Introduction}

Being one of the most unequal regions in the world (De Ferranti et al. 2004), inequality has a central role in the explanation of Latin American long-term development. A widespread view suggests that the current high levels of inequality are not anything new but one of the most salient features in the region since colonial times (Acemoglu et al. 2002; Engerman and Sokoloff 2012). According to this literature, Latin American countries inherited very unequal societies in terms of wealth, political power, and human capital at the time of their independence. Furthermore, it is argued that, given this initial level of inequality, the new Latin American states became rapidly controlled by small elites that did not have any interest in tax collection (Sokoloff and Zolt 2006) (since this would imply taxing themselves) or education spending (Engerman et al. 2009) (which would involve a redistribution of resources). By assuming the existence of institutional path dependence, these authors finally suggest that a fiscal equilibrium with low taxation and low spending in education persisted in the region until very recent decades, with only minor changes.

This view has been challenged (i.e., Coatsworth 2008; Herranz-Loncán and Peres-Cajías 2016). Recently, Williamson (2015) has suggested that inequality has not been constant in Latin America and, therefore, the region has not always been the most unequal in the world. Indeed, he suggests that inequality rose dramatically in Latin American countries and converged towards the most unequal ones during the First Globalization. More importantly, whereas inequality was reduced in most parts of the world during the twentieth century (the "Great Leveling"), it increased or stayed constant in Latin America. Therefore, the current high levels of inequality would not be the result of Iberian colonial powers but the outcome of a more contemporaneous process.

\footnotetext{
J.A. Peres-Cajías $(\square)$

Universidad Católica Boliviana "San Pablo", La Paz, Bolivia 
Whether a colonial legacy or a contemporaneous outcome, further research has proved that Latin American governments have had a relatively low interest in the promotion of public education during most of the twentieth century. For instance, Lindert (2010) indicates that, in contrast with developed economies, Latin American governments have invested in education less than what would be expected given its GDP per capita. Moreover, this author stresses that most public expenditure was devoted to tertiary education, restricting thus the redistributive impact of education spending. Likewise, Frankema (2009) points out that the higher priority of tertiary education also holds when the region is compared with other developing economies. He also affirms that, whereas Latin America has undertaken significant progress in terms of primary education enrollment, the region's achievements are not outstanding by international standards and are negatively affected by the absence of quality increases.

Taking into account these antecedents, this chapter aims at analyzing whether educational spending in Bolivia fits well into this regional description or, by contrast, changed radically and took distance from the regional pattern after the 1952 Revolution. The former hypothesis would seem a priori more likely, given that some of the main determinants of education spending expansion-such as economic growth or political voice (Lindert 2004; Espuelas 2012) - showed very bad records during several episodes after the revolution. For instance, following Brown and Hunter (2004)'s results, it would be expected that public spending in mass education was relatively low during the military dictatorships (1964-1982). Likewise, the low yearly long-term rate of Bolivian economic growth (below 1\%) during the second half of the twentieth century would also restrict the expansion of mass education spending. In the same vein, on the basis of the economic literature which suggests a negative relationship between ethnic diversity and public spending, ${ }^{1}$ or taking into account Dell's (2011) study for Peru, the Bolivian colonial legacy might be assumed to have restricted the expansion of education services towards the Bolivian indigenous population, a sector which constitutes a substantial share of total population - between 40 and $60 \%$, according to the 2001 national census (INE 2001). ${ }^{2}$

Nevertheless, it is also critical to consider the relevance of social empowerment and its ability to change public policies. Indeed, according to Kosack (2012), political entrepreneurs may foster (whatever the political regime of a country) the political organization of the poor which, in turn, may force governments to invest massively in mass education. In this context, it cannot be ignored that the 1952 Revolution represented a considerable shock in Bolivian history (Grindle and Domingo 2003; Klein 2011a, b: 209-222). This shock, in turn, generated some radical redistributive policies which in some cases had long-term consequences. For instance, Fundación Tierra (2007) has suggested that the 1953 Agrarian Reform allowed the recovery and total expulsion of former white terratenientes in the west side of the country by the Aymara population - the most important indigenous

\footnotetext{
${ }^{1}$ See Go and Lindert (2010) for a historical test of this hypothesis.

${ }^{2}$ See the INE webpage for a description of the different indicators used for the identification of the Bolivian indigenous population.
} 
group in that region. The 1952 Revolution also brought up an educational reform. In relation to this, previous work (Peres-Cajías 2014) has presented some evidence which suggests that these changes generated a substantial increase in social public spending (which includes education spending) from the 1950s onwards. In the same line, Klein (2011b) has stressed that these modifications in public policies are critical to understanding the continuous political empowerment achieved by the indigenous population during the second half of the twentieth century (Zavaleta Mercado 2011; Calderón 2010). ${ }^{3}$ Therefore, these ideas suggest that the long-term impact of the 1952 Revolution on public education spending is far from obvious.

On the basis of quantitative evidence previously presented (Peres-Cajías 2014), this chapter offers for the first time a long-term and comparative analysis of Bolivian public education spending. ${ }^{4}$ To begin with, following the framework proposed by Booth (2007) and Frankema (2011), the chapter shows that, after the 1952 Revolution, the Bolivian Central Government moved from a "minimal state" fiscal equilibrium to a "benign state" one, in which relatively low tax collection levels coexisted with non-negligible investments (by Latin American standards) in public education. However, looking at the evolution of education spending per capita, it becomes clear that this paradoxical fiscal equilibrium did not necessarily grant the sustainability of educational expenses. Furthermore, when controlling by per capita GDP, the evolution of public education spending in Bolivia does not stand out by international standards until recent decades, which is in contrast to the experience of other small Latin American countries. Likewise, following Lindert's (2010) suggestions, this chapter shows that the postrevolutionary increase in education spending did not imply any significant change in the tax support given to primary education. By contrast, the relative importance of primary over tertiary education spending was not different from the rest of the region and, more strikingly, today is relatively low even by Latin American standards.

It could still be assumed that, despite these limitations, the increase in Bolivian education spending since the Revolution was enough to foster substantial modifications in educational outputs. Rather than measuring the profitability of public expenditure, the last section of the chapter addresses this issue by analyzing if the increase in education spending was contemporaneous of any significant change in several educational outputs. The analysis of the available "quantity indicators" seems to confirm the pessimistic assessment previously offered by other authors, such as Contreras (2003). Furthermore, in the case of "quality indicators," Bolivia appears often in the lowest ranks of the region, which illustrates the limited impact of the public efforts in the educational area. Therefore, apart from its increase as a

\footnotetext{
${ }^{3}$ The most salient example of this progressive political empowerment is the arrival of Evo Morales to the Bolivian presidency in 2006. Additionally, previous researches have stressed that, during the last decades, and beyond the persistence of considerable inequalities, the Bolivian population has benefited from public education spending as an efficient instrument for social mobility (Andersen 2003; PNUD 2010: 58).

${ }^{4}$ Previous analyses on the impact of the 1952 Revolution have focused mostly on education outputs, such as literacy or enrollment rates (Contreras 1999, 2003).
} 
share of the GDP, the chapter stresses that the 1952 Revolution does not seem to have fuelled any significant long-term differentiation of Bolivia from the rest of the region in terms of education spending and education outputs.

\section{Why Bolivian Politics Should Matter: A Historical Background}

Bolivian history has often been analyzed by stressing the ability of nonindigenous elites to impose their own interests on the entire society. ${ }^{5}$ Despite its popularity, another view has stressed the nonelites' capacity — and particularly that of indigenous communities - to resist and propose alternative political projects. ${ }^{6}$ In this context, it has been suggested that although the evolution of formal institutions in Bolivia reflects a very unequal society until very recent decades, informal institutions may have counteracted these inequalities in different conjunctures of Bolivian history (Peres-Cajías 2012). This perspective is used in the following paragraphs to revise Bolivian history from independence onwards and to illustrate why a specific institutional shock such as the 1952 Revolution may have had long-term redistributive impacts.

A few years after Bolivian independence (1825), the National Congress approved a law which restricted the right to vote for those who had some economic and educational qualifications. This fact has been used to illustrate the idea that the vast majorities of the country did not participate in the configuration of the Bolivian state during the postindependence decades. However, thanks to the seminal work by Platt (1982), it has been proved that the indigenous political power has shaped the Bolivian state through alternative ways. Indeed, it has been stressed that in exchange of the re-instauration of the colonial capitation tax on the indigenous populationthe so-called Contribución Indigenal - the Bolivian Government accepted the social and political autonomy of indigenous communities.

This implicit political pact between the Bolivian state and the indigenous communities ended in the early 1860 s, once the government was able to exploit alternative and reliable fiscal revenue sources. This event, in turn, represents the beginning of the so-called oligarchic era (1860s-1930s), a period which is characterized by the consolidation of new political and mining elites and the expansion of latifundia at the expense of indigenous communities. Undoubtedly, both economic and political inequalities grew during this period. This, however, does not necessarily mean that

\footnotetext{
${ }^{5}$ According to this view, the elites' ability to configure economic and political institutions since colonial times up to recent decades has generated several long-term negative economic effects. One of the latest contributions on this perspective is that of Dell (2011) who suggests that the mita (a forced mining labor system instituted by the Spanish colonial power in Bolivia and Peru from 1573 to 1812) may explain present-day lower well-being indicators in those zones where this institution was imposed.

${ }^{6}$ Rivera's book title (1984) rightly summarizes this view: Oprimidos pero no vencidos (oppressed but not defeated).
} 
mining elites were able to constantly impose their interests on the configuration of the Bolivian state (Gallo 1991; Barragán and Peres-Cajías 2007), a statement frequently stressed by the common knowledge. Moreover, recent research has also underlined the ability of indigenous communities to resist the advance of latifundia either by legal or violent means (Gotkowitz 2007).

The Great Depression and the Chaco war against Paraguay (1932-1935) modified the previous political context. ${ }^{7}$ Indeed, new political groups arose (among these, the Movimiento Nacionalista Revolucionario, MNR, a middle-class political organization) with the explicit goal to overcome the institutions imposed by the oligarchy. Moreover, mining workers achieved a higher degree of political organization through the creation of a unified union; political pressure from peasant organizations also increased considerably. In this context, after the revocation of the MNR victory at the national election of 1951, its leaders decided to seize power by violent means. This was made in April of 1952 and, after 3 days of combat, the MNR, with the key support of urban workers, mining workers, and peasant organizations, consolidated the National Revolution.

Shortly after these events, permanent pressure from the social base of the Revolution forced the promulgation of different radical measures: universal adult suffrage, the nationalization of the three biggest mining companies (which represented three-quarters of mining output), and a radical land reform. Likewise, an educational reform was applied in 1953-1955 which met considerable consensus and was intended to reflect "... the new correlation of economic and social forces arising from the revolution" (Contreras 2003: 262).

The MNR also imposed a new economic model characterized by a higher intervention of the state in the economy and the increase of redistributive policies. Initially, this new model was financially unsustainable and, as a consequence, hyperinflation arose as one of the main characteristics of the Bolivian economy from 1952 to $1956 .^{8}$ The 1956 fiscal reform solved these initial macroeconomic disorders. The reform, however, was implemented with the technical and financial support of the IMF and the US Government. Both the left-wing group of the MNR and mining workers saw this process as a betrayal to the principles of the 1952 Revolution, so they reduced its support to the government. Anyway, the MNR won the national election of 1956 by a significant majority and, thanks to the maintenance of the land reform, peasants continued as key allies of the government. Moreover, despite some changes introduced by the 1956 fiscal reform, state intervention and redistributive policies continued as a central feature of the government's economic orientation.

The MNR won again by a significant majority the 1960 national election. Nevertheless, its political support reduced significantly during the victory of the 1964 election and, shortly after this event, a military coup took place. The coup modified the political alliances of the Bolivian Government. Indeed, following the principles of the National Security Doctrine, political and violent repression increased considerably towards left-wing groups and mining and urban workers.

\footnotetext{
${ }^{7}$ For further references, see Klein (2011a) and Cajías (2015).

${ }^{8}$ See Peres-Cajías (2014) to understand the causes and the dynamics of Bolivian hyperinflation.
} 
In contrast, the military maintained the political support from peasants through the so-called Pacto Militar-Campesino (Military-Peasant pact), which implied the maintenance of the land reform process as well as the increase of state investment in rural areas. Thus, whereas the military tended to repress some of the main political groups of the 1952 Revolution, the Military-Peasant pact assured the maintenance of one of the key redistributive measures implemented during the revolution.

The political context changed dramatically during the 1970s. On the one hand, the Military-Peasant pact ended with the Tolata's massacre (1974). Moreover, whereas military governments maintained the high degree of state intervention in the economy, its redistributive goals were different from those implemented during the 1952 Revolution and its aftermath. Likewise, a higher degree of political repression emerged in the country. Despite these changes, pressure from peasant organizations, mining workers, and urban workers was often able to resist or counteract government's actions. Thus, not surprisingly, the strength of these organizations was critical in the recovery of democracy (1982).

Taking into account these events, it becomes logical to question if, among the radical measures implemented by the 1952 Revolution, there was a major change in the evolution of public education spending in Bolivia. It also appears reasonable to believe that this hypothetical change may have had long-term consequences. On the one hand, the increase of public education spending may have persisted throughout time since the political party which managed the Revolution remained in power until 1964. On the other hand, a persistent indirect effect would be expected until 1974 through the "Pacto Militar Campesino." Finally, following Kosack (2012), it could be argued that the political strength of peasants and workers organizations forced the Bolivian Government to maintain a high level of educational expenses. These ideas are explored in the following sections.

\section{The Puzzle: The Bolivian Paradoxical Equilibrium Between Low Taxation and Human Capital Investment}

During the last decades, public finances have increasingly been considered as an instrument to understand the evolution of the implicit fiscal pact between the state and society. This approach has been used by political scientists (Lieberman 2002), economists focusing on the analysis of developing economies (Brautigam et al. 2008), or international organizations such as the World Bank. These have suggested, for example, that the size and composition of public finances reflect the institutional equilibrium achieved by each state, given the economic, political, and social restrictions it must face (De Ferranti et al. 2004; OECD 2009; CEPAL 2010). Economic historians have also used this approach as an efficient tool to assess, for instance, the institutional framework established by European colonial powers both in Southeast Asia (Booth 2007) and sub-Saharan Africa (Frankema 2011).

This section uses this approach to depict the plausible evolution of the Bolivian fiscal pact from the first decades of the twentieth century onwards. My analysis is 
based on Frankema (2011), who identifies four different types of institutional equilibriums on the basis of the relationship between tax pressure and a (human and physical) capital expenditure ratio. According to this author, those countries where both tax collection and the fiscal priority of capital investment are small and in a "nightwatchman" equilibrium - i.e., under a minimal state. The "extractive" scenario corresponds, in turn, to those cases where tax collection is high but is not reinvested in capital formation. If capital investment is high but tax collection is low, the equilibrium is characterized as a "benign state" one. Finally, a "developmental equilibrium" is reached when both tax collection and public capital formation are high.

In my case, I analyze the relationship between tax pressure levels ${ }^{9}$ and the fiscal priority of human capital spending (namely education and health) exclusively, and consider those four institutional equilibrium categories as implicit fiscal pacts. My analysis is limited to human capital investment, firstly, because the main interest of this chapter is education spending and, secondly, because (especially during the ISI period) public investment in physical capital was carried out not only by the Central Government (which is the object of this research) but also by state-owned companies. In order to distinguish between those four different fiscal pacts, I assume that the minimum ratio required for a significant impact of state intervention in the economy is around $20 \%$ of GDP for tax pressure and $6 \%$ of GDP for human capital investment. ${ }^{10}$

Graph 1 compares the Bolivian experience throughout the twentieth century with two of the most developmental states in Latin America (Chile and Uruguay; see Azar and Fleitas 2012). As a reference, it also shows the evolution of France, Spain, and the USA from 1960 onwards. ${ }^{11}$ As might be expected, during the second half of the twentieth century Latin American governments have had both lower revenue levels and less human capital spending than France and the USA. Indeed, during most of the period under analysis, tax pressure levels and public expenditure in human capital in both Chile and Uruguay did not exceed $20 \%$ and $6 \%$ of GDP, respectively. By contrast, those levels were surpassed both in the USA and France already in the 1960s. ${ }^{12}$ Likewise, whereas tax pressure and public expenditure in human capital in Spain were

\footnotetext{
${ }^{9}$ Tax revenues represent the most relevant part of Latin American current revenues and, consequently, fairly reflect the evolution of overall public revenues throughout the period under study. Moreover, since taxes are a transfer of money from citizens with neither proportional nor instantaneous counterparts from the government (IMF 2001) political scientists consider that the higher the government's dependence on tax revenues, the higher the incentives to negotiate and respond to the citizens' demands (Lieberman 2002; Moore 2007). Therefore, the study of the tax pressure may be used as an instrument to analyze the evolution of both the government size and the government's legitimacy in the public opinion.

${ }^{10}$ These are arbitrary figures, but they represent a good reference point of the experience of the most developed economies in the second half of the twentieth century (Lindert 2004).

${ }^{11}$ France and the USA have been chosen because they are representative examples of the so-called European and Anglo-Saxon Welfare States, respectively. The Spanish case is introduced in the analysis as an example of a country that caught up recently with the European Welfare State (Lindert 2004; Comín 1996).

${ }^{12}$ From the 1960s to 2007, whereas the evolution of tax pressure diverged-it remained more or less constant in the USA while it expanded in France-public expenditure in human capital reached levels above $10 \%$ of GDP in both countries.
} 


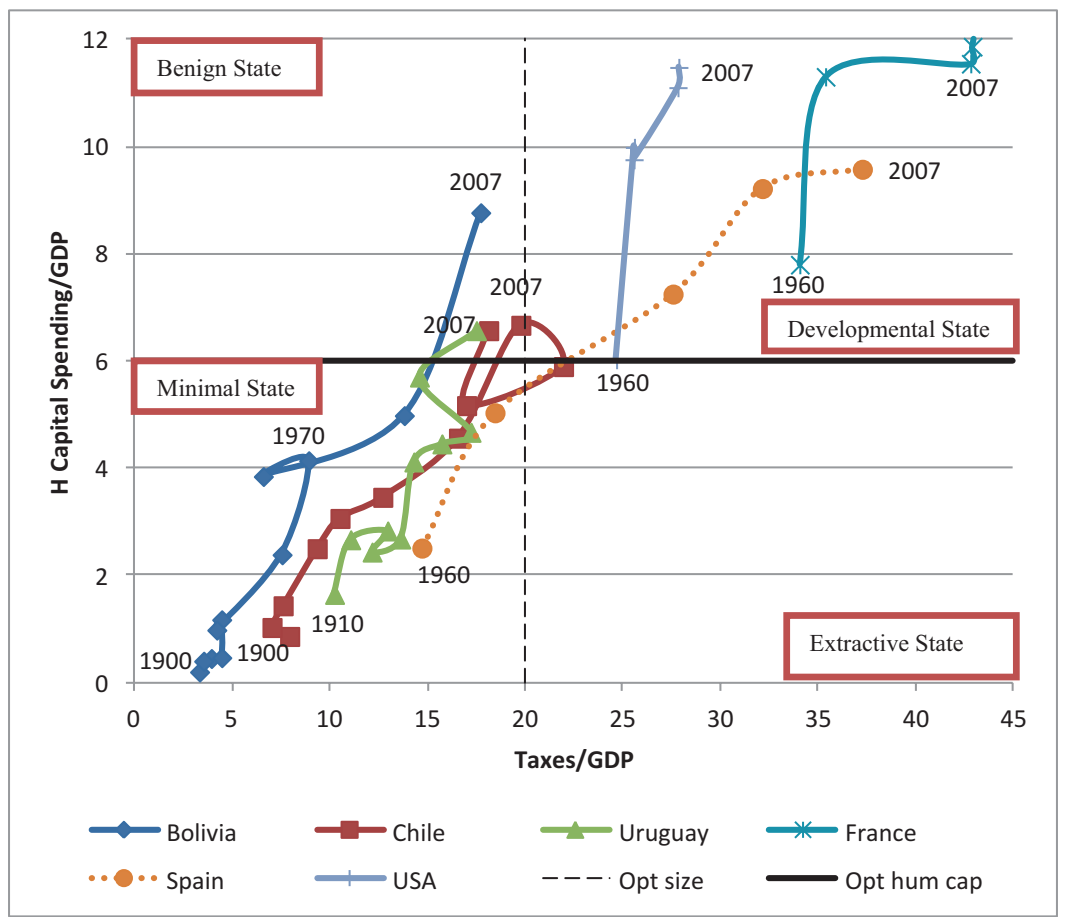

Graph 1 Evolution of the fiscal pact in some Latin American and OECD countries (10-year averages), 1900-2007. Sources: (a) Bolivia, from Peres-Cajias (2014); (b) Chile: from 1900 to1989, Base de datos EH CLIO LAB, Iniciativa Científica Milenio Mideplan; from 1990 to 2007, ECLAC database: www.eclac.cl.; (c) Uruguay: Azar et al. (2009); (d) OECD countries data come from Peter Lindert web page (http://lindert.econ.ucdavis.edu/), from Sergio Espuelas web page (https:// sites.google.com/site/sergiolespuelas/) and from the OECD database (www.oecd.org). Notes: Data referred to Latin American countries are 10-year average; data for France, Spain and United States correspond to $1965,1975,1985,1995$ and 2007

fairly similar to those of Chile and Uruguay during the 1960s, Spanish indicators converged steadily with the US and French ratios thereafter.

In the case of Bolivia, both tax collection and human capital investment were particularly small until the first half of the twentieth century. However, from the 1960 s to the 1980 s, the human capital ratio tended to converge with the Chilean and Uruguayan ones, despite the fact that tax pressure remained well below $10 \%$ of GDP. Later on, from the 1980s onwards, whereas Bolivian tax pressure levels have become similar to those of Chile and Uruguay, the ratio between human capital spending and GDP has approached the Spanish one.

Table 1 expands the previous comparison by incorporating information on the evolution of tax pressure in some of the most developed Latin American countries, as well as in some of the poorest ones. The table confirms the small size of the Bolivian Government and the persistence of a tax pressure gap with several countries of the region until very recent decades. Indeed, whereas tax revenues represented 
Table 1 Latin American Central Governments' tax revenues as a share of GDP (\%, 10 years' average), 1882-2007

\begin{tabular}{l|l|l|l|l|l|l|l}
\hline & Bolivia & Brazil & Chile & Colombia & Guatemala & Peru & Uruguay \\
\hline $1882-1889$ & 3.14 & N.a. & 7.06 & N.a. & N.a. & N.a. & N.a. \\
\hline $1890-1899$ & 2.74 & N.a. & 6.96 & N.a. & N.a. & N.a. & N.a. \\
\hline $1900-1909$ & 3.30 & 8.89 & 7.92 & 5.04 & N.a. & 4.10 & 11.90 \\
\hline $1910-1919$ & 3.91 & 6.57 & 7.01 & 3.87 & N.a. & 3.89 & 10.22 \\
\hline $1920-1929$ & 3.51 & 5.37 & 7.58 & 3.69 & N.a. & 3.95 & 11.05 \\
\hline $1930-1939$ & 4.44 & 6.88 & 9.33 & 4.31 & N.a. & 5.10 & 12.94 \\
\hline $1940-1949$ & 4.44 & 8.46 & 10.50 & 4.29 & 6.58 & 6.91 & 12.14 \\
\hline $1950-1959$ & 4.19 & 10.17 & 12.69 & 6.72 & 7.74 & 7.59 & 13.61 \\
\hline $1960-1969$ & 7.53 & 12.46 & 16.57 & 6.85 & 7.40 & 10.82 & 14.28 \\
\hline $1980-1979$ & 8.89 & 18.34 & 19.76 & 8.14 & 8.50 & 14.09 & 15.72 \\
\hline $1990-1999$ & 6.57 & 17.69 & 21.95 & 7.45 & 7.26 & 12.68 & 17.21 \\
\hline $2000-2007$ & 13.79 & 18.96 & 16.98 & 8.18 & 9.40 & 12.82 & 14.57 \\
\hline
\end{tabular}

Sources: (a) Bolivia, from Peres-Cajías (2014); (b) other countries from 1900 to1989: Brazil: IBGE. Estadísticas Históricas do Século XX; Chile: Base de datos EH CLIO LAB, Iniciativa Científica Milenio Mideplan; Colombia: Kalmanovitz (2011); Guatemala: ICEFI (2007); Peru: Portocarrero et al. (1992); Uruguay: Azar et al. (2009); (c) other countries from 1990 to 2007 from ECLAC database: www.eclac.cl

Notes: N.a.: Not available. Because of the lack of total tax collection from 1882 to 1899 and from 1936 to 1939 , the Bolivian averages in the 1880s, the 1890s, and the 1930s have been calculated by using total current revenue figures

around $7 \%$ of GDP in Chile during the 1880s and 1890s, they amounted to ca. $3 \%$ of GDP in Bolivia, i.e., less than half the Chilean figure. During the first half of the twentieth century, tax pressure in Bolivia reached a level similar to Colombia and Peru, but still well below the Chilean and Uruguayan figures. ${ }^{13}$ The 1952 Revolution did not change this and, until the 1980s, Bolivian tax levels remained similar to those of Colombia and Guatemala, and much lower than those of Chile, Peru, Uruguay, and even Brazil - a country with relatively low Central Government revenues due to its federal structure. It was not until the 1990s when Bolivian tax levels started to converge with the regional average.

As for human capital spending, Peres-Cajías (2015) has contrasted the Bolivian experience with that of Chile, Peru, and Uruguay. The analysis stressed that both education and health spending in Bolivia were lower than 1\% of GDP during the first half of the twentieth century. Thereafter, whereas health spending remained marginal, Bolivian public spending in education increased up to $3 \%$ of GDP, on average. Hence, in contrast with tax pressure levels, public spending in education as a share of the GDP was higher in Bolivia than in Uruguay already in the 1970s.

\footnotetext{
${ }^{13}$ Bolivian tax levels were similar to those of Brazil, one of the biggest economies in the region. However, Brazil is a federal country and, therefore, the underestimation of Brazilian total tax revenues - defined as tax collection of General Government-are higher than in the case of nonfederal countries.
} 
During the 1990s, Bolivian public education spending continued growing and, at the eve of the twenty-first century, public education spending as a share of GDP was around $6 \%$, i.e., double that of Peru and Uruguay.

Summing up, in coincidence with the pessimistic view on Latin American institutions, the analysis suggests that a "minimal state" fiscal equilibrium has characterized Bolivian history during the twentieth century. However, it cannot be ignored that during the second half of the twentieth century the Bolivian State has moved from that "minimal-state" equilibrium to a "benign-state" one. This transition has been spurred by the increase of public education spending. Indeed, over the second half of the twentieth century, the ratio between Bolivian public spending in education and GDP has converged and then surpassed the equivalent figures in some of the most developmental countries of Latin America. Therefore, the next sections explore if this peculiar transition may allow affirming that public education spending in Bolivia was an exceptional case in the Latin American context after the 1952 Revolution.

\section{The Evolution of Public Spending in Education: Was Bolivia a Special Case in the Latin American Context?}

The goal of this section is to assess the Bolivian pattern of public spending in education. Firstly, given the low level of Bolivian taxes until the 1980s, it is analyzed to what extent the Bolivian convergence in the ratio of education spending to GDP that has been identified in the previous section was affected by a limitation that can often be found in Latin America: the conflict between the presence of good policy objectives and the absence or instability of internal resources to achieve those objectives. According to some authors (Morales and Sachs 1990; Dornbusch and Edwards 1989; Weyland 1998), this conflict may end up by affecting negatively in the longrun previous public policy achievements. In this context, the following paragraphs analyze how the fiscal vulnerability of the Bolivian Government affected the sustainability of education expenditure during the Revolution and thereafter.

To begin with, Table 2 looks at the effects of public revenue cycles on the evolution of public expenditures; specifically, it displays the annual average growth rates of public revenues and each category of public expenditure in those periods when current revenues rose or fell. Regarding the former ones, the table indicates that the jump in current revenues from 1904 to 1913 generated a more than proportional increase in the different categories of expenses, with the exception of defense. By contrast, during the 1922-1929 years, the expansion of expenses was less than proportional than revenue growth. During the Chaco War (1932-1935) and after, while general administration spending grew less than current revenues, economic expenses grew at the same rate and social public expenditure at an even higher rate. From 1956 to 1978, once again general administration expenditures grew more slowly than current revenues, economic and social public expenditure grew at the 


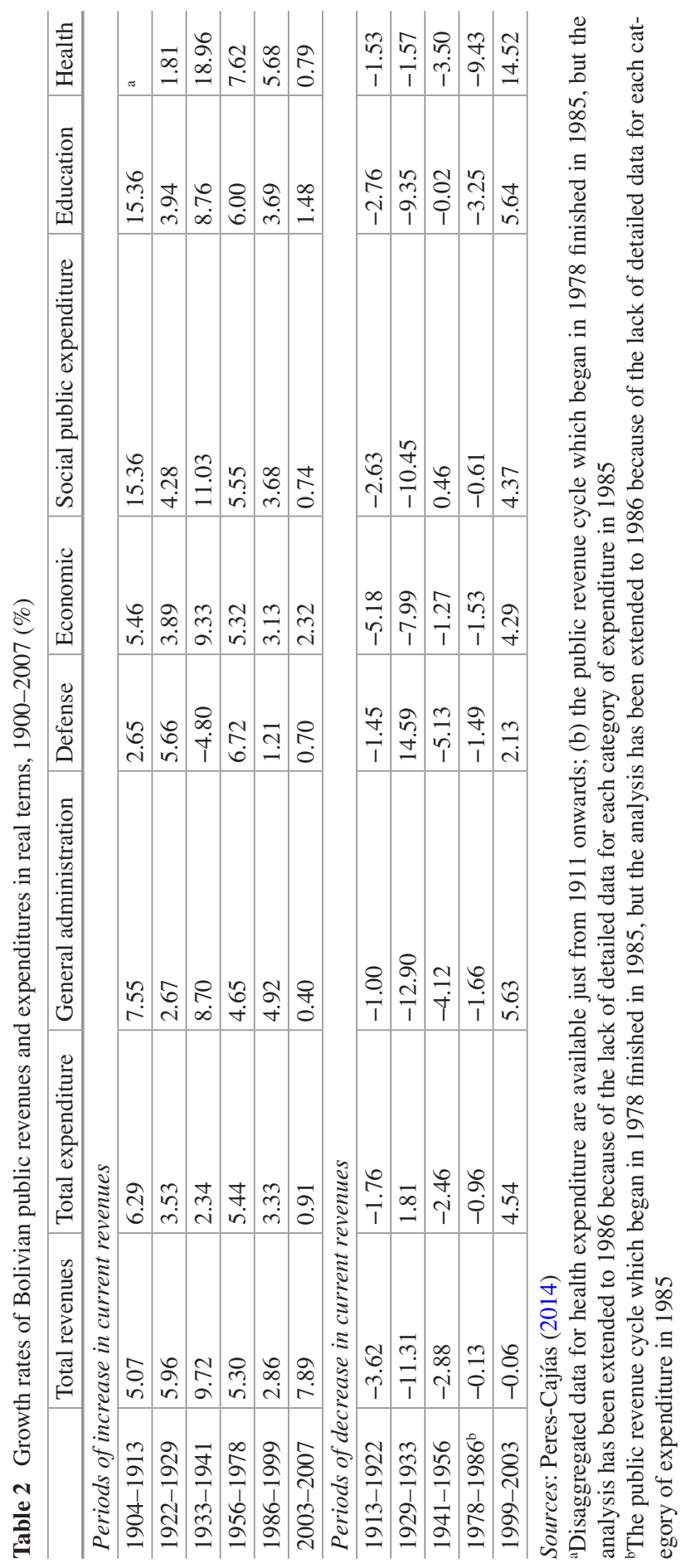


same rate and both education and health spending grew at higher rates. Finally, whereas in 1986-1999 all kind of expenses - with the exception of defense-grew more than current revenues, the opposite effect took place from 2003 to 2007.

What happened in those periods when current revenues decreased? During the unstable years of the First World War and the postwar years, the reduction of revenues was in line with a general reduction - at different rates - of all expenses. This was also the case during the post-Great Depression years-defense expenditures being the exception because of the Chaco War. The persistent reduction in real revenues that took place from the early 1940s to 1956 fuelled the reduction of general administration, defense, and economic expenditure, but not that of social public expenditure. Later on, during the years of the external debt crisis, by contrast, education and health spending were among those expenditures which decreased more than current revenues. Finally, the slight reduction in revenues of 1999-2003 did not generate a similar stagnation or decrease in any category of expenditures.

Therefore, focusing on the period after the 1952 Revolution, whereas education spending was particularly benefited from the expansion of public revenues from 1956 to 1978, it was also among those spending categories that were more affected by the subsequent public revenue crisis. This finding does not allow saying that the Revolution was ineffective in the expansion of education services, but it recalls the initial warning of this section: the lack of correspondence between good policy objectives and internal resources may end up by reversing previous achievements. ${ }^{14}$

This idea is further explored in Graph 2, which shows the evolution of education spending per capita in real terms. The graph shows a considerable increase at the eve of the twentieth century, which was derived from the centralization of education and the liberal educational reform. According to Contreras (1999: 486-487), this process can be understood as the government elites' effort to change the main characteristics of the educational public system by taking advantage of ideas and methods developed in Europe.$^{15}$ In this context, the stability of education spending per capita from the early 1910s to the late 1920s can be interpreted as an indication of the stability of the new model of public education. Beyond this political commitment with educational spending, the effects of both the Great Depression and the Chaco War on public revenues ended up affecting the evolution of education expenses per capita, which decreased substantially from 1930 to 1935.

Immediately after the war and until 1940, education spending grew spectacularly in per capita terms. In contrast with the previous experience, this increase was driven by the new role assigned by the Military-Socialist regimes to public education - the instrument to build the Nation - as well as by the demands from indigenous and popular classes, which identified education as an efficient tool to better defend its long-term claims towards the Bolivian state (Contreras 1999: 488-489).

Whereas these political elements remained, education spending per capita decreased in the aftermath of the 1952 Revolution. This process persisted until 1955

\footnotetext{
${ }^{14}$ It must be recalled that the new configuration of the state brought by the 1952 Revolution did not generate any substantive change in tax pressure or tax composition (Peres-Cajías 2014).

${ }^{15}$ See also Cajías (2011) for an analysis of the main characteristics of this educational reform.
} 


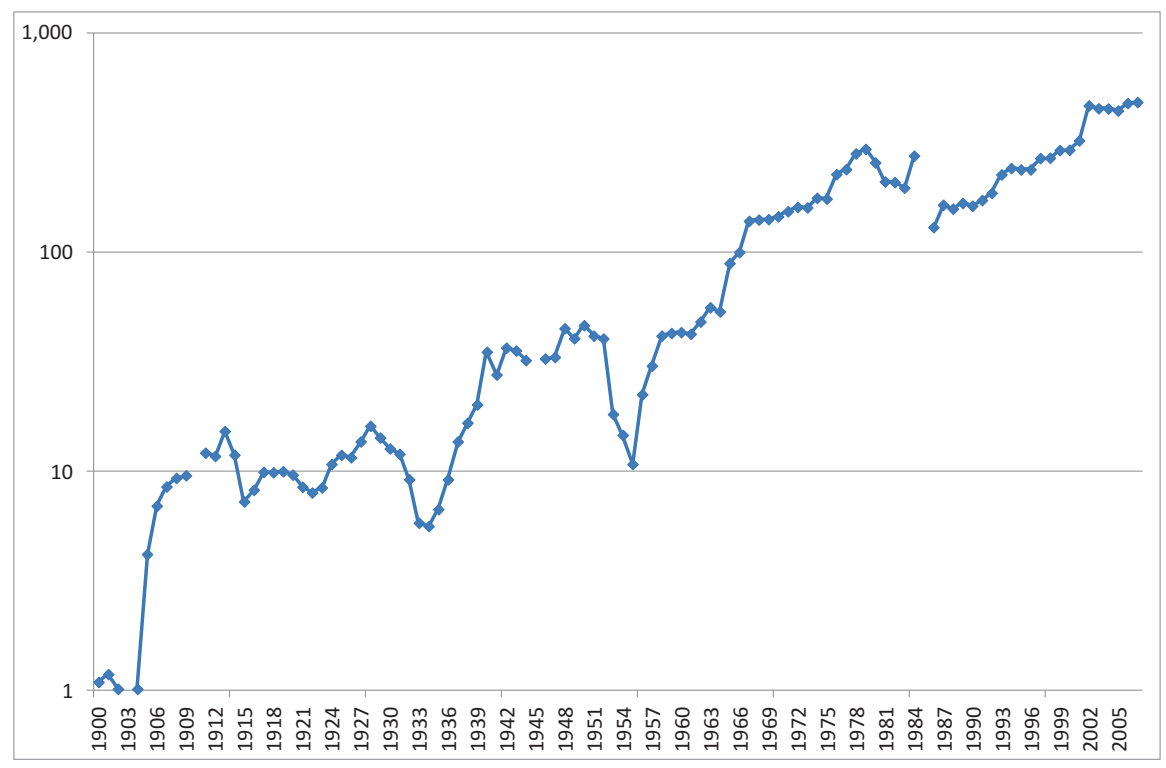

Graph 2 Bolivian Central Government's education spending per capita (Bs. 2000), 1900-2007. Source: Peres-Cajías (2014)

and was driven by the initial macroeconomic disorders generated by the revolutionary process. Thereafter, education spending per capita increased until the late 1970s. Some structural determinants may explain this expansion. On the one hand, after the stabilization program of 1956, foreign aid, initially, and both external debt and the steady growth of the Bolivian economy, thereafter, allowed the growth of government expenses. On the other hand, the increase in education spending was also a government response to the dramatic expansion of the Bolivian population during this period.

However, it stands out that the expansion of education spending per capita was not steadily from the mid-1950s to the late 1970s. This suggests the existence of different political goals related with education spending during this period. Indeed, the growth in education spending until 1964 was closely related with the revolutionary goals and the willingness to expand educational services across the entire country (Dirección Nacional de Informaciones 1962). In this context, whereas the growth rate of education spending decreased after the initial jump from 1956 to 1958, it was sufficient to recover and overpass those levels of education spending per capita which prevailed before the Revolution.

The evolution of education spending per capita accelerated dramatically from 1965 to 1967 and was followed by a steady increase from 1968 to 1975 . In contrast to the previous period, these changes were related with the military government's intentions to consolidate the Military-Peasant pact through the expansion of education services to the rural areas (Klein 2011a,b: 222-228). The widespread idea that more education investments were needed in order to foster human capital accumulation 


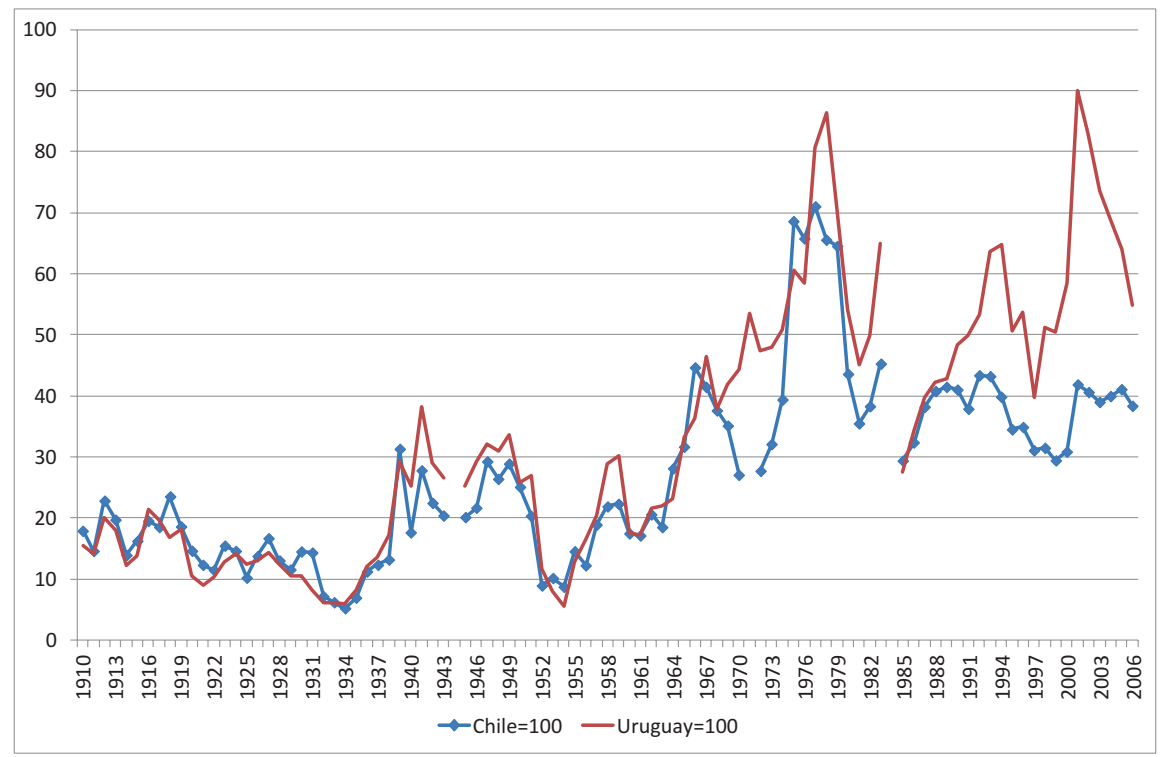

Graph 3 Public spending in education per capita in Bolivia as a share of the Chilean and Uruguayan ones (\%), 1911-2007. Source: See Table 1. Notes: These figures have been expressed in 1990 Geary Khamis international dollars and divided by total population. GDP and population series have been taken from the New Madisson Project Database

in the country also played a significant role (Ministerio de Educación y Cultura 1967: 14-22; PNUD 2010: 106). This last idea would be also critical to understand the expansion of education spending from 1976 to 1979.

Beyond the existence of different political goals and different intensities in the expansion of education spending, Graph 2 also confirms that the macroeconomic disorders of the early 1980s generated a new crisis in education spending per capita. This confirms once more that education spending has clearly been affected by the fiscal fragility of the Bolivian Government. Indeed, during those years when the main revenues of the Bolivian Central Government (external taxes, external borrowing, or external donations) decreased (1952-1956; 1979-1985), education spending also decreased substantially.

As can be observed in Graph 3, these fluctuations seriously affected the convergence of Bolivian education spending in per capita terms to the Chilean and Uruguayan figures. Firstly, during the years of the MNR government (1952-1964), the expansion of education spending just allowed recovering those levels achieved before the Revolution; that is, Bolivian education spending per capita moved around $20 \%$ and $30 \%$ of the respective figures in Chile and Uruguay. Thereafter, education spending per capita in Bolivia quickly converged up to $70 \%$ of the level of education spending per capita in both countries. However, it decreased to just $30 \%$ during the first half of the 1980s. Nowadays, there is not a convergence process and education spending per capita in Bolivia is still far away from the levels reached by these countries. 
Education spending increased more steadily from 1986 onwards. Initially, this was the consequence of macroeconomic stabilization and the educational reform of 1994. According to Contreras (1999: 491-493; 2003: 271-282) the goal of this reform was to expand education services both in quantity and quality across the country, in order to consolidate education as an efficient instrument for social mobility and economic growth. ${ }^{16}$ This reform was contemporaneous to similar changes in neighboring countries and received strong support from international organizations such as the World Bank or the Interamerican Development Bank. Later on, Evo Morales' administration (2006 onwards) made a new educational reform and showed a particular interest in the expansion of educational services towards the most disadvantaged groups of the Bolivian population-see Paz Arauco et al. 2013. Overall, all these changes fuelled the expansion of education spending as a share of GDP.

Hence, the new evidence stresses the reduction of educational spending during the initial years of the revolution. It also shows that, once the initial macroeconomic disorders were corrected, education spending increased and, interestingly enough, this increase continued until the late 1970s. During the early 1980s, however, fiscal instability substantially affected once more education spending. This event stopped a convergence process in terms of education spending per capita which has not been recovered since then. Altogether, these findings suggest that the non-existence of a reliable internal tax base affected the sustainability of education spending and, therefore, the long-term impacts of the 1952 Revolution.

An alternative way to evaluate the long-term impact of the revolution on education services is to analyze the evolution of public spending in education in correspondence with per capita GDP levels. Thus, following Lindert (2010), Graph 4 relates the ratio between education spending and GDP with the log of per capita GDP for Bolivia and different Latin American and OECD countries. As was stated in the introduction, Lindert (2010) suggests that Latin American governments have systematically invested in education much less than would a priori be expected given its level of economic development. Graph 4 helps assessing if the Bolivian experience fits into this classification; it also allows identifying if the Bolivian position changed after the revolution and the timing and magnitude of this hypothetical change.

Graph 4 stresses once more the impact of the initial macroeconomic disorders led by the 1952 Revolution. In effect, whereas the level of economic development in 1955 was quite similar to that of 1945 and 1950, education spending was lower than during these prerevolution years. The graph also stresses that education spending in 1960 was still lower than expected given the Bolivian GDP pc (i.e., below the international trend). Thus, it was not until the mid-1960s when Bolivian education spending increased and, contrary to Lindert's hypothesis, moved around what one would expect given the Bolivian GDP pc. However, the graph also shows that this relatively high level of Bolivian education spending (by Latin American standards and relative to its pc GDP) has been shared by other poor Latin American countries, such as Dominican Republic. This indicates that the Bolivian experience would not

\footnotetext{
${ }^{16}$ See also Contreras and Talavera (2005).
} 


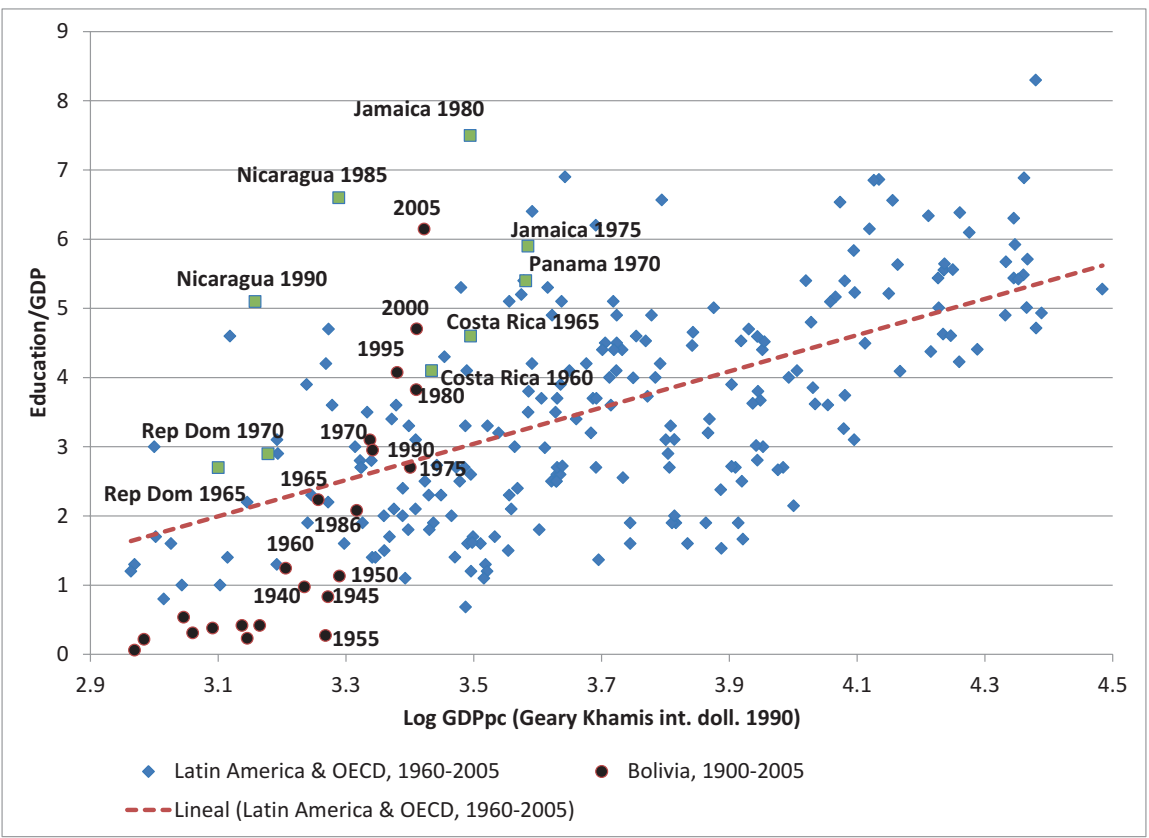

Graph 4 Public spending in education as a share of GDP and GDP pc in Bolivia, Latin America, and OECD countries. Sources: (a) GDP per capita: for Bolivia, Herranz-Loncán and Peres-Cajías (2016) and the New Madisson Project Database; for the rest of countries: New Madisson Project Database. (b) Public spending in education as a share of GDP: for Bolivia, Peres-Cajías (2014), for Uruguay, see Table 1; for the rest of Latin American countries: Frankema (2009: Table A3); for Spain and Portugal: Sergio Espuelas' webpage (https://sites.google.com/site/sergiolespuelas/); for the rest of OECD countries: Peter Lindert's webpage (http://lindert.econ.ucdavis.edu/). If unavailable, data was also obtained from UNESCO Institute of Statistics webpage (http://www.uis. unesco.org/). Notes: The green squares show particular Latin American cases which do not necessarily fit in Lindert's (2010) hypothesis. Bolivia presents data each 5 years from 1900 to 2005. Latin American countries present data each 5 years from 1960 to 2005; it corresponds to Argentina, Brazil, Chile, Colombia, Costa Rica, Dominican Republic, Ecuador, El Salvador, Guatemala, Haiti, Honduras, Jamaica, Mexico, Nicaragua, Paraguay, Peru, Uruguay, and Venezuela. OECD countries present data for 1960,1975, 1990, and 2005; it corresponds to Australia, Austria, Belgium, Canada, Denmark, Finland, France, Germany, Greece, Italy, the Netherlands, New Zealand, Portugal, Spain, Sweden, Switzerland, the UK, and the USA

be necessarily a Latin American exception. This idea can be reaffirmed by considering that public spending in education as a share of GDP has been systematically higher than expected in Cuba, ${ }^{17}$ Costa Rica, Panama, and Jamaica from the 1960s to the early 1980s; it has also been higher than expected in Nicaragua during the 1980s.

The volatility of Bolivian education spending as a share of GDP and relative to its per capita GDP from the early 1980s to the early 1990s stresses once more the impact of fiscal instability. It also stands out that Bolivian education spending has

${ }^{17}$ The Cuban experience is not plotted in Graph 4 since it distorted the international average. 
been systematically higher than expected given the Bolivian per capita GDP from the mid-1990s onwards. This confirms the idea that the 1994 educational reform and the support of multilateral organizations increased education spending up to high levels by worldwide standards (Contreras 1999: Table 2). Likewise, the continuous relatively high level of Bolivian education spending also confirms the Morales' administration interest in the expansion of education services. Thus, this stresses that it was not the 1952 Revolution, but the structural reforms of the $1990 \mathrm{~s}$ and the recent political changes which systematically prompted public education spending in Bolivia up to high levels by international standards.

Finally, any analysis concerned with the long-term consequences of the 1952 Revolution on education spending must be able to answer one critical question: Did the expansion of public expenditure benefit the poor? Due to the lack of micro-data, PeresCajías (2015) has analyzed the allocation of public education spending from the early 1950s onwards through two indirect indicators: the tax support ratio for primary pupils and the primary tertiary double ratio. ${ }^{18}$ The reconstructed evidence allows saying that the 1952 Revolution did not have any long-term impact on the distribution of educational expenditure. On the one hand, there was no major change in the support ratio to primary education from 1950 to the mid-2000s, around $12 \%$, on average, a similar figure to those of other Latin American countries. On the other hand, although there was a change in the prioritization of primary over tertiary education during the early 1970s, this was hardly sustainable over time. More strikingly, the relevance of tertiary over primary education spending is still highly noticeable in the most recent years and much higher than in several Latin American countries. ${ }^{19}$ Therefore, whereas it is not possible to say that Bolivian public spending in education since 1952 has not benefited the poorest, it cannot be stated either that it was particularly pro-poor.

\section{Were the Educational Achievements Revolutionary?}

It could be argued that, although restricted, public investment in primary education from the 1950s onwards was enough to improve Bolivian educational outputs. This section does not measure the profitability of education spending, but analyzes

\footnotetext{
${ }^{18}$ The first indicator measures the relative importance of public subsidies per attending student in primary education in relation to pc GDP. The second indicator measures the relative importance of public subsidies per attending student in primary education in relation to public subsidies per attending student in tertiary education. The rationale behind these indicators suggests that the higher the relative support to primary education, the higher the redistributive impact of public education spending.

${ }^{19}$ According to Lindert (2010), the optimal value for the primary tertiary double ratio is $50 \%$. The Bolivian figure has constantly been below this value. Moreover, whereas the ratio in most of Latin American countries is nowadays around or above $50 \%$, in Bolivia is still around $30 \%$. For a better understanding of the political economy factors behind the allocation of a considerable share of expenditures in tertiary education see Contreras (1999, 2003), Rodríguez (1998), and PeresCajías (2015).
} 
if the increase in education spending was contemporaneous to a similar increase in both quantity and quality indicators of educational output. To begin with, Table 3 shows the evolution of both the Bolivian literacy rate and the gross enrollment ratio in primary school throughout the twentieth century. At the eve of the twentieth century, no more than $20 \%$ of total population was able to write and read. Although the literacy rates increased thereafter, their growth rate was certainly low (around $1.1 \%$ per year, on average). Likewise, whereas literacy rates increased at a higher pace after the 1952 Revolution (2.5\% per year, on average) a non-negligible share of the Bolivian population was still unable to write and read at the eve of the twenty-first century. As a consequence of this restriction, the Morales' administration enacted the so-called Yo si puedo program, an aggressive alphabetization project exclusively oriented to the elderly. Hence, it was not until 2008 when the UNESCO could finally declare that Bolivia was a territory free of analphabetism (PNUD 2010: 167).

Table 3 also presents estimates of the evolution of the gross enrollment ratio in primary education and allows calculating its growth rate throughout the twentieth century: $3.2 \%$ from 1900 to $1920,2.8 \%$ from 1930 to 1950, and 5\% from 1950 to 1970. Undoubtedly, therefore, the expansion of the gross enrollment rate in primary education has been faster after the 1952 Revolution. However, it was not until the 1990s when Bolivia achieved a full primary school enrollment, which implies a substantial delay both by regional and international standards (Frankema 2009).

As for the analysis of the quality of educational services, the Bolivian literature offers some partial evidence which suggests that no major change took place after the Revolution. For instance, Contreras (2003: 266) quotes the claims by Fernando Díez de Medina-Minister of Education at the time-which in 1958 regretted the restricted impact of the Revolution on a system in which pedagogical practices were

Table 3 Literacy rates and gross enrollment ratio in primary schooling (\%), 1900-2001

\begin{tabular}{l|l|l|r}
\hline \multicolumn{2}{l}{ Literacy rate } & Gross enrolment ratio in primary schooling \\
\hline & & $\mathbf{1 8 8 0}$ & 2 \\
\hline & & $\mathbf{1 9 0 0}$ & 5 \\
\hline & & $\mathbf{1 9 1 0}$ & 8 \\
\hline $\mathbf{1 9 0 0}$ & 18.5 & $\mathbf{1 9 2 0}$ & 13 \\
\hline $\mathbf{1 9 2 0}$ & 22.5 & $\mathbf{1 9 3 0 / 5}$ & 15 \\
\hline $\mathbf{1 9 3 0}$ & 24.9 & $\mathbf{1 9 4 0 / 5}$ & 16 \\
\hline $\mathbf{1 9 4 0}$ & 27.9 & $\mathbf{1 9 5 0 / 5}$ & 21 \\
\hline $\mathbf{1 9 5 0}$ & 31.1 & $\mathbf{1 9 6 0}$ & 28 \\
\hline & & $\mathbf{1 9 7 0}$ & 43 \\
\hline $\mathbf{1 9 7 6}$ & 63.21 & $\mathbf{1 9 8 0}$ & 76 \\
\hline & & $\mathbf{1 9 9 0}$ & 84 \\
\hline $\mathbf{1 9 9 2}$ & 79.99 & $\mathbf{2 0 0 0}$ & 95 \\
\hline $\mathbf{2 0 0 1}$ & 86.72 & $L$ &
\end{tabular}

Sources: Own elaboration based on (a) Literacy rates: from 1900 to 1940 obtained from Contreras (1999: Cuadro 1), from 1950 to 2001 obtained from National Censuses; (b) gross enrolment ratio: from 1880 to 1920 obtained from Benavot and Riddle (1988: Appendix), from 1930/35 to 2000 from UNESCO statistical yearbooks 
still dominated by archaic methods. In this regard, the curricula of 1948 survived in both primary and secondary education, at least, until the late 1960s (Ministerio de Educación 1967). In the same vein, Contreras (2003: 270) quotes several studies which regretted the low productivity of educational expenditure as well as the considerable magnitude of dropout and repetition rates throughout the 1970s and 1980s.

The evolution of this last problem can be indirectly analyzed through the use of the methodology developed by Frankema (2008). Taking advantage of UNESCO statistical yearbooks, which presents the enrollment distribution per grade in both primary and secondary education, the author identifies the distribution of students enrolled by using the following formulas:

$$
\begin{aligned}
& \frac{X_{\mathrm{p}}}{X_{\mathrm{p}}+X_{\mathrm{s}}} * g_{\mathrm{pi}} \\
& \frac{X_{\mathrm{s}}}{X_{\mathrm{p}}+X_{\mathrm{s}}} * g_{\mathrm{si}}
\end{aligned}
$$

where $X_{\mathrm{p}}$ and $X_{\mathrm{s}}$ refer to the number of students enrolled in primary and secondary, respectively, and $g_{\mathrm{pi}}$ and $g_{\mathrm{si}}$ refer to the percentage share of students enrolled in the $i$ th grade of primary and secondary, respectively (Frankema 2008: 440).

Following this methodology, I have estimated the evolution of the enrollment distribution during the 12 years of school in Bolivia from 1965 to 2005 (Table 4). As in the case of developing economies, my 1965 estimations show a distribution considerably skewed towards the first degrees of school-i.e., most of the students enrolled in primary and secondary education were concentrated in the first three grades. Other variables constant, this skewed distribution would be reflecting that a non-negligible share of Bolivian children "... was either repeating one or more years or dropping out before reaching the higher grades." By looking at the 1975 estimations in Table 4 and Frankema's Figure 1, repeating and dropout problems in Bolivia seem to have been more severe than in Ghana or Syria, or as bad as in Colombia, which stresses that Bolivian education indicators were not necessarily better than in the rest of the region.

These distributional distortions would also reflect that children enrolled in primary education had a low probability to finish primary education and to graduate up to secondary education. The magnitude of this problem, which is certainly a current restriction in the Bolivian educational system (Contreras 2003: 279) and particularly identifiable in the case of rural (Urquiola and Calderón 2006) and poor families (PNUD 2010: 169), can be measured by looking at the grade distribution ratio. This indicator has been estimated by Frankema (2008) and shows the probability of the children who enter to the school had to reach the sixth grade-i.e., the probability to finish primary. Table 5 presents these estimations for a selected sample of countries which share some common features with Bolivia: poor countries of delayed demographic transition (El Salvador, Honduras, Nicaragua); small countries in which education spending was high by Latin American standards 


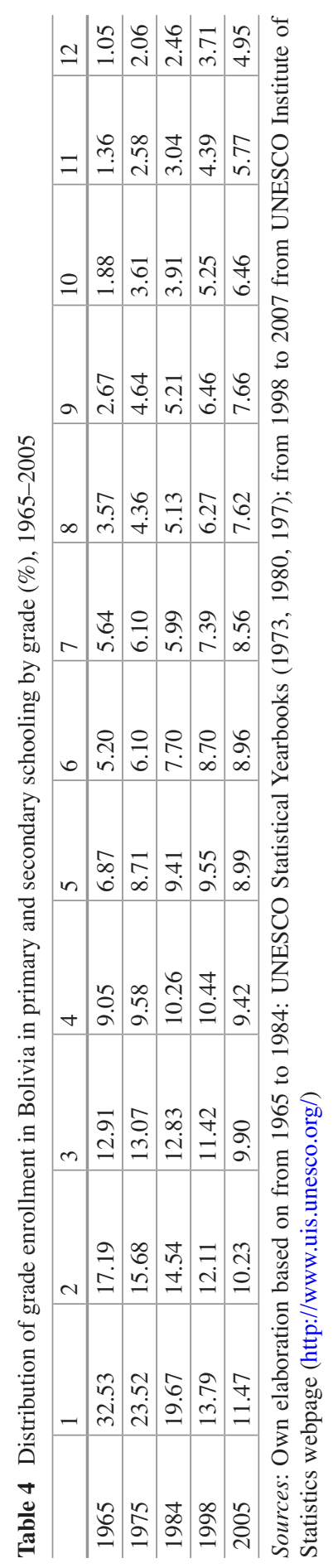


Table 5 Grade distribution ratio 6-1 (\%), 1960-2005

\begin{tabular}{l|l|l|l|l|l}
\hline & $1960 / 1965$ & $1970 / 1975$ & $1980 / 1985$ & $1990 / 1995$ & $2000 / 2005$ \\
\hline Bolivia & 0.32 & 0.44 & 0.47 & 0.63 & 0.83 \\
\hline Costa Rica & 0.41 & 0.68 & 0.85 & 0.79 & 0.9 \\
\hline Cuba & 0.34 & 0.54 & 0.98 & 0.99 & 1 \\
\hline Ecuador & 0.35 & 0.54 & 0.64 & 0.71 & 0.81 \\
\hline El Salvador & 0.29 & 0.46 & 0.54 & 0.67 & 0.7 \\
\hline Guatemala & 0.26 & 0.33 & 0.39 & & 0.49 \\
\hline Honduras & 0.2 & 0.33 & 0.39 & 0.56 & 0.61 \\
\hline Jamaica & & 0.69 & 0.92 & 0.96 & 0.94 \\
\hline Nicaragua & 0.18 & 0.35 & 0.32 & 0.41 & 0.59 \\
\hline Panama & 0.57 & 0.59 & 0.79 & 0.8 & 0.83 \\
\hline
\end{tabular}

Source: Frankema (2008: 445, 452)

(Costa Rica, Cuba, Panama, Jamaica); or small countries in which the indigenous population represents a non-negligible share of total population (Guatemala, Ecuador).

This ratio shows again the restrictions of Bolivian educational outputs. During the early 1960s, the Bolivian indicator was not very different from other countries (with the exception of Panama). However, during the 1970s and 1980s, this indicator improved considerably in countries characterized by high investments in public education (Cuba, Costa Rica, and Jamaica), but stayed below 50\% in the Bolivian case. Similarly, the probability of children to finish primary has constantly been higher in Ecuador than in Bolivia during the last three decades of the twentieth century. Thus, it has not been until the eve of the twenty-first century that the Bolivian indicator converged to better records. Therefore, the analysis of both quality and quantity indicators suggests that education spending and educational achievements did not present any significant correlation from the 1952 Revolution onwards.

\section{Conclusions}

This chapter has offered for the first time a long-term and comparative analysis of public education spending in Bolivia. The chapter has shown that, whereas tax collection levels remained among the lowest in the region until the 1980s, education spending as a share of GDP converged to the levels of Chile and Uruguay - two of the most developmental states in Latin America-after the 1952 Revolution. This paradoxical fiscal equilibrium, however, did not imply a substantial modification of the quality and redistributive character of the Bolivian education system. Four main findings support this claim: public spending in education was hardly sustainable over time; education spending, controlled by per capita GDP, was not outstanding by international standards; the non-existence of a substantial support to primary education may have reduced the redistributive impact of education spending; and education outputs, either in quantity or quality terms, were often among the worse in the region. 
Acknowledgements This research has benefited from financial support by the University of Barcelona through the APIF (2008-2012) fellowship program, and from the Catalonian Research and Universities Grant Agency through the BE-DGR-2011 fellowship program. The author specially thanks Alfonso Herranz Loncán for his constant support and critical readings of previous drafts. The author also thanks Luis Bértola, Manuel Contreras, Ewout Frankema, Alejandra Irigoin, Peter Lindert, Mar Rubio, and Jeffrey Williamson for their valuable comments to previous drafts. Usual disclaimer applies.

Open Access This chapter is distributed under the terms of the Creative Commons Attribution 4.0 International License (http://creativecommons.org/licenses/by/4.0/), which permits use, duplication, adaptation, distribution and reproduction in any medium or format, as long as you give appropriate credit to the original author(s) and the source, a link is provided to the Creative Commons license and indicate if changes were made.

The images or other third party material in this chapter are included in the work's Creative Commons license, unless indicated otherwise in the credit line; if such material is not included in the work's Creative Commons license and the respective action is not permitted by statutory regulation, users will need to obtain permission from the license holder to duplicate, adapt or reproduce the material.

\section{Bibliography}

Acemoglu, D., Johnson, S., \& Robinson, J. A. (2002). Reversal of fortune: Geography and institutions in the making of the modern world income distribution. Quarterly Journal of Economics, $117,1231-1294$.

Andersen, L. E. (2003). Baja movilidad social en Bolivia: Causas y consecuencias para el desarrollo. Revista Latinoamericana de Desarrollo Economico, Instituto de Investigaciones SocioEconómicas (IISEC), Universidad Católica Boliviana, 1, 11-36.

Azar, P., et al. (2009). De quiénes, para quiénes y para qué? Las finanzas públicas en el Uruguay del siglo XX. Montevideo: Fin de Siglo.

Azar, P., \& Fleitas, S. (2012). Gasto Publico Total y Social: El Caso De Uruguay En El Siglo XX. Revista de Historia Económica, 30, 125-156.

Barragán, R., \& Peres-Cajías, J. A. (2007). El armazón estatal y sus imaginarios. Historia del Estado. In El Estado del Estado. Informe Nacional de Desarrollo Humano 2007 (pp. 127-218). La Paz: PNUD.

Benavot, A., \& Riddle, P. (1988). The expansion of primary education, 1870-1940: Trends and issues. Sociology of Education, 61, 191-210.

Booth, A. (2007). Night watchman, extractive, or developmental states? Some evidence from late colonial south-east Asia. Economic History Review, 60, 241-266.

Brautigam, D., Fjeldstad, O., \& Moore, M. (2008). Taxation and state-building in developing countries: Capacity and consent. Cambridge, UK: Cambridge University Press.

Brown, D., \& Hunter, W. (2004). Democracy and human capital formation. Education spending in Latin America, 1980-1997. Comparative Political Studies, 37, 842-864.

Calderón, G. F. (2010). La fuerza política de las culturas. La Paz, Bolivia: Plural editores.

CEPAL. (2010). La hora de la igualdad: brechas por cerrar, caminos por abrir. Santiago, Chile: Cepal.

Coatsworth, J. H. (2008). Inequality, institutions and economic growth in Latin America. Journal of Latin American Studies, 40, 545-569.

Comín, F. (1996). Historia de la Hacienda Pública, I. Europa. Barcelona: Crítica. 
Contreras, M. E. (1999). Reformas y desafíos de la educación. In F. Campero (Ed.), Bolivia en el Siglo XX. La Formación de la Bolivia Contemporánea (pp. 483-507). La Paz, Bolivia: Harvard Club de Bolivia.

Contreras, M. E. (2003). A comparative perspective of education reforms in Bolivia: 1950-2000. In M. Grindle \& P. Domingo (Eds.), Proclaiming revolution: Bolivia in comparative perspective (pp. 259-286). Cambridge, MA: Institute of Latin American Studies.

Contreras, M. E., \& Talavera, M. L. (2005). Examen parcial: la reforma educativa Boliviana, 1992-2002. La Paz: PIEB.

De Ferranti, D., Perry, G., Ferreira, F., \& Walton, M. (2004). Inequality in Latin America: Breaking with history? Washington, DC: The World Bank.

Cajías de la Vega, M. (2011). Continuidades y rupturas: el proceso histórico de la formación docente rural y urbana en Bolivia. La Paz: PIEB, Programa de Investigación Estratégica en Bolivia.

Cajías de la Vega, M. (Coord.). (2015). Bolivia, su historia. Tomo VI. Constitución, desarrollo y crisis del estado de 1952 (Coordinadora de Historia. Serie Historia de Bolivia). La Paz: Imprenta Sagitario.

Dell, M. (2011). The persistent effects of Mita. Econometrica, 78, 1863-1903.

Dirección Nacional de Informaciones. (1962). Bolivia: 10 años de revolución 1952-1962. La Paz.

Dornbusch, R., \& Edwards, S. (1989). The macroeconomics of populism in Latin America. Washington, DC: Country Economics Dept., World Bank.

Engerman, S. L., Mariscal, E., \& Sokoloff, K. L. (2009). The evolution of schooling institutions in the Americas, 1800-1925. In D. Eltis, F. Lewis, \& K. L. Sokoloff (Eds.), Human capital and institutions: A long run view (pp. 93-142). New York: Cambridge University Press.

Engerman, S. L., \& Sokoloff, K. L. (2012). Economic development in the Americas since 1500: Endowments and institutions. Cambridge, NY: Cambridge University Press.

Espuelas, S. (2012). Are dictatorships less redistributive? A comparative analysis of social spending in Europe (1950-1980). European Review of Economic History, 16, 211-232.

Frankema, E. (2008). Comparing the distribution of education across the developing world, 1960-2005: what does the grade enrollment distribution tell about Latin America. Social Indicators Research, 88, 437-455.

Frankema, E. (2009). The expansion of mass education in twentieth century Latin America: A global comparative perspective. Revista de Historia Económica, 27, 359-396.

Frankema, E. (2011). Colonial taxation and government spending in British Africa, 1880-1940: Maximizing revenue or minimizing effort? Explorations in Economic History, 48, 136-149.

Fundación Tierra. (2007). Los nietos de la Reforma Agraria. Tierra y comunidad en el Altiplano de Bolivia. La Paz: Fundación Tierra/CIPCA.

Gallo, C. (1991). Taxes and state power: Political instability in Bolivia, 1900-1950. Philadelphia: Temple University Press.

Go, S., \& Lindert, P. (2010). The uneven rise of American public schools to 1850. Journal of Economic History, 70, 1-26.

Gotkowitz, L. (2007). A revolution for our rights: Indigenous struggles for land and justice in Bolivia, 1880-1952. Duke: Duke University Press.

Grindle, M., \& Domingo, P. (2003). Proclaiming revolution: Bolivia in comparative perspective. Cambridge, MA: Institute of Latin American Studies.

Herranz-Loncán, A., \& Peres-Cajías, J. A. (2016). Tracing the reversal of fortune in the Americas. Bolivian GDP per capita since the mid-nineteenth century. Cliometrica, 10, 99-128.

ICEFI (2007). Historia de la Tributación en Guatemala (desde los Mayas hasta la actualidad).

IMF. (2001). Government finance statistics manual 2001. Washington: International Monetary Fund.

Kalmanovitz, S. (Ed.). (2011). Nueva Historia Económica de Colombia. Bogotá: Taurus.

Klein, H. S. (2011a). A concise history of Bolivia. Cambridge, UK: Cambridge University Press.

Klein, H. S. (2011b). The emergence of a mestizo and indigenous democracy in Bolivia. Unpublished document.

Kosack, E. (2012). The education of nations: How the political organization of the poor, not democracy, led governments to invest in mass education. Oxford: Oxford University Press. 
Lieberman, E. S. (2002). Taxation data as indicators of state-society relations: Possibilities and pitfalls in cross-national research. Studies in Comparative International Development, 36, 89-115.

Lindert, P. H. (2004). Growing public: Social spending and economic growth since the eighteenth century. Cambridge, UK: Cambridge University Press.

Lindert, P. H. (2010). The unequal lag in Latin American schooling since 1900: Follow the money. Revista de Historia Económica, 28, 375-405.

Ministerio de Educación y Cultura. (1967). La educación en Bolivia. La Paz.

Moore, M. (2007). How does taxation affect on the quality of governance? Trimestre Económico, $\operatorname{LXXIV(2),281-325.}$

Morales, J. A., \& Sachs, J. D. (1990). Bolivia's economic crisis. In Country studies-Argentina, Bolivia, Brazil, Mexico (pp. 157-268). Chicago: The University of Chicago Press.

Organisation for Economic Co-operation and Development. (2009). Latin American Economic Outlook 2009. Organisation for Economic Co-operation and Development.

Paz Arauco, V., Gray Molina, G., Jiménez Pozo, W., \& Yáñez, E. (2013). Explaining low redistributive impact in Bolivia. Commitment to Equity, Working Paper No. 6.

Peres-Cajías, J. A. (2012). Repensando el desarrollo desde la historia económica: Crecimiento y lucha de débiles. In F. Wanderley (Ed.), Desarrollo en Cuestión: Reflexiones desde América Latina (pp. 99-131). La Paz: CIDES-UMSA and Plural.

Peres-Cajías, J. A. (2014). Bolivian public finances, 1882-2010. The challenge to make social spending sustainable. Revista de Historia Económica. Journal of Iberian and Latin American Economic History, 32(1), 77-117.

Peres-Cajías, J. A. (2015). Public finances and natural resources in Bolivia, 1883-2010: Is there a fiscal curse? In M. Badia-Miró, V. Pinilla, \& H. Willebald (Eds.), Natural resources and economic growth: Learning from history (pp. 184-203). London: Routledge.

Platt, T. (1982). Estado boliviano y ayllu andino: tierra y tributo en el norte de Potosí. Lima: Instituto de Estudios Peruanos.

PNUD. (2010). Los cambios detrás del cambio: desigualdades y movilidad social en Bolivia. La Paz: Programa de las Naciones Unidas para el Desarrollo.

Portocarrero, S., Beltrán, B., Romero, P., \& Elena, M. (1992). Compendio estadístico del Perú, 1900-1990. Lima, Perú: Universidad del Pacífico, Centro de Investigación CIUP.

Rodríguez, G. (1998). Autonomía y cogobierno paritario, entre la memoria, las dudas y las perspectivas. Revista Ciencia y Cultura, 3, 104-121.

Sokoloff, K. L., \& Zolt, E. (2006). Inequality and taxation: Evidence from the Americas on how inequality may influence tax institutions. Tax Law Review, 59, 1-76.

Urquiola, M., \& Calderón, V. (2006). Apples and oranges: Educational enrollment and attainment in across countries in Latin America and the Caribbean. International Journal of Educational Development, 26, 572-590.

Weyland, K. (1998). From Leviathan to Gulliver? The decline of the developmental state in Brazil. Governance, 11, 51-75.

Williamson, J. (2015). Latin American inequality: Colonial origins, commodity booms, or a missed 20th century leveling. NBER Working Paper 20915.

Zavaleta Mercado, R. (2011). René Zavaleta Mercado: obra completa. La Paz, Bolivia: Plural Editores.

José Alejandro Peres-Cajías holds a Ph.D. in Economic History and is a full-time professor at the Escuela de la Producción y la Competitividad (Catholic University of Bolivia "San Pablo"). His research interests are long-term economic growth, the long-term impact of state intervention in the economy, regional inequality, and trade policy in Latin America. He has published in specialized journals as well as in books edited inside and outside Bolivia. 


\title{
The Lingering Face of Gender Inequality in Latin America
}

\author{
María Magdalena Camou and Silvana Maubrigades
}

\section{Introduction}

The composition of the labour market in most Latin American countries has changed greatly in the last four decades with a huge increase in the proportion of women in the urban labour market (Camou 2012). Female labour force participation began to increase in the 1970s and this continued through the 1980s and 1990s. In Argentina, Brazil, Uruguay, Mexico and Chile the female participation rate of around $20 \%$ in 1960 increased to $40-50 \%$ in 2000.

The demographic, technological and economic factors behind this process are discussed in the literature. Although this change opens new opportunities for women to become more economically independent, a high proportion are still inactive, and increased women's participation has not eliminated segregation in the labour market.

Recent studies show that the Latin American countries are heterogeneous in this respect. The predominant trend in the 1980-1990s was increased inequality, although this began to reverse in the twenty-first century (Bourguignon et al. 2004; Bértola and Ocampo 2012). However, the gender component of inequality change has not been sufficiently incorporated into these results.

Our main aim in this study is to reconstruct the gender wage gap for a sample of Latin American countries to frame explanations of its evolution and impact on inequality. Our data come from the Censuses and Household Surveys in each country.

Our research involves an exhaustive analysis of wage differences between men and women and focuses on how the gender gap has changed over time and its relation to inequality in the different countries. Our sample consists of Argentina, Bolivia, Brazil, Chile, Colombia, Costa Rica, Ecuador, El Salvador, Guatemala, Honduras, Mexico, Nicaragua, Paraguay, Peru, Uruguay and Venezuela.

M.M. Camou $(\bowtie) \bullet$ S. Maubrigades

Universidad de la República, Uruguay 
Our emphasis is on reconstructing gender indicators for the long run, insofar as this is possible with the sources available, and we analyze the different trajectories and patterns of inequality that are specifically related to gender, and check them against global income distribution trends.

Our hypothesis is that the evolution of the gender wage gap is an important component of overall inequality and it has nonlinear effects. Although this gap has narrowed in recent decades, it is still wide, especially in the Latin American countries where inequality is high and where the incorporation of women into the labour force has lagged behind.

In the next section, we summarize the theoretical links between the increasing female labour supply and inequality, and set the most important results from Latin American research on the subject and the goals of the chapter. Section "The Current Situation" presents our methodology and the sources used. Section "Data and Methodology" discusses the latest data documenting the evolution of female labour force participation and education in twentieth-century Latin America. It also explores the relation between the levels of women's participation in the labour market and their education. In section "The Evolution of Female Labour Force Participation and Education Achievement During the Twentieth Century" we examine the evolution of the gender wage gap and inequality indicators. Section "Measuring Inequality and the Gender Wage Gap" estimates the impact of female labour supply, overall inequality and education on the gender gap. The last section draws some conclusions.

\section{Theoretical Approach}

Latin America has always had high levels of inequality, and today, in spite of recent improvements, it is still the second most unequal region in the world, just below sub-Saharan Africa.

Latin American studies agree that the main cause of increasing inequality in the region has been the process whereby political power, wealth and income have become concentrated in the hands of landowning and capitalist elites and of the people who control work and trade relations (Bértola and Ocampo 2012).

In the First Globalization period inequality in Latin America increased, and while the gap was not as wide as in other regions at that time like Africa and Asia it was still too great to enable these Hispanic countries to catch up with the developed world.

In the industrialization period (1930-1980), Latin American social development indicators had higher growth rates than at any other time in the region's history, although the improvement was more marked in some countries than others.

There was also an improvement in equity levels in the countries that managed to develop welfare state systems such as Argentina, Chile and Uruguay. However, other countries had high levels of inequality either because there were big differences in the composition of the population (indigenous people, peasants, descendants of 
slaves) or because their labour markets were strongly segmented with gaps between formal and informal workers that highlighted the differences in state regulation.

Starting in the 1970 s, the levels of equity that had been attained previously began to diminish. This was due to the drastic deregulation of labour markets, increasing segmentation in job markets, a widening gap between the skilled and the unskilled workforce, along with an industrialization slowdown, less state participation and a cutback on policies to redistribute wealth.

Many authors consider that the persistence of inequality is related to social, cultural and economic frameworks and the fact that discrimination and prejudice are embedded in formal and informal institutions. This particularly affects gender inequality, which according to the literature (Sarasúa and Gálvez 2003) is related to false beliefs and stereotypes that permeate education, family and functioning of the labour market.

Since 1970, women in Latin America have had considerably higher levels of well-being, measured in terms of health and education, than women in other developing regions. However, in spite of this progress, Latin American women have not had equal opportunities to earn income and have largely been excluded from positions of power in political and economic institutions. This makes the region an interesting context in which to consider the effects of globalization, both because the moves toward liberalization have been substantial and because women have had many of the prerequisites to participate in the market economy.

There is considerable discussion in the literature about the consequences of increasing women's participation in the labour force during the globalization period, and interpretations of the evidence are diverse. According to the neoclassical view, as exemplified by the Stolper-Samuelson model, in developing countries free trade leads to rising wages for unskilled work, which is the relatively abundant factor in these economies (Samuelson 1948). Since unskilled work is often done by women we can infer from the Stolper-Samuelson model that globalization leads to increased demand for women to work, and hence should have as a final consequence a relative expansion of female participation and a narrowing of the gender gap (see the case of Mexico in Dell 2005; Artecona and Cunningham 2002; Garcia Cuellar 2001).

However, the evidence for the period 1970-1990 does not support this theory insofar as the growth of demand for female labour has not produced any robust decline in the gender earnings gap, which varies greatly between different regions of the world (Çağatay and Ertürk 2004). Moreover, the narrowing of gender gaps cannot be attributed only to the globalization process because other changes also had an impact. It may be that the improved quality of female labour with the incorporation of workers who were more experienced and better educated (O'Neill and Polachek 1993, Goldin 2000) and the fall in wages for less skilled male workers (Blau and Kahn 1997) came into play, rather than just an increase in the demand for female labour.

The most common heterodox approach to this question has been to consider the effect of gender wage gaps on successful export-led growth. Given that women are excluded from certain occupations and sectors, trade opening brought with it an increase in the labour supply of women in certain kinds of work, and this raised unemployment rates and reduced wages (Bergmann 1974) or perpetuated wage gaps (Joekes 1999; Seguino 2000; Berik et al. 2003). 
Another approach in the literature has focused on the sacrifices that globalization has forced women in developing countries to make (Beneria 2003; Beneria et al. 2000). With very small or in some cases no improvements in household technologies, greater female participation levels in paid occupations have meant more total hours of work for women than for men. Adjustment policies and public expenditure cutbacks in the same period have had negative effects on welfare, health and other human capital services. This affects women more than men, since the former are usually responsible for the human capital formation of their children. Therefore changes in women's economic situations must be analyzed together with other human and social capital conditions that determine their final market power.

\section{The Current Situation}

Research on the evolution of the gender gap in the globalization era in Latin America has been addressed in various ways but there is scant literature with a historical perspective. One reason for this is that the data is very difficult to obtain. Prior to 1970 and before the first Household Surveys there is little aggregate statistical evidence relating to the gender wage gap.

Reyes Campo (2012) has studied the evolution of the gender wage gap in Chile using new sources of pre-1960 data. Prior to her work, there was no data for wages by gender for Chile. She has been able to document the gender gap from 1939 to 1974, using social security data. Although the gender wage gap diminished over time, the ratio of women's wages to male wages only increased 14 percentage points from 1939 to 1968. So the evidence points towards discrimination.

For Uruguay, Camou (2010) studied the evolution of the gender gap in the textile and meatpacking industries, based on business archives for the period of 19151957. Her research also shows a trend towards a shrinking gender wage gap in these industries of about $20 \%$. Another paper compares the forces responsible for the evolution of gender gap and wage inequality in South Asia, East Asia and Latin America (Camps et al. 2006). Human capital, health improvement, labour market liberalization and equal treatment enforcement laws seem to be the main exogenous variables affecting women's economic situation. Between 1975 and 2000 the gender gap narrowed, the main exception to the rule is China, where the economic gap between men and women increased. Everywhere else, the erosion in the gender gap has resulted in a fall of wage dispersion. In short, the narrowing of the gender gap during the second global era has tended to reduce wage inequality measured by both the Gini and Theil indexes.

Hoyos and Nopo (2010) focus on the changes in the 1990s and 2000s and analyze Household Survey data for 1992 and 2007, controlling by education, number of children and other characteristics of the population. Their research explores the impact of changing characteristics of the labour supply on gender earnings inequality. The research shows that the gender gap decreased by $7 \%$ overall during the 
period but with great heterogeneity among countries, and that cohort effects linked to life cycle influence gender earnings.

For the same two decades, Gálvez (2001) examined the dynamic of women joining the labour market and concluded that, despite improvements in the female activity rate, education level and the gender gap, their situation continued to be worse than men's on indicators like the unemployment rate, the activity rate and the persistence of the wage gap. Greater gender equality is reduced less to economic aspects and more to institutional, cultural or regulatory aspects. Mexico and Chile are good examples of this negative correlation as they have the lowest levels of women's income related to higher GDP per capita. Considering the impact of these changes on inequality, Gálvez remarks that the increase in inequality among women, which was due to uneven education gains, may have contributed to an increase in overall inequality.

Our research adds to this literature by extending the period under study thus to capture the impact of previous gender inequality on the present gender gap. Our purpose is to learn more about path dependency. Are the countries with an early high level of gender discrimination those in which it is more difficult to bring women into the workforce?

Lastly, we look at the relationship between overall inequality and gender inequality. We examine whether gender inequality and total inequality share the same trends, whether and why they can have an opposite trend.

\section{Data and Methodology}

Our research concentrates on the differences between women and men in paid work. We do not take into account women who do unpaid work, although this was the biggest group in the female population in the period. It is clear that although gender inequality cannot be reduced merely to a comparison between the sexes, the first step in the analysis must be to focus on a statistical breakdown by gender.

International comparisons are still constrained by the lack of reliable data. Part of the work that women do in poor countries is in the informal economy and at home and/or for piece rates. The information documenting this kind of work is scarce and is often not comparable across countries. Thus, we focus on market earnings only. Income inequality is higher than earnings inequality because wage earnings are less disperse than property and self-employment incomes.

Data on wage earnings disaggregated by gender come from Household Surveys ${ }^{1}$ in each country, and we use it to calculate the wage per hour for each sex. In most of the datasets we exploit, the unit of observation is the household, and this gives us Gini coefficients for income and expenditure (Deininger and Squire 1996, 1998; World Bank 1995; Higgins and Williamson 2002). Other approaches have focused on individuals instead of households, using national account information (see

\footnotetext{
${ }^{1}$ Household Surveys include individual and household information.
} 
Bourguignon and Morrison 2002; Sala-i-Martin 2003). Since our unit of analysis has to be the individual and not the household, Gini coefficients for household income hide important information about the unequal economic position of women in the household.

We calculate the Gini index for earnings inequality in the economy as a whole, and for inequality among men and among women. We supplement this measure with calculations of the so-called generalized entropy measures, the best known of which are the Theil indexes. These indexes enable us to estimate how much overall inequality is explained by inequality within groups and how much by inequality between groups. We use these indexes to disaggregate inequality into its gender sources.

\section{The Evolution of Female Labour Force Participation and Education Achievement During the Twentieth Century}

There is a line of research that documents female labour force participation in the long run. Important studies have been done by Goldin $(1994,2006)$ for the USA, and she finds a "U" relation between female employment rates and economic growth. This is due to the relation between education and economic development. At low levels of development, education increases more for men than for women. As income rises, women's participation decreases. When income increases further, education resources expand and women receive more education, which promotes their participation in the labour market. With more education and the expansion of non-industrial employment, women's participation continues to increase and thus forms the "U" (Psacharopoulos and Tzannatos 1989; Schultz 1990). This evolution has been explored for countries with different income levels. The results show that those with higher or lower levels of income have higher female labour force participation rates than middle-income countries (Pampel and Tanaka 1986; Psacharopoulos and Tzannatos 1989; Tzannatos 1999).

Documentation of the evolution of female labour force participation in Latin America is very recent (Camou and Maubrigades 2013). Researchers have to struggle with the fact that, in general, women workers have not been well documented. The censuses carried out in the first decades of the twentieth century are inconsistent in the way they register women's participation in the primary sector. This makes the total primary sector employment change atypical because work there tends to be less formalized and many women are involved in productive as well as home care activities.

There is another problem with the first censuses in Argentina, Chile and Uruguay carried out at the end of the nineteenth century and the early years of the twentieth century. These record each individual's occupations regardless of whether or not that person was employed at the time. The present-day concept of "unemployed" 
was less applicable when wage labour was the exception rather than the rule. However, this was a period of rapid economic growth which implies that unemployment was probably very low.

Three periods can be distinguished:

1. 1910-1940: a fall in female labour participation in some countries like Argentina and Chile

2. 1940-1970: few changes in the Latin American countries studied

3. 1970 to the present: explosive growth in female labour participation rates

The data collected for the years 1930-1970 give quantitative support to the thesis that female participation in labour markets decreased during the import substitution period. The state promoted a sort of male-breadwinner model during this period in Uruguay and Chile, which fostered a decrease in women's participation in the labour market (Todaro 2004; Espino and Azar 2007).

Female labour force participation began to increase moderately in the 1970s and this trend continued into the 1980s (Table 1). However, only in the 1990s did the region see a significant improvement, in general, and it still remained lower than in the developed countries (Camou and Maubrigades 2013).

Besides this, the trajectories of female activity rates diverged across Latin America. Chile, Uruguay and Argentina had a relatively high rate of female labour participation from the beginning of the period, while Brazil, Colombia and Mexico were much further behind. By the end of the period, Brazil and Colombia had caught up with the first three. The other countries considered in Table 1 have much lower participation rates and, despite some improvement, they have never reached the levels of the Latin leaders.

Although the long-term trend was upwards throughout Latin America, the evidence shows no single pattern in how these countries incorporated women into the labour market during their various stages of development.

As regards education, over the last 60 years the educational level of Latin American countries has progressed to an unprecedented degree. In 1950, the illiteracy rate was about $40 \%$ among persons aged 15 and over; by 2005 it had fallen below $10 \%$. The speed of progress has varied between countries and the illiteracy rate remains high in some countries, in particular those with large indigenous populations.

In the second half of twentieth century, in most of Latin America, female years of schooling increased to near or even slightly higher than men in countries like Argentina, Brazil, Costa Rica and Uruguay. Moreover, gender schooling differences have been reduced especially in recent decades. Only in countries with high illiteracy rates and/or large indigenous communities like Guatemala, Nicaragua or Honduras do we still see big gender gap in schooling.

Considering the expansion of primary education coverage followed by continual growth in basic education, Latin America has presented a set of education policies geared specifically to less privileged groups (in terms of ethnicity, geographical location and socioeconomic status). However, gender inequalities persist in a group of countries but are hidden behind overall averages. 


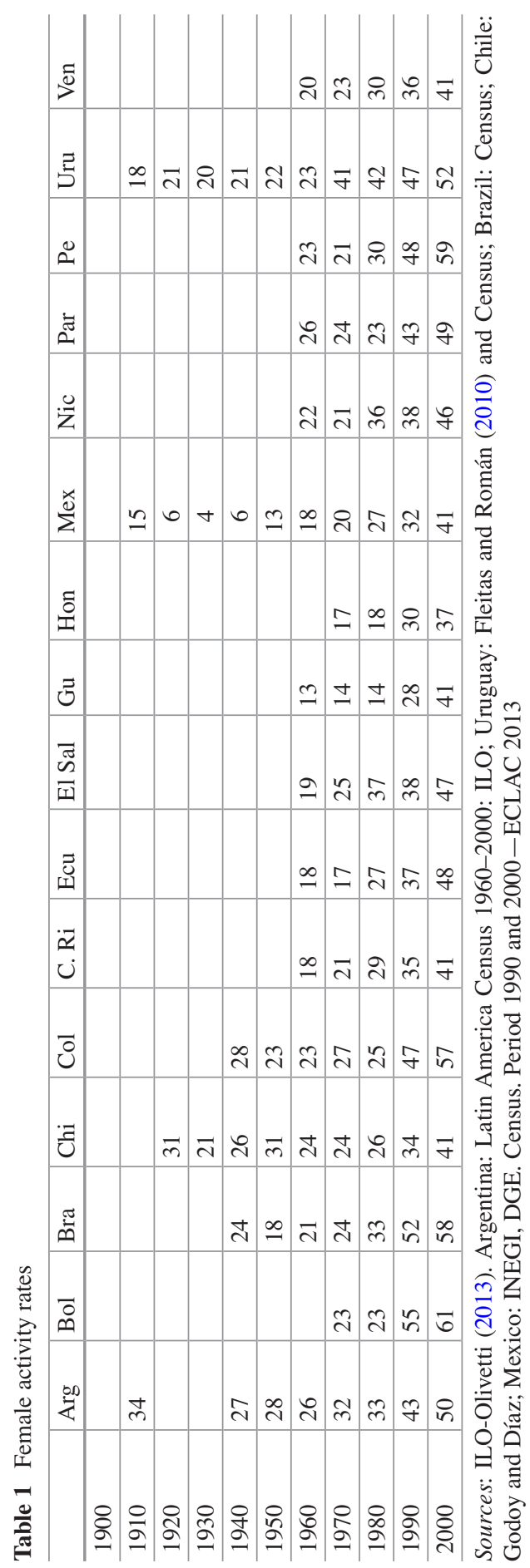




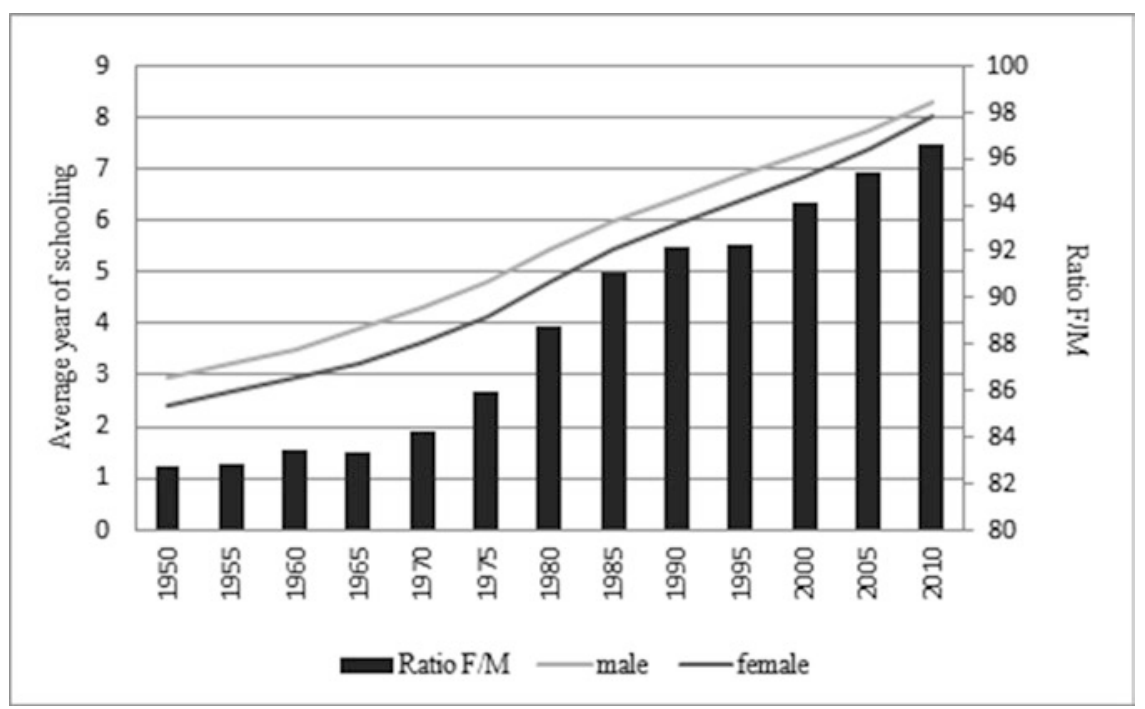

Fig. 1 Education attainment by sex. Sources: Based on Barro, R. J. and J. W. Lee (2012)

Figure 1 shows the evolution of education during the period of analysis, comparing average female to average male schooling. Both sexes improved but girls had not yet reached the boys' levels. The gender catching up in schooling started with the massive intake of women into primary education; it advanced with greater female participation in secondary education and progressed still further with more and more women at the higher education level.

However, when we examine the countries individually we find differences among them. One group of countries started the period with an average of years of study almost twice as high as the others. These were Argentina, Chile and Uruguay and to a lesser degree Costa Rica. This group implemented public policies to promote the enrolment of boys and girls in primary and secondary education. This resulted in sustained growth in years of schooling for both sexes during the second half of the twentieth century and women in Argentina and Uruguay performed even better than male.

In the second half of the century, another group of countries had average schooling of only 2 years, and girls still lagged behind boys even at the end of the period. This group included countries with larger indigenous and rural populations, and this may help explain why enrolment in formal educational institutions was so low. The group contains countries like Guatemala, Honduras, El Salvador and Nicaragua.

Mexico and Brazil are examples of good improvement in the period. The populations of both had low education levels in the late 1950s, but by the end of the period years of schooling had increased greatly in both. Although the causality has to be firmly established, it appears that rapid economic growth raised the demand for schooling during the period, and that both were proactive in education policies intended to improve human capital fast. 
The relationship between activity rates and education has not been linear. At low levels of schooling, there is a strong correspondence between years of schooling and female labour force participation. At higher levels of female years of schooling the elasticity of the female activity rate decreases.

Although average years of schooling increased in most of the Latin American countries during the period, there are big differences in the sample. In 2000 Chile and Costa Rica had high schooling rates and low activity rates, while Bolivia, Ecuador, Paraguay and El Salvador had high activity rates but only modest increases in years of schooling. Towards the end of the period the countries in the region returned to the free market model and opened up to trade. This shift increased the demand for technical skills and reduced the demand for low-skill workers, a sector in which the percentage of women is higher than the percentage of female economywide (Bértola and Ocampo 2012).

\section{Measuring Inequality and the Gender Wage Gap}

Although overall female labour force participation has increased over the last 50 years, there are still gender differences among countries. Gender discrimination in wages has persisted over time and is common in many countries. The persistence suggests structural causes rooted in institutions and cultural norms. For instance, women are more likely to respond positively to increased economic opportunities in the labour market when childcare services are available or when their participation is socially accepted. In contrast, where significant barriers remain their progress is more limited (Fig. 2).

In the first decade of the twenty-first century, Latin American women typically received less than $35 \%$ of total national income, although the figure was around $40 \%$ in six leaders (Fig. 3). The women's share increased strongly between 1990 and 2000 in Costa Rica, Ecuador, El Salvador, Honduras, Uruguay and Venezuela. In Costa Rica, Ecuador and El Salvador the reason behind this trend is more related to improvements in the female activity rate than to a narrowing of the gender wage gap but in Guatemala, Honduras, Uruguay and Venezuela the gap became considerably smaller during this period (Fig. 4).

In the first decade of the new century the countries with the narrowest wage gaps were Argentina, Colombia, Costa Rica, Guatemala, Honduras, Uruguay and Venezuela.

The other countries in our sample are falling behind. We can only partially reconstruct some countries' trajectories because sources are scarce. The data we have indicates that the countries that had a narrower gender wage gap in the past are the ones performing better at present. In the period 1970-2010 the gap in Brazil was wider than that in Argentina or Uruguay.

In Latin America, inequality among men has more weight in the total Gini level due to their greater participation in the labour market and to greater inequality among males (see Appendices 1, 2 and 3). The distribution of schooling and skills among sexes may be part of the explanation. 


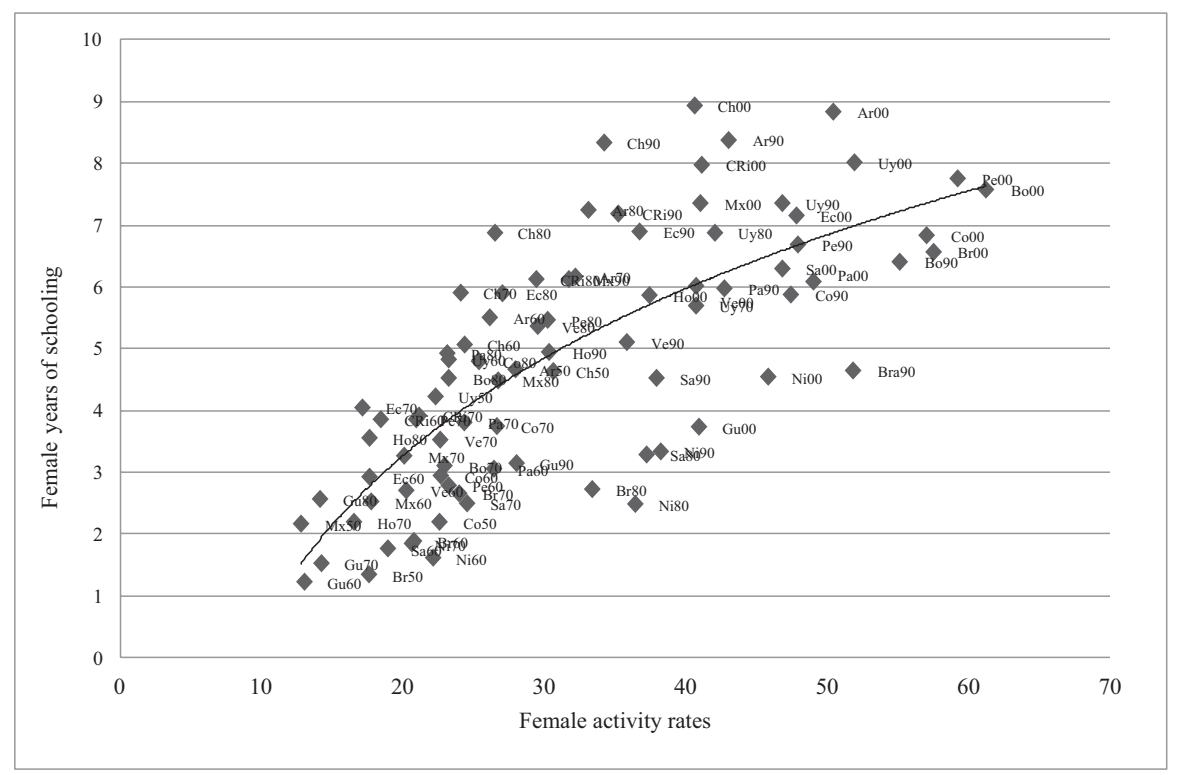

Fig. 2 Female activity rate and years of schooling, 1950-2000. Sources: Activity rates idem Table 1. Years of schooling - Barro and Lee (2012)

There is no a clear trend in the evolution of inequality among women. While the overall average remains unchanged over the period, there is a group of countries (Argentina, Uruguay, Costa Rica, Venezuela and Peru) with increasing inequality in women's wages. The overall inequality increase during the period probably affects women as well as men. The reason the spread among women's wages is greater is probably that they join the labour market with greater human capital because their years of schooling and work experience are increasing.

\section{Explaining the Gender Wage Gap}

In an international comparison, Blau and Kahn (1997) found that labour markets with highly unequal rates of remuneration also have high levels of gender inequality. Next we tested their relation between overall wage inequality and gender gap for Latin America.

At first glance, Latin American evidence confirms the postulated relation. The countries that are more unequal (with Gini ratings above 0.5: Fig. 5) also have wider gender gaps. When we look at the differences among countries over the period we can identify two groups. First, there are those in which overall inequality remained relatively high over the period and the gender gap narrowed but female wage earnings 


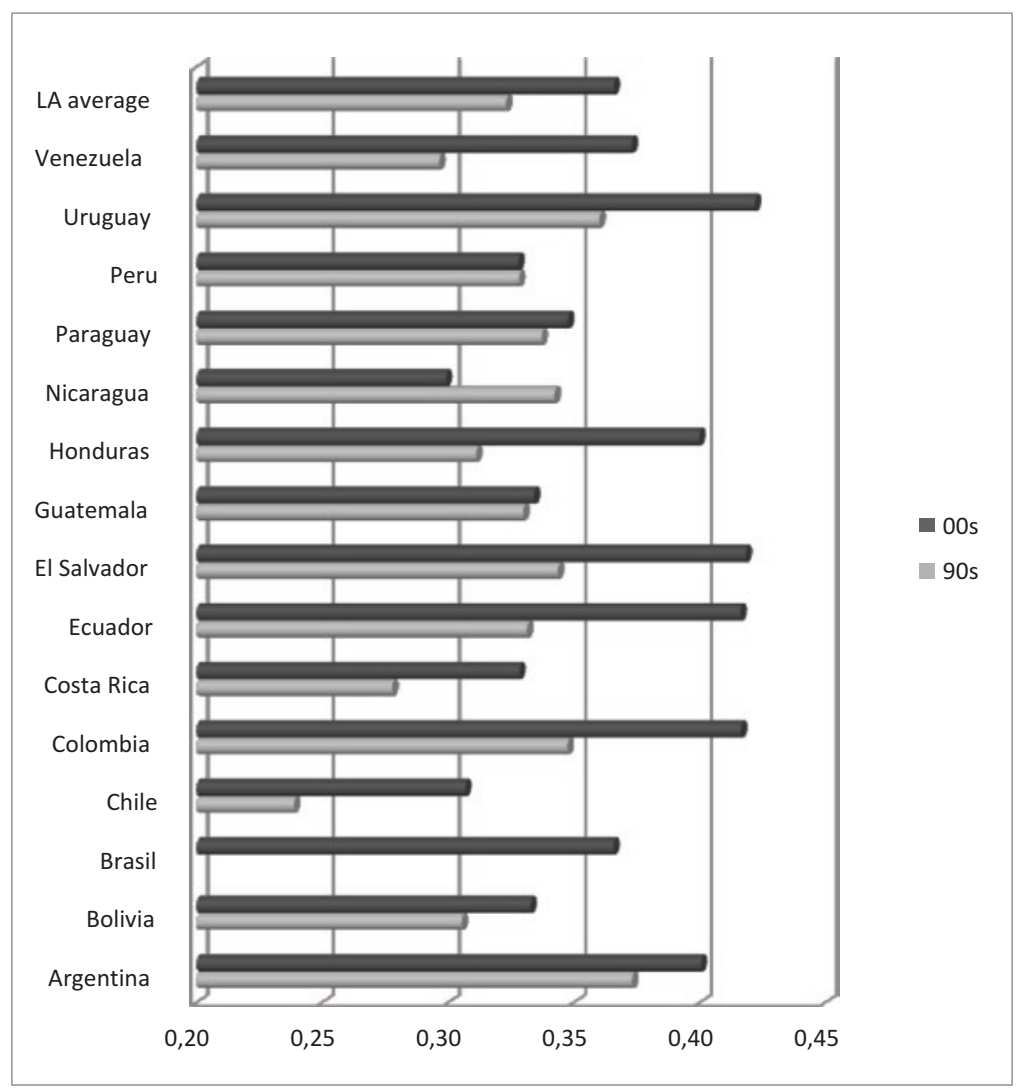

Fig. 3 Women's share of wage bill, 1990-2000. Sources: Household surveys

remained lower than male. This was the case in Chile, Bolivia, Honduras, Peru, Nicaragua and Ecuador. Brazil was a special case with high inequality and a wide gender gap (see Appendices 1, 2 and 3).

There is a second group with relatively low total inequality and a narrowing gender gap, and here we find Argentina, Uruguay, Costa Rica and Venezuela. In particular, Argentina and Uruguay are also countries with a lower gender gap in the past and a higher activity rate. In any case, path dependence does not seem to be the only way to achieve a narrower gender gap: Venezuela belongs to this group although traditionally it has had low female participation rate.

Another factor that probably impacts on the gender wage gap is the historical pattern of women's participation in the labour market. In the period 1940-1970, gender inequality was high in Latin America and this was expressed in a low level of female labour participation and a wide gender gap. There are few data available 


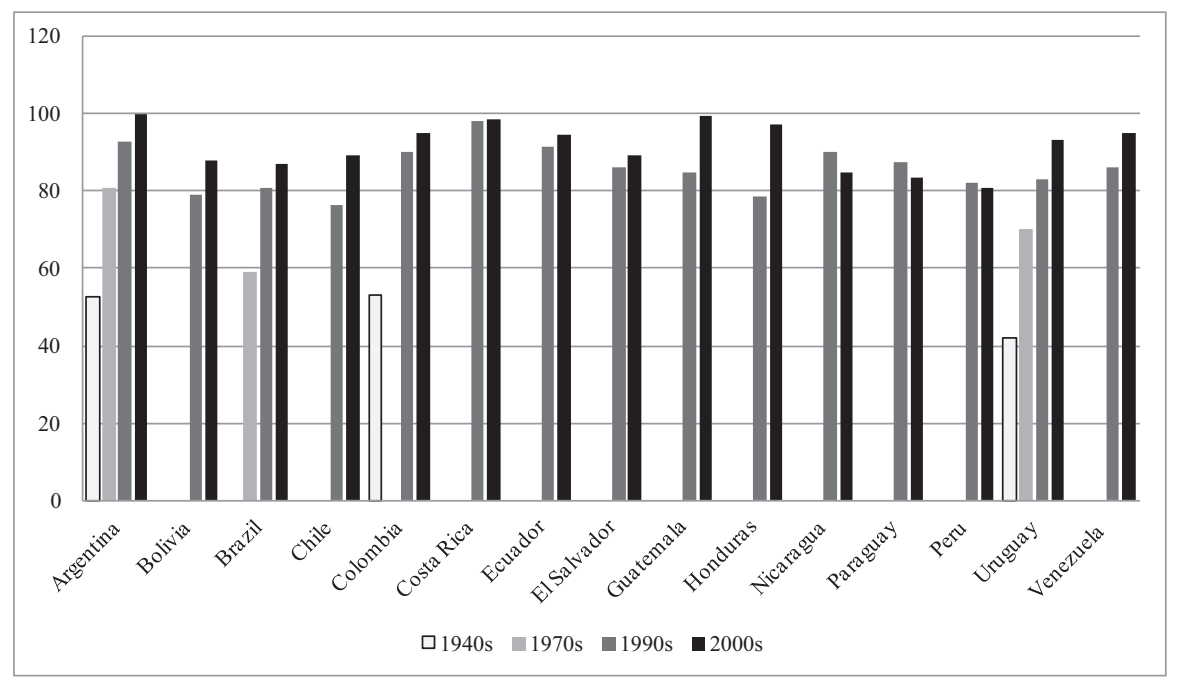

Fig. 4 Gender wage gap in Latin America, 1940-2000. Sources: ILO and household surveys

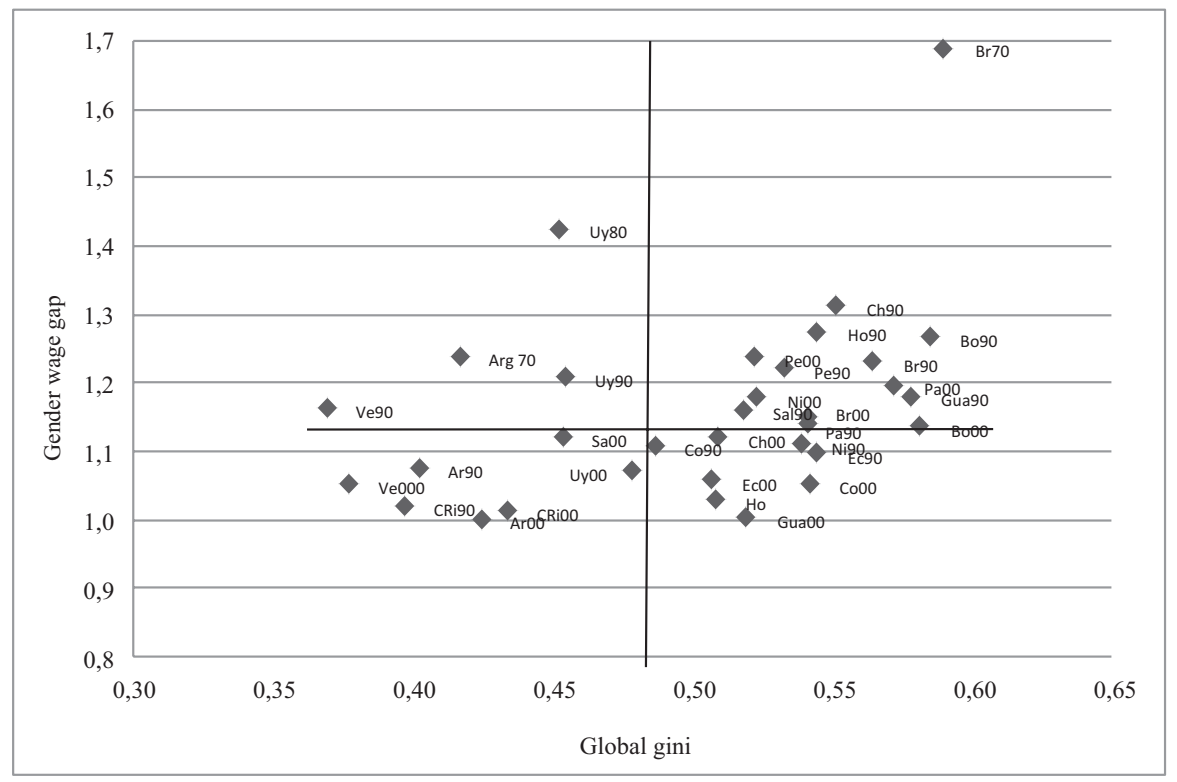

Fig. 5 Overall inequality and gender wage gap. Sources: Household surveys 


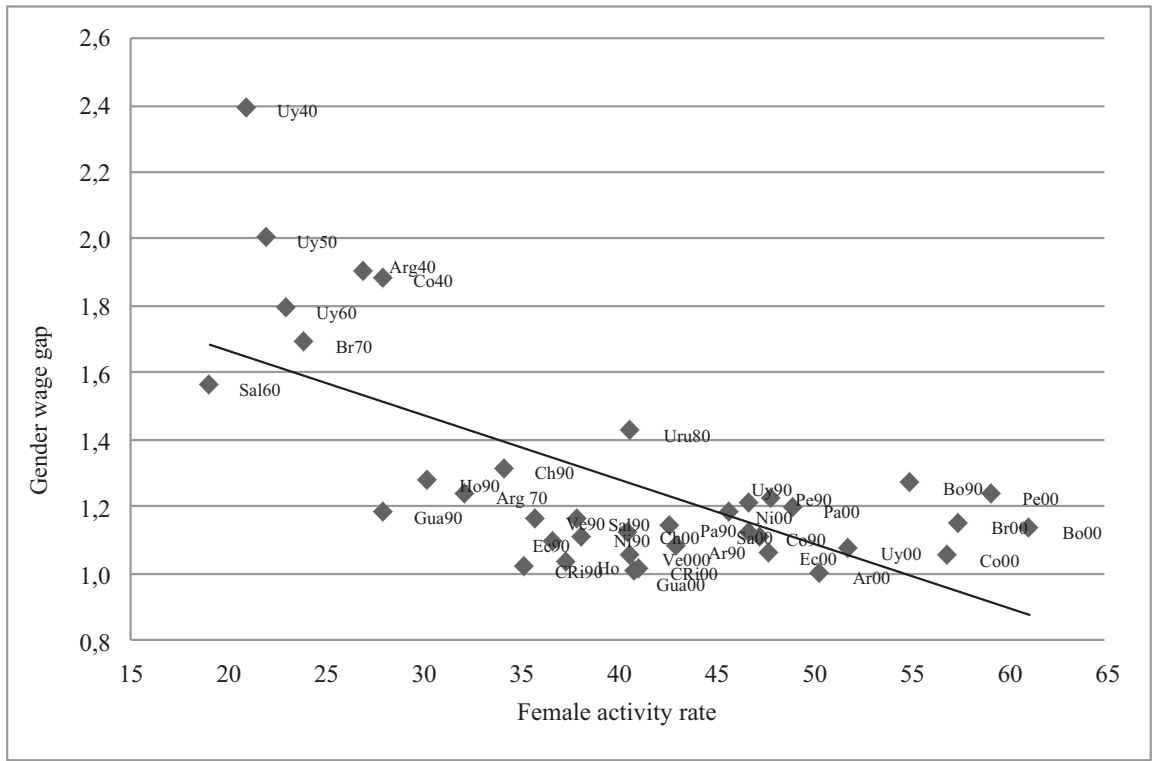

Fig. 6 Female activity rate and gender wage gap, 1940-2000. Sources: Activity rates idem Table 1. Gender wage gap: ILO and household surveys

for the 1980s, the so-called lost decade, and in the 1990s we entered a new phase with a narrower gender wage gap and greater variability in women's activity rates across the region. At the end of the period women's participation in labour markets was still rising but the gender gap had not significantly narrowed. It can be seen that this correlation between the two variables is not very strong towards the end of the period in which many countries have similar gender gaps and there is a wide spread in the participation rate.

The trends in women activity rates in Latin American labour markets in 2000s are very different between countries. While the general trend is rising over time, only in very few cases does the average reach $50 \%$. The heterogeneity revealed in Fig. 6 could have many explanations and is probably linked to the liberal deregulatory economic policies prevailing since the 1980s. But the gender gap remained stable in the 1990s and 2000s.

These results also show that increases in women's participation in the labour market do not necessarily mean a substantial change because as the participation rate increases the female occupation and wage dispersion also increase. Gender gap trends depend on individual investment in education and the returns to that education. In recent years, female education levels have risen relative to those of men. Although countries have achieved high female labour market participation rates, it is clear that educational equality is not sufficient to secure gender parity in income. One of the reasons why the gender gap has persisted is that it tends to be wider at 
higher levels of education. The evolution of the wage gap between men and women is different at different educational levels. In the tertiary education group the gender gap was wide at the start of the period and there was little subsequent improvement, which shows the glass ceiling effect, whereas in the group with only primary education the gap narrowed more during the same period.

Women's education improved considerably in the 1990s but, as we saw above, the increasing skill premium that accompanied the new economic model was less favourable for better educated women. Increasing female labour force participation and improved educational attainment in a context of relatively stable male labour force participation and educational attainment contributed to an overall narrowing of the gap. As we saw above, a steady convergence between the wages of women and those of men is not automatic. The portion of the wage gap that cannot be explained by labour market characteristics related to workers' skills is generally attributed to discrimination and to differences in preferences between men and women. Women tend to enter different careers than men.

There is still a tendency for occupations to be "male dominated" or "female dominated," and the female-dominated ones tend to pay less even when men and women have the same educational level. The majority of women work in the services and agricultural sectors, and the fact is that areas in which women are the vast majority - secretaries, teachers and nurses - are poorly paid.

In the last 50 years, schooling levels have increased and the upgrading of the occupational structure as a result of technological changes and economic growth has created a demand for more skilled and educated labour. The increasing demand for a skilled and highly educated labour has resulted, among other things, in policies to raise the overall educational level of the population. In spite of that Fig. 7 shows a high level of sex segregation persisting among employees with tertiary education, despite the relative equalization between men and women in overall level of educational attainment. There are wage disparities between men and women with the same educational qualifications in all Latin American countries analyzed and at all educational levels, but in particular among the more educated population.

Our in-depth study of the wage gap between men and women shows that the biggest differences that remain are among those with the highest levels of qualifications and incomes (Fig. 8). When we compare the evolution of the gender gap among the more educated population in the decade of 1990s and 2000s, we find that although the differences decrease, men's average wages stayed at around 25 percentage points higher than women's. At the end of that decade there were still large wage differentials between men and women with the same level of educational attainment.

In the light of these results, whether these wage differences in the group of tertiary education are related to women's human capital being underused in the labour market. One way to approach this is to examine the distribution of the most highly educated peoples by their income levels. However, we have been able to confirm that $80-90 \%$ of people of both sexes with tertiary education levels are in the highest wage level (see Appendices 1, 2 and 3). Even though our data do not show the structure of occupations by sex inside the group of high income level, we can assume that this might be different among female and males. 


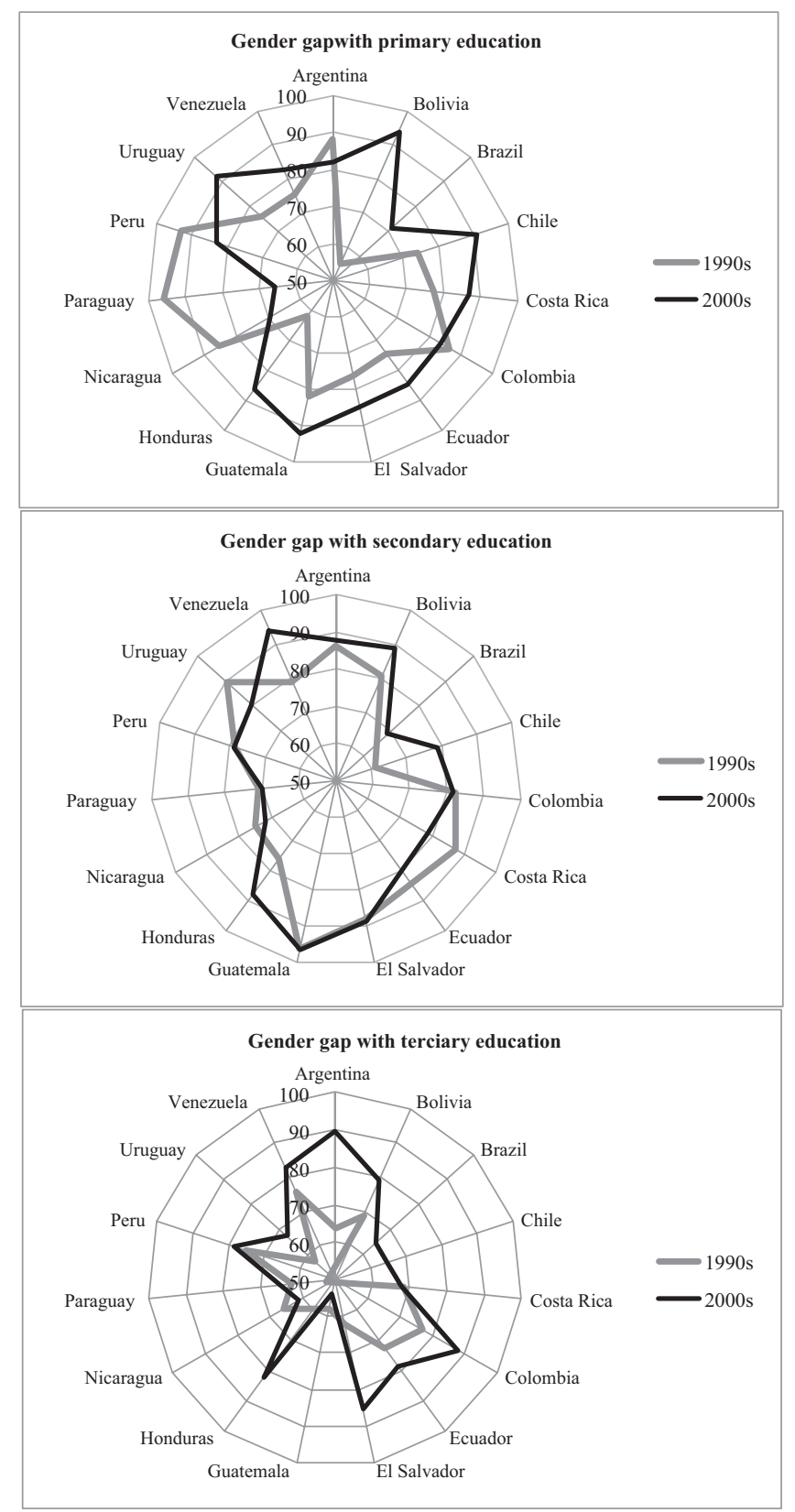

Fig. 7 Education and the gender gap. Sources: ILO and household surveys 


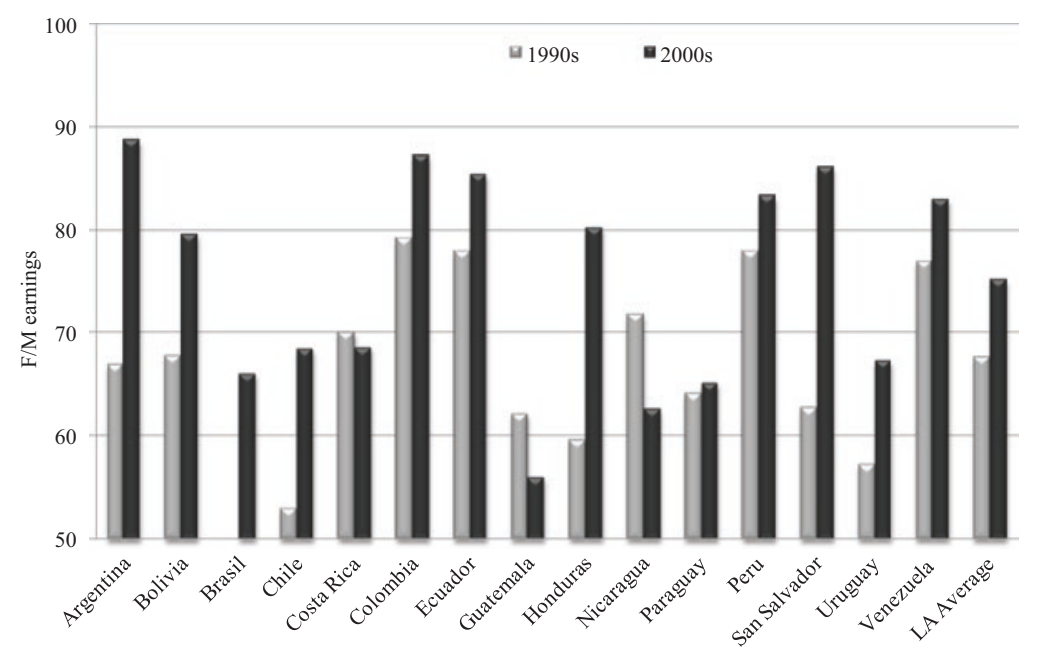

Fig. 8 Gender wage gap among people with high wage levels and tertiary education. Sources: Household surveys. Note: Population was classified according to their wages in three levels: low, middle and high

\section{Conclusion}

The aim of this chapter has been to help to bring the gender perspective into the discussion of the evolution of overall inequality. Our results enable us to map trends in female labour participation rates and schooling achievement in Latin America in the twentieth century.

First we find that the most unequal countries are also those with the greater gender wage gap, and recent history reveals much inertia. The most "advanced" countries in terms of gender equality are those in which female labour participation rates increased in the first half of the twentieth century and also have higher levels of educational attainment and a narrower gender wage gap. In the less "advanced" countries, women's entry into the labour market lagged behind that of the advanced group average, and this was associated with less developed economies with large indigenous and black population.

These results suggest that labour market structures are different in the two groups and that a narrowing of the gender gap does not depend only on women's participation at the end of the period but also on path dependence in labour occupational segregation. Contrary to what we expected, the gender gap widens gradually throughout as years of schooling rise.

The increased participation of women in the labour market impacts overall inequality: while their share of the wage bill has increased and they have gradually 
moved up the educational ladder, they have found the more skilled occupations to have higher gender wage gaps so that overall inequality has risen on that account.

Interestingly, the group that combines high wages with the highest average years of schooling is also the most resistant to this egalitarian trend. It seems that this group does not obey a logic that is purely economic but that there is an invisible barrier against incorporating these new actors into decision-making positions. 


\section{Appendix 1: Gender Inequality}

\begin{tabular}{|c|c|c|c|c|c|c|c|c|}
\hline & Country & Year & $\begin{array}{l}\text { Inequality } \\
\text { measures } \\
(\%)\end{array}$ & & & $\begin{array}{l}\text { Income } \\
\text { share } \\
(\%)\end{array}$ & & $\begin{array}{l}\text { Gender } \\
\text { gap }\end{array}$ \\
\hline & & & Total & Men & Women & Men & Women & \\
\hline \multirow[t]{14}{*}{ 1990s } & Argentina & 1992 & 0.40 & 0.41 & 0.39 & 0.63 & 0.37 & 93 \\
\hline & Bolivia & 1997 & 0.59 & 0.60 & 0.55 & 0.69 & 0.31 & 79 \\
\hline & Chile & 1990 & 0.55 & 0.56 & 0.52 & 0.76 & 0.24 & 76 \\
\hline & Colombia & 1996 & 0.49 & 0.49 & 0.47 & 0.65 & 0.35 & 90 \\
\hline & Costa Rica & 1992 & 0.40 & 0.39 & 0.42 & 0.72 & 0.28 & 98 \\
\hline & Ecuador & 1995 & 0.54 & 0.53 & 0.57 & 0.67 & 0.33 & 91 \\
\hline & El Salvador & 1991 & 0.52 & 0.51 & 0.53 & 0.66 & 0.34 & 86 \\
\hline & Guatemala & 2000 & 0.58 & 0.56 & 0.60 & 0.67 & 0.33 & 85 \\
\hline & Honduras & 1997 & 0.54 & 0.56 & 0.50 & 0.69 & 0.31 & 78 \\
\hline & Nicaragua & 1993 & 0.54 & 0.57 & 0.49 & 0.36 & 0.34 & 90 \\
\hline & Paraguay & 1997 & 0.54 & 0.55 & 0.53 & 0.66 & 0.34 & 88 \\
\hline & Peru & 1997 & 0.53 & 0.54 & 0.52 & 0.67 & 0.33 & 82 \\
\hline & Uruguay & 1992 & 0.45 & 0.45 & 0.45 & 0.64 & 0.36 & 83 \\
\hline & Venezuela & 1992 & 0.37 & 0.36 & 0.36 & 0.70 & 0.30 & 86 \\
\hline \multirow[t]{15}{*}{$2000 \mathrm{~s}$} & Argentina & 2006 & 0.43 & 0.42 & 0.43 & 0.60 & 0.40 & 100 \\
\hline & Bolivia & 2005 & 0.58 & 0.58 & 0.58 & 0.67 & 0.33 & 88 \\
\hline & Brazil & 2008 & 0.54 & 0.55 & 0.53 & 0.63 & 0.37 & 87 \\
\hline & Chile & 2006 & 0.51 & 0.51 & 0.51 & 0.69 & 0.31 & 89 \\
\hline & Costa Rica & 2006 & 0.43 & 0.43 & 0.45 & 0.67 & 0.33 & 99 \\
\hline & Colombia & 2006 & 0.54 & 0.54 & 0.54 & 0.58 & 0.42 & 95 \\
\hline & Ecuador & 2006 & 0.51 & 0.49 & 0.53 & 0.58 & 0.42 & 95 \\
\hline & El Salvador & 2005 & 0.45 & 0.46 & 0.45 & 0.58 & 0.42 & 89 \\
\hline & Guatemala & 2006 & 0.52 & 0.52 & 0.51 & 0.67 & 0.33 & 100 \\
\hline & Honduras & 2006 & 0.51 & 0.51 & 0.50 & 0.60 & 0.40 & 97 \\
\hline & Nicaragua & 2005 & 0.52 & 0.55 & 0.45 & 0.70 & 0.30 & 85 \\
\hline & Peru & 2006 & 0.52 & 0.53 & 0.51 & 0.67 & 0.33 & 81 \\
\hline & Paraguay & 2007 & 0.57 & 0.59 & 0.54 & 0.65 & 0.35 & 84 \\
\hline & Uruguay & 2006 & 0.48 & 0.49 & 0.47 & 0.58 & 0.42 & 93 \\
\hline & Venezuela & 2006 & 0.38 & 0.36 & 0.40 & 0.63 & 0.37 & 95 \\
\hline $\begin{array}{l}\text { Average } \\
1990 \mathrm{~s}\end{array}$ & 0.50 & 0.51 & 0.49 & 0.66 & 0.32 & 86 & & \\
\hline $\begin{array}{l}\text { Average } \\
2000 \mathrm{~s}\end{array}$ & 0.50 & 0.50 & 0.49 & 0.63 & 0.37 & 92 & & \\
\hline
\end{tabular}

Sources: Household surveys 


\section{Appendix 2: Gender Inequality in High Income Level and Tertiary Education Population}

\begin{tabular}{|c|c|c|c|c|c|c|c|}
\hline & \multirow[t]{2}{*}{ Country } & \multicolumn{3}{|c|}{ Inequality measures (\%) } & \multirow{2}{*}{$\begin{array}{l}\text { Income share } \\
(\%) \\
\text { Men }\end{array}$} & \multirow[b]{2}{*}{ Women } & \multirow[t]{2}{*}{ Gender gap } \\
\hline & & Total & Men & Women & & & \\
\hline \multirow[t]{14}{*}{$1990 \mathrm{~s}$} & Argentina & 0.35 & 0.38 & 0.29 & 0.54 & 0.46 & 67 \\
\hline & Bolivia & 0.41 & 0.43 & 0.34 & 0.68 & 0.32 & 68 \\
\hline & Chile & 0.49 & 0.50 & 0.38 & 0.76 & 0.24 & 53 \\
\hline & Colombia & 0.38 & 0.40 & 0.32 & 0.63 & 0.37 & 70 \\
\hline & Costa Rica & 0.31 & 0.31 & 0.29 & 0.68 & 0.32 & 79 \\
\hline & Ecuador & 0.38 & 0.38 & 0.37 & 0.66 & 0.34 & 78 \\
\hline & El Salvador & 0.40 & 0.42 & 0.28 & 0.76 & 0.24 & 63 \\
\hline & Guatemala & 0.44 & 0.45 & 0.35 & 0.79 & 0.21 & 62 \\
\hline & Honduras & 0.41 & 0.43 & 0.30 & 0.72 & 0.28 & 60 \\
\hline & Nicaragua & 0.47 & 0.47 & 0.44 & 0.69 & 0.31 & 72 \\
\hline & Paraguay & 0.44 & 0.46 & 0.35 & 0.70 & 0.30 & 64 \\
\hline & Peru & 0.38 & 0.40 & 0.32 & 0.66 & 0.34 & 78 \\
\hline & Uruguay & 0.40 & 0.40 & 0.32 & 0.61 & 0.39 & 57 \\
\hline & Venezuela & 0.25 & 0.25 & 0.23 & 0.63 & 0.37 & 77 \\
\hline \multirow[t]{15}{*}{$2000 \mathrm{~s}$} & Argentina & 0.28 & 0.30 & 0.26 & 0.45 & 0.55 & 89 \\
\hline & Bolivia & 0.38 & 0.41 & 0.31 & 0.64 & 0.36 & 80 \\
\hline & Brazil & 0.46 & 0.47 & 0.42 & 0.57 & 0.43 & 66 \\
\hline & Chile & 0.48 & 0.50 & 0.42 & 0.63 & 0.37 & 68 \\
\hline & Costa Rica & 0.33 & 0.35 & 0.27 & 0.61 & 0.39 & 69 \\
\hline & Colombia & 0.40 & 0.41 & 0.39 & 0.51 & 0.49 & 87 \\
\hline & Ecuador & 0.47 & 0.43 & 0.51 & 0.59 & 0.41 & 85 \\
\hline & El Salvador & 0.30 & 0.34 & 0.26 & 0.50 & 0.50 & 86 \\
\hline & Guatemala & 0.45 & 0.46 & 0.32 & 0.77 & 0.23 & 56 \\
\hline & Honduras & 0.36 & 0.36 & 0.34 & 0.60 & 0.40 & 80 \\
\hline & Nicaragua & 0.47 & 0.50 & 0.40 & 0.67 & 0.33 & 63 \\
\hline & Paraguay & 0.40 & 0.43 & 0.34 & 0.62 & 0.38 & 65 \\
\hline & Peru & 0.38 & 0.41 & 0.32 & 0.63 & 0.37 & 83 \\
\hline & Uruguay & 0.39 & 0.42 & 0.34 & 0.47 & 0.53 & 67 \\
\hline & Venezuela & 0.28 & 0.32 & 0.25 & 0.49 & 0.51 & 83 \\
\hline \multicolumn{2}{|c|}{ Average 1990s } & 0.39 & 0.41 & 0.33 & 0.68 & 0.32 & 68 \\
\hline \multicolumn{2}{|c|}{ Average 2000s } & 0.39 & 0.41 & 0.33 & 0.58 & 0.42 & 75 \\
\hline
\end{tabular}

Sources: Household surveys 


\section{Appendix 3: Distribution of the Population with Tertiary Education According to Income}

\begin{tabular}{|c|c|c|c|c|c|c|c|}
\hline & \multirow[t]{3}{*}{ Country } & \multicolumn{6}{|c|}{ Income levels } \\
\hline & & \multicolumn{3}{|c|}{ Men } & \multicolumn{3}{|c|}{ Women } \\
\hline & & Low & Medium & High & Low & Medium & High \\
\hline \multirow[t]{13}{*}{$1990 \mathrm{~s}$} & Argentina & 24.6 & 11.0 & 64.4 & 23.2 & 17.7 & 59.1 \\
\hline & Bolivia & 2.5 & 16.7 & 80.8 & 3.3 & 17.4 & 79.3 \\
\hline & Chile & 4.0 & 10.4 & 85.6 & 7.6 & 21.0 & 71.4 \\
\hline & Colombia & 1.8 & 7.5 & 90.7 & 1.6 & 12.3 & 86.1 \\
\hline & Costa Rica & 0.9 & 5.6 & 93.5 & 4.4 & 5.9 & 89.7 \\
\hline & El Salvador & 2.5 & 3.1 & 94.4 & 1.1 & 6.5 & 92.5 \\
\hline & Guatemala & 4.4 & 4.4 & 91.2 & 5.8 & 10.7 & 83.5 \\
\hline & Honduras & 1.5 & 5.8 & 92.7 & 0.0 & 8.8 & 91.2 \\
\hline & Nicaragua & 1.7 & 16.9 & 81.4 & 3.5 & 25.6 & 70.9 \\
\hline & Paraguay & 0.6 & 1.7 & 97.8 & 0.0 & 7.8 & 92.2 \\
\hline & Peru & 5.8 & 20.2 & 74.0 & 8.0 & 23.6 & 68.3 \\
\hline & Uruguay & 5.8 & 14.2 & 80.0 & 4.6 & 21.3 & 74.1 \\
\hline & Venezuela & 5.6 & 11.1 & 83.3 & 5.6 & 11.1 & 83.3 \\
\hline \multirow[t]{15}{*}{$2000 \mathrm{~s}$} & Argentina & 8.8 & 19.4 & 71.8 & 10.5 & 19.4 & 70.1 \\
\hline & Bolivia & 2.4 & 7.5 & 90.1 & 3.7 & 9.0 & 87.3 \\
\hline & Brazil & 4.6 & 9.5 & 85.9 & 4.6 & 12.0 & 83.5 \\
\hline & Chile & 5.5 & 11.8 & 82.7 & 8.6 & 16.6 & 74.8 \\
\hline & Costa Rica & 2.8 & 2.4 & 94.8 & 2.1 & 5.9 & 91.9 \\
\hline & Colombia & 6.1 & 13.3 & 80.7 & 7.0 & 12.2 & 80.8 \\
\hline & Ecuador & 13.1 & 15.6 & 71.3 & 21.1 & 15.8 & 63.2 \\
\hline & El Salvador & 11.5 & 5.3 & 83.2 & 7.3 & 7.0 & 85.7 \\
\hline & Guatemala & 1.4 & 3.4 & 95.2 & 5.6 & 5.0 & 89.4 \\
\hline & Honduras & 4.8 & 5.3 & 89.9 & 4.3 & 3.2 & 92.5 \\
\hline & Nicaragua & 4.5 & 6.2 & 89.3 & 4.7 & 9.2 & 86.1 \\
\hline & Paraguay & 2.7 & 8.0 & 89.4 & 4.4 & 9.1 & 86.6 \\
\hline & Peru & 8.0 & 21.1 & 70.9 & 12.5 & 23.2 & 64.3 \\
\hline & Uruguay & 5.6 & 11.4 & 83.0 & 5.7 & 12.8 & 81.5 \\
\hline & Venezuela & 4.6 & 16.2 & 79.3 & 6.0 & 17.6 & 76.5 \\
\hline
\end{tabular}

Sources: Household surveys

Open Access This chapter is distributed under the terms of the Creative Commons Attribution 4.0 International License (http://creativecommons.org/licenses/by/4.0/), which permits use, duplication, adaptation, distribution and reproduction in any medium or format, as long as you give appropriate credit to the original author(s) and the source, a link is provided to the Creative Commons license and indicate if changes were made.

The images or other third party material in this chapter are included in the work's Creative Commons license, unless indicated otherwise in the credit line; if such material is not included in the work's Creative Commons license and the respective action is not permitted by statutory regulation, users will need to obtain permission from the license holder to duplicate, adapt or reproduce the material.

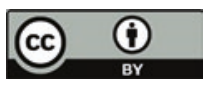




\section{References}

Artecona, R., \& Cunningham, W. (2002). Effects of trade liberalization on the gender wage gap in Mexico. Working Paper, The World Bank Development Group.

Barro, R. J., \& Lee, J.-W. (2012). A new data set of educational attainment in the world, 1950-2010. Journal of Development Economics, 104, 184-198.

Beneria, L. (2003). Gender, development and globalization. Economics as if all people mattered. New York: Rouledge.

Beneria, L., Floro, M., Grow, C., \& MacDonald, M. (2000). Globalization and gender. Feminist Economics, 63(3), VII-XVIII.

Bergmann, B. R. (1974). Occupational segregation, wages and profits when employers discriminate by race or sex. Eastern Economic Journal, 1(2), 103-110.

Berik, G., van der Meulen Rodgers, Y., \& Zveglich Jr. J. (2003). International trade and wage discrimination: Evidence from East Asia. World Bank Policy Research, Working Paper.

Bértola, L., \& Ocampo, J. A. (2012). The economic development of Latin America since independence. Oxford: Oxford University Press.

Blau, F. D., \& Kahn, L. M. (1997). Swimming upstream: Trends in the gender wage differential in the 1980's. Journal of Labor Economics, 15(1), 1-42.

Bourguignon, F., Ferreira, F. H. G., \& Lustig, N. (Eds.). (2004). The microeconomics of income distribution dynamics in East Asia and Latin America. Washington, DC: World Bank.

Bourguignon, F., \& Morrison, C. (2002). Income distribution among world citizens: 1820-1990. American Economic Review, 92(September), 1113-1132.

Çağatay, N., \& Ertürk, K. (2004). Gender and globalization: A macroeconomic perspective. Working Paper No. 19. Geneva: ILO.

Camou, M. M. (2010). Las instituciones del mercado de trabajo en dos ramas de la industria uruguaya, 1900-1960. Facultad de Ciencias Sociales, Montevideo, Universidad de la República. Tesis de Doctorado.

Camou, M. M. (2012). Historical patterns of gender inequality in Latin America: New evidence. 16th World Economic History Congress.

Camou, M. M., \& Maubrigades, S. (2013). Desigualdades de género y desarrollo en América Latina en el S.XX: su historia a través de indicadores del desarrollo humano. Revista del Centro de Estudios Interdisciplinarios Latinoamericanos (CEIL) vol vii, no. 2 (diciembre 2013) (pp208-238).

Camps, E., Camou, M., Maubrigades, S., \& Mora-Sitja, N. (2006). Globalization and wage inequality in South and East Asia, and Latin America: A gender approach. Working Paper No. 970, Departamento de Economía y Empresas, Universidad Pompeu Fabra, Barcelona.

Deininger, K., \& Squire, L. (1996). A new data set measuring income inequality. The World Bank Economic Review, 10(3), 565-591.

Deininger, K., \& Squire, L. (1998). New ways of looking at old issues: Inequality and growth. Journal of Development Economics, 57(2), 259-288.

Dell, M. (2005, December). Widening the border: The impact of Nafta on female labor force participation in Mexico. Oxford University WP.

Espino, A., \& Azar, P. (2007). Cambios de la política económica desde una perspectiva de género: de la sustitución de importaciones a la apertura económica. 1er Congreso Latinoamericano de Historia Económica, Montevideo.

Fleitas, S., \& Román, C. (2010). Evolución de la población económicamente activa en el siglo XX:un análisis de la estructura por por sexo, edad y generaciones. Boletín de Historia Económica, No. 9.

Gálvez, T. (2001). Aspectos económicos de la equidad de género. CEPAL.

Garcia Cuellar, R. (2001). Essays on the effects of trade and location on the gender gap: A study of the Mexican labor market. Doctoral Dissertation, Harvard University, Economics Department.

Goldin, C. (1994). The U-shaped female Labor force function in economic development and economic history. NBER Working Paper \#4707. 
Goldin, C. (2000). Labor markets in the twentieth century. In S. Engerman \& R. Gallman (Eds.), The Cambridge economic history of the United States (pp. 549-624). Cambridge: Cambridge University Press.

Goldin, C. (2006). The quiet revolution that transformed women's employment, education, and family. The American Economic Review, 96(2), 1-21.

Higgins, M., \& Williamson, J. G. (2002). Explaining inequality: The world round: Cohort size, kuznets curves, and openness. Journal of Southeast Asian Studies, 40(30), 268-302.

Hoyos, A., \& Nopo, H. (2010). Evolution of gender gaps in Latin America at the turn of the twentieth century. IDB Working Paper Series.

Joekes, S. (1999). A gender-analytical perspective on trade and sustainable development. In UNCTAD, Trade, sustainable development and gender (pp. 33-59). New York and Geneva: UNCTAD.

O’Neill, J., \& Polachek, S. (1993). Why the gender wages gap narrowed in the 1980's. Journal of Labor Economics, 11(1), 205-228.

Oaxaca, R. (1973). Male-female wage differentials in urban labor markets. International Economic Review, 14, 693-709.

Olivetti, C. (2013). The female labor force and long-run development: The American experience in comparative perspective. National Bureau of Economic Research.

Pampel, F. C., \& Tanaka, K. (1986). Economic development and female labor force participation: A reconsideration. Social Forces, 64(3), 599-619.

Psacharopoulos, G., \& Tzannatos, Z. (1989). Female labor force participation: An international perspective. World Bank Research Observer, 4(2), 187-201.

Reyes Campo, N. (2012). Women wages and the gender gap during the import substitution industrialization in Chile. Barcelona: Universidad de Barcelona.

Sarasúa, C., \& Gálvez, L. (2003). Privilegios o Eficiencia, Mujeres y Hombres en los Mercados de Trabajo. In C. Sarasúa, \& L. Gálvez (Eds.), Introducción. ¿Privilegios o eficiencia? Mujeres y hombres en el mercado de trabajo (pp. 9-33). Alicante: Universidad de Alicante.

Sala-i-Martin, X. (2003). The disturbing "Rise” of global income inequality. NBER WP.

Samuelson, P. (1948). International trade and the equalization of factor prices. The Economic Journal, 58, 163-184.

Schultz, T. P. (1990). Women's changing participation in the labor force: A world perspective. Economic Development and Cultural Change, 38, 457-488.

Seguino, S. (2000). Gender inequality and economic growth: A cross-country analysis. World Development, 28(7), 1211-1230.

Todaro, R. (2004). Chile under a gender lens: from import substitution to open markets, Unrisd.

Tzannatos, Z. (1999). Women and labor market changes in the global economy: Growth helps, inequalities hurt and public policy matters. World Development, 27(3), 551-569.

World Bank. (1995). World Development Report 1995: Workers in an integrating world. Oxford University Press: New York.

María Magdalena Camou has a Ph.D. in Economic History from Universidad de la República, Uruguay, where she is a Professor in the Economic and Social History Program. Her main research lines are labor markets during industrialization, international comparative wages, living standards, and gender inequality. She is one of the authors and editors of Gender Inequalities and Development in Latin America During the Twentieth Century and several other books and articles.

Silvana Maubrigades is a Sociologist. She holds an M.A. in Economic History and is a Ph.D. candidate in Social Sciences with mention in Economic History from Universidad de la República, Uruguay. She is a professor at the Economic and Social History Program at the Social Sciences Faculty in the same university. Her main research fields are gender, labor market, wage inequality, and development. 


\title{
Fiscal Redistribution in Latin America Since the Nineteenth Century
}

\author{
Leticia Arroyo Abad and Peter H. Lindert
}

\section{Introduction}

Economic historians now know that inequality has not been a constant feature of the Latin American landscape since the original colonization by Spain and Portugal. Rather it has fallen and risen several times over the two centuries of independence, and the dawn of the twenty-first century has also brought a welcome slight retreat from extreme inequality. ${ }^{1}$ Why the movements, and why the differences between countries?

Fortunately, the dawn of this century has brought not only a slight reversal of earlier inequality trends in Latin America, but also a blossoming of research on the sources of income inequality in the region today, lead by the World Bank and other international development agencies. ${ }^{2}$ This impressive wave of research has delivered an important part of what was promised by a World Bank call to arms back in the 1970s. Under the Presidency of Robert McNamara, a Bank team co-published the often-cited Redistribution with Growth, outlining how developing countries could produce more and share it more equally, and generating research momentum on these themes. Redistribution told a parable of some wise pro-growth egalitarians (Korea, Sri Lanka, Taiwan), in contrast to four Latin American countries that failed

\footnotetext{
${ }^{1}$ See in particular Frankema, Has Latin America Always Been Unequal? (2009); Williamson (2010); the entire special issues of Revista de Historia Económica, 28, 2 (2010); and Abad (2013a, b). See also the downloadable data set on inequality from around the world, 1820-2000, referenced and explained in van Zanden et al. (2014).

${ }^{2}$ See DeFerranti et al. (2004), Lindert et al. (2006), Braceda et al. (2009), ECLAC (2010, 2012, 2014), Lustig et al. (2011), the World Bank's Aspire database, Public Finance Review (2014), and the Commitment to Equity project led by Professor Lustig.
}

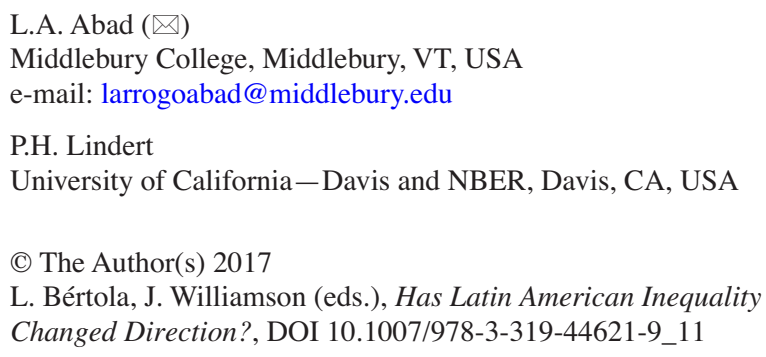


to follow this True Path. Brazil, Mexico, Panama, and Peru were characterized by some of the world's sharpest inequalities and not particularly strong growth. In later years, ECLAC $(1990,1992)$ and the World Bank study Inequality in Latin America: Breaking With History? explored the same questions more deeply. ${ }^{3}$

Did government fiscal preferences add to the inequality? That is, what distributional role has been played by movements in government fiscal policy, versus such market forces as changes in technological bias, trade expansion, shifts in labor supply, and shifts in the rate of private accumulation of human capital? For most of the two centuries of post-colonial history, inequality movements must have been caused largely by the ebb and flow of such larger forces outside of government, for the simple reason that government remained so small. Yet government's share of Latin American economies grew across the twentieth century and into the twenty-first, causing us to wonder how and when the region's regimes became "progressive" or "regressive" in their fiscal redistribution, breeding equality, or inequality.

The spate of recent studies suggests that countries' income inequalities in Latin America now differ as much from each other, and from inequalities in OECD countries on other continents, in their fiscal redistribution as in the pre-fisc original incomes they get from market forces. Among data-supplying countries, the Latin American countries stand out as the most unequal countries in terms of people's final incomes, partly because they have more unequal original incomes and partly because their governments redistribute less. ${ }^{4}$ Why have they had so little progressive redistribution lately, even after the much-heralded retreat from peak inequality? And has the same been true for a century or longer?

This chapter's strategy exploits the deep analysis of the twenty-first century distributional impact of fiscal policy, and uses it to explore episodes since the nineteenth century to initiate a history of fiscal incidence. We offer these tentative results:

(1) Social spending has accelerated in the postwar era: Tax-funded social spending has risen throughout the region since the 1980 s. $^{5}$

\footnotetext{
${ }^{3}$ Chenery et al. (1974), ECLAC (1990, 1992), and DeFerranti et al. (2004). Within the Redistribution with Growth study, most relevant for present purposes are Montek Ahluwalia's chapters on inequality and the policies for alleviating it (Chaps. 1 and 4). Its brief coverage of Cuba as of the early 1970s (pp. 262-268) identified this as an egalitarian experiment, but was guarded and inconclusive.

${ }^{4}$ This statement is based on a comparison of pre- and post-fisc inequalities in several countries in the first decade of this century. The sources are Lustig et al. (2011) for five Latin American countries, Buchele et al. (2013) for Uruguay, Sauma and Trejos (2014, Table 3, benchmark case) for Costa Rica, and Wang et al. (2012) for the rest. See these for the assumptions regarding fiscal incidence.

The estimates we are comparing here refer to the year 2004 with the following exceptions: Belgium-year 2000; Australia-2003; Sweden, France, and Israel-2005; Bolivia-2007; Chile-2008; Costa Rica 2010 and Argentina, Brazil, Peru, and Uruguay-2009. For alternative measures of the primary and final gini coefficients, 1979-2011, see Solt $(2009,2014)$.

${ }^{5}$ Like many of the statements in the literature and in this paper, this one must be read with the proviso "except for Cuba". Most comparisons have been forced to keep Cuba off to one side, for want of sufficient data. We will note Cuban results where we can.
} 
(2) The region invests little in its future today: Latin America redistributes less toward future generations than do other regions. Rather, the region is one of those, like Mediterranean Europe, where redistribution tilts away from investing in future generations and favoring the elderly in privileged formal sectors.

(3) It has invested relatively little in infrastructure and education ever since independence: Relative to other regions at comparable income levels, Latin America has invested less in its younger generations since the nineteenth century, and since the middle of the twentieth century it has favored its privileged seniors than other regions have done. Even before the 1990s, when public education was the main form of social spending, less was committed to mass education than in East Asia, East Europe, or the Middle East at similar levels of average income. In what follows we note some important historical exceptions to this rule.

(4) Progressivity has been meager. Aside from the Cuban Revolution, governments have redistributed only modestly, preferring a conflicted mix of "redistribution to the rich and the poor."6

(5) The rise of non-contributory public pension subsidies to retirees from the formal sectors stands out as a path-dependent legacy that will continue to retard progressivity and public investment. A telltale sign of the strength of this commitment is the design of the pension "reform" in Pinochet's Chile and the countries that sought to emulate it later.

(6) Chile has stood out, as a volatile, and initially regressive, redistributor since 1973. Redistributive policy was visibly regressive in the Pinochet era, both on the expenditure side and with a seemingly regressive tax structure. Yet since 1990 the net impact of its fiscal redistribution was slightly progressive in conventional Gini measures, because it benefited the rich less than their share of pre-fiscal income.

(7) Military autocracies differed in their redistributive strategies. Military rule periods did not affect redistribution in the same way in all countries. Unlike Chile (1973-1989), the junta in Uruguay (1973-1985) left the tax and social spending mix alone, at low absolute levels. Argentina's military rule (1976-1983) consolidated the social security system for most of the period, whereas Peru's military regime (1968-1980) was quite progressive.

(8) Human investments have brought more durable, though delayed, gains relative to transfers, both in the growth of GDP and in holding down inequality. In particular, Costa Rica has gained ground against Uruguay by emphasizing primary and secondary education over pensions.

(9) Social spending has been not only volatile but also pro-cyclical. Relative to GDP growth, annual changes in real social spending are at least two times or more variable. Moreover, they tend to follow the swings in economic activity. ${ }^{7}$

\footnotetext{
${ }^{6}$ This expression is borrowed from the title of Lindert et al. (2006).

${ }^{7}$ Clemens et al. (2007) have identified this pattern for 1990-2000s.
} 


\section{Strategies for Tracing a History of Fiscal Incidence}

Starting from the fiscal mix of this century and the distributional impacts on each household income quintile, we explore the implications of the historical movement in the fiscal mix. Like previous studies of fiscal incidence, ours uses imperfect and incomplete measures to provide insights into differences in progressivity and regressivity. These limitations are so strict that the fiscal incidence calculations are useful only as plausible suggestions about the direction of effect and the general orders of magnitude. As public finance textbooks warn their readers repeatedly, one should never imagine that all the possible effects of a particular set of budgetary flows have been worked out.

To be true to real-world budgetary processes and to pose interesting counterfactuals, one must weigh fiscal incidence on both the revenue side and the expenditure side, using a consistent definition of fiscal neutrality on both sides. Most studies have failed to do so. On the revenue side, studies of the progressivity (or regressivity) of taxation have typically assumed that the revenues are spent in proportion to pre-fisc original income, a rare outcome. On the expenditure side, studies of expenditure progressivity typically assume that the expenditures are financed by taxes that are fixed per person, another rare outcome. Real-world budgetary processes adjust revenues and expenditures together, requiring a two-sided measure of progressivity.

In Latin American history, the expenditure side of the fiscal coin reveals more about differences between countries, and also yields more data. On the revenue side, Kenneth Sokoloff and Eric Zolt have noted a strikingly consistent regional pattern: Latin America, more than any other region, relied on taxing domestic consumption, with little or no direct tax on individual incomes or property. Latin America also tended to concentrate fiscal authority more in the hands of the central government (Sokoloff and Zolt 2006). In what follows, we extract most of the information on differences in progressivity or regressivity from differences in the size and composition of social expenditures, rather than from differences in taxes or non-social expenditures.

To pose sensible counterfactuals about countries' fiscal incidence, the analysis should also make international comparisons. There should be little interest in comparing the actual fiscal patterns with the zero-government counterfactual, as in the presentation of most estimates. Rather we should compare governments' fiscal incidence with those of well-documented real-world alternatives, such as Chile or the USA. In our overview of the longer history of redistribution, we will take up the Chilean case first, and compare other countries to Chile.

\subsection{Redistribution Through Each Year's Social Spending and Taxes}

Governments channel their tax revenues into three kinds of expenditures: social spending, non-social spending, and debt reduction. The three have very different effects on the distribution of income. Estimating such effects requires figuring out 
which levels in the income ranks get more or less from each kind of expenditure and the revenues that back it.

The first effect is that of a given social spending budget. That is the traditional focus of much of the fiscal incidence scholarship, and it has been updated skillfully and energetically in the recent literature on Latin America. We shall pursue the same theme at length, taking care to include public spending on health and education as well as social transfers, while also incorporating tax incidence into the calculations of progressivity or regressivity when we can.

To define our measures of impact on the rich, the middle, and the poor, we start with a budget identity for government:

$$
\Sigma S_{i t}+\Sigma N_{j t}-D_{t}=\Sigma R_{k t}
$$

Here $S_{i t}=$ the amount of the $i$ th kind of social spending in time period $t$. Similarly, $N_{j t}$ is the amount of the $j$ th kind of non-social spending (general administration, police, the military, infrastructure, and so forth), and $R_{k t}$ is the $k$ th kind of government revenue (income tax, tariffs, other taxes, or income from government enterprises and assets). The revenues can cover less than the expenditures to the amount of $D_{t}$, this time period's government budget deficit. All magnitudes are in current prices. Later, to add economic meaning, they will be converted into per-household magnitudes and divided by national product or by an income class's average income.

The budget identity leads to measures of redistribution by following how the direct effects of spending and taxes on household incomes are divided among the five quintile ranks, from the poorest twenty percent of households $(q=1)$ to the richest $(q=5)$. Like most of the literature on fiscal incidence, we humbly acknowledge-and then ignore-all the serious reasons why these simple "flypaper" measures of redistribution fail to measure the full range of effects, including generalequilibrium effects through factor markets. To allocate each kind of social spending, and the taxes paying for it, across the income ranks, we define the benefits minus the costs for each quintile, or $B_{n e t, q i}$, as

$$
B_{n e t, q i t}=S_{i t}\left(b_{q i t}-c_{q i t}\right),
$$

where the five quintiles' shares of benefits add up to one, as do their shares of the revenue costs $\left(\sum_{q} b_{q i t}=1=\sum_{q} c_{q i t}\right) \cdot 8$

\footnotetext{
${ }^{8}$ Each is the result of two components that are not separated in our paper. One is the distribution of "benefits per recipient" in each quintile, and the other is "coverage," i.e., the number of persons in the quintile who receive any benefits at all. Incompleteness of coverage looms large in Latin America, and therefore affects the progressivity greatly: "Overall, about half of the population in LAC is not covered by any public transfer. Within the region, however, there is significant variation in coverage, with only $23 \%$ of Peruvian citizens not receiving any public transfer as compared with $73 \%$ of Mexicans without benefits" (Lindert et al. 2006, p. 23). Similarly, for each on the tax side, a quintile's tax burden is a combination of the tax collected person paying and the share paying any at all.
} 
To explore "effects" or "impacts," one must return to the familiar question of counterfactuals: "the effect of the observed budget-relative to what?" As we have already mentioned, the usual analysis unrealistically implies a zero-government alternative, because it tries to assign effects to the entire budget. To pose more realistic counterfactuals, we shrink the scale of the comparisons. We consider the social programs one by one, posing the counterfactual of removing that one real-world social program and the revenues that financed it, while leaving other social programs intact. Imagining a zero option for that one social program is not so unrealistic, since Latin America had done without most of these small social programs until just recently.

The other dimension of our implicit counterfactual about each social program hides within our phrase "and the revenues that pay for it." Which revenues? There is no point in imagining that all government revenues are at stake, since their amount far exceeds the social expenditures under discussion. Lacking any sound econometric estimates of which revenues increased at the margin when a given social program was introduced and expanded, we make a reasonable simplifying assumption about the revenues that would not have existed in the absence of each social program: For most of our historical measures, we assume that the same mix of revenue types would have held at the social program margin as we observe on the average. Thus if income tax were $16 \%$ of all government revenue, state monopoly proceeds were $6 \%$, indirect taxes were $70 \%$, and tariffs were the other $8 \%$, these same shares would be assume to apply to the scaled-down amount of the social expenditures in question. We do not assume any deficit finance of the social programs, in order to keep the issue of the deficit separate. ${ }^{9}$

To give the measures meaning as commitments to redistribution shares of income, we need to divide the absolute net benefit measures of $B_{\text {net,qit }}$ by an income denominator, also expressed in current prices. For convenience and brevity, we divide all quintile groups' benefit measures from social spending, whether gross or net of taxes, by the same common GDP denominator. We then compare such impacts on rich, middle, and poor income groups..$^{10}$

One other shortcut is dictated by data limitations. The net benefit measures change over time in response to changes in three components of any social program: the program's existence in a given year; its size as a share of national income; and its target efficiency, namely the extent to which it redistributes in favor of a particular group, usually the poor. We cannot pursue historical changes in the target efficiency of the social spending programs. Their history is just too complex and under-documented. Accordingly, our journey back into the redistributive history of social spending can only follow changes in the existence and size of each category

\footnotetext{
${ }^{9}$ In later writings, we will apply the same assumption to the revenues that finance non-social spending, such as military or infrastructure spending.

${ }^{10} \mathrm{~A}$ more common procedure is to divide all absolute redistributions to or from an income group by that same group's income. To trace a history of such measures, however, requires a running set of income distributions. No such time series is available before mid-twentieth century, apart from occasional benchmark years. The one virtuous exception consists of Javier Rodriguez Weber's time series on Chilean income inequality.
} 
of social spending, with the restrictive assumption that a given program had the same target efficiency in the past that it has today. This retreat is regrettable in large categories of social spending and taxation that kept the same name but shifted their progressivity or regressivity over time. As it happens, the Latin American history of fiscal redistribution limits the historical errors we commit by not following the changes in target efficiency over time. Many of the most progressive social programs did not exist before the 1980s, and have changed only a bit since. Also, the sizes of the individual social programs themselves capture most of the redistribution. We will also limit the loss from not knowing target efficiency by breaking up the historically dominant category of social spending, namely public education, into primary and secondary and tertiary education, which offer very different rewards to the different income ranks.

Fixing the target efficiency of social programs (again, the $i$ 's) at their present-day patterns means that our absolute measures of net fiscal benefits for any income class $(q)$ in years past (the variable $t$ 's) will be

$$
B_{n e t, q i t}=S_{i t}\left(b_{q i T}-c_{q i T}\right),
$$

where the " $T$ " subscript signals that the redistributive patterns ( $b$ 's and $c$ 's) are those from "today," usually a year at the start of the twenty-first century. In plainer words, our calculations of the fiscal incidence on different income classes will repeatedly ask The Question about any given year in the past:

The Question: How would the amounts of social spending programs, and the extra taxes that paid for them, have affected the incomes of the top, middle, and poorest income classes in that past year, if the benefits of those social programs, and those extra taxes, were distributed between income classes the way they are today?

In what follows we take advantage of the new information on how fiscal impacts are divided among quintiles to look not just at the movements of redistribution between rich and poor, but between rich and middle and poor, to explore the relationship of the "middle-income class" to the observed fiscal redistribution. When did the fiscal climate favor, or disfavor, the middle-income ranks relative to those at the top and bottom of society? To supplement the usual emphasis on overall inequality between rich and poor, we will break it into two parts, looking separately at movements in the fiscal treatment of the rich versus middle-income groups (top quintile vs. middle quintile) and at movements in the fiscal treatment of the middle and poorest groups (middle quintile vs. bottom quintile).

\subsection{Non-social Expenditures and the Deficit: Investment and Redistribution Over Time}

It would be tempting to explore how the different income ranks are affected by those other two kinds of public uses of funds: the government's non-social expenditures ( $N \mathrm{~s}$ in place of $S \mathrm{~s}$ ), or to the overall budget surplus. Unfortunately, the paucity of 
data on these incidences prevents our pursuing them in depth, and fixes our focus mainly on social spending and the revenues that pay for it.

Still, there is one major division within the non-social spending that has powerful redistributive meaning and is easy to document. Some kinds of non-social spending are investments that will clearly raise the incomes of future generations. If they are paid for by current taxes, these redistribute from older to younger generations. The most obvious examples are such infrastructure investments as transportation structures, public buildings, science centers, and experiment stations. Other kinds of non-social spending have a more questionable claim to being investments in future generations. Running a budget deficit similarly redistributes from future generations toward the current generation. While such inter-generational redistribution is not at all the usual focus of the now-conventional studies of "fiscal redistribution" within a single year, the inter-generational issue proves to have been a distinctive problem for Latin America, and we must confront it first, before launching a longer exploration of the redistributions that play out completely within 1 year.

\section{Today's Redistributive Patterns in Latin America}

The region redistributes income in distinctive ways. Before turning to today's richly documented patterns in social expenditures, let us first stay with the theme of the inter-generational redistributions implicit in the patterns of recent non-social spending. The simple redistributive pattern in non-social expenditures is one that carries over to the shares of human investments in social spending.

\subsection{Low Investment in Future Generations}

Perhaps the most pervasive kind of redistribution between parts of society in modern peacetime is the redistribution between present and future generations of adults. Governments, businesses, and households all decide what share of their current incomes should be borrowed from the future or invested in it. Borrowing from the future may or may not raise inequality, now and later, depending on economic growth and how the borrowed funds are spent.

Was Latin American policy worse at investing in the future than policy in other continents? When? What roles were played in investment setbacks like the Latin American debt crisis of 1982? And was the failure to invest especially bad in income-leveling types of human investments, such as public education for the masses?

The investment component of government spending is notoriously difficult to separate out in the data for most countries, blocking our view of how Latin America contrasts with other regions in public non-social investment. Our view is also clouded by the long-standing difficulty in resolving how private investment in the 


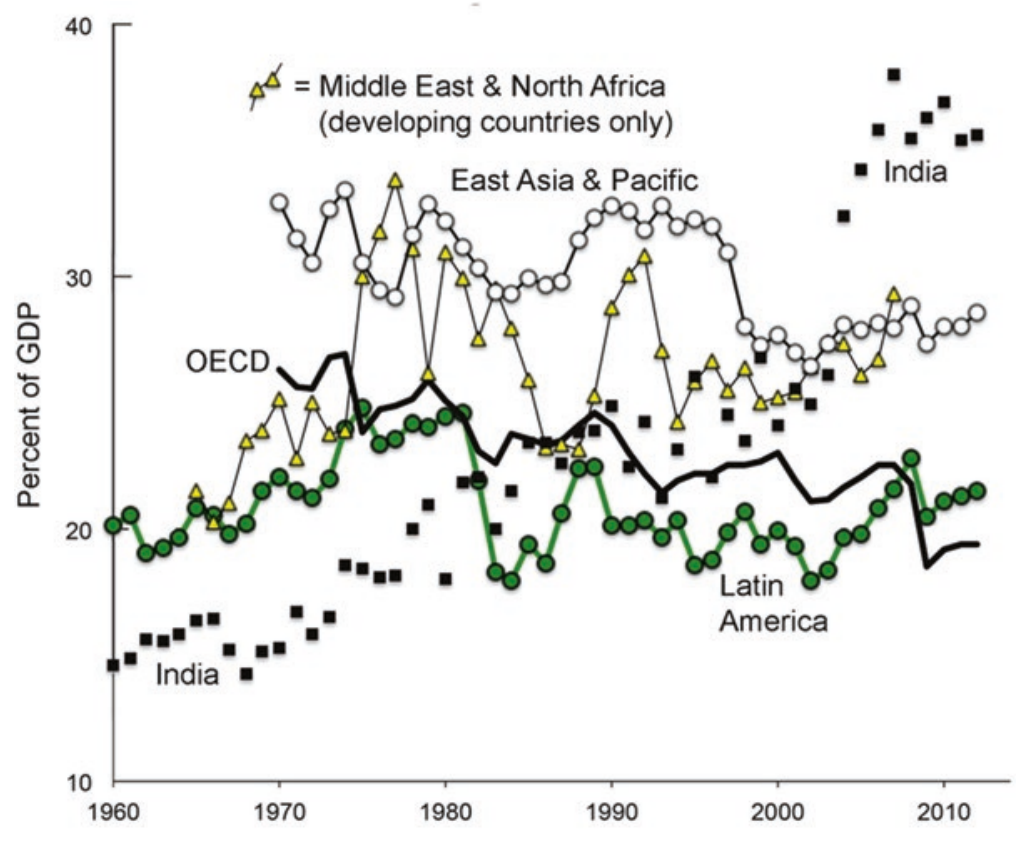

Fig. 1 Capital formation as share of GDP, World Regions, 1960-2012

future is affected by taxation and by government capital formation. Our best short route is to look at the official, and imperfect, measures of total private and public formation of non-human capital in the national product accounts. Taking this one step delivers a much clearer view of something distinctive about the region.

The best-known measure of a region's investing in the future is the share of national product that is channeled into forming non-human capital, both by private parties and by government. Ever since the 1960s we have been able to compare the private investment share for Latin America with the rest of the world's shares, with the results shown in Fig. 1. Latin America has consistently shown less sacrifice of current consumption for accumulating future assets than the world as a whole, and particularly less than East Asia and the developing countries of the Middle East and North Africa. ${ }^{11}$ Eastern Europe and Central Asia have also invested greater shares than Latin America, even in the austere 1990s, after the collapse of the Soviet Union and central planning. Granted, India had a lower investment share than Latin America from the 1960s to the debt crisis of the 1980s, when Latin America's investment rate was briefly the lowest among large regions; and granted, Africa South of the Sahara became the lowest-investing region from the late 1980s to the first decade of the twentieth century. Through it all, however, Latin America remained a below-average investor in future structures and equipment.

\footnotetext{
${ }^{11}$ The low investment share has already been underlined by United Nations, ECLAC (2012, p. 117).
} 


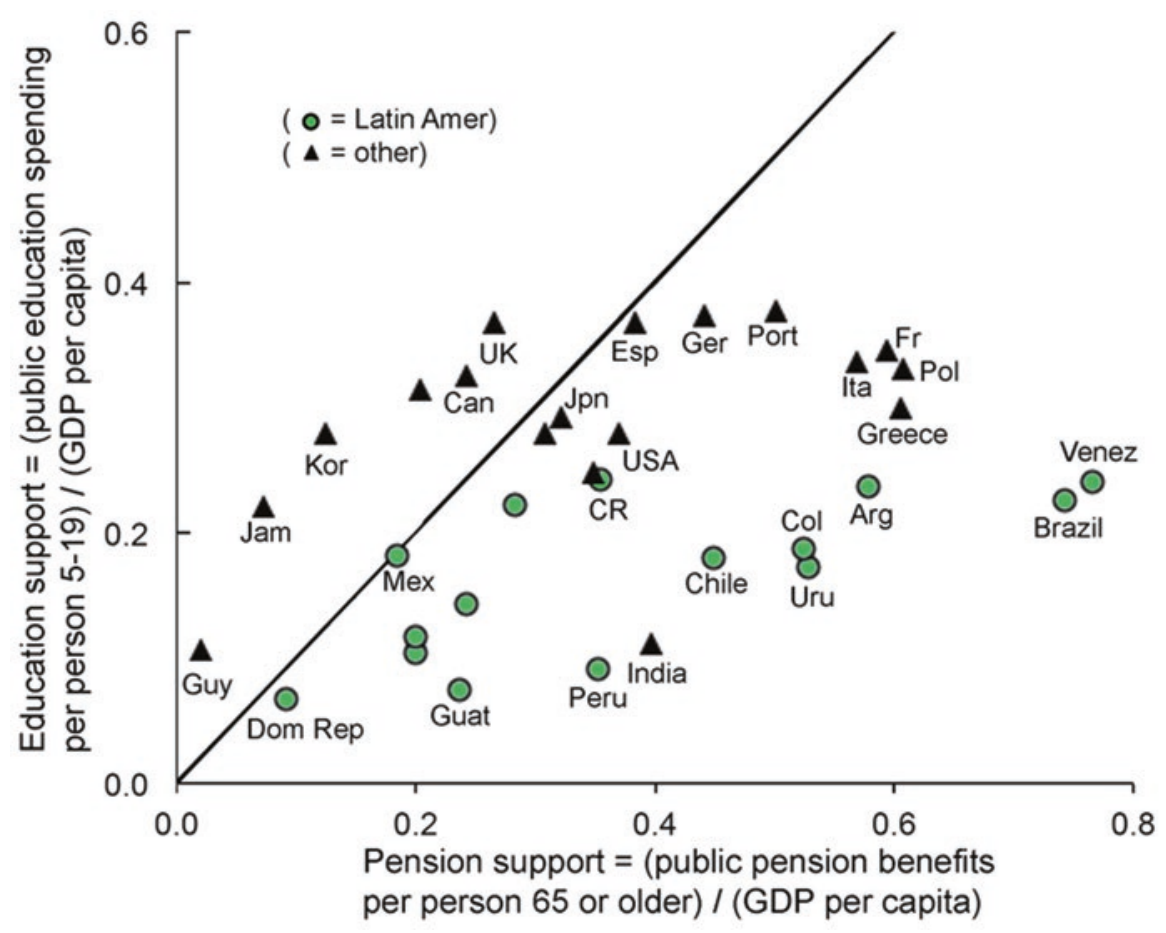

Fig. 2 Supporting pensions vs. education: Latin America vs. others, 2010

The region also invests little in human form. A cornerstone of modern growth has always been education in human skills and health. The traditional mechanism used by governments to promote such human development has been tax-based expenditures on formal education. Ever since the dawn of publicly funded mass education in Western Europe and its English-speaking offshoots in the nineteenth century, Latin American countries have lagged behind other regions, even where they had comparable incomes per capita and similar capacity for raising government revenue. ${ }^{12}$ Figure 2 and Table 1 underline this point with a present-day global snapshot. Latin American countries commit less to each child's public education than other countries, where commitment is reflected in the generosity of funding per schoolage child and the ability to pay for it is reflected in GDP per capita. ${ }^{13}$ Some countries

\footnotetext{
${ }^{12}$ For a quantitative historical overview of the region's disinclination to invest public money in mass schooling since 1870, see Lindert (2010). In terms of schooling outputs, its lagging behind all regions other than South Asia in the education attainment of adults since 1950 has been shown in Reimers (2006), Székely and Montes (2006, pp. 636-641), and Cohen and Soto (2007).

${ }^{13}$ In general, having lower average education expenditure per child of school age also tends to be correlated with having greater inequality in education inputs and education outcomes. To see this tendency within Latin America, compare the figures in Table 1 with the measure of inequality in educational attainment found in ECLAC (2014, pp. 78-79).
} 
Table 1 Supporting pensions versus educating the young: Latin America versus other countries, 2010

\begin{tabular}{|c|c|c|c|c|}
\hline & & & \multicolumn{2}{|l|}{ Support ratios } \\
\hline & \multicolumn{2}{|c|}{$\begin{array}{l}\text { Public spending as } \\
\text { a percent of GDP } \\
\text { pensions education }\end{array}$} & $\begin{array}{l}\text { Pension spending per } \\
\text { person } 65-\text { up, } / G D P \\
\text { per capita }\end{array}$ & $\begin{array}{l}\text { Education spending per } \\
\text { person 5-19/GDP per capita }\end{array}$ \\
\hline \multicolumn{5}{|l|}{ Latin America } \\
\hline Argentina & 7.4 & 5.8 & 0.58 & 0.24 \\
\hline Bolivia & 1.5 & 7.6 & 0.28 & 0.22 \\
\hline Brazil & 6.2 & 5.8 & 0.74 & 0.23 \\
\hline Chile & 5.0 & 4.2 & 0.45 & 0.18 \\
\hline Colombia & 3.5 & 4.8 & 0.53 & 0.17 \\
\hline Costa Rica & 2.8 & 6.3 & 0.35 & 0.24 \\
\hline Dominican Rep & 0.7 & 2.0 & 0.09 & 0.07 \\
\hline Ecuador & 1.8 & 4.2 & 0.24 & 0.14 \\
\hline El Salvador & 1.7 & 3.5 & 0.20 & 0.11 \\
\hline Guatemala & 1.2 & 2.8 & 0.24 & 0.08 \\
\hline Guyana & 0.1 & 3.7 & 0.02 & 0.10 \\
\hline Jamaica & 0.7 & 6.4 & 0.07 & 0.22 \\
\hline Mexico & 1.4 & 5.2 & 0.18 & 0.18 \\
\hline Paraguay & 1.2 & 3.8 & 0.20 & 0.12 \\
\hline Peru & 2.5 & 2.7 & 0.35 & 0.09 \\
\hline Uruguay & 8.8 & 4.2 & 0.53 & 0.19 \\
\hline Venezuela & 5.0 & 6.9 & 0.77 & 0.24 \\
\hline \multicolumn{5}{|l|}{ Other countries } \\
\hline Australia & 3.4 & 5.8 & 0.20 & 0.31 \\
\hline Canada & 4.2 & 5.5 & 0.24 & 0.33 \\
\hline France & 12.5 & 5.9 & 0.59 & 0.35 \\
\hline Germany & 10.7 & 5.1 & 0.44 & 0.37 \\
\hline Greece & 13.5 & 4.1 & 0.60 & 0.30 \\
\hline India & 2.2 & 3.3 & 0.40 & 0.11 \\
\hline Italy & 14.1 & 4.5 & 0.57 & 0.34 \\
\hline Japan & 8.8 & 3.8 & 0.32 & 0.29 \\
\hline Korea, Rep. & 1.6 & 5.1 & 0.12 & 0.28 \\
\hline Poland & 10.0 & 5.2 & 0.61 & 0.33 \\
\hline Portugal & 10.8 & 5.6 & 0.50 & 0.38 \\
\hline Russian Fed'n & 4.7 & 4.1 & 0.31 & 0.28 \\
\hline Spain & 8.0 & 5.0 & 0.38 & 0.37 \\
\hline UK & 5.4 & 6.2 & 0.27 & 0.37 \\
\hline USA & 6.0 & 5.4 & 0.37 & 0.28 \\
\hline Vietnam & 2.5 & 6.3 & 0.35 & 0.25 \\
\hline
\end{tabular}

Sources and notes for Table 1 and Fig. 2: Public pension expenditures as shares of GDP are taken from Pallares-Miralles et al. (2012, Annexes II and III), and based in turn on the World Bank Pensions Database. The latter source explicitly notes that their pension expenditure data included both contributory and non-contributory pension benefits, contrary to our preference for data on non-contributory only

Government education spending as a percent of GDP, 2010: Unesco 2013 estimates from http:// stats.uis.unesco.org/unesco/TableViewer

UN populations by age group, 2010:http://esa.un.org/wpp/ExcelData/population.htm, accessed 17 May 2013 
are reluctant to support anybody of any age group with taxpayers' money, as in the Dominican Republic or Guyana. Others support their average elderly person quite generously, yet still commit much less to each child of school age, two global extreme cases being Brazil and Venezuela. ${ }^{14}$ Whether the pension money goes to rich retirees or to poor ones is a question to be taken up shortly. The essential point, though, is that the share of income going into educating children for future earning power is lower in Latin America than elsewhere in the world.

\subsection{New Light on the Social Expenditure Side: Today's Redistribution to Rich and Poor}

What is now becoming clear about social expenditures comes to us mainly from some impressive team research efforts in The World Bank, the Inter-American Development Bank, and now the Commitment to Equity project headed by Nora Lustig. ${ }^{15}$ Taking advantage of the international agencies' vast accumulation of household surveys since the 1990s, these teams have been able to allocate the annual benefits from social programs among the different parts of the income spectrum, from the richest quintile (top $20 \%$ ) down to the poorest.

Table 2 displays what the international research teams have found about the "progressivity" or "regressivity" of distribution through different social expenditures in the decade 2000-2009. Our usual yardsticks for progressivity and regressivity of a public expenditure lie in the range between two popular assumptions about the taxes that pay for them. One assumption is an equal absolute tax, or foregone equal subsidy, on every household. This "poll tax" assumption divides the "clearly progressive" social programs of Table 2, in the left-hand column, from all the rest. Programs listed there on the left would prove to be progressive even if they were paid for by a (famously regressive) poll tax, a fixed amount of tax on each household. A more popular assumption, used by economists to define fiscal neutrality, is a flat percentage tax on all income or expenditure. This assumption divides the "clearly regressive" social programs, on the right-hand side of Table 2, from all the rest. The regressive ones are so tilted toward high-income recipients that they distribute benefits even more unequally than the distribution of pre-fisc original incomes, meaning that the distribution of final post-fisc incomes is even more unequal than the original distribution.

\footnotetext{
${ }^{14}$ Here, as will happen again in what follows, the measure of pensions is not the "redistributive" measure we seek. Rather we seek the amount of "non-contributory" payments for pensions, at the expense of the general taxpayer. All too often the available measures include pension benefits that are matched by the contributions of the employed, mixing such self-insurance in with true redistribution. Nonetheless, the available measures offer the right qualitative contrasts, even when they overstate the redistributive part of public pensions.

${ }^{15}$ DeFerranti et al. (2004), Lindert et al. (2006), Braceda et al. (2009), Lustig et al. (2011), Buchele et al. (2013), Sauma and Trejos (2014), and Public Finance Review (2014).
} 
Table 2 Progressive and regressive social spending programs, Latin American countries, 2000-2010

\begin{tabular}{|c|c|c|c|c|}
\hline & & \multicolumn{3}{|c|}{ Redistribution result (see notes for definitions) } \\
\hline \multicolumn{5}{|c|}{ "It depends": Regressive in \$ } \\
\hline & & Clearly progressive & $\begin{array}{l}\text { Progressive in } \\
\text { income shares }\end{array}$ & $\begin{array}{l}\text { Clearly } \\
\text { regressive }\end{array}$ \\
\hline \multicolumn{2}{|c|}{ Pensions, non-contributory part } & $\begin{array}{l}\text { Costa Rica, Chile } \\
\text { (PASIS) }\end{array}$ & $\begin{array}{l}\text { Chile (non- } \\
\text { PASIS), Mexico }\end{array}$ & $\begin{array}{l}\text { Colombia, } \\
\text { Guatemala, } \\
\text { Mexico }\end{array}$ \\
\hline Education & Pre-primary & $\begin{array}{l}\text { Bolivia, Brazil, } \\
\text { Colombia, Costa Rica, } \\
\text { Mexico, Peru, Uruguay }\end{array}$ & & \\
\hline " & Primary & $\begin{array}{l}\text { Argentina, Bolivia, } \\
\text { Brazil, Costa Rica, } \\
\text { Mexico, Peru, }\end{array}$ & Guatemala & \\
\hline$"$ & Secondary & $\begin{array}{l}\text { Brazil, Costa Rica, } \\
\text { Peru }\end{array}$ & $\begin{array}{l}\text { Argentina, } \\
\text { Bolivia }\end{array}$ & \\
\hline$"$ & Tertiary & & $\begin{array}{l}\text { Bolivia, Brazil, } \\
\text { Costa Rica, } \\
\text { Mexico, Peru, } \\
\text { Uruguay }\end{array}$ & \\
\hline Health & & Uruguay, Mexico & Brazil & \\
\hline \multicolumn{5}{|c|}{ Consumption subsidies } \\
\hline$"$ & Food aid & $\begin{array}{l}\text { Costa Rica, Peru, } \\
\text { Uruguay }\end{array}$ & & \\
\hline$"$ & $\begin{array}{l}\text { Gas, electricity } \\
\text { subsidies }\end{array}$ & Bolivia & Mexico & \\
\hline$"$ & Housing & Mexico (some) & Mexico (some) & \\
\hline ” & $\begin{array}{l}\text { Transportation } \\
\text { subsidies }\end{array}$ & & Argentina & \\
\hline$"$ & $\begin{array}{l}\text { Agricultural } \\
\text { subsidies }\end{array}$ & & & Argentina \\
\hline$"$ & Airline subsidies & & & Argentina \\
\hline$"$ & Water, potable & Chile & & \\
\hline Family aid & & $\begin{array}{l}\text { Argentina, Brazil, } \\
\text { Colombia, Chile, Peru, } \\
\text { Uruguay }\end{array}$ & Bolivia & \\
\hline $\begin{array}{l}\text { Underemployment } \\
\text { compensation }\end{array}$ & & Argentina, Mexico & Brazil, Chile & \\
\hline $\begin{array}{l}\text { Conditional cash } \\
\text { transfers (CCTs), }\end{array}$ & & Argentina, Brazil, & & \\
\hline $\begin{array}{l}\text { mostly child } \\
\text { related }\end{array}$ & & Chile, Mexico & & \\
\hline
\end{tabular}

Sources and notes

The sources = Lindert et al. (2006), Lustig et al. (2011), Sauma and Trejos (2014, Fig. 6) and Buchele et al. (2013)

The definitions of redistribution results are

- "Clearly progressive" = Delivers more dollars per household to the poorer (lower quintiles) than to the richer. Thus it would be progressive even if financed by a poll tax 
Table 2 (continued)

- "It depends"=Regressive in \$, progressive in income shares=Fewer net dollars per household go to the poorer, but they receive a greater percentage of income than do the rich. It would be regressive if financed by a head tax, but progressive if financed by a flat percentage tax on income

- "Regressive" = The distribution of benefits favors the rich even more than the distribution of original (pre-fisc) income

Some cases that straddle the border between "clearly progressive" and "it depends" are some programs that work out as nearly flat in absolute $\$$ terms

- Argentine water and sanitation aid, and PAMI health

- Bolivia pensions

- Costa Rica health care and hospitalization

- Peru's two health subsidy programs (clearly progressive SIS health vs. ESSALUD health), and

- Uruguay secondary education

The results have rightly been summarized as "redistribution to the poor and the rich" among Latin America's social expenditure programs since around the year 2000. Many programs were meant to be progressive, shifting income from rich toward poor; yet some programs may not do so, and a few programs clearly redistribute toward the rich. The most clearly progressive programs are basic family assistance and "conditional cash transfers" (CCTs). The latter involve giving cash to poor parents (usually mothers) conditional on proof that their children were attending school and getting essential health care. The idea of means-tested CCTs was successfully invented and implemented in Brazil (bolsa familia, an extension of the previous bolsa escola) and Mexico (oportunidades, previously progresa). The clearly progressive CCTs have diffused to other countries in Latin America and to other continents.

In the case of public subsidies to education, the progressivity of subsidies depends on the level of education. Having the taxpayers pay for primary education clearly helps out lower-income families in nearly every country studied in the recent literature on redistribution. Yet government subsidies to tertiary education, such as university, are often not progressive. The students getting the subsidies tend to be from better-off families than the average taxpayers, given that most taxes in Latin America are levied on items of mass consumption. Thus the progressivity or regressivity subsidies to tertiary education "depends," as shown in Table 2, on whether the government paid for the subsidies by levying the same absolute tax on every household or by levying a fixed share of household income. ${ }^{16}$

Consumption subsidies vary widely between clearly progressive and clearly regressive. The result depends on whether the subsidized commodity is a necessity of life or a luxury. Table 2 illustrates this variability by contrasting the means-tested subsidies on essential foods (Costa Rica, Peru, Uruguay) and water (Chile) with the subsidies on airlines and agricultural estates (Argentina).

The impacts of public pension programs vary greatly, as Table 2 illustrates. Some are found to be clearly progressive (e.g., in Costa Rica, and Chile's PASIS

\footnotetext{
${ }^{16}$ Cases of regressive or near-regressive subsidies to higher education abound throughout the globe. For a pioneering demonstration of the likely regressivity of funding for the University of California, see the widely cited and controversial study by Lee Hansen and Weisbrod (1969).
} 
Table 3 Average net pension subsidies in the early twenty-first century

\begin{tabular}{l|l|l}
\hline Country & Data year & Net pensions subsidy (deficit share of total benefits paid out) (\%) \\
\hline Argentina & 2003 & 57 \\
\hline Brazil & 2003 & 40 \\
\hline Chile & 2002 & 56 \\
\hline Colombia & 2003 & 77 \\
\hline Dom. Repub. & 2001 & 0 \\
\hline Guatemala & 2000 & 25 \\
\hline Mexico & 2002 & 84 \\
\hline Peru & 2004 & 89 \\
\hline
\end{tabular}

Source and notes: The source is Lindert et al. (2006, p. 116)

For Brazil, pensions included (a) the system for private sector workers (RGPS) and (b) a system for public sector workers at the federal and sub-national levels of government (formerly RJU, then called RPPS). The deficit rates on these were averaged

For Chile, the authors used a weighted average of the $94 \%$ deficit on INP benefits and an assumed zero percent deficit on AFP benefits. The figures necessarily exclude military pensions, for which the deficit was a high share

For the Dominican Republic, the general policy was for all pensions to be covered by contributions, even though not on a same-year basis

Mexico $=$ weighted average for IMSS and ISSSTE

Peru $=$ weighted average for SNP and Cedula Viva

pension benefits), while others are clearly regressive in four countries, and still others are in between.

In reaching these conclusions, the research teams have taken special care to isolate the effects of those pension benefits that are truly redistributed from those that are not. What they have isolated in their recent studies, and what we must isolate as much as possible in the historical data, are the non-contributory parts of the public pension programs, the parts paid for by general taxpayers. We need to avoid counting the pension benefits that are paid for by contributions from the employees themselves and by their employers. These are just part of the labor contract, and not redistributions through the government's budgets. ${ }^{17}$ The recent wave of research has revealed some very large average shares of pension benefits not paid for by the recipients or their employers. Table 3 illustrates with recent information on pension program deficits as a share of the benefits paid. The researchers' judgment is that these are true non-contributory (deficit) shares, and not run-downs from past contributions. We return to the issue of pension deficits when exploring the quantitative history of each country's redistributive social spending.

The same kind of research on redistribution through social programs is extending around the globe. Some more global comparisons restricted to developing countries suggest a split in the Latin American degree of inequality reduction recently achieved by social protection and labor market programs. At the regressive end of

\footnotetext{
${ }^{17}$ In the case of pension benefits for government employees, whose employer is also the spender of tax revenues, redistribution cannot be identified just by looking at who paid the pensions. Rather one needs data on the deficit or underfunding of the public employee pensions, i.e., the amounts not covered by employer or employee contributions past or present.
} 
the scale, El Salvador, Paraguay, and Peru are among the few data-supplying countries with slightly regressive programs, ones that actually raise the Gini coefficient of inequality above that for original market incomes (along with Ghana, Rwanda, and Cambodia). Toward the more progressive end of the developing-country ranks are the four Southern Cone countries (ABC and Uruguay). Yet even these redistribute less progressively through their social programs than do the countries of the former Soviet zone.

Latin America's status as an unequal and not-so-progressive region would likely show up in the intergenerational immobility, as distinct from inequality, of its incomes if we had sufficient data comparing income mobility around the world. As a workable proxy for such income mobility, we have a global comparison of intergenerational mobility in years of schooling for the late twentieth century. Of the 42 countries studied, the seven Latin American countries studied had the least educational mobility from parents to children. Clearly, the region has formidable barriers to one's chances of changing ranks in education, given the position on one's parents. ${ }^{18}$ These barriers will soon reappear when we look at the restraints on the progressivity of public education finance.

Why is there so little redistribution in Latin America today? The near-null result has not emerged because of lack of scale, at least not for the whole region. In some Southern countries social spending has surpassed $20 \%$ of GDP, a threshold that could define a "welfare state." Rather, the politically implemented design of social spending and taxes is itself a mix of "redistribution to the rich and the poor," with inconsistent social targets.

\section{How Did This Happen?}

\subsection{The Evolution of Fiscal Mixes Since the Nineteenth Century}

We can easily see the overall net result of fiscal redistribution since Latin American countries gained their independence. Indeed, if we were content to take a single leap back to the historical horizon of 200 years ago, the net result is obvious. Back then there was essentially zero government, as in most countries around 1820 . The net changes over 200 years are simply the present-day patterns we have summarized in Table 1 and in Figs. 1, 2, and 3.

How did this happen? To know what forces have led to the present redistributions, and their limits, one needs to know the where and when. Narrative histories have painted an historical landscape filled with regime changes and clashes between

\footnotetext{
${ }^{18}$ See Hertz et al. (2007). To this list of 42 , Mexico has now been added, and has the 14th lowest educational mobility between generations out of 43 (Velez-Grajales et al. 2014), just below the USA (16th lowest). We have not yet been able to determine whether the research procedures were the same for the Mexican study as for the other 42 countries.
} 


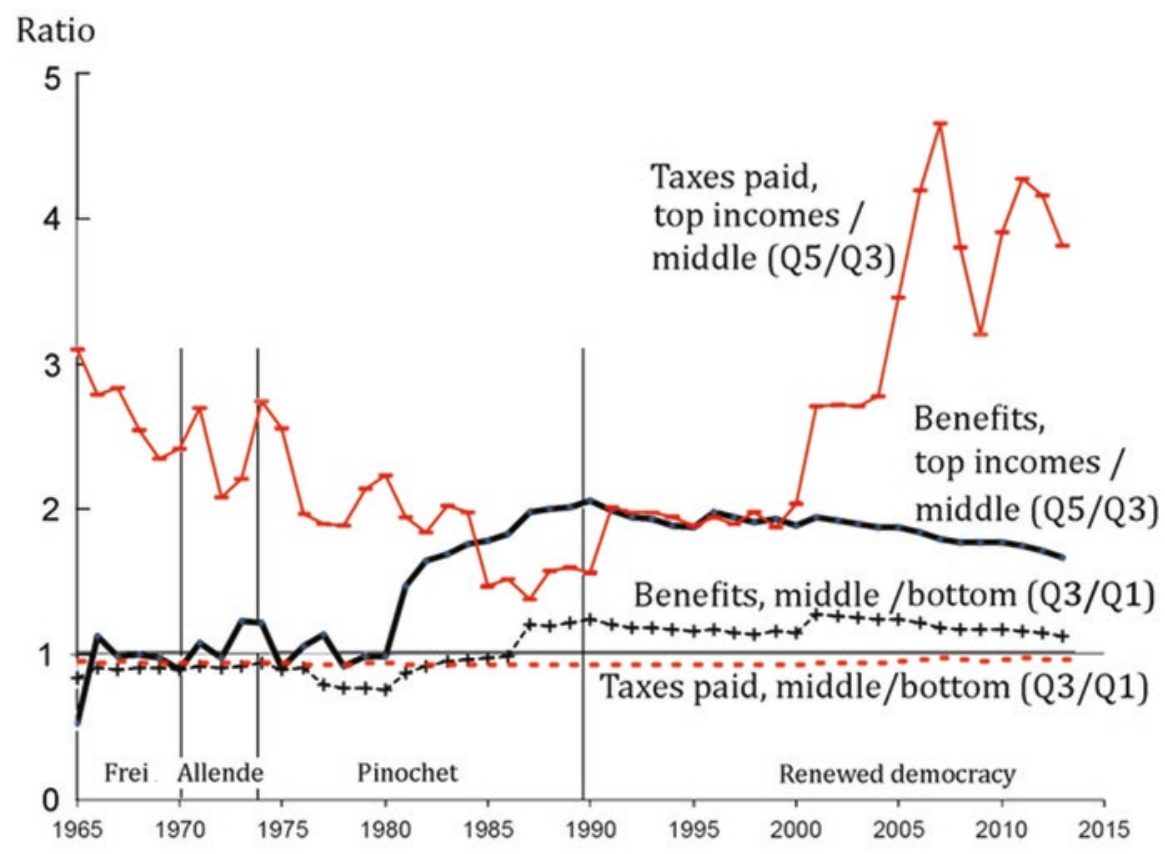

Fig. 3 Relative social spending benefits and tax burdens for Chile's top, middle, and bottom income classes, 1965-2013. Sources and notes: see Appendix 1

ethnic groups and special interests. New numbers can frame and support such paintings. We turn to the histories of some data-supplying countries, from which some patterns will emerge.

\subsubsection{Chile Since 1842}

Chile's experience with fiscal redistribution is the mostly richly documented, and in recent years the most dramatic and controversial, of all countries in the region, aside from the Cuban Revolution. We shall use the size of Chile's social budgets as a convenient baseline for commenting on the social spending efforts of each of our other five countries.

The rise of social spending as a share of GDP. Like the rest of the region since the 1960s, the central government of Chile has expanded social spending, a prime vehicle for fiscal redistribution, as shown in Table 4. And like the rest of the region, social spending evolved away from its being tiny and dominated by public education in the nineteenth century to devoting a rising share to transfers, especially pension payments, rather than to human investments like public education and public health. The annual detail behind Table 4, however, shows the instability of Chile's spending during the military dictatorship of Augusto Pinochet (1973-1989). Education spending 
Table 4 Social spending shares of GDP

\begin{tabular}{|c|c|c|c|c|c|}
\hline & \multicolumn{5}{|c|}{ Average social spending as \% of GDP, current prices } \\
\hline & Public education & Public health & $\begin{array}{l}\text { Non-contributory public } \\
\text { pensions }\end{array}$ & Other & Total \\
\hline \multicolumn{6}{|c|}{ Chile, central government } \\
\hline $1842-99$ & 0.40 & n.a. & 0 & 0 & 0.40 \\
\hline $1900-29$ & 1.08 & 0.03 & 0 & 0.03 & 1.14 \\
\hline 1930-39 & 1.94 & 0.56 & 0 & 0.17 & 2.67 \\
\hline $1940-49$ & 2.11 & 0.95 & 0 & 0.22 & 3.28 \\
\hline $1950-59$ & 2.15 & 1.31 & 0 & 0.11 & 3.57 \\
\hline $1960-73$ & 3.60 & 1.93 & 0 & 0.91 & 6.44 \\
\hline 1974-79 & 3.40 & 2.42 & 0 & 8.44 & 14.27 \\
\hline $1980-89$ & 3.18 & 2.72 & 1.92 & 10.52 & 18.34 \\
\hline 1990-99 & 2.90 & 2.27 & 5.68 & 1.83 & 12.67 \\
\hline $2000-09$ & 3.68 & 2.99 & 6.71 & 0.62 & 14.00 \\
\hline $2010-13$ & 4.05 & 3.64 & 6.34 & 0.60 & 14.64 \\
\hline \multicolumn{6}{|c|}{ Argentina, central government } \\
\hline $1870-99$ & 0.07 & n.a. & 0.04 & n.a. & 0.11 \\
\hline $1900-29$ & 0.34 & n.a. & 0.09 & n.a. & 0.43 \\
\hline 1930-39 & 1.97 & n.a. & 0.44 & 0.32 & 2.74 \\
\hline $1947-49$ & 1.91 & n.a. & 0.41 & n.a. & 2.31 \\
\hline \multicolumn{6}{|c|}{ Argentina, central, provincial, and municipal } \\
\hline $1950-59$ & 1.95 & 1.10 & 1.50 & n.a. & 4.55 \\
\hline 1960-69 & 2.45 & 1.35 & 1.75 & $\mathrm{a}$ & 5.55 \\
\hline \multicolumn{6}{|c|}{ Argentina, consolidated government } \\
\hline $1970-79$ & 3.55 & 1.95 & 5.22 & 4.62 & 15.33 \\
\hline $1980-89$ & 3.15 & 3.62 & 5.31 & 2.80 & 14.88 \\
\hline 1990-99 & 4.13 & 4.65 & 8.01 & 3.45 & 20.24 \\
\hline $2000-09$ & 5.09 & 4.80 & 7.42 & 4.36 & 21.67 \\
\hline \multicolumn{6}{|c|}{ Uruguay, central government } \\
\hline $1910-29$ & 1.20 & 0.96 & 1.30 & 0.01 & 3.47 \\
\hline 1930-39 & 1.56 & 1.27 & 3.99 & 0.05 & 6.87 \\
\hline $1940-49$ & 1.48 & 0.95 & 4.11 & 0.03 & 6.57 \\
\hline $1950-59$ & 1.56 & 1.12 & 5.44 & 0.15 & 8.27 \\
\hline $1960-69$ & 2.81 & 1.29 & 6.73 & $\mathrm{a}$ & 10.84 \\
\hline 1970-79 & 2.63 & 1.79 & 8.48 & 0.37 & 13.27 \\
\hline $1980-89$ & 2.37 & 2.26 & 10.50 & 0.54 & 15.68 \\
\hline $1990-99$ & 2.25 & 3.02 & 12.03 & 0.84 & 18.14 \\
\hline $2000-08$ & 3.12 & 3.64 & 12.69 & 1.45 & 20.89 \\
\hline \multicolumn{6}{|c|}{ Costa Rica, central government } \\
\hline $1936-39$ & 1.37 & 0.48 & 0.22 & n.a. & 2.06 \\
\hline 1940-49 & 1.52 & 0.49 & 0.30 & n.a. & 2.31 \\
\hline $1950-59$ & 1.44 & 0.29 & 0.39 & n.a. & 2.11 \\
\hline 1960-69 & 2.83 & 0.40 & n.a. & n.a. & 3.23 \\
\hline
\end{tabular}


Table 4 (continued)

\begin{tabular}{|c|c|c|c|c|c|}
\hline & \multicolumn{5}{|c|}{ Average social spending as $\%$ of GDP, current prices } \\
\hline & Public education & Public health & $\begin{array}{l}\text { Non-contributory public } \\
\text { pensions }\end{array}$ & Other & Total \\
\hline 1970-79 & 3.00 & 0.32 & n.a. & n.a. & 3.32 \\
\hline \multicolumn{6}{|c|}{ Colombia, central government } \\
\hline $1905-29$ & 0.37 & n.a. & 0.00 & 1.12 & 1.49 \\
\hline 1930-39 & 0.33 & 0.27 & 0.00 & 0.95 & 1.55 \\
\hline $1940-49$ & 0.36 & 0.16 & 0.00 & 0.93 & 1.46 \\
\hline $1950-59$ & 0.52 & 0.31 & 0.00 & 1.33 & 2.17 \\
\hline $1960-69$ & 1.26 & 0.45 & 0.00 & 1.63 & 3.34 \\
\hline $1970-79$ & 2.12 & 0.91 & 1.73 & 1.32 & 6.08 \\
\hline $1980-89$ & 2.63 & 0.79 & 2.55 & 1.02 & 6.99 \\
\hline 1990-99 & 2.50 & 1.03 & 4.29 & 0.95 & 8.76 \\
\hline $2000-09$ & 3.04 & 1.88 & 5.84 & 0.42 & 11.19 \\
\hline $2010-13$ & 2.98 & 1.99 & 7.36 & 0.88 & 13.20 \\
\hline
\end{tabular}

Costa Rica, consolidated government

\begin{tabular}{l|l|l|l|l|l}
\hline $1980-89$ & 4.04 & 4.80 & 4.26 & 1.98 & 15.07 \\
\hline $1990-99$ & 4.06 & 4.66 & 4.53 & 1.82 & 15.06 \\
\hline $2000-09$ & 5.41 & 5.39 & 5.46 & 1.89 & 18.15 \\
\hline $2010-13$ & 7.17 & 6.56 & 6.62 & 2.28 & 22.63 \\
\hline
\end{tabular}

Peru, central government

\begin{tabular}{|c|c|c|c|c|c|}
\hline 1900-29 & 0.08 & b & b & b & 0.66 \\
\hline $1930-39$ & 0.38 & 0.21 & b & b & 1.14 \\
\hline $1940-49$ & 0.97 & 0.37 & $b$ & $b$ & 1.42 \\
\hline $1950-59$ & 1.92 & 0.43 & b & b & 2.48 \\
\hline 1960-69 & 3.85 & 0.97 & b & b & 5.27 \\
\hline 1970-79 & 3.48 & 1.00 & $\mathrm{~b}$ & $\mathrm{~b}$ & 4.99 \\
\hline 1980-89 & 2.57 & 0.99 & b & b & 4.00 \\
\hline 1990-96 & 2.43 & 0.89 & b & $b$ & 3.86 \\
\hline
\end{tabular}

Peru, general government

\begin{tabular}{l|l|l|l|l|l}
\hline $1997-99$ & 3.13 & 1.25 & 2.55 & 0.59 & 7.52 \\
\hline $2000-09$ & 3.05 & 1.72 & 3.27 & 1.66 & 9.70 \\
\hline $2010-13$ & 3.01 & 2.24 & 2.41 & 1.79 & 9.45 \\
\hline
\end{tabular}

\section{Sources: See Appendix 1}

Notes

n.a = positive, but unknown and excluded from "other" and from "total"
(a) =included in pensions
(b) =included in total social spending

For each decade, the averages refer to the data-supplying years within that decade, sometime referring to fewer than 10 years

For the underlying annual data, see http://gpih.ucdavis.edu, folder on "Government budget historical series," under the heading "Latin American fiscal redistribution" 
gyrated, and pension spending gyrated even more. Let us first describe our resulting estimates of how these gyrations in overall social spending twisted the incomes of the rich, middle, and poorest income groups, before turning to our interpretation of the complex pension reforms that were at the center of the storm.

The distribution of social spending since 1965. How did social spending affect people in different income ranks? To answer this question requires the procedure we previewed above, in which we apply today's fiscal incidence of different social expenditures, and the average tax mix that is assumed to pay for them, to each year's social spending as a share of GDP. Table 5 summarizes the recent unit impacts

Table 5 Fiscal benefits and costs as shares of GDP for benchmark years

\begin{tabular}{|c|c|c|c|c|c|c|c|c|}
\hline & \multicolumn{4}{|c|}{ Social spending } & \multicolumn{3}{|l|}{ Taxes } & \multirow{2}{*}{$\begin{array}{l}\text { Benefits } \\
\text { minus } \\
\text { taxes }\end{array}$} \\
\hline & Education & Health & Pensions & All & Direct & Indirect & Total & \\
\hline \multicolumn{9}{|c|}{ Chile 1996-2000 } \\
\hline $\begin{array}{l}\text { Quintile } 1 \\
\text { (bottom) }\end{array}$ & 0.8 & 0.8 & 0.2 & 2.2 & 0.5 & 2.1 & 2.6 & -0.4 \\
\hline Quintile 2 & 0.8 & 0.7 & 0.5 & 2.3 & 0.5 & 2.0 & 2.5 & -0.2 \\
\hline Quintile 3 & 0.8 & 0.6 & 0.9 & 2.5 & 0.5 & 2.0 & 2.4 & 0.1 \\
\hline Quintile 4 & 0.8 & 0.4 & 1.7 & 3.1 & 0.5 & 2.0 & 2.5 & 0.6 \\
\hline Quintile 5 (top) & 0.7 & 0.2 & 3.1 & 4.9 & 1.0 & 4.0 & 5.0 & -0.1 \\
\hline All households & 3.9 & 2.7 & 6.4 & 15.0 & 2.9 & 12.1 & 15.0 & 0.0 \\
\hline \multicolumn{9}{|c|}{ Argentina 1999-2009 } \\
\hline $\begin{array}{l}\text { Quintile } 1 \\
\text { (bottom) }\end{array}$ & 1.8 & 2.4 & 4.4 & 9.6 & 0.0 & 1.6 & 2.6 & 7.0 \\
\hline Quintile 2 & 1.3 & 1.3 & 1.3 & 4.8 & 0.0 & 1.8 & 3.0 & 1.8 \\
\hline Quintile 3 & 1.0 & 0.8 & 1.1 & 3.7 & 0.0 & 2.2 & 3.7 & 0.0 \\
\hline Quintile 4 & 0.6 & 0.4 & 0.8 & 2.4 & 0.0 & 2.2 & 3.9 & -1.5 \\
\hline Quintile 5 & 0.2 & 0.1 & 0.2 & 0.9 & 4.5 & 2.1 & 8.3 & -7.3 \\
\hline All households & 5.0 & 5.0 & 7.9 & 21.4 & 4.5 & 9.8 & 21.4 & 0.0 \\
\hline \multicolumn{9}{|l|}{ Uruguay 2000} \\
\hline Quintile 1 & 1.8 & 2.1 & 11.5 & 16.4 & 0.4 & 4.3 & 4.7 & 11.6 \\
\hline Quintile 2 & 0.6 & 0.9 & 2.4 & 4.3 & 0.8 & 3.0 & 3.8 & 0.4 \\
\hline Quintile 3 & 0.3 & 0.5 & 0.8 & 1.8 & 1.2 & 2.6 & 3.8 & -2.0 \\
\hline Quintile 4 & 0.2 & 0.3 & 0.3 & 0.8 & 1.9 & 2.7 & 4.5 & -3.7 \\
\hline Quintile 5 & 0.1 & 0.1 & 0.1 & 0.3 & 4.1 & 2.6 & 6.7 & -6.4 \\
\hline All households & 3.0 & 3.8 & 15.0 & 23.5 & 8.3 & 15.2 & 23.5 & 0.0 \\
\hline \multicolumn{9}{|l|}{ Colombia 1966} \\
\hline Quintile 1 & 0.3 & 0.2 & & 0.5 & & & 0.1 & 0.4 \\
\hline Quintile 2 & 0.3 & 0.2 & & 0.6 & & & 0.2 & 0.4 \\
\hline Quintile 3 & 0.4 & 0.1 & & 0.5 & & & 0.3 & 0.2 \\
\hline Quintile 4 & 0.7 & 0.0 & & 0.9 & & & 0.5 & 0.3 \\
\hline Quintile 5 & 0.8 & 0.0 & & 1.0 & & & 2.5 & -1.4 \\
\hline All households & 2.6 & 0.5 & & 3.5 & & & 3.5 & 0.0 \\
\hline
\end{tabular}


Table 5 (continued)

Sources and notes

Our estimates actually use greater detail by social program than is shown in Table 5. For example, different unit impacts are applied for primary versus secondary versus tertiary education. See the Excel files within the Government Budget Historical Series folder of http://gpih.ucdavis.edu As noted in the text, the total taxes are equal to social expenditures, with the assumption that such expenditures are paid for in the same revenue-type proportions as in the aggregate budget

For Chile, the main sources are Engel et al. (1999), Lindert et al. (2006), Jorrat De Luis (2009), Rodriguez and Flores (2010), Cruz-Saco and Mesa Lago (1998, 69), and Acuña Rodrigo and Augusto Iglesias (2001, Table 5)

Note that for Chile the total social expenditures include more than the three subcategories (education, health, and pensions). Chile's tax incidence shares are from Engel et al. (1999), and refer to 1996. These shares of total revenue are applied to revenues and GDP for the year 2000

For Argentina the main sources are: Gasparini (1999), Sabaini et al. (2002), and Lustig et al. (2011). Note also that for Argentina the total tax revenues exceed the subcategories, due to inclusion of social security contributions. For Argentina's social security contributions, the quintiles paid these shares in 2000: Q1 paid $0.98 \%$ of GDP, Q2 paid 1.19\%, Q3 paid 1.57\%, Q4 paid $1.65 \%$, and Q 5 paid $1.73 \%$

For Uruguay, we lack a historical time series on social security taxes. We have, however, the estimated distribution of such taxes across quintiles. With this Uruguayan exception, we have included social security contributions separately in the revenues covering social expenditures. For the Uruguay estimates we had to allocate social security contributions to direct and indirect taxes, in the proportions assumed by the latter two

Around the year 2000, Uruguay's bottom quintile (Q1) paid 13.81\%, Q2 paid 16.74\%, Q3 paid $22.03 \%$, Q4 paid $23.21 \%$, and Q5 paid $24.20 \%$

For Colombia 1966, the main source is Berry and Urrutia (1976) Estimates covering the expenditure side for Colombia in 1974 can be found in Selowsky (1979). There were no public pensions in 1966

of each social program or tax on each of the five quintiles of households, in Chile and in three other countries. ${ }^{19}$

Concentrating on Chile's experience since 1965, Fig. 3 reveals the estimated effects on different ranks by following two kinds of ratios. The ratio of the social payments to households in the top income quintile to those in the middle quintile, or Q5/Q3, represents (one plus) the "upper gap" we introduced earlier, and the ratio of the payments to households in the middle and bottom quintiles (Q3/Q1) represents the "lower gap". During the military regime, the emphasis in social spending shifted in favor of the top $20 \%$ of the income ranks, and their advantage in such payments has persisted ever since, although it is slowly declining. The bulk of this increase consisted of rising pension benefits favoring higher income households, and the pension movements cry out for explanation.

Untangling the pension reforms of 1979-1981. The pension system set up by Chile's famous pension reform was, and still is, a huge share of annual GDP. To clear the way for understanding its effects, one should begin by noting that it is not what it

\footnotetext{
${ }^{19}$ Our estimates actually use greater detail by social program than is shown in Table 5. For example, different unit impacts are applied for primary versus secondary versus tertiary education. See the Excel files within the Government Budget Historical Series folder of http://gpih.ucdavis.edu.
} 
is often described to be. It was not a privatization of Social Security, as many have thought. There was no social security system to replace, but only a flawed and incomplete pension system for the privileged occupational groups of the formal sector. The reform also did not exactly privatize or liberalize pensions. It forced individuals to place pension contributions and benefits more firmly in the hands of the state and the private pension managing funds (AFPs) that the state appointed. It also raised the state's commitments and pension deficits, and these are projected to continue until 2045. Government pension spending, far from phasing out, truly soared.

The 1979-1981 pension reform needs to be understood as a system with these key features:

(1) The Pinochet regime inherited a badly broken and underfunded pension system in which formal sector workers were being subsidized. The regime chose to honor their underfunded entitlements by creating new government obligations to be covered by general taxpayers.

(2) The reform exempted the military from individualized forced savings or the defined-contribution feature. Military personnel continue to get generous net defined benefits from the taxpayers.

(3) To convert from defined benefit pensions to a defined-contribution system for civilians, the regime and its post-1989 successors have had to pay deficits to the transition generation. The deficits continue.

More specifically:

First, as mentioned, the previous system was badly broken, and the rise of unsustainable obligations was hidden from the official data of those pre-reform years. The occupational system for the more established formal-sector occupations, dating back to the 1920s, was increasingly mismanaged after about 1955 . What had been a contributory system that should have funded itself slid into deficit, as more and more employees evaded making contributions while keeping their benefit entitlements. Between 1955 and 1979 the ratio of contributors to pensioners fell from 12.2 to 2.5 , a result which cannot be explained by demographic trends, but rather resulted from allowing evasion of contributions while delivering generous benefits to those covered (Acuña Rodrigo and Augusto Iglesias 2001, p. 20).

For our accounting framework, this poses a huge problem of fiscal timing. As we had warned earlier, fiscal programs often give tax or benefit accruals in years that can be quite distant from the years of collection or payout. The 1979-1981 Chilean reform is perhaps the region's largest case of such a discrepancy. The obligations taken on in the 1980s in effect honored formal sector workers' evasion of pension contributions dating back to the 1950s, with benefits to be paid over subsequent years in ways that our studies have trouble tracking year by year. The military regime found itself inheriting a dilemma, one forcing it to choose between a shocking markdown of all occupational pension benefits and honoring the obligation to cover the full deficit. They chose the latter, with the result that the huge pension expenditures favoring higher-income beneficiaries suddenly show up in our graphs around 1975, even though they had secretly accrued over the previous two decades. 


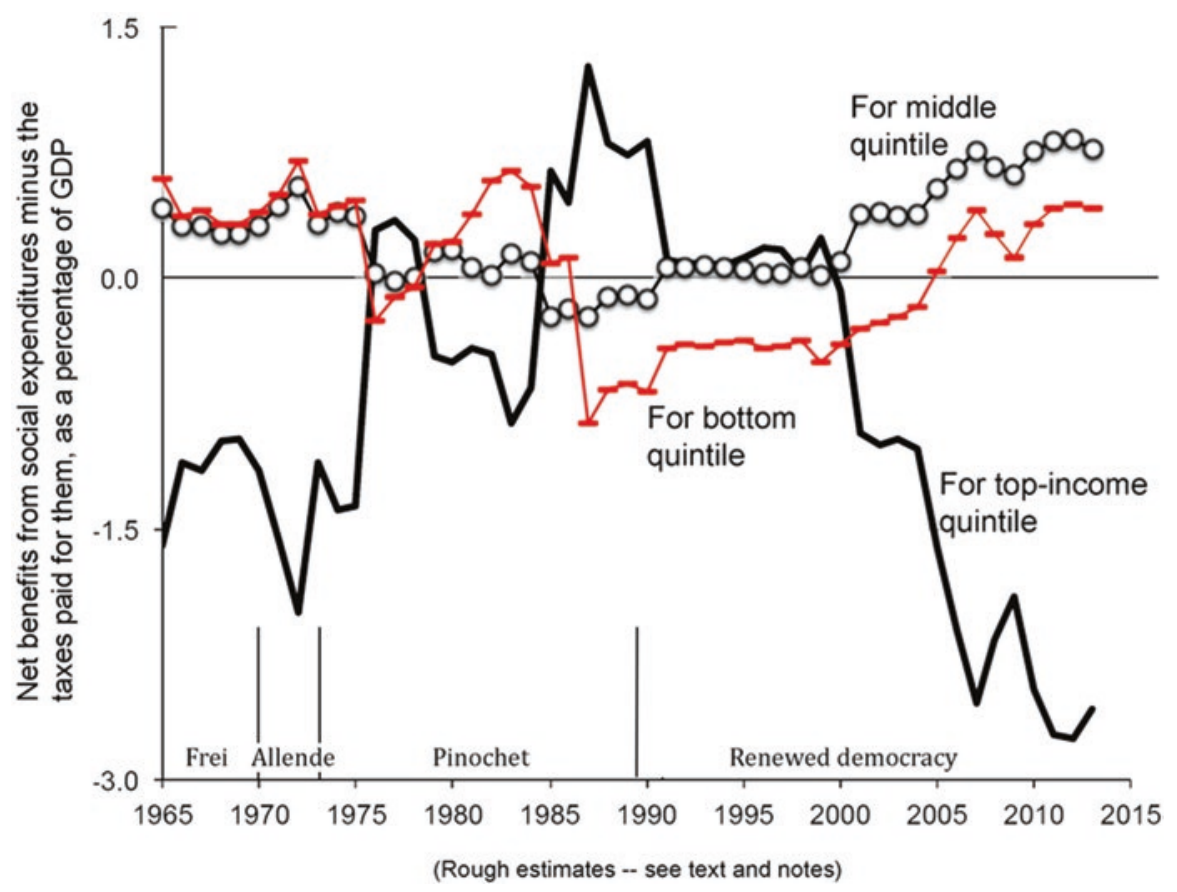

Fig. 4 Net benefits minus taxes paid, on social expenditure in Chile, 1965-2013. Sources and notes: see Appendix 1

Second, as we have noted, the Pinochet regime did not dare to slash military pensions, nor did it include them in the forced-saving reform, even when holding its firmest grip on power.

Third, like any change in pension regime that tightens up, in pursuit of eliminating deficits, Chile's new system faced the threat of double-taxing the transitional generation, forcing it to pay for the preceding generation's retirement while also paying for its own. Like the military exemption, this necessitated deficits lasting for a generation, from $8.4 \%$ of GDP in 1982 to $3.9 \%$ by the close of the century. ${ }^{20}$

At face value, the pension benefits suddenly became huge after the coup, and have stayed that way. In giving this impression Figs. 3 and 4 correctly portray what happened on an "accruals accounting" basis; yet they may mislead by portraying the movements as though the resources were paid out, in the cash accounting sense, at peak years like 1981-1986.

\footnotetext{
${ }^{20}$ One further drawback of the reform design was avoidable, rather than inherent. The Chilean AFP (private pension fund administrators) system levied charges that are widely agreed to have been exorbitant. "One quarter of net (of insurance fees) mandatory contributions of the average Chilean contributor who retired in 2000 went to administration fees." The fees loomed somewhat larger for lower earnings savers.
} 
To portray the level, and the distribution, of pension benefits correctly, we have taken care to use measures of just the redistributive, or non-contributory part of all pension payments. Again, the part covered by current contributions is not redistributive. For 1981 on, we can interpret the Acuña Rodrigo and Augusto Iglesias (2001, Table 5) social security deficit part of pension payments as the redistributive component. It was the "total social security deficit," most of which was the "transitory social security operational deficit," with much smaller amounts for Recognition Bonds and for the more permanent welfare and minimum pensions. ${ }^{21}$ The measures for the 1970s and earlier are less straightforward, for want of a clear measure of the pension deficit in those years. ${ }^{22}$

The deficit was huge, taking at least $8.4 \%$ of GDP in 1982, and still over $4 \%$ at the dawn of this century. Clearly, the transition from a broken and underfunded system to a fully funded "defined contributions" system was fiscally costly for Chile, as it has also proved for other countries imitating Chile's transition. It was also not progressive in Chile's case, since the beneficiaries of the deficit were, and still tend to be, upper income groups, largely the same formal sector groups that underpaid for their pension entitlements before the reform. ${ }^{23}$

Adding in the tax side. For Chile we have an opportunity to complete our counterfactual on the tax side. That is, there exist studies of how different kinds of taxes are distributed across the income groups "today," where today is the year 1996, thanks to Engel et al. (1999). Their article on "unpleasant redistributive arithmetic" derived Chile's distribution of direct taxes versus two kinds of indirect taxes in 1996, and we were able to apply their separate distributions to the shares of direct and indirect taxes back to 1965. This yields the distribution of taxes between high-, middle-, and low-

\footnotetext{
${ }^{21} \mathrm{Had}$ we instead used the "state subsidy to social security" share of GDP given by Cruz-Saco and Mesa-Lago (1998, p. 69), the estimates would have been slightly higher-e.g., $8.8 \%$ of GDP instead of $8.4 \%$ for 1982 , and $6.6 \%$ instead of $4.8 \%$ for 1993 .

${ }^{22} \mathrm{We}$ assume that before 1955 there was zero net deficit and zero redistribution. That is, we assume that the pre-1955 pensions in the public accounts were wholly contributory. Acuña Rodrigo and Augusto Iglesias (2001) note that there were many contributors per recipient then, but that the system fell apart under mismanagement until the Pinochet reforms. What to do about the years 19551981 ? It would seem natural to imagine a drop in the contributory share from 100 to $0 \%$ over these years. This would understate the rise in regressive redistribution toward the rich, since the official data on pension payments record only low out-payments in these years, and not the hidden buildup of obligations that were recognized only after 1981 . We have no choice but to go with the available data, using a current cash-flow approach and assuming that the out-payments occurred only from 1981 on. Much post-1981 regressivity actually accrued earlier. For 1976-1980, we interpret the "otros funciones sociales" as fully non-contributory and as regressive as the non-PASIS pensions at the end of the century. From 1981 on, we apply the Acuña-Iglesias social security deficit as the noncontributory part of both social security (previsión) and "other social programs."

Note that these pension payments and the special "otras funciones sociales" payments remain outside the usual calculations of annual disposable or final income in the year in which they are paid by the government. They trickled into benefits in earlier years in the case of pensions, and possibly later years for other programs.

${ }^{23}$ The quantitative embodiment of this statement is that for the pension recipients' payments out of the deficit we used the quintile shares estimated for Chile's non-PASIS pensions in Lindert et al. (2006, Tables 7 and 8).
} 
income groups shown already in Fig. 3, and now in Fig. 4. Both portrayals show that the years of military rule were remarkably favorable to top income groups and unfavorable to the bottom, relative to the earlier and later regimes of democratically elected governments. Adding taxes into the picture shows an additional reason why: the top $20 \%$ got a relative tax break, one that was largely reversed by the concertación government starting in 1991, as is also clear in Figs. 3 and 4.

Chile's shift toward more progressive redistribution, and lower post-fisc inequality, since 2000 has been widely noted. ${ }^{24}$ Our Figs. 3 and 4 confirm the rise in redistributive progressivity. The middle income groups regained a net positive fiscal effect across the 1990s, and the poorest quintile gained positive redistribution from 2005 on. The underlying mechanism, while not entirely clear, seems to have worked mainly on the tax side. Direct tax collections rose considerably as a share of government revenue, while the value added tax dropped. Given that the former fall mainly on the top quintile and the latter are neutral or slightly regressive, the revenue shift should have been progressive, as our figures imply.

\subsubsection{Argentina Since World War II}

Argentina's commitment to social spending gained steam during Perón's administration with expansion of education and social security; however, these policies were consolidated in later decades, as social spending became a larger share of the budget. This evolution was far from steady, as the Argentine economy failed to achieve stable economic growth. The social welfare state suffered a setback in the late 1970 s with a sharp impact on the social security and labor market programs paired with a more regressive taxation system. Employer contributions were seen as detrimental to the private sector's competitiveness, resulting into their subsequent abolition. With lower direct tax collection and increasing inflation tax, the net benefits of the bottom quintile stagnated at best. From the 1980s onwards, while social spending increased in terms of GDP, this rise was far from stable. Social spending has been more volatile than GDP growth and has run pro-cyclically. This combination has eroded its effectiveness as progress in education and health requires sustainable social spending. That said, the sheer magnitude of Argentina's tax effort on behalf of social spending, as a share of GDP, jumped far ahead of Chile's in the 1990s, under Menem. Argentina's greater social spending share has not fallen back in the twenty-first century, despite the depth of the 2001 crash and the steepness of the subsequent recovery.

State-induced redistribution. With the advent of populism in Argentina, income redistribution towards the popular class became a priority for the new government. Under Perón's initial presidencies (1946-1955), the public sector quickly expanded

\footnotetext{
${ }^{24}$ For example, see Chile's redistribution coefficients in global perspective in Solt $(2009,2014)$. Rodriguez Weber (this volume) finds a leveling in pre-fisc labor earnings from 1988 to 2000, but no pre-fisc leveling after 2000. Combining his result with the others would suggest, again, a shift toward progressive redistribution after 2000.
} 
with the proliferation of ministries and the takeover of public utilities. ${ }^{25}$ Social spending followed the trend, with education rising from $6 \%$ of the budget to nearly $15 \%$ by the end of the term. This commitment to education translated into a rise in enrollment reaching $50 \%$ of the children in schooling age, a net 12-percentagepoint increase from 1945 (Véganzonès and Winograd 1997). While education was an important component of social spending before 1970, the expansion of the pension system's coverage turned into an important source of benefits, mostly to the urban population. ${ }^{26}$ The redistributive efforts worked, as wage earners' GDP share climbed ten percentage points by 1954 to reach over $48 \%$ of GDP by $1954 .{ }^{27}$ This impressive gain, however, was mostly due to public credit policies increasing monetary wages, including a very popular innovation of the compulsory Christmas bonus (the "Aguinaldo"). ${ }^{28}$ Taking advantage of the taxation infrastructure established in the 1930s, the government expanded taxation by increasing rates . Faced with insufficient revenue, sales taxes rose from 1.25 to $8 \%$ while profit and export taxes were also targets (Blanco 1956; Gerchunoff 1989). Later, the government attempted to ameliorate the regressive character of the tax system by decreasing taxes of basic necessities (Banco Central 1955).

More significant was the progressive role of the income tax (see Fig. 5). The top rates were increased from 7 to $22 \%$ in 1942 to be revised again a decade later (Alvaredo 2007). Income tax collection grew accordingly reaching $2.7 \%$ of GDP during the Peronato compared to $0.7 \%$ during the previous decade.

The revenue-enhancing reforms failed to cover the growing public expenditure, and the government resorted to tapping social security funds. The growing imbalance of the fiscal accounts translated into inflation, reaching nearly $10 \%$ of GDP in 1949. Though it decreased subsequently, the inflation tax was to remain a feature in the fiscal and daily lives of Argentina.

Consolidation and retreat of social spending with less progressive taxation, 19551989. Life after Perón was plagued with sudden changes in economic policy. The intermittent and interrupted long-term and stabilization programs hampered economic growth. In terms of social spending, the central government devoted considerable resources in the 1960s and 1970s to reach around $10 \%$ of GDP, and over $25 \%$ for all levels of government combined. Social assistance transfers (pensions and "other") represented nearly $40 \%$ of all social spending by the central government. Progressive taxation remained in place for another decade post Perón but it had unraveled by mid-1970s with a substantial decrease in direct taxes as a source of revenue. ${ }^{29}$

\footnotetext{
${ }^{25}$ Moreover, an increasing share of public expenditure was off the treasury records such as state railroads, the trade institute (IAPI), and the national mortgage bank.

${ }^{26} \mathrm{By}$ the turn of the twentieth century, the pension system in Argentina included only public employees. Before Peronist times, the system expanded to include employees from banking, insurance, press, and naval and air transportation (Arza 2010).

${ }^{27}$ Estimations based on CEPAL (1958) considering only salaries.

${ }^{28}$ Established by Decree number 33.302/45. Technically, this extra salary was established before Perón's presidencies; however, the origin of this idea is traced to Perón's stint as Secretary of Labor between 1943 and 1945.

${ }^{29}$ Again see Fig. 5. Gaggero (2008) maintains that the elites and their short-run macroeconomic policies are to blame for this development.
} 


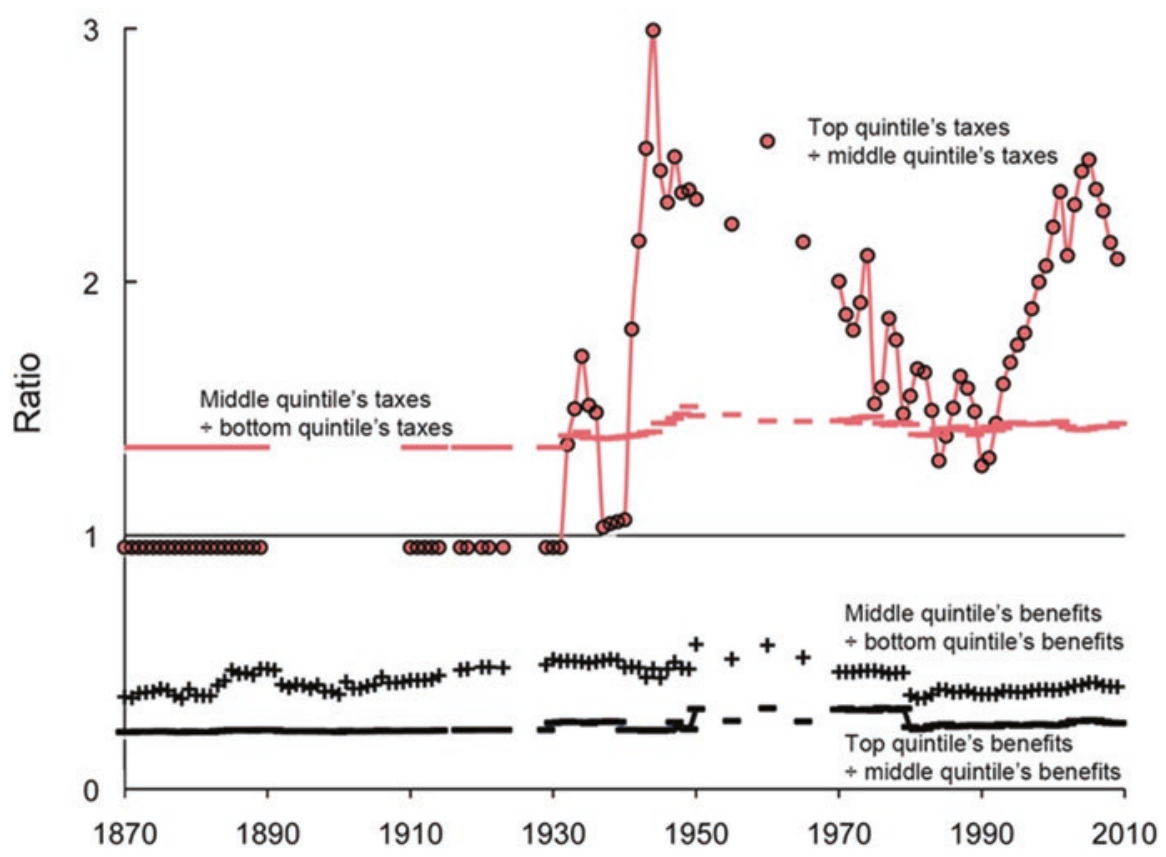

Fig. 5 Benefits of social spending, rich vs. middle vs. poor, Urban Argentina, 1870-2009. Sources and notes: see Appendix 1

Curiously the military governments did not eradicate the welfare state introduced by Perón, but consolidated it with an array of inefficient policies within the framework of a state-oriented economy. ${ }^{30}$ Dubbed as paternalistic and rooted in Catholic views of a more unified society, the state expanded social security to include a new national housing system (FONAVI) funded by employers' tax contributions. However, this expansion was short-lived. In 1979 the employers' contributions are abolished, defunding the pension system and the public housing program. This sharp turn in social policy reduced the relative benefits of the top and middle quintiles as shown in Fig. 5. This slash of the benefits was outweighed by the government's rising use of the sales tax to recoup revenue (Marshall 1988). With inflation graduating from moderate to high (and even reaching hyperinflation in 1989 and 1990), the taxation system turned much more regressive. ${ }^{31}$ For the 1980s, the inflation tax incidence on wage earners hovered around 2.2 to nearly $6 \%$ of GDP per year. However, the impact was 3:1 when comparing the first to the fifth quintile, making the tax incidence more regressive due to the increasing monetization of the fiscal

\footnotetext{
${ }^{30}$ Franco (1992) claims that the social policies in Latin America during this period were useless as they only granted segmented access and excluding universalism.

${ }^{31}$ As our estimations for relative tax incidence are based on 2009 figures, the impact of inflation tax is absent. Given its regressive nature, our estimates of tax incidence for the late 1980s most likely appear more progressive than they probably were.
} 


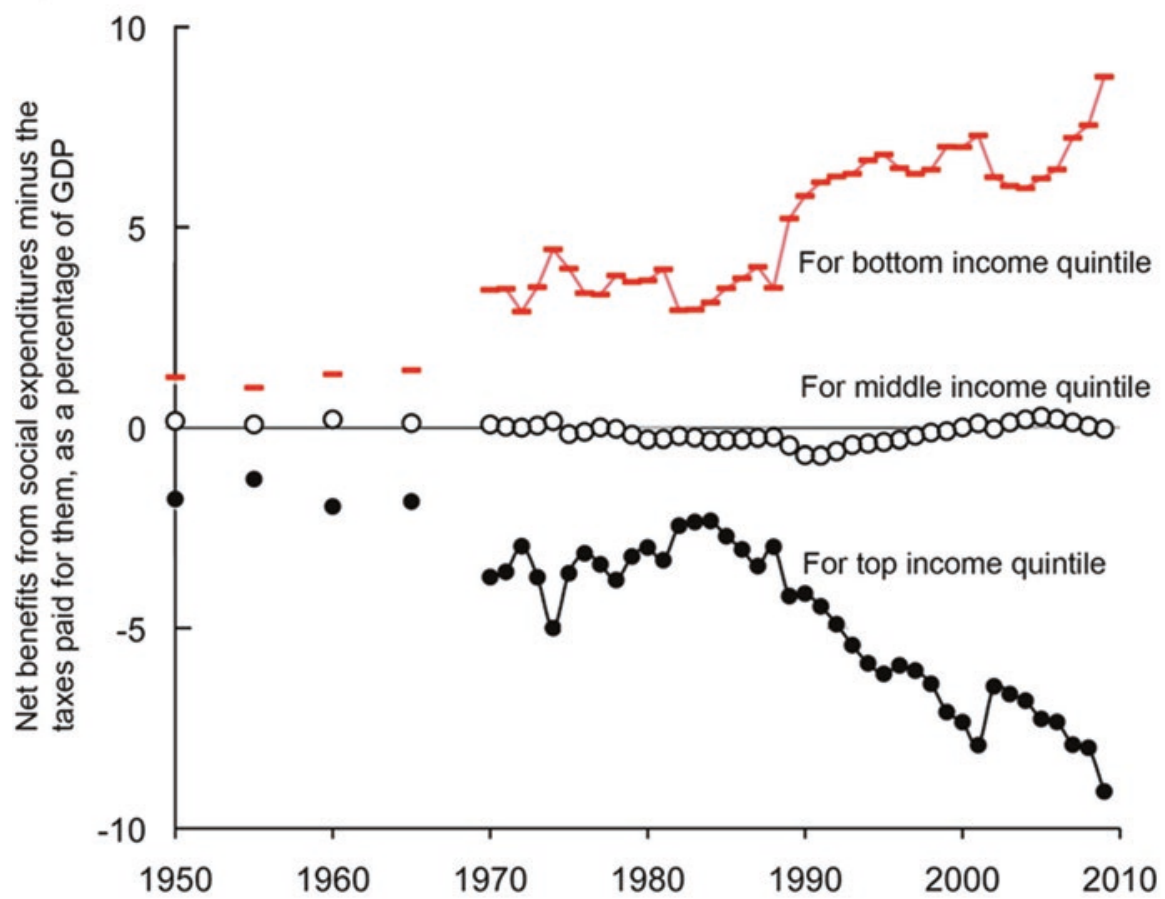

Fig. 6 Net Benefits minus taxes paid, on social spending by consolidated government, Argentina 1970-2009. Sources and notes: see Appendix 1

deficit (Ahumada et al. 1993). Figure 6 shows the regressive net effect of this combination in the 1980s.

The rise of social spending along with changes in taxation, 1990-2013. Since 1992 Argentina's social spending has been more volatile, pro-cyclical-and more progressive, as shown in Figs. 5 and 6. Spending on social security has expanded, and the pension system alone reached almost $74 \%$ of total spending in 2013 . This time, however, the rise in pensions was progressive. The extension of coverage and the rise in social security paychecks explains most of this increase. Consistent with the retreat of post-fisc inequality observed in the 2000s, the net fiscal benefits for the bottom quintile increased substantially to nearly reach $5 \%$ of GDP. ${ }^{32}$ On the taxation side, the Menem government introduced a two-sided change. On the regressive side, it relied more on the value-added tax with rates climbing to $21 \%$ while the income tax rate for the top bracket was reduced to $33 \%$ in 1997 (to be increased

\footnotetext{
${ }^{32}$ On volatility and pro-cyclicality, the correlation between real GDP and real social spending is above 0.8 for using both central and total government spending. When testing changes in real GDP vs. changes in real social spending the coefficient drops to 0.5 . The volatility of real social spending relative to real GDP (measured as the standard deviation of the annual real changes) is three times higher.
}

On the changes in the design of social security, see Selva and Iñiguez (2009). 
2 percentage points 3 years later). Yet at the same time, it improved tax collection by reducing evasion. This latter, progressive, side of the coin takes on a strong form in our Figs. 5 and 6, which show a trend toward progressivity shared by the otherwise very different presidencies from Menem to the Kirschners.

The impact of this mix actually worsened inequality in the late 1990s, according to CEPAL estimates. ${ }^{33}$ Still, the expansion of social spending with an increase of overall tax collection gave rise to a more progressive fiscal redistribution since 1992.

\subsubsection{Uruguay, the Social Spending Leader Over the Last 100 Years}

Though the region has lagged in public education spending ever since Independence, Uruguay was an early leader in education levels, helped by its initially high income (Lindert 2010; Rodriguez Weber and Thorp 2013). Its commitment to primary and secondary education did not flag, although Chile and Argentina caught up by the 1930s.

In terms of social assistance, the 1930s saw a jump, due to enlarging the social security system, and to expanding the pension system to cover workers in the formal industry and commerce sectors.

What shows up even more clearly in the history of social spending is a consistent Uruguayan tendency toward equalizing incomes. As shown in Fig. 7, Uruguay's

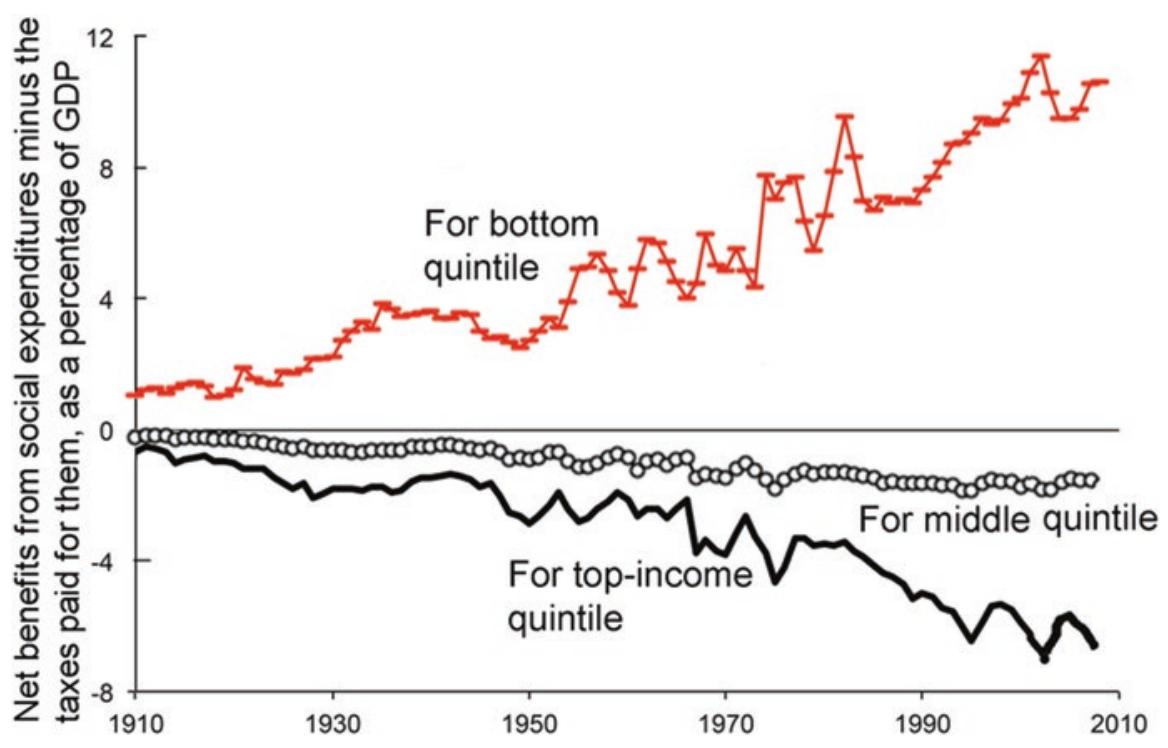

Fig. 7 Benefits of social spending benefits minus taxes for them, rich vs. middle vs. poor, Uruguay 1910-2008. Sources and notes: see Appendix 1

${ }^{33}$ Cetrángolo and Gómez-Sabaini (2006). 
social spending has been highly progressive throughout the last 100 years. The long rise of the redistribution in terms of GDP, so conspicuous in Fig. 7, is due mainly to the expansion in the size of social budgets, rather than to any shift toward greater unit progressivity of social programs. For at least a 100 years Uruguay has had a more progressive mix of social programs than in Chile. ${ }^{34}$ Certainly the mix is more progressive today, as Table 5 testifies.

One potential interruption to the upward march of social spending came with military rule in 1973-1985. In this respect Uruguay's time path could have resembled that of Chile and Argentina. Yet in Uruguay the military rule did not reverse either the expansionary trend or the progressivity of social programs, as evident in Fig. 7. Thus Uruguay stands out as the region with the longest-standing trend toward progressive redistribution.

\subsubsection{Colombia-Half Progressive, Half Regressive}

Colombia's patterns of fiscal incidence are decidedly mixed, according to two studies of social spending and taxes in the 1960s and 1970s. On the one hand, public primary education and all rural public services have been progressive, even in the "clearly progressive" sense delineated in Table 3 above. Subsidies to university education were highly regressive, in Colombia as elsewhere, although the magnitude of university subsidies was small in relation to the amounts given out in the other programs. Also regressive were urban public services. On balance, the entire fiscal system seems to have redistributed only a small share of national income, perhaps $1.4 \%$, from the top quintile the other $80 \%$ of the population as of $1966 .{ }^{35}$

On the pension front, once public pensions were started in 1967, Colombia has followed in Chile's footsteps, both in the under-contribution problem inherited by reformers in 1993 and in the regressive deficits that the reforms brought to light. Again, as in Chile, repairing and removing the handover from the previous defined benefit system have proven difficult ever since the reforms were launched, in this case by Law 100 in 1993 . Though the reform tried to set up a pension reserve, it was exhausted as early as 2004. Since the pension system covers only $25-27 \%$ of the labor market, under a dual private-public regressive scheme, the central government has been forced to cover pension deficits out of about a third of its total tax revenues, or nearly $5 \%$ of GDP. As shown in Table 4, Colombia fits the regional pattern of veering toward dominance of non-contributory pensions in its social programs, despite attempts to curb this tendency. ${ }^{36}$

\footnotetext{
${ }^{34}$ Azar et al. (2009) and Rodriguez Weber and Thorp (2013).

${ }^{35}$ For Colombia 1966, the main source is Berry and Urrutia (1976). Estimates covering the expenditure side for Colombia in 1974 are found in Selowsky (1979). For the net result in 1966, see Table 5.

${ }^{36}$ Clavijo 2009, pp. 3-14.
} 


\subsubsection{Costa Rica Since the 1940s}

As the available numbers in Table 4 suggest, Costa Rica has had a steadier growth of social spending than some of the other countries.

As compared with Uruguay, Costa Rica redistributes less progressively each year, in the sense of reducing the Gini coefficient of inequality. Yet as of 2003, it has achieved greater equality of final income, and also greater equality of original (market, or pre-fisc) income. How? The contrast can have many explanations, including the countries' fortunes in international trade. One element of social policy seems to have contributed. Since at least 1900, Costa Rica has poured a greater share of national product into public primary and secondary education than has Uruguay, and the difference persists in this century. Its broader skill base has produced more equality in the long run by equalizing basic earning power, thereby achieving a greater reduction in inequality than Uruguay's more ambitious pensions and other transfer payments, even though both have existed since the dawn of the twentieth century. Here again, we must remember that each year's egalitarian investments have a longer lasting, though delayed, effect on equality than that year's expenditures can show.

On the public pension front, Costa Rica started developing its system early. Its pre-1948 institutional innovations became a permanent feature of Costa Rica's equity oriented policy framework, despite the defeat of the system's original designers during the civil war in 1949-1950. Costa Rica has more recently had the same problems of incomplete pension coverage and underfunding as in other countries, but these never became as serious as in Chile or Brazil or Colombia. The guidelines of social policy, like the larger issues of governance, were effectively resolved in the middle of the twentieth century, with a combination of political cooperation, foresight, and a lucky boom in coffee exports. ${ }^{37}$

\subsubsection{Peru Since the 1940s}

Peru has always spent a lower share of GDP on social programs than even Chile, as Table 4 has shown. And on balance, its fiscal redistributions have not yielded any net progressivity. The social policies since the 1940s in Peru have derived from the role that the state played in the economy, swaying from interventionism to (neo) liberalism. The steady growth of social spending since the 1940s was abruptly interrupted with the crisis of the late 1980s, and then resumed in the following decades.

Modest progress under an interventionist state. From 1945 to 1948, the government adopted a pro-distribution stance through income policies (such as price freezes and wage increases) and extension of social policies (including free and universal secondary education and the Sunday wage). The state was seen as a means of economic development and social integration and social spending increased accordingly. With a change to a more liberal regime the government implemented a

\footnotetext{
${ }^{37}$ On the early innovations, see Gonzalez-Vega and Céspedes (1993, pp. 82-85). For an appraisal of Costa Rica's redistributive policies today, see Oviedo et al. (2015, pp. 23-61).
} 
more pragmatic social policy with selected programs in education and health. From a macroeconomic point of view, none of these initiatives amounted to more than $2 \%$ of GDP. The government intervention to foster social progress had limited impact by the early 1960s. While the net benefits were progressive, they did little to overcome the initial market-based inequalities, especially for the rural traditional sector. Confronted with this reality the military government headed by President Velasco (1968-1973) initiated an ambitious plan to redistribute income and wealth. This conscious commitment to redistribution translated into a significant increase in social spending. ${ }^{38}$

Crisis and reform. The 1980s meant a continuous struggle to achieve macroeconomic stabilization resulting in a decrease of social and total public spending culminating in hyperinflationary episodes in 1987-1990. In the following decade the reorganization of the public sector included an expansion of social spending, especially in education and health. That expansion notwithstanding, Peru's fiscal redistribution failed to be progressive overall, as shown by the studies that have led to Table 2.

\section{Summary: What the Emerging Historical Patterns Suggest}

Most countries' social expenditure programs end up redistributing to an intermediate degree - that is, in the intermediate range shown in Table 2. They deliver a greater absolute value of benefits to higher income groups, relative to a flat per capita "poll subsidy." That looks regressive. On the other hand, they deliver rewards that are less unequal than the distribution of original incomes. That means that their expenditure pattern dampens the serious inequalities of original income. This slightly progressive tendency is reinforced by the modest progressivity in tax rates as a share of original market income.

Of the six countries covered here, the two most progressive have been Uruguay and Argentina, which have historically met the standard of absolute progressivity for a few decades. To judge from the region-wide situation at the start of the twentyfirst century, those two countries may have been the only absolutely progressive countries in all of Latin America, aside from Cuba.

To this pattern of only middling progressivity in social programs and taxes, we have added the easily documented tendency of Latin America to redistribute toward the current senior generation by investing little in the younger generations. Over recent decades the countries in the region have increasingly squandered lost economic capital and growth by spending their political capital on subsidizing the older generations with non-contributory public pensions. Of the countries studied here, the Southern Cone has redistributed away from future generations the most, and

\footnotetext{
${ }^{38}$ On social policies up through the 1960s, see Contreras and Cueto (2004) and Webb (1975). President Velasco's wealth redistribution policies included land reform, nationalization, and worker cooperatives (Figueroa 1995).
} 
Costa Rica has done so the least. While Peru and Colombia have also tended to tilt toward pensions, they have done so with smaller overall budgets in relation to GDP, and their regressive side has manifested itself in more conventional ways.

This low-investment tendency has featured a hundred-year history of lower investment in primary and secondary education. The implied prescription is to seize the opportunity, at last, of achieving both more equality and faster growth with broader investments in human skills. In this prescription our study seems to be in accord with the present-day prescription of Augusto de la Torre and co-authors:

"[E]fforts to equalize opportunities for human capital formation, particularly by broadening the access to high quality education regardless of socio-economic background, must be at the core of the search for shared prosperity in [Latin America and the Caribbean]." 39

The region as a whole still has time to reduce the pension deficits that even Chile's reform have not yet tamed. The opportunity is there because the region's populations are still younger than those of the core OECD countries or Eastern Europe. Yet the political will may not be there, in view of how readily the appetite for non-contributory public pensions has grown since the 1960s, and how halfhearted the commitment to public education remains.

Acknowledgements Our historical mapping introduces six cases: Chile, Argentina, Uruguay, Costa Rica, Colombia, and Peru. Other countries are being researched, and will be added in later publications. We are also developing a set of downloadable files, giving supporting data for Figs. 1-14 on the site http://gpih.ucdavis.edu. The authors thank Maria Marcela Harriague, Alejandra Irigoin, Joaquin Marandino Peregalli, Bruno Seminario de Marzi, Juan Diego Trejos, the editors, and conference participants for constructive comments, and the US National Science Foundation for research support under grant SES 1227237.

\footnotetext{
${ }^{39}$ De la Torre et al. (2014, p. 7).
} 


\section{Appendix 1: Data Sources and Notes for Table 4 and Figs. 1, 2, $3,4,5,6$, and 7}

\section{Table 4}

\section{Argentina}

Revenue =1900-1931: Vasquez-Presedo (1971), 1932-1964: AFIP (2009), 1965-2006: Ministerio de Economía y Producción (2006), 2007-2013: AFIP (2010), AFIP (2011), AFIP (2012), AFIP (2013).

Expenditure =1900-1915: Dirección General de Estadística (1915); 1929-1939: Vasquez-Presedo (1971); 1940-1962: Based on national budgets, Infoleg (2014), and IEERAL (1986); 1965-2006: Ministerio de Economía y Producción (2006), Oficina Nacional del Presupuesto (2014).

Nominal GDP=1900-1932: Ferreres (2005); 1932-2013: Ministerio de Economia y Finanzas (2014ab).

\section{Chile}

Revenue and expenditure = until 2000: Díaz et al. (2010); 2000-2013: online data from Banco Central de Chile and Ministerio de Economía.

Nominal GDP=Warner et al. (2000).

\section{Colombia}

Revenue=1900-1920: Departamento Administrativo Nacional de Estadística (1973); 1920-2003: Junguito y Rincón (2007); 2004-2013: Banco Central de Colombia (2014). For detailed data on income and wealth taxes: Anuario de Estadística General, various numbers and Dirección General de Presupuesto Público Nacional (2014).

Expenditure = 1900-1920: Departamento Administrativo Nacional de Estadística (1973); 1920-2003: Junguito y Rincón (2007); 2004-2013: Banco Central de Colombia (2014). For detailed data on public expenditure by type: Anuario de Estadística General, Banco Central de Colombia (1997), Dirección General de Presupuesto Público Nacional (2014).

Nominal GDP=GRECO (1998, 1999) and Banco Central de Colombia (2014). Note that nominal GDP experienced significant increase in the 1990s and over $35 \%$ from 1999 to 2000 due to a change in methodology. For the data series, see in http:// gpih.ucdavis.edu, the folder for "Government budget historical series," under the heading "Latin American fiscal redistribution", the file "Colombia central gov't budgets 1901-2013."

\section{Costa Rica}

Revenue $=1870-1958$ : total public revenue and by type kindly provided by Juan Diego Trejos. According to the tables, the data correspond to central government as reported by Román Trigo (1995). 1959-1970s: total public revenue and by type from Ramírez (1977); 1970-2013: total public revenue and by type from the Ministerio de Hacienda and the Central Bank of Costa Rica. Resource revenue corresponds to taxes on bananas and coffee. 1997-2012: Total revenue (including local government and decentralized units excluding the financial sector): Ministerio de Hacienda. Gobierno General: Ministerio de Hacienda (2014). 
Expenditure $=1870-1958$ : total public revenue and by type kindly provided by Juan Diego Trejos. According to the tables, the data correspond to central government as reported by Román Trigo (1995). 1973-2013: Total and debt expenditure: from the Ministerio de Hacienda and the Central Bank of Costa Rica. 1991-2013: Social expenditure estimated based on CEPAL. 1997-2012: Total expenditure (including local government and decentralized units excluding the financial sector): Secretaría Técnica de la Autoridad Presupuestaria Unidad de Análisis y Seguimiento Fiscal (2014) and Sauma and Trejos (1999).

Nominal GDP and nominal investment $=1950-2003$ : data kindly provided by Juan Diego Trejos; 2004-2014: Central Bank of Costa Rica. Note that the GDP was re-estimated starting in 1991 resulting in a $25-35 \%$ increase in GDP.

For the data series, see in http://gpih.ucdavis.edu, the folder for "Government budget historical series," under the heading "Latin American fiscal redistribution", the file "Costa Rica fiscal 1870-2013."

\section{Peru}

Revenue $=$ Total and composition: 1900-1989: Portocarrero et al. (1992), 19902013: Banco Central de Peru (2014).

Expenditure $=$ Total: 1900-1989: Portocarrero et al. (1992), 1990-2013: Banco Central de Peru (2014). Composition: 1900-1989: Portocarrero et al. (1992); 19702013: Debt payments: Banco Central de Peru (2014); 1998-2013: Education and Health: Ministerio de Economía y Finanzas (2014b), Defense and Pensions: Ministerio de Economía y Finanzas (2014a).

Nominal GDP=1900-1949: Seminario and Beltrán (1998); 1950-2013: Banco Central de Peru (2014).

For the data series, see in http://gpih.ucdavis.edu, the folder for "Government budget historical series,"under the heading" Latin American fiscal redistribution," the file "Peru gov't budgets 1900-2013."

\section{Uruguay}

Revenue, expenditure, and nominal GDP= until 1999 Azar et al. (2009); 20002008 online data from Ministerio de Economia y Finanzas.

Figure 1 (gross capital formation)

The source is World Bank (http://databank.worldbank.org/data/), accessed 13 March 2014.

Figure 2 (education versus pensions)

The sources are as listed for Table 1 .

Figures 3 and 4 (Chile)

The sources for fiscal data and nominal GDP are as listed for Table 4. The estimates of fiscal redistribution have utilized the studies by Engel et al., K. Lindert et al., and Lustig et al., as quantified in http://gpih.ucdavis.edu, the folder for "Government budget historical series," under the heading "Latin American fiscal redistribution," the file "Chile quintile effects 1842-2013."

Figures 5 and 6 (Argentina)

The sources for fiscal data and nominal GDP are as listed for Table 4. The estimates of fiscal redistribution have utilized the studies by Gasparini, Gómez Sabaini et al., Subsecretaria de Coordinación Económica, Lustig et al., SEDLAC, and 
UNU-Wider cited in http://gpih.ucdavis.edu the folder for "Government budget historical series," under the heading "Latin American fiscal redistribution," the file "Argentina fiscal incidence 1870-2009."

The level of government portrayed here varies by parameter and by time period. As far as we can determine from Gasparini (1999) and Lustig (2011), the allocation of recent-benchmark fiscal incidence effects refers to the effects of all consolidated government, not just central government. These recent-benchmark allocations are based on survey data, without any clear distinctions as to the level of government doing the taxing or making the social expenditures. When it comes to the historical fiscal data, however, the scope of government differs as follows:

For 1870-1949, central government budgetary data only

For 1950, 1955, 1960, and 1965, central, provincial, plus municipal governments; and for 1970-2009, consolidated accounts for all levels of government

Figure 7 (Uruguay)

The historical series on social budgets are from Azar et al. (2009). The distribution of household income per capita by decile, year 2000 is from WIID2c, downloaded January 2014, www.wider.unu.edu/research/Database/en_GB/wiid/. The fiscal incidence assumptions are borrowed from Buchele et al. (2013). See the calculations in http://gpih.ucdavis.edu, the folder for "Government budget historical series," under the heading "Latin American fiscal redistribution," the file "Uruguay quintile fiscal effects 1910-2008."

Open Access This chapter is distributed under the terms of the Creative Commons Attribution 4.0 International License (http://creativecommons.org/licenses/by/4.0/), which permits use, duplication, adaptation, distribution and reproduction in any medium or format, as long as you give appropriate credit to the original author(s) and the source, a link is provided to the Creative Commons license and indicate if changes were made.

The images or other third party material in this chapter are included in the work's Creative Commons license, unless indicated otherwise in the credit line; if such material is not included in the work's Creative Commons license and the respective action is not permitted by statutory regulation, users will need to obtain permission from the license holder to duplicate, adapt or reproduce the material.

\section{References}

Abad, L. A. (2013a). Persistent inequality? Trade, factor endowments, and inequality in Republican Latin America. Journal of Economic History, 73.01(March), 38-78.

Abad, L. A. (2013b). Instabilidad, Costo de Vida y Salarios Reales en Venezuela en el Siglo XIX [Instability, Cost of Living, and Real Wages in Venezuela in the 19th Century]. América Latina en la Historia Económica, 20.3(September-December), 114-137.

Acuña Rodrigo, R., \& Augusto Iglesias, P. (2001). Chile's pension reform after 20 years. World Bank, Social Protection Discussion Paper 0129 (December).

Administración Federal de Ingresos Públicos (AFIP). (2007-2013). Anuario Estadísticas Tributarias. Retrieved October 12, 2014 from http://www.afip.gob.ar/estudios/anuario.asp. 
Ahumada, H., \& Canavese, A., Sanguinetti, P., \& Escudero, W. S. (1993). Efectos distributivos del impuesto inflacionario: una estimación para el caso argentino. Economía Mexicana, II(2), 329-383.

Alvaredo, F. (2007). The rich in Argentina over the twentieth century: From the conservative republic to the Peronist experience and beyond 1932-2004. Paris School of Economics Working Paper 2007-02.

Arza, C. (2010). La política previsional argentina: de la estratificación ocupacional a la individualización de los beneficios. In S. Torrado (Ed.), El costo social del ajuste (1976-2002), Buenos Aires, EDHASA, 2010.

Azar, P., Bertino, M., Bertino, R., Fleitas, S., Garcia Repetto, U., Sanguinetti, C., et al. (2009). ¿De Quiénes, para Quiénes, y para Qué? Las Finanzas Públicas en el Uruguay de Siglo XX. Montevideo: Editorial Fin de Siglo.

Banco Central de Colombia. (1997). Estadísticas Históricas, CD-ROM.

Banco Central de Colombia. (2014). PIB, producción, salarios y empleo. Retrieved November 1 , 2014 from http://www.banrep.gov.co/es/series-estadisticas/see_prod_salar.htm.

Banco Central de la República Argentina. (1955). Memoria. Buenos Aires: BCRA.

Banco Central de Venezuela. (2014). Agregados Macroeconómicos. Retrieved November 1, 2014 from http://www.bcv.org.ve/c2/indicadores.asp.

Berry, R. A., \& Urrutia, M. (1976). Income distribution in Colombia. New Haven: Yale University Press.

Blanco, E. A. (1956). La política presupuestaria, la deuda pública y la economía nacional. Buenos Aires: Ministerio de Hacienda de la Nación.

Braceda, K., Rigolini, J., \& Saavedra, J. (2009). Latin America and the social contract: Patterns of social spending and taxation. Population and Development Review, 35(4), 721-748.

Buchele, M., Lustig, N., Rossi, M., \& Amábile, F. (2013, January). Social spending, taxes, and income redistribution in Uruguay. Commitment to Equity Working Paper No. 10.

Central Bank of Costa Rica. (2014). Indicadores Económicos. Retrieved October 21, 2014 from http://www.bccr.fi.cr/indicadores_economicos_/finanzas_publicas.html.

CEPAL [United Nations, Economic Commission for Latin America and the Caribbean (ECLAC)]. (1958). El desarrollo económico de la Argentina. Santiago de Chile: CEPAL.

Cetrángolo, O., \& Gómez-Sabaini, J. C. (2006). Tributación en América Latina. En busca de una nueva agenda de reformas. Santiago de Chile: CEPAL.

Chenery, H., Ahluwalia, M., Bell, C., Duloy, J., \& Jolly, R. (1974). Redistribution with growth. London: World Bank and the Institute of Development Studies, University of Sussex by Oxford University Press.

Clavijo, S. (2009, March). Social security reforms in Colombia: Striking demographic and fiscal balances. IMF Working Paper WP/09/58.

Clemens, M.B., Faircloth, C., \& Verhoeven, M. (2007). Public expenditure in Latin America: Trends and key policy issues. IMF Working Papers WP/07/21.

Cohen, D., \& Soto, M. (2007). Growth and human capital: Good data, good results. Journal of Economic Growth, 12(1), 51-76.

Contreras, C., \& Cueto, M. (2004). Historia del Perú contemporáneo. Lima: Universidad del Pacífico.

Cruz-Saco, M. A., \& Mesa-Lago, C. (1998). Do options exist? The reform of pension and health care systems in Latin America. Pittsburgh: University of Pittsburgh Press.

de la Torre, A., Yeyati, E. L., Beylis, G., Didier, T., Castelán, C. R., \& Schmukler, S. (2014). Inequality in a lower growth Latin America. LAC Semiannual Report (October). Washington, DC: World Bank.

DeFerranti, D., Perry, G. E., Ferreira, F. H. G., \& Walton, M. (2004). Inequality in Latin America: Breaking with history? Washington: World Bank.

Díaz, J., Lüders, R., \& Wagner, G., \& La República en Cifras (2010). EH Clio Lab-Iniciativa Científica Milenio. Retrieved from http://www.economia.puc.cl/cliolab.

Dirección General de Estadística. (1915). Extracto estadístico de la República Argentina. Buenos Aires: Compañia Sud-Americana de Billetes de Banco. 
Dirección General de Presupuesto Público Nacional. (2014). Bitácora Cifras Presupuestales. Retrieved November 5, 2014 from http://www.minhacienda.gov.co/HomeMinhacienda/politicafiscal/GobiernoNacionalCentralGNC/Tab.

ECLAC. (2014). Compacts for equality: Towards a sustainable future. Santiago: United Nations.

ECLAC [United Nations, Economic Commission for Latin America and the Caribbean (or CEPAL)]. (2012). Structural change for equality: An integrated approach to development. Santiago: United Nations.

Engel, E. M. R. A., Galetovic, A., \& Raddatz, C. E. (1999). Taxes and income distribution in Chile: Some unpleasant redistributive arithmetic. Journal of Development Economics, 59, 155-192.

Felipe Portocarrero, S., Arlette Beltrán, B., \& Maria Elena Romero, P. (1992). Compendio estadistico del Peru, 1900-1990. Lima: Universidad del Pacífico.

Ferreres, O. J. (2005). Dos siglos de economía Argentina, 1810-2004: historia Argentina en cifras. Buenos Aires, Argentina: Editorial El Ateneo.

Figueroa, A. (1995). La cuestión distributive en el Perú. In J. Cotler (Ed.), Perú, 1964-1994. Lima: IEP.

Franco, R. (1992). Nuevas orientaciones de la política social en América Latina. CEPAL. Retrieved November 1, 2014 from http://repositorio.cepal.org/handle/11362/18993.

Gaggero, J. (2008). La progresividad tributaria: su origen en Occidente, su apogeo y extravío en Argentina y los desafíos de hoy. Paper presented the the XXI Jornadas de Historia Económica, Caseros, Buenos Aires, Argentina.

Gerchunoff, P. (1989). Peronist economic policies, 1946-1955. In G. di Tella \& R. Dornbusch (Eds.), The political economy of Argentina, 1946-83. Pittsburgh: Pittsburgh University Press.

González-Vega, C., \& Céspedes., V. H. (1993). Part I. Costa Rica. In S. Rottenberg (Ed.) Costa Rica and Uruguay (pp. 3-185). Oxford: Oxford University Press for the World Bank.

GRECO. (1998). El crecimiento económico colombiano en el siglo XX: aspectos globales. Documento de Trabajo del Banco Central de Colombia.

GRECO. (1999). El desempeño macroeconómico colombiano, series estadísticas. Documento de Trabajo del Banco Central de Colombia.

Hertz, T., Jayasundera, T., Piraino, P., Selcuk, S., Smith, N., \& Verashchagina, A. (2007). The inheritance of educational inequality: International comparisons and fifty-year trends. The B.E. Journal of Economic Analysis \& Policy, 7(2), Article 10.

IEERAL. (1986). Estadísticas de la evolución económica de Argentina, 1913-1984. Estudios 9(36).

InfoLeg. (2014). Presupuestos Nacionales. Retrieved 07/2014-11/2014 from http://infoleg.mecon. gov.ar/?page_id=837.

Junguito, R., \& Rincón, H. (2007). La política fiscal en el siglo XX en Colombia. In J. Robinson, \& M. Urrutia (Eds.), Economía Colombiana del Siglo XX: Un Análisis Cuantitativo. Colombia: Banco de la República y Fondo de Cultura Económica.

Lee Hansen, H. W., \& Weisbrod, B. A. (1969). The distribution of costs and direct benefits of public higher education: The case of California. Journal of Human Resources, 4(2), 176-191.

Lindert, P. H. (2010). The unequal lag in Latin American schooling since 1900: Follow the money. Revista de Historia Económica, 28(2), 375-405.

Lindert, K. A.,Skoufias, E., \& Shapiro, J. (2006, August). Redistributing income to the poor and the rich: Public transfers in Latin America and the Caribbean. World Bank, SP Discussion Paper 0605.

Lustig, N., Molina, G., Paz, V., Pereira, C., Scott, J., Pessino, C., et al. (2011, November). Fiscal policy and income redistribution in Latin America: Challenging the conventional wisdom. Tulane University Economics Working Paper 1124 (October). Also EcIneq Working Paper 227.

Marshall, A. (1988). Políticas sociales: el modelo neoliberal. Argentina (1976-1983). Buenos Aires: Editorial Legasa.

Ministerio de Economía, \& Finanzas y Banca Pública. (2014). Estadísticas Fiscales. Retrieved November 7, 2014 from http://www.mefbp.gob.ve/index.php?option=com_content\&view=arti cle\&id=245\&Itemid $=381$. 
Ministerio de Economía y Finanzas. (2014). Estadísticas. Retrieved November 5, 2014 from https://mef.gob.pe/index.php?option=com_content\&view=article\&id=364\&Itemid=100292\&1 ang=es.

Ministerio de Economía y Finanzas. (2014). Gasto Social Público. Retrieved November 7, 2014 from http://www.mef.gob.pe/index.php?option=com_content\&view=article\&id=280\&Itemid $=100850$ \&lang=es.

Ministerio de Economía y Producción. (2006). Presupuesto de la Administración Nacional: Gastos por Finalidad-Función y Naturaleza Económica, 1965-2006. Buenos Aires: Ministerio de Economía y Producción.

Ministerio de Hacienda. (2014). Cifras Fiscales y Estadísticas. Retrieved October 21, 2014 from http://www.hacienda.go.cr/contenido/698-gobierno-central.

Oficina Nacional del Presupuesto (2014). Series estadísticas, Administración Nacional por Finalidad-Función y Naturaleza Económica, 2007, 2008, 2009, 2010, 2011, 2012, 2013. Retrieved November 1, 2014 from http://www.mecon.gov.ar/onp/html/\#.

Olviedo, A. M., Sanchez, S. M., Lindert, K. A., \& Humberto Lopez, J. (2015). Costa Rica's development: From good to better. Washington: World Bank Systematic Country Diagnosis.

Pallares-Miralles, M., Romero, C., \& Whitehouse, E. (2012, June). International patterns of pension provision II: Worldwide overview of facts and figures. World Bank Social Protection \& Labor Discussion Paper 1211.

Public Finance Review. (2014, May). 42(3). Special Issue: Analyzing the Redistributive Impact of Taxes and Transfers in Latin America.

Ramírez, E. (1977). Los ingresos corrientes del Gobierno Central un análisis econométrico 19501975, UCR/IICE.

Reimers, F. (2006). Education and social progress. In V. Bulmer-Thomas, J. H. Coatsworth, \& R. Cortés Conde (Eds.), The Cambridge economic history of Latin America (Vol. II, pp. 427480). Cambridge: Cambridge University Press.

Rodriguez Weber, J., \& Thorp, R. (2013). The political economy of (re)distribution with low growth: Uruguay 1900-1973. As downloaded, 14 December, 2013. Las XXVIII Jornadas Anuales de Economía, Banco Central del Uruguay, Montevideo 8 de noviembre de 2013.

Román Trigo, A. C. (1995). Las finanzas públicas de Costa Rica: Metodología y Fuentes (18701948). Serie de Trabajos de Metodología, 3.

Rottenberg, S. (Ed.). (1993). Costa Rica and Uruguay. Oxford: Oxford University Press for the World Bank.

Sauma, P., \& Trejos, J. D. (1999). Costa Rica. In L. C. Delgado, C. E. Reyes Gonzalo, \& A. Sarmiento Gómez (Eds.), Gasto Público en Servicios Sociales Básicos en América Latina y el Caribe: análisis desde la perspectiva de la iniciativa 20/20. Santiago de Chile: CEPAL.

Sauma, P., \& Trejos, J. D. (2014, March). Social public spending, taxes, income, and poverty in Costa Rica. Commitment to Equity Working Paper No. 18.

Secretaría Técnica de la Autoridad Presupuestaria Unidad de Análisis y Seguimiento Fiscal. (2014). Consolidación por Clasificación Funcional. Retrieved October 31, 2014 from http:// www.hacienda.go.cr/docs/545165afe3643_FUNCIONAL\%202013\%20PARA\% 20 PUBLICAR.pdf.

Selowsky, M. (1979). Who benefits from government expenditure? A case study of Colombia. Oxford: Oxford University Press for the World Bank.

Selva, R., \& Iñiguez, A. (2009). Descripción de la evolucióndel Gasto Público Consolidado del Sector Público Argentino: 1980-2008. Buenos Aires: Ministerio de Economía.

Seminario, B., \& Beltrán, A. (1998). Crecimiento económico en el Perú, 1896-1995: nuevas evidencias estadísticas. Lima, Perú: Universidad del Pacífico, Centro de Investigación.

Sokoloff, K., \& Zolt, E. M. (2006). Inequality and taxation: Evidence from the Americas on how inequality may influence tax institutions. Tax Law Review, 59, 201-276.

Solt, F. (2009). Standardizing the world income inequality database. Social Science Quarterly, 90(2), 231-242.

Solt, F. (2014). The standardized world income inequality database. frederick-solt@uiowa.edu. Retrieved from October 2, 2014. 
Székely, M., \& Montes, A. (2006). Poverty and inequality. In V. Bulmer-Thomas, J. H. Coatsworth, \& R. Cortés Conde (Eds.), The Cambridge economic history of Latin America (Vol. II, pp. 585-645). Cambridge: Cambridge University Press.

Vasquez-Presedo, V. (1971). Estadisticas Historicas Argentinas (comparadas), Premier Parte $1875-1914$.

Véganzonès, M.-A., \& Winograd, C. (1997). Argentina in the 20th century: An account of long-awaited growth. Paris: OECD.

Velez-Grajales, R., Campos-Vazquez, R., \& Huerta-Wong, J. E. (2014). Report on social mobility in Mexico: Imagine your future. Mexico: The Espinosa Yglesias Research Centre (ceey).

Wang, C., Caminada, K., \& Goudswaard, K. (2012). The redistributive effect of social transfer programmes and taxes: A decomposition across countries. International Social Security Review, 65(3), 27-48.

Webb, R. (1975). Políticas gubernamentales y distribución del ingreso en el Perú, 1962-1971. In R. Webb \& A. Figueroa (Eds.), Distribución del ingreso en el Perú. Lima: IEP.

Williamson, J. G. (2010). Five centuries of Latin American inequality. Revista de Historia Económica., 28(2), 227-252.

Leticia Arroyo Abad is an associate professor of Economics at Middlebury College. Her research agenda looks at development and growth in historical perspective. With special focus on Latin America, she explores topics related to inequality, living standards, and economic growth. Her work was published in academic journals such as the Journal of Economic History, Explorations in Economic History, and the Journal of Iberian and Latin American Economic History.

Peter H. Lindert is an economic historian, Distinguished Research Professor of Economics at the University of California-Davis, and a Research Associate of the National Bureau of Economic Research. His works on the welfare state and inequality include his prize-winning book Growing Public: Social Spending and Economic Growth since the Eighteenth Century (Cambridge University Press 2004) and his book Unequal Gains: American Growth and Inequality since 1700 (Princeton University Press 2016), coauthored with Jeffrey Williamson. 


\section{Part II}

\section{The Recent Inequality Downturn}




\title{
Inequality in Latin America: ECLAC's Perspective
}

\author{
Verónica Amarante and Antonio Prado
}

Equality has been at the center of ECLAC's analysis of the region since structuralist times. In those pioneering writings, the distribution of assets and the concentration of power in the hands of elites were crucial aspects to understand (the lack of) equality in the region. Following this tradition, the last three documents that the institution submitted for consideration by the Governments of Latin America and the Caribbean at its three last sessions have put equality back in the center of the regional agenda, expanding the conception of equality beyond distributive fairness - whose scope tends to be confined to the distribution of transferable, quantifiable resources - taking in other dimensions and considering equality in a "relational" context of socialization, autonomy, and recognition.

As put forth in Time for equality: closing gaps, opening trails (ECLAC 2010), the quest for equality is part of the drive to abolish privileges and establish equal rights for all individuals, regardless of origin, affiliations, or position in society. It calls not only for universal civil and political rights but also for advancing towards distributive justice in which everyone enjoys the benefits of progress. Time for equality argued that equality stands at the crossroads between economic growth, social inclusion, and recognition of diversity, advocating a kind of development that forges a positive link between greater equality and gains in productivity, capacities, and sustainable growth. The document postulated that social equality and the kind of economic dynamism that transform production patterns are not at odds with each other and that the challenge is to find synergies between the two. The growth strategy should include less structural heterogeneity and more productive development, and the pursuit of equality through the enhancement of human capacities and the mobilization of state energies. The basic idea is the need of building more cohesive societies around productive dynamics, constructing positive social and territorial synergies, and strengthening the protection of individuals through improvements in labor markets.

\footnotetext{
V. Amarante $(\varangle) \cdot$ A. Prado

Economic Commission for Latin America and the Caribbean (ECLAC), Santiago, Chile 
The economic content of this approach was further developed in Structural Change for Equality: An Integrated Vision of Development (ECLAC 2012), which understands structural change as the path leading to greater equality. In this vision, structural change means putting qualitative changes in the production structure at the centre of the growth dynamic. Improved global insertion and virtuous growth in domestic productivity and employment call for greater participation by knowledge-intensive sectors in overall production. This fosters the building of capacities, knowledge, and learning in coordination with production and investment across the economy. For the region, structural change must take place on two interconnected fronts: enhancing the share of more knowledge-intensive sectors in production and trade, and diversifying towards sectors where domestic and external demand is expanding rapidly, so that demand can be met with domestic supply and imports and exports can grow in a balanced manner without putting unsustainable pressure on the balance of payments. By centering growth on the creation of new sectors and the dissemination of technology throughout the system, structural change creates job opportunities in higher productivity sectors while pushing labor market participation rates up and unemployment and informality rates down. In the long run, this strategy would lead to poverty and inequality reduction. When the production structure is very polarized, purely redistributive fiscal and social mechanisms do not solve the problems of inequality and slow growth in the long run. Sooner than later, policies will have to target the generation of job and training opportunities in the framework of structural change. The adoption of industrial policies that encourage this transformation should be considered, along with social policies, as they are key dimensions of the equality horizon. For example, production linkages are part of structural change; they prevent concentration and disseminate gains throughout society. Conversely, social and redistributive policies should accompany industrial policy. For one, they improve distribution and reduce vulnerability in the short term, creating an intertemporal linkage that enables structural change-oriented policies to achieve their redistributive impacts, which are longer term. Moreover, social policy should protect the most disadvantaged sectors during the disruptive periods of structural change (when sector realignment can involve periods of adjustment with unemployment), as well as from the social impacts of external or other shocks.

The most recent session document, Compacts for equality (ECLAC 2014a), gets deeper into the concept of equality that ECLAC wants to promote, stating that it includes equality of means, opportunities, and capacities, but in the framework of a deeper understanding of equality as the equal dignity of citizens, in which individuals are simultaneously autonomous and vulnerable and should be acknowledged for both qualities mutually. In this framework, the document provides a detailed analysis of inequality in different dimensions in Latin America, arguing that equality gains in the region in the last decade are not seen in all dimensions but mainly confined to means, most notably income inequality. The document also points to warning signs relating to structural components that drive inequality, both productive and social. Although many improvements took place, the main warning signs refer to the absence of structural changes mainly in the 
production sectors, but also in some aspects of social sectors. The closing part of the document focuses on how strategic visions of a more egalitarian and sustainable development can be built into the rationale for collective accords between stakeholders.

Embracing a broader conception of equality which goes beyond means or resources does not imply at all that resource inequality is considered unimportant in ECLAC's view. Indeed, alongside its history, ECLAC has contributed substantially to the analysis and understanding of income inequality in the region, considering its determinants both in terms of structuralist theory and from the various perspectives developed within the institution itself. Given the scope of this volume, the following pages aim to reflect some of the most recent contributions from ECLAC in relation to the analysis of income inequality. But this is done within this wider scope, reinforcing different dimensions of inequality and considering the importance of labour market institutions. In the following sections, we first describe the recent evolution of income inequality in Latin America (Sect. 1) and then consider the role that the labour market, and specifically the minimum wage and the formalization process, has had in some countries in the region (Sect. 2). We then turn into gender inequalities, analysing female labour participation and its potential impacts on poverty and inequality (Sect. 3). Finally, we present some concluding remarks (Sect. 4).

\section{Recent Evolution of Income Inequality in Latin America}

Inequality in resource distribution, and specifically in income distribution, is one distinguishing feature of Latin America. Recent comparisons of Gini coefficients on household consumption per capita calculated for developing regions do confirm that the median Gini is higher in Latin America and the Caribbean, although the mean Gini is slightly lower than in sub-Saharan Africa (Alvaredo and Gasparini 2015). In any case, the levels of inequality are high for almost every country in the region, and undoubtedly inequality is a persistent characteristic of LAC.

In the last 15 years, income inequality has shown a significant decrease. This decline in inequality derives from higher income growth at lower income percentiles in the region. Figure 1 illustrates this evolution, based on pooled countryspecific household data for 18 countries. We consider two alternative exchange rates to convert national currencies into a common numeraire: purchasing power parity (PPP) exchange rates, and ECLAC poverty lines for each country. For both variables, income growth has been significantly higher among lower income households, consistently with the important reduction in income poverty that the region experimented in this period (see ECLAC 2014b). 


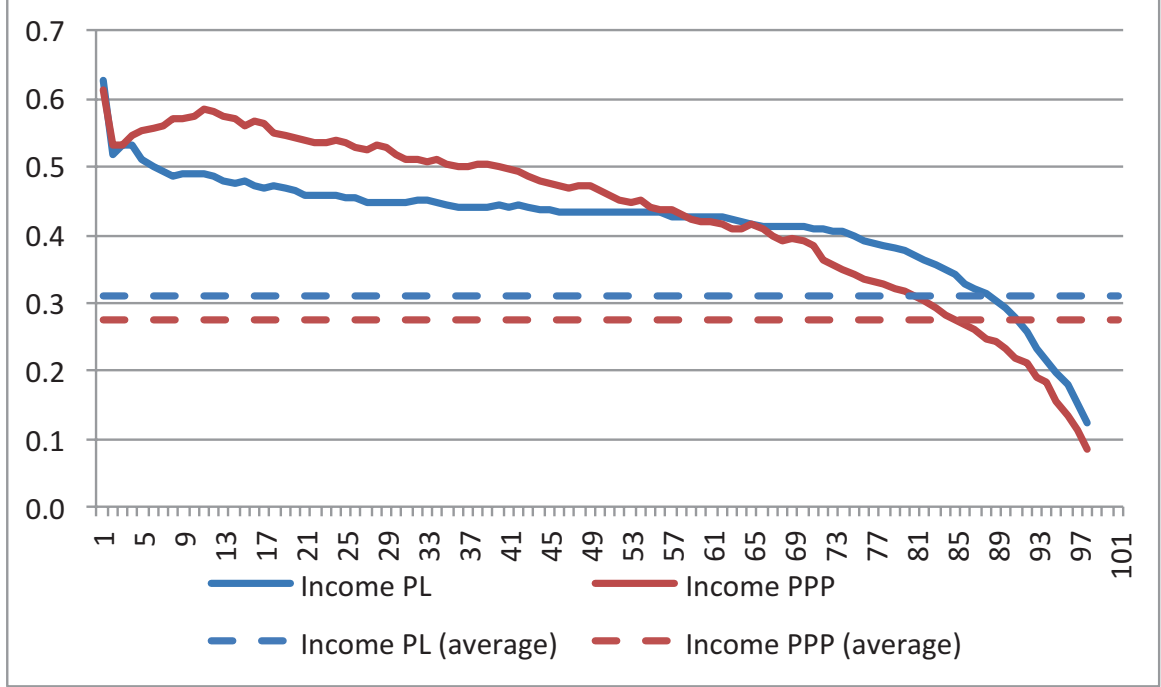

Fig. 1 Latin America: Growth incidence curve of household per capita income 2002-2012. Source: Economic Commission for Latin America and the Caribbean (ECLAC), on the basis of special tabulations of data from household surveys conducted in the respective countries, and World Development Indicators

If we turn into inequality by country, in all countries in the region, with the exception of Costa Rica, Dominican Republic, and Guatemala, household surveys report a decrease in the Gini coefficient of household per capita income between 2002 and 2013 (Table 1). The decreased trend is present when data for 2009 is considered, and continues for most countries for the latest available data. The magnitude of the decline has been differential by countries, with decreases above $5 \%$ in Argentina, Bolivia, and Venezuela. All other measures of income inequality show a similar pattern of statistically significant reduction in inequality (see ECLAC 2013, 2014b) among others.

Abundant research has tried to understand the distributive turnaround in Latin America. A microeconometric decomposition exercise presented by ECLAC (2011) notes that income per adult, and specifically earnings, was the main factor in the fall in inequality. The demographic factor was found to have had a modest effect on inequality, as the dependency ratio fell fairly evenly across all income levels. On the basis of an analysis of four middle-income countries in the region (Argentina, Brazil, Mexico, and Peru), López-Calva and Lustig (2010) conclude that two main factors account for the easing inequality in the countries: a narrowing of the wage gap between high-skilled and low-skilled workers and, to a lesser extent, an increase in government transfers to the lowest income households. This leads them to assert that in the famous "race between education and technology", to use Tinbergen's (1975) phrase, the former has taken the lead. Thus, whereas the demand for skills outpaced 
Table 1 Income inequality in Latin America

\begin{tabular}{l|l|l|l|l|l|l}
\hline & \multicolumn{3}{l}{ Gini coeficient } & \multicolumn{3}{l}{ Annual changes in Gini coefficient } \\
\hline & $\begin{array}{l}\text { Circa } \\
2002\end{array}$ & $\begin{array}{l}\text { Circa } \\
2009\end{array}$ & $\begin{array}{l}\text { Circa } \\
2013\end{array}$ & $\begin{array}{l}2002-2009 \\
(\%)\end{array}$ & $\begin{array}{l}2009-2013 \\
(\%)\end{array}$ & $\begin{array}{l}2002-2013 \\
(\%)\end{array}$ \\
\hline Argentina $^{a}$ & 0.578 & 0.510 & 0.475 & -1.8 & -1.8 & -4.8 \\
\hline Bolivia & 0.614 & 0.508 & 0.472 & -2.7 & -1.8 & -6.4 \\
\hline Brazil & 0.634 & 0.576 & 0.553 & -1.4 & -1.0 & -3.4 \\
\hline Chile & 0.552 & 0.524 & 0.509 & -0.7 & -0.7 & -2.0 \\
\hline Colombia & 0.567 & 0.553 & 0.536 & -0.4 & -0.8 & -1.4 \\
\hline Costa Rica & 0.488 & 0.501 & 0.512 & 0.4 & 0.5 & 1.2 \\
\hline Ecuador & 0.539 & 0.500 & 0.477 & -1.1 & -1.2 & -3.0 \\
\hline El Salvador & 0.525 & 0.478 & 0.453 & -1.3 & -1.3 & -3.6 \\
\hline Guatemala & 0.542 & 0.585 & & 1.1 & & \\
\hline Honduras & 0.588 & 0.554 & 0.573 & -0.8 & 0.8 & -0.6 \\
\hline Mexico & 0.514 & 0.515 & 0.492 & 0.0 & -1.1 & -1.1 \\
\hline Nicaragua & 0.579 & 0.478 & & -2.7 & & \\
\hline Panama & 0.567 & 0.526 & 0.527 & -1.1 & 0.0 & -1.8 \\
\hline Paraguay & 0.563 & 0.512 & 0.522 & -1.3 & 0.5 & -1.9 \\
\hline Peru & 0.530 & 0.469 & 0.444 & -1.7 & -1.4 & -4.3 \\
\hline Dominican Rep. & 0.537 & 0.574 & 0.544 & 1.0 & -1.3 & 0.3 \\
\hline Uruguaya & 0.455 & 0.446 & 0.380 & -0.3 & -3.9 & -4.4 \\
\hline Venezuela & 0.500 & 0.416 & 0.407 & -2.6 & -0.5 & -5.0 \\
\hline AL (simple average) & 0.548 & 0.513 & 0.492 & -1.0 & -1.0 & -2.7 \\
\hline Source Econ & & & & & & \\
\hline
\end{tabular}

Source: Economic Commission for Latin America and the Caribbean (ECLAC), on the basis of special tabulations of data from household surveys in the respective countries

aUrban areas

supply in the 1990s, the opposite appears to have happened in the past few years. Azevedo et al. (2013), analysing the employed population in 15 countries of the region, also conclude that the decline in the education premium has been driven by a greater supply of skilled workers.

A different view is put forward by Gasparini et al. (2012), who estimate the relative contribution of supply and demand factors to recent trends in the education premium in 16 countries of Latin America. They show that the relative supply of skilled and semi-skilled workers has been increasing since the 1990s. In both the 1990s and the 2000s, the returns on completion of secondary education diminished, while the returns on tertiary education increased in the 1990s but declined again in the 2000s. These authors argue that the rise in the skilled labour supply is not the only factor explaining the recent decline in inequality, and that the slowdown in relative demand for skilled labour in the last decade has also played a role. This shift in relative demand for workers with tertiary education appears to be a result of the commodity price surge, which has boosted demand for unskilled labour and driven down the education wage premium. De la Torre and Pienknagura (2012) also stress the importance of labour market changes, with workers moving from manufacturing sectors to service-intensive sectors tied to natural-resource-related production. The 
case studies presented in Cornia (2014) also show that the recent drop in inequality in the region has been facilitated by the commodity price boom, especially in the countries whose exports are most commodity intensive. It is argued that this has not been the only cause, however, as inequality has also been falling in countries that are semi-industrialized or heavily dependent on remittances.

These findings are disturbing, to say the least. They suggest that a situation could be occurring in which sectoral composition, heavily influenced as it is by natural-resource-centred economies, is generating greater relative demand for lowskilled workers, narrowing the gap in returns on education. Rather than a sign of development being reconciled with equality, this would be a warning that the combination of stagnating productivity and the region's specialization pattern is sending out signals that discourage educational progression and capability development. While this evidence is not yet conclusive and the debate is still open, it is necessary to consider this possible scenario and assess the potential implications of this interpretation of the region's recent decline in inequality. This recent story reminds us about the importance of the productive structure in the determination of income inequality.

It is also relevant to consider the political dynamic behind the recent decline in inequality in the region. Democratic life has given rise to new electoral preferences and brought social demands to greater prominence. This means that, in a positive cycle of economic stability, governments respond to these demands for social inclusion with new, more redistributive policies. In most cases, these are reforms inspired by the idea of "prudent redistribution with growth" (Cornia 2010) by way of fiscal, employment, and progressive transfer policies. Indeed, the fiscal system has generally become more redistributive than it was, although its contribution in this area remains limited.

Redistributive policies and social reforms have not been the sole preserve of left-wing governments in the region; rather, the institutionalization of electoral competition in contexts of pronounced economic and social inequality seems to have led parties and governments of different ideological stripes to strive to respond to popular demands for equality and social inclusion (Roberts 2014). In some of the countries of the region, labour market institutions do seem to have played a key role, although it has been mainly neglected by most of the related literature. As the next section discusses, some important changes in labour market institutions and dynamics may have played a key role in some specific countries.

\section{Inequality and Labour Market Institutions}

As discussed in the previous section, recent explanations for declining inequality in the region have focused on factors driving supply and demand for workers at different qualification levels. Some recent research from ECLAC suggests the importance 
of considering, in addition, the role of labour institutions in the distributive improvements in some countries of the region. Narrowing wage differentials could indeed be affected, in some countries of the region, by strengthening the minimum wage and other tools, such as formalization in the labour market. The following paragraphs, based on ECLAC (2014a) and Amarante and Arim (2015), provide some insights about the role of labour market institutions in the recent decline in wage inequality in the region.

\subsection{Inequality and Minimum Wage}

The potential effects of minimum wage hikes on labour market variables are controversial (see ECLAC 2014a). Given the fact that in some countries in the region the minimum wage rose and wage inequality declined simultaneously in a context of employment growth, it is important to assess the potential link between both features. In the following paragraphs we report some results presented in ECLAC (2014a) which illustrate the effects of minimum wage increases in Argentina, Brazil, and Uruguay (three countries where recovery of the minimum wage has been substantial) and Chile (where growth has been less striking). ${ }^{1}$

In Argentina, the minimum wage had remained at the same low nominal and real value since 1993 and plummeted in 2002. A forceful minimum wage updating policy was rolled out in 2003, leading to a sharp real increase of more than $200 \%$ between 2008 and 2012. But this uptrend faltered in 2007 as accelerating inflation ate into the gains in minimum wage purchasing power (Fig. 2). ${ }^{2}$ In Brazil, recovery began earlier than in Argentina, towards the mid-1990s, but really gathered momentum in the 2000s as the minimum wage rose around $100 \%$ in real terms between 2000 and 2012. The trend was similar, albeit less marked, in Chile, which posted an increase of about $40 \%$ over the same period. And Uruguay, the last country in which income inequality began to trend downwards, was also the last to start bolstering the minimum wage. The real value of the minimum wage in Uruguay had been dropping steadily in recent decades. The slide reversed in late 2004 , with the purchasing power of the minimum wage soaring $180 \%$ between 2005 and 2012.

The ability of governments to use the minimum wage as a labour policy instrument depends on the extent to which the economy is indexed to the minimum wage. Brazil and Uruguay are two cases in which the minimum wage has been linked to social benefits. In Brazil, under the 1988 Constitution, the minimum wage is the threshold for social benefits. In Uruguay, until 2004, the minimum wage was the reference point for determining eligibility for and the value of a

\footnotetext{
${ }^{1}$ These results are based on Maurizio (2013). It should be noted that this analysis covers countries with relatively low levels of informality in the region. In countries with highly informal economies, the minimum wage can influence informal sector wages more and tend to maintain segmentation barriers.

${ }^{2}$ Real variation is calculated using a weighted index of price indices for the provinces.
} 


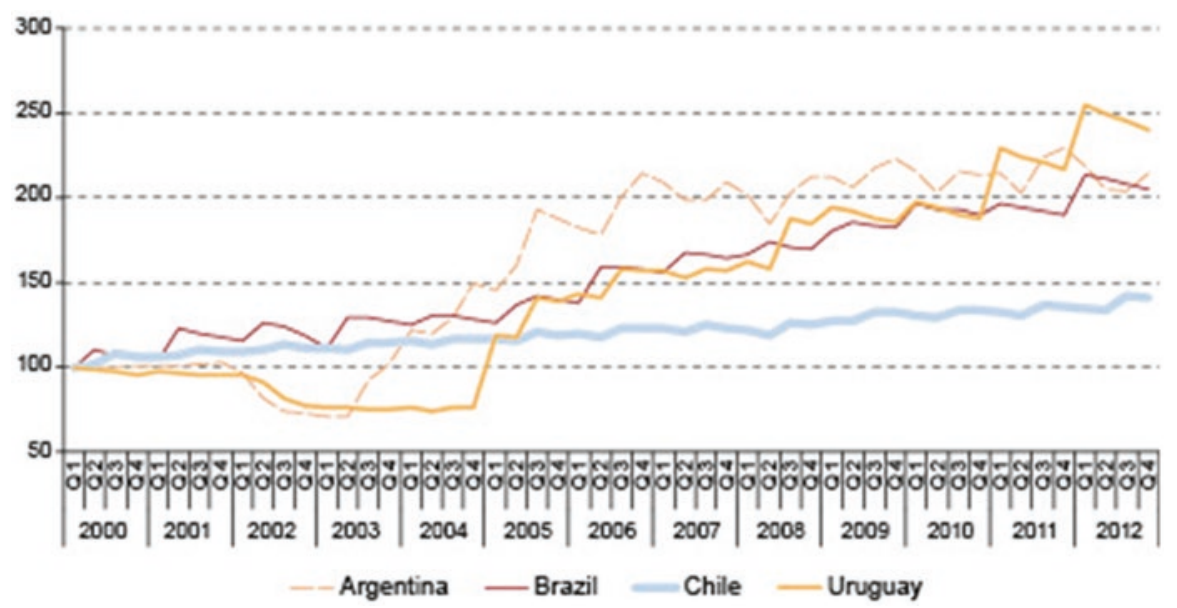

Fig. 2 Latin America (selected countries): Change in the real minimum wage, 2000-2012. (Local currencies, constant prices at latest observation.) Source: Economic Commission for Latin America and the Caribbean (ECLAC) and the International Labour Organization (ILO), on the basis of official data for the minimum wage and consumer price index (CPI) from countries

Table 2 Latin America (four countries): minimum wage in relation to the wage distribution (ratios)

\begin{tabular}{l|l|l|l|l|l}
\hline & & $\begin{array}{l}\text { Minimum } \\
\text { wage/average }\end{array}$ & $\begin{array}{l}\text { Minimum } \\
\text { wage/median }\end{array}$ & $\begin{array}{l}\text { Minimum wage/10th } \\
\text { percentile }\end{array}$ & $\begin{array}{l}\text { Minimum wage/20th } \\
\text { percentile }\end{array}$ \\
\hline \multirow{2}{*}{ Argentina } & 2003 & 0.30 & 0.39 & 0.79 & 0.61 \\
\cline { 2 - 6 } & 2012 & 0.47 & 0.53 & 1.06 & 0.81 \\
\hline \multirow{3}{*}{ Brazil } & 2003 & 0.25 & 0.44 & 0.88 & 0.65 \\
\cline { 2 - 6 } & 2011 & 0.30 & 0.50 & 0.86 & 0.72 \\
\hline \multirow{3}{*}{ Chile } & 2000 & 0.31 & 0.49 & 0.92 & 0.82 \\
\cline { 2 - 6 } & 2011 & 0.37 & 0.60 & 0.84 & 0.82 \\
\hline \multirow{2}{*}{ Uruguay } & 2004 & 0.13 & 0.18 & 0.43 & 0.31 \\
\cline { 2 - 6 } & 2012 & 0.30 & 0.37 & 0.74 & 0.59 \\
\hline
\end{tabular}

Source: ECLAC (2014a)

comprehensive package of social benefits, with the resulting fiscal impacts. The real minimum wage in Uruguay had to be de-indexed first before it could be increased. By contrast, Argentina and Chile do not use the minimum wage for setting other wage levels or social benefits, so raising it does not lead directly to higher fiscal costs.

The relationship between the minimum wages and salaries actually paid in each economy is tracked in Table 2 using the ratio between the minimum wage and various measures of distribution (average wage, the median (Kaitz index), and the lowest wage distribution percentiles). In the countries reviewed, the minimum wage represents approximately $50 \%$ of the median for the most recent year, except in Uruguay 
where the ratio is lower. In all countries, the minimum wage recovered more sharply than did other pay scale indicators, driving the ratios up. This indicates that the minimum wage has become more "operational" for all of the countries. Argentina has the highest minimum wage (equivalent to tenth-percentile wages). Uruguay has the lowest (74\% of tenth-percentile wages).

For the minimum wage to play its role properly, it must not only be appropriate in relation to the wage distribution - but it must also be complied with. In this regard, it is useful to break down employment by minimum wage brackets for the years taken for the simulation set out below. ${ }^{3}$ About $8 \%$ of wage workers in Argentina were drawing less than the legal minimum wage in 2012, and a similar portion were at or near the minimum wage. The remaining $84 \%$ were earning wages above the figure established by law. Among participants in the pension system (referred to here as formal workers), only $2 \%$ were below the minimum; this figure climbs to $27 \%$ for informal workers. The proportion of formal workers in the area of the minimum wage was very low (4\%), while $20 \%$ of informal workers were in that range. This means that in 2012, $94 \%$ of the reported workers were earning more than the statutory minimum wage. This figure was almost $100 \%$ in 2003 because the minimum wage was very low, making it completely non-binding.

In Brazil, compliance with the minimum wage seems to be higher than in the other three cases. In 2011 , only $1.3 \%$ of wage workers were paid less than the minimum; $8 \%$ were at or near the minimum wage (Table 3). Therefore, $90 \%$ of the workforce had incomes above the minimum wage. The percentage of unreported workers whose wages were below the minimum is also very low $(8.3 \%)$, significantly lower than, for example, in Argentina (27\%). Moreover, in Brazil the distribution of workers (wage earners and non-wage earners) with reference to the minimum wage has not changed substantially, even during a period when the minimum was strengthened considerably. This suggests that in Brazil the minimum wage is a reference value for setting wages for informal workers. Thus, minimum wage hikes translate into effective wage increases for them, confirming prior evidence of the "lighthouse effect". ${ }^{4}$ In Chile, about $3 \%$ of the wage-earning workforce is paid less than the legal minimum wage; a similar percentage is at or near that threshold. Together with Brazil, Chile has the lowest percentage of informal workers earning less than the minimum wage. But Chile also has a small percentage of these workers (around $7.5 \%$ ) at or near the minimum wage.

Lastly, Uruguay has the highest percentage $(95 \%)$ of wage workers drawing more than the minimum wage; only $3 \%$ are below it. This reflects the fact that almost all reported workers are wage workers. However, when it comes to informal workers, Uruguay is somewhere in the middle, with about $20 \%$ drawing less than

\footnotetext{
${ }^{3}$ The following criteria were used to determine whether workers were above, at, or below the minimum wage for any given value: (1) below the minimum wage-less than $90 \%$ of the value set by law; (2) at or near the minimum wage - between 90 and $110 \%$ of the legal minimum wage; and (3) above the minimum wage - equal to or greater than $110 \%$ of the legal minimum wage.

${ }^{4}$ Neri et al. (2000) and Lemos (2004).
} 


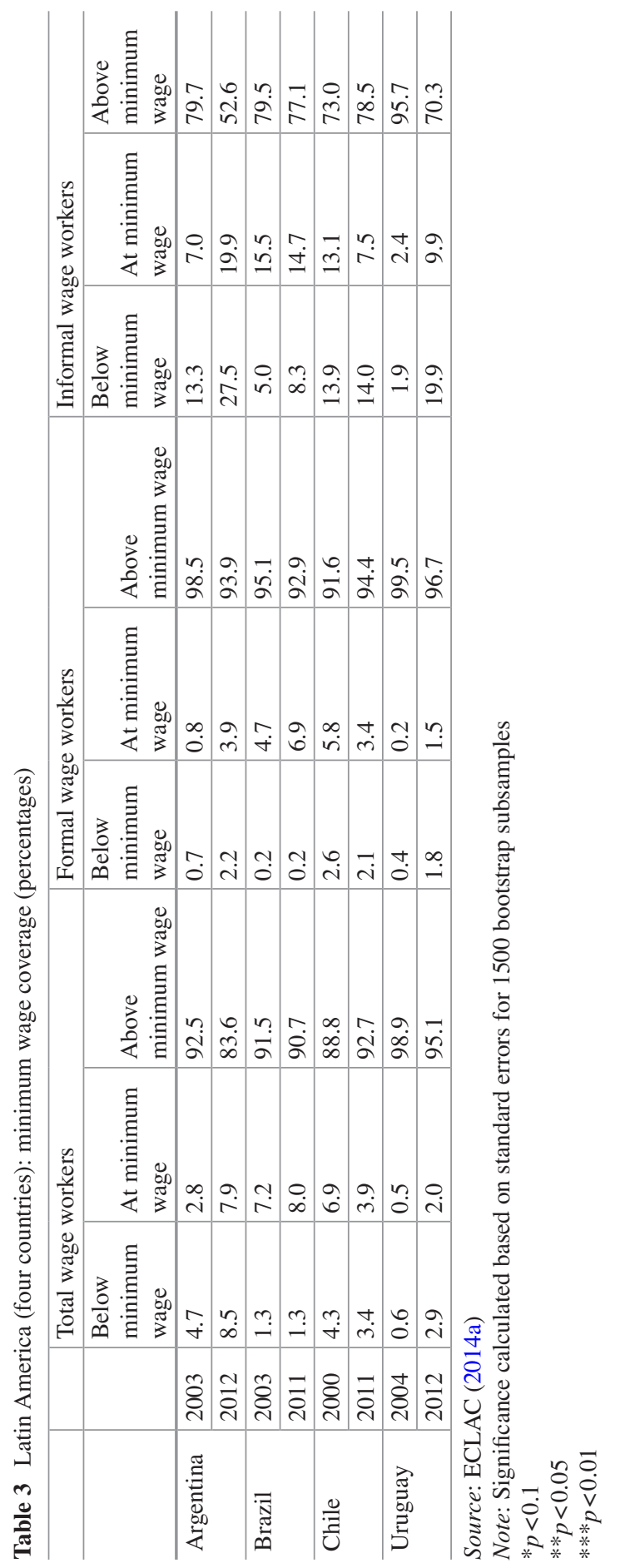


the minimum wage. This is twice the number in Chile and Brazil and 7 percentage points below Argentina.

So, the differences among the four countries with regard to the distribution of wage workers by minimum wage brackets reflect largely the situation for informal workers because the percentage of formal workers at or near the minimum wage is similar and very low in all four cases. Between 94 and $97 \%$ of formal workers earn more than the legal minimum wage.

The impact of changes in the minimum wage on wage inequality is estimated using the methodology proposed by DiNardo et al. (1996). By estimating counterfactual density functions, it assesses what the wage distribution would have been at the starting point if, keeping worker attributes constant, the minimum wage were the one in force at the endpoint. This new counterfactual distribution is then used to estimate wage inequality indicators such as the Gini coefficient, Theil index, and percentile ratios. Simulating changes in the minimum wage alone while holding other potential causes of distributional change constant makes it possible to deduce the distributive impact of an increase in the minimum wage by comparing inequality indicators at the starting point with those resulting from the simulation. ${ }^{5}$

The key findings are set out in Table 4. The first and third columns show the starting and final value of the average wage (expressed in the currency of each country, at beginning-of-period prices), the percentile ratios (percentile 90/percentile 10 , percentile 50/percentile 10, and percentile 90/percentile 50), the Gini coefficient, and the Theil index. The second column shows counterfactual density, which is the one that would have prevailed at the beginning if the minimum wage at the starting point had been the one at the endpoint. Thus, the difference between column 1 and column 2 shows the impact attributable to the change in the minimum wage (absolute and relative variation). In all cases the increase in the minimum wage drove the average wage up by between 1 and $4 \%$, depending on the country. In all of the cases there is also evidence that the minimum wage has an equalizing impact, although this impact is not significant in Chile. In Argentina, Brazil, and Uruguay, the drop in inequality is explained solely by compression at the lower end of the distribution.

In Chile, none of the slight decreases in all of these indicators (except for variance) were statistically significant. The real increase in the minimum wage in Chile was, at some $30 \%$, lower than the 100-200\% seen in the other countries reviewed. This could be one of the reasons why the rise was not enough to significantly alter the inequality indicators, which changed only marginally in absolute terms. And in Chile, unlike the other countries, the minimum wage seemed to lose

\footnotetext{
${ }^{5}$ See Maurizio (2014) for a more detailed discussion of methodological aspects. One of the limitations of this methodology is that it excludes potential negative impacts on the employment rate. However, employment grew sharply during this period in the countries under review, with a marked gain in formalization (except for Chile). A sustained rise in employment and in formal jobs would seem to suggest that increasing the minimum wage would not have had an adverse impact on employment. On the other hand, only those individuals with income below the minimum wage would be affected by any change. This lack of spillover effects points to conservative outcomes because the impacts could be larger if the intensity of the minimum wage effects decreased across the distribution.
} 


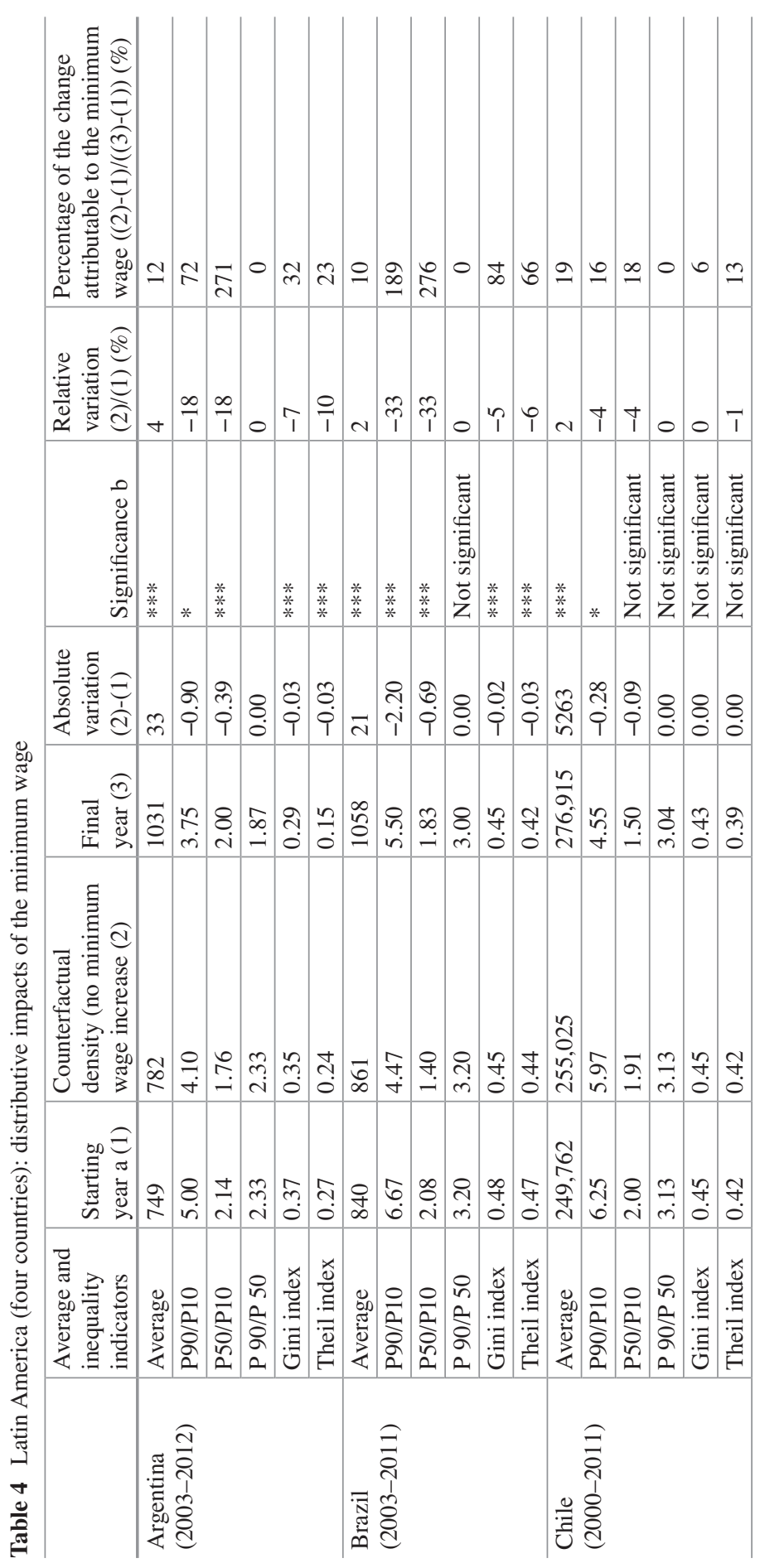




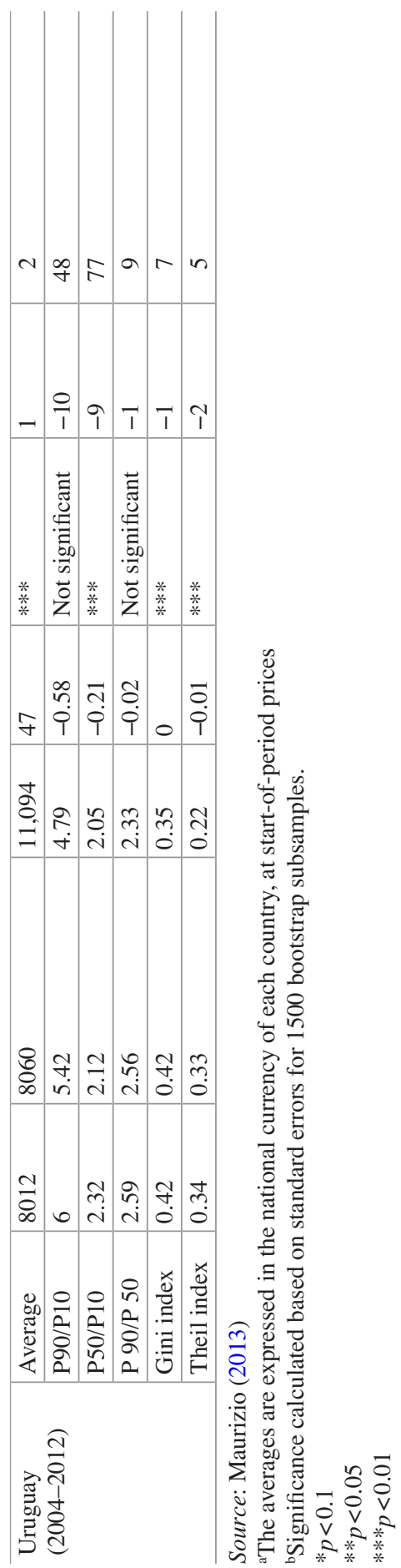


effectiveness during the second part of the subject period. As noted above, Chile is the only country where the percentage of wage workers earning one minimum wage or less is lower in year one than in the final year. Meanwhile, the minimumwage-to-first-percentile ratio declined sharply over the past few years.

In Argentina, the increase in the real minimum wage seems to be associated with a 2.6 percentage point drop in the Gini coefficient, equating to a $7 \%$ decline in this indicator compared with the initial year. About one-third of the decline in the Gini coefficient between 2003 and 2012 is attributable to changes in the minimum wage. Something similar is true of the Theil index. The ratio between the median and the 90th percentile does not change, but the percentile 50/percentile 10 gap narrows significantly, reflecting compression in the lower income brackets.

In Brazil, the Gini coefficient fell by 2.4 percentage points $(5 \%)$. The rise in the minimum wage has a very significant impact, accounting for $84 \%$ of the total drop in the Gini. As in Argentina, the equalizing impact is seen only at the bottom of the distribution. Unlike in the case of Argentina, however, the decrease is large enough to significantly narrow the gap between the outlier percentiles, 90 and 10 . The results suggest that with the minimum wage effect alone, the ratio between percentile 50 and percentile 10 of the end year would have been even lower than was actually recorded.

In Uruguay, the equalizing effects were smaller than in the two other cases. The Gini coefficient fell 0.5 percentage points; changes in the minimum wage accounted for some 7\% of the total decline in the Gini between 2004 and 2012. Outcomes for the Theil index were similar. Once again, the narrowing of the gap between the outlier percentiles of the distribution reflects only the impact at the low end, where the portion attributable to this factor was $77 \%$.

\subsection{Inequality and Formality}

A recent study for five Latin American countries (see Amarante and Arim 2015) performs a statistical decomposition of inequality measures, in order to separate what part of their changes can be attributed to changes in the distribution of observable worker characteristics (composition effect) and what part obeys to changes in returns to characteristics (price effect). Five countries are considered-Argentina, Brazil, Chile, Ecuador, and Uruguay - and the potential roles of human capital and labor informality are explored. The main finding that arises from the joint analysis of the five countries under consideration is that labour formalization, together with the combination of norms and institutional mechanisms that determine wage creation in the formal sector, contributed significantly to the decrease of inequality in the first decade of the twenty-first century in some countries of the region.

The recent body of literature investing the evolution of wage inequality over the last 15 years has identified the reduction of wage differentials conditional on education levels as the main factor explaining the recent fall. The results of the microeconometric decomposition exercises conducted in Amarante and Arim 
Table 5 Decomposition of the Gini index

\begin{tabular}{|c|c|c|c|c|c|c|}
\hline & & Argentina & Brazil & Chile & Ecuador & Uruguay \\
\hline \multirow{3}{*}{$\begin{array}{l}\text { Informality } \\
\text { (employees) }\end{array}$} & First year & $40 \%$ & $35 \%$ & $37 \%$ & $63 \%$ & $36 \%$ \\
\hline & Final year & $33 \%$ & $23 \%$ & $31 \%$ & $47 \%$ & $24 \%$ \\
\hline & Total change & $-7 \%$ & $-12 \%$ & $-6 \%$ & $-16 \%$ & $-12 \%$ \\
\hline \multirow[t]{3}{*}{ Gini (wages) } & First year & 0.414 & 0.529 & 0.413 & 0.441 & 0.410 \\
\hline & Final year & 0.353 & 0.482 & 0.394 & 0.372 & 0.351 \\
\hline & Total change & -0.061 & -0.047 & -0.019 & -0.069 & -0.059 \\
\hline \multirow{4}{*}{$\begin{array}{l}\text { Composition } \\
\text { effect }\end{array}$} & Total & 0.001 & 0.031 & 0.020 & -0.011 & -0.010 \\
\hline & Formalization (A) & -0.008 & -0.030 & -0.006 & -0.028 & -0.020 \\
\hline & Education $(\mathrm{C})$ & 0.004 & 0.055 & 0.016 & 0.013 & 0.010 \\
\hline & Others & 0.005 & 0.006 & 0.010 & 0.004 & 0.000 \\
\hline \multirow[t]{4}{*}{ Return effects } & Total & -0.062 & -0.077 & -0.024 & -0.079 & -0.062 \\
\hline & Formalization (B) & -0.020 & -0.002 & 0.011 & -0.064 & -0.030 \\
\hline & Education (D) & -0.025 & -0.049 & 0.024 & -0.007 & -0.040 \\
\hline & Others & -0.017 & -0.026 & -0.059 & -0.008 & 0.008 \\
\hline \multirow{2}{*}{$\begin{array}{l}\text { Total effect of } \\
\text { formality }\end{array}$} & $(\mathrm{A}+\mathrm{B})$ & -0.028 & -0.032 & 0.005 & -0.092 & -0.050 \\
\hline & $\%$ of Total change & $46 \%$ & $68 \%$ & $-26 \%$ & $133 \%$ & $85 \%$ \\
\hline \multirow{2}{*}{$\begin{array}{l}\text { Total effect of } \\
\text { education }\end{array}$} & $(\mathrm{C}+\mathrm{D})$ & -0.021 & 0.006 & 0.040 & 0.006 & -0.030 \\
\hline & $\%$ of Total change & $34 \%$ & $-13 \%$ & $-211 \%$ & $-9 \%$ & $51 \%$ \\
\hline
\end{tabular}

Source: Amarante and Arim (2015)

(2015) confirm the importance of this factor. However, changes in terms of formalization levels and wage differentials between formal and informal workers are factors as important in magnitude as returns to education and changes in workers' education levels - although there is high variation across the countries studied.

In the following table, results from these national studies are summarized. Tables 5 presents changes in informality (lack of contribution to the social security) and wage inequality for employees in the five countries, and then displays the Gini index decomposition highlighting the effects of formality and education. A large portion of the informality reduction observed in the five countries is explained by the impact of formality and returns to working in the formal sector. Indeed, the total impact of formality accounts for a fall of the Gini index that ranges from 2.8 percentage points in Argentina to 9 percentage points in Uruguay. In all countries except Chile, the total equalizing effect of formalization is higher than that of education. A differential pattern is observed in Chile, where changes in inequality and in the degree of formalization were of minor magnitude. In this country, even when the increase in the number of formal workers leads to greater equality, this impact is offset by the higher wage differential in favour of formal workers, and the overall effect of formalization ends up being unequalizing (increase of the Gini by 0.5).

In all five countries, the increase in labour formality - captured by the disaggregation of the composition effect (row A) - has an equalizing effect, although it varies in magnitude. The countries where the decrease in informality was the highest (Ecuador, Brazil, and Uruguay) exhibit a major impact. In all three cases, it 

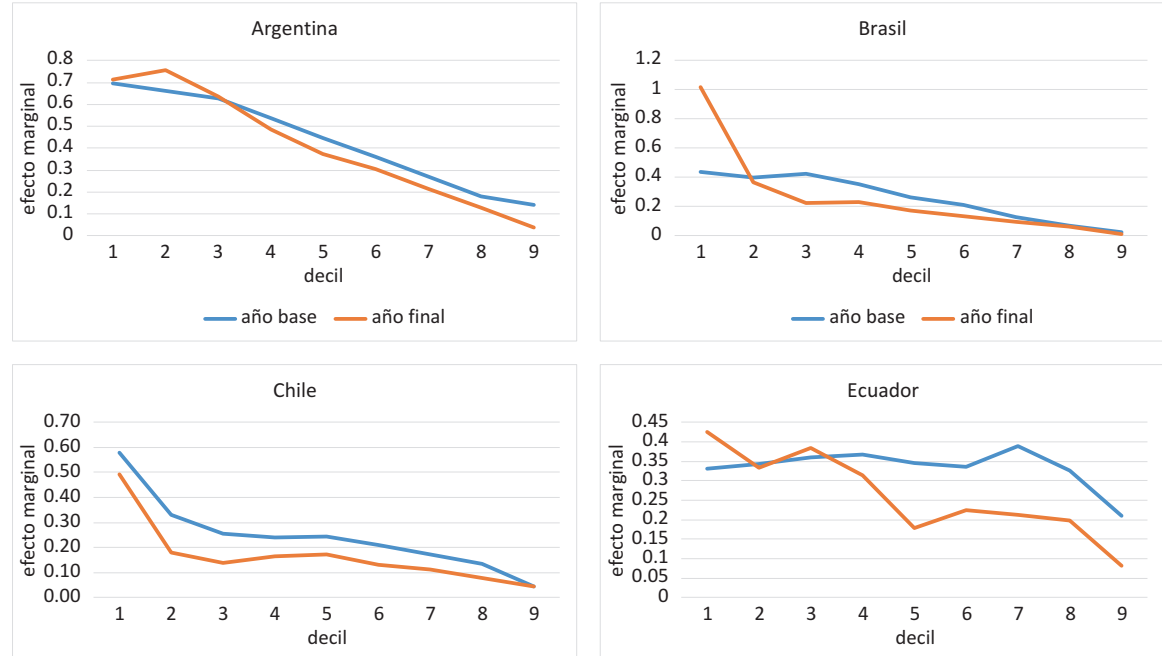

— año base —año final

— año base — año final

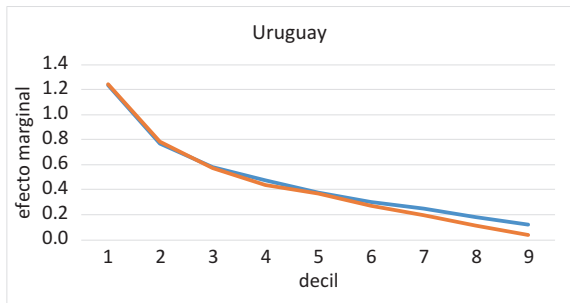

— año base —año final

Fig. 3 Marginal unconditional effect from being a formal worker, by deciles. Source: Amarante and Arim (2015)

represents three percentage points of the Gini index. In contrast, the impact of the increase in employees' education level is of the opposite sign, thus leading to high levels of dispersion in wages.

As for the decrease in the wage gap between the formal and informal sectors (row B, return effect), it favours low levels of inequality in all countries except Chile, where it has a concentrating effect. The equalizing impact of the return effect is particularly significant in Ecuador, which is directly followed by Uruguay and Argentina. The fall in wage differentials conditional on education levels leads to a decrease in inequality, again with the exception of Chile. ${ }^{6}$

Why does the reduction of informality appear to be such an important channel to reduce wage inequality? Figure 3 which displays the marginal impact of having a

${ }^{6}$ The case of Chile differs from others insofar a systematic reduction of returns to education is not observed. In particular, the gap between workers who have completed their tertiary education and workers with a primary education increases slightly. 
formal worker status for given deciles of the wage distribution, gives some hints to this question. In almost all cases, the returns to being in the formal sector appear to decrease monotonically with the decile. Given this pattern of marginal effects, a marginal increase in the degree of formalization is expected to have a greater impact in the lower parts of the distribution. In other words, these patterns are the reason why the composition effect associated with formalization results in an equalizing factor.

\section{Gender and Inequality}

Inequalities are generated in various dimensions of the market, in connection with variables such as income, participation, and access to different occupations. Not only does the labour market offer an unparalleled space for social relations, mutual recognition, and building autonomy and identity, it is also one of the arenas in which the struggle to overcome poverty and extend citizenship plays out, making it a crucial sphere for advancing towards the goal of equality. Several studies on the region's labour markets show significant changes in female labour force participation in recent decades. However, these changes have taken place at different rates in each country, and even among women in the same country, depending on their socioeconomic status, their education level, and the number of dependent minors in their households, among other factors. In the last decade, most countries have narrowed their gender gaps in labour participation and employment; yet these remain wide despite the fact that in the same period women overcame the educational disadvantages that were long considered the reason for their limited and poor labour market integration. With respect to income gaps and occupational segregation, the picture is more diverse across the countries and cannot be painted as one of progress for the region as a whole (ECLAC 2014b).

It is necessary to reduce gaps in participation, employment, and income, and to introduce policies for reconciling work and family life for men and women, as doing so will have positive effects at different levels. For one, there will be productivity gains, higher household income, and lower levels of socioeconomic inequality and household poverty. But it will also give impetus to equality in other spheres, such as the full exercise of autonomy, development of individual capacities and potential, access to contributory social protection, and broader participation in society beyond the household. All of these are central issues on the region's equality and rights agenda. A chapter in the recent Social Panorama (ECLAC 2014b) considers the gender inequalities in labour market and household income inequalities in the region. It examines the impact of women's employment on household well-being, measured in terms of their income and the distribution of that income. The following paragraphs are based on that chapter. 


\subsection{Participation, Employment, and Unemployment}

In the last decade, the overall participation rate in Latin America has held relatively steady, notwithstanding small fluctuations in different countries. The female participation rate, despite losing some momentum in relation to previous decades, continued to show moderate growth in some countries. Yet even with those increases in labour force participation, a third of working-age women still have no income of their own (ECLAC 2014a) and are classified for statistical purposes as economically inactive, regardless of their high workloads associated with their domestic responsibilities. Meanwhile, the growth in labour force participation rates for men has been less pronounced (see Fig. 4).

On the back of these developments, the gender participation gap has narrowed in most countries (ECLAC 2014b) (see Fig. 5). In 2002, the weighted average female participation rate was $63 \%$ of the rate for men, rising to $67 \%$ in 2012. Although the gap has narrowed, it nevertheless remains significant (Fig. 6). For example, the female participation rate in Guatemala, Honduras, and Nicaragua is on average half the male rate, and even in countries where the gap is smaller, the participation rate for women falls short of $80 \%$ of the rate for men (this is the case in Peru, the Plurinational State of Bolivia, and Uruguay). This means that, despite the considerable differences between the countries, there remains a broad scope for increasing women's labour market participation in all cases.

The moderate economic growth in the last decade has led to declines in the unemployment rate for both men and women. In aggregate terms for the region, the female-to-male unemployment ratio held relatively steady, although there are significant variations between countries in a context of low regional unemployment rates. However, in all countries of the region unemployment rates are significantly higher for women than for men (see ECLAC 2014b). As a result of these developments, the gender gap in employment between men and women has narrowed significantly, although broad differences still remain in all countries, as is the case for participation (see Figs. 4 and 5). On average for the region, the female employment rate stood at $65 \%$ of the male employment rate in 2012, compared with $61 \%$ in 2002. The largest gender gaps in employment were found in Guatemala, Honduras, and Nicaragua (see ECLAC 2014b).

\subsection{Labour Income of Women and Men}

A persistent feature of the region's labour markets is the systematic discrepancy between the average wages earned by men and women. In all countries of the region, women's average monthly earnings are lower than men's (see Fig. 7). The gaps vary significantly between countries: in the Plurinational State of Bolivia and Peru men earn on average over $50 \%$ more per month than women, but in El Salvador, Honduras, and Panama this difference is less than $10 \%$. This gap may in part be attributable to 


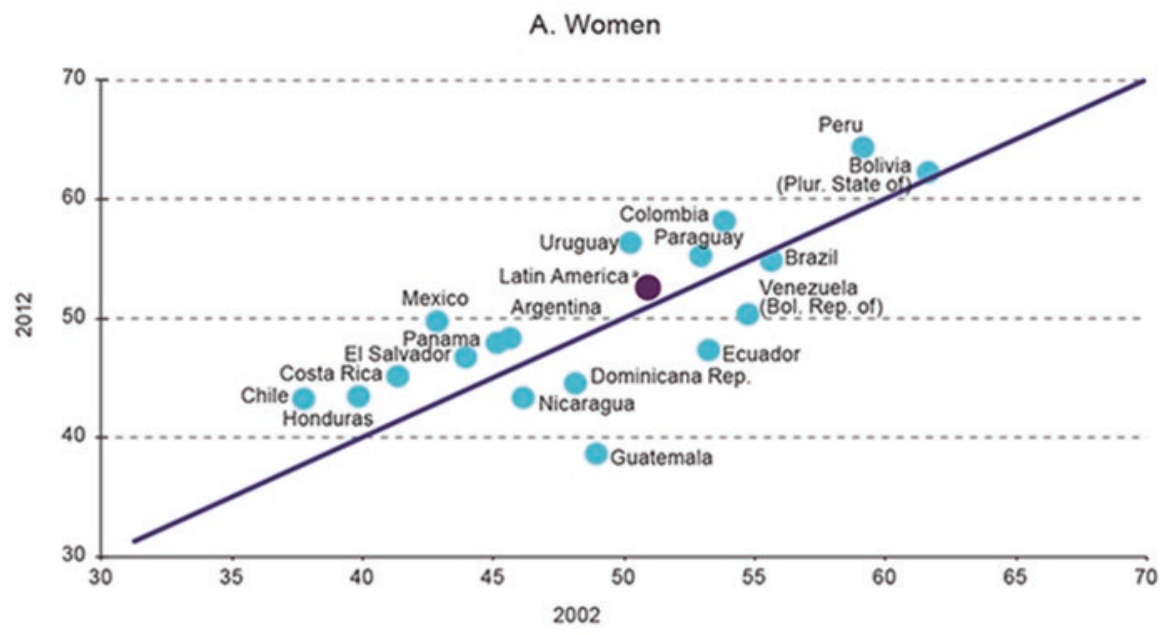

B. Men

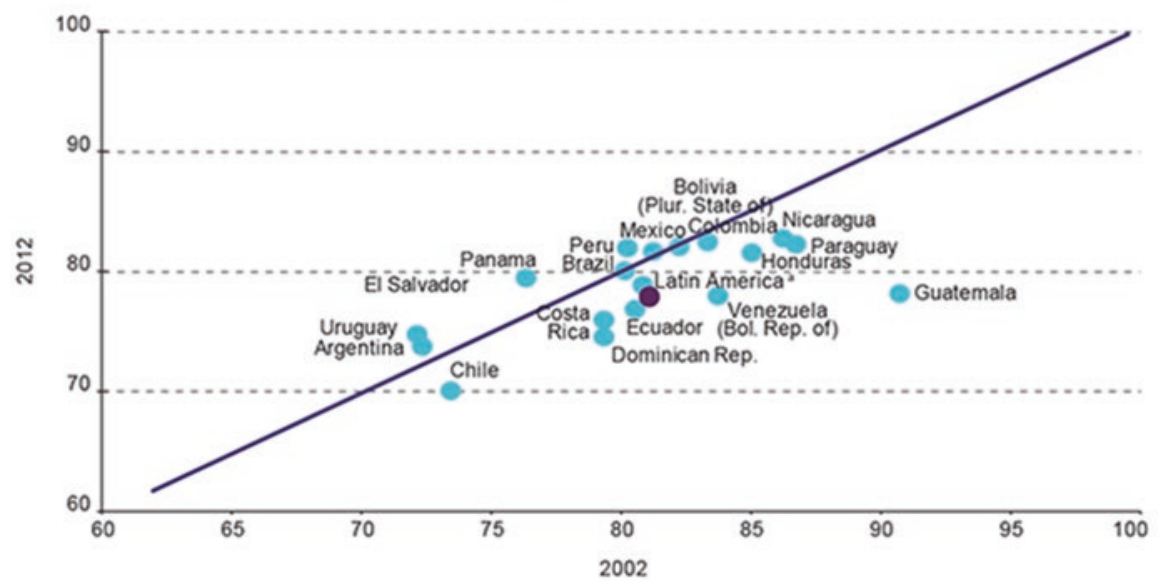

Fig. 4 Latin America (18 countries): Female and male labour force participation rates, around 2002 and 2012 (percentages). Source: Economic Commission for Latin America and the Caribbean (ECLAC), on the basis of special tabulations of data from household surveys conducted in the respective countries. ${ }^{a}$ Weighted average

the lower number of hours that women devote to paid work per month compared with men. Indeed, in 2012, men spent an average of $8 \mathrm{~h}$ per week more than women on paid work. But even when this factor is taken into account, there remains a considerable difference in average earnings by sex in most countries, although the gap does narrow somewhat. As in the case for monthly earnings, the largest gaps in hourly earnings to the detriment of women are seen in the Plurinational State of Bolivia and Peru. In some countries, such as Argentina, Costa Rica, El Salvador, Honduras, and 


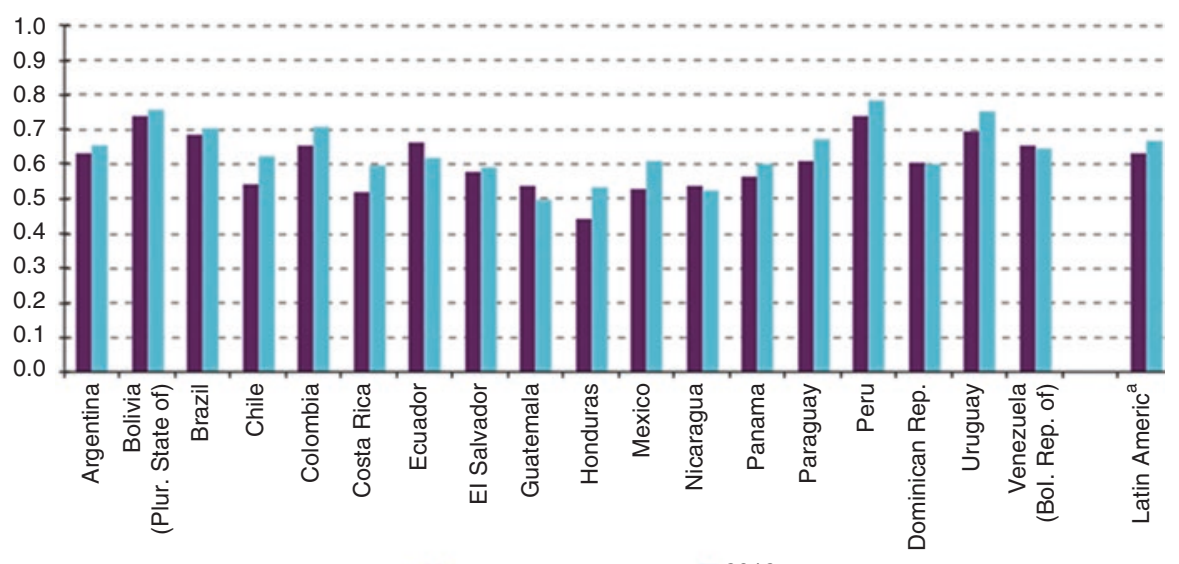

2002

프 2012

Fig. 5 Latin America (18 countries): Female-to-male participation ratio, around 2002 and 2012. Source: Economic Commission for Latin America and the Caribbean (b), on the basis of special tabulations of data from household surveys conducted in the respective countries. ${ }^{\text {a Weighted }}$ average

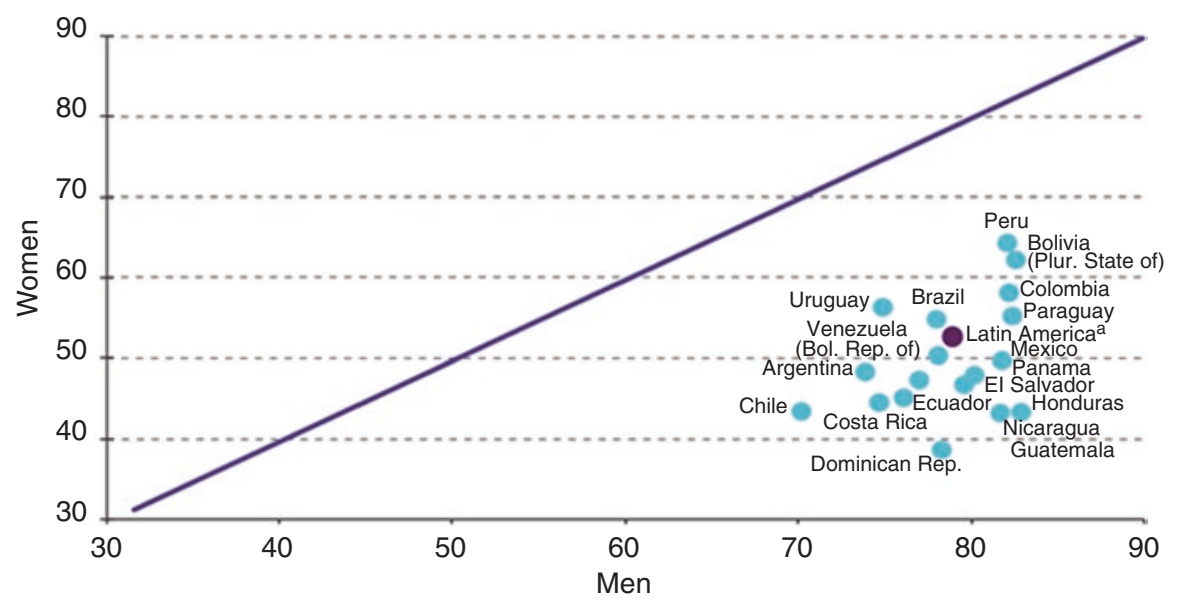

Fig. 6 Latin America (18 countries): Female and male participation rates, around 2012 (Percentages). Source: Economic Commission for Latin America and the Caribbean (ECLAC), on the basis of special tabulations of data from household surveys conducted in the respective countries. ${ }^{\text {a}}$ Weighted average

Nicaragua, wage differentials tend to disappear when controlling for hours worked. This means that in these countries, women's average hourly earnings are not lower than men's (and are even higher in some cases) (Fig. 7).

Differences in participation rates, employment, and wages between men and women combine to set a scenario in which female earnings contribute significantly 


\section{A. Monthly income}

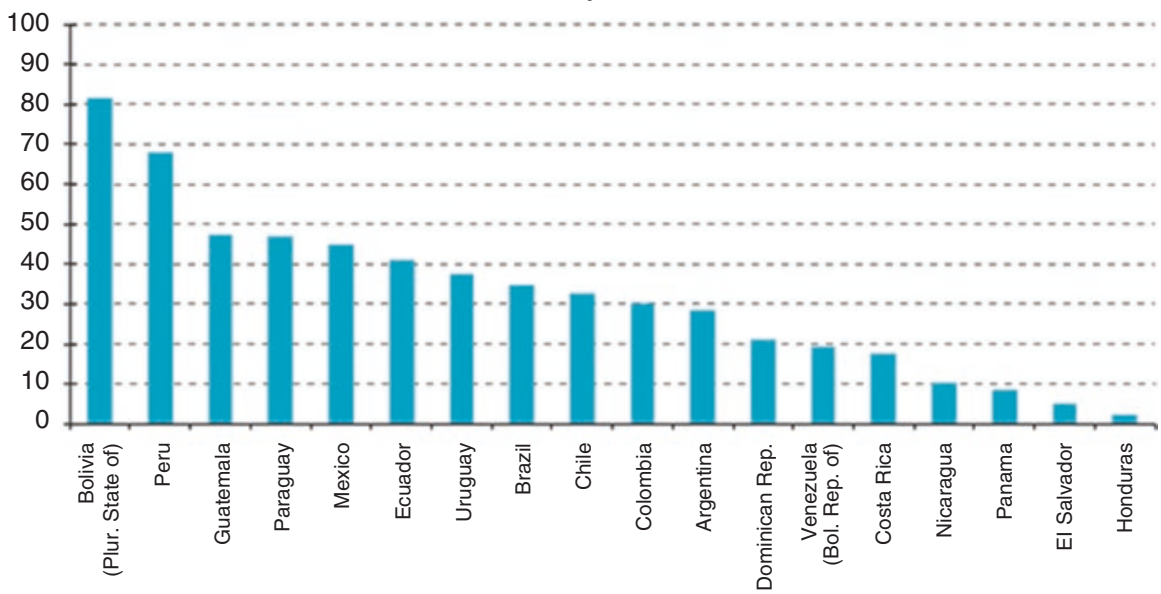

B. Hourly income

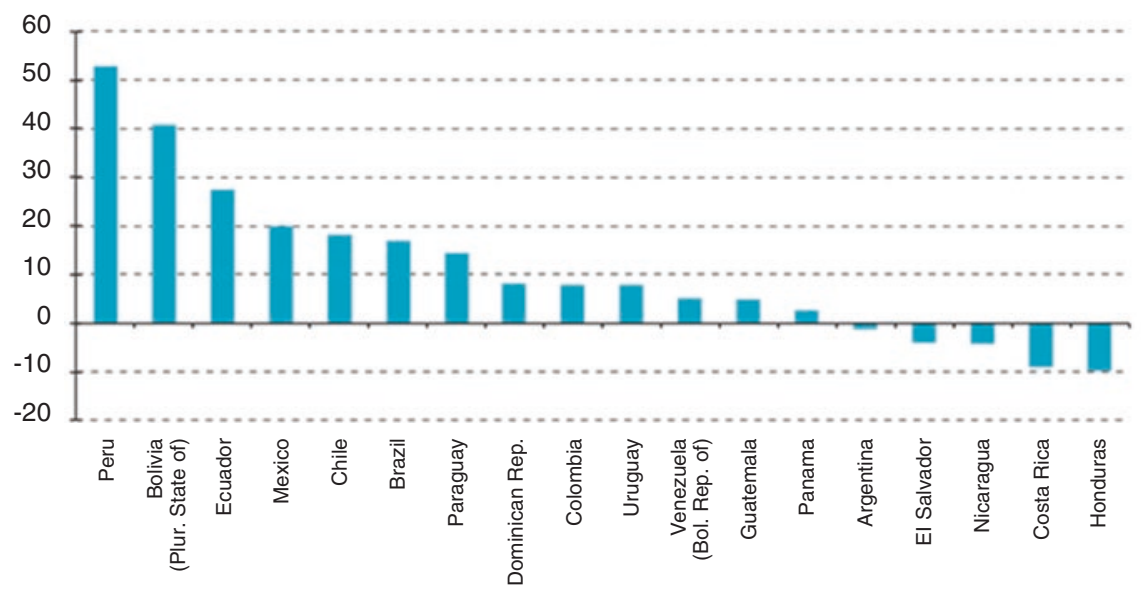

Fig. 7 Latin America (18 countries): Difference between average wages for men and women, around 2012 (percentages of female income). Source: Economic Commission for Latin America and the Caribbean (ECLAC), on the basis of special tabulations of data from household surveys conducted in the respective countries

less to household income than male earnings. Indeed, women consistently account for less than half of total household labour income. In fact, that proportion fell short of $40 \%$ in all of the countries in the region in 2012. Women make the largest proportional contribution in Uruguay, furnishing $39 \%$ on average of total household earnings, and the smallest in Dominican Republic, where their share is $26 \%$ (see Fig. 8).

Even greater heterogeneity is detected in the region regarding women's contribution to total household labour income in the lowest income quintile in each country. 


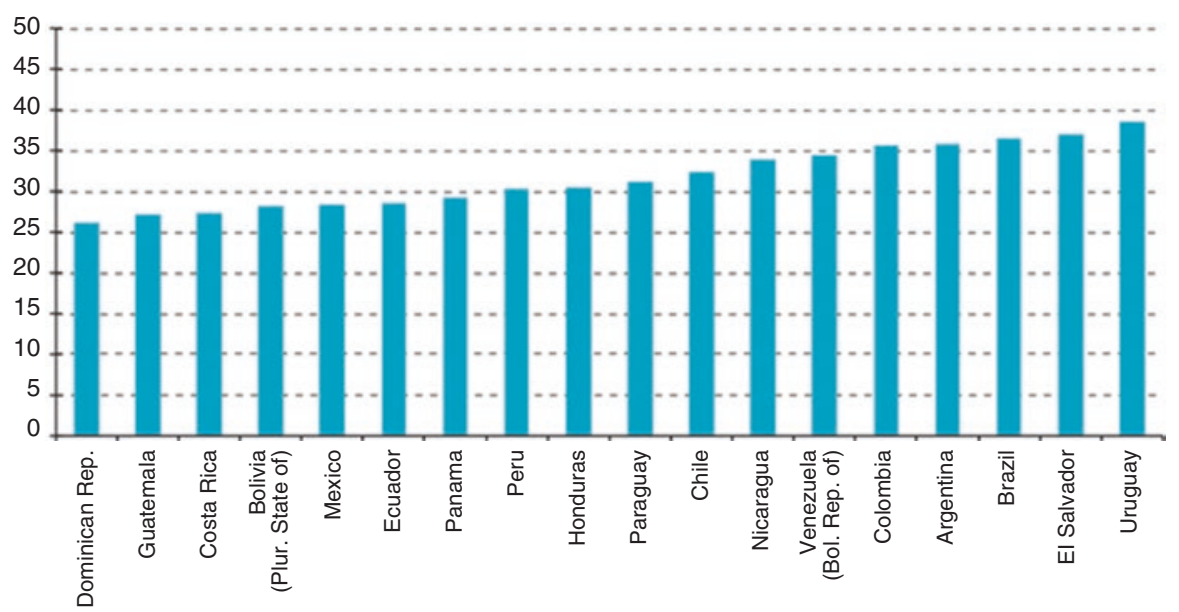

Fig. 8 Latin America (18 countries): Women's contribution to total household labour income, around 2012 (percentages). Source: Economic Commission for Latin America and the Caribbean (ECLAC), on the basis of special tabulations of data from household surveys conducted in the respective countries

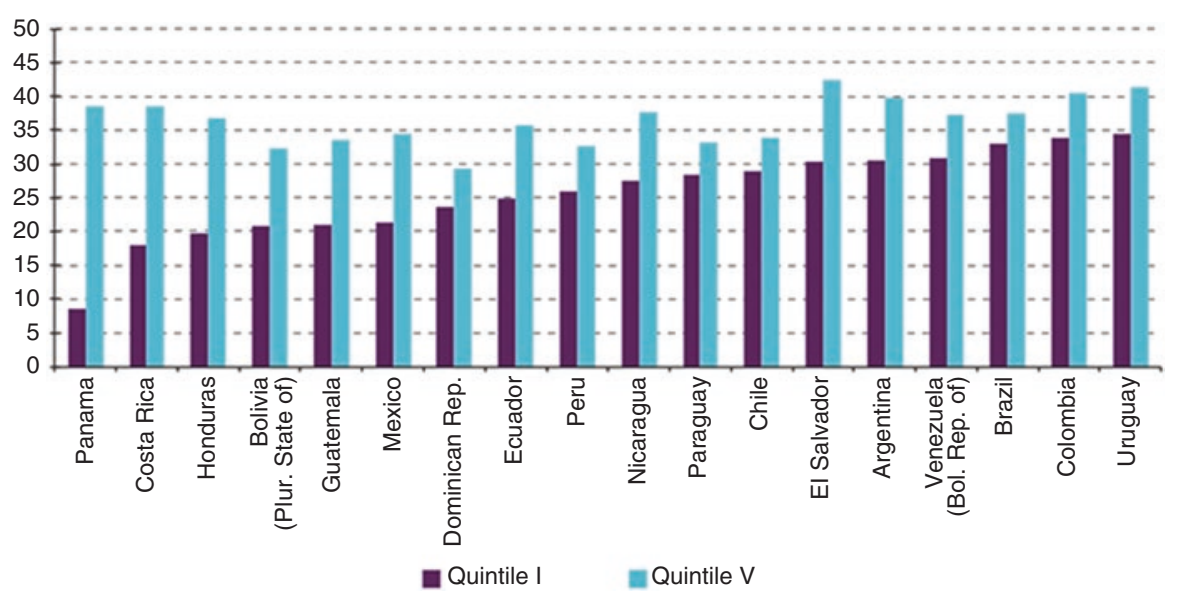

Fig. 9 Latin America (18 countries): Women's contribution to total household labour income in the first and fifth income quintiles, around 2012 (percentages). Source: Economic Commission for Latin America and the Caribbean (ECLAC), on the basis of special tabulations of data from household surveys conducted in the respective countries

Women's share of household labour income in the lowest quintiles ranges between 9 and $34 \%$, averaging $26 \%$. Meanwhile, in the highest income quintile in each country, women's contribution exceeds $29 \%$ in all cases and averages $36 \%$ (see Fig. 9). The significantly smaller share in the lowest quintile may reflect the reduced labour market participation of women in this economic stratum. 
There is therefore scope for increasing women's contribution to household income, either by expanding their labour market participation or by eliminating wage discrimination. Depending on the starting position of each country, the greatest gains can be achieved by advancing on one of these two fronts, although they are obviously not mutually exclusive. The next section examines the potential gains to be made, with the aim of promoting the formulation of public policies that are conducive to greater equality. The two scenarios taken into consideration would lead to advances in development for the countries and in the exercise of women's rights.

\subsection{Women's Labour Income and Its Effects on Inequality and Poverty}

Previously we have examined the profound differences and inequalities in the employment and earnings of men and women, showing that there is scope for improvement in terms of greater equality in these two dimensions, which will result in increased household well-being, and a more level playing field for men and women with regard to resource availability and economic capacities, and in the exercise of their social and economic rights. We now turn into quantifying the progress that could be made on some basic well-being indicators (namely the levels of socioeconomic inequality and poverty) if advances in gender equality were made in the region's labour markets.

In particular, it sets out to ascertain what the levels of income inequality and poverty would be in the region in two scenarios: (1) if the participation gap between men and women was closed, and (2) if women earned the same as men (with the same qualifications). The aim is to reflect on what the contribution of female earnings to overall household well-being could be if women's labour participation increased or the wage gap narrowed. The simulations are based on the latest information available from household surveys conducted in the respective countries, which in most cases corresponds to 2012.

Setting out to close these gaps is not a utopian exercise. The fact that these disparities are ingrained in multiple mechanisms of cultural reproduction may make them difficult to reverse, but international experience has showed that public policies on labour and care have much to contribute in these areas.

\subsubsection{Closing the Participation Gap}

The first analysis looked at what would happen if the participation rate for women in the intermediate age group (14-65 years) was similar to that for men. The first step was to develop a model of the female participation rate in order to better understand the variables determining women's participation and to be able to predict the 
probability of each woman actively entering the labour market. ${ }^{7}$ The exercise essentially consisted in simulating the incorporation of inactive women into the labour market, sorting them according to the probability predicted using the estimated model of labour force participation, and matching the female participation rates to the male rates by age group. ${ }^{8}$ That is, the women simulated as entering the labour market were those of the inactive group who were deemed most likely to become active. Once the participation gap had been closed, the probability of these newly active women being employed or unemployed was predicted, assuming a constant rate of female unemployment (that is, the percentage of unemployed women as a share of active women did not vary). ${ }^{9}$ A labour income was calculated for the women who were simulated as gaining employment, similar to the earnings of other women with the same characteristics (age and education level). A new vector of female earnings and household income was thus obtained, having knock-on effects on levels of household income, poverty, and inequality.

The simulation introduced significant changes in the participation rates for women by age group, almost closing the participation gaps between men and women (see Fig. 10).

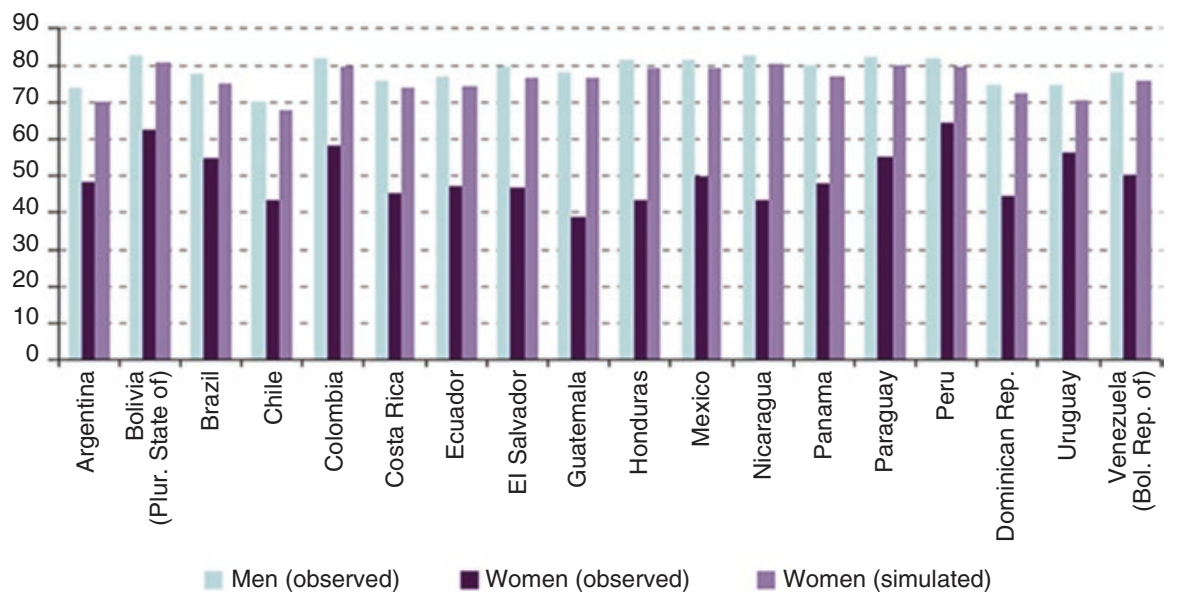

Fig. 10 Latin America (18 countries): Participation rates for men (observed) and women (observed and simulated), around 2012 (percentages). Source: Economic Commission for Latin America and the Caribbean (ECLAC), on the basis of special tabulations of data from household surveys conducted in the respective countries

\footnotetext{
${ }^{7} \mathrm{~A}$ probit model was estimated using the female participation rate as the dependent binary variable. ${ }^{8}$ The following age groups were considered: $15-24$ years, $25-49$ years, and 50-65 years. The labour force participation of women aged 65 years and older is not altered (that is, if they were originally active, they remain so).

${ }^{9} \mathrm{~A}$ second scenario was estimated matching both the participation rates and unemployment rates for men and women, thus closing the employment gap. As the results were very similar (although slightly higher) to those for the scenario of closing the participation gap, a decision was taken not to present them. The finding was attributable mainly to the low levels of unemployment recorded in the baseline year used for the simulation (2012).
} 
Such a rise in the female participation rate would lead to an increase in average household income ranging from 3 to $4 \%$ in Argentina, Brazil, Colombia, Mexico, and Uruguay, and reaching over $10 \%$ in El Salvador, Honduras, Nicaragua, and Peru. The countries with the largest gender gap in participation rates would gain the most in terms of average household income if those participation gaps disappeared. Evening up the rates of female and male participation would reduce poverty and inequality in the countries. The massive incorporation of women into the labour market could be expected to lead to declines in the poverty rate ranging from 1 percentage point in Argentina and Uruguay to over 10 percentage points in El Salvador and Nicaragua (see Fig. 11 and Table 6). In addition, if more women were to enter

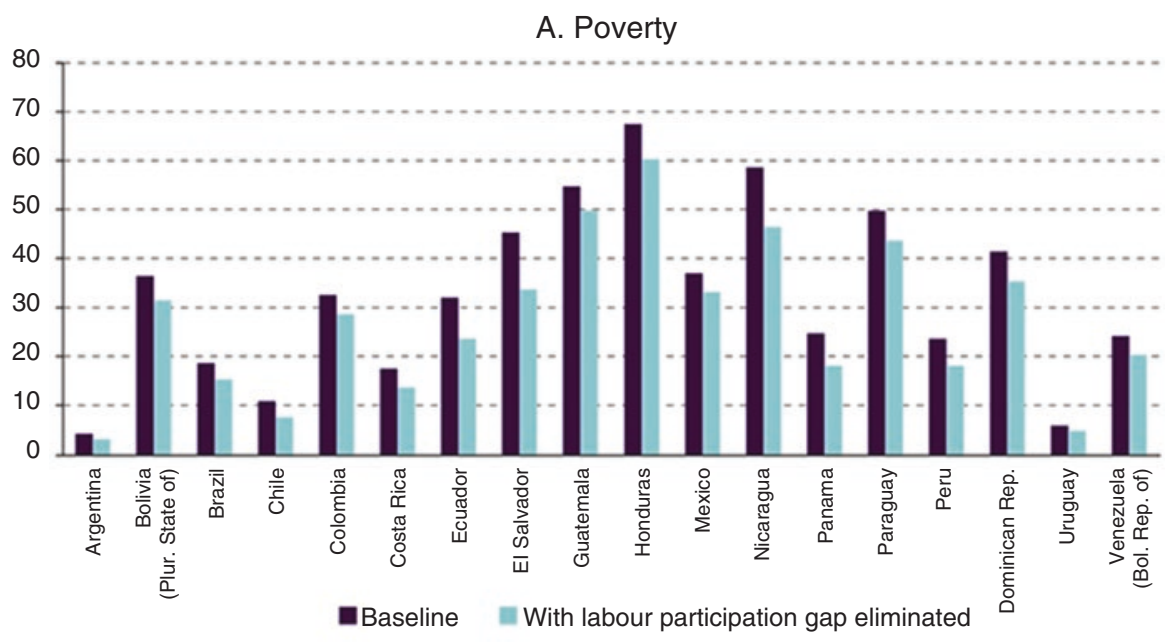

B. Gini index

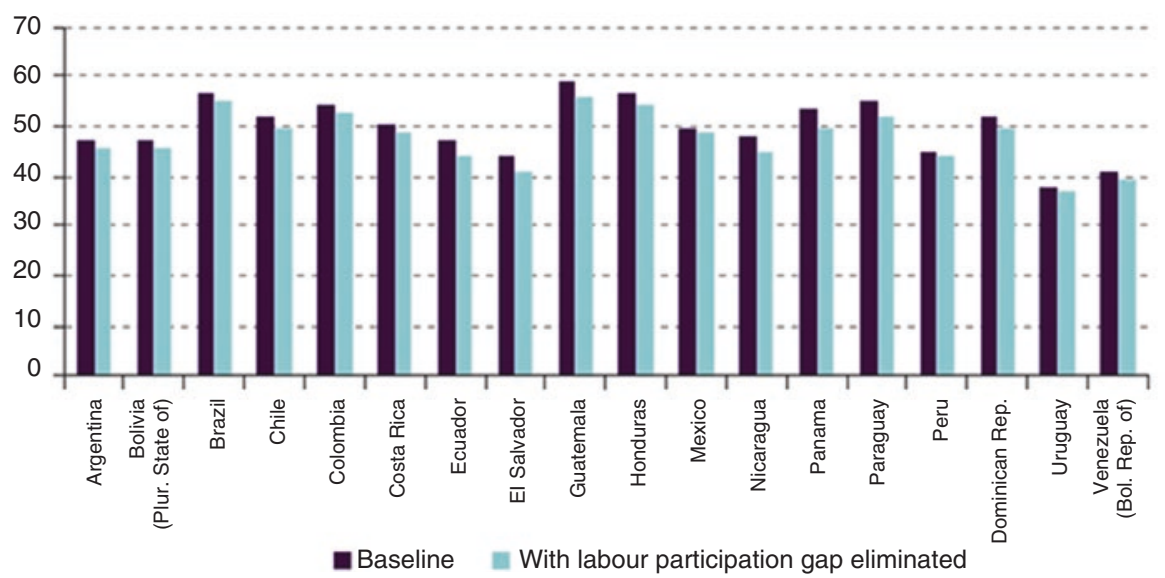

Fig. 11 Latin America (18 countries): Poverty and inequality levels as a result of closing the labour participation gap compared with a baseline scenario (percentages). Source: Economic Commission for Latin America and the Caribbean (ECLAC), on the basis of special tabulations of data from household surveys conducted in the respective countries 
Table 6 Latin America (18 countries): changes in poverty rates and inequality indicators as a result of closing the labour participation gap (percentage points)

\begin{tabular}{l|l|l|l}
\hline Country & Poverty & Gini index & Theil index \\
\hline Argentina & -1 & -2 & -4 \\
\hline Bolivia (Plurinational State of) & -5 & -1 & -3 \\
\hline Brazil & -3 & -2 & -5 \\
\hline Chile & -3 & -2 & -5 \\
\hline Colombia & -4 & -2 & -3 \\
\hline Costa Rica & -4 & -2 & -4 \\
\hline Dominican Republic & -6 & -3 & -5 \\
\hline Ecuador & -9 & -3 & -5 \\
\hline El Salvador & -12 & -3 & -5 \\
\hline Guatemala & -5 & -2 & -6 \\
\hline Honduras & -7 & -3 & -8 \\
\hline Mexico & -4 & -1 & -2 \\
\hline Nicaragua & -12 & -4 & -7 \\
\hline Panama & -7 & -4 & -8 \\
\hline Paraguay & -6 & -3 & -6 \\
\hline Peru & -6 & -1 & -1 \\
\hline Uruguay & -1 & -1 & -1 \\
\hline Venezuela (Bolivarian Republic of) & -4 & -2 & -2 \\
\hline
\end{tabular}

Source: Economic Commission for Latin America and the Caribbean (ECLAC), on the basis of special tabulations of data from household surveys conducted in the respective countries

the labour market it would help reduce inequality, measured using the Gini index, by 4 percentage points in Nicaragua and Panama, and by 3 percentage points in the Dominican Republic, Ecuador, El Salvador, Honduras, and Paraguay. The Theil index would drop sharply in some countries (6-8 percentage points in Guatemala, Honduras, Nicaragua, Panama, and Paraguay) because this measure of inequality is particularly sensitive to movements in the lower income segments and these countries would see a large increase in the proportion of women with lower levels of education entering the labour market.

The above findings show that if more women were to enter the labour market, great strides would be made in reducing poverty and inequality, with the most substantial progress being seen in the countries with the widest participation gaps, such as those in Central America. It is clear, however, that even the massive incorporation of women into the labour market would not eliminate poverty in Latin America owing to the structural characteristics of the region's labour markets. The income that these women would earn would help to improve their situation, but only to some extent. Nevertheless, some countries would register very significant progress, especially with regard to inequality. Even more importantly, the entry of women into the labour market would have a profound impact in terms of the full exercise of autonomy, the development of capacities and personal potential, access to contributory social protection, and broader participation in society. 
Accelerating changes in the proposed sense would clearly not be possible without active, resolute policies that promote and encourage such changes, including policies on care. The region has much ground to cover in this respect, because although progress has been made on a legal and regulatory front, scant substantial changes have been seen. Care services generally have low coverage and operate in a weak institutional framework, thus failing to meet the growing needs of societies. Nevertheless, several countries have incorporated the issue into their policy agendas and have made different degrees of progress (ECLAC 2012a). Active labour market policies can encourage greater participation by women in the labour market by helping to ensure that they are properly qualified and by facilitating their labour market integration. Of course, there are other policies that can influence the female participation rate, such as the provision of preschool education and extended schooldays at the primary stage. Lastly, as ECLAC has highlighted in several studies, what is needed is a new gender compact that involves a more equitable distribution of roles within the household and is thus conducive to female labour force participation.

\subsubsection{Closing the Income Gap}

The second question addressed was what would happen to poverty and inequality in the region if the income gap between men and women disappeared. In the simulations carried out for this purpose, a decision was taken to eliminate the monthly income gap between men and women, which also effaced the differences in hours worked. The first step was to estimate wage equations for employed men. The monthly earnings of women were then predicted using the coefficients of these equations. This calculation removed the gender differences in labour market returns and assumed that men and women receive equal pay in the market according to their education level and age.

Closing the gender income gap would lead to milestone achievements in poverty reduction in countries such as the Plurinational State of Bolivia and Peru (see Table 7 and Fig. 12) by significantly boosting household income. As noted above, a significant percentage of women in these countries are employed but not paid, which explains the dramatic changes that would take place if these women were to receive a similar income to men with the same level of education and work experience. The changes to the poverty level in Colombia, Ecuador, and Nicaragua would also be very significant. The Gini index would fall by between 2 and 8 percentage points, depending on the country, and the Theil index would mark an even larger decline in inequality, being more sensitive to the changes that occur in lower income households.

Again, the quest for progress on this front calls for public policy. Governments in the region have ratified international agreements and passed domestic legislation to endorse the principles of equal opportunity and non-discrimination between women and men. However, the figures indicate that these actions alone are insufficient to ensure the eradication of gender discrimination in the labour market. Once 
Table 7 Latin America (18 countries): Changes in poverty rates and inequality indicators as a result of closing the gender income gap (percentage points)

\begin{tabular}{l|l|l|l}
\hline Country & Poverty & Gini index & Theil index \\
\hline Argentina & -1 & -3 & -5 \\
\hline Bolivia (Plurinational State of) & -14 & -8 & -12 \\
\hline Brazil & -6 & -4 & -13 \\
\hline Chile & -2 & -4 & -8 \\
\hline Colombia & -9 & -5 & -12 \\
\hline Costa Rica & -4 & -3 & -7 \\
\hline Dominican Republic & -5 & -3 & -6 \\
\hline Ecuador & -8 & -4 & -8 \\
\hline El Salvador & -6 & -3 & -5 \\
\hline Guatemala & -4 & -2 & -7 \\
\hline Honduras & -1 & -2 & -6 \\
\hline Mexico & -5 & -3 & -6 \\
\hline Nicaragua & -8 & -4 & -8 \\
\hline Panama & -6 & -4 & -10 \\
\hline Paraguay & -7 & -5 & -12 \\
\hline Peru & -8 & -5 & -8 \\
\hline Uruguay & -2 & -3 & -4 \\
\hline Venezuela (Bolivarian Republic of) & -4 & -2 & -3 \\
\hline
\end{tabular}

Source: Economic Commission for Latin America and the Caribbean (ECLAC), on the basis of special tabulations of data from household surveys conducted in the respective countries

specific legislation on equal pay has been enacted, labour market institutions can play a role in helping to close gaps. Expanding the coverage of collective bargaining to include workers in traditionally excluded sectors, such as domestic workers, rural workers, and home workers, can help to narrow the gender income gap. Another approach is to address issues relating to the protection of maternal and paternal labour rights (see Maurizio 2010). Improving labour inspections can also help to eliminate discriminatory practices. Furthermore, as several studies have indicated that occupational segregation is responsible for a significant part of the gender wage gap (for example, Macpherson and Hirsch 1995), policies to address occupational segregation, for example, by training women for occupations that are not considered typically female, would narrow the wage gap. Similarly, little progress has been made to date on extending training to men for occupations that have traditionally been considered female with a view to eliminating the stereotypes and prejudices that also translate into wage discrepancies. 

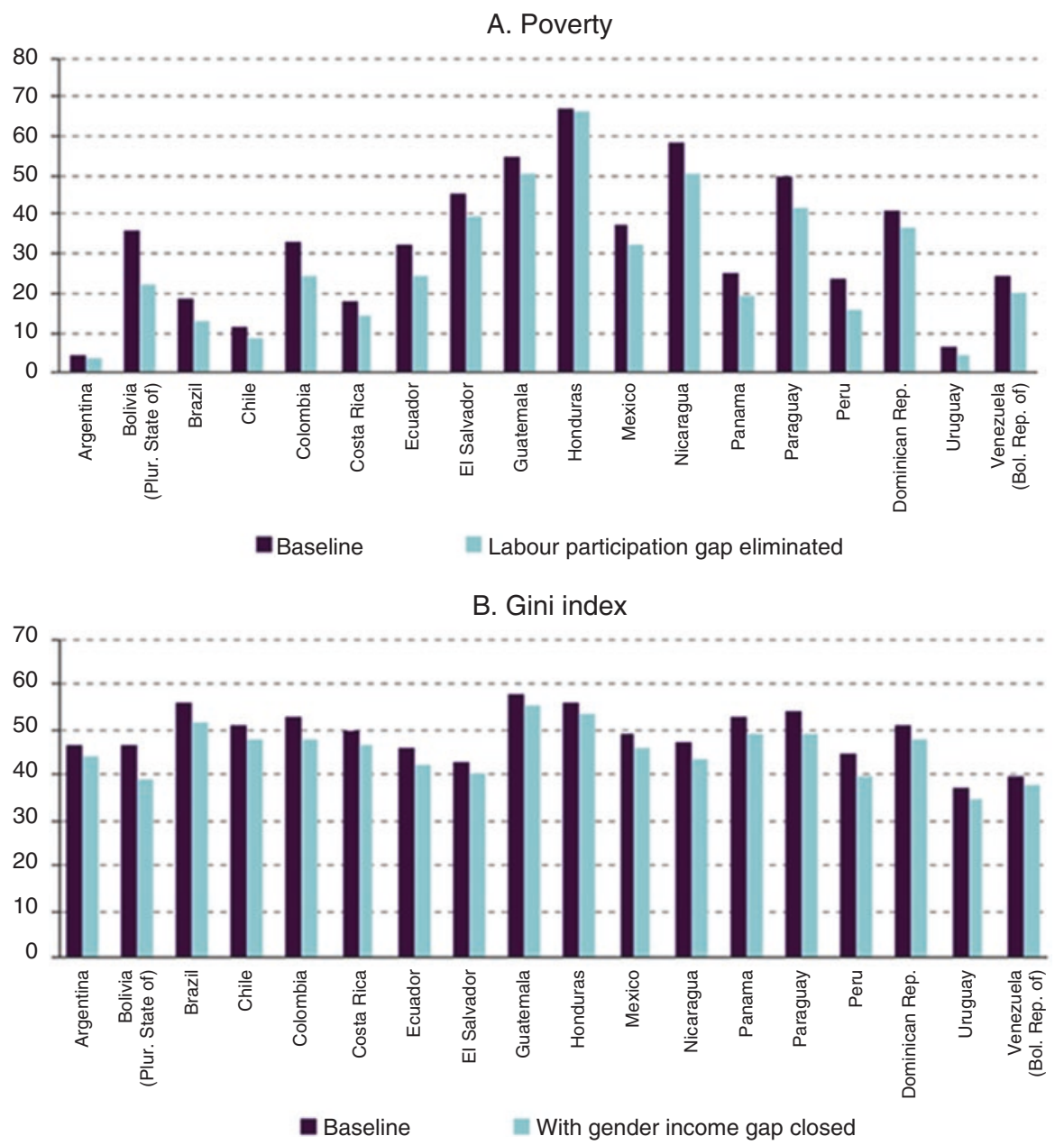

Fig. 12 Latin America (18 countries): Poverty and inequality levels as a result of eliminating the gender income gap compared with a baseline scenario (percentages). Source: Economic Commission for Latin America and the Caribbean (ECLAC), on the basis of special tabulations of data from household surveys conducted in the respective countries

\section{Final Remarks}

ECLAC has consistently promoted and reiterated the idea that the region should move towards the horizon of equality, understood in a broad sense. This chapter has summarized some recent studies from ECLAC which show that, even if very important advances were made during the last 15 years, inequality continues to be a major problem in the region. The labor market has a fundamental role to understand inequality in the region, and part of the recent inequality decline in some countries 
of the region responds to institutional factors, such as increases of the minimum wage and formalization in the labour market. Strengthening labour market institutions as well as implementing strategies for achieving gender equality are necessary actions in order to achieve higher equality.

\section{Annex (see Table A.1)}

Table A.1 Gini coefficients for the distribution of household consumption per capita. Developing countries. 2010

\begin{tabular}{l|l|l|l|l|l}
\hline & Mean & Median & Coef. var. & Min. & Max. \\
\hline East Asia and Pacific & 38.1 & 36.7 & 0.101 & 31.9 & 43.5 \\
\hline Eastern Europe and Central Asia & 33.6 & 33.7 & 0.144 & 25.6 & 43.6 \\
\hline Latin America and the Caribbean & 43.8 & 44.8 & 0.104 & 34.7 & 52.8 \\
\hline Middle East and North Africa & 36.0 & 36.1 & 0.091 & 30.8 & 40.9 \\
\hline South Asia & 35.0 & 36.3 & 0.081 & 30 & 38.1 \\
\hline Sub-Saharan Africa & 44.4 & 42.1 & 0.175 & 33.3 & 63.1 \\
\hline Developing countries & 39.8 & 39.2 & 0.181 & 25.6 & 63.1 \\
\hline
\end{tabular}

Note: Unweighted statistics

Source: Alvaredo and Gasparini (2015)

Open Access This chapter is distributed under the terms of the Creative Commons Attribution 4.0 International License (http://creativecommons.org/licenses/by/4.0/), which permits use, duplication, adaptation, distribution and reproduction in any medium or format, as long as you give appropriate credit to the original author(s) and the source, a link is provided to the Creative Commons license and indicate if changes were made.

The images or other third party material in this chapter are included in the work's Creative Commons license, unless indicated otherwise in the credit line; if such material is not included in the work's Creative Commons license and the respective action is not permitted by statutory regulation, users will need to obtain permission from the license holder to duplicate, adapt or reproduce the material.

\section{References}

Alvaredo, F., \& Gasparini, L. (2015). Recent trends in inequality and poverty in developing countries. In A. Atkinson, \& F. Bourguignon (Eds.), Chapter 10 in handbook of income distribution (Vol. 2).

Amarante, V., \& Arim, R. (2015). Desigualdad e informalidad en América Latina: Un análisis de cinco experiencias latinoamericanas. Santiago de Chile: CEPAL.

Azevedo, J. P., Dávalos, M. E., Diaz-Bonilla, C., Atuesta, B., \& Castañeda, R. A. (2013). Fifteen years of inequality in Latin America: How have labor markets helped? Policy Research Working Paper, No. 6384. Washington, DC: World Bank. 
Cornia, G. A. (2010). Income distribution under Latin America's new left regimes. Journal of Human Development and Capabilities, 11(1), 85-114.

Cornia, G. A. (Ed.). (2014). Falling inequality in Latin America. Policy changes and lessons. Oxford: Oxford University Press.

De la Torre, M., \& Pienknagura, S. (2012, October). The labour market story behind Latin America's transformation. LAC Semiannual Report. Washington, DC: World Bank.

DiNardo, J., Fortin, N., \& Lemieux, T. (1996). Labor market institutions and the distribution of wages, 1973-1992: A semiparametric approach. Econometrica, 64(5), 1001-1044.

ECLAC. (2010). Time for equality: Closing gaps, opening trails. Santiago de Chile: ECLAC.

ECLAC. (2011). Social Panorama of Latin America, 2011. Santiago, Chile: ECLAC.

ECLAC (2012). Structural change for equality: An integrated vision of development. Santiago de Chile: ECLAC.

ECLAC. (2013). Social Panorama of Latin America, 2013. Santiago, Chile: ECLAC.

ECLAC (2014a). Compacts for equality. Santiago de Chile: ECLAC.

ECLAC (2014b). Social Panorama of Latin America, 2014. Santiago de Chile: ECLAC.

Gasparini, L., Galiani, S., Cruces, G., \& Acosta, P. (2012). Educational upgrading and returns to skills in Latin America. Evidence from a supply-demand framework 1990-2010. CEDLAS Working Papers 127, Universidad de la Plata.

Lemos, S. (2004). Minimum wage policy and employment effects: Evidence from Brazil. Economia, 5(fall), 219-266.

López-Calva, L. F., \& Lustig, N. (2010). Declining inequality in Latin America: A decade of progress? Washington, DC: Brookings Institution Press.

Macpherson, D. A., \& Hirsch, B. T. (1995). Wages and gender composition: Why do women's jobs pay less? Journal of Labor Economics, 13(3), 426-471.

Maurizio, R. (2010). Enfoque de género en las instituciones laborales y las políticas de mercado de trabajo en América Latina. Serie Macroeconomía y Desarrollo, Nro. 104. Santiago de Chile: CEPAL.

Maurizio, R. (2013). El impacto distributivo del salario mínimo en la Argentina, el Brasil, Chile y el Uruguay. Serie Políticas Sociales, Nro. 194. Santiago de Chile: CEPAL.

Neri, M., Gonzaga, G., \& Camargo, J. (2000). Efeitos informais do salario mínimo e pobreza. Texto Para Discussao No. 724. Rio de Janeiro: IPEA.

Roberts, K. M. (2014). The politics of inequality and redistribution in Latin America's postadjustment era. In G. A. Cornia (Ed.), Falling inequality in Latin America. Policy changes and lessons. Oxford: Oxford University Press.

Verónica Amarante is a researcher in the area of poverty, inequality, labor market, and public policy. She worked as Social Affairs Officer at the Social Development Division in the United Nations Economic Commission for Latin America and the Caribbean. Since 2014, she has been Director of the ECLAC Office in Montevideo. Previously, she was a researcher at the Institute of Economy of Universidad de la República, Uruguay, and she still teaches at that institution. She holds a Ph.D. in Economics from the University of Sussex and an M.Sc. in Economics from Universitat Pompeu Fabra.

Antonio Prado is Deputy Executive Secretary of the United Nations Economic Commission for Latin America and the Caribbean. Prior to this, he served as Head of Governmental Affairs of the Presidency of the National Bank for Economic and Social Development (BNDES) of Brazil. During most of his professional career, Prado has specialized in the analysis of technological changes in industry and their impact on economic development, the labor market, and Brazil's industrial relations. He holds a Ph.D. in Economic Development Policies and a Master's in Industrial Economics from the State University of Campinas. 


\title{
The Inequality Story in Latin America and the Caribbean: Searching for an Explanation
}

\author{
Augusto de la Torre, Julian Messina, and Joana Silva
}

\section{Introduction}

Income inequality is a salient economic malaise in Latin America and the Caribbean, where for decades it has been higher than in any other region in the world (Williamson 2015). A growing body of literature suggests that after a long period of growing or stagnant inequality, the trajectory of household income inequality shows a visible kink around 2003 - rising during the 1990s and until about 2002, when it started to descend, a trend that was particularly steep during the boom period of 2003-2011 before flattening out during the post-2011 slowdown. This trajectory contrasts with that of Latin America and the Caribbean in previous periods or other regions in the same period (Alvaredo and Gasparini 2015; De Ferranti et al. 2004; De la Torre et al. 2014; Gasparini and Lustig 2011; López-Calva and Lustig 2010).

Although the path of household income inequality in Latin America and the Caribbean was not independent of (redistributive) social policy, this chapter argues that in the 2000s the behavior of the region's labor markets had the dominant role. In particular, pro-poor labor market dynamics led to a downward trajectory in labor income inequality that closely mirrored that of household income inequality. This is not to say that transfers to the poor and other social programs introduced or expanded during the first years of the millennium did not contribute to the trends. About one-third of the changes in household income inequality can be attributed to redistributive policies (Cord et al. 2014). This chapter is about the remaining two-thirds that correspond to the workings of the labor market. It examines the trends and discusses possible driving factors behind the historical facts.

A. de la Torre $\bullet$ J. Silva $(\bowtie)$

The World Bank, 1818 H Street NW, Mail stop I9-900, Washington, DC, USA

J. Messina

Inter-American Development Bank, 13000 New York Avenue NW, Washington, DC, USA

(C) The Author(s) 2017

L. Bértola, J. Williamson (eds.), Has Latin American Inequality

Changed Direction?, DOI 10.1007/978-3-319-44621-9_13 
An important stylized fact in Latin America and the Caribbean is that the reduction in labor income inequality was, in turn, largely driven by changes in the skill premium (as measured by the wage returns to tertiary versus primary education), which again followed a path that broadly mirrored, over the entire period, that of labor income inequality (De la Torre et al. 2014; 2015a, b). Previous empirical research on the region has linked this decreasing skill premium to several intuitive supply and demand mechanisms:

- Expanded access to education across the region's countries increased the skilled labor supply. The increased supply of skilled workers exerted downward pressure on wage inequality by decreasing the wage skill premium (Azevedo et al. 2013; Gasparini et al. 2011, Gasparini and Lustig 2011; López-Calva and Lustig 2010; Lustig et al. 2013).

- Changes in technology and international trade decreased the wage gap between skilled and unskilled workers by expanding the demand for unskilled labor relative to skilled labor (Gonzaga et al. 2006).

- Institutional factors that decreased the skill premium exerted upward pressure on wages at the bottom by rising minimum wages in Brazil (Barros et al. 2010) or enhancing unions' empowerment in Argentina (Gasparini and Cruces 2010).

This chapter adds to this growing literature by discussing the contribution of each of these factors as well as offering new hypotheses, using household survey data, ${ }^{1}$ on determinants of the evolution of the skill premium and the channels through which such determinants were transmitted.

The remainder of the chapter is organized as follows: Sect. 2 describes in detail the main stylized facts on labor inequality in Latin America and the Caribbean. Section 3 discusses the supply-side determinants (presenting some new hypotheses) and the demand-side drivers. Section 4 concludes.

\section{Stylized Facts}

\subsection{Falling Income Inequality: A Break with Recent History}

The 2000s were a period of inequality reduction in Latin America and the Caribbean. This trend contrasted sharply with the 1990s, when inequality increased in the region (Alvaredo and Gasparini 2015; De Ferranti et al. 2004; De la Torre et al. 2014; Gasparini and Lustig 2011; López-Calva and Lustig 2010; World Bank 2011a, b). Between 2002 and 2013, the Gini coefficient of household income

\footnotetext{
${ }^{1}$ Household survey data were compiled from the Socio-Economic Database for Latin America and the Caribbean (SEDLAC) of the Center for Distributive, Labor and Social Studies (CEDLAS) of the Universidad de La Plata, Argentina, and the World Bank, Washington, DC, http://sedlac.econo. unlp.edu.ar/eng/.
} 


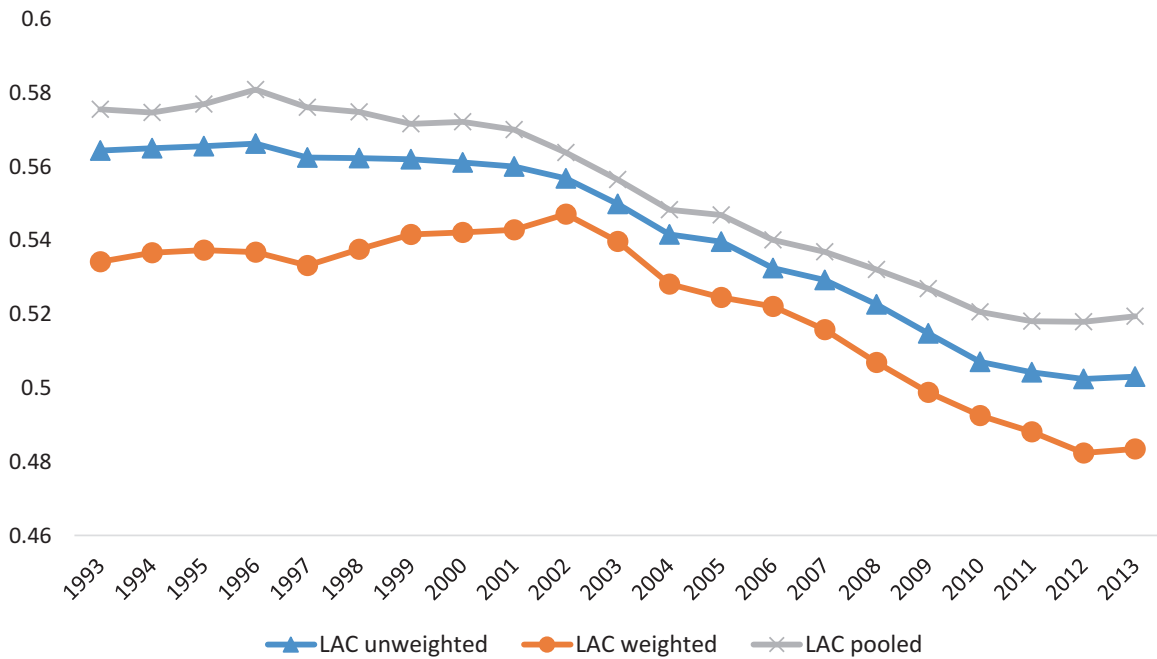

Fig. 1 Household income inequality: simple averages Gini LAC 1993-2013. Source: Based on SEDLAC (World Bank and CEDLAS). Note: LAC interpolated dataset, built using microdata for 17 countries. For more information about the interpolation see World Bank (2015). Source: Rodríguez-Castelán et al. 2016

inequality fell by 5.3 points, from 55.6 to 50.3 Gini points (Fig. 1). ${ }^{2}$ Using other inequality measures, the conclusions are the same: inequality fell strongly (Azevedo et al. 2013; Cord et al. 2014).

The Gini coefficient is the most commonly used measured of income inequality, but it is sometimes difficult to grasp its intuitive meaning. One useful way to interpret changes in the Gini coefficient is proposed by Atkinson and Morelli (2014). They note that "a Gini coefficient of $G$ percent means that, if we take any two households from the population at random, the expected difference is $2 \mathrm{G}$ percent of the mean." Thus, the reduction in household income inequality in Latin America and the Caribbean implies that the expected income difference between two households picked at random in the region has gone down by $10 \%$ of the mean income, from 111.2 to $100.6 \%$.

The reduction of inequality in Latin America and the Caribbean was not only unprecedented in recent history but also distinct when compared with the rest of the world (Lustig et al. 2013). For a global comparison of consumption inequality statistics, Alvaredo and Gasparini (2015) compiled data for as many as 130 countries for the period 1980-2010. ${ }^{3}$ The trends confirm the sharp inequality reduction in Latin America and the Caribbean and the contrast with developing countries in other regions, where inequality fell from an average of 40.6 Gini points to 39.4 points.

\footnotetext{
${ }^{2}$ The Gini coefficient is a measure of statistical dispersion representing the income distribution of a nation's residents. A coefficient of zero expresses perfect equality (every resident has the same income), whereas a coefficient of one (or $100 \%$ ) expresses maximal inequality (one person has all the income, and all others have none).

${ }^{3}$ The dataset was computed mostly from household survey microdata, using the World Bank's PovcalNet online analysis tool (http://iresearch.worldbank.org/PovcalNet/).
} 
Putting numbers in a (recent) historical perspective, Latin America and the Caribbean from the 1970s through the 1990s was nearly 10 points more unequal than Asia, 17.5 points more unequal than the 30 countries in the Organization for Economic Co-operation and Development, and 20.4 points more unequal than Eastern Europe (De Ferranti et al. 2004). During the 2000s, however, the data clearly indicate an inequality convergence, as the less unequal countries experienced larger increases in inequality (Alvaredo and Gasparini 2015).

The decline in income inequality was not driven by a single country or a group of countries. Instead, it was shared across 16 of the 17 countries in which we can consistently measure household income inequality in Latin America and the Caribbean. The only exception was Costa Rica, where inequality increased by 1.7 Gini points. ${ }^{4}$ In spite of the common trends, the reductions are heterogeneous in their magnitude, ranging from 1.4 annual Gini points in Nicaragua (2005-2009) to 0.09 annual Gini points in Colombia (Cord et al. 2014). In general, inequality declined more rapidly among the commodity-exporting countries, which suggests that the spectacular commodity boom may have played a role in the observed inequality dynamics - a hypothesis to which we will return below (Fig. 2).

a) Poverty rate (\$4 a day)

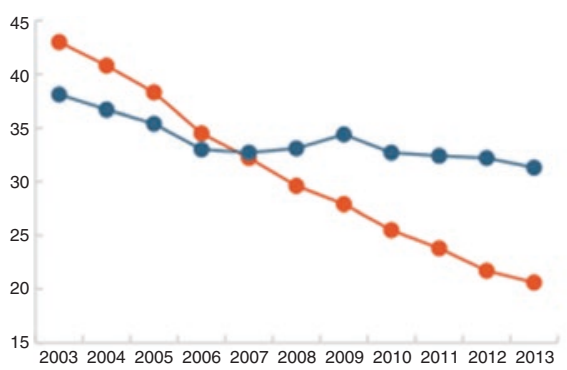

b) Gini coefficient

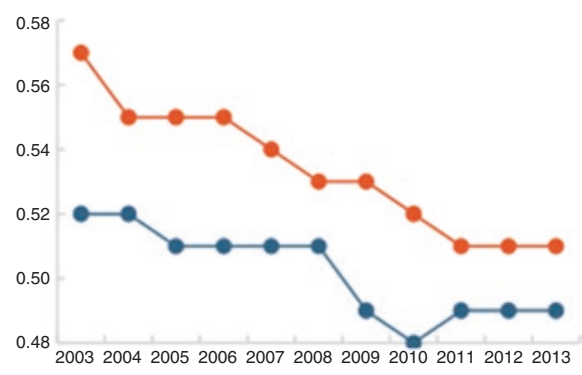

_ Countries without commodity boom —Countries with commodity boom

Fig. 2 Evolution on poverty and inequality in countries with commodity boom and countries without commodity boom, 2003-2013. Source: Based on SEDLAC (CEDLAS and the World Bank). Note: The inequality figures are the weighted average of country-specific Gini coefficients. In order to analyze the same set of countries every year, interpolation was applied when country data were not available for a given year. Commodity-boom countries are those which registered annualized growth in terms of trade above $2 \%$ in the 2003-2013 period (Chile, Bolivia, Colombia, Peru, Ecuador, Brazil, and Argentina). Non-boom countries are the Dominican Republic, Guatemala, Honduras, Mexico, Paraguay, El Salvador, and Uruguay. Due to data limitation, Costa Rica, Panama, and Nicaragua are excluded. Source: Castaneda et al (2015)

\footnotetext{
${ }^{4}$ Despite the change since 2010 in the official methodology to measure income in Costa Rica, there is no evidence of reduction; both the previous and current methodology show an increase.
} 


\subsection{The Role of Labor Income Versus Redistributive Policies}

The fall in labor income inequality was the most important factor that explains the recent downward trend in income inequality in most Latin American and Caribbean countries. There is an intimate relationship in the region between individual earnings inequality and household income inequality (De la Torre et al. 2014, 2015a, b). This is evident in Fig. 3, which shows similar trends in earnings and household income inequality for the region as a whole.

The close relationship between individual earnings and household income inequality is both an artifact and a reality, reflecting at least two important facts. The first regards measurement. The household surveys that we use to measure household income inequality do a good job of tracking earnings, but most likely underestimate the income from sources other than labor. Since nonlabor income tends to be more concentrated in the upper part of the income distribution and labor income is more spread throughout the income distribution (Piketty and Goldhammer 2014), our estimates of household income inequality are likely to be downward biased. Note, however, that in the few countries in which one can correct household income inequality measures in the household surveys using data from top income earners, the inequality levels are

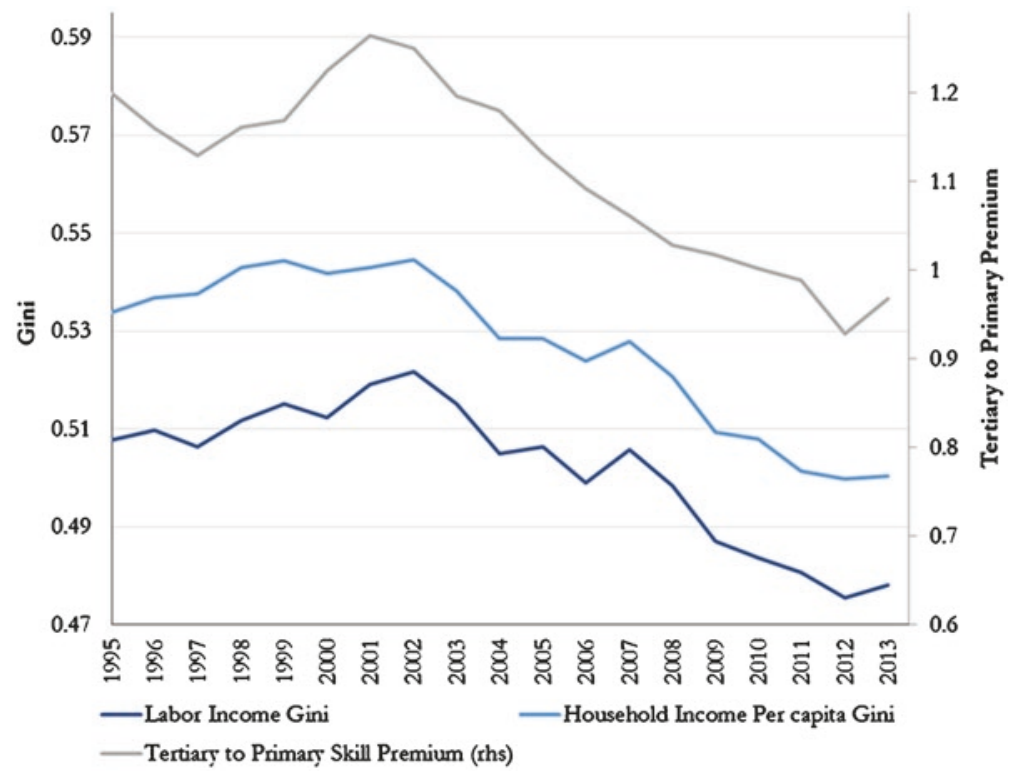

Fig. 3 Labor and total income Gini and the tertiary to primary education wage premium 19952013 (LAC Average). Source: Based on SEDLAC. Notes: The graph plots the simple average across countries of the labor income Gini and household income Gini, and the skill premium of tertiary education relative to primary education. Included are Argentina, Bolivia, Brazil, Chile, Colombia, Costa Rica, the Dominican Republic, Ecuador, Mexico, Panama, Paraguay, Peru, and Uruguay 


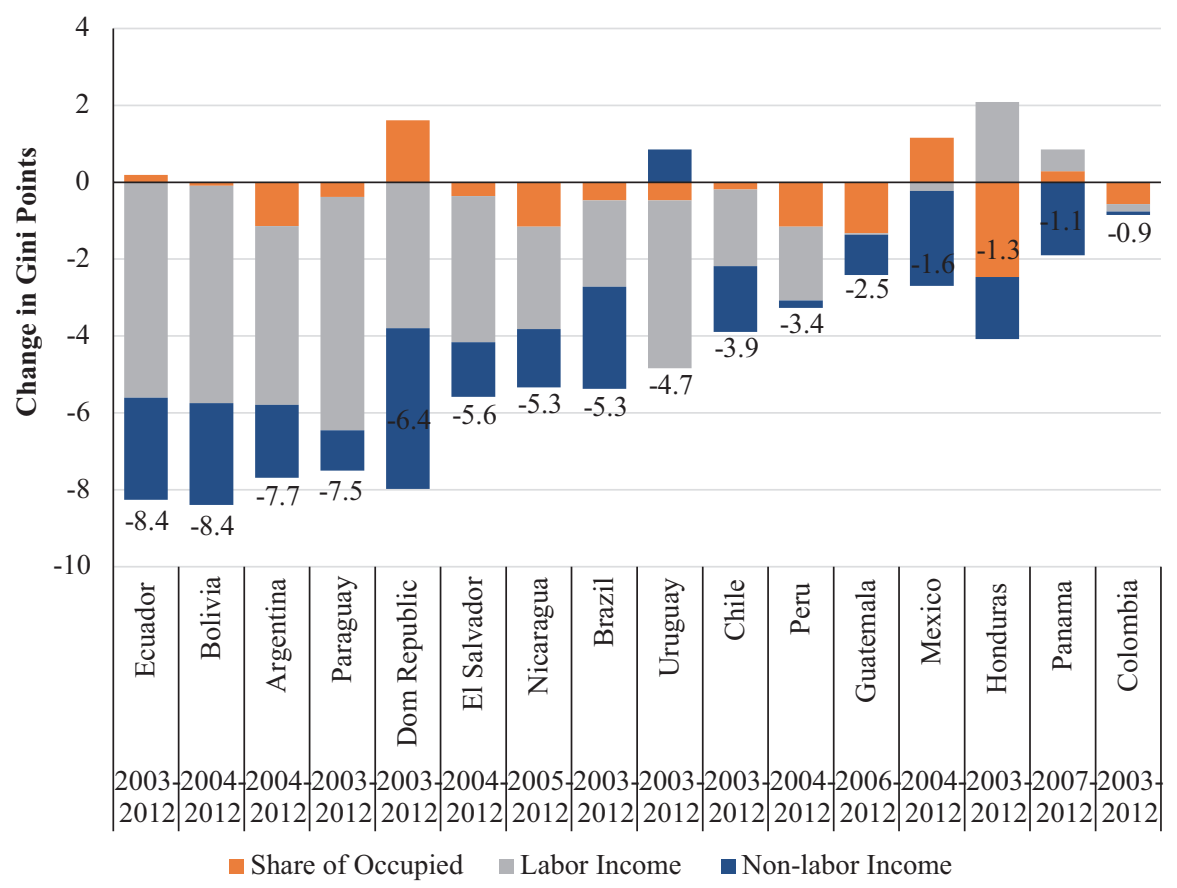

Fig. 4 Decomposition of the evolution of household income inequality in LAC (circa 2003-2012). Source: World Bank (2014). Note: Graph plots the change in the composition of the household income Gini between share of occupied people, labor income, and nonlabor income

altered but not the trends: it is still true that inequality in these countries fell during the 2000s (De la Torre et al. 2014). The second important fact concerns the limited capacity of Latin American states to redistribute income. While these factors might lead to a downward bias in the measurement of nonlabor income, as labor earnings account for the lion share of total income, they are unlikely to challenge the strong association between individual earnings and household income inequality remains.

In Fig. 4 we decompose changes in household income inequality in the evolution of three components: labor earnings, the share of occupied household members, and nonlabor income. A few messages stand out. In all countries considered except Honduras, the evolution of labor earnings contributed to a reduction in inequality. In most of the cases, this contribution was predominant: for Latin America and the Caribbean as a whole, the reduction in annual Gini points was 0.52 , with labor earnings representing 54\% of the overall trend (Azevedo et al. 2014; Cord et al. 2014). Notwithstanding the crucial role of labor incomes - the main asset of the poor-in the reduction of household income inequality, the contribution of nonlabor income cannot be disregarded as minor. In Brazil, in fact, the rapid growth of social programs had a redistributive effect similar in weight to labor income in the annual fall of inequality.

Although the Gini coefficient is a useful summary measure of inequality, other inequality measures are more informative about the potential mechanisms behind labor market developments. A common measure of inequality used by labor economists is 
the log ratio of the 90th to the 10th percentile in the distribution of earnings. This measure can be further decomposed into separate trends for bottom inequality (defined by the $\log (\mathrm{p} 50 / \mathrm{p} 10)$ ratio) and top inequality (approximated by $\log (\mathrm{p} 90 / \mathrm{p} 50)$ ). In most Latin American and Caribbean countries during the 2000s, the reduction of inequality was as important at the top of the earnings distribution as at the bottom (Table 1).

The reduction in inequality during the 2000 s constitutes a unique phenomenon in the recent history of Latin America. Figure 5 shows that there is a turning point in the extent of earning inequality in most countries during the 2000s, the exact moment of the trend reversal depending on each country. In many countries (Argentina, Colombia, Peru) the turning point is around 2002-2003, coinciding with a period of rapid growth and the commodity boom. Note, however, that this rapid decline contrasts with the upward trends of the 1990s, and some signs of stagnation and even raising earnings inequality started around 2012.

\subsection{Decline in the Skill Premium: A Primary Driver of the Fall in Earnings Inequality}

Why did labor earnings contribute so greatly to the reduction of household income inequality? This section shows that the evolution of labor earnings was intimately related to the evolution of the wage premium associated with schooling. More generally, the fall in earnings inequality was associated with a reduction in the returns to workers' skill, for which educational level serves as a proxy.

The evolution of the education premium is always a prime factor behind the evolution of labor earnings inequality. Figure 3 depicts the evolution of the labor income Gini (dark blue line), household income per capita Gini (light blue line), and tertiary versus primary education premium (gray line). As we can see, inequality has shown the same trend as the skill premium-increasing in the 1990s and decreasing throughout the 2000 s.

The reduction in the skill premium and the parallel trends with wage inequality are shared across the vast majority of Latin American and Caribbean countries (Gasparini et al. 2011). Figure 3 shows the tertiary education premium in Argentina, Brazil, Chile, Colombia, Mexico, and Peru. In all those countries except Colombia, the education premium fell rapidly as earnings inequality declined.

The reduction in the returns to education was paralleled by a reduction in the returns to other observable skills. Figure 6 shows the evolution of earnings inequality (as measured by the log ratio p90/p10) and the evolution of earnings inequality net of changes in the composition and returns to labor market observable skills (that is, labor market experience, approximated by the age of workers and education). ${ }^{5}$ Figure 6 plots the $\log$ ratio p90/p10 and the residual $\log$ p90/p10 from a Mincerian type of equation for four countries: Argentina, Brazil, Chile, and Mexico. It is

\footnotetext{
${ }^{5}$ Residual wage inequality is obtained by calculating the percentile ratios from the distribution of the residuals from a flexible Mincer equation with a quadratic term in age, a set of education dummies, and a full set of interaction terms that is estimated year by year.
} 


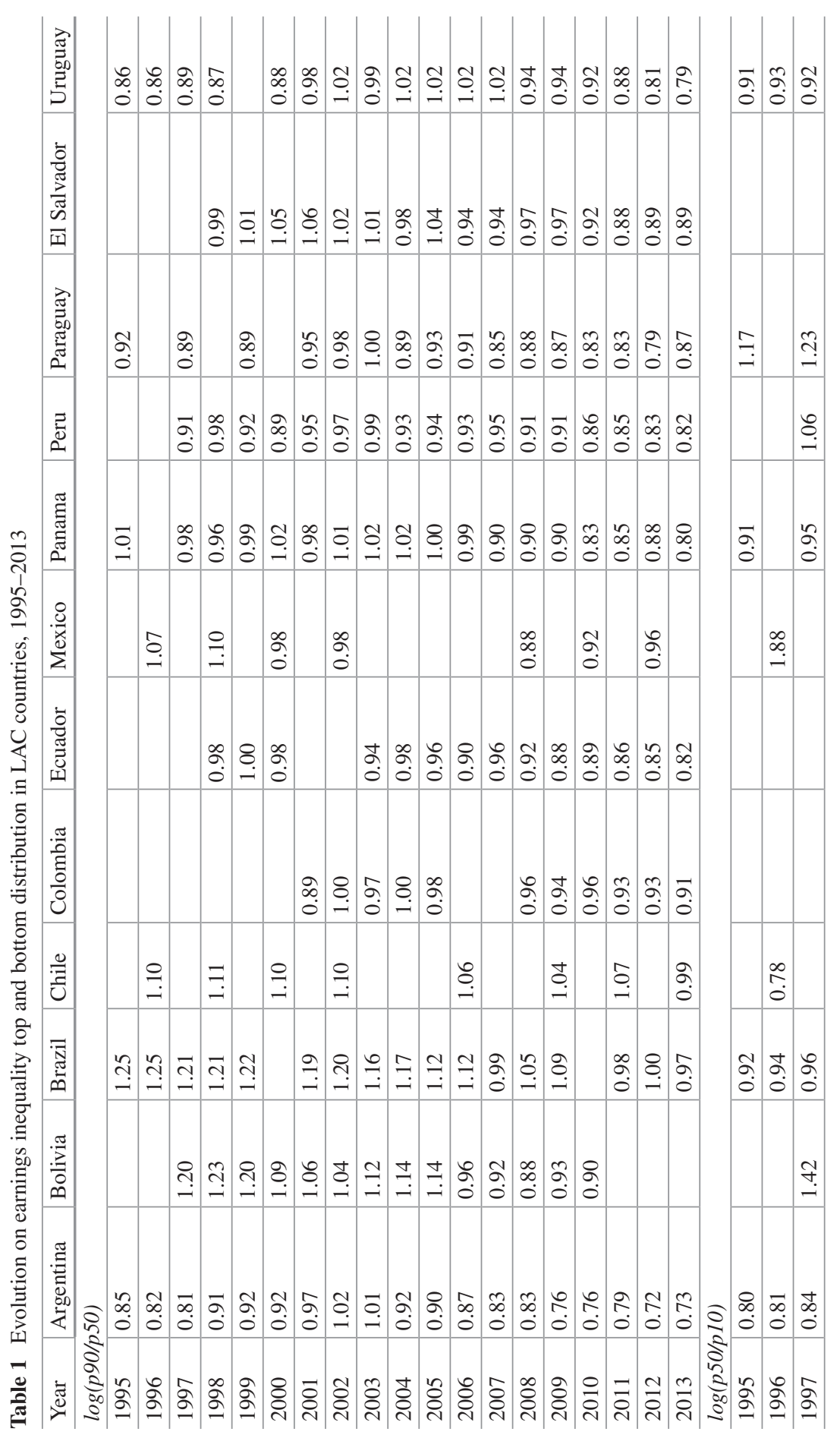




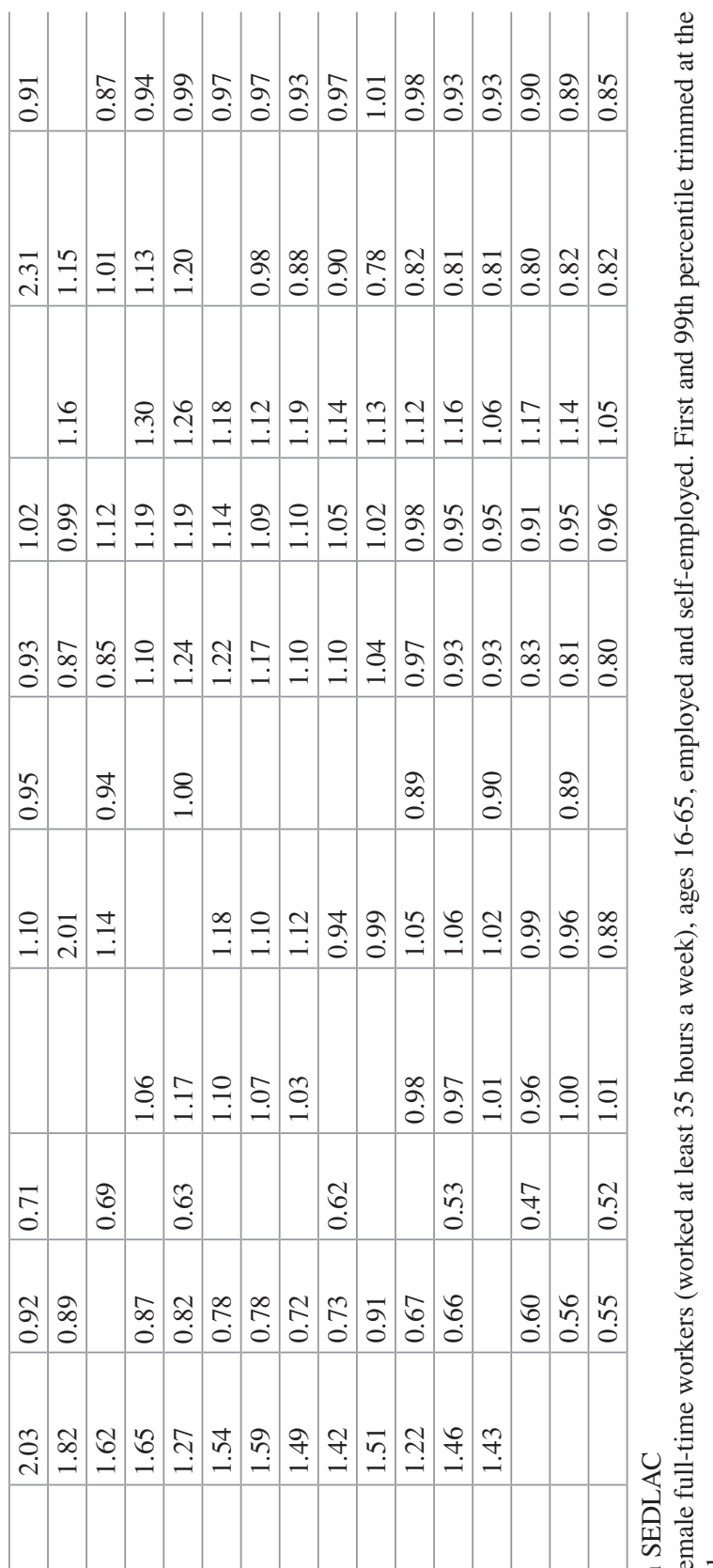

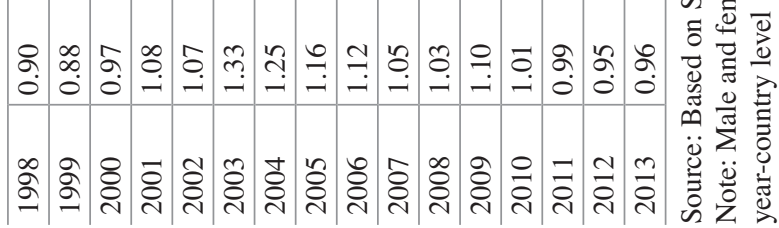




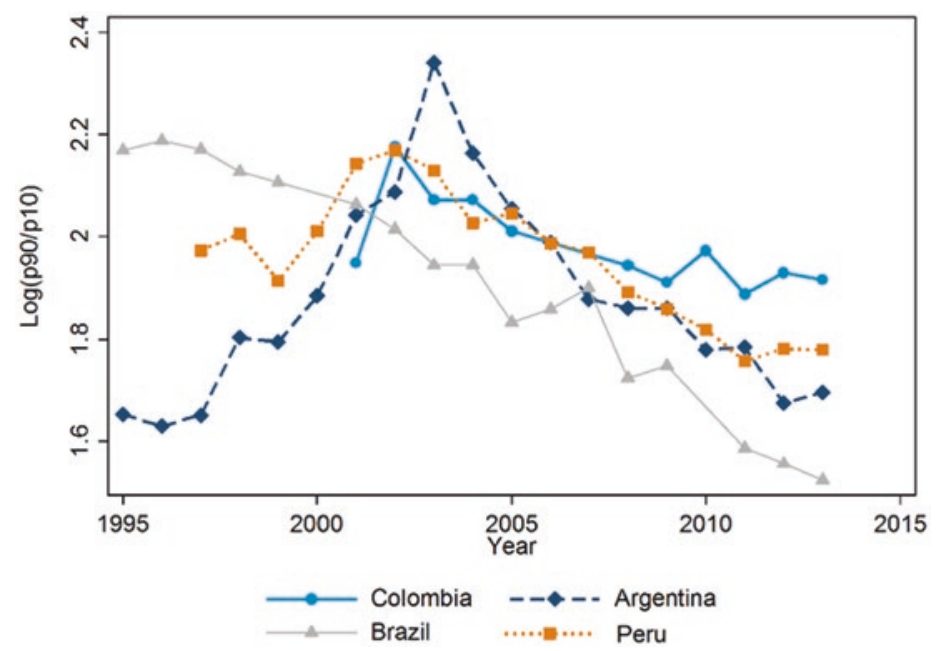

Fig. 5 Evolution of earnings inequality by country 1995-2013. Source: Based on SEDLAC. Note: Male and female full-time workers (worked at least 35 hours a week), ages 16-65, employed and self-employed. First and 99th percentile trimmed at the year-country level
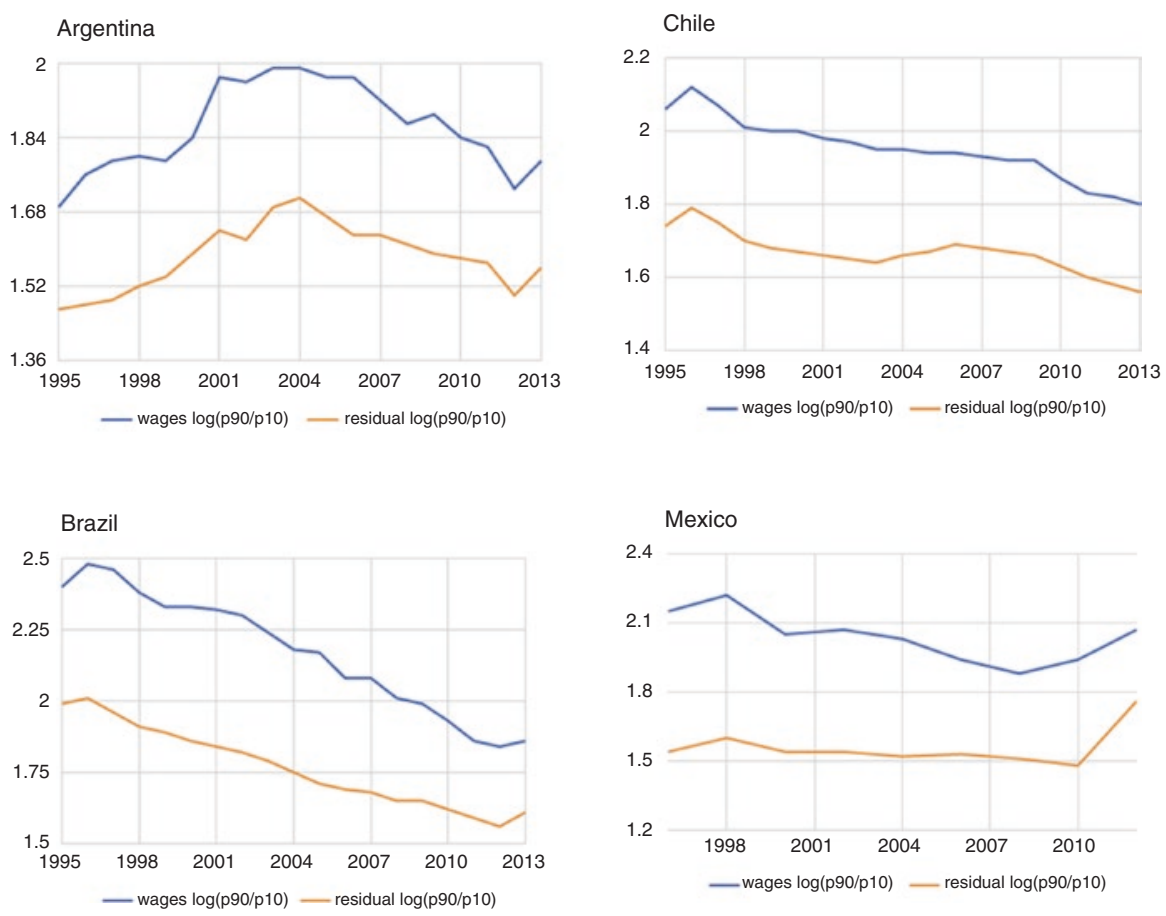

Fig. 6 Evolution of earnings inequality net of changes in the composition and returns to market labor observable skills 1995-2013. Source: Fernández-Sierra, M. and Messina, J. (2015) 
remarkable how similar the trends are between the two curves in all countries. Thus, in the 2000s, Latin America experienced a reduction not only in the returns to education but also in the returns to labor market skills in general.

\section{Why Did the Skill Premium Decrease?}

\subsection{Supply-Side Factors: Rising Numbers of More Educated Workers}

Labor supply developments are a primary determinant of the school premium. In a competitive labor market, if labor demand remains constant, changes in the supply of a particular type of labor (for example, college-educated workers) translate into changes in the education premium. The supply-demand framework has indeed done a remarkably good job of explaining the education premium in the USA (Autor et al. 1998; Katz and Murphy 1992).

At least since the 1990s, all Latin America and Caribbean countries greatly expanded educational attainment. The proportion of the labor force with aboveprimary education increased noticeably (Table 2). The unweighted average share of

Table 2 Evolution of the share of workers with completed primary, secondary, and tertiary

\begin{tabular}{|c|c|c|c|c|c|c|}
\hline Year & $\begin{array}{l}\text { Complete } \\
\text { primary }\end{array}$ & $\begin{array}{l}\text { Diff } \\
\text { primary }\end{array}$ & $\begin{array}{l}\text { Complete } \\
\text { secondary }\end{array}$ & Diff secondary & $\begin{array}{l}\text { Complete } \\
\text { tertiary }\end{array}$ & Diff tertiary \\
\hline \multicolumn{7}{|c|}{ Weighted average } \\
\hline 1990 & 0.09 & & 0.11 & & 0.06 & \\
\hline 1995 & 0.14 & 0.044 & 0.12 & 0.01 & 0.07 & 0.01 \\
\hline 2000 & 0.14 & 0.003 & 0.15 & 0.03 & 0.09 & 0.02 \\
\hline 2005 & 0.13 & -0.005 & 0.19 & 0.04 & 0.10 & 0.02 \\
\hline 2010 & 0.12 & -0.008 & 0.21 & 0.02 & 0.12 & 0.02 \\
\hline 2013 & 0.13 & 0.005 & 0.23 & 0.01 & 0.14 & 0.01 \\
\hline Total diff. & & 0.038 & & 0.11 & & 0.08 \\
\hline \multicolumn{7}{|c|}{ Unweighted average } \\
\hline 1990 & 0.20 & & 0.14 & & 0.07 & \\
\hline 1995 & 0.22 & 0.01 & 0.13 & -0.01 & 0.08 & 0.01 \\
\hline 2000 & 0.18 & -0.04 & 0.15 & 0.02 & 0.09 & 0.01 \\
\hline 2005 & 0.17 & -0.01 & 0.17 & 0.02 & 0.11 & 0.02 \\
\hline 2010 & 0.16 & -0.01 & 0.19 & 0.02 & 0.12 & 0.01 \\
\hline 2013 & 0.16 & 0.00 & 0.20 & 0.01 & 0.14 & 0.02 \\
\hline Total diff. & & -0.04 & & 0.06 & & 0.07 \\
\hline
\end{tabular}

Source: Based on SEDLAC

Note: Estimations used 15 Latin American and Caribbean countries. All female and male workers (salaried, self-employed, and employers) 
the working-age population that completed secondary education in the 15 countries for which data are available rose from 14 to $20 \%$ between 1990 and 2013. This rise is all the more remarkable if we consider the weighted (by population) average, which rose from 11 to $23 \%$ in the same period. ${ }^{6}$

The expansion of tertiary education was equally important. The weighted average share of workers who had completed college almost doubled, rising from $6 \%$ in 1990 to $14 \%$ in 2010 (from 7 to $14 \%$ if we consider the unweighted average). In Brazil and El Salvador, the ranks of working-age individuals with completed secondary and tertiary education more than doubled. In Argentina, Chile, Honduras, and Panama, the share of college graduates doubled. In a third group of countries (Bolivia, Colombia, Costa Rica, the Dominican Republic, Paraguay, and Peru), the registered improvements in educational attainment were significant but more modest (Table 3).

These broad patterns hide substantial country-specific differences in the temporal evolution of educational attainment of the labor force during the 1990s and the 2000s (Table 3). Some countries (Colombia, Costa Rica, and Paraguay) only achieved gains in years of schooling during the 2000s, after a decade of stagnation or (in the case of Paraguay) after a severe deterioration of educational attainment. Others (Brazil and Ecuador) rapidly expanded secondary education in the 1990s, followed by a more intense expansion of tertiary education in the 2000s. But in contrast with the reductions in inequality, which were mostly concentrated during the 2000s, several Latin American and Caribbean countries (notably El Salvador and Uruguay) expanded education more rapidly in the 1990s than in the past decade.

Education is not the only dimension of human capital that can potentially explain wage dynamics. The traditional Mincerian framework highlighted the importance of labor market experience, together with education, in determining wages. The role of experience is largely neglected in the Katz and Murphy (1992) framework, which implicitly assumes that all workers within an educational group are perfect substitutes. This need not be the case, as shown by Card and Lemieux (2001) for the USA and by Manacorda et al. (2010) for Latin America during the 1990s.

Changes in the composition of the labor supply may differ across educational groups. In a rapidly expanding educational system, younger cohorts are likely to be more educated than older cohorts, putting downward pressure on the education premium of workers with little experience in the labor market. These trends may be exacerbated if the rapidly increasing demand for education exerts such pressure on the educational system that a degradation of educational diplomas results (Campos et al. 2014).

Fueled by younger cohorts' increasing demand for education, the rapid expansion of low-quality higher education institutions in Latin America and the Caribbean has sparked concern. One hypothesis put forward, known as the "degraded tertiary"

\footnotetext{
${ }^{6}$ The large difference between the weighted and unweighted measure is mainly due to the spectacular performance of Brazil, where the share of the working-age population with complete secondary education more than doubled during the period, from $13 \%$ in 1990 to $31 \%$ in 2009 (De la Torre et al. 2014).
} 


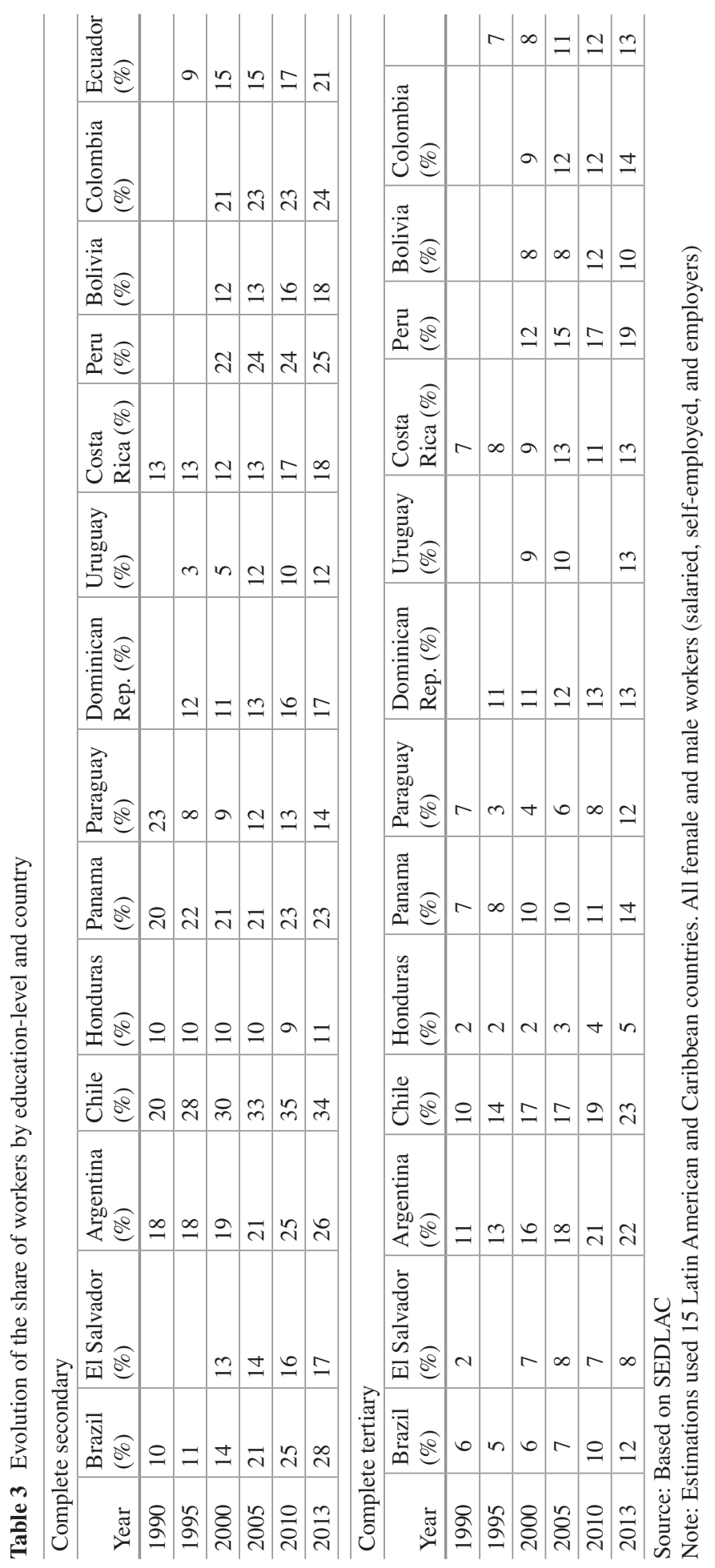


hypothesis (Campos et al. 2014), posits that expansion was accompanied by an increasing dispersion in the quality of education centers, pushing downward the average quality of tertiary education. The so-called garage universities may be eroding the value of educational diplomas, critics note, contributing to a decline in the quality of higher education among labor market entrants and thus to a decline in the returns to education. This hypothesis appears at odds with the empirical evidence, though. First, in several Latin American countries, the education premium has declined more among older cohorts than among younger cohorts. This is explored at length in the cases of Mexico (Campos et al. 2014) and Brazil (Wang 2015). The available evidence is thus more in line with a skill obsolescence hypothesis than with an eroded value of higher education (Campos et al. 2014). Direct evidence for Colombia also argues against this channel of decline in the education premium. In particular, Camacho et al. (2015) show that the value added of new higher education institutions and programs created in the 2000s is very similar to that of the traditional programs. Hence, there is little evidence that the supply of higher education has been degraded.

Another supply-side hypothesis relates to the composition of the supply of educated workers. According to this hypothesis, demographic changes have resulted in an increase in the share of older workers whose skills become obsolete at a more rapid pace due to the adoption of new technologies, and this effect outweighs the value of work experience. As a result, the wage premium for tertiary education (considering all tertiary educated workers) has fallen on average. Campos et al. (2014) provide some preliminary evidence for Mexico where the real wages of older workers have actually declined in absolute terms. Replicating their analysis for other countries De la Torre et al. $(2015 \mathrm{a}, \mathrm{b})$ find mixed evidence-the relative decline of the wages of older workers doesn't appear to be a widespread phenomenon in LAC. Certainly more research is warranted in this area, however.

Fernández-Sierra and Messina (2015) disentangle the roles of labor market experience and education in explaining the observed skill premium trends. They show that different education premium trends are present across workers with different levels of labor market experience, and such trends are partially explained by relative labor supply dynamics. However, an explanation of a reverse trend-the shift from increasing demand for highly skilled workers in the 1990s to declining demand after 2003 - is needed to fully account for the observed dynamics in the skill premium.

\subsection{Demand-Side Factors: Labor Demand Shifts}

As this chapter has broadly concluded thus far, changes in educational attainment and other human capital dimensions must have played a role in the falling inequality of labor earnings during the 2000s in Latin America and the Caribbean. However, the region's downward inequality trend cannot be explained solely by the increasing number of skilled workers. At the macroeconomic level, the shift in labor income inequality trends between the 1990s and the 2000s is not consistent with the 
constant improvement in the supply of education throughout the period. In other words, the acceleration in the educational attainment of the workforce during the 2000s was not sufficient to explain the rapid decline in the education premium. Rather, the shift in labor earnings inequality coincided more clearly with substantial increases in labor demand during this period.

The 1990s and 2000s were periods of pronounced business-cycle and labordemand trends. After a decade of disappointing growth, the region underwent rapid growth in the 2000s in the wake of rising commodity prices and high growth globally, particularly in China and the Group of 7 (G7) major advanced economies. ${ }^{7}$ The commodity-exporting countries (mostly in South America) ${ }^{8}$ grew substantially faster during the boom years (roughly 2003-2011) than the commodity-importing countries (mostly in Central America and the Caribbean), ${ }^{9}$ which experienced only small trade gains or even losses.

The argument that a reversal in demand trends is needed to account for the shift in wage inequality that occurred in the early 2000s is explored formally by Gasparini et al. (2011), applying Katz and Murphy (1992) to the Latin American data. Their conclusion is that while supply-side forces mattered for inequality dynamics, demand-side determinants - the focus of this section - are key.

Several demand factors have been highlighted in the literature as important drivers of wage inequality, including changes in the industrial structure; technological change (and, more recently, outsourcing); and international trade. These factors (for given (skilled and unskilled) labor supplies) could decrease the wage gap between skilled and unskilled workers, and therefore earnings inequality, by expanding the demand for unskilled labor relative to skilled labor.

Together with underlying supply-side factors discussed in the previous section did labor earnings inequality fall in the 2000 s because of

(a) A specialization pattern (of industrial production) that led to a slower rise in skilled labor demand than supply

(b) Technological change, particularly automation, that was particularly deleterious to skilled as opposed to unskilled occupations, leading firms in the region to become less skill intensive or to move some of the more skill-intensive production and service tasks offshore

(c) Fluctuations in aggregate demand/business cycle that favored unskilled workers relative to skilled ones

This section briefly discusses why neither (a) nor (b) provides a sufficient explanation for the inequality patterns in the 2000s and ultimately focuses on (c).

The specialization story refers to that hypothesis that deindustrialization in the region by eliminating high-skilled manufacturing job sector in favor of low-skilled

\footnotetext{
${ }^{7}$ The G7 countries include Canada, France, Germany, Italy, Japan, the UK, and the USA.

${ }^{8}$ Net commodity-exporting countries in Latin America and the Caribbean include Argentina, Bolivia, Brazil, Chile, Colombia, Ecuador, and Peru.

${ }^{9}$ Net commodity-importing countries in Latin America and the Caribbean include Costa Rica, the Dominican Republic, El Salvador, Guatemala, Honduras, Mexico, Paraguay, and Uruguay.
} 
positions in the construction and service sectors would decrease the skill premium (Gasparini et al. 2011). Under this hypothesis, we should see a decline in the share of the labor force (and a deeper wage compression) in skill-intensive sectors relative to the rest. This fact, however, is not fully consistent with the fact that sectors that in average demand more education grew comparatively more over this period, in contradiction to the premise of a demand shift towards low-skill sectors (De la Torre et al. 2014). Moreover, the implicit assumption that services in LAC are less skill intensive than manufactures is not validated by the data (De la Torre et al. 2015a, b).

Another hypothesis includes skill-biased technological change (Acemoglu 1998; Esquivel and Rodriguez-Lopez 2003). This literature emphasizes that, in developed countries, technological change (particularly automation) is complementary to high-education occupations, a substitute for middle-education occupations, and neither complementary nor a substitute for low-skilled occupations, consistent with a U-shaped change in employment shares across skill levels in the recent decades in the USA. However, in Latin American and Caribbean countries, evidence suggests that employment shares remained fairly constant across skill levels (Messina et al. in press; Silva et al. 2015). In a related strand of the literature, Acemoglu (2003) and Feenstra and Hanson (1997) emphasize the role of outsourcing in the USA, an issue that deserves further research in Latin America and the Caribbean. However, there is some evidence that skill-biased technical change may have actually reduced labor income distribution in LAC through a different channel, i.e., by accelerating skill obsolescence in a way that more than offsets the effects of work experience. The fact that in some LAC countries (e.g., Mexico and Argentina) the wages of older workers fell relative to those of younger workers is consistent with this hypothesis, although the relative impact of this effect on overall labor income distribution is yet to be ascertained (Campos et al. 2014; De La Torre et al. 2015b).

Importantly, in high-income countries, labor demand shifts for skilled versus unskilled workers are typically interpreted as emanating from firm-level changes, that is, as evidence of skill-biased technological change associated with changes in the organization of production (Autor 2007; Autor et al. 1998; Goldin and Katz 2007). However, in Latin America and the Caribbean-where business cycles are much more pronounced and external shocks play a major role in explaining aggregate demand behavior - demand-driven inequality may have a different, more macroeconomic nature. External shocks in the region during the 2000s such as the commodity boom had different effects on commodity-exporting countries (winners from growing demand for commodities) than on commodity-importing countries (losers from higher prices of commodities and import competition) (De la Torre et al. 2015a). This divide between these two types of country groups is also reflected in wage trends, with commodity-exporting countries experiencing faster growth in average wages than commodity-importing countries (Fig. 7). Perhaps even more importantly, labor income inequality fell in both sets of countries but for very different reasons: In commodity exporters, this happened because both skilled and unskilled earnings were rising, but the unskilled component was rising faster in commodity importers, low-skilled workers' earnings were rising, and the skilled 


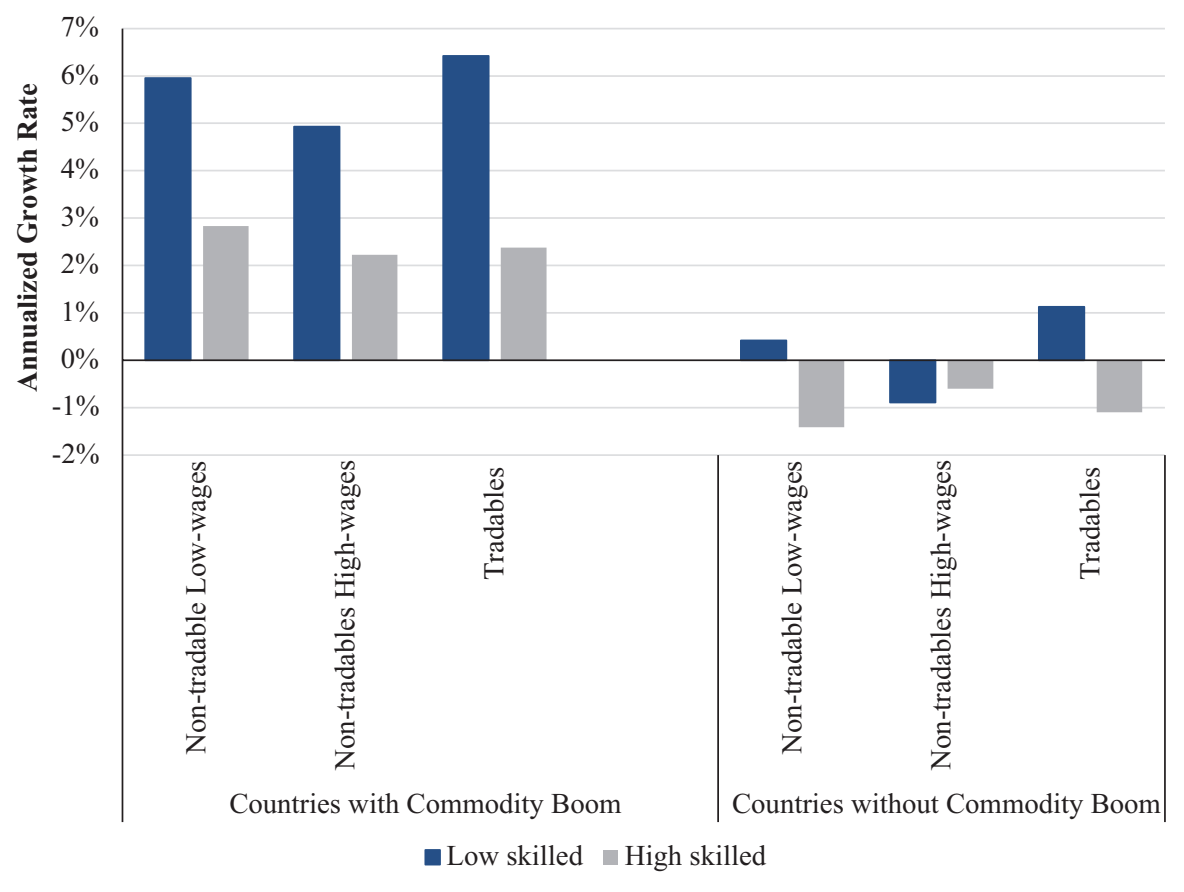

Fig. 7 Wage growth by sector in commodity-boom and no-boom countries in Latin America and the Caribbean, circa 2003-2013. Source: Based on SEDLAC. Notes: The graph plots the change in the simple average wage across countries for each sector and skill level between 2002 and 2011. Countries with commodity boom are Argentina, Brazil, Chile, Colombia, Ecuador, and Peru; countries without commodity boom are Mexico, Peru, and Uruguay. Tradables sector includes primary and manufacturing; non-tradable low-wage sector includes construction, hotels and restaurants, public administration, wholesale retail, and private households; non-tradable high-wage sector includes all other services. Low skilled is up to incomplete secondary education and high skilled completes secondary or more

workers' earnings were falling (Fig. 7). This difference and its role behind the unexpected decline in the labor income Gini throughout the region is a topic that deserves further research. ${ }^{10}$

Moreover, beyond the commodity boom and China's economic rise in the 2000s, other external shocks shifted demand in the 1990s in Latin America and the Caribbean, including the important change in trade patterns due to trade liberalization. ${ }^{11}$ Most trade models suggest that changes in output prices drive changes in wage inequality. In fact, the links between product prices and factor returns are a key element of general equilibrium trade models. Interest in these links was

\footnotetext{
${ }^{10}$ For a comprehensive discussion, see De la Torre et al. (2015a, b).

${ }^{11}$ Importantly, other factors linked with globalization have been shown to contribute to inequality trends. These include outsourcing (Acemoglu et al. 2015; Feenstra and Hanson 1997); exchange rate movements (Verhoogen 2008); and the rise of China (Chiquiar and Ramos-Francia 2008; Dussel Peters and Gallagher 2013).
} 
heightened by the "trade and wages" debate, where lower prices of unskilled labor-intensive products were advanced as one explanation for the decline in the relative wage of unskilled workers in advanced, skill-abundant countries (Silva and Bastos 2008). The underlying argument was based on the Stolper-Samuelson theorem, which implies that trade liberalization in countries where unskilled labor is relatively scarce will lead to a fall in both the relative price of unskilled laborintensive imports and the relative return to unskilled labor, and therefore to an increase in wage inequality as well (Falvey et al. 2010). In contrast, in countries where unskilled labor is abundant, the theory would predict that liberalization would lead to a fall in wage inequality.

Hence, these models are less fit to explain why while most trade liberalization occurred in the 1990s, ${ }^{12}$ wage inequality was stagnant or rising in Latin America and the Caribbean during that period (Goldberg and Pavcnik 2007). Moreover, in this strand of the literature, the mechanism by which trade affects labor markets (and thus wage inequality) is through reallocation between sectors, and shifts of employment between sectors in Latin America and the Caribbean were limited in the 2000s when inequality fell. ${ }^{13}$

Recent papers provide several intuitive theoretical mechanisms for such a relationship. Specifically, Acemoglu (2003) presents a model whereby increased international trade induces skill-biased technological change, and therefore trade opening can cause a rise in inequality. Moreover, Halliday et al. (2015) focus on a different factor-firm heterogeneity - and present a trade model whereby variations in the relative price of tradable goods can explain the decline in wage inequality. ${ }^{14}$ Fully uncovering the channels through which aggregate demand has affected income distribution in Latin America and the Caribbean is an important topic for follow-up research.

\section{Conclusion}

This chapter has examined the main trends in labor income inequality in Latin America and the Caribbean and discussed possible driving factors behind the historical facts. It documented three main stylized facts:

\footnotetext{
${ }^{12}$ For example, (a) Mexico's accession to the General Agreement on Tariffs and Trade (GATT) (later the World Trade Organization [WTO]) in 1986 (Revenga 1997); and (b) Brazil's trade liberalization from 1988 to 1995 (Gonzaga et al. 2006).

${ }^{13}$ On labor mobility costs across sectors, see Artuc et al. (2015), Hollweg et al. (2014), and the references therein.

${ }^{14}$ In addition to market forces that affect supply and demand of skilled and unskilled workers, institutional factors such as the minimum wage and unionization can also come into play. Barros et al. (2010) argue that, in Brazil, minimum-wage policy played an important role in inequality reduction. In a linked paper, Ferreira et al. (2014) find that although the minimum wage contributed significantly to inequality reduction, factors such as the decrease in wage gaps between urban and rural residents, formal and informal workers, and men and women (which could have also been influenced by the minimum-wage policy indirectly) were also key. Papers on the role of unionization in Latin America and the Caribbean are rarer. An important exception is Gasparini and Cruces (2010), which argues that, in Argentina, empowerment of unions contributed to wage compression within firms.
} 
- After decades of growing or stagnant inequality, household income inequality throughout the region fell substantially during the 2000s, a remarkable break from the upward trajectory of household income inequality during the 1980s and 1990s.

- Such trends in household income inequality were driven predominantly by the behavior of Latin American labor markets.

- The reduction in labor income inequality was, in turn, largely driven by changes in the skill premium (as measured by the wage returns to tertiary versus primary education), which again followed a path that broadly mirrored-over the entire period - that of labor income inequality.

The chapter also presented evidence that the region's rising inequality of labor market earnings in the 1990s and falling inequality in the 2000s cannot be explained solely by supply-side factors such as the increasing number of more educated workers. Providing evidence in this direction is the region's experience during the 1990s and early 2000s, when household and labor income distribution worsened but the rates of increase in the supply of education were very similar (and even higher) than during the boom years (2003-2011), when income inequality declined. The decline in the quality of supply (lower quality of tertiary education among new entrants to the labor force) and faster skill obsolescence due to changes in demand provide complementary explanations, but there is relatively little evidence on these factors.

In search of an explanation for the reversal in inequality trends, this chapter suggests that more research is needed but that we are not completely in the dark. It argues that supply-only stories are not sufficient to explain the skill premium trajectory and that demand seems to have played a significant role (not least because it can be one of the common factors behind the unexpected decline in the labor income Gini throughout the region). Fully uncovering the channels through which demand operated is, however, a difficult task and an important topic for follow-up research.

Acknowledgements We are grateful to Alejandra Martinez who provided excellent research assistance, Daniel Valderrama who provided very useful inputs, and participants at the regional conference "Latin American Inequality in the Long Run" in Buenos Aires, December 3-5, 2014, for helpful comments. We remain responsible for any errors. The views expressed in this chapter are those of the authors and should not be attributed to the institutions they are affiliated with.

Open Access This chapter is distributed under the terms of the Creative Commons Attribution 4.0 International License (http://creativecommons.org/licenses/by/4.0/), which permits use, duplication, adaptation, distribution and reproduction in any medium or format, as long as you give appropriate credit to the original author(s) and the source, a link is provided to the Creative Commons license and indicate if changes were made.

The images or other third party material in this chapter are included in the work's Creative Commons license, unless indicated otherwise in the credit line; if such material is not included in the work's Creative Commons license and the respective action is not permitted by statutory regulation, users will need to obtain permission from the license holder to duplicate, adapt or reproduce the material.

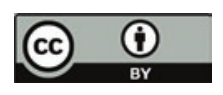




\section{References}

Acemoglu, D. (1998). Why do new technologies complement skills? Directed technical change and wage inequality. Quarterly Journal of Economics, 113(4), 1055-1089.

Acemoglu, D. (2003). Patterns of skill premia. Review of Economic Studies, 70(2), 199-230.

Acemoglu, D., Gancia, G., \& Zilibotti, F. (2015). Offshoring and directed technical change. American Economic Journal: Macroeconomics, 7(3), 84-122.

Alvaredo, F., \& Gasparini, L. (2015). Recent trends in inequality and poverty in developing countries. In A. B. Atkinson \& F. Bourguignon (Eds.), Handbook of income distribution (Vol. 2, pp. 697-805). Amsterdam: Elsevier.

Artuc, E., Lederman, D., \& Porto, G. (2015). A mapping of labor mobility costs in the developing world. Journal of International Economics, 2015, 28-41.

Autor, D. (2007). Structural demand shifts and potential labor supply responses in the new century. In Paper prepared for the Federal Reserve Bank of Boston conference on "Labor Supply in the New Century," June 19-20.

Autor, D., Katz, L., \& Krueger, A. (1998). Computing inequality: Have computers changed the labor market? Quarterly Journal of Economics, 113(4), 1169-1214.

Atkinson, A. B. and Morelli, S. (2014). "Chartbook of Economic Inequality.” ECINEQ WP 324.

Azevedo, J., Inchauste, G., \& Sanfelice, V. (2013). Decomposing the recent inequality decline in Latin America. Policy Research Working Paper 6715. Washington, DC: World Bank.

Azevedo, J., Inchauste, G., \& Sanfelice, V. (2014). Understanding changes in poverty. Directions in development series. Washington, DC: World Bank.

Barros, R., De Carvalho, M., Franco, S., \& Mendonca, R. (2010). Markets, the state and the dynamics of inequality in Brazil. In L. F. Lopez-Calva \& N. Lustig (Eds.), Declining inequality in Latin America: A decade of progress? Washington, DC: Brookings Institution and UNDP.

Bastos, P., \& Silva, J. (2008). The wage and unemployment impacts of trade adjustment. In: D. Greenaway, R. Upward, \& P. W. Wright (Eds.), Globalization and labour market adjustment. New York: Palgrave Macmillan.

Camacho, A., Messina, J., \& Uribe, J. (2015). Heterogeneous returns to higher education: 'Bad' Programs or 'Bad' Students? Unpublished manuscript. Washington, DC: World Bank. Background Paper for the Chief Economist Office study on Wage Inequality in LAC.

Campos, R., Lopez-Calva, L. F., \& Lustig, N. (2014). Declining wages for college-educated workers in Mexico: Degraded tertiary or skills obsolescence? Unpublished manuscript. Washington, DC: World Bank. Background paper for the Chief Economist Office study on Wage Inequality in LAC.

Card, D., \& Lemieux, T. (2001). Can falling supply explain the rising return to college for younger men? A cohort-based analysis. Quarterly Journal of Economics, 116(2), 705-746.

Castañeda, A., Del Carmen Hasbun, G. E., Lucchetti, L. R., Moreno Herrera, L. L., De Gouvea Scot De Arruda, T., Sousa, L. D. C., et al. (2015). Working to end poverty in Latin America and the Caribbean: Workers, jobs, and wages. Washington, DC: World Bank Group.

Chiquiar, D., \& Ramos-Francia, M. (2008). A note on Mexico and U.S. manufacturing industries' long-term relationship. Working paper 2008-08, Banco de México, Mexico City.

Cord, L. J., Cabanillas, O. B., Lucchetti, L., Rodríguez-Castelán, C., Sousa, L. D., \& Valderrama, D. (2014). Inequality stagnation in Latin America in the aftermath of the global financial crisis. Policy Research Working Paper 7146. Washington, DC: World Bank.

De Ferranti, D., Perry, G., Ferreira, F., \& Waltin, M. (2004). Inequality in Latin America: Breaking with history? Washington, DC: World Bank.

De la Torre, A., Beylis, G., \& Ize, A. (2015a, October). Jobs, wages and the Latin American slowdown. Latin America and the Caribbean semiannual report. Washington, DC: World Bank.

De la Torre, A., Lederman, D., \& Silva, J. (2015b). The inequality story in LAC: Searching for an explanation. Presentation at inequality conference, Bank of Spain.

De la Torre, A., Yeyati, E., Beylis, G., Didier, T., Rodríguez-Castelán, C., \& Schmukler, S. (2014). Inequality in a lower growth Latin America. Latin America and the Caribbean Semiannual Report (October). Washington, DC: World Bank. 
Dussel Peters, E., \& Gallagher, K. P. (2013). NAFTA's uninvited guest: China and the disintegration of North American trade. CEPAL Review, 110(August), 83-108.

Esquivel, G., \& Rodriguez-Lopez, J. A. (2003). Technology, trade, and wage inequality in Mexico before and after NAFTA. Journal of Development Economics, 72(2), 543-565.

Falvey, R., Greenaway, D., \& Silva, J. (2010). Trade liberalization and human capital adjustment. Journal of International Economics, 81(2), 230-239.

Feenstra, R. C., \& Hanson, G. H. (1997). Foreign direct investment and relative wages: Evidence from Mexico's maquiladoras. Journal of International Economics, 42(3-4), 371-393.

Fernández-Sierra, M., \& Messina, J. (2015). The role of human capital in the trend reversal of wage inequality in Latin America. Unpublished manuscript. Washington, DC: World Bank. Background paper for the Chief Economist Office study on Wage Inequality in LAC.

Ferreira, F., Firpo, S., \& Messina, J. (2014). A more level playing field? Explaining the decline in earnings inequality in Brazil, 1995-2012. IRIBA (International Research Initiative on Brazil and Africa) Working Paper 12, University of Manchester, United Kingdom. Background paper for the Chief Economist Office study on Wage Inequality in LAC.

Gasparini, L., \& Cruces, G. (2010). A distribution in motion: The case of Argentina. In L. F. LópezCalva \& N. Lustig (Eds.), Declining Inequality in Latin America: A decade of progress (pp. 100-133). Washington, DC: Brookings Institution and United Nations Development Programme (UNDP).

Gasparini, L., Galiani, S., Cruces, G., \& Acosta, P. (2011). Educational Upgrading and Returns to Skills in Latin America: Evidence from a Supply-demand Framework, 1990-2010. Policy Research Working Paper 5921. Washington, DC: World Bank.

Gasparini, L., \& Lustig, N. (2011). The rise and fall of income inequality in Latin America. Working Paper 1110. Tulane University, New Orleans.

Goldberg, P., \& Pavcnik, N. (2007). Distributional effects of globalization in developing countries. Journal of Economic Literature, 45(1), 39-82.

Goldin, C., \& Katz, L. F. (2007). The race between education and technology: The evolution of U.S. educational wage differentials, 1890-2005. Working Paper 12984. Cambridge, MA: National Bureau for Economic Research.

Gonzaga, G., Menezes Filho, N., \& Terra, C. (2006). Trade liberalization and the evolution of skill earnings differentials in Brazil. Journal of International Economics, 68(2), 345-367.

Halliday, T., Lederman, D., \& Robertson, R. (2015). Tracking wage inequality trends with prices and different trade models: Evidence from Mexico. Unpublished manuscript. Washington, DC: World Bank. Background paper for the Chief Economist Office study on Wage Inequality in LAC.

Hollweg, C. H., Lederman, D., \& Mitra, D. (2014). Structural reforms and labor market outcomes: International panel data evidence. Policy Research Working Paper Series 7122. The World Bank.

Katz, L., \& Murphy, K. (1992). Changes in relative wages, 1963-1987: Supply and demand factors. Quarterly Journal of Economics, 107(1), 35-78.

López-Calva, L., \& Lustig, N. (Eds.). (2010). Declining inequality in Latin America: A decade of progress? Washington, DC: Brookings Institution and United Nations Development Programme (UNDP).

Lustig, N., López-Calva, L., \& Ortiz-Juarez, E. (2013). Declining inequality in Latin America in the 2000s: The cases of Argentina, Brazil, and Mexico. World Development, 44, 129-141.

Manacorda, M., Sánchez-Páramo, C., \& Schady, N. (2010). Changes in returns to education in Latin America: The role of demand and supply of skills. Industrial \& Labor Relations Review, 63(2), 307-326.

Messina, J., Pica, G., \& Oviedo, A. M. (in press). From occupations to skills: Changes in skill demand in LAC. Unpublished manuscript. Washington, DC: World Bank. Background paper for the World Bank LAC Chief Economist Office study on Wage Inequality. Piketty 2014.

Piketty, T., \& Goldhammer, A. (2014, March). Capital in the twenty-first century. Print. Harvard University Press.

Revenga, A. (1997). Employment and wage effects of trade liberalization: The case of Mexican manufacturing. Journal of Labour Economics, 15(3), 20-43. 
Rodríguez-Castelán, C., López-Calva, L. F., Lustig, N., \& Valderrama, D. (2016, August 15). Understanding the dynamics of labor income inequality in Latin America. World Bank Policy Research Working Paper No. 7795.

Silva, J., Almeida, R., \& Strokova, V. (2015). Sustaining wage and employment gains in Brazil: A skills and jobs agenda. Washington, DC: World Bank. Directions in development series.

Verhoogen, E. A. (2008). Trade, quality upgrading, and wage inequality in the Mexican manufacturing sector. Quarterly Journal of Economics, 123(2), 489-530.

Wang, Y. (2015). Decomposing the changes in male wage distribution in Brazil. Unpublished manuscript. Washington, DC: World Bank. Background paper for the World Bank LAC Chief Economist Office study on Wage Inequality.

Williamson, J. G. (2015). Latin American inequality: Colonial origins, commodity booms, or a missed 20th century leveling? Working Paper 20915. Cambridge, MA: National Bureau of Economic Research.

World Bank. (2011a). A break with history: Fifteen years of inequality reduction in Latin America. LCSPP Poverty and Labor Brief No. 2. Washington, DC: World Bank.

World Bank. (2011b). On the edge of uncertainty: Poverty reduction in Latin America and the Caribbean during the great recession and beyond. LCSPP Poverty and Labor Brief No. 3. Washington, DC: World Bank.

World Bank. (2014). Social gains in the balance-A fiscal policy challenge for Latin America and the Caribbean. LAC Poverty and Labor Brief (February). Washington, DC: World Bank.

World Bank. (2015). Working to end poverty in Latin America and the Caribbean-workers, jobs and wages. LAC Poverty and Labor Brief (June). Washington, DC: World Bank.

Augusto de la is the Chief Economist for Latin American and the Caribbean at the World Bank. Prior to this, he has held the positions of Senior Advisor in the Financial Systems Department and Senior Financial Sector Advisor, both in the Latin America and the Caribbean region. He has published extensively on a broad range of macroeconomic and financial development topics. He is a member of the Carnegie Network of Economic Reformers. He earned his Ph.D. and M.A. in Economics at the University of Notre Dame and holds a Bachelor's degree in Philosophy from the Catholic University of Ecuador.

Julián Messina is lead research economist at the research department of the Inter-American Development Bank. Previously, he worked for the World Bank and the European Central Bank. He has taught at the Universities of Barcelona GSE, Georgetown, Girona, Frankfurt, and Mainz. He is the author of two flagship reports of the Latin America region at the World Bank, and his research has been extensively published in leading academic journals. He has experience advising governments in Latin America, Europe, and Asia. He obtained his Ph.D. in Economics at the European University Institute.

Joana Silva is a Senior Economist at the Office of the Chief Economist for Latin America and the Caribbean Region of the World Bank. She has expertise in labor economics, international trade, poverty and inequality, and policy evaluation. Her research has been published in academic journals, including the Journal of International Economics, Economics Letters, Review of International Economics, and Review of World Economics. She authored three books, including a World Bank flagship report. She is currently leading a regional research report on wage inequality in Latin America and a number of impact evaluations. Before joining the Bank, Joana worked for the Globalization and Economic Policy Research Center and taught at the University of Nottingham. She holds a Ph.D. in Economics from the University of Nottingham. 


\title{
The Political Economy of Inequality at the Top in Contemporary Chile
}

\author{
Diego Sánchez-Ancochea
}

\section{Introduction}

The recent focus on top incomes at the international level (Atkinson and Piketty 2010; Piketty 2014; Piketty and Saez 2006) should help placing the spotlight on Latin America. The region has traditionally been characterised by high concentration of income and political influence of the elite (World Bank 2003). The interaction between economic and political concentration has led to periodic social conflicts and often contributed to institutional weakness. Social policy has also failed to redistribute income significantly, benefiting small segments of the population instead - as shown by Arroyo and Lindert in their contribution to this volume.

According to the historical literature, initial control over resources by a rentseeking elite led to a highly skewed development model. Although there is a debate on whether this process begun in colonial times (Acemoglu et al. 2001; Engerman and Sokoloff 1997 and earlier Furtado 1974; Cardoso and Pérez Brignoli 1979 and other authors cited in Bertola 2012) or during the late nineteenth century (Coatsworth 2008; Williamson 2010), there is no doubt of the negative consequences of inequality in the last century. The elite profited from commodity booms, often rejected progressive taxation and failed to incorporate large segments of the population into social policy. ${ }^{1}$

Given the historical relevance of top incomes and elite power, it is surprising that scholarly work on the reduction of income inequality in the last decade has ignored them, concentrating instead on short-term growth in formal employment and reduction in the skill premium (Cornia 2010). According to the most optimistic accounts,

\footnotetext{
${ }^{1}$ Following Amsden and DiCaprio (2012: 352), I define the elite as "those who enjoy privileged status and exercise decisive control over the organization of society".

D. Sánchez-Ancochea $(\square)$

University of Oxford, Oxford, UK
}

(C) The Author(s) 2017 
higher education spending increased the supply of skilled workers and reduced their relative remuneration (López-Calva and Lustig 2010). The creation of conditional cash transfers, non-contributory pensions and other social assistance programmes enhanced the redistributive capacity of the state (Cornia 2014).

What has happened with economic and political concentration at the top? Has the influence of the elite been eroded? It is likely to decrease in the future? Answering this question requires us to go beyond econometric analysis based on flawed household data available only for a few years. It also demands a more rigorous analysis of the ways top incomes are reproduced over time that goes beyond the skilled premium.

In this chapter, I consider these questions through the case of Chile-a country where the top decile has a major contribution to overall inequality (Torche 2005; Yotopoulos 1989). I draw on the recent political economy literature on institutions and elites (Acemoglu and Robinson 2012; Amsden et al. 2012; Martínez Franzoni and Sánchez-Ancochea 2013) as well as the analysis of top incomes across the world and available (quantitative and qualitative) data on Chile.

Echoing Javier Rodriguez Weber's contribution to this volume (see also Rodríguez Weber 2014), I illustrate how the Pinochet dictatorship contributed to a deepening of concentration at the top and redefined Chile's political economy. I then review studies on income distribution to show that the current share of income of the richest 1 and $10 \%$ is very high. I argue that the likelihood of a reversal of this situation in the future is limited for several reasons. ${ }^{2}$ First, market concentration is high, large business groups are powerful and production policies have changed slowly. Second, trade unions remain weak and cannot act as a countervailing force in the labour market. Third, tax reform has only increased slowly, partly due to elite opposition. At the same time, the chapter recognises Chile's gradual move towards redistributive universalism in social policy (Huber and Stephens 2012) and explores whether these policies can transform the country's political economy in the future. In the conclusion I call for more research on the elites to evaluate future distributional trajectories in Latin America. Given the lack of data and the need to consider the interactions between political, social and economic processes, future studies will need to adopt multidisciplinary approaches.

\footnotetext{
${ }^{2}$ There are also political and institutional reasons that also contribute to the persistence of inequality, including the persistent popularity of right-wing parties (who still receive $40-45 \%$ of the votes), the nature of the electoral system, the need for supermajorities to pass some important reforms and the role of the media. I thank Alan Angel for pointing out to me these factors, which will not be explored in this chapter.
} 


\section{Income Inequality and Top Incomes in Latin America}

Historically, in Latin America more resources have gone to the wealthy than anywhere else in the world. ${ }^{3}$ Although we do not have long-term data on concentration at the top, the situation in the early 1990s may constitute a good representation of earlier patterns (Table 1). ${ }^{4}$ In 1992, the richest decile in Latin America received $48 \%$ of total income, 1.7 times more than in OECD countries. ${ }^{5}$

Latin America's unique pattern of inequality becomes even clearer in Table 2, which compares income distribution in each region with the OECD. Each observation

Table 1 Various regions of the world. Income distribution by decile, 1992

\begin{tabular}{l|l|l|l|l|l}
\hline Decile & LA & Africa & Asia & Eastern Europe & OECD \\
\hline $\mathbf{1}$ & $\mathbf{1 . 6}$ & $\mathbf{2 . 1}$ & $\mathbf{2 . 6}$ & $\mathbf{2 . 2}$ & $\mathbf{2 . 5}$ \\
\hline 2 & 2.4 & 3.0 & 3.5 & 3.8 & 3.4 \\
\hline 3 & 3.0 & 3.7 & 4.8 & 5.1 & 5.3 \\
\hline 4 & 3.4 & 4.6 & 5.8 & 5.7 & 6.3 \\
\hline $\mathbf{5}$ & $\mathbf{5 . 0}$ & $\mathbf{5 . 5}$ & $\mathbf{6 . 5}$ & $\mathbf{7 . 5}$ & $\mathbf{7 . 3}$ \\
\hline 6 & 6.0 & 6.5 & 7.5 & 8.2 & 8.6 \\
\hline 7 & 7.6 & 8.6 & 9.0 & 9.4 & 10.5 \\
\hline 8 & 9.0 & 10.5 & 10.5 & 10.8 & 12.2 \\
\hline 9 & 14.0 & 13.3 & 12.4 & 12.8 & 14.8 \\
\hline $\mathbf{1 0}$ & $\mathbf{4 8 . 8}$ & $\mathbf{4 2 . 2}$ & $\mathbf{3 7 . 4}$ & $\mathbf{3 4 . 7}$ & $\mathbf{2 9 . 1}$ \\
\hline
\end{tabular}

Source: World Bank (2003)

Table 2 Various regions of the world. Income shared compared to that of the OECD, 1992

\begin{tabular}{l|l|l|l|l|l}
\hline Decile & LA & Africa & Asia & Eastern Europe & OECD \\
\hline $\mathbf{1}$ & $\mathbf{0 . 6 4}$ & $\mathbf{0 . 8 4}$ & $\mathbf{1 . 0 4}$ & $\mathbf{0 . 8 8}$ & $\mathbf{1 . 0 0}$ \\
\hline 2 & 0.71 & 0.88 & 1.03 & 1.12 & 1.00 \\
\hline 3 & 0.57 & 0.70 & 0.91 & 0.96 & 1.00 \\
\hline 4 & 0.54 & 0.73 & 0.92 & 0.90 & 1.00 \\
\hline $\mathbf{5}$ & $\mathbf{0 . 6 8}$ & $\mathbf{0 . 7 5}$ & $\mathbf{0 . 8 9}$ & $\mathbf{1 . 0 3}$ & $\mathbf{1 . 0 0}$ \\
\hline 6 & 0.70 & 0.76 & 0.87 & 0.95 & 1.00 \\
\hline 7 & 0.72 & 0.82 & 0.86 & 0.90 & 1.00 \\
\hline 8 & 0.74 & 0.86 & 0.86 & 0.89 & 1.00 \\
\hline 9 & 0.95 & 0.90 & 0.84 & 0.86 & 1.00 \\
\hline $\mathbf{1 0}$ & $\mathbf{1 . 6 8}$ & $\mathbf{1 . 4 5}$ & $\mathbf{1 . 2 9}$ & $\mathbf{1 . 1 9}$ & $\mathbf{1 . 0 0}$ \\
\hline $\mathbf{S}$ & & & & &
\end{tabular}

Source: Own calculations based on data from Table 1

\footnotetext{
${ }^{3}$ Some of the subsequent discussion borrows from Sanchez-Ancochea (2009).

${ }^{4}$ Focusing in the early 1990s is more meaningful than using more recent data because in the rest of the chapter we are precisely interested in recent changes. Ideally, we would use comparative data from the 1960s in the midst of import substitution, but this is not available.

${ }^{5}$ As we will discuss later in the chapter, using household surveys to analyse income concentration at the top is problematic. High-income groups tend to be underrepresented in many of these surveys and capital income is poorly measured. Yet comparative historical data on top-income groups in most developing countries is so far unavailable (see Piketty 2014).
} 
represents the income share of a specific decile in relation with the same share in OECD countries. For example, the poorest decile in Latin America received (in relative terms) just $64 \%$ of what the poorest decile in OECD countries earned.

In Latin America, all deciles but the top one received in 1992 a lower share of income than in any other part of the world. The situation was particularly dramatic at the bottom of the distributional structure, but the lower middle class was also affected. Latin Americans in the middle decile, for example, received just $68 \%$ of that in OECD countries (in relative terms). At the same time, the share of the richest $10 \%$ was significantly higher than in the OECD as well as Africa, Asia and Eastern Europe. The emerging literature on top incomes based on tax statistics has confirmed this problem for the 2000s. The share of the richest $1 \%$ in the Latin American countries where data is available is significantly higher than in the USA (Alvarado and Londoño 2012; Medeiros et al. 2014).

The extent of the concentration at the top is also evident when considering the distribution of wealth. Merrill Lynch in collaboration with Capgemini publishes an annual estimation of the number of high net wealth individuals (HNWI) - people who hold at least US\$ one million in financial assets (Lynch 2006). In 2006, Latin America has 300,000 HNWI (3.6\% of the world total), each of which had an average of US\$14 million in financial assets, more than four times that of rich individuals in North America or Europe (Table 3).

\subsection{Chile as a Good Example of the Regional Trend}

Chile shares with Latin America the extreme concentration at the top, something that becomes evident in Fig. 1. While the ratio of the median income to that of the poor is lower in Chile than in the USA and Israel, the Chilean top earners get more

Table 3 Number of high net wealth individuals, total wealth and average wealth per person, 2006

\begin{tabular}{l|l|c|c}
\hline Region & Number $^{\mathrm{a}}$ & Total wealth $^{\mathrm{b}}$ & Wealth per person $^{\mathrm{c}}$ \\
\hline Europe & 2.8 & 9.4 & 3.4 \\
\hline North America & 2.9 & 10.2 & 3.5 \\
\hline Asia Pacific & 2.4 & 7.6 & 3.2 \\
\hline Latin America & 0.3 & 4.2 & 14.0 \\
\hline Middle East & 0.3 & 1.2 & 4.0 \\
\hline Africa & 0.1 & 0.8 & 8.0 \\
\hline World & 8.7 & 33.3 & 3.8 \\
\hline
\end{tabular}

Source: Lynch (2006)

Notes: High net wealth individuals are defined as those with at least one million in financial assets

${ }^{a}$ Millions of people

${ }^{\mathrm{b}}$ Trillions of US\$

${ }^{\mathrm{c} M i l l i o n s}$ of US\$ 


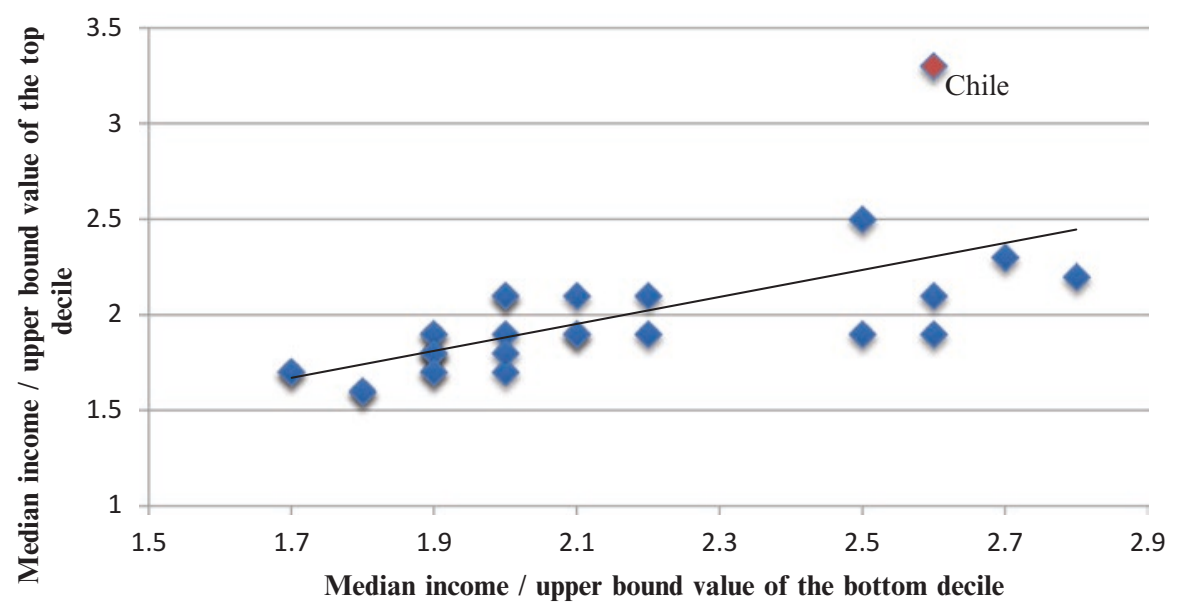

Source: own elaboration with data from OECD

Fig. 1 OECD. Income distribution, comparison of deciles, 2011. Source: Own elaboration with data from OECD

than anywhere else in the OECD. Social mobility in Chile among the bottom $90 \%$ is also high, while the opportunities to become part of the top decile are extremely low (Torche 2005). The Chilean rich have thus succeeded in protecting their social position over the long run while maintaining unique political influence (Rodríguez Fisse and Thomas 2014).

Have things changed in recent years? Has inequality gone down? For Cornia (2010: 109) Chile is a good illustration of Latin America's success at consolidating a "prudent redistribution with growth" paradigm committed to reducing the inequality inherited from the colonial past. Sandbrok et al. (2007) go as far as to place post1990 Chile as one of their four cases of social democracy in the periphery.

To evaluate the extent to which this is true, Fig. 1 presents the income share of the bottom $40 \%$, the middle $50 \%$ and the top $10 \%$ during the period 1987-2011 based on household surveys - replicating an exercise in Palma (2011). In the 1990s, Chile's income distribution changed relatively little and the top decile received around four times more than the bottom four deciles combined. Yet since 2003 there has been a gradual reversal as the income share of the top $10 \%$ decreased from 44.0 to $40.7 \%$.

Using household surveys, Friedman and Hofman (2013) argue that the income share of the top $10 \%$ actually began going down in 1990. Yet their study also shows the inconsistencies in measurements of income at the top and the difficulties to rely on household surveys to study the rich. Research based on tax information may be more satisfactory and questions the results presented in Fig. 2. Two studies are particularly useful: López et al. (2013) and Fairfield and Jorratt (2014).

Fairfield and Jorratt (2014) present the most reliable estimations and also offer a longer time spam than other studies. They benefited from access to an unpublished 


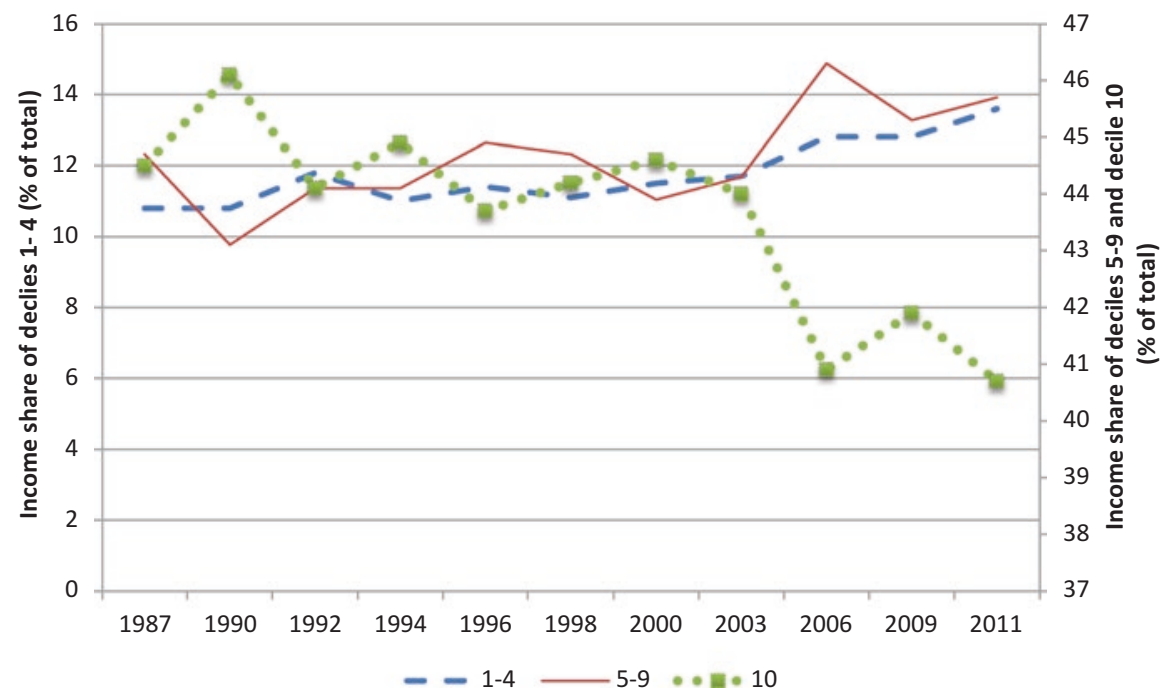

Source: own elaboration with data from SEDLAC, which comes from household surveys

Fig. 2 Distribution of household equalised income in Chile, 1987-2011, groups of deciles. Source: Own elaboration with data from SEDLAC, which comes from household surveys

database of all Chileans who paid taxes between 2005 and 2009 and used publicly available data to extend their series to 2004, 2010 and 2011. They allocate nondistributed profits to different income groups based on information from business tax returns - something that no other study has done. According to their results, the income share of the top $1 \%$ varies between $15 \%$ with no adjustments for nondistributed profits and unreported income and $33 \%$ when adjusting for profits and for tax evasion. This last number is significantly higher than the USA (18\%) - the most unequal developed country - or even Colombia. Fairfield and Jorratt (2014) do not find any clear trend for the period 2004-2011: the income level at the top shows some variance from year to year but does not go down or up overall.

López et al. (2013) rely on publicly available data, which is divided into eight different tax schedules. Their allocation of non-distributed profits is based on shaky assumptions about ownership of assets in Chile. Yet their estimations are not that different than those by Fairfield and Jorratt (2014): according to their calculations, the income level of the top $1 \%$ varies between $22 \%$ (without accounting for non-distributed profits but considering tax evasion) and $31 \%$ when all the numbers are considered. Even the lower bound estimation is higher than in South Africa, Colombia, Argentina and the USA. They also calculate the Gini coefficient adjusted by top incomes and compare it with that based on household surveys. The differences are significant: in 2010, the adjusted Gini was 0.63 and the standard Gini was 0.55 .

Two conclusions from these studies are particularly relevant for this chapter. First, despite the lack of data, it is hard to believe that distribution at the top has 
gone down significantly in the last decade. ${ }^{6}$ How much larger than $30 \%$ could the share of the top $1 \%$ have been two decades ago? Second, studies of inequality and its evolution over time cannot rely only on estimations of income distribution. Even rigorous studies like Fairfield and Jorratt (2014) are forced to make heroic assumptions and show large variation between the lower and upper bounds. If we are interested in having a full picture of economic concentration, we may need to consider multiple (qualitative and quantitative) sources, including newspaper articles on consumption and investment patterns of the rich.

\section{Top Incomes and the Political Economy of Redistribution}

Much of the economic literature on inequality has treated the top $1 \%$ like any other group, emphasising, for example, the role of human capital in determining its income. As a result, the policies proposed to reduce income concentration are the same as the ones suggested to decrease the Gini coefficient: (1) increases in the minimum wages; (2) expansion in education spending and improvement of its quality; and (3) creation of new anti-poverty social interventions (see, for example, World Bank 2003).

Yet high-income groups are different than all others in society. They are owners of the largest firms and their income depends as much on profits as on wages. When studying these groups, we must account for both the functional distribution of income and the overall process of redistribution.

In developing countries, a significant share of capital income goes to the richest groups in society. For example, in Chile, López et al. (2013) estimate that $85 \%$ of retained profits go to the top 1\%. Four-fifths of the income received by the $0.01 \%$ richest Chileans actually come from capital earnings (Fairfield and Jorratt 2014). Many factors shape the functional distribution, but two are particularly important: the level of market concentration and the strength of trade unions. Market concentration partly depends on the strength of family conglomerates, which have traditionally controlled a larger share of the economy in developing than in developed countries (Amsden 2001; Fernández Jilberto and Hogenboom 2007; Schneider 2013). Market concentration also depends on the number of firms per sector and on the productivity gap between large and small firms. Strong trade unions will also reduce the capital share.

By promoting collective bargaining, trade unions can additionally contribute to lower wage dispersion (Bhattacherjee 1987). This is most likely to happen when bargaining is centralised across the whole economy (Aidt and Tzannatos 2002). The distribution of wages also depends on the skill premium-i.e. the wage gap between skilled and unskilled workers. The skill premium is driven by the level of

\footnotetext{
${ }^{6}$ These findings coincide with recent research in other Latin American countries based on tax information and following the methodology proposed by Atkinson, Piketty and Saez; see, in particular, the work on Medeiros et al. (2014) for the case of Brazil.
} 
education - which shapes labour supply - and the productive structure of the economy - which determines labour demand. While the skill premium has received ample attention in the recent literature on inequality in Latin America (López-Calva and Lustig 2010; Gasparini et al, 2011; Gindling and Trejos 2013), it may actually be less important to explain top incomes than some of the other variables.

Finally, we should consider the redistribution of income, which depends on taxes and government spending. Some social policies redistribute in favour of the poor without eroding the income share of the wealthy. This is, for example, the case of conditional cash transfers, which given their small size do not usually demand tax increases. Universal policies, on the contrary, are more likely to create pressures towards higher taxation, thus exerting a more powerful downward pressure on top incomes (Martínez Franzoni and Sánchez-Ancochea in press).

Political forces and struggles influence the functional distribution of income, wage distribution and fiscal policy. The way markets are regulated, incentives to large firms are set, trade unions are treated and tax and social policies are designed depend directly on the strength of different actors. Unfortunately in all these areas, the economic elite usually have more influence than others. The elite play a central role in shaping political institutions and policies (Robinson 2012). In Shamus Kahn's words, "although elites are not representative of society, the distribution of power in their favor often means that elites are the engines of inequality" (Kahn 2012: 362).

The rest of this chapter explores the key factors shaping the distribution of income at the top in Chile today. I am not only interested in the situation at a point in time (e.g. how redistributive policies are in a certain year) but also in the political processes that different policies may trigger (Martínez Franzoni and SánchezAncochea 2016). To undertake this analysis, it is important to first understand the "regressive revolution" that took place in the 1970s.

\section{The Pinochet Years: A "Successful" Redistribution Towards the Top}

During the 1950s and 1960s, the improvements in income distribution-clearly illustrated in Rodriguez Weber's contribution to this book - went hand in hand with an erosion of the power of the elite. The political system moved to the left and new social groups acted as countervailing forces (Pinto 1970). ${ }^{7}$

\footnotetext{
${ }^{7}$ The significance of the political changes but also its limitations are clear when one considers social policy. During the 1950s and 1960s, social programmes in health, pensions and education expanded rapidly and by the early 1970 s social security covered $75 \%$ of the economically active population (Huber and Stephens 2012). The growing in social spending led to higher social security contributions and a larger tax burden. Yet these policies were highly segmented, primarily favouring some groups within the middle class. Social insurance involved more than ten different funds with entitlements and obligations contained in more than 2000 legal texts (Mesa-Lago 1978; Segura-Ubiergo 2007).
} 
Yet all the advances quickly reversed after the 1973 coup d'état, which was enthusiastically supported by large segments of the elite (Palma 2011). Pinochet's dictatorship triggered a return to an elite-based political economy model (Silva 1996) and led to a process of economic concentration. The redistribution of income towards the top was extraordinary - even larger than the one the USA has experienced in the last three decades. Between 1973 and 1989 the income share of the top $10 \%$ increased by $50 \%$ while that of the bottom $70 \%$ decreased by more than $35 \%$ (Palma 2011; see also Ricardo 2010).

The coup affected all the channels of economic and political concentration that we have previously discussed. First, capital concentration increased significantly, particularly as a result of the processes of privatisation. Of the 500 companies in public hands in the early 1970 s, 481 were transferred to a small number of players within the private sector. Privatisation together with the allocation of credit to a few business groups "increased the size concentration of firms and further enhanced the economic power of the 20 or so major industrial and banking groups" (Yotopoulos 1989: 696). By 1978, Chile's five most powerful conglomerates controlled $60 \%$ of the assets of the 100 largest firms, compared to $46.5 \%$ in 1969.

Second, trade unions were systematically persecuted and changes in the regulation of the labour market expanded outsourcing and free wage setting (Berg 2006). The weakening of trade unions contributed to a reduction in overall wages and eliminated a significant progressive political force. In contrast, the influence of large business groups in policymaking grew significantly during this period (Rodríguez Fisse and Thomas 2014).

Third, the capacity of the state to redistribute income weakened. Collective pensions were replaced by individual capitalisation pensions managed by private companies. All the redistributive components of the system were eliminated and pensions became exclusively linked to the financial returns on contributions (Riesco 2007). Public healthcare survived, but private providers grew significantly. A large share of health costs was passed to individuals (through private insurance contributions and copayments) and the share of public spending in the total decreased from 38 to $21 \%$ (Gogna 2004). At the same time, the taxes paid by high-income groups compared to those paid by the middle class decreased significantly, thus reducing the contribution of the wealthy towards redistribution. According to calculations by Arroyo Abad and Lindert presented elsewhere in this volume, the net benefit from social spending minus taxes received by the top quintile increased from a negative number in 1973 to more than three percentage points of GDP in the mid-1980s.

\section{Chile Since 1990: Why No More Advances?}

If we accept that top incomes have remained stable after the return of democracysomething more evident in the tax data than in household surveys - how can we explain it? In which areas has Chile experienced advances and where have things stayed the same? In this section I review some of the channels discussed in Sect. 3. 


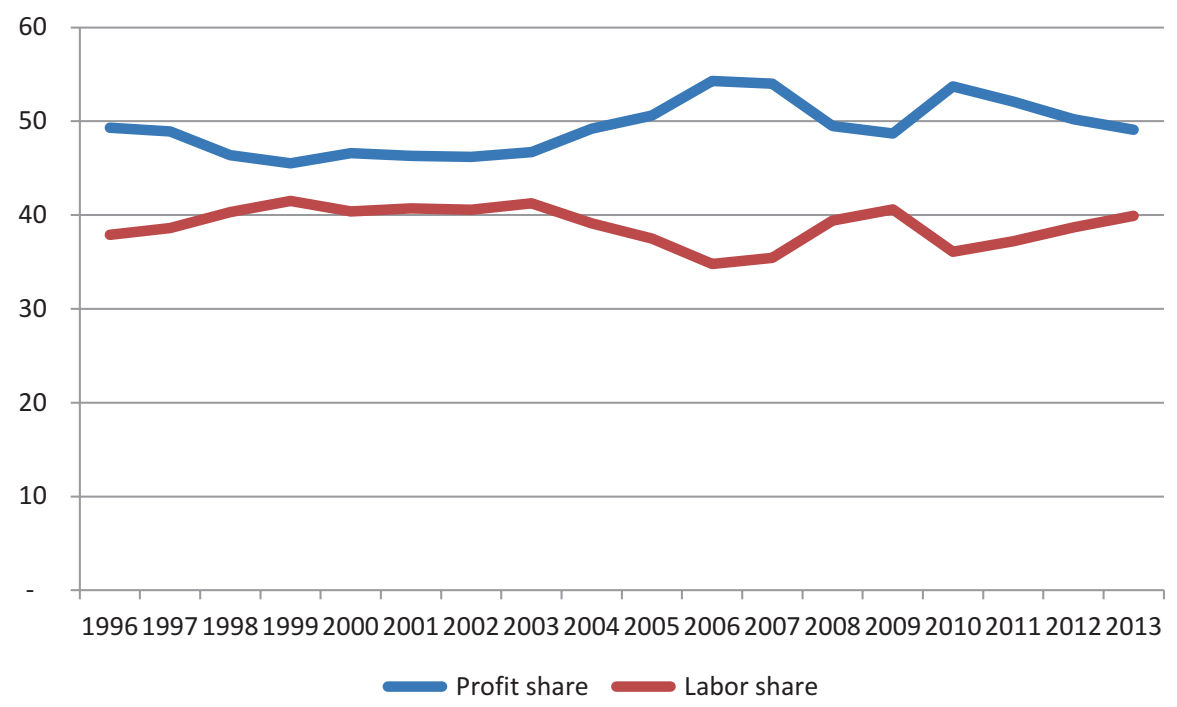

Source: own elaboration from National Income Accounts, Central Bank webpage

Fig. 3 Labor and capital share, \% GDP, 1996-2013. Source: Own elaboration from National Income Accounts, Central Bank webpage

I show that the concentration of economic power has not changed and public policy has not paid enough attention to the reduction of productivity gaps. Trade unions also remain weak and cannot act as an influential national force. In contrast, some reforms have made social policy more redistributive and could trigger progressive political trajectories in the long run. The key unanswered question is not whether Chile is still unequal, but whether these new opportunities can truly modify the political economy of inequality in the future.

\subsection{The Capital Share and Market Concentration}

During the last two decades, the capital share in GDP has remained relatively stable (Fig. 3). It increased by nine percentage points between 1999 and 2006, but has then gone back to its 1996 level. Guerreiro (2012) confirms these general patterns in a global study that corrects for the level of self-employment. She also shows that recent stability has come after large swings in previous decades, in favour of capital during the Pinochet years and against after the return to democracy. ${ }^{8}$ Chile's performance in this area is in line with global trends and consistent with many

\footnotetext{
${ }^{8}$ Studying the evolution of the capital and labour shares leads us to question the dominant discourse on the recent improvement in income distribution in Latin America. For example, according to CEDLAS data based on household surveys, Peru's Gini coefficient went down from 0.52 in
} 
other countries where capital concentration and income inequality have increased simultaneously (Karabarbounis and Neiman 2013; Piketty 2014).

Data on market concentration is patchier and does not allow us to explore changes over time systematically. Additionally, some of the best qualitative studies on business groups and economic concentration rely on data from the 1990s, thus limiting what we can say about the last decade. Nevertheless, there is enough empirical evidence to believe that concentration has not decreased significantly and remains high. ${ }^{9}$

Three conglomerates have been particularly prominent: Luksic, Angelini and Matte. In the late 1990s, these three groups alone owned all Chilean publicly traded companies with market value over 600,000 million pesos. In the last decade, large family groups have succeeded in adapting to changing global conditions by creating new ties to transnational corporations, expanding into nontradable sectors like commerce and diversifying into many different sectors (Fazio 1999; Schneider 2008).

For example, through different holdings like Quiñenco or Madeco, Luksic participates in manufacturing activities like copper and aluminium, fibre optics and flexible packaging as well as beer, wine and sodas. Luksic has also created strategic alliances in other sectors, including banking, telecommunication, electricity and tourism (Fazio 1999). The group Matte has built a diversified portfolio that includes the largest paper factory in South America together with participation in more than 30 firms in finance, mining, health, telecommunications energy, ports and others.

To explore the links between market concentration and the highest incomes, I consider the 2015 Forbes list of world billionaires. Although this kind of list only provides limited information on a few prominent families, it is still helpful to understand economic concentration. In 2015 there were ten Chileans on the Forbes list, although several were part of the same families (Table 4). Together these ten individuals have an estimated wealth of US\$34.5 billion, equivalent to $12 \%$ of Chile's GDP. Table 4 also highlights the extent to which a small number of business groups are present in multiple sectors and own a large number of companies. The top Chilean groups control most retail operations - a sector that expanded by an average annual rate of $8.2 \%$ between 2007 and 2011 - and have a strong presence in media, banking, mining and manufacturing. ${ }^{10}$

Concentration is also high at the sectoral level. In hardware stores, two companies (Easy and Sodimac) have become dominant players, contributing to the disappearance of almost 3500 companies that operated in the sector in the 1990s. Three pharmaceutical chains (Cruz Verde, Salcobrand and FASA) are responsible for more than $90 \%$ of sales. The list of sectors dominated by just two or three companies - many

\footnotetext{
2003 to 0.43 in 2013. Yet this happened at the time when the wage share decreased by more than a third according to Guerreiro (2012)'s estimations.

${ }^{9}$ For a discussion of the persistence of business groups and its economic influence in Chile and other Latin American countries, see Schneider (2008).

${ }^{10} \mathrm{http} / / / \mathrm{www}$. bloomberg.com/news/articles/2013-01-15/falabella-billionaires-surface-with-lowprofile-fortune (last accessed 7 May 2015).
} 
Table 4 Main Chilean family groups, Forbes billionaire list, 2015

\begin{tabular}{|c|c|c|c|c|c|}
\hline Name & $\begin{array}{l}\text { Estimated } \\
\text { wealth }^{\mathrm{a}}\end{array}$ & Group & $\begin{array}{l}\text { Year of } \\
\text { creation }\end{array}$ & $\begin{array}{l}\text { Some companies } \\
\text { (full or part } \\
\text { ownership) }\end{array}$ & Sectors \\
\hline $\begin{array}{l}\text { Iris } \\
\text { Fontbona }\end{array}$ & 13.5 & Luksic & $1950 \mathrm{~s}$ & $\begin{array}{l}\text { Antofagasta, } \\
\text { conglomerate } \\
\text { Quinenco }\end{array}$ & $\begin{array}{l}\text { Mining, beverages, } \\
\text { banking, } \\
\text { manufacturing, } \\
\text { energy, transportation } \\
\text { and ports }\end{array}$ \\
\hline $\begin{array}{l}\text { Horst } \\
\text { Paulmann }\end{array}$ & 4.4 & Cencosud & $1970 \mathrm{~s}$ & $\begin{array}{l}\text { Jumbo, Santa Isabel, } \\
\text { Disco, Vea, Easy, } \\
\text { Banco Paris }\end{array}$ & $\begin{array}{l}\text { Department stores, } \\
\text { supermarkets, home } \\
\text { improvement stores, } \\
\text { banking, shopping } \\
\text { malls }\end{array}$ \\
\hline $\begin{array}{l}\text { Matte } \\
\text { (Elidoro, } \\
\text { Patricia and } \\
\text { Bernardo) }\end{array}$ & 2.8 & Matte & $\begin{array}{l}\text { 19th } \\
\text { century }\end{array}$ & $\begin{array}{l}\text { CMPC, Banco Bice, } \\
\text { Entel, Colbun }\end{array}$ & $\begin{array}{l}\text { Paper, telecom, } \\
\text { banking, shipping }\end{array}$ \\
\hline $\begin{array}{l}\text { Sebastian } \\
\text { Piñera }\end{array}$ & 2.5 & LAN & 1970s & $\begin{array}{l}\text { Formerly owned } \\
\text { LAN and Chilevision }\end{array}$ & Airline, media, sports \\
\hline $\begin{array}{l}\text { Alvaro } \\
\text { Saieh } \\
\text { Bendeck }\end{array}$ & 2.5 & Corp & $1990 \mathrm{~s}$ & $\begin{array}{l}\text { Corpbanca, Copesa, } \\
\text { Unimarc, SMU, } \\
\text { Unimarc, } \\
\text { Telemercados, } \\
\text { Construmart, La } \\
\text { Tercera }\end{array}$ & $\begin{array}{l}\text { Banking, hotels, } \\
\text { supermarket } \\
\text { insurance, media }\end{array}$ \\
\hline $\begin{array}{l}\text { María Luisa } \\
\text { Solari } \\
\text { Falabella } \\
\text { and family }\end{array}$ & 2.4 & $\begin{array}{l}\text { SACI } \\
\text { Falabella }\end{array}$ & $\begin{array}{l}19 \text { th } \\
\text { century }\end{array}$ & $\begin{array}{l}\text { Falabella, Viveros, } \\
\text { Enaex, Las Condes } \\
\text { clinic }\end{array}$ & $\begin{array}{l}\text { Department stores, } \\
\text { supermarket, home } \\
\text { improvement, } \\
\text { banking and interests } \\
\text { in many other sectors }\end{array}$ \\
\hline Julio Ponce & 2.1 & SQM & $1980 \mathrm{~s}$ & $\begin{array}{l}\text { Chemical and } \\
\text { Mining Society of } \\
\text { Chile }\end{array}$ & $\begin{array}{l}\text { Fertilisers, lithium, } \\
\text { iodine, finance }\end{array}$ \\
\hline $\begin{array}{l}\text { Angelini } \\
\text { Rossi } \\
\text { (Roberto } \\
\text { and Patricia) }\end{array}$ & 2.9 & Angelini & $1950 \mathrm{~s}$ & $\begin{array}{l}\text { Holding Antarchile, } \\
\text { Arauco }\end{array}$ & $\begin{array}{l}\text { Fuel distribution, } \\
\text { fishing, shipping, } \\
\text { energy, forestry }\end{array}$ \\
\hline $\begin{array}{l}\text { Luis } \\
\text { Enrique } \\
\text { Yarur }\end{array}$ & 1.2 & Yarur & $1930 \mathrm{~s}$ & $\begin{array}{l}\text { Bank BCI, City } \\
\text { National Bank of } \\
\text { Florida, Salcobrand }\end{array}$ & $\begin{array}{l}\text { Banking, pharmacy, } \\
\text { other retail }\end{array}$ \\
\hline
\end{tabular}

an US\$ billion, valuation as 6 May 2015 Sebastian Piñera had to sell all his interests when he became president of Chile

Source: www.forbes.com and various web pages for information on groups

of which are part of larger conglomerates-also includes telecommunications (mobile and Internet), cable, supermarkets and electricity (Ruiz and Boccardo 2010; Fazio 1999).

Additionally, in the mid-2000s just five groups owned directly or indirectly almost half of all shares of the companies in Santiago's stock exchange (Solimano 2009). 
In 2007, the three largest companies (administradoras de fondos de pensiones, AFPs) controlled $74 \%$ of all pension funds in the country. Solimano also calculates an index of economic concentration for six sectors (pharmaceuticals, forestry, banking, pension funds, mining and healthcare), showing an increase in four of them during the 2000s.

\subsection{Structural Heterogeneity and Production Policies}

Like other Latin American countries, Chile has been characterised by large productivity gaps. Data in Infante and Sunkel (2009) for 2003 finds differences in employment and productivity in two different axes: between sectors and between small and large firms. Large firms are more productive than small and medium firms in all economic sectors. Also, mining, utilities and financial services are more productive than agriculture and community services - although productivity gaps by sector are lower than by size. As a result, the difference between a large mining company and a small agricultural producer is astonishing: the former is almost 40 times more productive than the latter. Most employment is located in low-productivity sectors and, as a result, is of low quality (Velasco and Huneeus 2011).

Between 1990 and 2005, successive governments of the Concertación (an alliance of centre and left-wing parties that have fought against Pinochet) did little to tackle dependence on natural resources and promote productivity diffusion to other sectors. The dominance of market-friendly ideas made state-led interventions particularly difficult (Palma 2011). Things partly changed in 2005 when a new royalty on copper, mining and other natural resources was created. The royalty taxed net profits from natural resource activities with a rate of up to $5 \%$, which can be deducted from taxable income coming from other taxes. Although Chile still has one of the lowest royalty levels in the world-it represents less than $2 \%$ of profits and $0.6 \%$ of the value of sales (López and Miller 2008) - the new tax infused the government with welcomed new resources.

The royalties were earmarked for innovation and the promotion of new sectors and funded the creation of the National Council for Innovation and Competitiveness (Consejo Nacional de Innovación para la Competitividad, CNIC). ${ }^{11}$ The initial design of the CNIC was prepared at the request of the Concertación senators Alejandro Foxley and Edgardo Boeninger and borrowed on the experiences of Australia, New Zealand, Finland and Ireland. Its creation was a top-down bureaucratic initiative: although the CNIC incorporated members from business associations to its board, the private sector's involvement and commitment to the project were quite small.

Soon after its creation, the CNIC published a White Book (volume 1), which established the economic justification for innovation policy. The document proposed

\footnotetext{
${ }^{11}$ The following discussion is partly based on interview with a former high-ranking official of the CNIC, Santiago, Chile, July 2012.
} 
selective interventions based on the promotion of clusters. The CNIC created then 11 thematic roundtables in areas like higher education and innovation culture to agree on the following steps to take. Composed by experts, government officials and some members of the private sector, the roundtables resulted in a shopping list of measures that informed the proposals of the White Book's second volume. ${ }^{12}$

The CNIC developed an ambitious strategy of cluster promotion and took some useful steps to accelerate economic dynamism. Nevertheless, its interventions shared at least three common problems with other industrial policy initiatives. First, the CNIC was primarily a technocratic project with weak support from the private sector and few mechanisms to force private sector cooperation. Its initial top-down and technocratic bias continued in subsequent years. When Eduardo Bitrán was named president of the Consejo in 2008, he promoted better integration between ministries and more support from different political parties. Yet he made no effort to embed the organisation within the private sector. The creation of more dynamic links between large firms and small and medium firms was never in the agenda either.

Second, the main goal of the CNIC was to increase the innovation capacity by supporting sectors that were globally dynamic and where Chile had comparative advantages. The aim was exclusively to accelerate GDP growth and the strategy did not pay any attention to the link between innovation, firm size and income distribution. Other industrial policies have shared a similar problem, providing insufficient support to small and medium firms. For example, CORFO's GIF lending programme-which does concentrate on small and medium firms-managed only $1.1 \%$ of the total portfolio of the Chilean financial system in 2006, well below Mexico's NAFIN (9.7\%) and Colombia's BANCOLDEX (5.3\%) (Agosin et al. 2010). In key sectors like forestry, which are controlled by a few large groups, "the lack of a competition policy, as well as comprehensive public policy promotion of economic transformation, has impeded the upgrading and/or entrance of small and medium sized firms" (Devlin and Moguillansky 2012: 6).

Third, the efforts of the CNIC have lacked continuity: after the election of President Piñera in 2010 the sectoral interventions based on cluster promotion were discontinued (Devlin and Moguillansky 2012). The new administration (2010-2014) discouraged the active promotion of structural change, focusing exclusively on the creation of an efficient business environment (Agosín and Grau 2013). The conservative government was also reluctant to use the government's purchasing power to support small and medium firms. ${ }^{13}$

President Piñera's decision and Chile's overall weak and inconsistent approach to industrial policy responds in large part to the preferences of the private sector. Business groups and business associations have maintained a critical approach to direct state intervention (Rodríguez Fisse and Thomas 2014). For example, a

\footnotetext{
${ }^{12}$ Volume 2 defined nine sectors to promote (including fishery, offshoring, wine and mining) based on those discussions as well as a report prepared by the Boston Consulting Group.

${ }^{13}$ Interview with former government official and expert on production policies, Santiago, July 2012.
} 
high-ranking official from the Confederation for Production and Commerce I interviewed argued that innovation policy mobilised a lot of resources but was quite inefficient. He also suggested that the private sector should drive innovation efforts and, when discussing strategic sectors, came back repeatedly to the central role of mining. ${ }^{14}$ This is not surprising: as previously discussed, the business elite's main interests are in mining, finance and non-tradable goods and services. Promoting new sectors is not their priority and could lead to the emergence of threatening competition.

\subsection{Trade Unions and the Influence of Labor}

Trade unions play a significant role in the (re)distribution of income, at least in OECD countries (Blau and Kahn 1996; Huber and Stephens 2001). They pressure median wages upward and often contribute to reduce the wage gap (see Panagides and Patrines 1994 for the Mexican case and a review of the literature in Torrés 2014). They can also influence the functional distribution between wages and profits and reduce top incomes. In the case of the USA, for example, Volscho and Kelly (2012) show that a 1 percentage point increase in union membership would result in a 0.4 percentage point reduction in the income share of the super-rich.

In Chile, as we mentioned before, trade unions were severely repressed after the 1973 coup. The main trade union confederation was outlawed and many of its leaders detained. All existing labour contract regulations were suspended and labour markets liberalised (Berg 2006). Unionisation rates plummeted: the share of union workers in the total labour force went from $33.7 \%$ in 1973 to just $9.8 \%$ in 1985 while union size halved (Donoso 2013a).

With the return to democracy in 1990, trade unions were free again to negotiate contracts and organise strikes, but they never recuperated its previous influence. The main trade union confederation was co-opted by successive Concertación administrations and played a secondary political role (Donoso 2013a). Unionisation rates stagnated and collective agreements remain sparingly used. In 2013 the percentage of workers under collective bargaining or under joint contract-a weaker type of agreement-was below $12 \%$, more than four percentage points lower than in $1990 .{ }^{15}$

A combination of political and economic factors explains the ongoing weakness of trade unions (Donoso 2013a; Leiva 2012; Winn 2004). On the political front, the

\footnotetext{
${ }^{14}$ Interview with a member of the Confederación de la Producción y del Comercio, Santiago, July 2012.

${ }^{15}$ The Labor Department only publishes data on new agreements signed every year. Each collective agreement can last between 2 and 4 years but data on the average length is not available (Departamento de Trabajo 2014). If all agreements lasted 2 years, only $8 \%$ of all workers would benefit in 2013. If all agreements lasted for 4 years, $15 \%$ of workers would be included. I have chosen as the best approximation the average of those two numbers (11.6\%). The data for 1990 comes from Leiva (2012).
} 
memory of the dictatorship and its terrible consequences contributed to the adoption of a moderate strategy. Union leaders were also reluctant to oppose governments led by anti-dictatorship colleagues. The dominance of liberal ideologies was also important. Successive Chilean administrations focused on growth promotion through free markets and trade liberalisation, fighting inequality exclusively through social policy (Palma 2011). As part of this policy approach, the government maintained "labour legislation that is one of the most restrictive on union bargaining power in the world" (Landerretche et al. 2013: 166). The business elite also opposed ferociously various attempts to reform labour laws, watering down proposals that were quite timid to start with (Sehnbruch 2006).

On the economic front, labour market deregulation and expansion of subcontracting arrangements constrain the opportunities for effective union organisation (Berg 2006). Structural heterogeneity - particularly the dominance of small, low-productivity firms - and the growing share of services - where unionisation is significantly harder than in manufacturing - have also been problematic. ${ }^{16}$

In the last decade, there have been some advances. Unionisation rates have recuperated slightly, going from $10.9 \%$ of the working population in 2000 to $11.9 \%$ in 2013 (Fig. 4). The size of trade unions has also expanded from a low of 72 workers

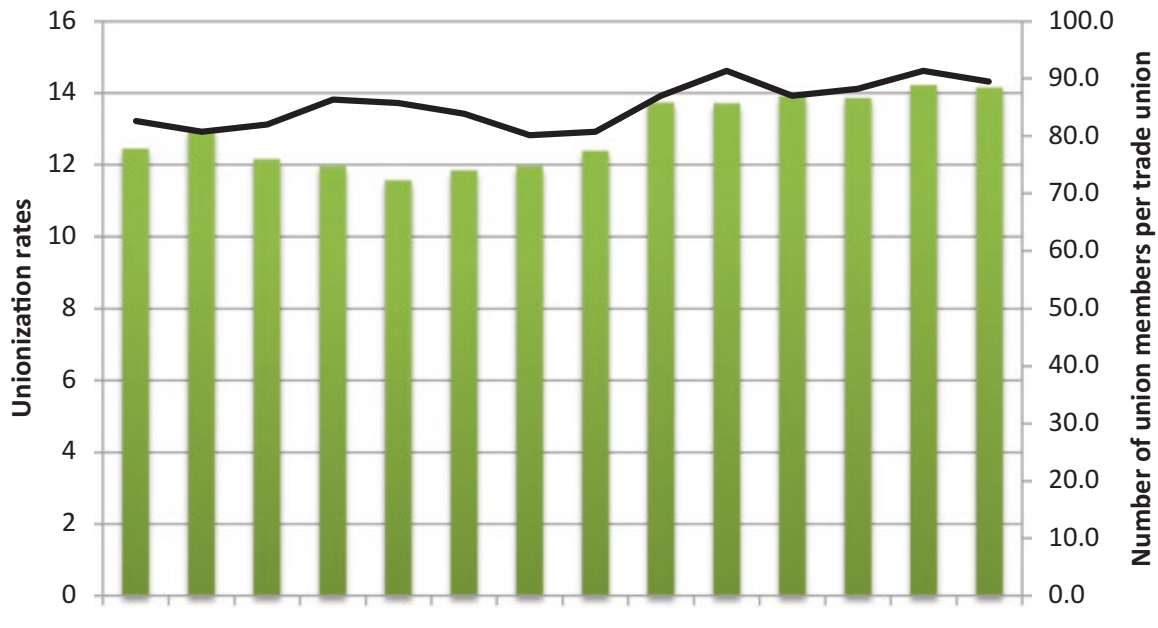

20002001200220032004200520062007200820092010201120122013

- • Total labor force _ Population allowed to unionized

Fig. 4 Unionisation rates and trade union size, 2000-2013. Source: Own elaboration with data from Departamento de Trabajo (2014). Note: The dots represent the ratio between the unionised population and all workers, while the line only considers those workers who can legally associate. It thus excludes public servants. The OECD statistics show a similar trend although with slightly higher values (e.g. unionisation rate in 2012 is 15.2)

\footnotetext{
${ }^{16}$ According to Landerretche et al. (2013) more than half of all large firms have unions compared to just $3 \%$ of small firms and $1 \%$ of microenterprises.
} 
per union in 2004 to 88 in 2013. The emergence of grass-roots unions with more direct links to the rank and file constitutes an even more significant change. Led by subcontracted workers, who demand equal treatment to those employed directly by companies, the new groups first appeared in the state-owned National Copper Corporation (Corporación Nacional del Cobre, CODELCO). ${ }^{17}$ The first organised protests took place in 2003 and led to the creation of the National Association of Subcontracted Workers (CNTC) (Hughes 2013). An indefinite strike in 2006 in several mines forced CODELCO to negotiate directly with the subcontracted workers and grant them a special bonus. The government also passed a Subcontracting Law in January 2007. The slow implementation of that law subsequently led to the intensification of the conflict between subcontracted workers and the state, strengthening the new labour movement in the process (Donoso 2013a). In recent years, grassroots unions have progressively expanded to private mining companies, forestry and salmon processing (Leiva 2012) and have opened new opportunities to developed countervailing social forces.

Nevertheless, these changes should not be exaggerated: trade unions are weak and have a limited influence on income concentration. Unionisation rates are still well below the highs of the early 1970s. Laws still discriminate against trade unions, which are not allowed to negotiate either at the business group or national levels. ${ }^{18}$ The impact of grass-roots unions on collective rights and state behaviour has also been smaller than initially expected (Donoso 2013a). New unions will only revitalise the labour movement if they can ally with traditional organisations and build more productive interactions with left-wing parties - something they have so far failed to do. Otherwise, their political influence and contribution to the erosion of top incomes in the long run will be limited.

\subsection{More Advances in Tax and Social Policies?}

While the Chilean Government has been reluctant to adopt an interventionist stand in production and the labour market, it has gradually implemented more active policies in the social realm. Since 2005, Chile has gradually moved "toward a more universal system of social protection, inspired by left commitments to social equity, justice and solidarity" (Huber et al. 2010: 82). The expansion of social spending has in turn created new conflicts over taxation and could gradually consolidate a broader redistributed cross-class coalition. Overall, the system has become more redistributive from a historical perspective: since 1990 the top quintile pay more in taxes than

\footnotetext{
${ }^{17}$ Subcontracting in the copper sector expanded rapidly in the 2000s. Between 1999 and 2004 the share of firms with subcontracted workers went from 37 to $63 \%$. In $201182 \%$ of the companies in the sector were subcontractors (Hughes 2013).

${ }^{18}$ The minimum wage has also increased less than in neighbouring countries: between 2003 and 2009 , the minimum wage increased by an annual average of $2.4 \%$ compared to $6.6 \%$ in Brazil and a double-digit growth in Uruguay (ILO 2010).
} 
receive in benefits (Arroyo Abad and Lindert, this volume) and the redistributive capacity of the state keeps improving.

The creation of basic health entitlements for the population at large through the Plan for Universal Access with Explicit Guarantees (Plan de Acceso Universal con Garantías Explícitas, Plan AUGE) has probably been the most significant of these pro-universal moves (Martínez Franzoni and Sánchez-Ancochea, 2014). The AUGE plan created a universal mandate for a list of services that every health insurer is obliged to provide within explicit timelines, thus stopping the practice of private providers offering plans that omitted key procedures such as reproductive healthcare for women (Ewig 2008). The plan introduced price limits on private insurance plans and created incentives to reduce age and gender discrimination (Ewig and Palmucci 2012). In addition to the AUGE bill (passed as Ley 19.996 of September 2004), three additional bills were introduced: two established more regulation over private providers and a third, the Sanitation Authority Law (Ley de Autoridad Sanitaria), gave hospitals greater autonomy.

Financial needs and electoral pressures explain why the government succeeded in passing a reform that favoured the poor and the middle class (Pribble 2013). Public health spending had increased steadily during the 1990s partly because the state covered the costs of services that the private insurance did not include. The Lagos administration (2000-2006) had to find new ways to control public spending while increasing the state's funding capacity simultaneously. At the same time, an expansionary reform had cross-class appeal as the middle class was increasingly using state services.

The ultimate impact of the reform was constraint by the influence of the elite. Private insurance companies operating often through right-wing political parties succeeded in limiting cross-subsidies between the private and public sector (Pribble 2013). During implementation, they also adopted pricing strategies that limited AUGE's positive impacts on gender and age inequalities (Ewig and Palmucci 2012).

Despite these problems, AUGE clearly contributed to move Chile's social policy into a universal path. The basket of required treatments has been expanded steadily based upon their cost-effectiveness in preventing death and disability (Ewig and Kay 2011). ${ }^{19}$ A draft bill currently discussed following recommendations from a public-private commission will likely establish a minimum, common insurance for public and private providers, create a common pull with all private contributions and establish a new fund for high-cost medicines in both systems (Oxford Analytica 2014). This process of unification will further enhance cross-class coalitions in support of further expansions of healthcare.

New pension benefits have also been important. The 2008 pension reform introduced a new redistributive benefit program, the Basic Solidarity Pension (Pensión Básica Solidaria). This pension can reach up to $\$ 160$ per month and involves a public subsidy to households earning up to $60 \%$ of the income scale. The reform

\footnotetext{
${ }^{19}$ The most recent changes added 9 new pathologies, increasing the total number to 80 . See, for example, http://www.supersalud.gob.cl/difusion/572/w3-article-8260.html (last accessed 23 November 2014).
} 
also included a bonus for each live birth that women have, therefore acknowledging time devoted to child birth and child-rearing (Ewig and Kay 2011).

While the pension reforms maintained private individual accounts as the core of the pension system, they opened the door for subsequent progressive changes in the system. Upon taking office for the second time in 2014, President Bachelet created a high-level commission to explore the sustainability of the pension system and the link between its various components. The most important proposal on the table is the creation of a state-led insurance company (a public AFP). If introduced, this reform would reduce the large commissions that the private AFPs charge and weaken private providers more generally.

The most evident display of cross-class coalition and middle-class "voice" has taken place in education. In recent years, secondary school and college students have repeatedly protested against the excessive costs of education and the lack of a high-quality, public education. ${ }^{20}$ In a first round of protests, in 2006 secondary school students (the so-called Pingüinos) succeeded in putting education reform in the agenda, even if they did not have much influence in the design of the subsequent legal framework (Donoso 2013b). More recent protests from college students placed the demand for free education at the centre of the agenda, and influenced the 2014 electoral campaign. This messier and less predictable policy process can be considered as an indication of an emerging politics of redistribution that is less complacent with the elite. In fact, according to Fairfield (2014: 16), "the 2011 and 2012 student protests ... dramatically expanded the scope of debate on progressive taxation".

This is welcome news for tax policy and a demonstration of the links between social policies and taxation politics in Chile. In the last two decades, the need to expand social policy in the context of fiscal discipline has created periodic pressures to expand revenues (Fairfield 2015; Pribble 2013). Increases focused primarily on the value-added tax, whose rate was raised as a result of the creation of AUGE and earlier education reforms (Pribble 2013). VAT increases, in turn, were used to demand progressive changes in income taxes in several instances including during the discussion of the 2001 Anti-Evasion Law (Fairfield 2014).

Successive tax reforms have contributed to a moderate expansion in the tax burden. Taxes as percentage of GDP grew from $17 \%$ in 1990 to $23 \%$ in 2007, decreasing more recently as a result of the global financial crisis and the end of the commodity boom (Fig. 5). More significantly for redistribution, income taxes have been behind this positive trend: their share in the total went from only $23 \%$ in 1990 to $46 \%$ in 2007 . The 2014 reform should further increase both total revenues in general and income taxes in particular, expanding the progressive capacity of the state.

Despite these improvements, the Chilean state still struggles to tax high-income groups. Fiscal loopholes, which benefit the elite disproportionally, represent an estimated $4 \%$ of GDP, more than in any other OECD country but Mexico (López 2011).

\footnotetext{
${ }^{20}$ In the late 2000 s, the public sector spent just $20 \%$ more than the private sector despite having to serve nine times more students (López 2011). The Chilean education system also has significant spatial inequalities and the costs of tertiary education remains high.
} 


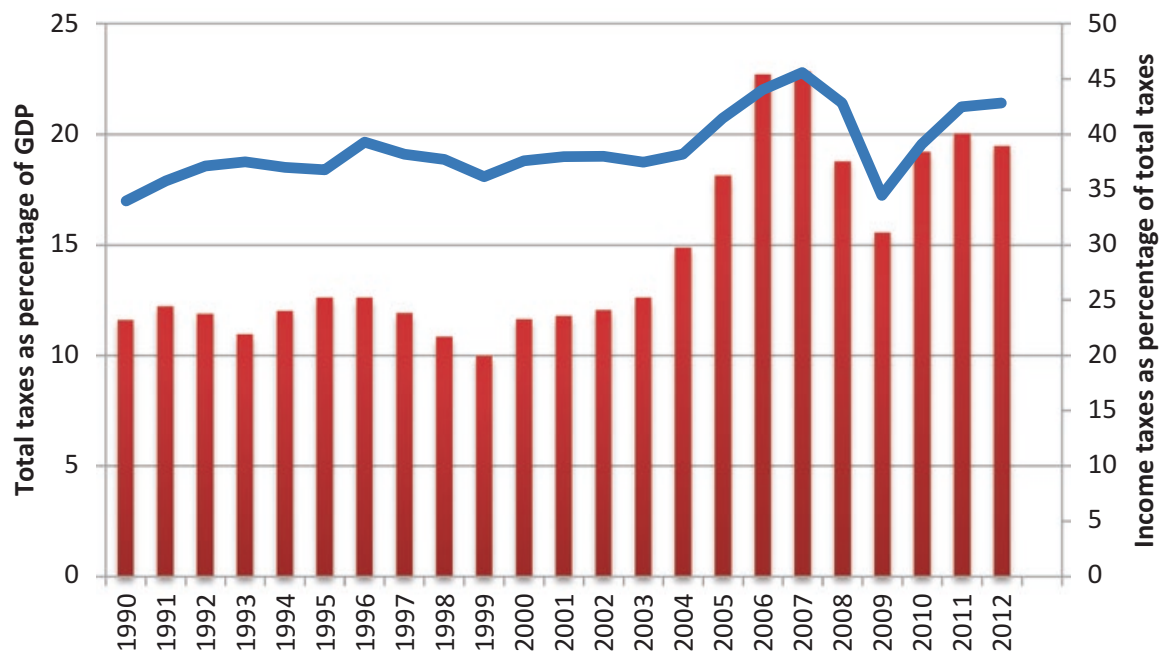

Income taxes (\% total) Total taxes

Source: own elaboration with OECD data

Fig. 5 Tax burden (\% GDP) and income taxes (\% total), 1990-2012. Source: Own elaboration with OECD data

Taxes on natural resource rents in sectors like aquaculture, fisheries and forestry remain low (López and Miller 2008) and the tax rates of the wealthy are significantly below other countries. The average effective tax rate for the richest $1 \%$ is around $16 \%$, compared to $24 \%$ in the USA and a higher level in other OCDE countries (Fairfield and Jorratt 2014).

These problems reflect the ability of the elite to water down various reform attempts. Thanks to its close ties to right-wing opposition parties and its resources to lobby the government, the business elite has succeeded in leaving the corporate tax and access to bank information outside of the policy agenda (Fairfield 2010). The business elite was also successful in watering down Bachelet's ambitious reform proposals in 2015. The results of future struggles over taxes and social policy will depend on the capacity of the emerging cross-class redistributive coalitions to confront this persistent elite power.

\section{Conclusion}

The recent literature on Latin America's performance (much of which is discussed in other chapters of this volume) has praised the reduction in inequality since the early 2000s (Cornia 2014; Gasparini and Lustig 2011; López-Calva and Lustig 2010). Yet how sustainable is this positive trend? Is Latin America truly in a new era? 
To answer these questions, we should consider how much the income share of the wealthy is changing and why. Given data limitations and the importance of politics, this requires a multidisciplinary approach that combines statistics with the study of policymaking and political trajectories.

This chapter adopted this approach to explore the case of Chile-one of the Latin American countries where inequality at the top is most striking. I collected a variety of evidences to show persistent concentration of income at the top. To understand this persistence and consider future trajectories, I studied changes in the structure of the economy, trade unions and the state's redistributive capacity. My analysis illuminates some contradictory trends. Economically, capital income and market concentration remain high with a few business groups controlling large segments of the economy. The state's capacity to make changes in production and reduce structural heterogeneity is persistently low. At the same time, however, social policy has become more redistributive and may be contributing towards the creation of new progressive cross-class coalitions. Higher social spending has also pushed taxation upwards - even if the elite is still paying well below its fair share. A positive scenario for the future would be one in which new social policies create new social expectations and demands, which, in turn, lead to higher taxes. Given the lack of the government's commitment to more radical measures, only in this indirect way will the income share of the rich decrease over the very long run.

Acknowledgements Research funded partly by CAF-Development Bank of Latin America and the Fell Fund at the University of Oxford. Special thanks to Giorgio Bocccardo for valuable research assistance and to Alan Angel, Luis Bertola, Juliana Martínez Franzoni, Javier Rodríbuez Weber and Jeffrey Williamson for comments on an earlier draft.

Open Access This chapter is distributed under the terms of the Creative Commons Attribution 4.0 International License (http://creativecommons.org/licenses/by/4.0/), which permits use, duplication, adaptation, distribution and reproduction in any medium or format, as long as you give appropriate credit to the original author(s) and the source, a link is provided to the Creative Commons license and indicate if changes were made.

The images or other third party material in this chapter are included in the work's Creative Commons license, unless indicated otherwise in the credit line; if such material is not included in the work's Creative Commons license and the respective action is not permitted by statutory regulation, users will need to obtain permission from the license holder to duplicate, adapt or reproduce the material.

\section{References}

Acemoglu, D., Johnson, S., \& Robinson, J. (2001). The colonial origins of comparative development. American Economic Review, 91(5), 1369-1401.

Acemoglu, D., \& Robinson, J. (2012). Why nations fail: The origins of power, prosperity and power. New York: Crown Business. 
Agosín, M., \& Grau, N. (2013). Industrial policy in Chile. unpublished manuscript, University of Chile (an earlier version of the paper was published as "Industrial Policy in Chile" IDB Working Papers no IDB-WP-170).

Agosin, M., Larrain, C., \& Grau, N. (2010). Industrial policy in Chile. Working Paper No. IDB-WP-170. Washington, DC: Inter-American Development Bank.

Alvarado, F., \& Londoño, J. (2012). High incomes and personal taxation in a developing economy: Colombia 1993-2010. CEQ Working Paper.

Amsden, A. (2001). The rise of "the rest": Challenges to the west from late-industrializing economies. New York, NY: Cambridge University Press.

Amsden, A., \& Di Caprio, A. (2012). Understanding the dynamics of elite behaviour in a development context. In A. Amsden, A. Di Caprio, \& J. Robinson (Eds.), The role of elites in economic development. Oxford: Oxford University Press.

Amsden, A., Di Caprio, A., \& Robinson, J. (Eds.). (2012). The role of elites in economic development. Oxford: Oxford University Press.

Atkinson, A., \& Piketty, T. (2010). Top incomes in global perspective. Oxford: Oxford University Press.

Berg, J. (2006). Miracle for whom? Chilean workers under free trade. London: Routledge.

Bertola, L. (2012). Institutions and the historical root of Latin American divergence. In J. A. Ocampo \& J. Ros (Eds.), Oxford handbook of Latin American economics. Oxford: Oxford University Press.

Bhattacherjee, D. (1987). Union-type effects on bargaining outcomes in Indian manufacturing. British Journal of Industrial Relations, 25(2), 247-266.

Blau, F., \& Kahn, L. (1996). International differences in male wage inequality: Institutions versus market forces. Journal of Political Economy, 104(4), 791-836.

Cardoso, C. F. S., \& Pérez Brignoli, H. (1979). Historia éconómica de América Latina. Barcelona: Critica.

Coatsworth, J. (2008). Inequality, institutions and economic growth in Latin America. Journal of Latin American Studies, 40, 545-569.

Cornia, A. (2010). Income distribution under Latin America's new left governments. Journal of Human Development and Capabilities, 11(1), 85-114.

Cornia, A. (Ed.). (2014). Falling inequality in Latin America: Policy lessons and changes. Oxford: Oxford University Press (WIDER Studies in Development Economics).

Departamento de Trabajo (2014). Compendio de Series Estadísticas 1990-2013. Santiago: Gobierno de Chile. Retrieved May 10, 2015 from http://www.dt.gob.cl/documentacion/1612/ w3-propertyvalue-22777.html.

Devlin, R., \& Moguillansky, G. (2012). What's new in the new industrial policy in Latin America? World Bank Policy Research Working Paper 6191, Washington.

Donoso, S. (2013a). Reconstructing collective action in the Neoliberal Era: The emergence and political impact of social movements in Chile since 1990. Thesis submitted in partial fulfilment of the requirements for the Degree of Doctor of Philosophy in Development Studies, University of Oxford.

Donoso, S. (2013b). Dynamics of change in Chile: Explaining the emergence of the 2006 Pingüino movement. Journal of Latin American Studies, 45(1), 1-29.

Engerman, S., \& Sokoloff, K. (1997). Factor endowments, institutions and differential paths of growth among new world economies: A view from economic historians of the United States. In S. Haber (Ed.), How Latin America fell behind: Essays on the economic histories of Brazil and Mexico (pp. 1800-1914). Stanford, CA: Stanford University Press.

Ewig, C. (2008). Reproduction, re-reform, and the reconfigured state: Feminists and neoliberal health reforms in Chile. In I. Bakker \& R. Silvey (Eds.), Beyond states and markets: The challenges of social reproduction (pp. 143-158). New York: Routledge.

Ewig, C., \& Kay, S. (2011). Post-retrenchment politics: Policy feedbacks in health and pension reforms in Chile. Latin American Politics and Society, 53(4), 67-99.

Ewig, C., \& Palmucci, G. (2012). Inequality and the politics of social policy implementation: Gender, age and Chile's 2004 health reforms. World Development, 40(12), 2490-2504. 
Fairfield, T. (2010). Business power and tax reform: Taxing income and profits in Chile and Argentina. Latin American Politics and Society, 52(2), 37-71.

Fairfield, T. (2014). The political economy of progressive tax reform in Chile. Washington: Woodrow Wilson Center Update on the Americas.

Fairfield, T. (2015). Private wealth and public revenue in Latin America. Business power and tax politics. Cambridge, UK: Cambridge University Press.

Fairfield, T., \& Jorratt, M. (2014). Top income shares, business profits and effective tax rates in contemporary Chile. ICTD Working Paper, 17. Brighton: Institute of Development Studies.

Fazio, H. (1999, December) La transnacionalización de la economía chilena. Mapa de la extrema riqueza al año 2000. Santiago: LOM Ediciones.

Fernández Jilberto, A., \& Hogenboom, B. (2007). Big business and economic development. Conglomerates and Economic groups in developing countreis and transition economies under globalization. London/New York, NY: Routledge.

Friedman, J., \& Hofman, A. (2013). Inequality and the top of the income distribution in Chile 1990-2012: Questioning the consensus. Retrieved from http://papers.ssrn.com/sol3/papers. cfm?abstract_id $=2242259$.

Furtado, C. (1974). La economía Latinoamericana desde la Conquista Ibérica hasta la Revolución Cubana. Mexico: Siglo XXI.

Gasparini, L., Galiani, S., Cruces, G., \& Acosta, P. (2011). Educational upgrading and returns to skills in Latin America: Evidence from a supply-demand framework, 1990-2010. IZA Discussion Paper 6244.

Gasparini, L., \& Lustig, N. (2011). The rise and fall of income inequality in Latin America. ECINEQ Working paper 2011-213.

Gindling, T. H., \& Trejos, J. D. (2013). The distribution of income in Central America. In D. Sánchez-Ancochea \& S. Martí (Eds.), Handbook of Central American governance. London: Routledge.

Gogna, M. (Ed.). (2004). Las reformas en el sector salud en la Argentina y Chile. Oportunidades y obstáculos para la promoción de la salud sexual y reproductiva. Buenos Aires: CEDES.

Guerreiro, M. (2012). The labour share of income around the world. Evidence from a panel dataset. Development Economics and Public Policy Working Paper Series, No. 32/2012.

Huber, E., Pribble, J., \& Stephens, J. (2010). The Chilean left in power: Achievements, failures and omissions. In K. Weyland, R. Madrid, \& W. Hunter (Eds.), Leftist governments in Latin America: Successes and shortcomings. New York, NY: Cambridge University Press.

Huber, E., \& Stephens, J. (2001). Development and crisis of the welfare state: Parties and policies in global markets. Chicago, IL: University of Chicago Press.

Huber, E., \& Stephens, J. (2012). Democracy and the left. Social policy and inequality in Latin America. Chicago, IL: Chicago University Press.

Hughes, M. (2013). Re-estructuración capitalista: precariedad laboral y resistencia. La protesta de los mineros del cobre en Chile. Horizontes Antropológicos, 19(39), 99-124.

Infante, R., \& Sunkel, O. (2009). Chile: Towards inclusive growth. CEPAL Review, 97, 133-152.

International Labor Organization (ILO). (2010). Panorama Laboral 2010, América Latina. Lima: International Labor Organization.

Kahn, S. (2012). The sociology of elites. Annual Review of Sociology, 38, 361-377.

Karabarbounis, L., \& Neiman, B. (2013). The global decline of the labor share. NBER Working Paper 19136.

Landerretche, O., Lillo, N., \& Puente, E. (2013). The union effect on wages in Chile: A two-stage. Labour, 27(2), 164-191.

Leiva, F. (2012). Flexible workers and gender in Chile: Contending strategies for confronting the crisis of labor. Latin American Perspectives, 39(4), 102-128.

López, R. (2011). Fiscal policy in Chile: Promoting faustian growth? Working Paper 11-01. College Park: The University of Maryland.

López, R., Figueroa, E., \& Gutiérrez, P. (2013). La Parte del León: Nuevas Estimaciones de la Participación de los Súper Ricos en el Ingreso de Chile. Working Paper 379, Facultad Economía y Negocios, Universidad de Chile, Departamento de Economía. 
López, R., \& Miller, S. (2008). Chile: The unbearable burden of inequality. World Development, 36(12), 2679-2695.

López-Calva, L., \& Lustig, N. (Eds.). (2010). Declining inequality in Latin America. A decade of progress? Washington, DC: Brookings Institution Press.

Lynch, M. (2006). World Wealth Report, 2006. Merryll Lynch and Capgemini.

Martínez Franzoni, J., \& Sánchez-Ancochea, D. (2013). Good jobs and social services: How Costa Rica achieved the elusive double incorporation. Basingstoke: Palgrave McMillan.

Martínez Franzoni, J., \& Sánchez-Ancochea, D. (2014). The double challenge of market and social incorporation progress and bottlenecks in Latin America. Development Policy Review, 32(3), 275-298.

Martínez Franzoni, J., \& Sánchez-Ancochea, D. (2016). The quest for universal social policy in the South: Actors, ideas and architectures. Cambridge: Cambridge University Press.

Medeiros, M., Souza, P., \& Castro, F. (2014). O Topo da Distribuição de Renda no Brasil: primeiras estimativas com dados tributários e comparação com pesquisas domiciliares. Retrieved from SSRN: http://ssrn.com/abstract=2479685.

Mesa-Lago, C. (1978). Social security in Latin America: Pressure groups, stratification and inequality. Pittsburgh, PE: University of Pittsburgh Press.

Oxford Analytica (2014). Chile private healthcare reforms signal wider plans. Oxford Analytica Daily Brief. 19 November.

Palma, G. (2011). Homogeneous middles vs. heterogeneous tails, and the end of the 'Inverted-U': It's all about the share of the rich. Development and Change, 42(1), 87-153.

Panagides, A., \& Patrines, H. (1994). Union-non-union wage differentials in the developing world: A case study of Mexico. Policy Research Working Paper \# 1269.

Piketty, T. (2014). Capital in the 21st century. Cambridge, MA: Harvard University Press.

Piketty, T., \& Saez, E. (2006). The evolution of top incomes: A historical and international perspective. American Economic Review, 96(2), 200-205.

Pinto, A. (1970). Desarrollo Económico y relaciones sociales. In CESO: Chile, hoy. Santiago: Siglo XXI Editores.

Pribble, J. (2013). Welfare and party politics in Latin America. Cambridge: Cambridge University Press.

Ricardo, F.-D. (2010). Economic reforms in Chile: From dictatorship to democracy (2nd ed.). Basingstoke: Palgrave McMillan.

Riesco, M. (2007). Se derrumba un mito: Chile reforma sus privatizados sistemas de educación y salud. Santiago: Centro de Estudios Nacionales de Desarrollo Alternativo CENDA.

Robinson, J. (2012). Elites and institutional perspective. In A. Amsden, A. Di Caprio, \& J. Robinson (Eds.), The role of elites in economic development. Oxford: Oxford University Press.

Rodríguez Fisse, H., \& Thomas, C. (2014). The Chilean big business lobby: A long-standing and major influence on public policy. Journal of Public Affairs, 14(3-4), 310-330.

Rodríguez Weber, J. (2014). La Economía Política de la Desigualdad de Ingreso en Chile, 1850-2009. Doctoral Thesis in Economic History, Universidad de la República, Montevideo (Uruguay).

Ruiz, C., \& Boccardo, G. (2010). Problemas sociales de la Concentración Económica (vistos desde la crisis). Revista Análisis del año 2009. Revista del Departamento de Sociología.

Sanchez-Ancochea, D. (2009). Public budgets and income inequality in Latin America: A comparative perspective. In D. Sánchez-Ancochea \& I. Morgan (Eds.), The political economy of the public budget in the Americas. London: Institute for the Study of the Americas.

Sandbrok, R., Edelman, M., Heller, P., \& Teichman, J. (2007). Social democracy in the global periphery: Origins, challenges, prospects. Cambridge: Cambridge University Press.

Schneider, B. (2008). Economic liberalization and corporate governance: The resilience of economic groups in Latin America. Comparative Politics, 40(4), 379-397.

Schneider, B. (2013). Hierarchical capitalism in Latin America: Business, labor, and the challenges of equitable development. New York, NY: Cambridge University Press.

Segura-Ubiergo, A. (2007). The political economy of the welfare state in Latin America: globalization, democracy, and development. Cambridge: Cambridge University Press. 
Sehnbruch, K. (2006). The Chilean labor market. A key to understanding Latin American labor markets. New York: Palgrave Macmillan.

Silva, E. (1996). The state and capital in Chile: Business elites, technocrats, and market economics. New York, NY: Westview Press.

Solimano, A. (2009). Concentración económica y heterogeneidad productiva en Chile. documento preparado para la Fundación Chile XXI.

Torche, F. (2005). Unequal but fluid social mobility in Chile in comparative perspective. American Sociological Review, 70(3), 422-450.

Torrés, N. (2014). The role of labor unions and collective bargaining in labor markets: Correction of market imbalances and redistribution of wealth. Thesis submitted at the Central European University, Budapest.

Velasco, A., \& Huneeus, C. (2011). Contra la desigualdad: el empleo es la clave. Santiago: Editorial Debate.

Volscho, T., \& Kelly, N. (2012). The rise of the SuperRich: Power resources, taxes, financial markets, and the dynamics of the top 1 percent, 1949-2008. American Sociological Review, 77(5), 679-699.

Williamson, J. (2010). Five centuries of Latin American income inequality. Revista de Historia Económica, 28(2), 227-252.

Winn, P. (2004). Victims of the Chilean Miracle: Workers and Neoliberalism in the Pinochet Era, 1973-2002. Durham, NC: Duke University Press.

World Bank (2003) Inequality in Latin America. Breaking with History? Washington, DC: World Bank.

Yotopoulos, P. (1989). The (rip) tide of privatization: Lessons from Chile. World Development, 17(5), 683-702.

Diego Sánchez-Ancochea is the Director of the Latin American Centre and Associate Professor of Political Economy at the University of Oxford. His research focuses on income inequality and social policy. Together with Professor Juliana Martínez Franzoni, he is the author of The Quest for Universal Social Policy in the South: Actors, Ideas and Architectures (Cambridge University Press 2016) as well as other manuscripts and papers in international journals. He is also co-editor of the Journal of Latin American Studies. 


\title{
Structural Change and the Fall of Income Inequality in Latin America: Agricultural Development, Inter-sectoral Duality, and the Kuznets Curve
}

\author{
Martin Andersson and Andrés Palacio
}

\section{Introduction}

One oft-noted observation of the twentieth-century economic history of Latin America in general and of the import-substitution industrialization strategy (ISI) in particular is the neglect of agriculture and the related structural heterogeneity (Baer 1972; Kay 2002; Bertola and Ocampo 2012). In Latin America, the transformation of agriculture has not been regarded as a centerpiece of the adopted development strategies and, despite some attempts at rural reform, seldom promoted. It might be fair to say that biases against the rural sector have been a defining characteristic of Latin American economic development (Lipton 1977; Griffin et al. 2002; Johnston and Kilby 1975; Reynolds 1996). The dual structure remained even after the ISI period and the switch to the new economic model. A stylized fact is that the continent, even beyond the so-called lost decade of the 1980s, has been in a state of stagnation: weak structural transformation, slow growth, and consistently unequal distribution of income (Bulmer-Thomas 2005). Since the early 2000s, however, many economic indicators, as reported from Economic Outlooks and Reports by the World Bank, IMF or OECD, have been pointing in another direction: steady and relatively high income growth per capita, advances on the commodity export markets, and increasing inflows of foreign direct investments. In terms of social indicators, improvements have also been made: the number of people classified as middle class now surpasses the number of poor; poverty declined from 152 million people living below 2.5 dollars a day in 2000 to around 83 million people in 2010

\footnotetext{
M. Andersson $(\triangle)$

Department of Economic History, Lund University, Lund, Sweden e-mail: martin.andersson@ekh.lu.se
}
A. Palacio
Department of Economic History, Lund University, Lund, Sweden
Universidad Externado de Colombia, Bogotá, Colombia 
(World Bank online); and income inequality in the last decade declined in 15 out of 16 countries with comparable data at a rate of $1.1 \%$ per year (Lustig et al. 2013).

It has been advocated that the fall in income inequality in Latin America provides support for the Kuznets curve (Tsounta and Osueke 2014; Kanbur 2011). The most cited reasons for the improvement relate to policies and political changes over the last decades such as the expansion of elementary education, reduction of the skill-premium, cash transfer programs, and macroeconomic stability (Lustig et al. 2011; Cornia 2012). No doubt, redistributive policies and changes in social spending and legislation are regarded as important proximate causes for narrowing the income distribution and lend support to the notion that income distribution might follow the inverted U-shaped pattern. True, the rise of the income share of the lower segments of the nonagricultural population was already suggested by Kuznets (1965) to be the key for narrowing the income distribution, and studies indicate that this is what we have witnessed in Latin America over the recent decades (Tsounta and Osueke 2014). However, a complementary way to assess whether Latin America is moving downward on the Kuznets curve is to capture the deeper dynamics of structural change in the form of inter-sectoral inequalities. While overall labor productivity has improved only slowly, agricultural labor productivity growth has been more impressive, suggesting a potential for diminishing the long-standing urbanrural duality in the Latin American economies.

In this study we approach the recent decline in income inequality in Latin America from the perspective of structural change with a focus on the relative performance of the agricultural sector. Our focus is on the underlying forces implied by Kuznets (1965). We zoom in on the relative performance of agriculture in the development process and the rural-urban duality and pay particular attention to the last couple of decades in relation to the entire post-1950 period. We attempt to estimate empirically possible theoretical relations with regard to these patterns by posing the following basic questions: how does the resurgence of agriculture relate to the reduction of income inequality and to what extent is this an expression of Latin America moving downward on the Kuznets curve?

The literature on agriculture's relation to the recent changes of income distribution in Latin America is quite limited. For instance, in a recent ECLAC report titled "Structural change for equality" (2012), the role of agriculture is not even mentioned. By agriculture we mean both farming and agro-business that processes and transports that output. To our knowledge, this paper is the first attempt to investigate this relationship for the recent decades in the perspective of structural change in Latin America. There are strong theoretical reasons to connect agricultural development to income distribution. The closing of the rural-urban income gap reflects what Reynolds (1975) called a "dynamic" transformation of agriculture and relates to the contribution agriculture provides for overall growth of the economy. In addition, the elasticity of poverty reduction with respect to growth is estimated to be stronger when growth emanates in the agricultural sector (Ravallion and Chen 2007; De Janvry and Sadoulet 2009). Productivity growth in the lagging sector should also contribute to sectoral labor productivity to convergence and thus helps to reduce inequality (Timmer 1988). For these reasons, the resurgence of agriculture driven 
partly by improving commodity prices should be given due attention when assessing the decline in income inequality in Latin America. According to the logic of the Kuznets curve, the hypothesized "turning point" of the inverted U-curve is generated by a reduction of income inequality in one or both of the sectors and/or a reduction of the rural-urban income gap as the weight of the agricultural sector diminishes, and the income per capita gap between them declines.

We find that the recent decline in income inequality is related to the recent resurgence of Latin American agriculture, and, by inference, its lack of decline across most of the twentieth century must be related to a lack of productivity change in agriculture. We provide estimates showing that during the recent decades intersectoral duality has been reduced by agricultural productivity growth. The duality expressed as an inter-sectoral Gini shows the shape of an inverted U-curve and as such the closing of the rural-urban income gap corroborates with the theoretical expectations postulated by Kuznets. The wider implication of the study is, however, that with slower growth in agricultural labor productivity, continuing improvement in the income distribution becomes more difficult. In the absence of strong manufacturing growth, agriculture might be able to reduce income inequality further if agro-industries remain unskilled labor intensive, thus raising the opportunity cost of unskilled workers. On the other hand, the traditional service sector has perhaps become the "new agricultural sector" in terms of productivity and labor surplus. In other words, the source of the remaining dualism does not come only from rural areas, but also from urban areas.

In the next section, we relate the current agricultural resurgence to previous periods, in particular the so-called belle époque, and we discuss some possible differences between these periods. We then explore theoretically the structural relationship between agricultural development and income distribution. The subsequent sections contain the data and the methodology that we use for OLS (and fixed effects) regressions related to sectoral income inequality and a simple decomposition of agricultural labor productivity. We concluded with a summary of the main findings and the conclusions.

\section{Commodity Export Booms, Land Inequality, and Development in Latin America}

The economic history of Latin America indicates that commodity export booms and busts have been an important component of its development: in the nineteenth century sugar in Cuba and guano in Peru stand out, later nitrates in Chile, coffee in Colombia, Brazil, and Costa Rica, and in the twentieth century oil in Ecuador and Venezuela, just to mention a few cases (Bulmer-Thomas 1994). The export booms have indeed triggered growth spells, but no country in Latin America has experienced sustained structural transformation and industrialization (Sachs and Warner 1999; Bertola and Ocampo 2012). 
The commodity export boom over the last decade seems to have been driven by demand from China and other emerging markets. Many Latin American countries such as Argentina, Brazil, Chile, Colombia, and Peru, among others, experienced a large increase in investment in land and agriculture (Borras et al. 2012) ${ }^{1}$ in response to a rising terms of trade in spite of the sharp, but temporary, decline of prices during the 2009-2011 crisis (FAO 2014). The wave of rising terms of trade lasted 7 years compared to 3 years in past episodes in the 1970s and 1980s (Adler and Magud 2013), ${ }^{2}$ and its timing coincided with the recent improvement of the income distribution in Latin America. Poverty and income inequality fell simultaneously in most countries of the region while other developing regions experienced the opposite (Lustig et al. 2011). In Latin America this stands in sharp contrast to the commodity boom period of the late nineteenth century. What might be different today in Latin America allowing improvements in the income distribution?

Land inequality has been regarded as one of the main historical determinants of the income distribution in Latin America (Engerman and Sokoloff 1997). Measured by Gini coefficients, land inequality has remained high over time and larger than income inequality (Solbrig 2006; Frankema 2009; World Development Report 2008). Likewise, estimates based on agricultural census data indicate that small farms in Latin America have less than $1 \%$ of total land while the same statistics is around $15 \%$ in East Asia and $55 \%$ in sub-Saharan Africa (Anríquez and Bonomi 2007). Attempts to redistribute land have been many, but with varying degrees of success (Solbrig 2006). ${ }^{3}$ The recent commodity boom has made land reforms less appealing because land prices went up with the recent large increase of land and agricultural investments in the region (Borras et al. 2012).

At the same time the impact of land distribution on income inequality is dependent on a variety of factors such as the weight of agriculture in the total economy and inter-sectoral linkages. The contribution of agriculture in total GDP and labor employment has been in relative decline. The manufacturing and service sectors depend less on land than does agriculture, and therefore labor has increased its share of total income. Gasparini et al. (2011a) provide evidence that $81 \%$ of total income in the region comes from labor for the period 1992-2006. The remaining $19 \%$ is nonlabor income, which includes income from capital, rents and profits, pensions,

\footnotetext{
${ }^{1}$ Borras et al. (2012) indicate that the presence of recent large foreign investment in land occurred in Argentina, Bolivia, Brazil, Chile, Colombia, Ecuador, Paraguay, Peru, Uruguay Mexico, Nicaragua, the Dominican Republic, Guyana, Costa Rica, Panama, and Guatemala.

${ }^{2}$ Sachs and Warner (1999) developed a theoretical model to study when and how increases in commodity prices, including minerals, benefitted or damaged nine Latin American countries for the period 1960-1994. They found that on average countries with commodity booms longer than 3 years did not experience an increase of GDP in the years after, with the exception of Ecuador. Countries like Bolivia, Peru, Mexico, and Venezuela even saw a decline in their GDP during and after the boom.

${ }^{3}$ Mexico in 1917, Bolivia in 1952, Cuba in 1959, Chile in 1965, and Peru in 1971; Venezuela and Brazil had minor attempts that can be summarized as colonization policies rather than land reforms, and Argentina did not have the need to pursue it because the agricultural sector was the most advanced in the economy and the share of landless peasants was small.
} 
inter-household transfers and remittances, government transfers, and the implicit rent from owned property.

There are reasons to believe that the recent boom has provided more room to stimulate inter-sectoral linkages today than in previous episodes. During the socalled belle époque (1860-1929) the commodity boom enriched the landowning elite and marked a turning point upward in the evolution of income inequality in the region (Williamson 2010a). During the period increasing international demand and declining costs of transportation promoted the expansion of the export sector, but labor mobility was constrained by the residuals of slavery and encomienda systems, let alone the repression of organized labor and the impact of European immigration in the Southern cone (Frankema 2009; Kay 2001; Williamson 1999; BulmerThomas 1994, p. 87; Bauer 1975). Not surprisingly, in a period of stable farm wages, the landowning elite and the holders of capital reaped bigger benefits, and income inequality rose during the period, arguably to Gini levels around 0.60 (Williamson 2010b; Bertola et al. 2008; Rodriquez Weber 2014).

The main difference between the recent boom and the belle époque might be that agriculture is not isolated anymore and that improved terms of trade has translated into higher value not only for land but also for rural labor. Since the 1960s, it seems as if the emergence of linkages between the rural and urban economies in the region became apparent with the massive reallocation of agricultural labor into other sectors of the economy. The positive impact on rural labor may also have been stimulated by the demand of more commodity processing and internal transport. While agricultural employment recorded negative growth rates as the sector shrank, nonagricultural employment in rural areas has been growing since the 1970s and continues doing so in the 1990s in Ecuador, Chile, Colombia, Costa Rica, Mexico, and elsewhere (Reardon et al. 2001; Haggblade et al. 2010). On average, $40 \%$ of rural income in the late 1990s came from rural nonagricultural employment. Hence, there is reason to believe that an agricultural sector fuelled by improved terms of trade would today promote the expansion of the rural service sector. Indeed, low unemployment rate in the region has been driven by the service sector, which has employed an increasing number of workers, including the rural service sector (World Bank 2012).

In addition, the recent commodity boom is also related to the emergence of "flex crops." Flex crops include soya, sugarcane, oil palm, and corn, among others. Their main trait is the multiplicity of their uses (food, feed, fuel, industrial material), which can be interchanged (Da Silva et al. 2010). For instance, soya can be used for feed, food, and biodiesel. In other words, the reliance on few export products, which has been historically prevalent in the agricultural export sector of Latin America, makes their economies less vulnerable to price fluctuations when the final use can be altered. As an example, the area planted to soya in hectares has risen in Bolivia from 172,354 in 1990 to one million in 2009 (Urioste 2011). In short, technological development has allowed agriculture to diversify their risks even within a single crop sector (Borras et al. 2012).

Also, the urban bias has receded in most countries for domestic policy reasons. After the 1980s price distortions on tradable products fell and enabled producers to exploit economic opportunities (Eastwood and Lipton 2004). Brazil, Chile, Peru, 
and Mexico are good examples of the trend, where the new economic model allowed regional groups, which were less able to reap the benefits of their comparative advantages before, to benefit from positive changes in factor and product markets, and political disposition to invest in health, education, and infrastructure (Da Silva et al. 2010; David et al. 2000). The overall urban-rural income gap in the region fell from 2.5 in 2002 to 2.2 in 2006 (Gasparini et al. 2011b). Furthermore, even though there are few studies linking the role of agriculture in reducing poverty at the country level, recent estimates indicate that rural poverty fell more than urban poverty for the period 2005-2012 in every country (ECLAC 2014). However, there is some contrasting evidence that even though the floor has been lifted, the spatial gap in the human development index has remained stable (for Mexico, CamposVazquez et al. 2014).

In short, in the first decade of the twenty-first century we have witnessed one of the longest commodity price booms and the fall of income inequality in the region. The belle époque, however, marked the upswing of income inequality. The landed elite was the winner from the rising terms of trade and rural labor was excluded. While land was the main source of income in preindustrial Latin America, it remains highly concentrated as before, with land Ginis that go beyond $60 \%$ in most countries. However, land has lost weight as the agricultural share of labor and GDP has fallen over time. Labor benefitted from the boom this time because labor markets are less segmented than they used to be, linkages between rural and urban activities have opened new job opportunities in the service and construction sectors, and safety nets and redistribution policies have protected people against income volatility. All these changes have an impact on the sectoral structure of the economy and therefore on wage inequality marking a turning point in the evolution of income inequality in the region.

\section{Agricultural Productivity and the Kuznets Curve}

It is almost a truism that a sustained increase in living standards requires increased productivity in the economy as a whole. Long-term gains in productivity imply structural change, which has been forcefully argued by Kuznets (1966), Syrquin (2006), and Timmer (2007). One of the major structural changes is the sectoral reallocation of labor into more productive sectors. However, less straightforward is the net effect of the different forces of structural change on income inequality. In this section we will present some of the theoretical and empirical avenues of how structural change, here mainly discussed in a two-sector perspective (agriculture and nonagriculture), affects income inequality. One of the reasons why agricultural development is relevant for inequality is the observation that the elasticity of poverty reduction with respect to growth is typically higher for agriculture than nonagriculture. Timmer, for instance, suggests that growth "originating in agriculture contributes to a more equal distribution of income" (2007: 60, drawing on the work of Kuznets 1955 and Chenery and Syrquin 1975). 
Kuznets $(1965,1966)$ argued that both reallocation of agricultural labor into more productive sectors constitute the major structural change in a developing economy, plausibly leading to long-term inter-sectoral convergence in productivity. The whole process has repercussions on the pattern of income distribution. According to the Kuznets-curve logic, in the initial stages of development the reallocation of agricultural labor into the nonagricultural sector reduces both the relative share of people employed in agriculture and its share of total GDP without any significant increase in agricultural productivity. As a result, the rural-urban income gap widens along with the urban intra-sectoral inequality. Later on, the productivity (or income) gap between sectors converges as the productivity in agriculture improves. When the inter-sectoral convergence gets stronger, and as labor mobility increases, the overall income distribution improves. By then, the absolute number of employed agriculture falls with rural-urban migration. The inequality is also strengthened by distributive policies and legislation following the increasing importance of the political voice of both urban and rural lower-income classes. This ideal model represents a dynamic transformation of agriculture as opposed to a static one. Agriculture is mostly driven by its productivity dynamics (Johnston and Mellor 1961). In the latter, agriculture is instead squeezed out of its resources and intersectoral linkages are weak (cf. Reynolds 1975).

The Kuznets hypothesis provides broad ideas for thinking about changes in the long run income distribution. In a two-sector economy, when the majority at first resides in the agricultural sector and the nonagricultural sector is small, average income per worker is low as is the variance of the income distribution. When people leave agriculture, the average per capita income in the agricultural sector may rise but since the more unequal sector will gain in relative importance the overall income distribution might become more widespread.

The overall income distribution is the net effect of intra-sector distribution, intersector income differences, and sector weights. In some cases, the process of structural change might create forces working in opposite directions. Yet structural changes in a two-sector model may increase inequality in five possible ways: (1) income inequality is increased in both sectors simultaneously; (2) income inequality is increased in the agricultural sector only; (3) income inequality is increased in the nonagricultural sector only; (4) a divergence of average income between the poor agricultural sector and the rich nonagricultural sector; or (5) shifting weights in the more unequal nonagricultural sector. Estimating such a complex socioeconomic process is difficult. However, given the resurgence of Latin American agriculture, we may address the inter-sectoral productivity differences and weights. It should be emphasized that Kuznets was very careful to discuss the caveats of his hypothesized inverted U-curve; that it was a historical-theoretical speculation rather than an established empirical law.

One way of relating the rise of agricultural productivity with the income distribution is suggested by Timmer (2004), who argues that the turning point of the Kuznets hypothesis can be also associated with the closing gap between the share of GDP and employment in agriculture. He has estimated the gap in a sample of eight Asian countries (Indonesia, Malaysia, the Philippines, Thailand, India, Pakistan, South Korea, and China) for the period 1960-2000 by using the "inter-sectoral Gini 
coefficient" as a proxy for the inequality of labor productivity (or income) between agriculture and nonagriculture. His results show that the inter-sectoral Gini is positively associated with the overall Gini and captures one-third of its variation, controlling for relative labor productivity, the GDP share of the service sector, savings, rice prices, and other variables.

Using evidence from 86 countries between 1965 and 2000, Timmer and Akkus (2008) show that the gap between the GDP and employment shares in agriculture does narrow with higher incomes and explains that this convergence is part of the structural change, reflecting better financial and labor markets. Furthermore, the agricultural productivity gap widens during the early stages of development and reaches a turning point at the per capita level of GDP above US 5063 in the year 2000, controlling for terms of trade, and US 9255 without controlling for them. The main implication of these findings is that agricultural price policy can be used to influence their domestic terms of trade, connect the agricultural labor to the rest of the economy, and thus reduce inequality.

\section{Data and Methods}

The aim here is to study the relationship between income inequality and agricultural development in nine Latin American countries: Argentina, Bolivia, Brazil, Chile, Colombia, Costa Rica, Mexico, Peru, and Venezuela. These countries cover more than $82 \%$ of the total GDP of LAC and more than $91 \%$ of the population in 2012. The period covered 1950/1960-2010, which we divide into three subperiods that reflect alternative policy views: the import substitution (ISI) period between 1960 and 1975, the turmoil period between 1975 and 1995, and the agricultural resurgence/fall in income inequality period between 1995 and 2010.

We decompose aggregate labor productivity change to identify the contribution of agriculture relative to other sectors of the economy. Labor productivity is an indicator of real income per capita, and its change over time can be decomposed into sectoral productivity change and the reallocation between sectors. We follow the approach taken by Ocampo et al. (2009) and Roncolato and Kucera (2013). This can be expressed as follows:

$$
\text { Labor productivity growth }=\sum\left\{\varphi_{i 0}\left(g_{i}-e_{i}\right)+e_{i}\left(\varphi_{i 0}-\left(\frac{q_{1}}{q_{0}}\right) \lambda_{i 0}\right)\right\}
$$

The sectoral productivity growth is the difference between the growth rate of sectoral value added $g_{i}$ and the growth rate of sectoral employment $e_{i}$, weighted by the sectoral output share $\varphi_{i 0}$. Sectoral productivity growth (within) reflects technological change and rates of investment. Sectoral reallocation is the difference between sectoral output share $\varphi_{i 0}$ and sectoral employment share $\lambda_{i 0}$ adjusted by the ratio of labor productivity multiplied by the growth rate of sectoral employment $e_{i}$. 
Reallocation is usually the most common term to capture structural change. However we view structural change as the interplay of both terms. We agree with the idea that reallocation of agricultural labor is indeed the major structural change in economic development, but realize that without increases in overall sectoral productivity reallocation might not contribute to growth as labor can end up in low productivity nonagricultural sectors.

To implement the decomposition, we use the Groningen Growth and Development Centre Data (GGDC) that contains data on sectoral value added and employment for nine Latin American countries. The data cover the period 1950-2010 for all countries, except Bolivia, Peru, and Venezuela. Their series start from the 1960s onward. We convert local currency value added at 1990 prices to dollars using 2005 deflators by sectors and exchange rates. Labor productivity is computed dividing sectoral value added by employment. ${ }^{4}$ Note that unemployed people are not available in the GGDC data. We combine two of the original sectors (Government services and community, Social and personal services) into a single one, leaving the sample with nine sectors. The sectoral distribution and details on the sources of the data are available at the GGDC website.

The Gini coefficient is used as our measure of income distribution. We build on the work of Timmer (2004) to compute the inter-sectoral Gini from the share of the agricultural economy in overall economic activity in relation to its share of the labor force. Note that the inter-sectoral Gini is not the Gini of the agricultural sector, but the Gini coefficient of the agricultural sector compared with the nonagricultural sector. The inter-sectoral Gini coefficient should be positively related to the overall Gini coefficient.

The inter-sectoral Gini coefficient is computed as

$$
\text { Inter }- \text { sectoralGini }=1-p_{\text {agri }} S_{\text {agri }}-2 S_{\text {agri }}\left(1-p_{\text {agri }}\right)-\left(1-p_{\text {agri }}\right)\left(1-S_{\text {agri }}\right),
$$

$p$ is the share of the labor force in agriculture, and $S$ is its share of economy-wide income.

$$
\text { Gini }=\text { constant }+ \text { Intersectoral Gini }+ \text { controls }
$$

The Gini coefficient is the version 5.0 of the Solt ${ }^{5}$ dataset that provides inequality measures for 153 developing and advanced countries for the period 1960-2010. The Gini coefficient we use as the dependent variable is the pre-fisc or market inequality $^{6}$ or inequality before taxes and transfers. The literature indicates that taxation

\footnotetext{
${ }^{4}$ The sectoral distribution is composed of nine sectors: agriculture, hunting, forestry, fishing; mining; manufacturing; public utilities; construction; wholesale and retail trade, restaurants, hotels; transport, storage, communication; financial services, real estate, insurance; other services (community and personal and government services).

${ }^{5}$ Solt (2014) produced the dataset of comparable series of Gini coefficient for net and market inequality.

${ }^{6}$ Missing data is completed through linearized estimates, in particular for the 1960s and 1970s.
} 
policies in Latin America have little impact on market inequality (Goñi et al. 2008; ECLAC 2012). However, we use the difference between market and net (or postfisc) inequality to capture redistribution in the period 1995-2010. The latter period has been characterized by an expansion of redistribution schemes, including noncontributory pensions, health insurance, and cash transfers to the poor, which have been widely praised.

We also recognize that there are many forces acting upon the Gini. The first of them is the distribution and changes in value assets or wealth over time. They should be studied jointly with the income Gini because the distribution of wealth is the result of past income distributions and savings rates. Furthermore, there is evidence that on average aggregate savings grew more than in previous boom episodes, and that the public sector contributed more to savings than the private sector (Adler and Magud 2013). ${ }^{7}$ In this line, we borrow the idea from Timmer (2004), who studies the inter-sectoral Gini in eight Asian countries, that gross domestic savings are a crude proxy of nonlabor income. Savings rate in the full sample range from $11 \%$ of GDP in Bolivia to $21 \%$ in Chile and $31 \%$ in Venezuela (see descriptive statistics in the Appendix). Likewise, we examine the impact of the service sector GDP on the Gini coefficient. The decomposition literature indicates that agricultural labor is released mostly into the traditional service sector, where productivities are low, and in many cases informal.

We examine the hypothesis that increases in agricultural labor productivity has a direct impact on the inter-sectoral Gini through its inner components: land productivity and land/labor ratio. On one hand, the identity below captures increases in efficiency that relates to improvements in the agricultural production such as quality of crops, or use of fertilizer, but also other effects such as improvement in the organization of production or institutional changes. On the other hand, the identity accounts for changes in the resource endowments such as increases in relative abundance of land relative to labor that can impact income during a commodity boom, given that land frontier can be expanded and high yield technology can be used. We take the data of arable $^{8}$ and agricultural ${ }^{9}$ land from the World Development Indicators. We use both datasets, but the results here are presented based on arable land alone. The estimates do not vary much.

$$
\frac{\text { Value added in agriculture }}{\text { Labor force in agriculture }}=\frac{\text { Value added }}{\text { Land }} \times \frac{\text { Land }}{\text { Labor }}
$$

\footnotetext{
${ }^{7}$ Bolivia, Colombia, and Peru saved more out of the boom than the rest, while Chile and Brazil stand out on the other extreme with lower marginal saving rates.

${ }^{8}$ Arable land defined by the FAO as land under temporary crops (double-cropped areas are counted once), temporary meadows for mowing or for pasture, land under market or kitchen gardens, and land temporarily fallow. Land abandoned as a result of shifting cultivation is excluded.

${ }^{9}$ Agricultural land is the share of land area that is permanent pastures, arable, or under permanent crops. Permanent pasture is land used for 5 or more years for forage, including natural and cultivated crops.
} 
Combining the GGDC data of agricultural value added and employment with the land data from the World Bank Indicators, we run an OLS regression with country and year dummies. All variables are logged, and land productivity and land-labor ratio are regressed on the inter-sectorial Gini. Finally, we contrast the results with the sectoral decomposition, which identifies sectoral productivity and reallocation.

\section{Results}

The first sign of an agricultural resurgence in Latin America was the rise in agricultural productivity relative to economy-wide productivity. The ratio has been growing at an unweighted average rate of 1.6\% per year for the period 1960-2010 but our results indicate that the period 1995-2010 accounts for $43 \%$ of that impressive growth rate. ${ }^{10}$ Some countries record a faster growth than others like Bolivia and Brazil in contrast with Chile and Costa Rica, but the gap between agriculture and nonagriculture was closing from 1995 to 2010 in every country in the sample. ${ }^{11}$

Agriculture has indeed been no obstacle to growth during the last 50 years and an engine of growth during the last two decades. In Table 1 we show that since the

Table 1 Closing the gap: the agricultural resurgence in Latin America between 1995 and 2010

\begin{tabular}{l|l|l|l|l|l|l}
\hline Country & $\begin{array}{l}\text { Agri. } \\
(\%)\end{array}$ & $\begin{array}{l}\text { Manuf. } \\
(\%)\end{array}$ & $\begin{array}{l}\text { Trad. } \\
\text { serv. }(\%)\end{array}$ & $\begin{array}{l}\text { Finance } \\
(\%)\end{array}$ & $\begin{array}{l}\text { Other } \\
\text { sectors } \\
(\%)\end{array}$ & $\begin{array}{l}\text { Economy-wide labor } \\
\text { productivity growth }(\%)\end{array}$ \\
\hline Argentina & 0.32 & 0.40 & 0.03 & -0.14 & 0.32 & 0.93 \\
\hline Bolivia & 1.58 & -0.01 & -0.84 & 0.13 & 0.05 & 0.91 \\
\hline Brazil & 1.14 & 0.31 & 0.01 & 0.17 & -0.69 & 0.93 \\
\hline Chile & 0.64 & 0.56 & -0.50 & 0.48 & 1.15 & 2.33 \\
\hline Colombia & 0.43 & 0.19 & -0.88 & 0.14 & 0.62 & 0.51 \\
\hline Costa Rica & 0.43 & 0.73 & -0.52 & 0.12 & 0.48 & 1.24 \\
\hline Peru & 0.76 & 0.42 & 0.07 & 0.38 & 0.41 & 2.03 \\
\hline México & 0.26 & 0.13 & -0.18 & 0.31 & -1.04 & -0.53 \\
\hline Venezuela & 0.20 & 0.03 & -0.68 & -0.12 & -0.23 & -0.80
\end{tabular}

Source: Labor productivity growth decomposition estimated with yearly data from the Groningen Growth and Development Centre (GGDC)

\footnotetext{
${ }^{10}$ The growth rate of the ratio for the period $1960-2010$ is $1.8 \%$ (40\% in the period 1995-2010) in Argentina, $1.8 \%$ (68\% in the period 1995-2010) in Bolivia, $1.5 \%$ (73\% in the period 1995-2010) in Brazil, $2.7 \%$ (34\% in the period 1995-2010) in Chile, $0.6 \%$ (33\% in the period 1995-2010) in Colombia, $1.5 \%$ (29\% in the period 1995-2010) in Costa Rica, $0.8 \%$ (58\% in the period 1995 2010 ) in Peru, $0.9 \%$ (58\% in the period 1995-2010) in Mexico, $3.6 \%$ (25\% in the period $1995-$ 2010) in Venezuela.

${ }^{11}$ We examined the finding further by trying different specifications of the ratio such as manufacturing over agriculture, labor-intensive services over agriculture and even their marginal productivities, and excluding Argentina, whose agricultural productivity has been larger than the average in the economy and in the region.
} 
Table 2 Testing the inter-sectoral Gini in nine Latin American countries between 1960 and 2010

\begin{tabular}{l|l|l|l|l}
\hline Inter-sectoral Gini & 1 & 2 & 3 & 4 \\
\hline Ln (income per head) & $2.951^{* * * *}$ & $2.494 * * *$ & $1.560^{* * *}$ & $1.561 * * *$ \\
\hline Ln (square income per head) & $-0.144 * * *$ & $-0.122^{* * * *}$ & -0.080 & $-0.084 * * *$ \\
\hline Terms of trade & & & & -0.00017 \\
\hline Year & & $\mathrm{X}$ & $\mathrm{X}$ & $\mathrm{X}$ \\
\hline Country & & & $\mathrm{X}$ & $\mathrm{X}$ \\
\hline Constant & $\mathrm{X}$ & $\mathrm{X}$ & $\mathrm{X}$ & $\mathrm{X}$ \\
\hline$R$-squared & $20 \%$ & $55 \%$ & $92 \%$ & $92 \%$ \\
\hline Number of obs. & 459 & 459 & 459 & 459 \\
\hline
\end{tabular}

Note: Statistical significance is indicated as $*$ at the $10, * *$ at the 5 , and $* * *$ at the $1 \%$ levels

mid-1990s the agricultural contribution lies ahead that of manufacturing, with the exception of Argentina and Costa Rica. In other words, during the period 19952010 the agricultural sector has consistently contributed more than manufacturing to aggregate labor productivity in seven out of nine countries in the sample. We also confirm the pattern that traditional services such as wholesale retail and trade, hotels and restaurants reduce aggregate labor productivity while dynamic services such as financial services enhance it, but not to the same extent as agriculture. For instance, Chile is a country with low agricultural GDP (5\%) and employment (9\%) shares compared to other middle-income countries, but most of the decline in poverty seems to be attributed to agricultural productivity growth. Anríquez and López (2007) estimate the unskilled labor demand elasticity of agricultural output to be three times larger than that of skilled labor. In general, even though our results do not account for the informal sector, the falling productivity in the service sector is a clear indication that the manufacturing sector cannot fully cope with the reallocation of agricultural labor and therefore the conditions for relatively high inequality will probably persist in the region.

Agricultural productivity has a role to play in closing the inter-sectoral labor productivity gap. Even though labor productivity does not necessarily translate into income in imperfect markets, we think that our estimates of the negative association between the inter-sectorial Gini and higher levels of income per head are appearing in many Latin American countries. Table 2 indicates that the income elasticity is 1.56 and the square of income is -0.08 . In other words, the gap closes with rising income, and the turning point was 17.154 dollars per head at 2013 EKS PPP prices. We added the terms of trade ${ }^{12}$ to check whether increasing trade would reduce the turning point, and the result was 10.847 dollars per head at 2013 prices. Argentina, Chile, Costa Rica, and Venezuela surpassed that threshold around 2000, and Mexico in the early 1980s. Brazil, Colombia, and Peru are coming closer to 10.000 dollars per head, and Bolivia is on 4.517 dollars by 2010 (see Table 5 in Appendix).

The literature has ambiguous results with respect to the association between terms of trade and inequality during the recent commodity boom. For instance,

\footnotetext{
${ }^{12}$ We combined the series of terms of trade from the World Bank and the Montevideo-Oxford Latin American Economic History Database (Moxlad). GDP per head at 2013 prices is taken from the Conference Board Total Economy Database (TED-GDCD).
} 
Table 3 Explaining the log of the Gini coefficient across time and countries in Latin America

\begin{tabular}{l|l|l|l|l}
\hline \multirow{2}{*}{ Logged Gini } & $1960-2010$ & \multicolumn{2}{l}{} & $1995-2010$ \\
\cline { 2 - 5 } & 1 & 2 & 2a: excluding Argentina & 3 \\
\hline Inter-sectoral Gini & $0.078^{* * *}$ & $-0.018^{*}$ & $0.044^{* * *}$ & $0.03 * *$ \\
\hline GDP service & & 0.055 & 0.202 & $-0.70^{* * *}$ \\
\hline Saving & & $-0.001^{*}$ & -0.0002 & $-0.003^{* * *}$ \\
\hline Redistribution & & $1.438^{* * *}$ & $1.554^{* * *}$ & -0.72 \\
\hline Time period & & $\mathrm{X}$ & $\mathrm{X}$ & $\mathrm{X}$ \\
\hline Country & & $\mathrm{X}$ & $\mathrm{X}$ & $\mathrm{X}$ \\
\hline Constant & $\mathrm{X}$ & $\mathrm{X}$ & $\mathrm{X}$ & $\mathrm{X}$ \\
\hline$R$-squared & $21 \%$ & $76 \%$ & $76 \%$ & $87 \%$ \\
\hline Number of obs. & 411 & 411 & 374 & 131 \\
\hline
\end{tabular}

Note: Statistical significance is indicated as $*$ at the $10, * *$ at the 5 , and $* * *$ at the $1 \%$ levels. The coefficients of the inter-sectoral Gini for the period 1960-2010 is $0.078 * * *$ for Bolivia, $0.092 *$ for Brazil, $0.035 * * *$ for Chile, -0.035 for Colombia, -0.019 for Costa Rica, $0.098 *$ for Peru, 0.069 for Mexico, and $0.072 *$ for Venezuela. The coefficients for the period 1995-2010 is 2.04 for Argentina, $0.14 * * *$ for Bolivia, $0.10 * * *$ for Brazil, $0.05 * * *$ for Chile, 0.005 for Colombia, -0.043 for Costa Rica, $0.11 *$ for Peru, -0.024 for Mexico, and $0.09 * *$ for Venezuela

Astorga (2014) finds no evidence that the commodity price boom has favored unskilled labor, but Gasparini et al. (2011a) find that it has shifted resources, including labor, toward non-tradable sectors such as construction and services and favored the employment of unskilled labor in these sectors. Timmer and Akkus (2008) report that as in the case of East Asia the negative association between terms of trade and inequality indicate some room to design agricultural policies that improve the well-being of the rural population in the income distribution. Our estimates show a small and negative coefficient for terms of trade, and even if it is statistically insignificant, it seems to support the findings of Timmer and Akkus.

Table 1 shows that the inter-sectoral Gini is positively related to the overall Gini. Model 1 indicates that a $1 \%$ increase in the inter-sectoral Gini raises the overall Gini by $0.08 \%$. Adding the controls, the inter-sectoral Gini in model 2 is $-0.018 \%$ and significant at the $10 \%$ level. We examined the result by running separate regressions for every country and found that the downward bias comes from Argentina. Model $2 \mathrm{a}$ excludes Argentina and yields a coefficient of $0.04 \%$. Note that the coefficient is small relative to our first model, but the coefficient is larger and significant at the country level: $0.08 \%$ in Bolivia, $0.09 \%$ in Brazil and Peru (see note in Table 1). The inter-sectoral Gini explains $21 \%$ and $25 \%$ of the variation in the overall Gini coefficient for the period 1960-2010 and 1995-2010, respectively. It is worth noting that Timmer (2004) found that the inter-sectoral Gini in eight Asian countries for the period 1960-1999 accounted for $25 \%$ of the variation of the overall Gini, but the beta coefficient of the inter-sectoral Gini was around 0.43 . We did not get coefficients that high in any of the Latin American countries. One wonders which Asian country has driven the results: South Korea, with low inequality and rapid industrialization; the Philippines and Malaysia with high and relatively stable income inequality; or Thailand and China, with high income inequality today in comparison with the 1960s. Inequality in Latin America has been very stable and high in most countries regardless of their initial or current conditions. 
Model 3 estimates the inter-sectoral Gini to be $0.031 \%$ in the period $1995-2010,{ }^{13}$ during which the decline in income inequality became clear in most countries of the region. The larger coefficients of the inter-sectorial Gini are found in Bolivia $(0.14 \%)$, Peru $(0.11 \%)$, and Brazil $(0.10 \%)$, (see note in Table 1$)$. We control for GDP service, savings and redistribution, and all coefficients are significant, and of the right sign. They all reduce income inequality. This would lead us to think that even though the service sector has some low productivity segments, it is absorbing labor and providing levels of income that might at least be better than in agriculture.

Our findings also show that the inter-sectoral Gini contributes to reduced income inequality and that the inter-sectorial gap is closing. The decomposition exercise presents evidence of the agricultural productivity growth having a larger impact on aggregate labor productivity growth than manufacturing or services. The intersectoral Gini for the most recent period explains around one-fourth of the variation in the overall Gini coefficient. We think that this supports the case for the renewed role of agriculture in Latin American development. We decompose agricultural productivity into land productivity and the land/labor ratio to connect both pieces of evidence, and examine their impact on the inter-sectoral Gini.

For the period 1960-2010, land productivity and land/labor ratio explain around $86 \%$ of the variation in the inter-sectorial Gini (results not shown here). Both coefficients are highly significant, but land/labor ratio is higher than land productivity in every model estimated over the entire period. An increase of $1 \%$ in land productivity reduces the inter-sectorial Gini by $0.23 \%$. For the ISI period, only $20 \%$ of the variation in the inter-sectoral Gini coefficient can be explained by labor productivity. For instance, Reis (2014, p. 10) writes that "ISI in Brazil is associated with urban concentration, economies of scale and agglomeration and therefore a slow decrease in the spatial inequality of labor productivity." In other words, land productivity was still overwhelmed by the abundance of labor in rural areas in spite of rural-urban migration. However, in the 1995-2010 period the effect of land productivity gets stronger, which coincides with the commodity export boom. Over this period it seems as if land productivity and the factor endowments reinforce each other: the land/labor ratio has increased and so has the productivity per unit of land. Reis (2014) confirms the trend in Brazil, where intense use of land and other natural resources led to the spatial dispersion of economic activities and faster convergence of labor productivity across regions.

Land productivity has played a larger role in the recent period. A look at the agricultural productivity in the initial decomposition exercise presents the increase in agricultural productivity reliant on technological and institutional changes rather than crude reallocation of labor. In other words, as the inter-sectoral Gini is falling, the potential for reallocation is diminishing, which is a clear sign of the transition toward development. We interpret this as a sign of a more dynamic transformation of agriculture not mainly driven by extensive growth and rural to urban migration but also internal productivity growth in the sector.

\footnotetext{
${ }^{13}$ The coefficients for the inter-sectorial Gini are not statistically significant during the 1960-1975 and 1975-1995 periods.
} 


\section{Conclusions}

This study explores the agricultural resurgence of the recent decades in a Kuznetsian structural change perspective and how it relates to the observed reduction in income inequality. We first establish that agricultures' relative labor productivity growth has improved over the last 15 years. Inspired by a recent literature on the role of agriculture and Kuznets' seminal discussion of how the forces of economic change might influence the income distribution, we focus on the part of overall income inequality made up by rural-urban duality, proxied by inter-sectoral income difference. According to our estimates the inter-sectoral Gini explains $20-25 \%$ of overall inequality in Latin America over the entire period. We find that the long-term pattern of sectoral inequality declines with increase in per capita income. Based on this, we find support for income equalization due to inter-sectoral income convergence. Narrowing of the sectoral productivity gap suggests stronger inter-sectoral linkages and together with the expansion of agriculturerelated employment opportunities it is likely that the opportunity cost of unskilled labor has been raised. This is consistent with the finding that the effect of agricultural productivity stemming from land productivity growth, rather than only changes in land/labor ratio, has grown in importance over the last 15 years. Compared to the belle époque, it seems as if improved terms of trade for agriculture not only increased the value of land but also rural labor and possibly also the political commitment to invest in rural areas. Interpreted in the framework of the Kuznets curve we have only addressed part of the dynamics and can therefore neither prove nor disprove whether the decline of inequality over the last decades constitutes the downturn of the Kuznets curve. The agriculture-led reduction of inter-sectoral productivity is however consistent with Kuznetsian forces bending the curve downward.

We also note that while agriculture has emerged as a stronger contributor to overall productivity growth, there has been a large expansion of low-productivity employment in parts of the service sector. This expansion seems to have contributed to the decline in overall income inequality, consistent with the implementation of policies directed toward the lower income segments of the urban population over the last decades. However, the rural-urban duality has transformed into an urban one. A remaining caveat is that even if agriculture has started to close the gap to other sectors, it is probable that productivity gains have been stronger among large capital-intensive agricultural units than smallholders. In this sense, the income distribution might not have been substantially narrowed within the agricultural sector.

Acknowledgements The authors want to thank participants at the Economic History seminar, September 2014, Lund University, for comments on an earlier version of this paper and participants at the Conference Latin American Inequality in the Long Run, Buenos Aires, 3-5 December, as well as the editors. The authors also gratefully acknowledge funding from the Swedish Research Council (\#348-2013-115). 


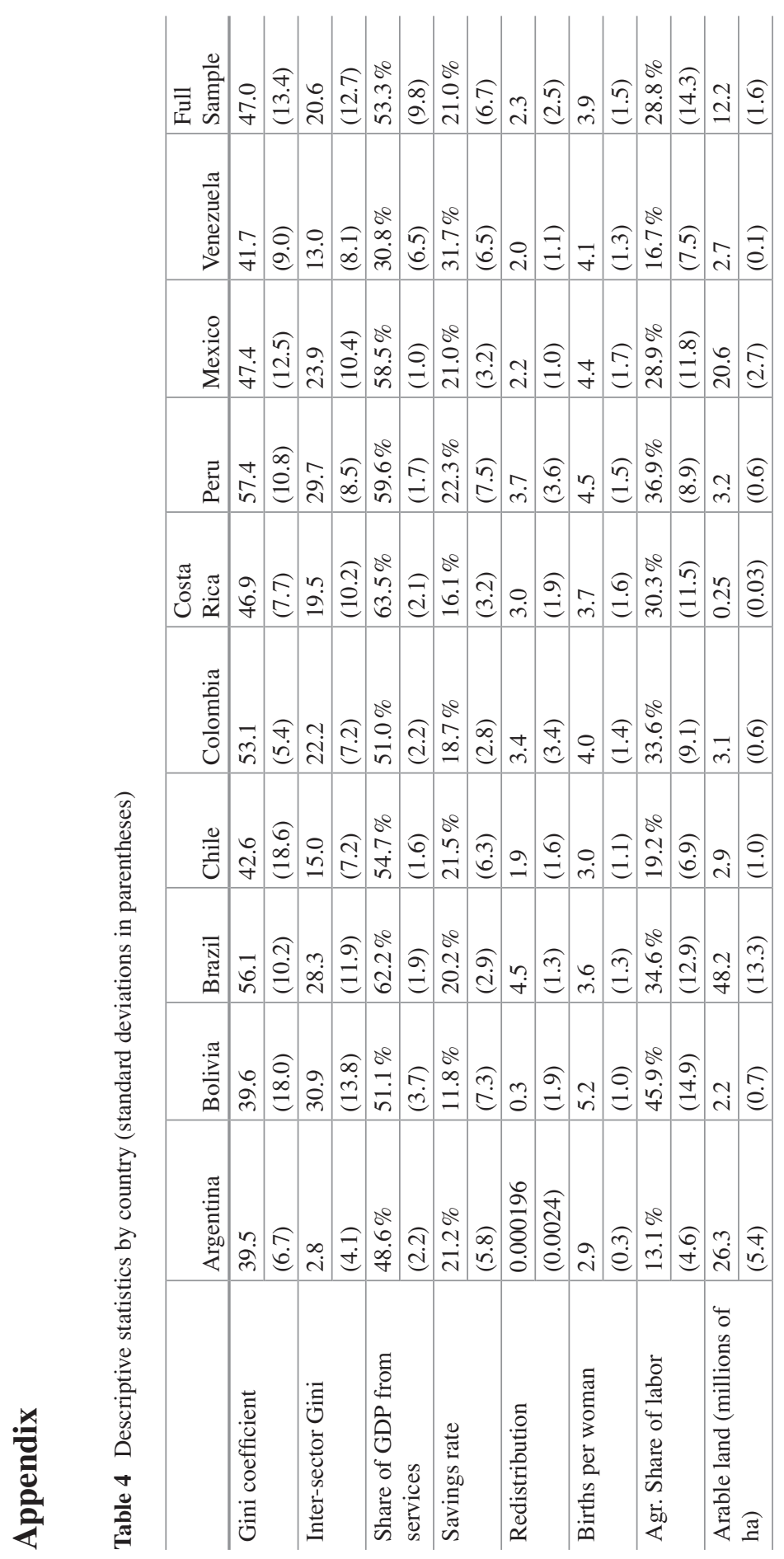


Table 5 GDP per capita in 2013 US\$ (converted to 2013 price level with updated 2005 EKS PPPs)

\section{GDP per Capita, in 2013 EKS\$}

\section{Latin America}

\begin{tabular}{|c|c|c|c|c|c|c|c|c|c|}
\hline & Argentina & Bolivia & Brazil & Chile & Colombia & $\begin{array}{l}\text { Costa } \\
\text { Rica }\end{array}$ & Mexico & Peru & Venezuela \\
\hline 1950 & 6679 & 2829 & 2460 & 4164 & 2802 & 3254 & 4345 & 3598 & 8424 \\
\hline 1951 & 6795 & 2967 & 2505 & 4233 & 2798 & 3235 & 4551 & 3782 & 8651 \\
\hline 1952 & 6318 & 2993 & 2578 & 4417 & 2882 & 3504 & 4600 & 3878 & 9022 \\
\hline 1953 & 6529 & 2653 & 2625 & 4666 & 2963 & 3900 & 4481 & 4020 & 8982 \\
\hline 1954 & 6670 & 2651 & 2719 & 4433 & 3069 & 3795 & 4786 & 4027 & 9503 \\
\hline 1955 & 7014 & 2732 & 2834 & 4510 & 3088 & 4078 & 5038 & 4214 & 9878 \\
\hline 1956 & 7079 & 2514 & 2791 & 4489 & 3111 & 3815 & 5222 & 4289 & 10,300 \\
\hline 1957 & 7314 & 2379 & 2934 & 4838 & 3123 & 3988 & 5446 & 4380 & 11,355 \\
\hline 1958 & 7632 & 2382 & 3107 & 4983 & 3101 & 4318 & 5557 & 4276 & 11,082 \\
\hline 1959 & 7020 & 2322 & 3268 & 4586 & 3219 & 4307 & 5541 & 4182 & 11,286 \\
\hline 1960 & 7446 & 2368 & 3436 & 4845 & 3249 & 4502 & 5796 & 4629 & 10,890 \\
\hline 1961 & 7851 & 2363 & 3586 & 4954 & 3305 & 4513 & 5827 & 4899 & 10,162 \\
\hline 1962 & 7604 & 2438 & 3695 & 5066 & 3375 & 4616 & 5899 & 5114 & 10,226 \\
\hline 1963 & 7307 & 2536 & 3625 & 5264 & 3380 & 4839 & 6140 & 5198 & 10,312 \\
\hline 1964 & 7937 & 2597 & 3638 & 5263 & 3481 & 4909 & 6602 & 5402 & 10,795 \\
\hline 1965 & 8533 & 2662 & 3603 & 5193 & 3499 & 5183 & 6801 & 5603 & 11,110 \\
\hline 1966 & 8466 & 2787 & 3718 & 5655 & 3579 & 5402 & 7004 & 5906 & 10,925 \\
\hline 1967 & 8571 & 2892 & 3758 & 5725 & 3623 & 5551 & 7206 & 5972 & 11,201 \\
\hline 1968 & 8810 & 3064 & 3979 & 5818 & 3740 & 5798 & 7481 & 5746 & 11,571 \\
\hline 1969 & 9426 & 3124 & 4208 & 5923 & 3873 & 6005 & 7689 & 5732 & 11,586 \\
\hline 1970 & 9780 & 3208 & 4498 & 5936 & 4027 & 6223 & 7935 & 6009 & 12,048 \\
\hline 1971 & 10,086 & 3249 & 4824 & 6351 & 4157 & 6448 & 8018 & 6105 & 11,793 \\
\hline 1972 & 10,226 & 3332 & 5206 & 6159 & 4366 & 6827 & 8454 & 6126 & 11,566 \\
\hline 1973 & 10,664 & 3474 & 5710 & 5711 & 4554 & 7159 & 8914 & 6272 & 11,995 \\
\hline 1974 & 11,163 & 3564 & 6005 & 5664 & 4708 & 7344 & 9209 & 6422 & 11,862 \\
\hline 1975 & 10,879 & 3708 & 6162 & 4848 & 4712 & 7288 & 9476 & 6744 & 11,822 \\
\hline 1976 & 10,668 & 3902 & 6577 & 4932 & 4832 & 7470 & 9633 & 6658 & 12,338 \\
\hline 1977 & 11,123 & 3967 & 6718 & 5333 & 4936 & 7906 & 9724 & 6481 & 12,701 \\
\hline 1978 & 10,457 & 4001 & 6884 & 5685 & 5260 & 8074 & 10,278 & 6312 & 12,604 \\
\hline 1979 & 11,019 & 3908 & 7195 & 6064 & 5436 & 8222 & 10,963 & 6518 & 12,327 \\
\hline 1980 & 10,991 & 3791 & 7644 & 6445 & 5540 & 8141 & 11,611 & 6646 & 11,446 \\
\hline 1981 & 10,188 & 3754 & 7136 & 6731 & 5537 & 7760 & 12,339 & 6770 & 11,110 \\
\hline 1982 & 9705 & 3529 & 7008 & 5713 & 5469 & 7020 & 11,966 & 6621 & 10,562 \\
\hline 1983 & 9894 & 3315 & 6619 & 5458 & 5433 & 7012 & 11,183 & 5603 & 9873 \\
\hline 1984 & 9946 & 3293 & 6832 & 5685 & 5503 & 7347 & 11,321 & 5730 & 9735 \\
\hline 1985 & 9155 & 3214 & 7231 & 5707 & 5559 & 7195 & 11,379 & 5715 & 9620 \\
\hline 1986 & 9675 & 3057 & 7654 & 5931 & 5772 & 7371 & 10,718 & 6152 & 9849 \\
\hline 1987 & 9775 & 3079 & 7754 & 6218 & 5957 & 7510 & 10,688 & 6536 & 9940 \\
\hline 1988 & 9449 & 3131 & 7585 & 6558 & 6077 & 7561 & 10,601 & 5872 & 10,251 \\
\hline
\end{tabular}


(continued)

GDP per Capita, in 2013 EKS\$

\begin{tabular}{|c|c|c|c|c|c|c|c|c|c|}
\hline \multicolumn{10}{|c|}{ Latin America } \\
\hline & Argentina & Bolivia & Brazil & Chile & Colombia & $\begin{array}{l}\text { Costa } \\
\text { Rica }\end{array}$ & Mexico & Peru & Venezuela \\
\hline 1989 & 8733 & 3152 & 7687 & 7129 & 6150 & 7789 & 10,836 & 5046 & 9138 \\
\hline 1990 & 8616 & 3239 & 7240 & 7263 & 6280 & 7869 & 11,178 & 4690 & 9385 \\
\hline 1991 & 9315 & 3330 & 7192 & 7698 & 6299 & 7866 & 11,438 & 4721 & 10,056 \\
\hline 1992 & 9890 & 3305 & 7037 & 8490 & 6442 & 8382 & 11,635 & 4603 & 10,425 \\
\hline 1993 & 10,378 & 3368 & 7265 & 8929 & 6677 & 8760 & 11,645 & 4724 & 10,229 \\
\hline 1994 & 10,885 & 3446 & 7571 & 9283 & 6888 & 8915 & 11,948 & 5225 & 9783 \\
\hline 1995 & 10,442 & 3529 & 7770 & 10,110 & 7118 & 9013 & 11,025 & 5570 & 9970 \\
\hline 1996 & 10,861 & 3605 & 7818 & 10,700 & 7154 & 8858 & 11,407 & 5611 & 9764 \\
\hline 1997 & 11,565 & 3705 & 7963 & 11,245 & 7296 & 9122 & 11,989 & 5897 & 10,199 \\
\hline 1998 & 11,932 & 3810 & 7849 & 11,449 & 7239 & 9652 & 12,407 & 5768 & 10,054 \\
\hline 1999 & 11,448 & 3747 & 7755 & 11,213 & 6857 & 10,208 & 12,705 & 5737 & 9300 \\
\hline 2000 & 11,264 & 3761 & 7938 & 11,574 & 6995 & 10,172 & 13,364 & 5826 & 9493 \\
\hline 2001 & 10,681 & 3746 & 7939 & 11,830 & 7040 & 10,090 & 13,186 & 5761 & 9671 \\
\hline 2002 & 9451 & 3760 & 8076 & 11,958 & 7127 & 10,215 & 13,128 & 5973 & 8688 \\
\hline 2003 & 10,108 & 3784 & 8070 & 12,299 & 7306 & 10,702 & 13,151 & 6138 & 7898 \\
\hline 2004 & 10,732 & 3864 & 8417 & 12,916 & 7588 & 10,989 & 13,525 & 6367 & 9208 \\
\hline 2005 & 11,508 & 3956 & 8564 & 13,505 & 7837 & 11,465 & 13,804 & 6724 & 10,012 \\
\hline 2006 & 12,272 & 4066 & 8779 & 13,993 & 8251 & 12,293 & 14,334 & 7165 & 10,840 \\
\hline 2007 & 13,105 & 4172 & 9191 & 14,499 & 8706 & 13,080 & 14,646 & 7716 & 11,616 \\
\hline 2008 & 13,432 & 4348 & 9530 & 14,886 & 8901 & 13,247 & 14,655 & 8380 & 12,048 \\
\hline 2009 & 12,861 & 4414 & 9405 & 14,589 & 8937 & 12,931 & 13,620 & 8368 & 11,488 \\
\hline 2010 & 13,787 & 4517 & 9958 & 15,284 & 9181 & 13,388 & 14,185 & 9009 & 11,147 \\
\hline 2011 & 14,397 & 4670 & 10,139 & 16,030 & 9677 & 13,797 & 14,578 & 9534 & 11,440 \\
\hline 2012 & 14,467 & 4830 & 10,139 & 16,769 & 9950 & 14,318 & 14,965 & 10,032 & 11,896 \\
\hline 2013 & 14,683 & 5007 & 10,254 & 17,437 & 10,206 & 14,631 & 15,027 & 10,468 & 11,841 \\
\hline
\end{tabular}

Source: The Conference Board Total Economy Database ${ }^{\mathrm{TM}}$, January 2014, http://www.conferenceboard.org/data/economydatabase/

Open Access This chapter is distributed under the terms of the Creative Commons Attribution 4.0 International License (http://creativecommons.org/licenses/by/4.0/), which permits use, duplication, adaptation, distribution and reproduction in any medium or format, as long as you give appropriate credit to the original author(s) and the source, a link is provided to the Creative Commons license and indicate if changes were made.

The images or other third party material in this chapter are included in the work's Creative Commons license, unless indicated otherwise in the credit line; if such material is not included in the work's Creative Commons license and the respective action is not permitted by statutory regulation, users will need to obtain permission from the license holder to duplicate, adapt or reproduce the material.

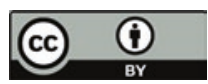




\section{References}

Adler, G., \& Magud, N. E. (2013). Four decades of terms-of-trade booms: Saving-investment patterns and a new metric of income windfall. IMF Working Paper 13/103.

Anríquez, G., \& López, R. (2007). Agricultural growth and poverty in an archetypical middle income country: Chile 1987-2003. Agricultural Economics, 36, 191-202.

Anríquez, G., \& Bonomi, G. (2007). Long-term farming trends. An inquiry using agricultural censuses (No. 07-20).

Astorga, P. (2014, December 3-5). Functional inequality in Latin America: 1900-2011. Paper presented at the regional conference: Latin American inequality in the long run, Buenos Aires.

Baer, W. (1972). Import substitution and industrialization in Latin America: Experiences and interpretations. Latin American Research Review, 7(1), 95-122.

Bauer, A. J. (1975). Chilean rural society: From the Spanish conquest to 1930 (Cambridge Latin American studies). Cambridge: Cambridge University Press.

Bertola, L., \& Ocampo, J. A. (2012). The economic development of Latin America since independence. Oxford: Oxford University Press.

Bertola, L., Castelnovo, C., Rodríguez, J., \& Willebald, H. (2008). Income distribution in the Latin American Southern Cone during the first globalization boom, ca: 1870-1920.

Borras, S. M., Jr., Franco, J. C., Gómez, S., Kay, C., \& Spoor, M. (2012). Land grabbing in Latin America and the Caribbean. Journal of Peasant Studies, 39(3-4), 845-872.

Bulmer-Thomas, V. (1994). The economic history of Latin America since independence (Vol. 77). Cambridge: Cambridge University Press.

Bulmer-Thomas, V. (2005). Globalization and the new economic model in Latin America. In V. Bulmer-Thomas, J. H. Coatsworth, \& R. Cortés Conde (Eds.), The Cambridge economic history of Latin America volume 2: The long twentieth century. New York: Cambridge University Press.

Campos-Vazquez, R. M., Domínguez-Flores, C., \& Márquez, G. (2014, December 3-5). Long-run human development in Mexico: 1895-2010. Paper presented at the regional conference: Latin American inequality in the long run, Buenos Aires.

Chenery, H. B., \& Syrquin, M. (1975). Patterns of development, 1950-1970. London: Oxford University Press.

Cornia, G. A. (2012). Inequality trends and their determinants: Latin America over 1990-2010 (No. 2012/09). WIDER Working Paper.

Da Silva, J. G., Gómez, S., \& Castañeda, R. (2010). Boom agrícola y persistencia de la pobreza rural en América Latina. Algunas reflexiones. Revista Austral de Ciencias Sociales, 18, 5-20.

David, M. B. D. A., Dirven, M., \& Vogelgesang, F. (2000). The impact of the new economic model on Latin America's agriculture. World Development, 28(9), 1673-1688.

De Janvry, A., \& Sadoulet, E. (2009). Agricultural growth and poverty reduction: Additional evidence. The World Bank Research Observer, 25(1), 1-20.

Eastwood, R., \& Lipton, M. (2004). Rural and urban income inequality and poverty: Does convergence between sectors offset divergence within them? Inequality, Growth, and Poverty in an Era of Liberalization and Globalization, 4, 112-141.

Economic Commission for Latin America and the Caribbean (ECLAC). (2012). Structural change for equality -An integrated approach to development, 2012 (LC/G.2524(SES.34/3)), Santiago, Chile.

Economic Commission for Latin America and the Caribbean (ECLAC). (2014). Social Panorama of Latin America, 2014 (LC/G.2635-P), Santiago, Chile.

Engerman, S. L., \& Sokoloff, K. L. (1997). Factor endowments, institutions, and differential paths of growth among new world economies. In S. Haber (Ed.), How Latin America fell behind (pp. 260-304). Stanford: Stanford University Press.

Food and Agriculture Organization (FAO). (2014). Statistical yearbook: Latin America and the Caribbean food and agriculture, 2014 (ISSN 2311-2824), Santiago, Chile.

Frankema, E. (2009). Has Latin America always been unequal? A comparative study of asset and income inequality in the long twentieth century (Vol. 3). Leiden: Brill. 
Gasparini, L., Cruces, G., Tornarolli, L., \& Mejía, D. (2011a). Recent trends in income inequality in Latin America [with comments]. Economia, 11(2), 147-201.

Gasparini, L., Galiani, S., Cruces, G., \& Acosta, P. (2011a). Educational upgrading and returns to skills in Latin America: Evidence from a supply-demand framework, 1990-2010. World Bank Policy Research Working Paper (5921).

Goñi, E., López, J. H., \& Servén, L. (2008). Fiscal redistribution and income inequality in Latin America (Vol. 4487). Washington, DC: World Bank Publications.

Griffin, K., Kahn, R., \& Ickowitz, A. (2002). Poverty and the distribution of land. Journal of Agrarian Change, 2(3), 279-330.

Haggblade, S., Hazell, P., \& Reardon, T. (2010). The rural non-farm economy: Prospects for growth and poverty reduction. World Development, 38(10), 1429-1441.

Johnston, B. F., \& Mellor, J. W. (1961). The role of agriculture in economic development. The American Economic Review, 51, 566-593.

Johnston, B. F., \& Kilby, P. (1975). Agriculture and structural transformation-Economic strategies in late-developing countries. New York: Oxford University Press.

Kanbur, R. (2011, September). Does Kuznets still matter? Cornell University (Festschrift in honour of Montek Ahluwalia).

Kay, C. (2001). Asia's and Latin America's development in comparative perspective: Landlords, peasants and industrialization. No. 336, Institute of Social Studies Working Paper Series.

Kay, C. (2002). Why East Asia overtook Latin America: Agrarian reform, industrialisation and development. Third World Quarterly, 23(6), 1073-1102.

Kuznets, S. (1965). Economic growth and structure-Selected essays. New York: W.W. Norton \& Company.

Kuznets, S. (1955). Economic growth and income inequality. American Economic Review, 49(1), $1-28$.

Kuznets, S. S. (1966). Modern economic growth: Rate, structure, and spread. New Haven: Yale University Press.

Lipton, M. (1977). Why poor people stay poor: Urban bias in world development. Cambridge, MA: Harvard University Press.

Lustig, N., Lopez-Calva, L. F., \& Ortiz-Juarez, E. (2013). Declining inequality in Latin America in the 2000s: The cases of Argentina, Brazil, and Mexico. World Development, 44, 129-141.

Lustig, N., Lopez-Calva, L. F., \& Ortiz-Juarez, E. (2011, April 24). The decline in inequality in Latin America: How much, since when and why. Since when and why.

Ocampo, J. A., Rada, C., \& Taylor, L. (2009). Growth and policy in developing countries: A structuralist approach. New York: Columbia University Press.

Ravallion, M., \& Chen, S. (2007). China's (uneven) progress against poverty. Journal of Development Economics, 82(1), 1-42.

Reardon, T., Berdegué, J., \& Escobar, G. (2001). Rural nonfarm employment and incomes in Latin America: Overview and policy implications. World Development, 29(3), 395-409.

Reis, E. (2014, December 3-5). Historical perspectives on regional income inequality in Brazil, 1872-2000. Paper presented at the regional conference: Latin American inequality in the long run, Buenos Aires.

Reynolds, L. (1975). Agriculture in development theory. New Haven: Yale University Press.

Reynolds, L. (1996). Some sources of income inequality in Latin America. Journal of InterAmerican Studies and World Affairs, 38(2/3), 39-46.

Rodriquez Weber, J. E. (2014, December 3-5). Income inequality in Chile since 1850. Paper presented at the regional conference: Latin American inequality in the long run, Buenos Aires.

Roncolato, L., \& Kucera, D. (2013). Structural drivers of productivity and employment growth: A decomposition analysis for 81 countries. Cambridge Journal of Economics, 38(2), 399-424.

Sachs, J. D., \& Warner, A. M. (1999). The big push, natural resource booms and growth. Journal of Development Economics, 59(1), 43-76.

Solbrig, O. T. (2006). Structure, performance, and policy in agriculture. In V. Bulmer-Thoma, J. H. Coatsworth, \& R. Cortés Conde (Eds.), The Cambridge economic history of Latin AmericaThe long twentieth century. New York: Cambridge University Press. 
Solt, F. (2014, October). The standardized world income inequality database. Working Paper. SWIID Version 5.0.

Syrquin, M. (2006). Structural transformation. In D. A. Clark (Ed.), The Elgar companion to development studies (pp. 601-607). Cheltenham: Edward Elgar.

Timmer, C. P. (2007, October 30). The structural transformation and the changing role of agriculture in economic development: Empirics and implications. Wendt Lecture. Washington, DC: American Enterprise Institute.

Timmer, C. P. (1988). The agricultural transformation. In H. Chenery \& T. N. Srinivasan (Eds.), Handbook of development economics (Vol. 1). Amsterdam: North Holland.

Timmer, C. P. (2004). The road to pro-poor growth: The Indonesian experience in regional perspective. Bulletin of Indonesian Economic Studies, 40(2), 177-207.

Timmer, C. P., \& Akkus, S. (2008). The structural transformation as a pathway out of poverty: Analytics, empirics and politics. WP 150, Center for Global Development.

Tsounta, E., \& Osueke, A. I. (2014). What is behind Latin America's declining income inequality? IMF WP: 124.

Urioste, M. (2011). Dinámica del Mercado de la tierra en América Latina ey el Caribe: El caso de Bolivia. Santiago: FAO. Retrieved from http://www.rlc.fao.org/fileadmin/content/events/semtierras/acaparamiento.pdf.

Williamson, J. G. (2010a, January). Latin American growth-inequality trade-offs: The impact of insurgence and independence. NBER Working Paper Series, WP 15680. Cambridge, USA.

Williamson, J. G. (2010b). Five centuries of Latin American income inequality. Revista de Historia Económica/Journal of Iberian and Latin American Economic History (Second Series), 28(02), 227-252.

Williamson, J. G. (1999). Real wage inequality and globalization in Latin America before 1940. Revista de Historia Económica XVII/Journal of Iberian and Latin American Economic History, 17, 101-142.

World Bank. (2008). World development report: Agriculture for development, 2008. Washington, DC: World Bank. eISBN-13: 978-0-8213-6809-1.

World Bank. (2012). The labor market story behind Latin America's transformation. Washington, DC: World Bank.

World Bank. (online). Retrieved March 15, 2015, from http://povertydata.worldbank.org/poverty/ region/LAC.

Martin Andersson is an Associate Professor in Economic History at Lund University. His research interests include agricultural, structural, and institutional change and the relation between economic growth, poverty reduction, and distribution of income in the developing world. He has published several books and journal articles on economic development in a variety of geographical settings, including Diverse Development Paths and Structural Transformation in the Escape from Poverty (Oxford UP 2016 with T. Axelsson). He has worked as a consultant for the World Bank and the African Center for Economic Transformation (ACET) and is a member of the Global Research Consortium on Economic Structural Transformation (GReCEST). He has been a Marie Curie postdoc at EUI in Florence and a visiting scholar at UC Berkeley and the University of Queensland.

Andrés Palacio is a Senior Lecturer in Economic History at Lund University and research fellow at the Department of Finance, Government and International Affairs at the Externado de Colombia University in Bogotá. His research interests include social demography and health, long-term growth, structural change and institutions, and impacts of climate change on the developing world. He worked as a Deputy Minister of Labor Affairs of the Colombian Government and financial analyst in the private sector for several years. 


\title{
Fiscal Policy and Inequality in Latin America, 1960-2012
}

\author{
Judith Clifton, Daniel Díaz-Fuentes, and Julio Revuelta
}

\section{Introduction}

Latin America is a region which has been plagued with persistent problems of social cohesion linked to inequality (Bértola and Ocampo 2012; Fitzgerald et al. 2011; Huber et al. 2006; Milanovic and Muñoz de Bustillo 2008; Williamson 2010). Over the long term, the excessive degree of inequality in Latin America was considered an anomaly in international comparisons (Deininger and Squire 1996, 1998). However, over the last two decades, income inequality actually decreased across most countries in the region, though it still remains above the world average (ECLAC 2010; Cornia 2012). With this, Latin America has emerged as a positive anomaly, going against the grain of recent world trends which are heading towards greater inequality (Hvistendahl 2014, Ravallion 2014).

This historical shift in inequality in Latin America has attracted considerable research aiming to uncover the causes of this change (De la Torre 2014; Salazar 2014; Székely 2014). Contributing to this recent literature, this chapter provides new knowledge about the role of fiscal policy on income redistribution in the Latin American context. The role of fiscal policy on income distribution has been at the heart of some of the most controversial economic and political discussions surrounding the history of economic policy (Bastagli et al. 2012; Lindert 2004; Piketty 2014). Today, the role of fiscal policy on income distribution remains highly pertinent, given the distinct positions scholars have taken about its effectiveness as a tool of redistribution in the Latin American context (Arroyo Abad and Lindert 2014; Bastagli et al. 2012; Bárcena and Kacef 2011; Goñi et al. 2011).

We use the available historical data on 18 Latin American countries for the time period 1960-2012 to investigate the impact of public spending and public revenues

J. Clifton $(\varangle) \bullet$ D. Díaz-Fuentes $\bullet J$. Revuelta

University of Cantabria and Cornell University, Cantabria, Spain 
on income inequality, using the Gini index. While previous studies examined the impact of fiscal policy on inequality using data from 1990 onwards — often using a smaller number of countries - our aim is to contribute to the literature by extending the time period to the longest possible due to data restrictions while increasing the number of countries under study to the maximum, 18. Given the turn in fiscal policy from Washington Consensus-style approaches to more progressive ones (Hausmann 1997), and differences in the methodology used to produce the data, we split the time period into two subperiods, 1960-1998 and 1999-2012. Another novelty of this chapter is that we analyze results at the national and urban levels for this second subperiod, which is of interest given the high degree of urbanization in Latin America. We apply several econometric methods, specifications, and definitions of variables, based on fixed and random effects and panel-corrected standard errors. We test the direction and magnitude of the historical effect that fiscal policy has had on income distribution for the period. We examine both the impact of aggregate public spending and public revenues and the main functional categories of spending and taxation.

The rest of the chapter is divided into four sections. In Sect. 2, we present a brief literature review of income inequality and fiscal policy in the Latin American context. In Sect. 3, we present the data and methodology. In Sect. 4, we set out the results of our analysis, at both the general Latin American and specific national levels. Section 5, concludes by presenting the main findings and their implications in terms of fiscal policy.

\section{Inequality and Fiscal Policy in Twentieth-Century Latin America: A Background}

In this section we firstly highlight the main contributions on income inequality, highlighting those with particular relevance for the Latin American context. We then turn to analyze the literature on the importance of fiscal policy for inequality in Latin America, and then set out our approach in this chapter in the context of this most recent literature.

\subsection{Income Inequality in Latin America: A Contemporary Debate}

Economic inequality defines in general the differences among individuals or groups in a given population - which may be regional, national, or international-as regards wealth, resources, income, or opportunities (World Bank 2006). The concern about economic inequality in capitalist development was a central issue for the classical political economists from Adam Smith to John Stuart Mill. In contrast, economic inequality within and among countries became a secondary concern for 
neoclassical economists from the last quarter of nineteenth century onwards. As regards income inequality in particular, one of the most influential exceptions was Kuznets $(1953$, 1955), whose studies gave support to the "inverted-U Kuznets hypothesis." This hypothesis predicted a pattern of increasing income inequality in the early stages of economic growth, while it also predicted that at higher levels of economic growth, inequality would decrease. In general, from the 1950s to the 1990s, the literature on inequality and development was divided on the validity of the Kuznets hypothesis. Much of the earlier literature supported the Kuznets hypothesis (Milanovic 1994; Higgins and Williamson 1999; Barro 2000). However, more recently, scholarship identified limits to the general validity of the hypothesis (Deininger and Squire 1996, 1998; Atkinson 1997; Bértola 2005). In any case, until the 1990s, the main problem characterizing most of the attempts to verify or otherwise test the hypothesis was associated with the attempts to identify temporal relations by means of cross-country data. A key contribution was Deininger and Squire (1996), which overcame this problem through the use of panel data and regional dummies. By introducing Latin American countries as a dummy, their results showed that the inverted-U Kuznets hypothesis vanished. In other words, the authors demonstrated that the cross-sectional results of previous works that had supported the Kuznets hypothesis had been biased by the relatively high level of inequality of the group of middle-income Latin American countries.

So, the high levels of inequality in Latin American have been considered an anomaly in the international patterns of income distribution. Indeed, the reduction of inequality in Latin America over the last few decades, along with the shift of some countries from low- to middle-income levels and increasing inequality levels among the higher income countries, has significantly flattened the Kuznets curve in the world economy. Despite this, with or without empirical evidence for the Kuznets hypothesis, many economists and politicians believed that increasing inequality was a necessary condition for economic growth at the earlier stages of development. Hence, policy efforts to reduce inequality were held to impede or reduce economic growth (Ravallion 2014). This assumption was reinforced by argument of the so-called big trade-off between equality and efficiency as predicted by Okun (1975). He claimed that all "societies inevitably face an invidious choice between efficient production and equitable wealth and income distribution." Moreover, he stated that "Not only more equal distribution of incomes reduce incentives to work and invest, but the effort to redistribute." " Okun's assumption has been influential in providing reasons to avoid income redistribution through fiscal policy.

Latin America constitutes a middle-income region with well-known problems of development and social cohesion linked to long-term inequality as regards wealth, income, and opportunities (Bértola and Ocampo 2012; Milanovic and Muñoz de Bustillo 2008; Huber et al. 2006; Sánchez-Ancochea 2014; Williamson 2010). As Fig. 1 shows, from the first decade of the 2000s, income inequality actually decreased across most countries in the region, though inequality in Latin America is

\footnotetext{
${ }^{1}$ This apparent trade-off between efficiency and equality has been recently challenged by IMF researchers (Berg and Ostry 2011; Ostry et al. 2014).
} 


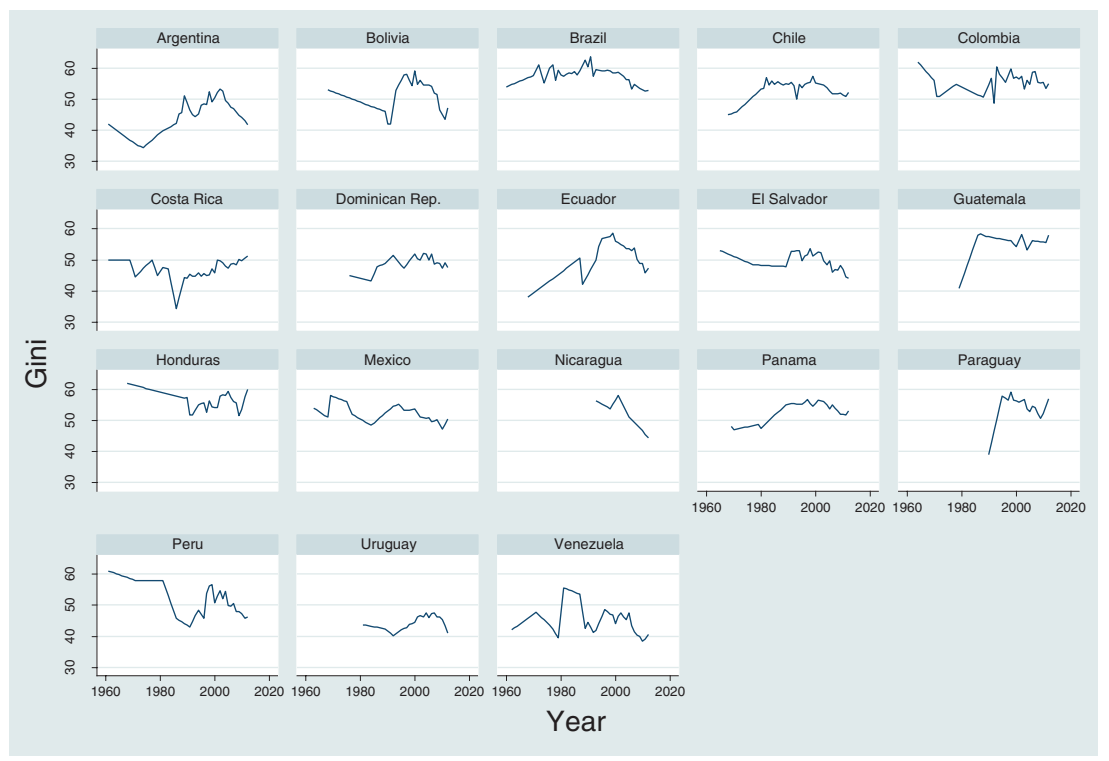

Fig. 1 Gini coefficient in Latin America, 1960-2012. Source: Elaborated by authors using data from Milanovic (2014)

still above the world average (ECLAC 2010, 2014; Cornia 2012; Salazar 2014). Indeed, Latin America now represents a positive anomaly at the international level, since the reduction in income inequality goes against the grain of recent trends in the rest of the world, which are heading towards greater inequality (Hvistendahl 2014; Ravallion 2014).

As renewed attention around issues of inequality preoccupies scholars of social science, the humanities, and even science ${ }^{2}$ in the contemporary period, a central question is to explain why inequality is decreasing in Latin America, after decades of persistent inequality while, in the rest of the world, inequality is again on the rise (Atkinson and Piketty 2010; Milanovic 2013; OECD 2008; Piketty 2014; Piketty and Saez 2014).

A significant number of scholars have been attracted to the task of identifying the major political and economic determinants of the historical shift in income inequality in Latin America since the 2000s (Anderson and Palacio 2014; Astorga 2014; Cornia 2012, 2014a, b; González and Martner 2012; Lustig et al. 2013; McLeod and Lustig 2011; Tsounta and Osueke 2014; De la Torre 2014). Regarding the possible political determinants, scholars have studied in particular the effects of democracy and progressive government on reducing inequality (McLeod and Lustig 2011; Milanovic and Muñoz de Bustillo 2008; Montecino 2011). Other scholarly works

\footnotetext{
${ }^{2}$ See, for example, how inequality has become a key international issue among scientists, as summarized in a special issue of American Association of Advancement of Science (Chin and Culotta 2014).
} 
have focused on institutional factors such as human capital and labor market failures (Lustig et al. 2013; Tsounta and Osueke 2014; Irigoin and Giardili 2014). Finally, scholars have investigated the extent to which economic factors have determined reduced inequality, including foreign trade and foreign direct investment (Székely and Sámano-Robles 2014; Tsounta and Osueke 2014). However, much less attention has been paid to the role of fiscal policy as regards this historical shift in Latin America, and it is to this we now turn.

\subsection{Fiscal Policy and Income Distribution in Latin America}

The role of fiscal policy in income distribution has been at the heart of some of the most controversial economic and political discussions throughout history (Comín and Díaz-Fuentes 2005; Bastagli et al. 2012; Lindert 2004; Piketty 2014). This question has also been examined in the Latin American context (Arroyo Abad and Lindert 2014). The question is a highly pertinent one for Latin America today. Fiscal policy has been held to be an important tool of redistribution in the Latin American context (Bárcena and Kacef 2011; González and Martner 2012; Goñi et al. 2011). Bastagli et al. (2012) demonstrated that, even in the context of a worldwide trend towards increased inequality, fiscal policy mattered. This is because the level of available income before and after fiscal policy (tax and transfer) shows a wide difference among countries due to tax incidence, tax progressivity, and social spending policies.

Despite this debate on fiscal policy and income distribution, there is a lack of empirical work which identifies the variables of public spending and revenue that affect income distribution in Latin America. Among the existing studies that consider fiscal policy and income distribution, Goñi et al. (2011) described the performance of tax and transfers on income distribution in six Latin American countries in comparison to Western Europe at the beginning of the 2000s. This study concluded that the fiscal system proved weak as regards reducing income inequality in Latin America. Gómez Sabaini and Martner (2008) compared the Gini indices before and after taxes in a broad sample of Latin American countries. They found that fiscal policy was slightly more effective than the Goñi et al. (2011) study, but this finding was not significant until around 2005. More recently, Cornia (2012) concluded that tax, social spending, and other institutional variables were significant factors as regards income distribution in Latin America. In a further study, Cornia et al. (2014) updated and confirmed their results, that is, that taxation had progressive effects on income distribution.

More specifically, two recent contributions sought to identify the effects of taxation and public spending on income distribution for most Latin American countries from the 1990s onwards. Working from the United Nations-Economic Commission for Latin America and the Caribbean (ECLAC), González and Martner (2012) identified a positive role of fiscal policy on income distribution, in particular social spending, education, public investment, and a progressive tax system, in addition to other institutional and macroeconomic variables. From the International Monetary 
Fund (IMF), Tsounta and Osueke (2014) found that government policies could explain more than a half of the reduction in income inequality in Latin American countries in the first decade of the 2000s, while education spending and tax revenues were the most significant identified variables of income redistribution.

Our study builds on this literature by analyzing the effects of fiscal policies on income distribution for different periods and 18 Latin American countries. We test whether public spending and public revenues and its main components determined income distribution for the subperiods 1960-1998 and 1999-2012. As regards public revenues, we enquire whether the public revenue incidence had a significant effect on income distribution and whether each tax category had different effects on income distribution. It is generally assumed in the literature that typical direct taxes, such as personal income taxes, are more progressive in redistributive terms than indirect taxes, such as taxes on goods and services. However, given that there are other categories of direct and indirect taxes that affect income distribution, we have also considered the effects of property taxes and social contributions. Thus our derived questions are these: Which categories of taxes had more effect on income distribution? Did the progressiveness of the tax structure determine income distribution? It is important to state that we have not considered other variables of fiscal efficiency such as tax compliance, tax evasion, or horizontal exemptions which may also feasibly affect income distribution.

In addition, we enquired whether public spending had a significant effect on income inequality. Given that spending categories could have different progressive or regressive effects on income distribution, we examined the effects of different categories of public spending, including education, health, social security, and housing on income distribution. Our approach, therefore, to assessing public spending goes beyond examining only education, which is the category most commonly dealt with by scholars, and broadens the study to items that typically receive much less attention: health, social security, and housing, which may well have a significant effect.

As regards the evolution of public spending and public revenues in Latin America, as seen in Fig. 2, we observe a great heterogeneity in national fiscal policies. In some countries, such as Brazil and Ecuador, fiscal policy has assumed a great direct relevance while, in others, the public sector has played a more passive role, as in the cases of Guatemala and Paraguay. However, we can also note some common elements associated with the region as a whole, namely, the growth of both public spending and public revenues (Díaz-Fuentes and Revuelta 2011). Despite these increases, these variables still have less weight as a percentage of GDP in Latin America than do they in the average of OECD countries (ECLAC 2014; OECD 2015). In addition, there are significant differences between Latin American countries and OECD members in terms of tax. Broadly speaking, in Latin America there is a bias towards indirect taxation while tax systems in OECD countries are biased towards direct taxes (ECLAC 2014; OECD 2015). Another important difference is that fiscal policies in Latin America are in general much less progressive as regards their capacity to redistribute than those in OECD countries (Amarante 2014). 


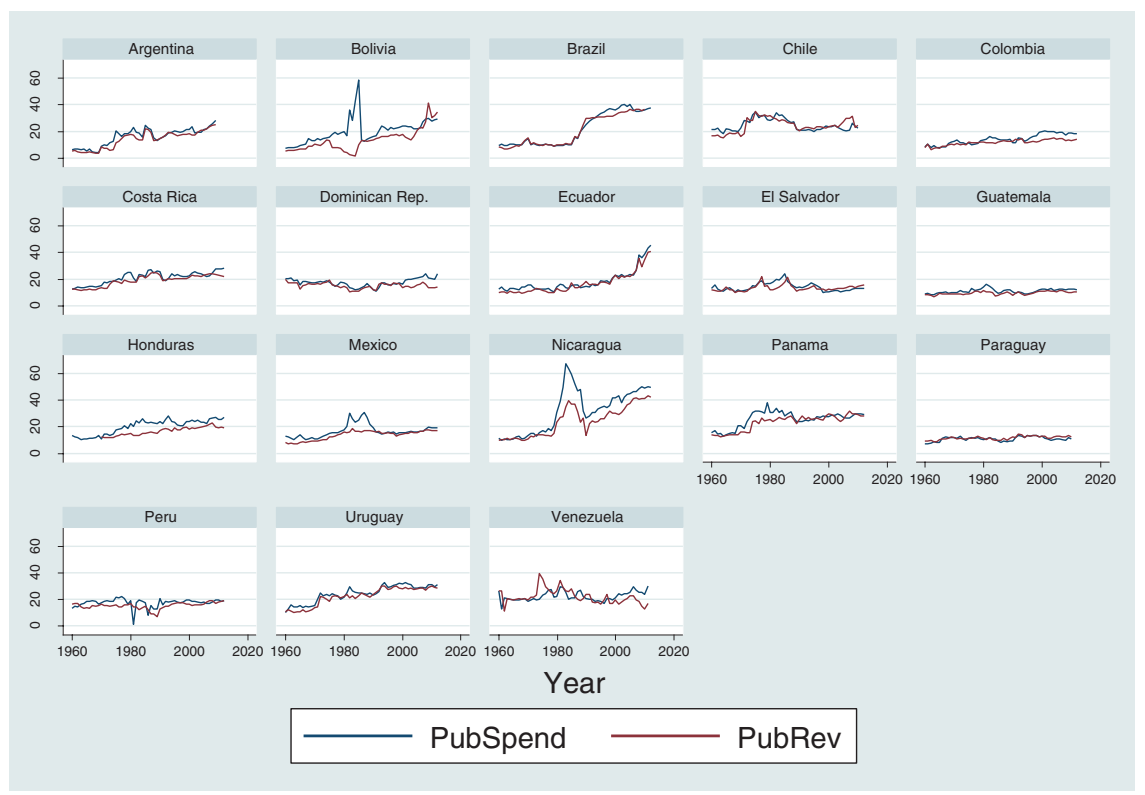

Fig. 2 Public spending and public revenues in Latin America, 1960-2012. Source: Elaborated by authors using data from ECLAC (2014) and MOxLAD (2014)

\section{Data and Methodology}

In order to empirically analyze the impact of fiscal policy on inequality in Latin America we first describe the variables used to measure inequality and fiscal policy, as well as the control variables. These are set out in Table 1. To measure income inequality we use the Gini index. The Gini index is the most common indicator used by scholars when analyzing income inequality from the 1960s across Latin America (and other regions) for extended periods. Since the aim of this chapter is to conduct a historical analysis including the greatest possible time period, the Gini index suits our study well.

Given the different sources for the estimation of the Gini index along time, we follow the approach as found in Milanovic (2014). This approach reduces the problem of temporal and international comparability through the compilation and standardization of a wide series of Gini coefficients based on household surveys from $1950,{ }^{3}$ and thus avoids the use of other sources produced by regressions or shortcuts. These remain today the best Gini indices available for international comparison over the long term. However, despite the fact that issues around comparability have been reduced, it is still desirable to use other estimations of the Gini index from more recent years which are derived from more homogeneous sources.

\footnotetext{
${ }^{3}$ In the case of Latin America, the Milanovic Gini index begins in the 1960s.
} 
Table 1 Variable descriptions and data sources

\begin{tabular}{|c|c|c|}
\hline Variable & Source & Description \\
\hline Gini & Milanovic (2014) & Standardized Gini index \\
\hline Gininat & ECLAC (2014) & National Gini index \\
\hline Giniurb & ECLAC (2014) & Urban Gini index \\
\hline PubSpe & $\begin{array}{l}\text { ECLAC (2014), } \\
\text { MoXLAD (2014) }\end{array}$ & Total public spending (\% GDP) \\
\hline PubSpeEdu & $\begin{array}{l}\text { ECLAC (2014), } \\
\text { MoXLAD (2014) }\end{array}$ & Public spending on education ( $\%$ GDP) \\
\hline PubSpeHea & ECLAC (2014) & Public spending on health (\% GDP) \\
\hline PubSpeSocSec & ECLAC (2014) & Public spending on social security (\% GDP) \\
\hline PubSpeHou & ECLAC (2014) & Public spending on housing (\% GDP) \\
\hline PubRev & $\begin{array}{l}\text { ECLAC (2014), } \\
\text { MoXLAD (2014) }\end{array}$ & Total public revenues (\% GDP) \\
\hline PubIncTax & $\begin{array}{l}\text { ECLAC (2014), } \\
\text { MoXLAD (2014) }\end{array}$ & Personal income taxes (\% GDP) \\
\hline PubPropTax & ECLAC (2014) & Property taxes (\% GDP) \\
\hline PubTaxG\&S & ECLAC (2014) & Indirect taxes on goods and services (\% GDP) \\
\hline SocCont & ECLAC (2014) & Social contributions (\% GDP) \\
\hline GDPpc & World Bank (2014) & GDP per capita \\
\hline Unemp & World Bank (2014) & Unemployment rate (\%) \\
\hline Depend & World Bank (2014) & Dependency rate; Pop. 65 and over/Pop. 15-64 (\%) \\
\hline Pop & World Bank (2014) & Total population \\
\hline Open & World Bank (2014) & Openness: (Exports + imports)/GDP (\%) \\
\hline ToT & World Bank (2014) & Terms of trade \\
\hline Invest & $\begin{array}{l}\text { World Bank (2014), } \\
\text { MoXLAD (2014) }\end{array}$ & Investment (\% GDP) \\
\hline Inf & World Bank (2014) & Annual variation of GDP deflator (\%) \\
\hline Dem & Marshall et al. (2014) & Institutionalized democracy \\
\hline NatRes & World Bank (2014) & Natural resource rents (\% GDP) \\
\hline
\end{tabular}

In the case of Latin America, the ECLAC has provided data on the Gini index since 1990. ${ }^{4}$ As this is the higher quality of the two datasets and since the turn of fiscal policy from Washington Consensus inspired approaches to more progressive ones (Hausmann 1997), we divided the sample of our analysis into two subperiods: 1960-1998, using the Milanovic Gini standardizations, and 1999-2012, using the

\footnotetext{
${ }^{4}$ An alternative source to ECLAC (2014) is SEDLAC (2014). However, given the differences between the values of the Gini coefficients of both sources, we opt to use the ECLAC data as it corrects for income underreporting. According to Montecino (2011) "the key difference between data from SEDLAC and ECLAC is that the latter corrects for income underreporting-when households in an income survey underreport their true amount of income, thus biasing the measurement of inequality - while the former does not. Because income underreporting is likely more pronounced in wealthier households, failing to adjust for underreporting is expected to lead to a lower and biased estimate of inequality."
} 
ECLAC (2014) Gini index. In this second subperiod, use of ECLAC data allows for the separation of inequality across the nation as a whole (Gininat) and also inequality in cities (Giniurb). We acknowledge that the Gini coefficient has some limitations (Atkinson 1997), not least, because it is an index of relative concentration which provides synthetic information on the income distribution in a single coefficient. For example, the Gini index has been criticized on the grounds it fails to capture issues related to income polarization, at the top and bottom income levels. In addition, it does not capture all kinds of incomes, such as those related to income from capital. Despite these shortcomings, the advantages of using the Gini index as regards its availability, information, and simplicity outweigh the disadvantages. In addition, using the Gini index facilitates a longer term comparison, although we need to exercise caution as regards potential biases when interpreting results.

Turning to the dimension of fiscal policy, we consider its two principal variables, public spending (PubSpe) and public income or revenue (PubRev). We use both variables at the aggregate level as well as at the functional level, that is, social spending related to income redistribution, on the one hand, and to tax structure, on the other. Thus, public social spending is disaggregated into public spending on education (PubSpeEdu), health (PubSpeHea), social security (PubSpeSocSec), and housing (PubSpeHou). As regards revenues, we consider social contributions (SocCont), as well as the main components of the tax structure. These are income (PubIncTax), property (PubPropTax), and goods and services (PubTaxG\&S). For the subperiod 1999-2012, we have data on all these variables, whereas for the subperiod 1960-1998, less disaggregated data on spending and income is available.

Finally, we use a series of control variables that have been identified as potential determinants of inequality, income distribution, and wealth in the theoretical and empirical literature. Thus, we consider the logarithm of GDP per capita (lnGDPpc), as considered by González and Martner (2012), Huber et al. (2006), Milanovic (1994), McLeod and Lustig (2011), Roine et al. (2009), Tsounta and Osueke (2014), and Williamson (2010); unemployment rate (Unemp) as used in González and Martner (2012); dependency rate (Depend) as deployed in Cornia (2012) and Lee et al. (2013); logarithm of population (lnPop) as used by Roine et al. (2009); trade openness (Open) as used in Lee et al. (2013) and Roine et al. (2009); terms of international trade (ToT) by Cornia (2012), Montecino (2011), and McLeod and Lustig (2011); investments (Invest) as found in Lee et al. (2013); inflation (Inf) as used in González and Martner (2012), Montecino (2011), and McLeod and Lustig (2011); democratic institutions (Dem) as used in Cornia (2012) and Huber et al. (2006); and natural resource rents (NatRes) as utilized in Loayza et al. (2013).

To test the adequate use of these variables we estimated the correlation coefficients among them, and did not detect serious correlation problems that would impede their use, as shown in Table 2. Other variables were considered, such as life expectancy or secondary enrollment rate. However, when estimating the correlations with the rest of the variables of the sample we observed problems of high correlation that could bias the estimations and invalidate them as control variables.

As regards the appropriate methodology to analyze the impact of fiscal policy on inequality, a review of the literature on inequality shows that most authors use OLS 


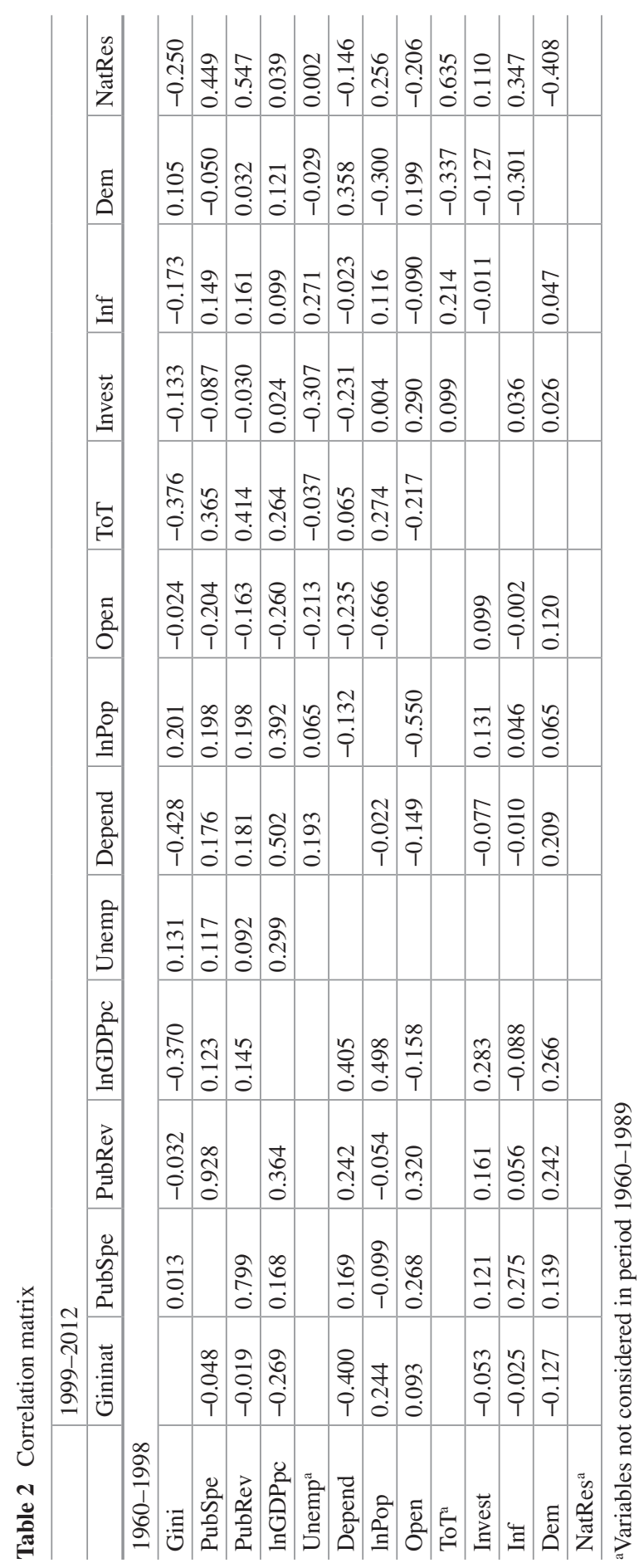


regression in order to analyze potential determinants of inequality (González and Martner 2012; Lee et al. 2013; Milanovic 1994; Williamson 2010). In our case, since we are using an unbalanced panel, which includes a sample of 18 countries and 39 or 14 temporal periods, depending on the subperiod under analysis (1960 1998 or 1999-2012), the use of OLS could produce bias in the results. We therefore opt to estimate a series of models which have diverse assumptions about the sample and are more robust. Following McLeod and Lustig (2011), Montecino (2011), and Tsounta and Osueke (2014), we use as basic models the panel regressions with fixed and random effects, depending on the result of the Hausman test. We correct for the presence of serial correlation and heteroskedasticity, testing these with the Wooldridge test and the modified Wald statistics for groupwise heteroskedasticity test, respectively, and correlation across panels using the panel-corrected standard error model, also used by Huber et al. (2006). In this way, we perform diverse regressions adapting the following general equation to the fixed effect, random effect, and panel-corrected standard error models:

$$
\text { Gini }_{i t g}=F_{i t k}+X_{i t m}+\varepsilon_{i t}
$$

where $i$ includes each of the 18 Latin American countries in the sample (Argentina, Bolivia, Brazil, Chile, Colombia, Costa Rica, the Dominican Republic, Ecuador, El Salvador, Honduras, Guatemala, Mexico, Nicaragua, Panama, Paraguay, Peru, Uruguay, and Venezuela); $t$ is the year; $g$ is the Gini index considered (Gini, Gininat, Giniurb); $F$ is a vector that includes $k$ fiscal variables considered (PubSpeEdu, PubSpeHea, PubSpeSocSec, PubSpeHou, PubIncTax, PubPropTax, PubTaxG\&S, SocCont); and $X$ is a vector of variables of $m$ control variables (lnGDPpc, Unemp, Depend, InPop, Open, ToT, Invest, Infl, Dem, NatRes). Estimations are performed separately for the subperiods 1960-1998 and 1999-2012.

\section{Results}

When the null hypothesis in the Hausman test is rejected we use the fixed effect model, using the random effect model in the other case. The rejection of the null hypothesis both in the Wald test for heteroskedasticity and in the Wooldridge test signals potential problems of heteroskedasticity and serial correlation. This makes it worthwhile to consider the panel-corrected standard error model.

We now focus on the results of the regressions, looking first at those obtained for the first subperiod, 1960-1998, as shown in Table 3. Looking across the two components of fiscal policy for which we have available information-public spending on education and personal income taxes - we find evidence showing how these policies were either neutral or regressive in their effect on income distribution. In this subperiod, among the control variables, two in particular stand out in most of the estimated models. Both an aging population and increasing openness were found to have a regressive effect on inequality. Our results confirm the findings of 
Table 3 Income distribution, public spending, and tax structure, at the national level, 18 Latin American countries, 1960-1998 (dependent variable: Gini)

\begin{tabular}{l|l|l|l|l|l|l|l|l}
\hline & $\mathrm{FE}$ & & PCSE & & FE & & PCSE & \\
\hline Constant & 90.213 & $* * *$ & 32.759 & $* * *$ & 98.161 & $* * *$ & 23.329 & $* * *$ \\
\hline PubSpeEdu & 0.325 & & 0.199 & & & & & \\
\hline PubIncTax & & & & & 0.234 & $* *$ & 0.141 & \\
\hline lnGDPpc & 4.524 & $* * *$ & -4.377 & $* * *$ & 1.165 & & -4.893 & $* * *$ \\
\hline Depend & 1.337 & $* * *$ & -0.209 & & 1.843 & $* * *$ & -0.114 & \\
\hline InPop & -5.414 & $* * *$ & 3.195 & $* * *$ & -4.646 & $* * *$ & 3.587 & $* * *$ \\
\hline Open & 0.078 & $* * *$ & 0.044 & $* * *$ & 0.120 & $* * *$ & 0.048 & $* * *$ \\
\hline Invest & -0.179 & $* * *$ & -0.019 & & -0.054 & & -0.011 & \\
\hline Inf & -0.000 & $*$ & 0.000 & & -0.000 & & -0.000 & \\
\hline Dem & 0.148 & $* *$ & 0.016 & & -0.099 & & 0.018 & \\
\hline$N$ & 478 & & 478 & & 403 & & 403 & \\
\hline$R^{2}$ & 0.15 & & 0.78 & & 0.15 & & 0.78 & \\
\hline$F$ & 10.94 & $* * *$ & & & 11.38 & $* * *$ & & \\
\hline Wald Chi ${ }^{2}$ & & & 78.98 & $* * *$ & & & 85.12 & $* * *$ \\
\hline Hausman test & 69.98 & $* * *$ & & & 67.62 & $* * *$ & & \\
\hline Wald test for heteroskedasticity & 3142.71 & $* * *$ & & & 754.58 & $* * *$ & & \\
\hline Wooldridge test & & & 18.004 & $* * *$ & & & 17.077 & $* * *$ \\
\hline
\end{tabular}

* Significant at $10 \%$.

**Significant at $5 \%$.

*** Significant at $1 \%$

many scholars: in this subperiod, fiscal policy did little or nothing to reduce inequalities in the region. This contrasts sharply with the next subperiod, as we now explain.

Since the late 1990s, fiscal policy shifted away from Washington Consensus approaches towards more progressive ones. This was mainly due to two main changes: firstly, the coming into power of more center-left or left governments, starting in Venezuela in 1999, when Chávez was elected president of Venezuela, followed by Kirchner's and Lula's victory in Argentina and Brazil in 2003, the election of Vázquez in Uruguay in 2005, and so on, and secondly, policy transfer as regards the dominant ideas circulating in international organizations as to best practice fiscal policy (Hausmann 1997).

Analyzing this second subperiod, spanning the years from 1999 to 2012, we find fiscal policy making a difference to inequality in Latin America. Our findings therefore confirm the findings of other scholars that a shift in policy had observable progressive consequences. To explore this shift in more detail, we first analyze the estimations of the impact of fiscal policy on income inequality at the national level, as presented in Table 4. Here, looking inside the functional structure of public spending, the evidence is mixed. We can observe that public spending on health has reduced inequality, but we can also see how public spending on housing has exacerbated inequalities further. However, when we look inside the category of tax structure, we can observe that several elements have contributed to inequality 
Table 4 Income distribution, public spending, and tax structure, at the national level, 18 Latin American countries, 1999-2012 (dependent variable: Gininat)

\begin{tabular}{|c|c|c|c|c|c|c|c|c|}
\hline & FE & & PCSE & & $\mathrm{FE}$ & & PCSE & \\
\hline Constant & -170.025 & $* *$ & 26.385 & $* * *$ & 50.495 & & 24.909 & $* * *$ \\
\hline PubSpeEdu & -0.189 & & 0.186 & & & & & \\
\hline PubSpeHea & -1.217 & $* * *$ & -0.706 & $* *$ & & & & \\
\hline PubSpeSocSec & -0.161 & & 0.230 & & & & & \\
\hline PubSpeHou & 0.391 & & 0.784 & $* *$ & & & & \\
\hline PubIncTax & & & & & -0.889 & $* * *$ & -0.500 & $* *$ \\
\hline PubPropTax & & & & & -0.358 & & 0.638 & \\
\hline PubTaxG\&S & & & & & -0.604 & $* *$ & 0.139 & \\
\hline SocCont & & & & & -0.711 & $* *$ & 0.177 & \\
\hline $\operatorname{lnGDPpc}$ & -6.226 & $* *$ & -2.456 & $* *$ & -2.309 & & -3.043 & $* * *$ \\
\hline Unemp & 0.202 & $*$ & 0.324 & $* * *$ & 0.132 & & 0.286 & $* * *$ \\
\hline Depend & -1.808 & $* * *$ & -0.414 & $* *$ & -1.467 & $* * *$ & -0.418 & $*$ \\
\hline $\operatorname{lnPop}$ & 17.541 & $* * *$ & 2.773 & $* * *$ & 2.786 & & 3.128 & $* * *$ \\
\hline Open & -0.094 & $* * *$ & 0.049 & $* * *$ & -0.030 & & 0.051 & $* * *$ \\
\hline ToT & 0.003 & & -0.009 & & -0.026 & $* * *$ & -0.020 & \\
\hline Invest & 0.029 & & -0.118 & & 0.190 & $* * *$ & -0.030 & \\
\hline Inf & 0.013 & & -0.026 & & -0.039 & $*$ & -0.040 & $* *$ \\
\hline Dem & -0.089 & & 0.283 & & 0.184 & & 0.403 & $* *$ \\
\hline NatRes & -0.055 & & -0.072 & & 0.101 & $* * *$ & -0.025 & \\
\hline$N$ & 175 & & 175 & & 210 & & 210 & \\
\hline$R^{2}$ & 0.90 & & 0.98 & & 0.78 & & 0.98 & \\
\hline$F$ & 18.63 & $* * *$ & & & 22.58 & $* * *$ & & \\
\hline Wald $\mathrm{Chi}^{2}$ & & & $220,286.98$ & $* * *$ & & & $182,262.42$ & $* * *$ \\
\hline Hausman test & 28.68 & $* * *$ & & & 25.30 & $* *$ & & \\
\hline $\begin{array}{l}\text { Wald test for } \\
\text { heteroskedasticity }\end{array}$ & 87.65 & $* * *$ & & & 57.16 & $* * *$ & & \\
\hline Wooldridge test & & & 38.589 & $* * *$ & & & 29.571 & $* * *$ \\
\hline
\end{tabular}

* Significant at $10 \%$

**Significant at $5 \%$

*** Significant at $1 \%$

reduction. Personal income taxes, social contributions, and taxes on goods and services are all observed to act progressively on inequality. Overall, we observe how public revenues contribute more to reducing inequality than public spending.

We now focus on the determinants of inequality at the urban level. Table 5 presents the results of our analysis which tracks the evolution of the impact of fiscal policies on the Gini index in urban zones in Latin America. We first look inside the functional components of public spending, and observe how public spending on urban health reduces inequality. In contrast, we observe that spending on urban housing and social security is regressive. We then turn to looking inside the functional components of the tax structure, and find that personal income taxes, social contributions, and taxes on goods and services help reduce urban inequality. 
Table 5 Income distribution, public spending, and tax structure, urban level, 18 Latin American countries, 1999-2012 (dependent variable: Giniurb)

\begin{tabular}{l|l|l|l|l|l|l|l|l}
\hline & RE & & PCSE & & RE & & PCSE & \\
\hline Constant & 25.057 & $* *$ & 34.862 & $* * *$ & 27.113 & $* *$ & 18.877 & $* *$ \\
\hline PubSpeEdu & 0.153 & & -0.012 & & & & & \\
\hline PubSpeHea & -1.728 & $* * *$ & -0.995 & $* * *$ & & & & \\
\hline PubSpeSocSec & -0.119 & & 0.390 & $* * *$ & & & & \\
\hline PubSpeHou & 0.655 & $*$ & 0.464 & & & & & \\
\hline PubIncTax & & & & & -1.070 & $* * *$ & -0.516 & $* *$ \\
\hline PubPropTax & & & & & 0.947 & $*$ & 0.135 & \\
\hline PubTaxG\&S & & & & & -0.914 & $* * *$ & -0.152 & \\
\hline SocCont & & & & & -0.995 & $* * *$ & -0.294 & \\
\hline lnGDPpc & -0.572 & & -0.704 & & 0.686 & & -1.652 & $* *$ \\
\hline Unemp & 0.309 & $* * *$ & 0.491 & $* * *$ & 0.309 & $* * *$ & 0.418 & $* * *$ \\
\hline Depend & -0.297 & & -0.443 & $* * *$ & -0.292 & & -0.080 & \\
\hline lnPop & 2.687 & $* *$ & 1.563 & $* * *$ & 1.932 & & 2.797 & $* * *$ \\
\hline Open & -0.041 & $* *$ & 0.003 & & -0.029 & $*$ & 0.017 & \\
\hline ToT & -0.035 & $* * *$ & -0.029 & $*$ & -0.039 & $* * *$ & -0.022 & \\
\hline Invest & -0.088 & & -0.091 & & 0.199 & $* * *$ & 0.003 & \\
\hline Inf & 0.011 & & 0.009 & & 0.014 & & 0.005 & \\
\hline Dem & -0.108 & & 0.124 & & -0.040 & & 0.109 & \\
\hline NatRes & -0.027 & & 0.041 & & 0.066 & $*$ & 0.028 & \\
\hline$N$ & 186 & & 186 & & 218 & & 218 & \\
\hline$R^{2}$ & 0.88 & & 0.98 & & 0.87 & & 0.98 & \\
\hline Wald Chi ${ }^{2}$ & 833.22 & $* * *$ & $229,528.65$ & $* * *$ & 1105.03 & $* * *$ & $166,914.20$ & $* * *$ \\
\hline Hausman test & 7.35 & & & & 11.06 & & & \\
\hline Wald test for & 201.77 & $* * *$ & & & 61.39 & $* * *$ & & \\
\hline heteroskedasticity & & & & & & & & $* * *$ \\
\hline Wooldridge test & & & 46.167 & $* * *$ & & & 19.500 & \\
\hline Signifcant at & & & & & & & & \\
\hline
\end{tabular}

*Significant at $10 \%$

** Significant at $5 \%$

*** Significant at $1 \%$

However, we find property taxes are regressive. In general terms, tax structure is more progressive than public spending in terms of reducing inequality.

It is illuminating to compare the effects of fiscal policy on inequality at the national level with those acting in the urban context, since the performance of a given policy may have a varying effect depending on the context. For example, fiscal policy that may not be observed to influence inequality at the national level may well do so at the urban level, with important practical consequences for policy makers. When we do so, we find some evidence of differential effects of fiscal policy according to its context. First, some fiscal policy which is important at the national level proves to be even more significant in urban areas. Here we have the case of public spending on health, personal income taxes, taxes on goods and services, and social contributions. These were significant factors in reducing inequality at the 
national level, but had an even more intense effect at the urban level. In the opposite direction, public spending on housing, which was found to be regressive in urban areas, was even more intensely regressive at the national level. Then, we observe some policies which are important in determining inequality in urban regions, but they are not significant at the national level. Here, public spending on social security and property taxes show a regressive effect in urban areas, but not at the national level.

As regards the control variables in this subperiod, population size and unemployment rate are related to more inequality at both the national and urban scales. The rest of the control variables are influential at different scales. For example, increases in the dependency rate and GDP per capita reduce inequality at the national level. Meanwhile, increases in openness and terms of trade reduce urban inequality.

When calculating the interaction effect between the estimated coefficient and public spending and revenue levels for each Latin American country, we observe important national differences. As regards public spending on health, we find that this is most progressive in Brazil, Argentina, and Uruguay, while it is least progressive in Bolivia, Guatemala, and the Dominican Republic. For personal income taxes, Brazil, Peru, and Chile stand out for achieving the highest degrees of progressivity while, in contrast, Paraguay, Guatemala, and the Dominican Republic are the countries with the lowest progressive effect. Regarding social contributions, Brazil, Argentina, Costa Rica, and Venezuela led the way in the region, while the Dominican Republic, Venezuela, and Chile exhibited the lowest range of progressivity using this tool. Finally, as regards public spending on housing, which we generally found to be regressive, Guatemala, Brazil, and Costa Rica were those countries with a highest regressive effect.

\section{Conclusions}

This chapter sought to enquire whether fiscal policy impacted upon inequality in Latin America from 1960 to 2012. One of the aims of this chapter was to extend the number of Latin American countries included in our sample to the longest time period possible, given data availability. Given the shift in fiscal policy to progressive approaches and the differences in the methodology used to produce the data, we split the time period into two subperiods, 1960-1998 and 1999-2012. In this second subperiod, we analyzed the effects of fiscal policy on income inequality at the national and urban levels, to produce new knowledge about the potentially differential effects of fiscal policy. Our chapter also contributes to knowing more about the role of fiscal policy in the region by disaggregating fiscal policy into subcomponents, both for public spending and for public revenue. Our results clearly show that fiscal policy was much more influential on inequality in the second subperiod than the first. Our main findings are the following.

For the subperiod 1960-1998, fiscal policy in general seemed to have either a regressive or nonsignificant relationship with inequality. Moreover, when some of its components were associated with inequality, this was in the direction of increasing 
income inequality. For example personal income taxes, which could potentially be implemented in order to increase income redistribution and level equal, were associated with actually increasing income inequality in this earlier period.

This contrasts sharply with our findings in the second period, from late 1990s, where we find that fiscal policy significantly reduced regional inequality. Disaggregating fiscal policy into its two main components, public spending and public revenues, we find that both have a significant and positive effect on inequality reduction. Overall, the effect of public revenues on inequality was more significant than that of public spending. The most significant components of public revenues and public spending to contribute to reducing inequality at the national level were spending on health, personal income taxes, taxes on goods and services, and social contributions.

When contrasting analysis across the national and urban levels, we found that most of the fiscal instruments under analysis had a much more intense effect at the urban than the national level. This means that it is the Latin American urban areas which are most seeing the benefits of fiscal policy on income inequality, rather than the rural areas. Of particular importance in decreasing inequality at the urban level are personal income taxes, taxes on goods and services, social contributions, and public spending on health. In contrast, public spending on housing, found regressive in urban areas, was even more intensely regressive at the national level. Certain fiscal policies show significant effects in urban areas but they are not significant at the national level. This is the case of public spending on social security and property taxes, which were found to be regressive only in urban areas.

In addition, there are some interesting national differences as regards fiscal reform and policy transfers across the region. Broadly speaking, some governments have taken strides to deepen income tax reform, including the implementation of property taxes, leading to an increased tax incidence, and in turn to greater equality. Other governments, however, have proved unwilling or unable to implement real reform. To take two extreme cases, the Brazilian Government has successfully implemented many progressive taxation reforms, particularly income tax. The other extreme is found in the Guatemalan Government, which has proved reluctant to take on tax reform; in consequence, inequality levels have failed to decline significantly. Further research is required to unravel and evaluate the varieties of fiscal reform across countries.

Our chapter shows showed that fiscal policy in Latin America has played an essential role in reducing inequality. Moreover, further extension of fiscal policy has a huge potential. Fiscal policies - in particular tax reforms - in Latin America have embarked on a path of convergence with OECD members, similar to what occurred in Spain and Portugal from the 1980s onwards (Díaz Fuentes 1994; Comín and Díaz-Fuentes 2005; Díaz-Fuentes and Revuelta 2013). It is interesting to reflect on the extent to which there may be a process of international policy transfer going on in this field. For example, the OECD is currently expanding to emerging countries, now comprises two Latin American countries-Mexico and Chile-and has two candidates-Colombia and Costa Rica (Clifton and Díaz-Fuentes 2014). Even though there are still differences as regards the tax burden, this amounts to an average of $34 \%$ in OECD members in 2012 (OECD 2015), and only $25 \%$ in Latin 
America in the same year (ECLAC 2014), this is to be expected given the different levels of GDP per capita by region. The same could be said of the differences in the relative weight in favor of direct taxes in the OECD countries and indirect taxes in Latin America.

Coinciding with other recent studies, this chapter offers clear empirical evidence that certain fiscal policies have significantly contributed to reducing income inequalities in the region. For example, increases in tax incidence and public spending in general, and reforms of personal income tax, social contributions, and public spending on health, have clearly contributed to diminishing income inequality. Given we found that direct taxation was more strongly associated with reducing inequality than indirect taxation, an interesting policy option is to encourage governments to increase direct over indirect taxation. This could be a high-impact policy to reduce income inequality, considering that the ratio of indirect to direct taxation in the region was 1.76 in 2012 (ECLAC 2014). This therefore provides solid evidence which can be used to support future fiscal reform by governments committed to further reducing inequality in the region. Clearly, the redistributive effect will also depend on the efficiencies of tax compliance and public spending (Comín and Díaz-Fuentes 2005).

Open Access This chapter is distributed under the terms of the Creative Commons Attribution 4.0 International License (http://creativecommons.org/licenses/by/4.0/), which permits use, duplication, adaptation, distribution and reproduction in any medium or format, as long as you give appropriate credit to the original author(s) and the source, a link is provided to the Creative Commons license and indicate if changes were made.

The images or other third party material in this chapter are included in the work's Creative Commons license, unless indicated otherwise in the credit line; if such material is not included in the work's Creative Commons license and the respective action is not permitted by statutory regulation, users will need to obtain permission from the license holder to duplicate, adapt or reproduce the material.

\section{References}

Amarante, V. (2014). Igualdad y desigualdad en América Latina y el Caribe. In Conference on Latin American inequality in the long run. Buenos Aires.

Anderson, M., \& Palacio, A. (2014). Structural change and the fall of income inequality in Latin America-Agricultural development, inter-sectoral duality and the Kuznets curve. In Conference on Latin American inequality in the long run. Buenos Aires.

Arroyo, L., \& Lindert, P. (2014). Fiscal redistribution in Latin America since the nineteenth century. In Conference on Latin American inequality in the long run. Buenos Aires.

Astorga, P. (2014). Functional inequality in Latin America: 1900-2011. In Conference on Latin American Inequality in the Long Run. Buenos Aires.

Atkinson, A. B. (1997). Bringing income distribution in from the cold'. The Economic Journal, 107(441), 297-321.

Atkinson, A. B., \& Piketty, T. (2010). Top incomes over the twentieth century: A global perspective. Oxford: Oxford University Press. 
Bárcena, A., \& Kacef, O. (Eds.). (2011). La política fiscal para el afianzamiento de las democracias en América Latina. Reflexiones a partir de una serie de estudios de caso. Santiago de Chile: ECLAC.

Barro, R. (2000). Inequality and growth in a panel of countries. Journal of Economic Growth, 5(1), 5-32.

Bastagli, F., Coady, D., \& Gupta, S. (2012). Income inequality and fiscal policy. IMF Staff Discussion Note SDN/12/08.

Berg, A. G., \& Ostry, J. D. (2011). Equality and efficiency. Finance and Development, 48(3), $12-15$.

Bértola, L. (2005). A 50 años de la curva de Kuznets: crecimiento económico y distribución del ingreso en Uruguay y otras economías de nuevo asentamiento desde 1870. Investigaciones de Historia Económica, 3, 135-176.

Bértola, L., \& Ocampo, J. A. (2012). The economic development of Latin America since independence. Oxford: Oxford University Press.

Chin, G., \& Culotta, E. (2014). The science of inequaltiy. What the numbers tell us. Science, 344(6186), 819-821.

Clifton, J., \& Díaz-Fuentes, D. (2014). The OECD and the rest: Analyzing the limits of policy transfer. Journal of Comparative Policy Analysis, 16(3), 249-265.

Comín, F., \& Díaz-Fuentes, D. (2005). Sector público administrativo y Estado del Bienestar. In Estadísticas históricas de España: siglos XIX-XX. Bilbao: Fundación BBVA.

Cornia, G. A. (2012). Inequality trends and their determinants: Latin America over 1990-2010. UNU-WIDER Working Paper 2012/09.

Cornia, G. A. (Ed.). (2014a). Falling inequality in Latin America: Policy changes and lessons. Oxford: WIDER Studies in Development Economics, Oxford University Press.

Cornia, G. A. (2014b). Income inequality in Latin America: Recent decline an prospects for its further reduction. DISEI-Università degli Studi di Firenze Working Papers-Economics $14 / 2014$.

Cornia, G. A., Gómez-Sabaini, J. C., \& Martorano, B. (2014). Tax policy and income distribution during the last decade. In G. A. Cornia (Ed.), Falling inequality in Latin America: Policy changes and lessons. Oxford University Press.

De la Torre, A. (2014). The inequality story in LAC: Searching for an explanation. In Conference on Latin American inequality in the long run. Buenos Aires.

Deininger, K., \& Squire, L. (1996). A new data set measuring income inequality. World Bank Economic Review, 10, 565-591.

Deininger, K., \& Squire, L. (1998). New ways of looking at old issues: Inequality and growth. Journal of Development Economics, 57, 249-287.

Díaz Fuentes, D. (1994). Fraude y Amnistías Fiscales en la España contemporánea 1940-1990. Hacienda Pública, 1(94), 389-402.

Díaz-Fuentes, D., \& Revuelta, J. (2011). Gasto público y crecimiento económico en América Latina y España entre 1960 y 2000. Revista Uruguaya de Historia Económica, 1, 12-33.

Díaz-Fuentes, D., \& Revuelta, J. (2013). La relación a largo plazo entre crecimiento económico y gasto público en España (1850-2000). Investigaciones de Historia Económica, 9(1), 32-42.

ECLAC. (2010). Time for equality: Closing gaps, opening trails. Santiago de Chile: UN-ECLAC.

ECLAC. (2014). CEPALSTAT. Santiago de Chile: Economic Commission for Latin America and the Caribbean.

FitzGerald, V., Heyer, J., \& Thorp, R. (Eds.). (2011). Overcoming the persistence of inequality and poverty. UK: Palgrave-Macmillan.

Gómez Sabaini, J. C., \& Martner, R. (2008). América Latina: Panorama global de su sistema tributario y principales temas de política. Santiago de Chile: Latin American and Caribbean Institute for Economic and Social Planning (ILPES)-ECLAC.

Goñi, E., López, J. H., \& Servén, L. (2011). Fiscal redistribution and income inequality in Latin America. World Development, 39(9), 1558-1569. 
González, I., \& Martner, R. (2012). Overcoming the "empty box syndrome”. Determinants of income distribution in Latin America. Cepal Review, 108, 7-25.

Hausmann, R. (1997). Foreward. In Latin America after a decade of reforms. Washington, DC: Inter-American Development Bank.

Higgins, M., \& Williamson, J. G. (1999). Explaining inequality the world round: Cohort size, Kuznets curves, and openness. NBER Working Paper no. 7224.

Huber, E., Nielsen, F., Pribble, J., \& Stephens, J. D. (2006). Politics and inequality in Latin America and the Caribbean. American Sociological Review, 71, 943-963.

Hvistendahl, M. (2014). While emerging economies boom, equality goes bust. Science, 344, $832-835$.

Irigoin, A., \& Giardili, S. (2014). The short-run effect of afirmative action on human capital accumulation incentives. In Conference on Latin American inequality in the long run. Buenos Aires.

Kuznets, S. (1953). Shares of upper income groups in income and savings. New York: National Bureau of Economic Research.

Kuznets, S. (1955). Economic growth and income inequality. American Economic Review, 45, $1-28$.

Lee, H. Y., Kim, J., \& Cin, B. C. (2013). Empirical analysis on the determinants of income inequality in Korea. International Journal of Advanced Science and Technology, 53, 95-109.

Lindert, P. H. (2004). Growing public. Social spending and economic growth since the eighteen century. Cambridge: Cambridge University Press.

Loayza, N., Mier y Terán, A., \& Rigolini, J. (2013). Poverty, inequality and the local natural resource curse. IZA Discussion Papers 7226.

Lustig, N., \& Lopez-Calva, L. F., \& Ortiz-Juarez, E. (2013). Deconstructing the decline in inequality in Latin America. World Bank Policy Research Working Paper 6552. doi: 10.1596/1813-9450-6552.

Marshall, M. G., Gurr, T. R., \& Jaggers, K. (2014). Polity IV project: Political regime characteristics and transitions, 1800-2013. Center for Systemic Peace.

McLeod, D., \& Lustig, N. (2011). Inequality and poverty under Latin America's new left regimes. Tulane Economics Working Paper Series 1117.

Milanovic, B. (1994). Determinants of cross-country income inequality: An "Augmented” Kuznets hypothesis. World Bank Policy Research Working Paper 1246.

Milanovic, B. (2013). The inequality possibility frontier: Extensions and new applications. World Bank Policy Research Working Paper 6449.

Milanovic (2014). All the ginis dataset. World Bank. http://go.worldbank.org/9VCQW66LA0

Milanovic, B., \& Muñoz de Bustillo, R. (2008). La desigualdad de la distribución de la renta en América Latina: situación, evolución y factores explicativos. América Latina Hoy, 48, $15-42$.

Montecino, J. A. (2011). Decreasing inequality under Latin America's "Social Democratic" and "Populist" governments: Is the difference real? Center for Economic Policy Research.

MOxLAD (2014). Montevideo Oxford Latin American economic history database. Universidad de la República, Montevideo. http://moxlad.fcs.edu.uy/en.html.

OECD. (2008). Growing unequal? Income distribution and poverty in OECD countries. Paris: OECD Publishing.

OECD (2015). OECD.StatExtracts. http://stats.oecd.org/

Okun, A. M. (1975). Equality and efficiency: The big trade-off. Washington: Brookings Institution Press.

Ostry, J. D., Berg, A., \& Tsangarides, C. G. (2014). Redistribution, inequality, and growth. Staff Discussion Note 14/2. Washington: International Monetary Fund.

Piketty, T. (2014). Capital in the twenty-first century. Cambridge, MA: Belknap.

Piketty, T., \& Saez, E. (2014). Inequality in the long run. Science, 344, 838-842.

Ravallion, M. (2014). Income inequality in the developing world. Science, 344, 851-855.

Roine, J., Vlachos, J., \& Waldenström, D. (2009). The long-run determinants of inequality: What can we learn from top income data? Journal of Public Economics, 93, 974-988. 
Salazar, H. (2014). Desigualdad en la última década. In Conference on Latin American inequality in the long run. Buenos Aires.

Sánchez-Ancochea, D. (2014). Inequality and the elite: Chile in historical perspective. In Conference on Latin American inequality in the long run. Buenos Aires.

SEDLAC (2014). Socio-economic database for Latin America and the Caribbean. CEDLASWorld Bank.

Székely, M. (2014). Declining inequality in LAC during the 21st Century: ¿structural shift, or temporary improvement? In Conference on Latin American inequality in the long run. Buenos Aires.

Székely, M., \& Sámano-Robles, C. (2014). Trade and income distribution in Latin America: Is there anything new to say? In G. A. Cornia (Ed.), Falling inequality in Latin America. Oxford University Press.

Tsounta, E., \& Osueke, A. I. (2014). What is behind Latin America's declining income inequality? IMF Working Paper 14/124.

Williamson, J. G. (2010). Five centuries of Latin American income inequality. Revista de Historia Económica/Journal of Iberian and Latin American Economic History, 28(2), 227-252.

World Bank (2014). World development indicators. Washington: World Bank. http://data.worldbank.org/data-catalog/world-development-indicators.

World Bank. (2006). World development report 2006: Equity and development. Washington: World Bank.

Judith Clifton is Professor at the Faculty of Business and Economic Sciences and Editorin-Chief of Journal of Economic Policy Reform. She serves on the editorial board of Utilities Policy and Annals of Public and Cooperative Economics and has guest edited in journals such as Cambridge Journal of Regions, Economy and Society, Business History, Review of International Political Economy, and Global Policy. She has published in leading international journals including Journal of European Public Policy, Journal of Regulatory Economics, Regional Studies, Health Policy, Cambridge Journal of Regions, Economy and Society, Review of International Political Economy, Public Administration, Journal of Comparative Policy Analysis, International Review of Applied Economics, Revista de Economía Mundial, and Global Policy.

Daniel Díaz-Fuentes is Full Professor of Economics at the University of Cantabria, Santander. He received his Ph.D. from the University of Alcalá (Madrid) and has since been Visiting Research Fellow at universities including Michigan, Oxford, London School of Economics, Manchester, European University Institute, and Cornell. He has worked as a consultant for the United Nations and European Commission. He has published on topics including the Public Service Reforms, International Financial Institutions, and Economic Development in prestigious international reviews. His main areas of research interest include Fiscal and Taxation Policies, Privatization, Regulation, New Public Management, and Foreign Direct Investment policies, with particular expertise on Europe and Latin America.

Julio Revuelta holds a Ph.D. in Economics from the University of Cantabria. He is Lecturer in the Department of Economics at the University of Cantabria. He has been visiting researcher at Trinity College Dublin and Politecnico di Milano. He has published his research work in prestigious international journals such as Journal of European Public Policy, Utilities Policy, Economics of Governance, International Review of Applied Economics, and Revista de Economía Mundial. 


\title{
Challenges for Social Policy in a Less Favorable Macroeconomic Context
}

\author{
Suzanne Duryea, Andrew Morrison, Carmen Pagés, Ferdinando Regalia, \\ Norbert Schady, Emiliana Vegas, and Héctor Salazar
}

Over the last decade and a half Latin America and the Caribbean have made notable advances in reducing poverty and improving social outcomes. Extreme poverty fell by more than a third from $19.3 \%$ in 2002 to $12.0 \%$ in $2014 ;^{1}$ and inequality, as measured by the Gini coefficient, fell from 0.56 to $0.51 .^{2}$ In parallel, child mortality fell from 32 to 18 deaths per 100,000 children from 2000 to 2013 (see UN IGME 2014). By 2013, school attendance rates among 6-11-year-olds reached $98 \%$, and among 12-17-year-olds rose to $87 \% .^{3}$ Although gaps remain across income and demographic groups, the biggest advances in reducing chronic malnutrition and improving school age-attendance profiles occurred for children from the lowest socioeconomic groups.

Many of these gains were fueled by the substantive increase in public expenditure. As can be seen in Fig. 1, from 2000 to 2012 overall social spending increased at a much faster rate than GDP; indeed, over this period the share of social spending in GDP rose from $14 \%$ to almost $19 \%$ of GDP. Rapid increases in GDP per capita also directly contributed to improving social outcomes. Decompositions of the reduction in inequality attribute between a third and a half to the higher labor income of the poor associated with faster growth (Levy and Schady 2013). This report suggests that these two channels for improved social outcomes-rapid increases in

\footnotetext{
Previously published as Chapter "Macroeconomic Challenges for Social Policy" of the monograph "The Labyrinth: How Latin America and the Caribbean can Navigate the Global Economy," IDB, 2015. The authors thank Santiago Levy for his numerous suggestions.
}

${ }^{1}$ ECLAC (2014). The poverty rate for 2014 was predicted.

${ }^{2}$ Population-weighted calculations from IDB-harmonized household surveys for the period 2003-2013.

${ }^{3}$ IDB/SCL-harmonized household surveys - 16 countries with data 2000-2013, weighted population average.

S. Duryea $(\square) \bullet$ A. Morrison $\bullet$ C. Pagés $\bullet$ F. Regalia $\bullet$ N. Schady $\bullet$ E. Vegas $\bullet$ H. Salazar Social Sector, Inter-American Development Bank, Washington, DC 20577, USA e-mail: suzanned@iadb.org 


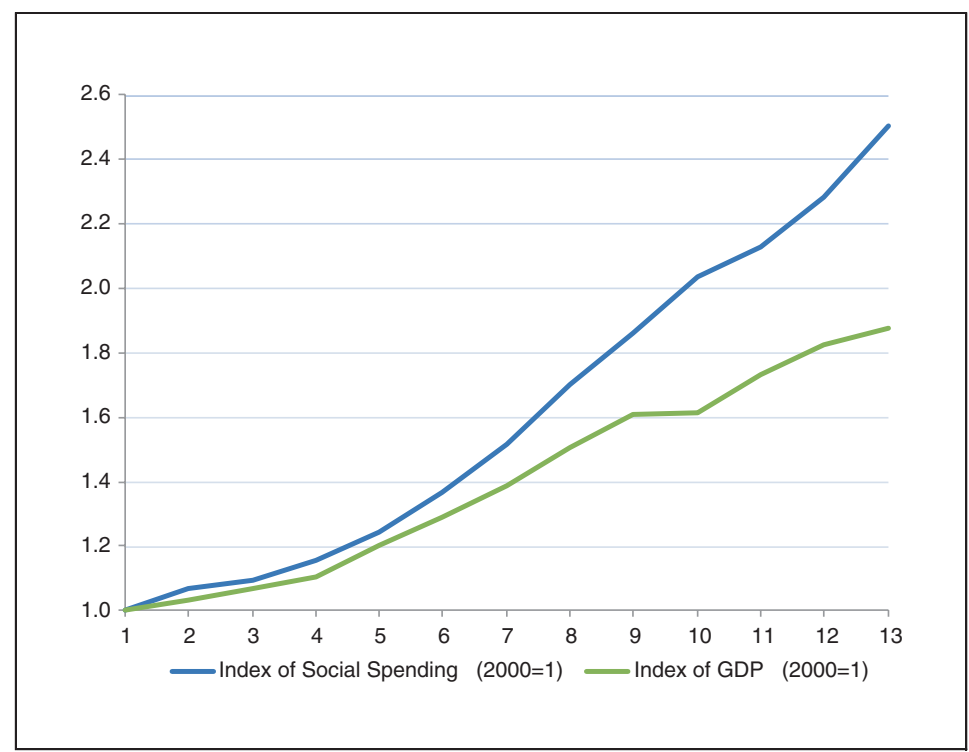

Source: ECLAC (2014) and IMF (2014). Population weighted for countries with spending and GDP data.

Fig. 1 Latin American and Caribbean social spending and GDP 2000-2012. Source: ECLAC (2014) and IMF (2014). Population weighted for countries with spending and GDP data

social expenditures and high rates of growth-may be less favorable in coming years. The increasingly constrained fiscal space faced by most countries, combined with a possible protracted period of lower growth, indicates that the recent pace of increases in social spending is unlikely to be sustainable in the coming years. While there is heterogeneity across countries, many are likely to face pressure to accomplish more with similar or lower levels of resources.

In this context, it is essential to avoid undercutting recent gains in social outcomes. In fact, it appears that progress in reducing poverty has already stalled. Deploying policies to consolidate and increase social gains is of the essence. More precisely, the region faces two challenges: (1) ensuring that the less favorable macroeconomic environment does not translate into increased inequality and poverty, and (2) designing social policies that help raise productivity and accelerate mediumterm growth. Despite their best intentions, social policies that are not aligned with productivity will set Latin America and the Caribbean on a path to lower welfare. Smarter social spending needs to be a key response to the challenging scenario of protracted low growth - by promoting better functioning labor markets, encouraging human capital accumulation, helping workers to be more effective in their jobs, and, ultimately, closing productivity gaps with other regions.

This chapter addresses how aspects of social policy in the areas of labor markets and social insurance, poverty programs, health, and education can be designed to 
protect the important social gains achieved, and better position the region for longrun growth. The discussion focuses on three areas:

- Improve efficiency with a focus on quality

- Promote income stability and protection without distorting workers' incentives

- Exercise caution with respect to creating potentially costly and irreversible commitments

\section{Improve Efficiency with a Focus on Quality}

In Latin America and the Caribbean there is ample space to improve the efficiency of spending and accomplish more with a similar amount of resources. In sectors such as health, social protection, labor training, and education, service quality remains the key challenge to be addressed.

\subsection{Health}

Health systems in the region face pressure from population aging, rising chronic diseases, demand to expand coverage, and adoption of technological advances. In a fiscally constrained scenario the priority is to adopt policies to increase technical and allocative efficiency without sacrificing coverage and quality. Policies should focus on two areas: (1) spending better, and (2) shifting more resources toward preventive services.

An analysis of 191 countries found that Latin America and the Caribbean are between 12 and 44 percentage points below the most efficient countries in producing healthy life expectancy -Evans et al. (2001). Marinho et al. (2012) reveal large discrepancies in returns on investment in the countries of the region expressed in indicators such as life expectancy, infant survival rate, and years of life recovered from communicable and noncommunicable diseases and external causes. Inefficiencies relate to human resources, health technology and drugs, organization of providers, misuse of resources, and inappropriate intervention packages.

Measures for improving efficiency include (1) closing gaps between planning and budget allocation by implementing strategic purchasing or value-for-money approaches, in which health financing decisions are based on explicit prioritization criteria, evidence of the cost-effectiveness of interventions, and provider quality and efficiency, and (2) providing incentives for productivity, quality, and innovation through payment mechanisms such as result-based financing.

On the other hand, implementation of preventive services - key to reducing the rate of growth of health spending and containing the increasing incidence of chronic diseases - is at an incipient stage in the region. An IDB survey of regional users that replicates a methodology applied in OECD countries found that only $31-52 \%$ of 


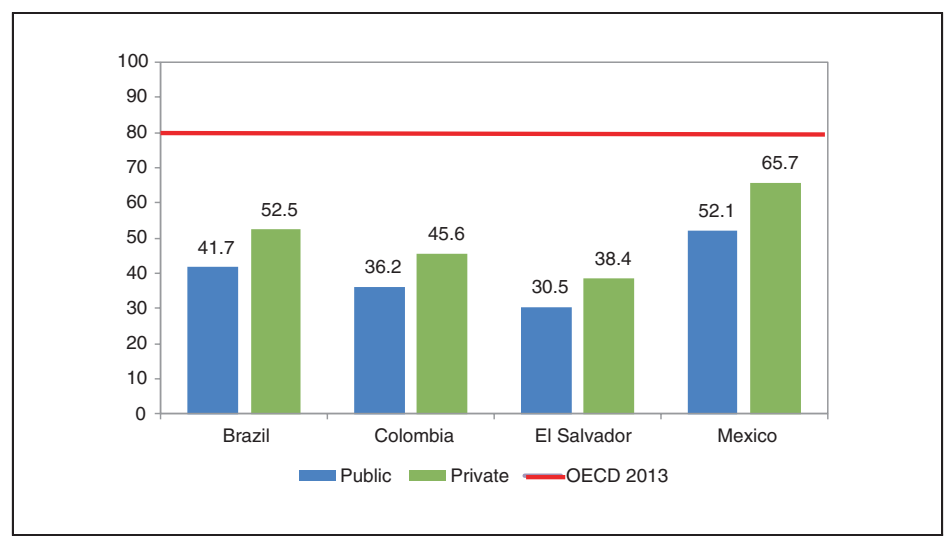

Source: Guanais et al., forthcoming. OECD is average of 11 OECD countries in International Health Policy Survey.

Fig. 2 Percentage of population up to date in preventive health measures. Source: Guanais et al. (forthcoming). OECD is average of 11 OECD countries in International Health Policy Survey

users of public health services in countries surveyed reported being up to date on a minimum set of preventive health measures, in contrast to an average of $80 \%$ in OECD countries (see Fig. 2 and Guanais et al. forthcoming). In seven countries in the region it was estimated that $20 \%$ of hospitalizations could be avoided with good primary care (Guanais et al. 2012). Strengthening the response capacity and quality of early care levels, as a gateway to the health system, can reduce the need for complex and expensive services (OECD 2010; Smith 2012).

\subsection{Social Protection: Conditional Cash Transfer Programs}

Since the 1990s, when cash transfers were complemented with co-responsibility mechanisms to encourage human capital accumulation, conditional cash transfer programs (CCTs) have expanded rapidly in the region. In 2010 approximately 129 million individuals in 18 countries in Latin America and the Caribbean-24\% of the population-were receiving transfers that represented on average 20-25\% of family income. CCTs have been effective in reducing the incidence and especially the intensity of poverty. They have also improved school attendance and reduced child labor, contributing to school progression (see Levy 2006; Fiszbein et al. 2009; Saavedra and Garcia 2012). And they have promoted the use of health services and reduced mortality for specific age groups (Gaarder et al. 2010; Rasella et al. 2013).

However, at least three issues need to be addressed. First, expansion of coverage has led to more benefits being received by the extreme nonpoor, while the coverage of the extreme poor is below universal. Thus, although in general CCTs have achieved better targeting than previous programs, there are ongoing challenges of 


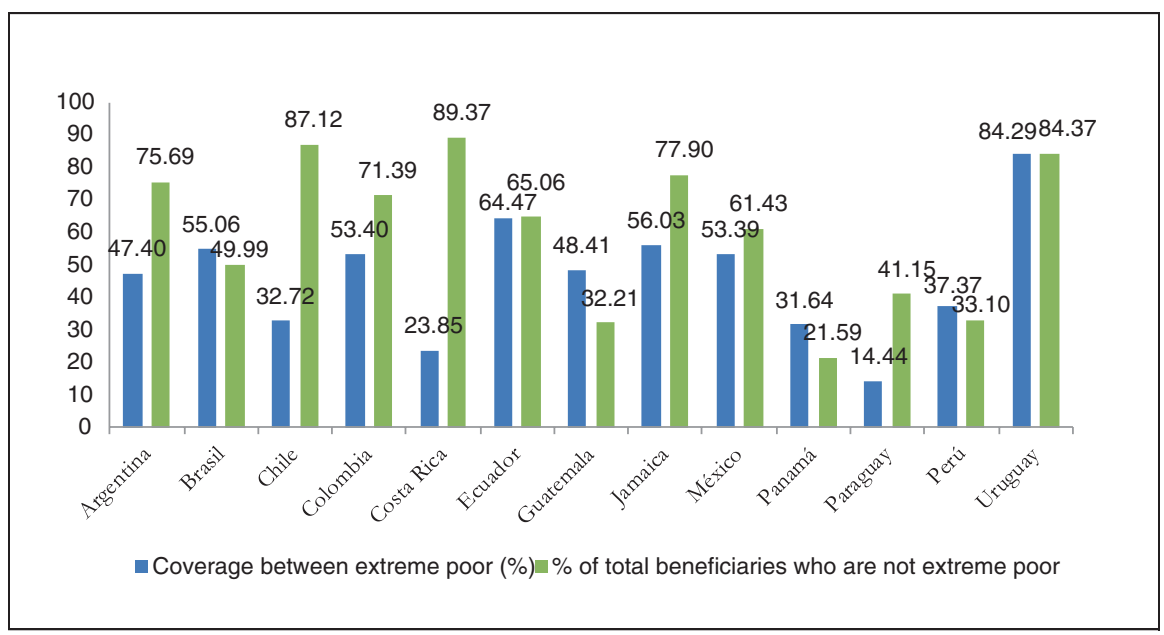

Source: Stampini and Tornarolli (2012)

Fig. 3 Conditional cash transfer programs in Latin America and the Caribbean. Source: Stampini and Tornarolli (2012)

program leakage and under-coverage, as shown in Fig. 3 and Stampini and Tornarolli (2012). To maintain their effectiveness as a tool to combat poverty, CCTs should prioritize targeting the poorest groups, particularly in rural areas where poverty is chronic.

Second, in several countries the real value of transfers, measured as a percentage of household income beneficiaries, has increased to $40 \%$ of household income (Stampini and Tornarolli 2012; Levy and Schady 2013). Transfer levels should be reasonably modest in magnitude (no higher than 20-25\% of average household income of beneficiaries before the transfer). Increases in transfer levels should be carefully considered in the context of the potential for negative incentives for labor supply. Finally, in some countries benefits have been made contingent on the form of workers' participation in the labor market, in particular on their informal status. This has led to incentives to remain informal, which is detrimental to workers' own income and the economy's productivity.

\subsection{Training}

Labor productivity is partly determined by the skills that an employee brings to the job and how these skills are used by the firm. Decades of poor educational policies have left the region with a stock of workers with relatively low skills, a major bottleneck both for the adoption of new technologies and the productive use of existing ones. Investing in workers can raise labor productivity and with it the potential for 
economic growth (Bassanini et al. 2005). Training may be particularly relevant during economic slowdowns, when the opportunity cost is lower.

All countries in the region implement labor taxes to finance training for workers, ranging from $0.25 \%$ in Uruguay to $3 \%$ of the total payroll in Jamaica. However, in many cases there is little or no information on returns and accountability is lacking. A recent IDB study finds that on-the-job training appears to raise productivity, but only in the case of large firms. A one percentage point increase in the proportion of trained employees raises productivity by $0.8 \%$ in firms of more than 100 employees (Flores Lima et al. 2014). The study also shows that the vast majority of firms selffinance their training rather than using public resources. Only 14-19\% of firms reported using public funds for training purposes in the last 3 years while 78-94\% reported using self-financing. ${ }^{4}$ This underscores the need to revise the coverage, targeting, and relevance of the public tools that support on-the-job training in the region.

A greater impact could be achieved by investing these resources in (1) developing mechanisms to align training with the needs of companies and workers; (2) improving the quality of training offered; and (3) establishing systems for monitoring and evaluation. An improvement in the quality of training would promote productivity gains, and potentially reduce job loss.

\subsection{Education}

During the last three decades, Latin America and the Caribbean have achieved enormous progress in school enrollment. Some countries in the region also saw modest progress in student learning. However, students from Latin America and the Caribbean continue to perform in the bottom quartile in the distribution of student test scores in most international assessments, notably the most recent Programme of International Student Assessment (PISA). In PISA 2012, the performance of students in the seven countries participating from the Latin American and Caribbean region was among the bottom 14 out of 65 countries (Bos et al. 2014).

Poor performance in terms of quality contrasts with budgetary outlays. Spending on education has risen from 4.2\% of GDP in 2000 to $5.6 \%$ in 2013 (ECLAC 2014). Yet there is no consistent evidence that spending on inputs such as physical infrastructure, classroom technology, flexible education funding grants, or smaller class sizes improves students' learning outcomes. The effectiveness of teachers is the main lever to improve student learning and mounting evidence indicates that the performance of teachers in classrooms and the quality of teacher-student interactions determine learning outcomes (Hamre et al. 2014; Araujo et al. 2014). To improve the quality of teaching, the region may wish to consider (1) introducing selective processes to recruit the most talented individuals into the teaching profession, and (2) strengthening

\footnotetext{
${ }^{4}$ The range represents the difference between the average of small and large firms. In other words, $14 \%$ of small firms reported using public resources for training activities compared to $19 \%$ of large firms.
} 
mechanisms to motivate teachers to perform at their best, including ongoing professional development and support as well as instruments to reward teacher excellence. These factors need not imply more spending, but rather better targeted spending.

In parallel, demographic trends in relation to students and teachers present an opportunity for efficiency gains. On the one hand, the overall composition of students will continue to shift away from primary school; on the other, approximately one-sixth of the teaching force will reach retirement age over the next 5 years. It will be important to monitor population shifts to plan appropriate class sizes, and deploy newly recruited teachers where needed and with the right skills. Given these changes, opportunities exist in some countries to reallocate spending more efficiently by merging classes, schools, and/or school districts.

In order to identify these opportunities prospective expenditure monitoring requires strengthening various education data management systems (including censuses of students, teachers, schools, and student learning assessments). In turn, this will require institutional strengthening of education offices at all levels.

\section{Promote Income Stability and Protection Without Distorting Workers' Incentives}

There are understandable incentives, particularly during economic downturns to extend the coverage of social insurance, and to protect workers against income loss. However, some such policies may inadvertently become permanent and may be detrimental to long-run growth. This section discusses policy options that are compatible with promoting income stability while maintaining incentives for participation in the formal sector to increase long-run productivity.

\subsection{Improve Protection for Job Loss}

In general, the region has a precarious and truncated system of protection against job loss that increases the costs of downturns and impedes automatic income stabilization. Almost all countries in Latin America and the Caribbean have mandatory severance pay, but only 8 provide unemployment insurance (11 if those including obligatory individual savings accounts are included). However, these instruments are only available to a select group of formal salaried workers, which constitute only $42 \%$ of the workforce. ${ }^{5}$ So, for most workers, there is no preestablished unemployment protection mechanism.

\footnotetext{
${ }^{5}$ Mean for 19 countries in 2013, from IDB Labor Market and Social Security System of Indicators. The figure represents the proportion of formal salaried workers in relation to the total active population (employed and unemployed workers).
} 
Under a severance system, the lump-sum payment paid to a dismissed formal worker accumulates over time, and is only due in case of unjust dismissal, providing firms with incentives to shorten job tenure below optimal levels or enter into litigation regarding the cause for separation. A severance pay scheme may also generate distortions by encouraging firms to hire permanent workers under temporary contracts, which has been shown to reduce productivity (Dolado and Stucchi 2008). There is considerable scope to improve the coverage and design of employment protection instruments toward those that enhance long-run productivity such as unemployment insurance, and away from those like severance pay that can inadvertently hinder productivity and discourage the creation of formal employment.

Unemployment insurance can help families smooth income loss while providing consistent incentives for workers and firms with respect to on-the-job training and the retention of experienced, productive workers. A reform of severance policies would lower the labor cost associated with uncertainty arising from the high degree of litigiousness, which in turn would promote more formal employment of longer duration. The increase in formal employment contracts of indefinite duration would have the added benefit of improving the coverage of contributory pension and health programs, providing more fiscal space in the long run. In turn, more formality and a lower degree of temporary employment would generate productivity gains.

For formal workers, there are advantages to moving away from a standard severance pay instrument to a mixed instrument that includes compensation, in case of dismissal or layoff as well as individual accounts, funded by companies (and possibly workers) that would be available to the worker in case of voluntary resignation or dismissal. The pre-savings will improve the effectiveness of the instrument, particularly in economic downturns.

A complementary action would be to strengthen public employment services so that unemployment insurance and severance pay/individual accounts can be linked with active policies for training and job placement. Programs can be integrated through "single windows," which consolidate services and provide synergies to job seekers with the ultimate objective to achieve rapid and effective reintegration of workers.

In the event of a crisis, temporary employment programs (TEP) or public works are often aimed at workers without certification and/or very low skills. These can be effective in providing protection for income loss for informal workers, but they should be careful not to detract from laying the groundwork for effective systems of protection in the long term, that is, from promoting formality. It is also important to learn from past experience with TEPs: design projects that are straightforward to implement, minimizing administrative costs so that the bulk of the resources reach the workers, and set a low transfer level that incentivizes the self-targeting of labor supply (entry and exit of work). 


\subsection{Reduce Labor Taxes to Promote Formal Sector Jobs}

As reviewed in Powell (2015), raising taxes may not be the most appropriate form of fiscal adjustment. This is particularly true for labor taxes that tend to promote informality. Indeed, there is a negative relationship between the cost of labor and the rate of formal job creation, and while this elasticity varies from country to country, it is clear that higher taxes on labor can lead to a destruction of formal employment (Bosch et al. 2013). As described in the 2014 Latin American and Caribbean Macroeconomic Report, lowering labor taxes may enhance productivity and medium-term growth in part by reducing informality.

\subsection{Promote Female Labor Force Participation}

Enhancing female participation in the labor force may also enhance productivity as well as promote gender equality and increase income per capita. Estimates from the region indicate that the loss from low female participation ranges from $3.4 \%$ of GDP in the case of Mexico to $17 \%$ of GDP for Honduras (Mateo Díaz and Rodíguez-Chamussy 2015). Estimates for OECD countries include $5 \%$ of GDP for the USA and $9 \%$ of GDP for Japan (Elborgh-Woytek et al. 2013). Although Latin America and the Caribbean are the regions experiencing the highest growth in female labor force participation in the world (increasing from $49 \%$ in 2000 to $54 \%$ in 2013), participation levels for women still lag behind those in East Asia and the Pacific (54\% against $63 \%$ for 2013). Younger cohorts of women are achieving similar or higher levels of educational attainment than men in most countries of the region. Investing in quality childcare and after-school programs, promoting flexible job arrangements, and revising labor and social insurance legislation to ensure equal treatment of women can lower barriers and, in turn, further promote labor insertion.

\section{Exercise Caution with Respect to Creating Potentially Costly and Irreversible Commitments}

As recognized by various authors (Duryea et al. 2009), measures considered by policymakers as temporary may, due to political economy reasons, become very difficult to change, thus creating irreversible commitments. Moreover, some such policies may be extremely costly, especially considering the demographic changes facing the region. This section discusses some selected policies that are particularly vulnerable in this regard. 


\subsection{Minimum Wage Policies}

Minimum wages continue to grow in real terms in Latin America and the Caribbean, generating important gains for some workers. However, minimum wages also generate losers: those who cannot find formal employment, or any employment, given the higher labor costs associated with the minimum wage. A substantial proportion of the salaried workforce receives wages below the minimum in the region, ranging from $15 \%$ to $17 \%$ in Mexico and Uruguay, respectively, to $61 \%$ and $74 \%$ in Guatemala and Honduras. These figures increase as the level of the minimum wage increases in relation to the average wage. As such, it is important to exercise caution before raising the level of the minimum wage to avoid increasing unemployment and reducing formal employment, both of which hurt long-term growth and productivity, to the detriment of workers themselves.

\subsection{Adjustment Mechanisms and Levels for Noncontributory Pensions}

Only four in ten adults aged 65 and older receive a contributory pension in Latin America and the Caribbean. Low coverage of contributory pensions has led to a rapid expansion of so-called noncontributory pensions (NCPs), even though, of course, in the end somebody must pay. This has allowed coverage of older adults receiving a pension to expand. All countries have instituted some form or other of an NCP to address poverty in old age. Taking both together, the proportion of older adults who receive a pension increases from four to six out of ten, and the number of people receiving an NCP continues to increase rapidly in the region.

While this is positive from the point of view of poverty reduction, if appropriate measures are not taken, NCPs may become unsustainable from a fiscal and economic perspective. This reflects both the weight of demographic trends and the incentives to refrain from contributing to pensions that NCPs can generate. In the next 35 years, the proportion of adults aged 65 and over will increase from 7 to $20 \%$ of the total population. In light of this change in the age structure, fiscal costs of NCP will triple. It is therefore important to establish measures to safeguard their sustainability. As can be seen in Fig. 4, considerable heterogeneity currently exists across countries in the transfer level of NCP. While among eight countries the total cost of NCP is currently less than $0.5 \%$ of GDP, in Bolivia expenditures are more than double that at over $1 \%$ of GDP. If the current pension is adjusted in real terms, current spending on NCP will pass from approximately $1 \%$ in Bolivia and rural Brazil to over 2 or $3 \%$ of GDP by 2050 (Bosch et al. 2013). In this context, it is critical to design automatic adjustment mechanisms and strong institutions capable of safeguarding the amount of pensions against short-term pressures associated with the political process. 


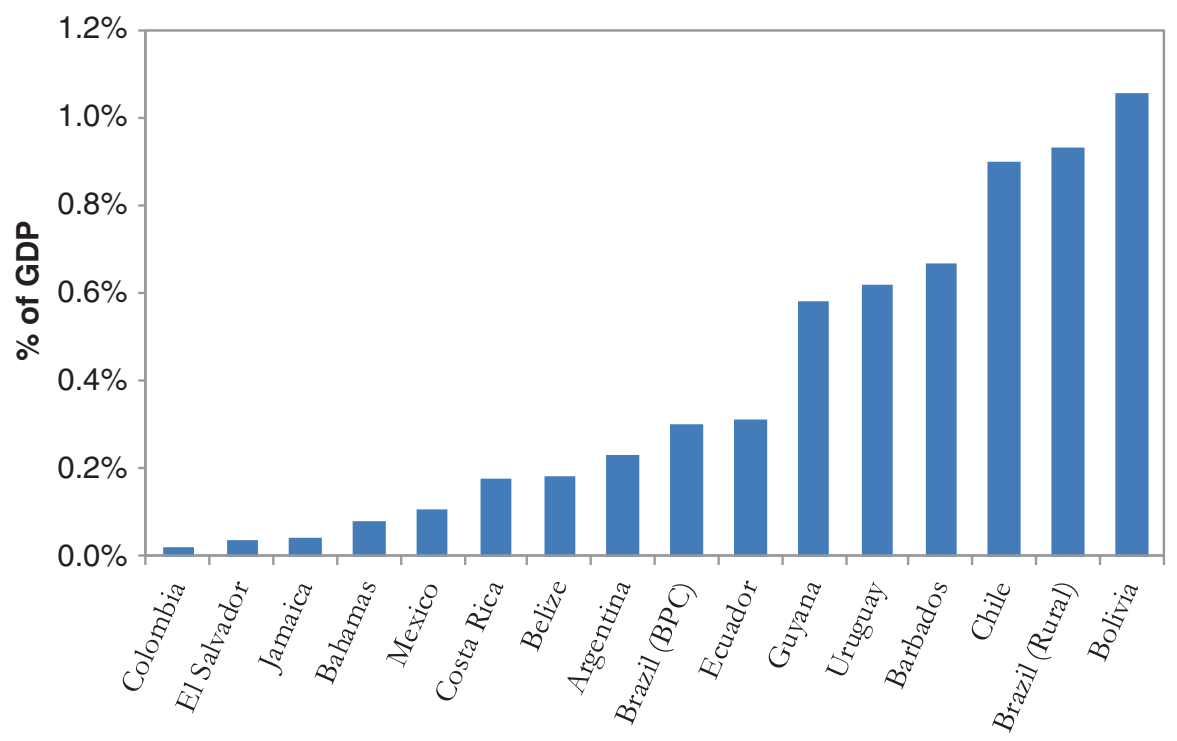

Source : Bosch, Melguizo and Pagés (2013).

Fig. 4 Public spending on noncontributory pensions in 2012 (percentage of GDP). Source: Bosch et al. (2013)

In addition, if they are not designed correctly, NCPs can produce undesirable incentives. This is particularly the case when eligibility for an NCP is limited to individuals who do not have a contributory pension; this can provide a disincentive to participate in contributory pensions, and increase informality, which is clearly undesirable from the point of view of productivity. More broadly, it is important to integrate the noncontributory and contributory pension pillars and seek to increase the coverage of the contributory system. Mutatis mutandis, similar remarks can be made of noncontributory health insurance programs.

Open Access This chapter is distributed under the terms of the Creative Commons Attribution 4.0 International License (http://creativecommons.org/licenses/by/4.0/), which permits use, duplication, adaptation, distribution and reproduction in any medium or format, as long as you give appropriate credit to the original author(s) and the source, a link is provided to the Creative Commons license and indicate if changes were made.

The images or other third party material in this chapter are included in the work's Creative Commons license, unless indicated otherwise in the credit line; if such material is not included in the work's Creative Commons license and the respective action is not permitted by statutory regulation, users will need to obtain permission from the license holder to duplicate, adapt or reproduce the material.

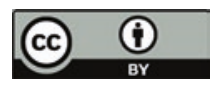




\section{References}

Araujo, M.C., Carneiro, P., Cruz-Aguayo, Y., \& Schady, N. (2014, October). A helping hand? Teacher quality and learning outcomes in kindergarten, Working Paper.

Bassanini, A. Booth, A. L., Brunello, G., de Paola, M., \& Leuven, E. (2005). Workplace training in Europe. IZA Discussion Paper. No 1640. Bonn.

Bos, M. S., Ganimian, A. J., \& Vegas, E. (2014). Brief \#5: ¿Cómo se desempeñan los varones y las mujeres? Serie de Briefs-América Latina en PISA 2012. Washington, DC and Paris, France: Inter-American Development Bank and Organisation for Economic Co-operation and Development.

Bosch, M., Melguizo, Á., \& Pages, C. (2013). Better pensions, better jobs: Towards universal coverage in Latin America and the Caribbean. Washington, DC: Inter-American Development Bank.

Dolado, J. J., \& Stucchi, R. (2008). Do temporary employment contracts affect TFP? Evidence from Spanish manufacturing firms. IZA Discussion Paper No. 3832. Bonn.

Duryea, S., Mazza, J., \& Regalia, F. (2009). Social and labor market policies for tumultuous times: Confronting the global crisis in Latin America and the Caribbean. Washington, DC: InterAmerican Development Bank.

ECLAC (Economic Commission for Latin America and the Caribbean) (2014, December). Social Panorama of Latin America 2014. Flagships.

Elborgh-Woytek, K., Newiak, M., Kochhar, K., Fabrizio, S., Kpodar, K., Wingender, P., et al. (2013). Women, work, and the economy: Macroeconomic gains from gender equity. IMF Staff Discussion Notes No. 13/10.

Evans, D. B., Tandon, A., Murray, C. J. L., \& Lauer, J. A. (2001). The comparative efficiency of National Health Systems in producing health. GPE Discussion Paper Series No. 29. EIP/GPE/ EQC, World Health Organization.

Fiszbein, A., Schady, N. R., \& Ferreira, F. H. (2009). Conditional cash transfers: reducing present and future poverty. World Bank Publications.

Flores Lima, R., Gonzalez-Velosa, C., \& Rosas Shady, D. (2014). Five facts about labor training in firms in Latin America and the Caribbean. Washington, DC: Inter American Development Bank (in Spanish).

Gaarder, M. M., Glassman, A., \& Todd, J. E. (2010). Conditional cash transfers and health: Unpacking the causal chain. Journal of Development Effectiveness, 2(1), 6-50.

Guanais, F. C., Gómez-Suárez, R., \& Pinzón, L. (2012). Series of avoidable hospitalizations and strengthening primary care. En Publicación, BID.

Guanais, F. C., Macinko, J., Mullachery, P., \& Jiménez, G. (Forthcoming). Results from the IDB Survey on Primary Health Care and Health System Performance in Latin America and the Caribbean. IDB working paper. Inter-American Development Bank, Washington, DC.

Hamre, B., Hatfield, B., Pianta, R., \& Jamil, F. (2014). Evidence for general and domain-specific elements of teacher-child interactions: Associations with preschool children's development. Child Development, 85(3), 1257-1274.

IMF (International Monetary Fund) (2014). World Economic Outlook Database.

Levy, S. (2006). Pobreza y transición democrática en México: La continuidad de ProgresaOportunidades. Fondo de Cultura Económica (FCE).

Levy, S., \& Schady, N. (2013). Latin America's social policy challenge: Education, social insurance, redistribution. The Journal of Economic Perspectives, 27(2), 193-218.

Marinho, A., Cardoso, S. D. S., \& Almeida, V. V. D. (2012). Avaliação de Eficiência em Sistemas de Saúde: Brasil, América Latina, Caribe y OCDE. Texto para Discussão 1784. Rio de Janeiro: Instituto de Pesquisa Econômica Aplicada.

Mateo Díaz, M., \& Rodíguez-Chamussy, L. (2015). Cashing in on education: Women, childcare, and prosperity in Latin America and the Caribbean. Unpublished manuscript. 
OECD (2010). Health care systems: Getting more value for money. OECD Economics Department Policy Notes, No. 2. Smith, Peter C. 2009. Measuring value for money in healthcare: Concepts and tools. London: The Health Foundation.

Paes-Sousa, R., Regalia, F., \& Stampini, M. (2013). Condiciones para el éxito de la puesta en práctica de programas de transferencias monetarias condicionadas: lecciones de América Latina y el Caribe para Asia.

Powell, A. (Coord.). (2015). The labyrinth: How can Latin America and the Caribbean navigate the global economy. Washington: Inter-American Development Bank.

Rasella, D., Aquino, R., Santos, C. A., Paes-Sousa, R., \& Barreto, M. L. (2013). Effect of a conditional cash transfer programme on childhood mortality: A nationwide analysis of Brazilian municipalities. The Lancet, 382(9886), 57-64.

Saavedra, J. E., \& Garcia, S. (2012). Impacts of conditional cash transfer programs on educational outcomes in developing countries: A meta-analysis. RAND labor and population working paper WR-921-1. Santa Monica, Calif.: Rand.

Smith, P. C. (2012). What is the scope of health system efficiency gains and how can they be achieved? Eurohealth, 18(3), 3-6.

Stampini, M., \& Tornarolli, L. (2012). The growth of conditional cash transfers in Latin America and the Caribbean: Did they go too far? (No. 49). IZA Policy Paper.

UN Inter-Agency Group (2014). Levels and trends in child mortality. Report 2014. Estimates Developed by the UN Inter-agency Group for Child Mortality.

Suzanne Duryea is a Principal Research Economist in the Social Sector of the Inter-American Development Bank where her work focuses on youth development in Latin America and the Caribbean. Prior to joining the Social Sector, she worked as a Senior Economist in the Research Department of the IDB. Her publications have appeared in peer-reviewed journals such as Journal of Development Economics, Journal of Human Resources, and American Economic Journal: Applied Economics. She is a research affiliate at the Population Studies Center at the University of Michigan and a member of the executive committee of the Latin American and Caribbean Economic Association (LACEA). She holds a Ph.D. in economics from the University of Michigan. 